
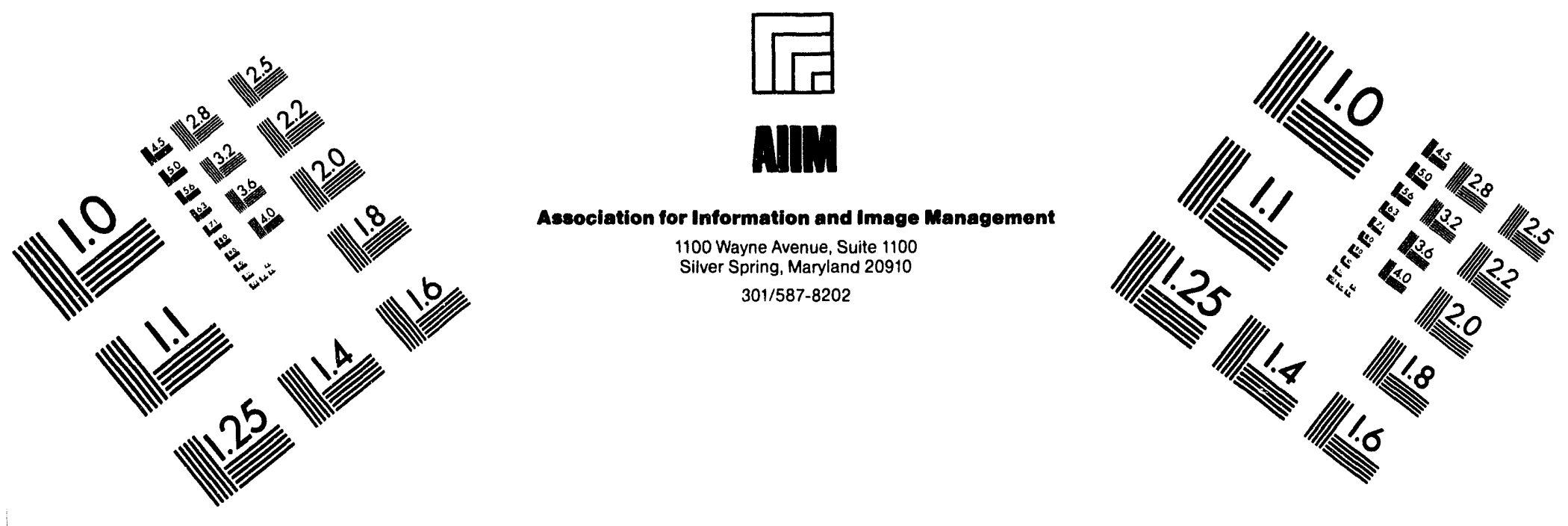

\title{
Centimeter
}

$\begin{array}{llllllllllllllll}1 & 2 & 3 & 4 & 5 & 6 & 7 & 8 & 9 & 10 & 11 & 12 & 13 & 14 & 15 & \mathrm{~mm}\end{array}$

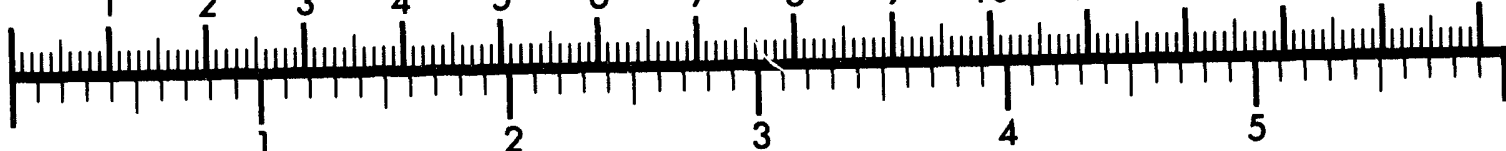
Inches
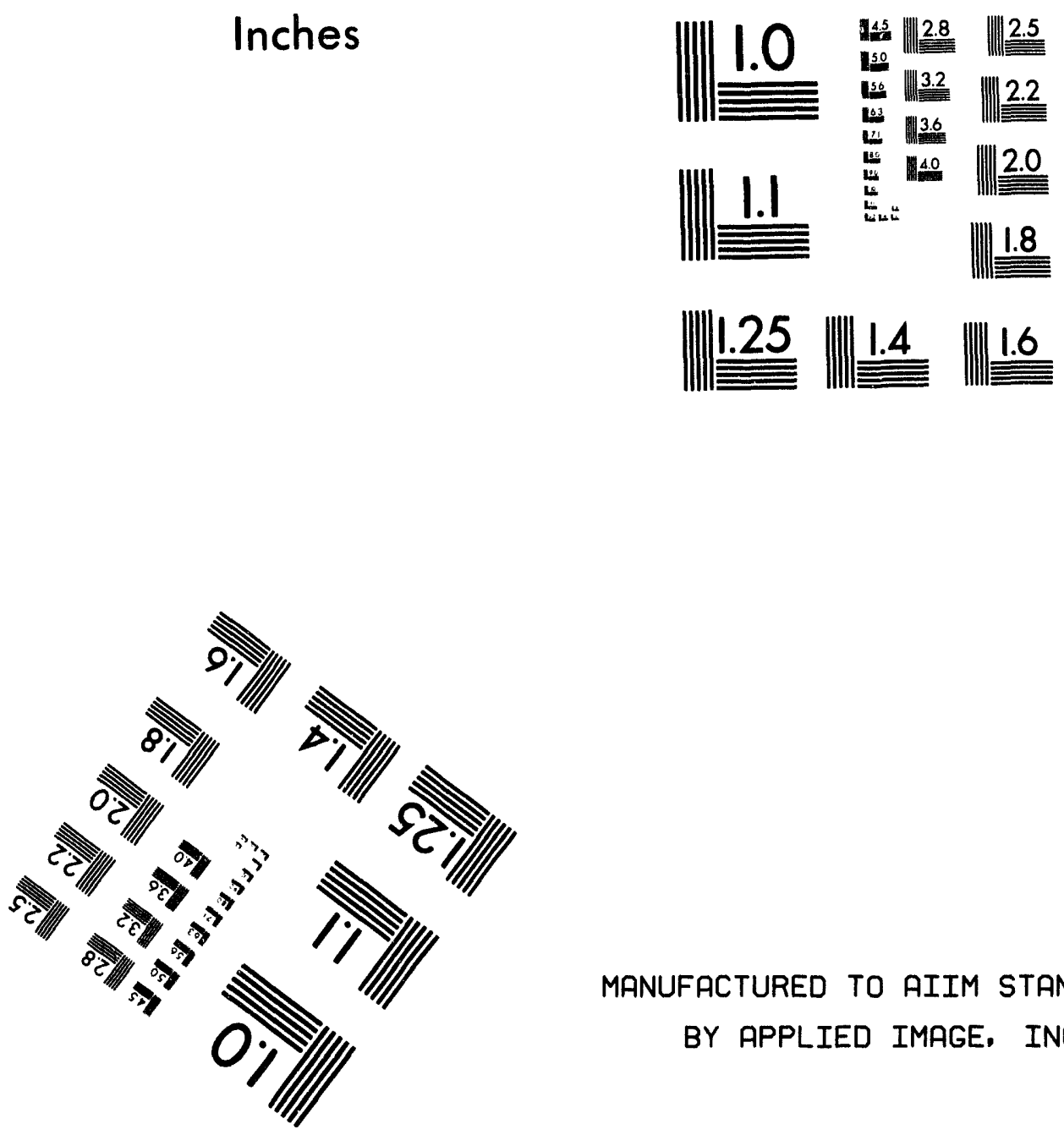

MANUFACTURED TO AIIM STANDARDS

BY APPLIED IMAGE, INC.

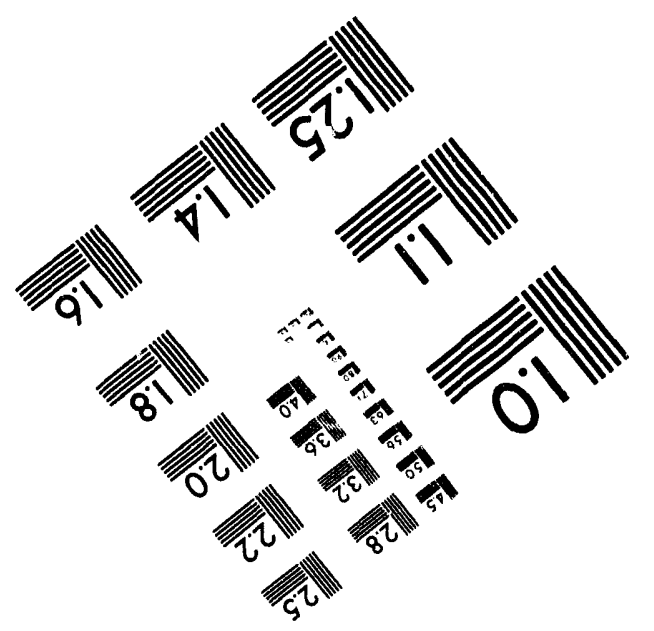



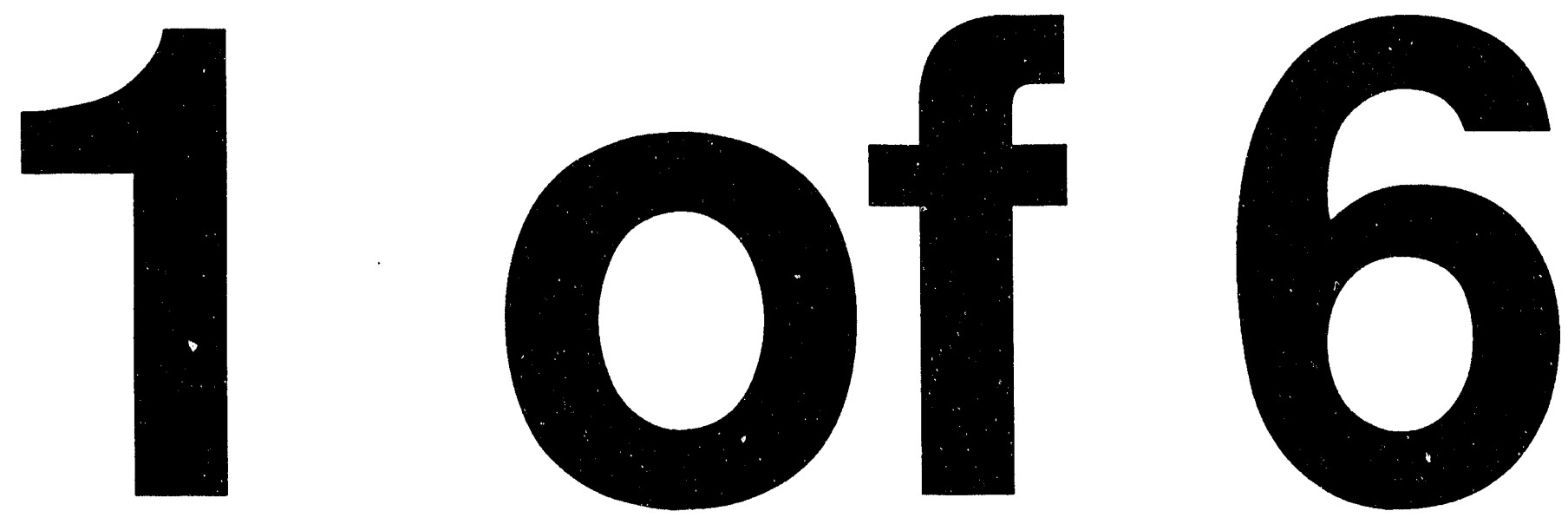
Combustion Engineering, Inc.

\title{
DOE PLUTONIUM DISPOSITION STUDY
}

SCREENING STUDY FOR EVALUATION OF THE POTENTIAL

FOR SYSTEM 80 + TO CONSUME EXCESS PLUTONIUM

CONTRACT NO. DE-AC03-93SF19682

\author{
A FINAL REPORT \\ BY \\ COMBUSTION ENGINEERING, INC. \\ WINDSOR, CONNECTICUT \\ APRIL 30, 1994
}

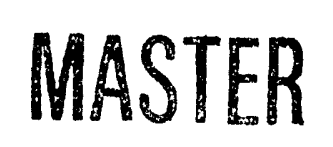




\section{Combustion Engineering, Inc.}

\section{ABB COMBUSTION ENGINEERING \\ WINDSOR, CT 06095}

\section{DISCLAIMER}

This document is prepared under a contract sponsored by an agency of the United States Government. Neither the contractor nor any subcontractor of any tier nor any employee of any of them makes any warranty, express or implied, or assumes any legal liability or responsibility for the accuracy, completeness, or usefulness of any information, apparatus, product or process disclosed, or represents that its use would not infringe on any privately owned rights. Reference herein to any specific commercial product, process or service by trade name, trademark, manufacturer, or otherwise, does not necessarily constitute or imply its endorsement, recommendation or favoring by any contractor of any tier. 


\section{TABLE OF CONTENTS}

VOLUME 1

SECTION

IITLE

PAGENO.

EXECUTIVE SUMMARY $\ldots \ldots \ldots \ldots \ldots \ldots \ldots$ ES-1

1.0

INTRODUCTION . . . . . . . . . . . . . . . . . . . 1-1

1.1 Technical Synopsis of Study from Inception to Present . . . . 1-1

1.1.1 Program Background .............. 1-1

1.1 .2 Initial Study Results . . . . . . . . . . . 1-2

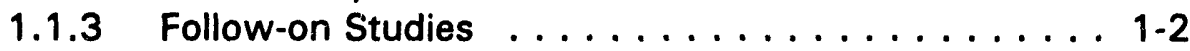

1.1.4 ABB-CE System $80+$ Overview . . . . . . . . 1-3

1.2 Definition of Commercial Power System Basis for PDS . . . . 1-4

1.3 System $80+$ Licensing Status . . . . . . . . . . . . . . . 1-5

1.4 Reference Case and Alternatives . . . . . . . . . . . . 1-6

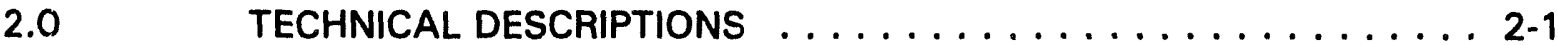

2.1 Reactor and Reactor Cooling System . . . . . . . . . . 2-1

2.1.1 Mechanical and Neutronic Design, Performance .... 2-1

2.1.2 Cooling Under Normal Operations, Design Accidents 2-38

2.2 Infrastructure . . . . . . . . . . . . . . . 2-43

2.3 Reactor Safety Systems . . . . . . . . . . . . . . . 2 2-44

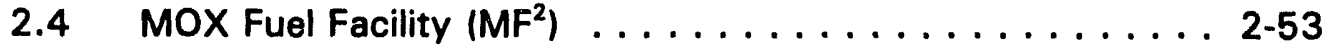

2.4 .1 Introduction ................. 2-53

2.4.2 $\mathrm{MF}^{2}$ Activities Identification and Effective Capacity 2-54

2.4.3 Facility Layout . . . . . . . . . . . . . . 2-56

2.4 .4 Facility Description . . . . . . . . . . . . 2-57

2.4.5 MF $^{2}$ Processing Areas . . . . . . . . . . 2-63

2.4.6 SNM Powders Receiving and Storage Area . . . . . 2-63

2.4.7 SNM Powder Blending . . . . . . . . . . . . . 2-64

2.4.8 MOX Powder Storage Vault . . . . . . . . . . 2-66

2.4.9 Pellet Processing Area . . . . . . . . . . . 2-66

2.4.10 Fuel Rod Fabrication Area . . . . . . . . . . 2-67

2.4.11 Fuel Rod Inspection Area . . . . . . . . . . 2-67

2.4.12 Fuel Fod Assembly Area . . . . . . . . . . . 2-68

2.4.13 Clean Scrap Recovery . . . . . . . . . . . . . 2-69

2.4.14 $\mathrm{MF}^{2}$ General Chemistry Laboratories . . . . . . . . 2-69

2.4.15 $\mathrm{MF}^{2}$ Other Laboratories . . . . . . . . . . 2-69

2.4.16 $\mathrm{MF}^{2}$ Health Physics . . . . . . . . . . 2-69

2.4.17 $\mathrm{MF}^{2}$ Equipment Maintenance Room . . . . . . 2-69

2.4.18 $\mathrm{MF}^{2}$ Mechanical Room ............... 2-69

2.4.19 $\mathrm{MF}^{2}$ Piping and Ductwork . . . . . . . . . . 2-70

2.4.20 $\mathrm{MF}^{2}$ Sanitary Lagoon . . . . . . . . . . 2-70 


\section{IABLE OF CONTENTS}

SECTION

IITLE

PAGENO.

2.4.21 Operational Personnel and Organization of the Plant 2-70

2.4.22 Design Criteria ... . . . . . . . . . . . 2-71

2.5 Fuel Handlirg and Storage Facilities . . . . . . . . . . 2-77

2.6 Fuel Management ... . . . . . . . . . . . . . . 2-79

2.6.1 Reactor Startup Plutonium Inventory and Discharge

Rate . . . . . . . . . . . . . . . . . . . . . . 2-84

2.6.2 Fuel Cycle Characteristics . . . . . . . . . . 2-86

2.6.3 As-charged fuel actinide isotopic composition ... 2-86

2.6.4 Discharged fuel actinide isotopic composition ... 2-87

2.7 Nuclear Material Transporation ... . . . . . . . . . . . 2-90

2.7.1 Fresh Fuel from fuel fabrication plant . . . . . . . . 2-90

2.7.2 Waste from fuel fabrication plant . . . . . . . . 2-90

2.7.3 Waste from Reactor ............... 2-91

2.7.4 Spent Fuel from the Reactor . . . . . . . . . . 2-91

3.0

TECHNOLOGY NEEDS $\ldots \ldots \ldots \ldots \ldots \ldots \ldots$. . . . . . .

3.1 Reactor Technology Needs . . . . . . . . . . . . 3-1

3.1.1 Introduction and Summary ............ 3-1

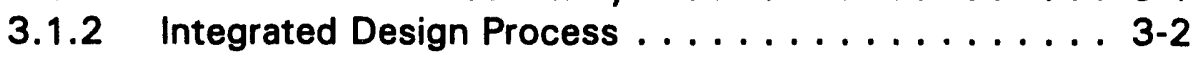

3.1.3 Increased Reactor Coolant System (RCS)

Design Margins and Improvements . . . . . . . . . . 3-3

3.1.4 Advanced Control Room Design . . . . . . . . . . . . 3-4

3.1.5 Highly Reliable Engineered Safeguards Systems . . . 3-4

3.1.6 Plant Structures and Arrangements . . . . . . . . 3-6

3.1.7 Analytical Methods . . . . . . . . . . 3-6

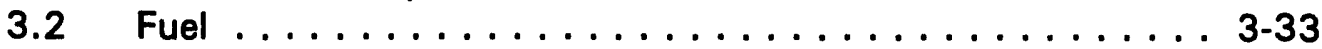

3.2.1 Introduction $\ldots \ldots \ldots \ldots \ldots \ldots \ldots \ldots \ldots \ldots .33$

3.2.2 Experience with MOX . . . . . . . . . . . . 3-34

3.2.3 Fuel Rod/Assembly Material Properties and

Performance ............. . . . . 3-38

3.2.4 Summary/Recommendations . . . . . . . . . . 3-47

3.2.5 Summary of MOX Fuel Qualification Plan .... . . 3-48

3.3 Development Issues . . . . . . . . . . . . . . . 3-62

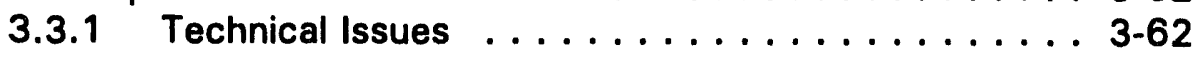

3.3.2 Development and Test Facilities . . . . . . . . 3-62

$4.0 \quad$ OPERATIONS $\ldots \ldots \ldots \ldots \ldots \ldots \ldots \ldots \ldots \ldots \ldots \ldots \ldots$

4.1 Government, Utility and Private Industry Interface . . . . . . 4-1

4.1.1 Introduction .................. 4-1

4.1.2 Deployment Concept .............. 4-1 


\section{TABLE OF CONTENTS}

SECTION

IITLE

PAGENQ.

4.1.3 Organization of the Consortium . . . . . . . 4-2

4.1.4 Power Purchase Agreements . . . . . . . . . . . 4-6

4.1.5 Financial Institutions . . . . . . . . . . 4-7

4.1.6 Role of the Government . . . . . . . . . . . 4-8

4.1.7 Contractual Arrangements . . . . . . . . 4-9

4.2 Checkout and Startup Tests ... . . . . . . . . . 4-10

4.2.1 Fuel Storage and Handling . . . . . . . . . . 4-11

4.2.2 Boron Management ............... 4-11

4.2.3 Core Neutionics . . . . . . . . . . . . . . . 4-12

4.3 Startup and Initial Operation ... . . . . . . . . . . 4-31

4.4 Related Operational Experience on Availability, Capacity

Factors ..................... 4-33

4.4.1 Plant Capacity Factor Experience . . . . . . . 4. 43

5.0 REACTOR COMPLEX SAFETY AND LICENSING . . . . . . . . . 5-1

5.1 Reactor Transient and Accident Analysis . . . . . . . . . . 5-1

5.1 .1 Bases for Analyses . . . . . . . . . . . 5-1

5.1 .2 Event Analyses ................ 5-14

5.2 Licensing the Reactor Facility . . . . . . . . . . . . 5-41

5.3 Licensing the Fuel Fabrication Facility . . . . . . . . . . . . 5-46

5.3.1 Safety Analysis and Impact on the Environment . . 5-46

5.3.2 Normal Operation ... . . . . . . . . . . . . 5-46

5.3.3 Accidental Events . . . . . . . . . . . . . 5 5-46

5.3.4 Licensing, DOE Orders, Design Codes and Procedures5-47

5.4 Environmental Impact Review Process . . . . . . . . . 5 5-51

6.0 ESTIMATED COST AND SCHEDULE $\ldots \ldots \ldots \ldots \ldots \ldots$

6.1 Summary Life Cycle Cost . . . . . . . . . . . . 6-1

6.2 Cost Estimate Detail . . . . . . . . . . . . . . 6 6-3

6.3 Operations and Maintenance Cost Detail . . . . . . . . . 6-8

6.3.1 Staffing ................... 6.8

6.3.2 Elements of O\&M Cost . . . . . . . . . . . 6-23

6.4 Other Life Cycle Cost Detail . . . . . . . . . . . . . . 6-28

6.5 Anticipated Cost Risks . . . . . . . . . . . . . 6-30 6

6.6 Base Schedule . . . . . . . . . . . . . . . . 6-30

6.7 Anticipated Schedule Risks . . . . . . . . . . . . 6-32

6.7 .1 MOX Fuel Facility $\ldots \ldots \ldots \ldots \ldots$ 6.32

6.8 Incremental Tritium Related Cost . . . . . . . . . . 6 6-32

6.9 Other Depluyments ... . . . . . . . . . . . . . 6-32

6.9.1 Plutonium Fabrication Capability Currently Available 6-32 


\section{TABLE OF CONTENTS}

SECTION

7.0

8.0

\section{IIILE}

PAGENO.

SAFEGUARDS AND SECURITY $\ldots \ldots \ldots \ldots \ldots \ldots \ldots \ldots$ 7-1



7.1 .1 Delay and Denial Systems . . . . . . . . . . 7-2

7.1.2 Detection and Assessment Systems . . . . . . . . 7-3

7.1 .3 Security Areas . . . . . . . . . . . . . 7-5

7.1.4 Physical Access Control . . . . . . . . . . 7-10

7.1.5 Other Site-Wide Protection Systems . . . . . . . 7-11

7.2 Material Control and Accountability ............ . 7-13

7.2 .1 Purpose .................. 7-13

7.2 .2 Scope $\ldots \ldots \ldots \ldots \ldots \ldots \ldots \ldots \ldots \ldots \ldots \ldots \ldots \ldots \ldots .13$

7.2 .3 Facilities . . . . . . . . . . . . . 7-14

7.2 .4 Categorization ............... 7.15

7.2.5 Nuclear Materials Accounting . . . . . . . . 7-16

7.2.6 Nuclear Material Control . . . . . . . . . . . . 7. 7-20

7.3 International Atomic Energy Association (IAEA) Safeguards . 7-25

7.3.1 IAEA Safeguards . . . . . . . . . . 7-25

7.3.2 Transparency ................. 7-25

7.3.3 Classified "Pits" . . . . . . . . . . . . . 7-25

ENVIRONMENT, SAFETY AND HEALTH . . . . . . . . . 8 8-1

8.1 Nuclear Material Transportation . . . . . . . . . . . . . 8 8-1

8.1.1 Introduction ................ 8-1

8.1.2 Fresh Fuel from Fuel Fabrication Plant . . . . . . 8-2

8.1.3 Waste from fuel fabrication plant . . . . . . . 8. 8-3

8.1.4 Waste from the Reactor ............. 8.3

8.2 Fuel Activities . . . . . . . . . . . . . . . . . . 8 8-4

8.2.1 Confinement and Ventilation ........... 8.4

8.2.2 MF $^{2}$ Thermal Wastes ............... 8-10

8.2.3 Safety Analysis and Impact on the Environmert . . 8 8-10

8.2.4 Spent Fuel . . . . . . . . . . . . 8.11

8.3 Waste Streams ................... 8-15

8.3.1 Waste Minimization Measures ......... 8-15

8.3.2 Plutonium Carryover . . . . . . . . . . . . . . 8-34

8.4 Protection Against Criticality . . . . . . . . . . . . . 8 8-37

8.4.1 Prevention ................. 8.37

8.4 .2 Detection and Alarm $\ldots \ldots \ldots \ldots \ldots \ldots . \ldots . . \ldots 8$ 8-37

8.4.3 Evacuation ................. 8-37 


\section{TABLE OF CONTENTS}

SECTION

IITLE

PAGE NO.

9.0

NON-PLUTONIUM DISPOSITIONING OPERATIONS . . . . . . . . . 9-1

9.1 Tritium Production . . . . . . . . . . . . . . . 9-1

9.1.1 Introduction ................. 9-1

9.1 .2 Scope of Study .................. 9-1

9.1.3 Tritium Production Assembly Design

Description .................... . 9-1

9.1.4 System 80 + PT Operational Features . . . . . . . . 9-14

9.1.5 Safety Impacts ................. . 9-15

9.1.6 Impact On Plant Operations . . . . . . . . . . 9-18

9.1 .7 Support Facilities ................ 9-21

9.1.8 Uranium Start-up Core Tritium Production Options . 9-26

9.1.9 Conclusions ... . . . . . . . . . . . . 9-27

9.2 Commercial Fuel Operation . . . . . . . . . . . . . 9 9-41

9.3 Spent Fuel Storage (Final Ten Years) . . . . . . . . . . . 9 9-43

9.4 Other Applications of this Technology . . . . . . . . . . 9-43

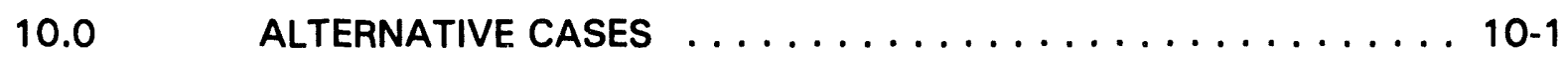

10.1 Departures from Information in Sections 2.0 through 9.0 for

Alternates 1,2 and $3 \ldots \ldots \ldots \ldots$ 10-1

10.2 Other Proposed Variations - Plant Design Features . . . . . 10-1

10.1 Capacity Factor Increased from $75 \%$ to $87 \%$. . . 10-2

10.2.2 Life of the Plant Increased from 40 Years to 50 Years $\quad \ldots \ldots \ldots \ldots \ldots$ 10-3

10.3 Other Proposed Variations - Financial Parameters . . . . . . . 10-4 10.3.1 Capacity "Firmness" Penalty. . . . . . . . . . . 10-5

10.4 Summary of Cases . . . . . . . . . . . . . . . . . . 10-6

10.5 Results ........................ 10-16

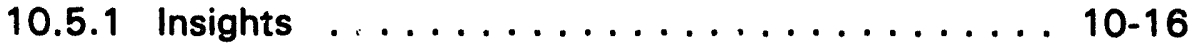

10.5.2 Conclusions ............... 10-17

11.0 LINKAGE WITH DISPOSITION IN RUSSIA AND OTHER COUNTRIES 11-1

11.1 Transparency and Proprietary Issues ........... 11-1

11.2 Transferability of Technology and Equipment ......... 11-1

11.3 Potential for Joint Programs . . . . . . . . . . . . 11-1

11.4 Enduring Monitoring and Control of Fissile Materials . . . . . 11-2

12.0 PUBLIC AND POLITICAL ACCEPTANCE $\ldots \ldots \ldots \ldots \ldots \ldots$

12.1 Approach for Achieving Public Acceptance . . . . . . . . 12-1

12.1.1 Introduction .................. 12-1

12.1.2 The Outreach Plan ............... 12-2 


\section{TABLE OF CONTENTS}

SECTION

IITLE

PAGENO.

12.2 Likelihood of National Political Acceptance . . . . . . . . . 12-6

12.3 Likelihood of Local or Regional Acceptance . . . . . . . . . . 12-7

13.0 CONCLUSIONS AND RECOMMENDATIONS $\ldots \ldots \ldots \ldots \ldots \ldots$

13.1 Five Key Challenges to Implementing Proposed Operation . . 13-1

13.2 Five Key Advantages to Implementing Proposed Operation . 13-1

13.3 Recommendacion .................... 13-2

\section{VOLUME 2}

Appendix A Uniform Descriptive Technical Data

Appendix B Summary of Nuclear Engineering Codes

Appendix C Summary of System $80+$ Design Description

Appendix D Program Plan for Qualifying Mixed Oxide Fuel 


\section{IABLE OF CONTENTS}

SECTION

LSST OF TABLES

PAGENO.

ES-1

Summary of Results

2.1.1-1

APR Impact on PWR System Requirements

2.1.1-2

Mixed-Oxide Fuel Cycle Characteristics

2.1.1-3

Safety Related Physics Characteristics for Mixed-Oxide Cycles

2.1.1-4

System $80+\mathrm{UO}_{2}$ Equilibrium Cycle

2.1.1-5

System $80+$ Pu Burner MOX Core Design

Characteristics

2.1.1-6

System $80+$ Tritium Production Core

Design Characteristics

2.1.1-7

Thermal Output Data for System $80+$

Plutonium Burner

2.1.1-8

Safety Related Physics Characteristics

for Mixed-Oxide Cycles . . . . . . . . . . . . . . . 2-34

2.1.1-9

Boric Acid Solubility in Water

2.1.1-10

Preliminary Physics Data for Plutonium

Disposition Core

2.1.1-11

Lithium Concentrations (ppm) Required for Combinations of Boron and $\mathrm{pH}$ at RCS

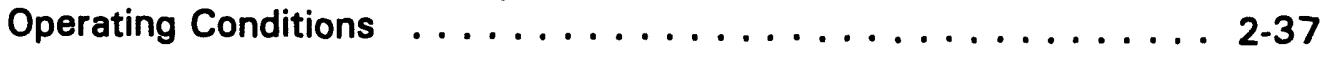

2.4.4-1 Process time and space Requirements for a $50 \mathrm{mt} /$ year MOX Fuel Facility . . . . . . . . . . . . 2-61

2.6-1 System 80 + Pu Burner MOX Core Design

Characteristics ........................ 2-82

2.6-2 Comparison of Safety Related Physics

Parameters 


\section{TABLE OF CONTENTS}

SECTION

2.6.1-1

2.6.3-1

2.6.4-1

3.1.7-1

3.1.7-2

3.1.7-3

3.1.7-4

3.1.7-5

3.1.7-6

3.1.7-7

3.1.7-8

3.1.7-9

3. $1.7-10$

3.1.7-11

3.2-1

$3.2-2$

3.2-3

4.2-1

\section{LISI OF TABLES (Cont'd)}

PAGENO

Deployment Strategy 2-85

As-charged Fuel Actinide Isotopic Composition Core Tonnes

Discharged Fuel Actinide Isotopic Composition Core Tonnes $2-89$

Critical Experiments: Uniform $\mathrm{UO}_{2}$ Lattices 3-19 Critical Experiments: Uniform $\mathrm{UO}_{2}-$ PuO Lattices 3-20 Summary of ROCS/DIT Calculation Uncertainties 3-21 ABB-CE Pin Cell Benchmark 3-22 CE Pin Cell CE Pin Cell 3-24 CE Pin Cell 3-25 CE Pin Cell 3-26 CE Pin Cell 3-28 CE Pin Cell 3-30 CE Pin Cell

Review Items as Specified in Section 4.2 Of the NRC SRP

Fuel Rod Thermal/Mechanical Performance Models

Summary Listing of MOX Types and Conditions

Discussed in References 3-60 Preoperational Tests 


\section{IABLE OF CONTENTS}

SECTION

LIST OF TABLES (Cont'd)

PAGE NO

4.2-2

Post-core Hot Functional Tests

4-22

$4.2-3$

Low Power Physics Tests

4.2-4

Power Ascension Tests

4.2-5

Power Ascension Tests

4.2-6

Lower Power Physics Test Parameters

4.2-7

Power Ascension Test Sequence

4.3-1

Standard $\mathrm{UO}_{2}$ Required Physics Test Program

$5.1-1$

Ranges of Initial Conditions for Safety Analyses

$5.1-2$

Parameters for Safety Analyses Commercial

Uranium Reactor Versus Plutonium Burner

$5.1-3$

Design Basis Events for Safety Analyses

$5.1-4$

Single Failures Assumed for Safety Analyses

$5.1-5$

Thermal Power of a Single Fuel Assembly for Pu and $U$ Cores

$5.1-6$

Comparison of Fission Product Activity at

Discharge

5.1-7 Comparison of Activities by Element at Discharge and 96 Hours After Shutdown

5.2-1 Typical Regulatory and Environmental Permits and Licenses for PlutoniumDisposition Facility . . . . . . . . . . . . . . . . . . 5-44

$6.1-1$

$6.1-2$

Capital and Operating Costs System $80+$

Plutonium Disposition Plants

Capital Cost Estimate by EEDB Cost Account 1 Unit

$25 \mathrm{mt} / \mathrm{yr}$ MOX Facility East/West Central Site 


\section{IABLE OF CONTENTS}

SECTION

LIST OF TABLES (Cont'd)

PAGENO.

6.1-3

6.1-4

6.1-5

6.1-6

6.1-7

6.1-8

6.1-9

6.1-10

6.1-11

6.1-12

6.2-1

6.3.1-1

6.3.1-2

6.3.1-2

6.3.1-2

6.3.2-1

6.3.2-2
Capital Cost Estimate by EEDS Cost Account 2 Unit $50 \mathrm{mt} / \mathrm{yr}$ MOX Facility East/West Central Site

Capital Ccost Estimate by EEDS Cost Account 4 Unit $100 \mathrm{mt} / \mathrm{yr}$ MOX Facility East/West Central Site

Capital Cost Estimate by EEDS Cost Ascount 1 Unit $25 \mathrm{mt} / \mathrm{yr}$ MOX Facility Savannah River Site

Capital Cost Estimate by EEDS Cost Account 2 Unit $50 \mathrm{mt} / \mathrm{yr}$ MOX Facility Savannahı River Site

Constant Dollar LCC Summary

Constant Dollar Capital Cost Forecast

Constant Dollar Capital Cost Forecast

Constant Dollar Capital Cost Forecast

Constant Dollar Capital Cost Forecast

Constant Dollar Capital Cost Forecast

Manual Manhours By Craft

Staffing Assumptions

6-16

One-Unit Staffing Matrix (Sheets 1 and 2)

Two-Unit Staffing Matrix (Sheets 3 and 4)

Four-Unit Staffing Matrix (Sheets 5 and 6)

Annual 0 \& M Costs

Production Costs (\$/MW Hr)

6-27 


\section{TABLE OF CONTENTS}

SECTION

7.2.4-1

8.2.4-1

8.2.4-2

8.3.1-1

8.3.1-2

8.3.1-3

8.3.1-4

8.3.1-5

8.3.2-1

9.1-1

9.1-2

$9.1-3$

$9.1-4$

9.1-5
LIST OF TABLES (Cont'd)

PAGENO.

Categories and Attractiveness of Nuclear

Materials ......................... 7-16

Shipping Cask Evaluation Parameters $\ldots \ldots \ldots \ldots$. . . . . . 8-13

New and Spent Fuel Shipment . . . . . . . . . . . . . 8-14

Summary of Environmental Conditions for Nuclear Fuel

(Uranium) Cycle . . . . . . . . . . . . . . . . . . . . 8-27

Commercial Scale Mixed Oxide Fuel Fabrication Plant

Parameters and Solid Waste Volume . . . . . . . . . . . . . . . 8-29

Estimated Doses from Radioactive Liquid Effluents

Released from the Station . . . . . . . . . . . . . . 8 8-31

Estimated Annual Doses from Gaseous Effluent from

a Single Unit . . . . . . . . . . . . . . . . . 8-32

Cessar System $80+$ Estimated Solid Waste Generation

Burial Volume Basis . . . . . . . . . . . . . . . . 8-33

Cessar system 80 + solid waste Source Term for

Normal Operation Estimated Average

Radionuclide Concentrations (uci/gm)

Summary of System $80+P$ and System $80+P T$

Design Parameters . . . . . . . . . . . . . . . . . . . . . . . 9-29

Target Design for the System $80+$ PT . . . . . . . . . . . . 9-31

Cost Estimate for Completion of the TTDP9-32

Components/Assemblies for Fabrication of

Target Rods

Estimates of Equipment, Unit Operational

Space, and Direct Manning Requirements for

Components Receiving Inspection, Target Rod

Assembly, and Final Inspection Operations 


\section{IABLE OF CONTENTS}

SECTION

LIST OF TABLES (Cont'd)

PAGENO.

9.1-7

Tritium Extraction Facility Costs . . . . . . . . . . . 9-38

$9.2-1$

System $80+\mathrm{UO}_{2}$ Equilibrium Cycle

10.4-1

Case Characteristics .

$10.4-2$

Alternative Case Descriptions Plutonium

Disposition Study . . . . . . . . . . . . . . . . . . . 10-8

$10.4-3$

Deployment Strategy . . . . . . . . . . . . . . . . 10-9

$10.4-4$

Deployment Strategy

$10-10$

10.4-5

Alternative 3 - $100 \mathrm{mt} \mathrm{Pu}$ in 40 Years Schedule -

Months Since Start of Project $\ldots \ldots \ldots \ldots \ldots \ldots \ldots$ 10-11

10.4-6

Alternate Rc 87\% CF and 3 @ 15-mo Cycles

$10-12$

10.4-7

Deployment Strategy

$10-13$

$10.4-8$

Alternate A2cl 87\% CF 3 @15-mo Cycles 60

Year Plant Life

$10.4-9$

Discharged Fuel Actinide Isotopic Composition

$87 \%$ CF and Higher Burnup Options Core Tonnes 10-15

$10.5-1$

Constant Dollar LCC Summary .

C-1-1

Envelope of Plant Site Design Parameters

C-3

C-2-1

Major Building Functions

C-22 


\section{IABLE OF CONTENTS}

SECTION

LIST OF TABLES (Cont'd)

PAGE NO.

C-8-1

Personnel Required for Fast Refueling . . . . . . . . . . . . . . C-437

C-8-

On-site Operations and Maintenance Functions $\ldots \ldots \ldots \ldots$. . . . 339

C-8-3

Minimum Shift Crew Composition

C. 145

C-9-1

System $80+$ Estimated Solid Waste Generation

Burial Volume Basis

C-9-2

System $80+$ Solid Waste Source Term for

Normal Operacion Estimated Average

Radionuclide Concentrations ( $\mu \mathrm{ci} / \mathrm{gm})$

C-9-3

Sources, Estimated Volumes and Activities

of Liquid Waste Management System Inputs

C-9-4

Sources, Volumes and Flow Rates of Stripped

Gases from the Primary Coolant

C-10-1

Plant and Fuel Rod Integrity Limits for

Design Basis Events . . . . . . . . . . . . . . . . . . . C-193

C-10-2 LOCA Acceptance Criteria . . . . . . . . . . . . . . . C-194

C-10-3 Dose Limits for Normal Operating Conditions

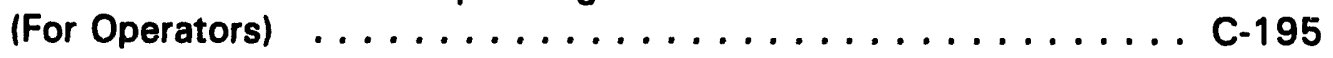

C-10-4 Dose Limits for Normal Operating Conditions

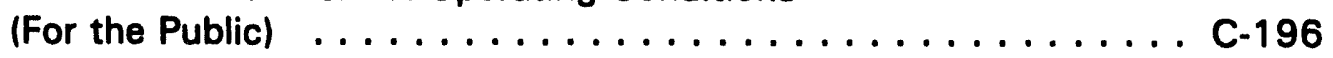

C-10-5 Dose Limits Based on Frequency of Fault

Sequences from Deterministic Fault

Schedule . . . . . . . . . . . . . . . . . . . . . . . . . C-197

C-10-6 Core Damage Frequency Contributions

for Dominant Accident Sequences

by Initiating Internal Event 


\section{IABLE OF CONTENTS}

SECTION

LIST OF TABLES (Cont'd)

PAGE NO.

C-10-7a

Sequence of Events for Full Power Inadvertent Opening of a Steam

Generator Atmospheric Dump Valve (IOSGADV)

with Loss of Offsite Power

C-203

C-10-7b Sequence of Events for Full Power Inadvertent Opening

of a Steam Generator Atmospheric Dump Valve with Loss

of the Feedwater Control System Reactor Trip Override

(IOSGADV + SF) and with Loss of Offsite Power . . . . . . . . . C C-204

C-10-7c Sequence of Events for a Large Steam Line

Break During Full Power Operation with

Offsite Power Available (SLBFP) . . . . . . . . . . . . . . . . . C-205

C-10-8 Core Damage Frequency Contribution by

Initiating Event . . . . . . . . . . . . . . . . . . . . . . . C-206

C-10-9 Single Failures $\ldots \ldots \ldots \ldots \ldots \ldots \ldots \ldots \ldots \ldots \ldots$. . . . . . . . . .

C-0-1 Summary Comparison of Plant Parameters $\ldots \ldots \ldots \ldots \ldots$ C-210

D-3-1 Postirradiation Examinations $\ldots \ldots \ldots \ldots \ldots \ldots \ldots$ D-231

D-3-2 $\begin{aligned} & \text { Postirradiation Examinations of ATR } \\ & \text { Rods (Total of } 20 \text { ) } \ldots \ldots \ldots \ldots \ldots \ldots \ldots \ldots \ldots \ldots \ldots \ldots \ldots \ldots \ldots\end{aligned}$

D-3-3 Program Tasks and Performing Organizations . . . . . . . D-233

D-3-4 Program Task and Activity Outline . . . . . . . . . . D-234

D-3-5 Milestone List and Schedule $\ldots \ldots \ldots \ldots \ldots \ldots \ldots \ldots$

D-3-6 Estimated Cost $\ldots \ldots \ldots \ldots \ldots \ldots \ldots \ldots \ldots \ldots \ldots$

D-4-1 Example Specifications for $\operatorname{MOX}(80+1 \ldots \ldots \ldots \ldots \ldots$

D-4-2 Tasks and Activities for Fuel Fabrication . . . . . . . . D-244

D-4-3 Milestone Schedule for Fuel Fabrication . . . . . . . . . . D-246

D-6-1 Examinations on Samples from ATR MOX-80 + Rods . . . . . D-252 


\section{IABLE OF CONTENTS}

\section{LST OF FIGURES}

EIGURENO. ELGURE TITLE

2.1.1-1 Reactor Core Cross Section

2.1.1-2 4 and 12 Finger Control Element Assemblies

2.1.1-3 Full Strength Control Element Assembly (12 Finger)

2.1.1-4 Twelve-Fingered CEA Inserted In Five Fuel Assemblies

2.1.1-5 Upper Guide Structure Assembly

2.1.1-6 Control Element Assembly and In-Core Instrument Locations

2.1.1-7 Control Element Assembly Locations - All Plutonium Reactor

2.1.1-8 Erbium Abundances and Depletion Chain

2.1.1-9 Comparison of $\mathrm{Er}^{169}$ and $\mathrm{Pu}^{239}$ Neutron Cross Characteristics

2.1.1-10 System $80+$ Plutonium Tritium Production Fuel Assembly Layout

2.1.1-11 System $80+$ Plutonium Burner Fuel Assembly Layout

2.3-1 Shutdown Cooling \& Containment Spray Systems

2.3-2 Emergency Feedwater System Diagram

2.3-3 Safety Injection System

2.3-4 Safety Depressurization System

2.4.2-1 Overall MOX Process

2.4.3-1 Conceptual MF² Site Plan

2.4.4-1 Conceptual $M^{2}$ Main Floor Layout

2.4.4-2 Conceptual $M^{2}$ Process and Fuel Assembly Areas Layout 


\section{Combustion Eingineering, Inc.}

\section{IABLE OF CONTENTS}

\section{LST OF FIGURES (Cont'd)}

EIGURE NO FIGURE TITLE

2.4.7-1 Representative Flow MOX Pellet Process

2.5-1 Fuel Handling Arrangement

2.6-1 Loading Pattern (Typical)

2.6-2 Core Rod Worths vs Exposure

2.6-3 Inverse Boron Worth vs Burnup

2.6.4 Core Rod Worths vs Exposure

2.6-5 MTC vs Burnup

2.7.4-1 Levelized Schedule For Shipping (Base Case)

6.3.1-1 Organization Structure

6.3.1-2 Staffing Assumptions

6.3.2-1 Production Costs ( $\$ / M W H R$ ) vs. Capacity Factor

6.4-1 Discontinued Dollar Sensitivity Curve - System $80+$

6.6-1 Project Summary Network

9.1-1 System $80+$ P Fuel Assembly Layout

9.1-2 System 80+ PT Fuel Assembly Layout

9.1-3 Reactivity Burnup Curve for System 80+ PT Fuel

9.1-4 Moderator Temperature Coefficient Curves for System $80+P$ and System $80+$ PT Fuel

9.1-5 Doppler Coefficient Curve for System 80+ PT Fuel

9.1-6 Plutonium Isotopic Fractions As A Function Of Burnup For System $80+P$ and System $80+$ PT Fuel 


\section{IABLE OF CONTENTS}

\section{LIST OF FIGURES (Cont'd)}

EIGURENO. EIGURE TITLE

9.1-7 System $80+$ PT Target Cross Sectional View

9.1-8 Getter-Barrier Target Rod Qualification Plan for the System $80+$ Reactor

9.1-9 Target Fabrication Facility Process Flow Diagram

9.1-10 Tritium Recovery Facility Process Fiow Diagram

10.5-1 Constant Dollar LCC Summary

\section{APPENDICIES LIST OF FIGURES}

FIGURENO. EIGURE TITLE

C-1-1 Plot Plan Plutonium Disposition Study - 1 Unit

C-1-2 Plot Plan Plutonium Disposition Study - 2 Units

C-1-3 Plot Plan Plutonium Disposition Study - 4 Units

C-1-4 System $80+$ Process Overview of the Plutonium Disposal Complex

C-2-1 System $80+$ Nuclear Island Elevation View

C-2-2 System $80+$ Nuclear Island Elevation View Rotated 90

C-2-3 Nuclear Island General Arrangement Plan at Elevation $115+6$

C-3-1 Reactor Coolant System Arrangement

C-3-2 Reactor Coolant System

C-3-3 Reactor Vessel

C-3-4 Reactor Vessel Supports

C-3-5 Reactor Arrangement 


\section{TABLE OF CONTENTS}

\section{APPENDICIES LIST OF FIGURES (Cont'd)}

FIGURENO. FIGURE TITLE

C-3-6 Reactor Upper Guide Structure Assembly

C-3-7 Reactor Core Cross Section

C-3-8 Fuel Assembly

C-3-9 4 and 12 Finger Control Element Assemblies

C-3-10 Control Element Drive Mechanism

C-3-11 Steam Generator

C-3-12 Steam Generator Economizer Arrangement (Elevation View)

C-3-13 Stream Generator Economizer Region

C-3-14 Centrifugal Separator

C-3-15 Hooked Vane Dryers

C-3-16 Steam Generator Bend Region Tube Supports

C-3-17 Steam Generator Horizontal Tube Support Details

C-3-18 Steam Generator Blowdown Duct Arrangement

C-3-19 Steam Generator Supports

C-3-20 Pressurizer

C-3-21 Reactor Coolant Pump

C-3-22 Reactor Coolant Pump Supports

C-4-1 Safety Depressurization System

C-4-2 Shutdown Cooling System 


\section{IABLE OF CONTENTS}

\section{APPENDICIES LIST OF FIGURES (Cont'd)}

\begin{tabular}{ll} 
EIGURE NO & ElGURE TITLE \\
C-4-3 & Safety Injection System/Containment Spray System Short-Term Mode \\
C-4-4 & Safety Injection System/Containment Spray System Long-Term Mode \\
C-4-5 & Emergency Feedwater System \\
C-4-6 & Component Cooling Water System \\
C-4-7 & Containment General Arrangement \\
C-5-1 & Chemical and Volume Control System Block Diagram \\
C-5-2 & Process Sampling System Flow Diagram \\
C-5-3 & Nuplex 80+ Advanced Control Complex \\
C-5-4 & Nuplex 80+ Control Room Configuration \\
C-5-5 & Main Control Room and Technical Support Center \\
C-5-6 & Typical Nuplex 80+ Control Panel \\
C-5-7 & DIAS-N Segment Block Diagram \\
C-5-8 & Data Processing System Configuration \\
C-5-9 & PPS Basic Block Diagram \\
C-5-10 & ESFAS Functional Logic (SIAS) \\
C-5-11 & Power Control System Simplified Block Diagram \\
C-6-1 & Reactor Building Refueling Equipment Arrangement \\
C-6-2 & Reactor Building Pool Arrangement (Plan View) \\
C-6-3 & Reactor Building Pool Arrangement (Elevation View) \\
C-6-4 & Refueling Machine \\
\hline
\end{tabular}




\section{TABLE OF CONTENTS}

\section{APPENDICIES LIST OF FIGURES (Cont'd)}

FIGURENO. FIGURE TITLE

C-6-5 Fuel Transfer System Carriage and Upender (Reactor Building)

C-6-6 Fuel Transfer System Carriage and Upender (Nuclear Annex System)

C-6-7 Closure Head Lifting Rig Assembly

C-6-8 CEDM Cooling Manifold

C-6-9 Head Area Cable Tray System

C-6-10 Upper Giside Structure Lift Rig Assembly

C-6-11 CEA Change Platform

C-6-12 CEA Elevator

C-6-13 Dummy Fuel Assembly

C-6-14 12 Rod Dummy CEA

C-6-15 Spent Fuel Handling Machine

C-6-16 Fuel Transfer Tube Assembly

C-6-17 Spent Fuel Handling Tool

C-6-18 New Fuel Handling Tool

C-7-1 Heat Balance Diagram

C-7-2 Compensate, Feedwater and Heater Drain Systern

C-7-3 Main Steam and Extraction Steam Systems

D-3-1 Qualifying Mixed Oxide Fuel - Major Program Elements 
Combustion Engineering, Inc.

\section{IABLE OF_CONTENTS \\ APPENDICIES LIST OF FIGURES (Cont'd)}

EIGURENO FIGURE TITLE

D-3-2 Fuel Performance Testing of MOX Rods

D-3-3 Milestone Chart for MOX Fuel Irradiations

D-4-1 Example Pellet Production Flow Sheet 


\section{LIST OF ACRONYMS AND TERMINOLOGY}

Generally, terms and abbreviations are defined at the time they are first introduced in the following report. The more commonly found terms and abbreviations which are appropriate to the System $80+{ }^{m}$ station design and Plutonium Disposition Study are compiled below as a convenient reference for the reviewer. In the interest of practical application, not every possible scientific term or abbreviation is listed.

$\begin{array}{ll}\text { ABB-CE } & \text { Asea Brown Boveri-Combustion Engineering } \\ \text { ADV } & \text { Atmospheric Dump Valve } \\ \text { ALARA } & \text { As Low As Reasonably Achievable } \\ \text { ALWR } & \text { Advanced Light Water Reactor } \\ \text { APR } & \text { All Plutonium Reactor } \\ \text { APS } & \text { Alternate Protection System } \\ \text { ASTM } & \text { American Society for Testing and Materials } \\ \text { ATR } & \text { Advanced Test Reactor } \\ \text { ATWS } & \text { Anticipated Transient Without Scram } \\ \text { AVS } & \text { Annulus Ventilation System } \\ \text { BAST } & \text { Boric Acid Storage Tank } \\ \text { BNWL, BNL } & \text { Battelle Northwest Laboratories } \\ \text { BPR } & \text { Burnable Poison Rod } \\ \text { CA } & \text { Controlled Area } \\ \text { CAS } & \text { Central Alarm Station } \\ \text { CBC } & \text { Critical Boron Concentration } \\ \text { CCTV } & \text { Closed Circuit Television } \\ \text { CCW(S) } & \text { Component Cooling Water (System) } \\ \text { CEA } & \text { Control Element Assembly } \\ \text { CEDM } & \text { Control Element Drive Mechanism } \\ \text { CEG } & \text { Cost Estimating Guidelines } \\ \text { CESSAR-DC } & \text { Combustion Engineering Standard Safety Analysis Report - Design } \\ & \text { Certification } \\ \text { CIS } & \text { Commonwealth of Independent States } \\ \text { CM } & \text { Corrective Maintenance } \\ \text { CPC } & \text { Core Power Calculator } \\ \text { CRO } & \text { Clean Rejected Oxide } \\ \text { CRT } & \text { Cathode Ray Tube } \\ \text { CS } & \text { Containment Spray (System) } \\ \text { CSAS } & \text { Containment Spray Actuation Signal } \\ \text { CSB } & \text { Core Support Barrel } \\ \text { CVCS } & \text { Chemical and Volume Control System } \\ \text { DBE } & \text { Design Basis Event } \\ \text { D\&D } & \text { Decontamination \& Decommissioning } \\ \text { DE\&S } & \text { Duke Engineering and Services } \\ \text { DIAS } & \text { Discrete Indication and Alarm System } \\ \text { DIT } & \text { Discrete Integral Transport } \\ \text { DNB } & \text { Departure from Nucleate Boiling } \\ & \end{array}$




\begin{tabular}{|c|c|}
\hline $\begin{array}{l}\text { DDO } \\
\text { DOE } \\
\text { DOT } \\
\text { DPS } \\
\text { DRO } \\
\text { DVI } \\
\text { ECA } \\
\text { ECS } \\
\text { EFPD } \\
\text { EFW(S) } \\
\text { EFWST } \\
\text { EIS } \\
\text { EOC } \\
\text { EOP } \\
\text { EPRI } \\
\text { ESFAS } \\
\text { ESW(S) } \\
\text { EWG } \\
\text { FBR } \\
\text { FEA } \\
\text { FMEF } \\
\text { FPF } \\
\text { FRS } \\
\text { FTC } \\
\text { FTFF } \\
\text { GVR } \\
\text { GWD } \\
\text { GWMS } \\
\text { HACTS } \\
\text { HEPA } \\
\text { HJTC } \\
\text { HPSI } \\
\text { HRA } \\
\text { HVAC } \\
\text { IAEA } \\
\text { ICI } \\
\text { ID } \\
\text { IDS } \\
\text { INEL } \\
\text { INPO } \\
\text { IPP } \\
\text { IPSO } \\
\text { IRWST } \\
\text { ITAAC }\end{array}$ & $\begin{array}{l}\text { Destruction Deployment Option } \\
\text { U.S. Department of Energy } \\
\text { Department of Transportation } \\
\text { Data Processing System } \\
\text { Dirty Rejected Oxide } \\
\text { Direct Vessel Injection } \\
\text { Energy Conversion Area } \\
\text { Entry Control Systems } \\
\text { Effective Full Power Days } \\
\text { Emergency Feedwater (System) } \\
\text { Emergency Feedwater Storage Tank } \\
\text { Environmental Impact Staternent } \\
\text { End of Cycle } \\
\text { Emergency Operating Procedures } \\
\text { Electric Power Research Institute } \\
\text { Emergency Safety Features Actuation Signal } \\
\text { Essential Service Water (System) } \\
\text { Electric Wholesale Generator } \\
\text { Fast Breeder Reactor } \\
\text { Fuel Element Assembly } \\
\text { Fuels and Material Examination Facility } \\
\text { Fuel Pin Fabrication } \\
\text { Fuel Receiving and Storage } \\
\text { Fuel Temperature Coefficient } \\
\text { Fuel and Target Fabrication Facility } \\
\text { Gas-to-Volume Ratio } \\
\text { Gigawatt-Days } \\
\text { Gaseous Waste Management System } \\
\text { Head Area Cable Tray Structure } \\
\text { High Efficiency Particulate Air (Filter) } \\
\text { Heated Junction Thermocouple } \\
\text { High Pressure Safety Injection } \\
\text { Human Reliability Analysis } \\
\text { Heating, Ventilation and Air Conditioning } \\
\text { International Atomic Energy Agency } \\
\text { In-Core Instrumentation } \\
\text { Intrusion Detection } \\
\text { Intrusion Detection System } \\
\text { Idaho National Engineering Laboratory } \\
\text { Institute of Nuclear Power Operations } \\
\text { Independent Power Producer } \\
\text { Integrated Process Status Overview } \\
\text { In-Containment Refueling Water Storage Tank } \\
\text { Inspection, Test, Analysis Acceptance Criteria }\end{array}$ \\
\hline
\end{tabular}




\section{LIST OF ACRONYMS AND TERMINOLOGY (Cont'd)}

\begin{tabular}{|c|c|}
\hline $\begin{array}{l}\text { LAA } \\
\text { LCO } \\
\text { LDB } \\
\text { LHGR } \\
\text { LOCA } \\
\text { LTA } \\
\text { LTOP } \\
\text { LWMS } \\
\text { MAA } \\
\text { MBA } \\
\text { MF' } \\
\text { MF } \\
\text { MFIV } \\
\text { MOPS } \\
\text { MOX } \\
\text { MRS } \\
\text { MSIV } \\
\text { MSSA } \\
\text { MST } \\
\text { MT, MTU } \\
\text { MTC } \\
\text { MTHM } \\
\text { MTM } \\
\text { MWD } \\
\text { MW(t) } \\
\text { NDE } \\
\text { NEPA } \\
\text { NRC } \\
\text { NPR } \\
\text { OBE } \\
\text { O\&M } \\
\text { ONM } \\
\text { PA } \\
\text { PBRC } \\
\text { PBRF } \\
\text { PDR } \\
\text { PDS } \\
\text { PIE } \\
\text { PM } \\
\text { PRA } \\
\text { PRF } \\
\text { PSAP } \\
\text { PSN } \\
\text { PVNGS }\end{array}$ & $\begin{array}{l}\text { Limited Access Area } \\
\text { Limiting Conditions of Operation } \\
\text { Licensing Design Basis } \\
\text { Lineal Heat Generation Rate } \\
\text { Loss of Coolant Accident } \\
\text { Lead Test Assembly } \\
\text { Low Temperature Over Pressurization } \\
\text { Liquid Waste Management System } \\
\text { Material Access Area } \\
\text { Material Balance Area } \\
\text { Mixed Oxide Fuel Facility } \\
\text { MOX Fabrication Facility } \\
\text { Main Feedwater Isolation Valve } \\
\text { Moisture Preseparators } \\
\text { Mixed Oxide } \\
\text { Material Receiving and Storage } \\
\text { Main Steam Isolation Valve } \\
\text { Master Safeguards and Security Agreeme } \\
\text { Multiple Stud Tensioner } \\
\text { Metric Ton (Uranium) } \\
\text { Moderator Temperature Coefficient } \\
\text { Metric Tons of Heavy Metal } \\
\text { Metic Ton of Metal } \\
\text { Megawatt-Days } \\
\text { Megawatt-Thermal } \\
\text { Non-Destructive Examination } \\
\text { National Environmental Policy Act } \\
\text { Nuclear Regulatory Commission } \\
\text { New Production Reactor } \\
\text { Operating Basis Earthquake } \\
\text { Operation and Maintenance } \\
\text { Other Nuclear Materials } \\
\text { Protected Area } \\
\text { Plutonium Burner Reactor Complex } \\
\text { Plutonium Burner Reactor Facility } \\
\text { Plutonium Disposition Reactor } \\
\text { Plutonium Disposition Study } \\
\text { Post Irradiation Examinations } \\
\text { Preventive Maintenance } \\
\text { Probabilistic Risk Assessment } \\
\text { Permeation Reduction Factci } \\
\text { Personnel Security Assurance Program } \\
\text { Project Summary Network } \\
\text { Palo Verde Nuclear Generating Station }\end{array}$ \\
\hline
\end{tabular}


LIST OF ACRONYMS AND TERMINOLOGY (Cont'd)

\begin{tabular}{|c|c|}
\hline $\begin{array}{l}\text { PWR } \\
\text { RAA } \\
\text { RCB } \\
\text { RCM } \\
\text { RCP } \\
\text { RCGV } \\
\text { RCS } \\
\text { RD } \\
\text { RDT } \\
\text { RPCS } \\
\text { RPS } \\
\text { RSPT } \\
\text { SA } \\
\text { SAF } \\
\text { SAS } \\
\text { SBO } \\
\text { SC } \\
\text { SCRUPS } \\
\text { SCS } \\
\text { SCV } \\
\text { SDS } \\
\text { SF-O } \\
\text { SF-1 } \\
\text { SF-2 } \\
\text { SFS } \\
\text { SG } \\
\text { SGF } \\
\text { SGR } \\
\text { SIISI } \\
\text { SIT } \\
\text { S-O } \\
\text { SMB } \\
\text { SNM } \\
\text { SRS } \\
\text { SSE } \\
\text { SSSP } \\
\text { SWEC } \\
\text { SWMS } \\
\text { TID } \\
\text { T\&Q } \\
\text { TSD } \\
\text { TTDP } \\
\text { UBC }\end{array}$ & $\begin{array}{l}\text { Pressurized Water Reactor } \\
\text { Restricted Access Area } \\
\text { Reactor Containment Building } \\
\text { Reliability Centered Maintenance } \\
\text { Reactor Coolant Pump } \\
\text { Reactor Coolant Gas Vent } \\
\text { Reactor Coolant System } \\
\text { Requirements Document } \\
\text { Reactor Drain Tank } \\
\text { Reactor Power Cutback System } \\
\text { Reactor Protection System } \\
\text { Reed Switch Position Transmitter } \\
\text { Site Area } \\
\text { Secure Automated Fabrication } \\
\text { Secondary Alarm Station } \\
\text { Station Black Out } \\
\text { Shutdown Cooling (System) } \\
\text { Special Cross-Under Pipe Separators } \\
\text { Shutdown Cooling System } \\
\text { Steel Containment Vessel } \\
\text { Safety Depressurization System } \\
\text { Spent Fuel Deployment Option } \\
\text { Spent Fuel Deployment Option - 1 Reactor } \\
\text { Spent Fuel Deployment Option - 2 Reactors } \\
\text { Spent Fuel Storage } \\
\text { Steam Generator } \\
\text { Site Guard Force } \\
\text { Self Generated Recycle } \\
\text { Safety Injection (System) } \\
\text { Safety Injection Tank } \\
\text { Spiking Deployment Option } \\
\text { Safety Margin Basis } \\
\text { Special Nuclear Materials } \\
\text { Savannah River Site } \\
\text { Safe Shutdown Earthquake } \\
\text { Site Safeguards and Security Plan } \\
\text { Stone and Webster Engineering Corporation } \\
\text { Solid Waste Management System } \\
\text { Tamper Indicating Device } \\
\text { Training and Qualification (Program) } \\
\text { Transportation Safeguards Division } \\
\text { Tritium Target Development Program } \\
\text { Uniform Building Code }\end{array}$ \\
\hline
\end{tabular}




\section{Combustion Engineering, Inc.}

\section{LIST OF ACRONYMS AND TERMINOLOGY (Cont'd)}

$\begin{array}{ll}\text { UGS } & \text { Upper Guide Structure } \\ \text { UPS } & \text { Uninterruptible Power Supply } \\ \text { URD } & \text { Utility Requirements Document } \\ \text { VA } & \text { Vital Area } \\ \text { WANO } & \text { World Association of Nuclear Operators } \\ \text { WNP, WNPP } & \text { Washington Nuclear Power Project }\end{array}$




\section{EXECUTIVE SUMMARY}

Under contract from the Department of Energy, ABB-CE has been furthering the stury of the System 80 + reactor to dispose of mission quantities of excess weapons grade plutonium, by fabricating it into fuel assemblies suitable for insertion in the System $80+$ reactor, irradiating the fuel to produce electric power, and discharging the spent fuel in a condition similar in activity and plutonium isotopic content to uranium-fueled LWR spent fuel. This has been named the Spent Fuel Option, to distinguish it from other options of disposition.

The initial phase of the study, completed and reported in May, 1993, together with similar studies by other reactor vendors, was the basis for the Technical Review Committee Report, issued by the DOE in July, 1993. This report concluded that the fission option would increase the proliferation resistance of the excess weapons grade plutonium in three ways: by diluting it with other materials; by isotopically diluting the plutonium by nuclear transmutation; and by creating a built-in radiation protection barrier due to the generation of fission products. Although each reactor concept studied and each endpoint alternative would provide this desired increase in the proliferation resistance, the study showed that the Spent Fuel Option appeared to be the most effective way to achieve that goal. Furthermore, the evolutionary LWRs, specifically System $80+$, had significant advantages over other concepts in technological readiness, schedule, plutonium throughput and economics.

The initial phase of the study was also the source of another assessment report, by the National Academy of Sciences, which was issued in February, 1994. This report confirmed the findings of the DOE report, and recommended that, for the long-term disposition of the excess weapons plutonium, the technologies of vitrification with high-level waste, and use of the material as fuel in existing or modified nuclear power plants, were the most promising. In this report, it was specifically mentioned that the C-E System 80 reactors, which were originally designed for $100 \%$ plutonium fuel operation, were particularly suitable for the mission. The System $80+$, which retains the plutonium-affected features of System 80 , along with features meeting the EPRI guidelines for increased safety, reliability and operability, therefore remains the reactor of choice for the plutonium disposition mission.

The continuation of the study, which is the subject of this report, focused on the application of the System $\mathbf{8 0}+$ plant to the plutonium disposition mission under four scenarios. In addition, variations in the defined parameters of the evaluation, including an increase in plant capacity factor from $75 \%$ to $87 \%$, and an increase in plant life from 40 years to 60 years, both of which are believed to be justified on the basis of the System 80 + design features and the level of industrial experience, were studied. In every case, the mission goals of plutonium throughput, discharged isotopic content, and electric generation were successfully accomplished. Table ES-1 summarizes the results of the study. 
The licensed power level of the System $80+$ reactor with uranium fuel is $3914 \mathrm{MWt}$. With MOX fuel, wherein the mission quantities are still in a conceptual stage, and the level of fuel management analysis has not reached the detailed stage that is available for uranium cores, the assumed power level of the System $80+$ with MOX fuel has been set about $3 \%$ lower, to $3800 \mathrm{MWt}$. It is quite conceivable that when the details of the mission are established, additional fuel management analysis can be performed that would allow an increase in the power output to the licensed System $80+$ level. In any event, since the plutonium disposition mission is in most cases completed before the reactor has reached the plant life limit, continuing operation of the unit with uranium fuel at the licensed maximum power level is assumed.

Estimates of the safety analysis of System $80+$ that would result with MOX fuel have been made, on the basis of the preliminary safety parameters affected by the presence of plutonium in mission quantities 16.7 wt. \% weapons plutonium oxide in depleted uranium). No threat to the performance of the reactor under normal operation, Design Basis Events or Severe Accident events, that would indicate a potential licensing concern, has been identified. This conclusion confirms earlier studies, performed under the Generic Environmental Statement on Mixed Oxide fuel program (GESMO).

Preliminary estimates of a MOX fuel fabrication facility were made. A facility capable of 50 Metric Tons of Heavy Metal (MTHM/yr) output of delivered fuel, about 120 assemblies of the System $80+$ design, was selected as the base case. The expansion of the output to as much as $100 \mathrm{MTHM} / \mathrm{yr}$ was made possible by the addition of extra sintering furnaces: this would also require two shift operation. The facility construction schedule, which is dependent on the front-end licensing process, allows the completion of the facility in time to produce the fuel for the System 80 + reactors (each taking about 100 MTHM of fuel for a full core load), which are to be placed into operation approximately two years apart. The fuel process is very similar to one now in operation at Los Alamos, in the TA-55 area, on an experimental basis. However, brief comparisons with world-wide experience, notably in Europe, indicate that the process would benefit considerably, in cost of product and in safeguards and security, by detailed refinement based on the experience of others.

The System $80+$ MOX fuel loading consists of a fuel pellet, containing 6.7 wt. \% weapons-grade plutonium in oxide form, admixed with up to $2.5 \%$ erbium oxide, with the balance depleted uranium oxide. The remainder of the fuel is identical to commercial uranium oxide fuel, in terms of design, structure, and assembly processes. A full core loading of 241 assemblies is loaded into the core, and will reside in the core without refueling for 3.5 to 4 years, depending on the capacity factor, until the desired burnup has been reached. During that residence period, the fuel assemblies will undergo two or three shufflings to assure more uniform burnup and control of local power distribution. At the end of this residence time, the spent fuel is removed to the fuel storage pool, and replaced with an entire fresh fuel loading. There is no difference between the initial core and the reload cores. Upon completion of the mission, the core is reloaded with uranium fuel to run for the balance of the plant life. 
Conceptually, this is the simplest fuel management plari. Other plans involving batch reloads of one-half, one-third or one-quarter of the core have been found to work, and may be shown to have some advantages over the four-year core, when detailed fuel management calculations are made.

There are no technology needs for System $80+$. It has a rating of 7 , the final level of technology readiness, on the Omberg and Walter scale. This is backed up by the CESSAR System 80 + Design Certification (FSER released by the NRC with no open items) and the successful operation of three System 80 reactors at Palo Verde Nuclear Generating Station. The MOX fuel technology needs are limited to the completion of fabrication and irradiation of qualification fuel. There is considerable experience with MOX fuel, as it is being used commercially in Europe. All of the experience indicates that there are no essential differences between the performance of MOX fuel and uranium fuel.

Operation of System $80+$ with MOX fuel will be very similar in nature to operation with uranium fuel. Apart from the fuel management differences, the only noticeable differences would be in the receipt of fresh fuel, and in some of the operating characteristics of the reactor. Fresh fuel will be received with remote handling, and stored under water. This is recommended to increase the safeguards and security, and as a precaution against the possible radioactivity of the fuel due to the decay of $\mathrm{Am}^{241}$. Reactor operating characteristics will be different because of small changes in the reactivity coefficients, in the reactivity worth of soluble boron and in control rod worth. These can be accommodated by crew training, and possibly by some revision to Technical Specifications. The fuel management differences may actually result in smoother, shorter outages for the times when the fuel is shuffled only and not replaced.

Reactor licensing readiness is assessed at a level of 5 on the Omberg and Walter scale. The System 80 + Final Safety Evaluation Report (FSER), with no open items, was released by the NRC staff in February, 1994, for review by the ACRS and NRC Commissioners, prior to the issuance of the FSER for Design Certification. Since System 80 + was specifically designed for the accommodation of all-plutonium cores, and no safety parameters associated with MOX fuel have been identified that would require the addressing of new safety questions, the licensing readiness assessment is deemed to be justified. The licensing plan for MOX fuel in System $80+$ will be based on the existing license application and evaluation, with submittal of revised analysis in a few areas affected by the different reactor parameters, and modification of sections of the Safety Analysis Report as appropriate.

Because System $80+$ as designed is directly applicable to the plutonium disposition mission, the cost and construction schedule can be based on commercially derived information with a high level of reliability. Construction quantities are based on material takeoffs from design drawings, with adjustments based on experience with similar plants. Vendor quotations were used for major equipment. Pre-engineering, 
erection and construction management were all estimated based on existing designs and experience. As System $\mathbf{8 0 +}$ is a commercial product, the cost estimates have been exposed to a considerable level of review and justification. Similarly, the construction and licensing schedules are based on commercial experience. A construction schedule of $\mathbf{4 8}$ months from first concrete to fuel load is considered to be achievable, but aggressive. The overall schedule from project initiation to first unit commercial operation is $\mathbf{8 0}$ months. A second unit, where needed, is slipped by about two years off this schedule to allow for levelizing construction crew workloads, and to allow the fuel facility time to fabricate the required initial cores. This results in a considerable saving of costs and fuel facility requirements.

Safeguards and security is a primary issue for the plutonium disposition mission. Efforts to reduce the exposure of Category 1 materials to vulnerable situations must be minimized. The deployment of a special purpose reactor and fuel fabrication facility, complying with the applicable regulations, will ensure the best protection of the weapons material. The area of major concern is the fuel fabrication facility. Collocation of the fuel fabrication facility and the reactor within the same security fence offers the best protection in this regard. Once the weapons material is in the fuel assemblies and in the reactor facility, the safeguards and security concerns are quite similar to those of uranium LWR fuel. The configuration, weight and inaccessibility of the fuel assemblies, and their activity once irradiated, are considered to be adequate deterrents to unauthorized use.

The environmental, health and safety issues attendant to the plutonium disposition mission are of major concern to the fuel fabrication facility. Techniques for handling plutonium are well known and are adaptable to a high volume fuel production facility. Once the plutonium is encapsulated in the fuel assembly the issues are essentially no different than for uranium fuel. Additional concerns from the reactor, including waste streams, personnel exposure, criticality and carryover of plutonium, should be negligible.

Tritium can be produced in specially designed target rods that fit into fuel rod and poison rod lattice locations in the fuel assembly. Target development, which was begun under the Light Water Tritium Target Development Program, needs to be completed. Both plutonium and uranium are acceptable as driver fuels for the tritium production mission. The concurrent missions of tritium production and plutonium disposition can be accomplished, but fuel management differences and a reduction in core power level needed to accommodate the tritium targets will limit the plutonium throughput and burnup.

Public and political acceptance of the plutonium disposition mission is recognized as a problem that must be dealt with effectively from the start. The debates in the public forum are likely to be sharper, simply because of the involvement of plutonium, although there are no new technical reasons why this should be so. In fact, the deployment of a plutonium burning reactor and fuel facility on a government 
reservation should be the safest course to take based on public acceptance. Multilateral agreements, with the nations of the Former Soviet Union and others, that result in the disposition of foreign weapons material as well as our own, could even result in positive acceptance attitudes, where previously there were only negative feelings.

The most challenging aspects of the plutonium disposition mission are wrapped up in the public and political acceptance, which then influence the DOE decision making process, the subsequent programs and allocation of resources. The chief advantages offered by the System $80+$ application to the mission are in its readiness for deployment, the existence of a commercial infrastructure (except for the MOX fuel), the economic advantages of saleable electricity, and the ability to carry out the mission safely, promptly and effectively. These advantages should be very instrumental in countering the challenges of acceptance. 
IABLE ES-1

SUMMARY OF RESULTS

\begin{tabular}{|c|c|c|c|c|c|c|c|}
\hline & \multicolumn{7}{|c|}{ CASE } \\
\hline & REFERENCE & ALT. 1 & ALT. 2 & ALT. 3 & $\begin{array}{c}\text { INCREASE CAP. } \\
\text { FACTOR }\end{array}$ & $\begin{array}{l}\text { INCREASE } \\
\text { PLANT LIFE }\end{array}$ & $\begin{array}{l}\text { INCREASE PLANT } \\
\text { LIFE AND CAP. FAC. }\end{array}$ \\
\hline $\begin{array}{r}\text { PU THROUGHPUT - MT } \\
\text { TIME FROM START, YRS. } \\
\text { CAPACITY FACTOR } \% \\
\text { PLANT LIFE, YRS. }\end{array}$ & $\begin{array}{l}50 \\
25 \\
75 \\
40\end{array}$ & $\begin{array}{l}100 \\
25 \\
75 \\
40\end{array}$ & $\begin{array}{l}50 \\
\text { LOP } \\
75 \\
40\end{array}$ & $\begin{array}{r}100 \\
\text { LOP } \\
75 \\
40 \\
\end{array}$ & $\begin{array}{l}50 \\
25 \\
87 \\
40\end{array}$ & $\begin{array}{l}50 \\
25 \\
75 \\
60\end{array}$ & $\begin{array}{l}50 \\
\text { LOP } \\
87 \\
60\end{array}$ \\
\hline $\begin{array}{r}\text { SYSTEM } 80+\text { CAPABILITY } \\
\text { NO. UNITS } \\
\text { TOTAL PU DISPOSITIONED - MT }\end{array}$ & $\begin{array}{c}2 \\
53.4\end{array}$ & $\begin{array}{c}4 \\
100.1\end{array}$ & $\begin{array}{c}1 \\
53.4\end{array}$ & $\begin{array}{c}2 \\
100.1\end{array}$ & $\begin{array}{c}2 \\
53.4\end{array}$ & $\begin{array}{c}1 \\
53.4\end{array}$ & $\begin{array}{c}1 \\
53.4\end{array}$ \\
\hline $\begin{array}{r}\text { SCHEDULE - MONTHS FROM START } \\
\text { INITIAL FUEL LOAD (MOX) } \\
\text { COMMERCIAL OPERATION } \\
\text { MISSION COMPLETED } \\
\text { PU TO REPOSITORY COMPLETED }\end{array}$ & $\begin{array}{r}74 \\
80 \\
288 \\
428\end{array}$ & $\begin{array}{c}74 \\
80 \\
300 \\
422 \\
\end{array}$ & $\begin{array}{c}74 \\
80 \\
462 \\
620\end{array}$ & $\begin{array}{c}74 \\
80 \\
462 \\
596\end{array}$ & $\begin{array}{c}74 \\
80 \\
277 \\
416\end{array}$ & $\begin{array}{c}74 \\
80 \\
462 \\
620\end{array}$ & $\begin{array}{r}74 \\
80 \\
425 \\
583 \\
\end{array}$ \\
\hline $\begin{array}{l}\text { THROUGHPUT - MTMR. } \\
\text { PRE-OP COST - \$M } \\
\text { CAPITAL COST - \$M. } \\
\text { O\&M COST - \$MTR. } \\
\text { FUEL QUALIFICATION - \$M. }\end{array}$ & $\begin{array}{c}50 \\
42 \\
372 \\
42 \\
34\end{array}$ & $\begin{array}{c}100 \\
47 \\
508 \\
79 \\
34\end{array}$ & $\begin{array}{c}25 \\
40 \\
250 \\
35 \\
34\end{array}$ & $\begin{array}{c}50 \\
42 \\
372 \\
42 \\
34\end{array}$ & $\begin{array}{c}50 \\
42 \\
372 \\
42 \\
34\end{array}$ & $\begin{array}{c}25 \\
40 \\
250 \\
35 \\
34\end{array}$ & $\begin{array}{c}25 \\
40 \\
250 \\
35 \\
34\end{array}$ \\
\hline $\begin{array}{r}\text { SYSTEM 80+ PLANT COSTS } \\
\text { PRE-OP COST - \$M } \\
\text { CAPITAL COST - \$M } \\
\text { O\&M COST - \$M/YR. } \\
\text { CAPITAL IMPROVEMENTS - \$M }\end{array}$ & $\begin{array}{c}182 \\
4,870 \\
125 \\
16\end{array}$ & \begin{tabular}{|c|}
238 \\
8,728 \\
220 \\
32 \\
\end{tabular} & $\begin{array}{c}156 \\
2,905 \\
77 \\
8\end{array}$ & $\begin{array}{c}182 \\
4,870 \\
125 \\
16\end{array}$ & $\begin{array}{c}182 \\
4,870 \\
125 \\
16\end{array}$ & $\begin{array}{c}156 \\
2,905 \\
77 \\
8\end{array}$ & $\begin{array}{c}156 \\
2,905 \\
77 \\
8\end{array}$ \\
\hline NET COST/(REVENUE) - \$M & (949) & $(4,769)$ & 784 & $(1,022)$ & $(2,264)$ & 221 & (545) \\
\hline
\end{tabular}




\subsection{INTRODUCTION}

\subsection{Technical Sxnopsis of Study from Inception to Present}

\subsubsection{Program Backoround}

The historic arms agreements between the United States government and the government of the former Soviet Union set an accelerated pace for greater stability between the two super powers. The Intermediate-Range Nuclear Forces (INF) Treaty, signed in 1987, and the Strategic Arms Reductions Treaty (START), signed in 1991, provided the framework for the dismantlement and destruction of thousands of intermediate-range and intercontinental nuclear ballistic missiles. In addition, the Presidential directive signed by President Bush in 1991, called for the unilateral elimination of all forward-deployed tactical, short-range nuclear weapons.

Though the aforementioned treaties and directive required the destruction of nuclear missiles and their accompanying launch systems, the actual warheads and associated fissile materials from the missiles were excluded from destruction or disposal. In part, the justification for this approach was based on the lack of information, research and consensus toward identifying the most effective approach toward the management and disposition of the surplus nuclear materials. Currently, the United States has three potential options for dealing with excess plutonium: 1. Long-term storage above ground; 2. vitrification with high-level waste; and, 3. fission in a nuclear reactor.

As part of the U.S. effort to evaluate technologies offering solutions for the safe disposal or utilization of the surplus nuclear materials, the fiscal year 1993 Energy and Water Appropriations legislation, provided the Department of Energy (DOE) the necessary funds to conduct multi-phased studies to determine the technical feasibility of using reactor technologies for the triple mission of burning weapons grade plutonium, producing tritium for the existing, smaller weapons stockpile and generating commercial electricity. DOE limited the studies to five advanced reactor designs. Among the technologies selected is the ABB-Combustion Engineering (ABB-CE) System $80+$. The DOE study, currently in Phase ID, is proceeding with a more detailed evaluation of the design's capability for plutonium disposition.

The initial study, completed and submitted in May, 1993, focused on the three requested alternatives for disposition of the excess weapons-grade plutonium: spiking, spent fuel and destruction. The spiking alternative required that the fuel be irradiated as quickly as possible to create a radiation barrier to diversion. The spent fuel alternative, through longer irradiation, would convert the plutonium into a spent fuel form similar to the commercial spent fuel already being stored in the U.S. and the Newly Independent States of the former Soviet Union. The destruction alternative would accomplish maximum destruction of the total amount of plutonium, including all isotopes, within the allotted 25 year mission time frame. 


\subsubsection{Initiol Studx Bonulte}

It was demonstrated that a single System 80 + plant, taking seven years from initiation to start of operation, could accommodate a full Mixed Oxide (MOX) fuel loading, in excess of that required to maintain criticality, and "spike" $100 \mathrm{MT}$ of weapons Pu in 15 years of operation. That single System $80+$ plant could also fulfill the Spent Fuel alternative for $100 \mathrm{MT} P \mathrm{Pl}$ in 60 years of operation - equivalent to the design life of System $80+$. A two-unit plant, also with a seven year schedule to start of operation, would be able to halve these operating times: 7.5 years for spiking and 30 years for spent fuel. The destruction alternative, with 4 units deployed, resulted in a net $\mathrm{Pu}$ destruction of $61 \%$ of the 100 MT in the given time limit. None of the LWR designs in the study was able to fulfill the destruction mission requirement.

The life cycle cost of System $80+$ applied to the alternatives was estimated. For the spiking alternative, a cost ltotal discounted life cycle costs over the useful life of the facilityl of $\$ 2,483 \mathrm{M}$ resulted. For the spent fuel alternative, a negative cost, or net revenue, of $\$ 3,196 \mathrm{M}$ resulted, the best of all designs in the study. The destruction alternative cost was also negative, at $\$ 3,172 \mathrm{M}$.

The tritium production capability was also estimated. The basic conservative, flexible design of System $80+$ allows it to accommodate tritium targets without any significant redesign, using the targets developed under the DOE Light Water New Production Fieactor program. Goal quantities of tritium could be produced with 32 target rods per assembly. In this case, the power rating of the plant would have to be reduced to $3410 \mathrm{MWt}$ in order to preserve core design margins.

The fabrication of MOX fuel for System $80+$ is mechanically similar to that for uranium fuel, with the consideration of the added safeguards and radiological hazards attendant to the Pu material. MOX fuel fabrication facilities have been designed and constructed in the U.S., such as the Hanford Secure Automated Fabrication line, but not placed in operation. In Europe, where Pu recycle is practiced commercially, fabrication facilities that bracket the throughput quantities desired for the spent fuel alternative with System $80+$ exist, giving confidence that there would be no technical limits to fabrication of MOX fuel.

\subsubsection{Eollow-on Studies}

Additional studies were authorized by the DOE by modifications to the original contract. The objective of these modifications was to continue the work initiated under the original scope of work, to pursue some of the identified uncertainties in more detail, concentrating on the Spent Fuel alternative, and with less emphasis on the tritium aspects. These tasks are covered in this report. The mission requirements were revised, to include a base case of 50 MT Pu to be put into the spent fuel mode in 25 years from the start of the program (including design and construction), with alternatives of $50 \mathrm{MT}$ Pu over the life of the plant, $100 \mathrm{MT}$ Pu in 25 years, and 100 
MT Pu over the life of the plant. The program evaluation requirements, including cost, licensing status and safeguards evaluation, were also put on a more systematic basis.

An additional modification has been added to the workscope, to study existing ABB-CE reactors for their capability to undertake the Pu disposition mission. This work is to be covered in a later final report.

\subsubsection{ABB-CE System $80+$ Overviow}

The System $80+$ nuclear plant design was derived from Combustion Engineering's System 80 nuclear steam supply system. Currently, there are three System 80 units operating at the Palo Verde, Arizona nuclear plant and four units under construction in the Republic of Korea (ROK). In the ROK, two additional System 80 units have been ordered for 1994.

The System $80+$ Design Team is currently working together to develop and license the System $\mathbf{8 0}+$ standard nuclear plant design. System 80 + is an Evolutionary Advanced Light-Water Reactor (ALWR) plant designed to produce a net $1297 \mathrm{MWe}$. The reactor is a pressurized water reactor (PWR) type and the reactor coolant system is a traditional Combustion Engineering two loop arrangement. However, one of the most unique features the System 80 + carries forward from its predecessor, the System 80 , is its specific design to run on a mixed oxide (MOX) core that uses plutonium as the only fissile material. Indeed, the System 80 and System $80+$ are the only reactor designs in the world designed for an all plutonium core.

The System 80 + ALWR has been under development and licensing since 1986, as a part of the Department of Energy's Design Certification Program. The plant has been designed to conform with the ALWR Utility Requirements Document (URD). The URD is a comprehensive set of design criteria established by utilities, to assure that the next generation of nuclear plants apply the lessons learned from the first generation. The System 80 + standard design offers substantial improvements in safety, economics, constructability, operability and maintainability. These high design standards assure that System 80 + deployment will be a relatively low risk venture.

System 80 + will be one of the first two ALWR designs to be preapproved by the Nuclear Regulatory Commission (NRC), under its new licensing process for future plants (IOCFR52). System $80+$ is scheduled by the NRC to receive its Final Design Approval (FDA) by August, 1994. There are no open items remaining to be resolved. Only documentation and procedural steps remain. Following a public rulemaking proceeding, the NRC Commissioners will issue a formal Design Certification for the System $80+$ standard design.

As an ALWR, System $80+$ has also received recognition from the scientific community. In a 1992 report issued by the National Academy of Sciences (NAS), the Academy concluded the reported safety levels of the more advanced reactor designs 
were indistinguishable from the greatly improved safety levels of the large, evolutionary ALWRs such as the System $80+$. The same report also concluded that large, evolutionary ALWRs (System $80+$ ) will provide the most economical electricity and be available for deployment well ahead of the other designs and without the need for testing and demonstration programs.

In January, 1994, the NAS also released a preliminary report providing recommendations to the U.S. government on options for the management and disposition of excess weapons grade plutonium retrieved from the dismantled nuclear arsenal. The study was commissioned by the then National Security Advisor to President Bush, General Brent Scowcroft. The NAS Committee, in the section discussing reactor options for plutonium disposition, singled out the ABB-CE System 80 and System $80+$ designs "with the inherent capability to handle a full core of Mixed Oxide (MOX) fuel". Further, the recent study acknowledges the System 80 + 's departure from existing reactor designs by placing greater emphasis on passive safety features.

\subsection{Definition of Commercial Power System Basis for PDS}

The ABB-CE System 80 + nuclear plant is an Advanced Evolutionary Pressurized Water Reactor. For the reference mission of dispositioning 50 MT of excess weapons grade plutonium within a time period 25 years after contract award, two System $80+$ units, and a MOX fuel fabrication facility having an annual capacity to deliver 50 MTHM of fuel, approximately $120 \mathrm{MOX}$ fuel assemblies, are required. Construction of the two units will take place with a two year slip between the first and second units. Simultaneously, construction of the MOX fuel fabrication facility, and qualification testing of the MOX fuel to confirm the acceptability of the as-fabricated components, will be carried out. Fuel loading for the first System $80+$ unit will be at month 74, and the unit will be placed into commercial operation 80 months after contract award, with the second unit at month 98 . The two units will operate at $3817 \mathrm{MWt}$ each (reactor power of $3800 \mathrm{MWt}$ and pump heat of $17 \mathrm{MWt}$ ), producing $1256 \mathrm{MWe}$ saleable power. This power level is $3 \%$ less than the System $80+$ design maximum level of $3931 \mathrm{MWt}$; the reduction being assumed at this stage to allow flexibility in loading and fuel management to meet the mission requirements.

Each reactor will be loaded with 241 fuel assemblies. The MOX fuel facility, producing 120 fuel assemblies per year, will be in operation prior to the first fuel load. Should the MOX fuel facility experience a delay in operation, a supplemental source of fuel assemblies will be needed to complete the first cores of both units, a total of 482 fuel assemblies. The TA-55 area of Los Alamos National Laboratory has been identified as a potential source of this supplemental fuel, after facility upgrades have been accomplished. Other possibilities include European sources, where MOX fuel is currently being made on a commercial basis. The full core load of 241 fuel assemblies will contain about 6.7 MT of excess weapons grade plutonium, tails uranium, and erbia as a burnable poison. 
For the reference case, a single core loading will remain in the reactor for about 4 years, producing full power at a $75 \%$ capacity factor, with shutdowns for reshuffling the fuel and other plant maintenance. The burnup characteristics of the plutonium and the erbia are such that the reactivity rundown over four years is very gradual, enabling the fuel to remain in the core over that time period without introducing reload assemblies. At the end of the four year period, the entire first core is unloaded, and replaced with a fresh core identical to the first core. Each reactor operates in this fashion to consume a total of four MOX cores each, thereby disposing of about 53 MT of excess weapons grade plutonium. The final MOX core is removed from the second unit at Year 24. The average burnup of the MOX fuel is 42,200 MWD/MT upon discharge, and the Pu-240 content is $23 \%$ of total Pu.

Studies have been made of the expected capacity factor of System $80+$ plants in commercial operation. Based on data from existing System 80 plants, and the expected improvements in operation and maintenance due to the System $80+$ modifications, an annual capacity factor of $87 \%$ is anticipated. In this event, the fuel residence time for the same burnup as above is reduced from 4 years to 3.5 years, and the final MOX core is removed from the second unit at Year 23 instead of Year 24.

Upon removal of the MOX fuel from the reactor, it is placed in the Spent Fuel Storage Pool for a period of 10 years, before shipment off-site to a repository. The first shipment occurs in Year 21 (for the reference $75 \%$ capacity factor case), and shipments of approximately 120 assemblies annually follow thereafter, until the final shipment is complete in Year 35. Regardless of shipment off-site, there is sufficient spent fuel storage capacity to accommodate all of the spent fuel generated.

After the final MOX fuel is removed from the reactor, it is reloaded with $\mathrm{UO}_{2}$ fuel for the remainder of the plant life, and run as a commercial power reactor. System $80+$ is designed for 60 year operation. The two-unit plant will therefore be expected to operate until the end of Year 68. During the $\mathrm{UO}_{2}$ fuel operation, the power level would be increased to the design maximum level of $3931 \mathrm{MWt}$ (1297 MWe of saleable power) as currently being licensed.

\subsection{System 80+ Licensing Status}

In 1987, ABB-CE began the process of submitting the Combustion Engineering Standard Safety Analysis Report - Design Certification (CESSAR-DC) to the NRC in support of an evolutionary standard plant Design Certification review. The design review of CESSAR-DC by the NRC staff has been completed without any open technical issues and the NRC staff issued an advance copy of the Final Safety Evaluation Report (FSER) to the NRC Commission in February 1994. The FSER is scheduled to be released in June 1994 upon completion of an ACRS review as well as administrative review. Following issuance of an FSER and FDA, a rulemaking process which may involve a hearing will be initiated for a standard design certification. This 
process is expected to take more than one year. The following table summarizes the licensing milestones.

\section{System $80+$ Licensing Milestones}

$\begin{array}{lr}\text { First submittal } & 11 / 87 \\ \text { CESSAR-DC docketing } & 5 / 91 \\ \text { Draft SER } & 9 / 92 \\ \text { FSER to Commission and ACRS } & 2 / 94 \\ \text { FSER issuance } & 6 / 94 \\ \text { FDA (Final Design Approval) } & 8 / 94 \\ \text { Design Certification } & 12 / 95\end{array}$

AS indicated in the above table, the System $80+$ Standard Design is in the final stages of licensing review by the NRC and once the FSER is issued in June 1994, the remaining task associated with Design Certification primarily relates to administrative review rather than technical design review. Additionally, the System $80+$ Standard Design was specifically designed for maximum fuel management flexibility and can accommodate plutonium fuel loadings up to and including all-plutonium-reactor operation with relatively minor modifications. Accordingly, a licensing status of 5 (per Section 3.5 of UCRL-ID-113055) is assigned to the System $80+$ Standard Design.

\subsection{Reference Case and Alternatives}

The cases evaluated are summarized in Table 10.4-1.

The base case (50 MT over 25 years) is discussed in other sections (2.0 through 9.0) with annual cycles at a capacity factor of $75 \%$. This section discusses the results of analyzing the other required alternatives $(A 1, A 2, A 3)$ also with annual cycles and at 75\% capacity factors. In addition, results are presented for additional alternatives, described above, that will either provide more energy extraction (more revenue) and/or shorter time to accomplish the mission.

The alternatives are compared to the base case in Table 10.4-2. The first three required alternatives differ only in the number of units necessary to accomplish the mission. Alternatives 2 and 3 relax the time to perform the mission and show that the number of units required is half that of the Reference case and Alternative 1 resulting in lower plant cost to accomplish the respective missions.

The deployment strategies are illustrated in Tables 10.4-3 through 10.4-5 for Alternatives 1 through 3, respectively. The deployment strategies for the additional cases are illustrated in Tables 10.4-6 through 10.4-8 for Alternatives Rc, A2L, and $\mathrm{A} 2 \mathrm{CL}$, respectively. 
Alternative $R \mathbf{c}$ is presented as a variation of the base case operating with a capacity factor of $87 \%$ and a plant life of 40 years. The increase in plant life from 40 years to 60 years is illustrated in two cases, $A 2 L$ and $A 2 c L$. Alternative $A 2 L$ shows the effect of modifying case A2 with a longer plant life; resulting in longer time to burn commercially available uranium fuel. With the increase of the capacity factor to $87 \%$ and the increase plant life, the results are shown in alternative $A 2 \mathrm{cL}$. 
2.0 TECHNICAL DESCRIPTIONS

2.1 Reactor and Reactor Cooling System

\subsubsection{Mechanical and Neutronic Desion. Performance}

\subsubsection{Reference System $80+$ Reactor Desion}

The System $80+$ standard PWR design is used as the reference design for the plutonium burner concept evaluated in this study. The System $80+$ design has several advantages for this application, which include the following:

- $\quad$ System $80+$ was specifically designed for maximum fuel management flexibility and can accommodate plutonium fuel loadings up to and including all-plutonium-reactor (APR) operation with relatively minor modifications.

- The System $80+$ design is based on the proven System 80 design in operation at the Palo Verde Nuclear Generating Station (PVNGS). The evolutionary improvements in the System $80+$ design are based on extensive plant operating experience, industry and regulatory feedback, and integrated design analyses using probabilistic risk assessment (PRA).

-

The System 80 + design conforms with the EPRI Utility Requirements for Evolutionary Advanced Light Water Reactors.

-

The System 80 units currently under construction in Korea include numerous evolutionary features of the System $80+$ design (e.g., ring-forged reactor vessel, greater design margins for major components, improvements to safety systems) and represent an active program of procurement, manufacturing and construction.

The System 80 + reference design described in CESSAR-DC has completed extensive review by the NRC covering all regulatory requirements for new plant designs. The design successfully addresses all current US regulations and policies. The NRC staff has completed its review without any open technical issues and issued an advance copy of the Final Safety Evaluation Report (FSER) to the NRC Commissioners in February 1994. The FSER is scheduled to be released in June 1994 upon completion of administrative review as well as ACRS review.

Basic technical characteristics of the System 80 + design are included in Appendix C of this report. The reference System $80+$ design described in CESSAR-DC has a core power rating of $3914 \mathrm{MWt}$ (reference $\mathrm{UO}_{2}$ core design) and a corresponding thermal rating of the nuclear steam supply system (NSSS) of $3931 \mathrm{MWt}$, which includes the thermal input of the reactor coolant pumps. The reference System $80+$ NSSS 
components consistent with this power rating are maintained for the plutonium burner design. However, the core power rating is reduced for the fuel cycle applications in this study (i.e., core power of $3800 \mathrm{MWt}$ for the plutonium disposition fuel cycle, and core power of $3410 \mathrm{MWt}$ for the tritium production fuel cycle). In these applications the core power is limited in order to maintain the same level of core thermal margin as the reference $\mathrm{UO}_{2}$ fuel cycle. Additional fuel managment analysismay open the way to increasing these ratings.

The pertinent characteristics of the System $80+$ reactor which provide for plutonium disposition fuel cycles are unique design features of the fuel assembly, control element assemblies (CEAs) and the reactor internals which increase control rod coverage of the core. Although the reader is referred to a more general description in Appendix $\mathrm{C}$ of this report, these features are briefly summarized below:

The core is comprised of 241 fuel assemblies, each assembly having a $16 \times 16$ fuel rod array with five large structural guide tubes leach guide tube occupies $2 \times 2$ fuel lattice locations), as shown in Figure 2.1.1-1. The four outer guide tubes are for CEA fingers (or elements), while the center guide tube is for in-core instrumentation. The in-core instruments are bottomentry and therefore do not interfere with the upper internals design for CEA guidance.

The control element assemblies have either 4- or 12-element arrangements, as illustrated in Figure 2.1.1-2. The large CEA element design (for the $2 \times 2$ guide tube) provides a higher degree of mechanical ruggedness and increased absorber surface area per element than in PWR designs where the control rod fingers occupy a single fuel rod lattice location. The 12-element CEA mechanical design with $\mathrm{B}_{4} \mathrm{C}$ neutron absorber is further shown by Figure 2.1.1-3.

The 12-element CEA has the unique characteristic of inserting into five adjacent fuel assemblies, as illustrated by Figure 2.1.1-4. This characteristic is made possible by the upper guide structure design of the reactor internals which provides continuous guidance for each individual CEA element into the fuel assembly guide tube, while providing adequate flow area for primary coolant exiting the core. The upper guide structure, illustrated in Figure 2.1.1-5, is a rugged, all-welded structure and protects each CEA element from flow forces and dynamic loads associated with seismic events and design basis accidents.

$\bullet$

The CEA pattern for the reference System $80+$ design, shown in Figure 2.1.1-6, consists of forty-eight (48) full-strength 12-element CEAs, twenty (20) full-strength 4-element CEAs, and 25 part-strength 4-element CEAs, or a total complement of ninety-three (93) CEAs. The pattern using 12element CEAs enables coverage of adjacent fuel assemblies by CEAs, so 
that a large portion of the fuel assemblies (213 of 241 assemblies) contain either four or two CEA elements. This provides a high degree of core shutdown worth through distribution of CEA elements over the core. The 12-element CEAs are used in shutdown banks. The 4-element full strength CEAs are used in regulating banks. The 4-element part-strength CEAs (which contain Inconel absorber) are provided for rodded maneuvering.

System $80+$ is designed to accommodate plutonium fuel in the form of $\mathrm{PuO}_{2}-\mathrm{UO}_{2}$ mixed-oxide (MOX). The mechanical characteristics of MOX fuel are similar to those of $\mathrm{UO}_{2}$ fuel. The nuclear and irradiation characteristics of MOX fuel for lower fissile plutonium loadings characteristic of commercial LWR fuel reprocessing are established based on early evaluation (e.g., the US Generic Environmental Statement on Mixed Oxide Fuel in LWRs issued in 1974) furthered by the experience in commercial fuel recycling outside the US.

The System 80 + reference design, when configured with the CEA pattern shown in Figure 2.1.1-6 for $\mathrm{UO}_{2}$ fuel loading, can accommodate MOX fuel loadings up to the level of self-generated recycle (SGR) without modification. SGR is defined as the amount of plutonium generated by the reference $\mathrm{UO}_{2}$ fuel cycle. This would allow approximately one-third of the feed fuel assemblies to contain MOX fuel, while the remaining feed assemblies would contain $\mathrm{UO}_{2}$ fuel. Design modifications to accommodate higher loadings of MOX fuel, including all-plutorium-reactor (APR) operation, are described below.

\subsubsection{Desion Modifications for APR Operation}

Utilization of commercial MOX fuel at the SGR and APR levels has been extensively investigated for the System 80 design (Refs. 2.1.1-1 through 2.1.1-5). The early design studies showed that design modifications are required for PWR systems to accommodate large loadings of MOX fuel. These modifications include additional control rods to provide required shutdown margin, equipment modifications to accommodate higher soluble boron concentrations, core and spent fuel cooling equipment sized to accommodate the higher decay heat loads associated with irradiated MOX fuel, design of the reactor vessel and internals to tolerate a greater flux of high energy neutrons than arises in uranium fueled operation, modifications to the radwaste systems to accommodate higher tritium activity in the primary coolant, and design of fuel storage and fuel handling facilities to safely accommodate MOX fuel.

Table 2.1.1-1 summarizes the basic impact of APR operation on PWR plant system design requirements. The System 80 design was specifically developed to accommodate MOX fuel loadings up to and including APR. Consequently, design requirements for APR operation were incorporated in the basic systems of the System 80 NSSS, or design provision made which facilitate modifications for APR operation. These system features to enable APR operation have been preserved in the evolutionary System $80+$ design. The summary below describes physical effects of 
MOX fuel operations at the APR level and the accommodation of these effects in the System $80+$ APR design.

- Irradiated MOX fuel exhibits higher long-term decay heat generation rates for APR operation are higher by approximately twenty percent than for $\mathrm{UO}_{2}$ operation one day after shutdown and continue to diminish more slowly with time. This higher heat load must be accommodated in the design of plant cooling systems. For the System $\mathbf{8 0}+$ design, the higher heat loads are accommodated in the following systems:

- $\quad$ Shutdown Cooling System (SCS)

- $\quad$ Spent Fuel Pool Cooling System (SFPCS)

- Component Cooling Water System (CCWS)

- Higher soluble boron concentrations are required in the primary coolant due to lower reactivity worth of $B^{10}$ with MOX cores. For APR operation the required soluble boron concentrations are approximately doubled relative to $\mathrm{UO}_{2}$ operation. For the System $80+$ design, the higher soluble boron requirements for APR operation are accommodated by increasing the soluble boron concentration in the Safety Injection System (SIS) and In-containment Refueling Water Storage Tank (IRWST). ArI attractive alternative to increasing thesoluble boron concentrationis thhe use of boric acid enrichedin the $B^{10}$ isotope.

- The tritium concentration in the primary coolant is substantially higher for APR operation than for $\mathrm{UO}_{2}$ operation. This results from the higher operating concentrations of soluble boron causing increased tritium production by the $B^{10}\left(n, 200 H^{3}\right.$ reaction. The resulting tritium buildup in the primary coolant is approximately seventy percent higher for APR operation in comparison to $\mathrm{UO}_{2}$ operation. For the System $80+$ design the higher tritium levels are accommodated in the design and operation of the liquid and gaseous radwaste systems, and provision of a tritium removal system for APR operation.

- The rate of high energy $(>1 \mathrm{MeV})$ neutron irradiation of the reactor vessel and internals is increased by approximately six percent for APR operation in comparison to $\mathrm{UO}_{2}$ operation. This is due to an increase in the number of prompt neutrons emitted in plutonium fission and a slightly higher average energy of the fission neutrons. The higher neutron fluence levels are not sufficient to require additional design and materials controls of the System $80+$ reactor vessel and internals.

- Gamma emission rates are higher by approximately twenty percent for APR operation compared to $\mathrm{UO}_{2}$ operation. This leads to correspondingly higher 
heating rates which are accommodated by the design of the reactor internals.

- Radioactive decay of plutonium isotopes (and small quantities of americium) in fresh MOX fuel requires provision of shielding in the fuel receipt, handling and inspection area. The ? fuel is stored under water for this reason, and to aid in the safeguards and security considerations.

- The relative individual control rod worth is reduced by twenty-five to thirty percent for APR operation in comparison to $\mathrm{UO}_{2}$ or SGR operation. The control rod requirements for APR operation are accommodated in the System 80 + design by incorporating an extended CEA complement. The extended CEA complement is achieved starting with the reference ninety-three (93) CEA pattern, shown in Figure 2.1.1-6, and modifying the CEA pattern by utilizing the eight (8) spare CEA nozzles provided in the reference System $80+$ design, and by utilizing full-strength ( $B_{4} C$ absorber) CEAs in all locations. The resulting extended CEA pattern for APR operation is shown in Figure 2.1.1-7. This pattern provides coverage of 221 of 241 fuel assembly locations by the full-strength CEAs. Because of the high shutdown worth of the reference System $80+$ CEA pattern, and the modifications to increase the number and strength of CEAs, the extended CEA pattern provides the necessary shutdown requirements for APR operation. Core maneuvering is more restricted for APR operation due to the elimination of part-strength CEAs and rodded operating restrictions associated with shutdown worth and safety margins. Normal operating capabilities for startup, shutdown, power operations, and power level changes are not significantly affected, however.

\subsubsection{Safety Implications of APR Operation}

The evaluation of commercial MOX fuel utilization for the System 80 design included fuel management and safety analyses for fuel cycles transitioning from $\mathrm{UO}_{2}$ operation to equilibrium SGR or equilibrium APR operation. Table 2.1.1-2 gives the characteristics of comparative equilibrium cycles for $\mathrm{UO}_{2}, \mathrm{SGR}$ and APR operation. The safety related physics characteristics for these fuel cycles are summarized in Table 2.1.1-3.

The parameters in Table 2.1.1-3 show trends in the core physics characteristics with higher loadings of plutonium. These trends are expected based on the nuclear properties of $\mathrm{Pu}^{239}$ in comparison to $\mathrm{U}^{235}$. A major effect of increased plutonium loadings is stronger thermal absorption in the fuel which alters various core physics parameters. In particular, the reactivity worth of soluble boron and control rods are reduced, and the prompt neutron lifetime $\left(l^{*}\right)$ is reduced. The delayed neutron fraction $\left(B_{\text {off }}\right)$ is also reduced with increased plutonium loading. The change in these parameters is relatively small from $\mathrm{UO}_{2}$ to $S G R$ operation (since $U^{235}$ reactions are predominant) 
and greater for APR operation (where $\mathrm{Pu}^{239}$ reactions are predominant). Consequently, the required soluble boron concentrations are approximately doubled for APR operation in comparison to $\mathrm{UO}_{2}$ or SGR operation, and the extended CEA complement is required for APR operation.

Moderator temperature coefficient (MTC) and fuel temperature coefficient (FTC) are affected to a lesser extent with higher plutonium loadings. MTC is more negative at beginning-of-cycle (BOC) conditions for SGR or APR operation. For end-of-cycle (EOC) conditions the MTC for APR operation is comparable to that for $\mathrm{UO}_{2}$ operation, while the MTC for SGR operation is more negative. FTC becomes slightly less negative with the higher plutonium loadings.

Basic safety implications of the core physics characteristics for APR operation are summarized below.

- The effective delayed neutron fraction $\left(B_{\text {eff }}\right)$ and prompt neutron lifetime $\left(0^{\circ}\right)$, which are important to short term power transients, are decreased for APR operation. While this result in itself would appear to have an adverse effect upon short period transients such as a rod ejection accident, the overall consequence is mitigated by the lowered reactivity worth of the ejected rod and a reduced sensitivity of the core power distribution to local reactivity perturbations. These mitigating effects are a consequence of the strong thermal absorption properties which reduce the thermal diffusion length of the MOX fuel lattice.

CEA ejection analyses previously performed for SGR and APR operations of the System 80 design at full power and hot zero power initial conditions have shown acceptable consequences in all cases li.e., comparable to results expected for $\mathrm{UO}_{2}$ operation). For the System 80 and System $80+$ designs the control rods allowed to be inserted in the core when the reactor is critical are of the 4-element type. The insertable reactivity worths of 4element full-strength CEAs are small in comparison to $B_{\text {eff }}$ so that the core power transient is small in comparison to the local power transient. The core power transients associated with the CEA ejection events for APR operation were, in fact, predicted to be self-limiting below the power conditions which would be expected to result in a reactor trip, despite the lower values of $B_{\text {eff }} l^{\circ}$, and fuel temperature coefficient. The more favorable results analyzed for APR operation are a consequence of a less adverse initial power distribution, reduced ejected CEA worth, and reduced response of the core power distribution to the reactivity insertion.

- For events with decrease in primary coolant temperature, the negative moderator temperature coefficient associated with $\mathrm{UO}_{2}$, SGR or APR operation results in a positive reactivity insertion. The positive reactivity insertion results in a power increase transient which is opposed by the 
negative fuei temperature coefficient and may, for larger cooldown events, result in a reactor trip. The extended CEA pattern for APR operation is provided to offset the reduced individual CEA worth in order to provide adequate scram worth for the most limiting cooldown events. It is noted that cooldown events are more limiting near end-of-cycle (EOC) for the equilibrium cycles due to the more negative MTC values at EOC, as shown in Table 2.1.1-3. The CEA worth increases as a function of burnup for plutonium fuel cycles (as shown in Section 2.6), thus providing higher scram worth for the most limiting postulated cooldown events near en-of-life.

For events associated with reduced reactor coolant flow or reduced heat removal the consequences are characterized by a decreased margin to departure from nucleate boiling (DNB). The plutonium content of the fuel does not affect the consequences of such events to any significant degree.

The consequences for loss of coolant accidents (small LOCA or large LOCA) are not expected to be significantly affected by the plutonium content of the fuel. A potential difference for APR operation is in the requirement to prevent post-LOCA boric acid build-up during the long-term emergency cooling. APR operation requires a higher concentration of soluble boron in the safety injection system and the in-containment refueling water storage tank (IRWST) for System $80+$. However, the specification of enriched boron eliminates thhis concern. System 80 design indicates that operator response time to provide hot-leg injection flow during long-term cooling based on standard procedures (i.e., several hours after the event) is sufficient for the most limiting postulated large LOCA.

\subsubsection{Design Features for Utilizing Weapons-Grade Plutonium}

The System $80+$ design for utilizing weapons grade plutonium is based on the reference design modified for APR operation. Specifically, the extended CEA pattern and plant system requirements as described in Section 2.1.1.2 are implemented in the design. Additional features are provided based upon consideration of the higher fissile content of weapons-grade plutonium (versus plutonium from commercial reprocessing) and specific mission requirements in the DOE Plutonium Disposition Study Requirements Document. Major requirements include:

- Disposition of weapons-grade plutonium; reference case and alternatives, see Section 1.4;

-

The fuel cycle design for plutonium disposition, is designated as Spent Fuel (the requirements for this design are described separately in Sections 2.7.4 following): 
- In all cases, the design should produce electric power and be capable of producing tritium. Recommended changes to optimize the design for tritium production should be included.

These requirements lead to several practical considerations, reflected in the design objectives for this study:

- The reactor design should be capable of accommodating large loadings of weapons-grade plutonium. This would favor a large core size and the capability for APR operation utilizing weapons-grade feed plutonium in order to accomplish the plutonium burning mission with realistic constraints on capital investment.

- The reference reactor design and features for APR operation should be based to the maximum extent on proven technology, proven operating experience of the reference design, and assurance of licensability based on substantial completion of NRC licensing review of the reference design as a new plant design. These considerations are essential in order to realistically meet the schedule for design, construction, startup and disposition of the reference case: $50 \mathrm{MT}$ of weapons-grade plutonium within a 25 year period. If authorization to proceed is granted in October 1994, the mission will be completed by October of 2018.

- The reference design should have the flexibility to accommodate the required fuel cycle for spent fuel and the requirement for tritium production operation without major in-service modification of plant systems and reactor design features. The design differences for these modes of operation should be limited to fuel assembly design details and core operating power level.

The additional System $80+$ nuclear design features which address the requirements and design objectives for utilizing weapons-grade plutonium are described below.

- Mixed-Oxide Fuel Design

Table 2.1.1-4 shows relative concentrations of plutonium discharge isotopes for a reference 18-month $\mathrm{UO}_{2}$ fuel cycle of the System $80+$ design (average discharge burnup of approximately $48 \mathrm{GWD} / \mathrm{MTU})$. This provides a basis of comparison of differences of feed fuel for the weapons-grade plutonium burner versus a "commercial-grade" plutonium burner (i.e., using reprocessed plutonium from $\mathrm{UO}_{2}$ discharge fuell. Secondly, it provides a basis for comparing the discharge plutonium isotope ratios for the weaponsgrade plutonium burner (i.e., Spent Fuel Alternative) with those of the reference $\mathrm{UO}_{2}$ fuel cycle characteristic of the System $80+$ design. 
The feed fuel concentrations of plutonium isotopes, particularly Pu $\mathrm{Pu}^{239}$ and $\mathrm{Pu}^{240}$, are a principal consideration in the utilization of weapons-grade plutonium in the nuclear design. The effects of basic differences between the weapons-grade and commercial-grade plutonium on the safety-related physics parameters were evaluated for the fuel cycle alternatives developed in this study and are summarized in Section 2.6. The results indicate that safety-related characteristics of APR operation do not change significantly for utilization of weapon-grade plutonium fuel compared to use of reprocessed plutonium from commercial LWRs.

The specifications for the weapons-grade plutonium are expected to vary relative to the values in Section 2.6.3. These may include variations in the concentration of the $\mathrm{Pu}^{239}$ and $\mathrm{Pu}^{240}$ isotopes, presence of small concentrations of $\mathrm{Pu}^{241}, \mathrm{Pu}^{242}, \mathrm{Am}^{241}$, etc. These variations are of less significance to the core nuclear design than to the fuel fabrication process, however, and can be accommodated without significant modification of the core and fuel cycle designs described below for the System 80 + plutonium burner.

The fuel design used is mixed-oxide (MOX), consistent with reference System $80+$ design for commercial APR operation. Based on the design objective of providing as high as practical loading of weapons-grade plutonium in the core, the APR design utilizes MOX feed fuel in the form of $\mathrm{PuO}_{2}-\mathrm{UO}_{2}-\mathrm{Er}_{3} \mathrm{O}_{2}$, with the followirig characteristics:

- Weapons-grade plutonium comprising approximately $6.7 \mathrm{wt} \%$ of the heavy metal (HM);

- Uranium tails $\left(0.2 \mathrm{wt} \% \mathrm{U}^{235}\right.$ tails assay) comprising the balance of the HM;

- Erbium burnable poison admixed in the form of natural $\mathrm{Er}_{3} \mathrm{O}_{2}$ in the metal-oxide with typical concentrations of $1-2 \mathrm{wt} \%$ of the MOX fuel.

The loading of approximately $6.7 \mathrm{wt} \%$ weapons-grade plutonium in the System $80+$ APR design enables 100 MT of the material to be loaded in approximately fifteen (15) full cores. The use of uranium tails and erbium burnable poison facilitates the nuclear characteristics for reactivity and power distribution control with the high plutonium fissile loading, in an analogous fashion to design applications for higher burnup, higher enrichment $\mathrm{UO}_{2}$ fuel cycles.

The use of uranium tails in the fuel is desirable in order to minimize fuel material costs and the additional fissile content in the fuel (i.e., essentially eliminate the effects of $\left.\mathrm{U}^{238}\right)$. It is also desirable from the standpoint of 
reducing the uranium tails inventoried at DOE uranium separation facilities. Howver, the presence of $\mathrm{U}^{230}$ prolongs the depletion of $\mathrm{Pu}^{239}$ over lifetime due to its fertile characteristic (i.e., conversion to $\mathrm{Pu}^{238}$ by neutron absorption reactions). The presence of $U^{238}$ provides beneficial effects on the nuclear design characteristics, however, including partially offsetting the low $\mathrm{B}_{\mathrm{oft}}$ of $\mathrm{Pu}^{239}$ and providing for a more gradual change in core physics parameters over lifetime. The ivotope characteristics of the plutonium in discharge MOX fuel at end-of-life were evaluated to be similar to those of plutonium in discharge $\mathrm{UO}_{2}$ fuel, as shown in Table 2.1.1-4. In particular, the relative concentration of $\mathrm{Pu}^{240}$ in the discharge plutonium is approximately twenty-three percent in both cases.

The use of erbium as a burnable poison in the MOX fuel is an innovative design application for the plutonium burner, which provides substantial benefits for accommodating high concentrations of $\mathrm{Pu}^{239}$. Erbium is a rare earth, similar in chemical and metallurgical properties to gadolinium. Like gadolinium, erbium is comprised of several natural occurring isotopes. The natural abundancies and depletion chain of erbium are illustrated in Figure 2.1.1-8. $\mathrm{Er}^{167}$ is the primary neutron absorber. The energy-dependent neutron absorption properties of $\mathrm{Er}^{167}$ include a large double resonance in the vicinity $0.5 \mathrm{ev}$, as shown in Figure 2.1.1.9. This enhances the thermal neutron absorption of erbium (i.e., providing a non-1/v absorption characteristic), and provides the additional characteristic of improving the negative fuel temperature and moderator temperature coefficients due to the location of the resonance at the high end of the thermal energy spectrum. In contrast to gadolinium, erbium has a slower depletion characteristic as a burnable poison, releasing reactivity gradually over a longer period of fuel burnup.

Erbium has been extensively used in TRIGA (Ref. 2.1.1-6) to provide a more negative fuel temperature coefficient for the high enrichment uranium fuel. ABB-CE has more recently developed the application of erbium as a burnable poison for PWRs, in the form of $\mathrm{Er}_{2} \mathrm{O}_{3}$ admixed with enriched $\mathrm{UO}_{2}$. This application was developed and is in commercial operaton as an optimized burnable poison design for 18- and 24-month $\mathrm{UO}_{2}$ fuel cycles (i.e., the cycle lengths currently in operation for all US ABB-CE plants). For extended $\mathrm{UO}_{2}$ cycle lengths the erbium burnable poison design shows major advantages of improving thermal margins (reducing power peaking over long cycle lengths by distribution of the required burnable poison over a large number of fuel rod locations) and providing a negative moderator coefficient at beginningof-cycle lenabling high total loading of erbium to control excess reactivity with higher $\mathrm{UO}_{2}$ enrichments). The ABB-CE erbium burnable poison design has completed irradiation demonstrations in two operating ABB-CE plants and is scheduled for full batch implementation by 1994. The design has 
been generically approved by the NRC for $\mathrm{Er}_{2} \mathrm{O}_{3}$ concentrations up to 2.5 wt\% in enriched $\mathrm{UO}_{2}$ (Ref. 2.1.1-7).

The application of erbium burnable poison offers key benefits for the System $80+$ plutonium burner design, analogous to the benefits provided for longer $\mathrm{UO}_{2}$ fuel cycles. These include the following:

- The admixture of $\mathrm{Er}_{2} \mathrm{O}_{3}$ in $\mathrm{MOX}$ is analogous to its use in $\mathrm{UO}_{2}$ fuel and provides the capability to accommodate high fissile plutonium loading. Since the erbium poison is admixed homogeneously in the fuel it provides the ability to control a large amount of excess reactivity, while precluding the possibility of loss of this reactivity control by any mechanism, including misoperation or mechanical disassembly of the fuel.

- The 0.5 ev neutron absorption resonance of $\mathrm{Er}^{107}$ overlaps significantly with the $0.3 \mathrm{eV}$ resonance of $\mathrm{Pu}^{239}$, as shown by Figure 2.1.1-9. This enhances the neutron absorption worth of erbium burnable poison in comparison to use of purely $1 / v$ absorbers, such as $B^{10}$, which have significantly diminished reactivity worth in the presence of a high loading of $\mathrm{Pu}^{239}$. Consequently, the required reactivity holddown for $7 \mathrm{wt} \%$ loadings of weapons-grade plutonium in the MOX is provided with low concentration of $\mathrm{Er}_{2} \mathrm{O}_{3}$ leach wt\% of $\mathrm{Er}_{2} \mathrm{O}_{3}$ corresponds to approximately $6 \% \Delta \rho$ reactivity holddown at full power conditions).

- The inng-term resctivity control characteristics and ability to vary the distribution of the erbium concentration over the fuel lattice provide a high degree of flexibility for control of power distribution over lifetime, in order to minimize peaking factors and provide a high degree of thermal operating margin.

\section{Fuel Assembly Design}

The fuel assembly design for the MOX fuel designs described above is based on the reference System $80+16 \times 16$ fuel assembly design. The analyses of fuel depletion show that it is desirable to include a limited number of $\mathrm{Al}_{2} \mathrm{O}_{3}-\mathrm{B}_{4} \mathrm{C}$ burnable poison rods in the fuel lattice. The reference fuel asseinbly designs for the System 80 + plutonium burner concept are based on the use of $\mathrm{PuO}_{2}-\mathrm{UO}_{2}-\mathrm{Er}_{3} \mathrm{O}_{2} \mathrm{MOX}$ fuel rods. Fuel assembly design arrangements for the System 80 + Plutonium Burner core design are shown in Figure 2.1.1-10. The basic fuel assembly types shown in this figure are designated 0-shim, and 12-shim arrangements. 
The 0-shim fuel assembly arrangement contains 236 fuel rods, which is the maximum number of fuel rod locations provided in the standard System $80+16 \times 16$ assembly design.

The 12-shim fuel assembly arrangement incorporates twelve $\mathrm{Al}_{2} \mathrm{O}_{3}-\mathrm{B}_{4} \mathrm{C}$ burnable poison rods in the fuel lattice. Each 12-shim fuel assembly contains 224 fuel rods and 12 non-fuel burnable poison rods. The $\mathrm{Al}_{2} \mathrm{O}_{3}-\mathrm{B}_{4} \mathrm{C}$ burnable poison rods are located in a standard arrangement used in ABB-CE $\mathrm{UO}_{2}$ fuel assemblies, as shown in Figure 2.1.1-10. Unlike standard ABB-CE application, which have the burnable poison rods permanently fixed in the fuel lattice, 12-shim design for the plutonium burner application has the $\mathrm{Al}_{2} \mathrm{O}_{3}-\mathrm{B}_{4} \mathrm{C}$ burnable poison rods contained in non-structural guide tubes within the fuel assembly (each non-structural guide tube occupies $1 \times 1$ lattice locations). The burnable poison rods are designed to be insertable/removable by removing the upper end fitting of the fuel assembly in order to access the burnable poison rods. Such operations would be required infrequently, however, and would not be on the critical path of fuel cycle operations. Removing and replacing the upper end fitting of the ABBCE fuel assembly design is a simple operation, but requires use of special tools in a controlled area of the spent fuel pool. Therefore, mishandling of the burnable poison rods would be precluded during normal core loading and offloading operations.

Table 2.1.1-5 includes a summary of fuel assembly design parameters and fuel cycle characteristics for the MOX fuel design for the Spent Fuel Alternative. The System $80+$ Plutonium Burner fuel cycles represented in these tables use 0-shim and 12-shim fuel assembly designs in 80 and 160 core locations, respectively. The inclusion of $\mathrm{Al}_{2} \mathrm{O}_{3}-\mathrm{B}_{4} \mathrm{C}$ burnable poison rods in the fuel cycle design serves the following purposes:

- The $\mathrm{Al}_{2} \mathrm{O}_{3}-\mathrm{B}_{4} \mathrm{C}$ burnable poison rods supplement the long-term reactivity holddown of the erbium burnable poison and facilitake the design for a gradual, negative rundown characteristic of the fuel $k_{\infty}$ with burnup;

- The $\mathrm{Al}_{2} \mathrm{O}_{3}-\mathrm{B}_{4} \mathrm{C}$ burnable poison rods can be selectively removed prior to fuel load in later cycles le.g., fourth annual cycle for Spent Fuel Alternative or Plutonium Destruction Alternative) in order to remove thie residual reactivity holddown. This feature adds flexibility for fuel management and achieving cycle length near end-of-life;

- Target rods for tritium production can be substituted for the $\mathrm{Al}_{2} \mathrm{O}_{3}-\mathrm{B}_{4} \mathrm{C}$ in any operating cycle (except near end-of-life) in order to provide tritium production capability. This capability would exist in all cases las specified by the DOE Requirements). The evaluation of tritium production (see Section 9.1) indicates that substitution of the tritium 
production target rods, which contain $\mathrm{Li}^{6}$, can be accommodated at different times in life due to similarity of the reactivity holddown characteristic relative to the $\mathrm{Al}_{2} \mathrm{O}_{3}-\mathrm{B}_{4} \mathrm{C}$ burnable poison design (note that both $\mathrm{Li}^{6}$ and $\mathrm{B}^{10}$ have a $1 / \mathrm{v}$ thermal neutron absorption characteristic).

To meet contract quantity tritium production requirements set forth in DOE guidance, multiple System $\mathbf{8 0}+$ Plutonium Burner units would be required to meet the required tritium production rate capability using the core designs described in Table 2.1.1-5 or 2.1.1-6. However, Table 2.1.1-6 describes a Tritium Production core design which provides the capability for meeting the specified tritium production rate with a single System 80 + Plutonium Burner unit. This design uses a 32-shim assembly arrangement, as shown in Figure 2.1.1-11, for accommodating either $\mathrm{Al}_{2} \mathrm{O}_{3}-\mathrm{B}_{4} \mathrm{C}$ burnable poison rods or target rods for tritium production. The tritium production capability is described in more detail in Section 9.1.

\section{Core Thermal Rating}

Table 2.1.1-7 summarizes the core thermal parameters for the System $80+$ Plutonium Burner design in three modes of power operation. The core designs for which these modes of power operation apply are described below:

- $\mathrm{UO}_{2}$ Fuel Cycle. This mode of power operation applies for the reference System $80+\mathrm{UO}_{2}$ fuel cycle design, which is an 18-month cycle length design using $\mathrm{Er}_{2} \mathrm{O}_{3}-\mathrm{UO}_{2}$ burnable poison. Other $\mathrm{UO}_{2}$ fuel cycle designs with cycle lengths ranging from 12-months to 24-months are also available for this mode of power operation. The core power level is 3914 MWth, consistent with the reference System $80+$ design described in CESSAR-DC.

- Blutonium Disposition. This mode of power operation applies for the Spent Fuel Alternative described in Section 2.6, using the $\mathrm{PuO}_{2}-\mathrm{UO}_{2}$ $\mathrm{Er}_{3} \mathrm{O}_{2} \mathrm{MOX}$ core design features described in Table 2.1.1-5. In this mode of power operation the core power level is limited to $3800 \mathrm{MWth}$ in order to maintain the same core thermal operating margins as in the reference $S_{\gamma}$ stem 80 + design, accounting for the displacement of fuel rod locations by $\mathrm{Al}_{2} \mathrm{O}_{3}-\mathrm{B}_{4} \mathrm{C}$ burnable poison rods or target rods.

- Iritium Production. This mode of power operation applies for the singleunit Tritium Production core design described in Table 2.1.1-6. The core and fuel cycle design is based on $\mathrm{PuO}_{2}-\mathrm{UO}_{2}-\mathrm{Er}_{3} \mathrm{O}_{2} \mathrm{MOX}$ fuel, with the capability to accommodate 32 target rods per fuel assembly. (An alternate Tritium Production design using enriched $\mathrm{UO}_{2}$ fuel in lieu of MOX fuel is also possible, and is analyzed in Section 9.1) The core 
power rating for this mode of operation is limited to $3410 \mathrm{MWth}$ in order to maintain the same core thermal operating margins as in the reference System 80 + design, accounting for the displacement of fuel rod locations by target rods or $\mathrm{Al}_{2} \mathrm{O}_{3}-\mathrm{B}_{4} \mathrm{C}$ burnable poison rods.

\subsubsection{Soluble Poison Study}

\section{Introduction}

The use of mixed-oxide (MOX) fuel affects a number of safety and performance-related PWR core parameters to a degree which increases with the level of plutonium loading. The basic effects include reduced control rod worth, reduced soluble boron worth, increased prompt fission neutrons, and increased inventory of transuranic isotopes in the fuel. Due to higher reactivities associated with plutonium usage, the soluble born concentration in the primary coolant must be increased. This, in turn, necessitates an increase in the boron concentration in the various soluble poison storage tanks (i.e., the BAST, IRWST, and SITs), as well as an increase in the size of the normal soluble poison source tank (the BAST). Consideration must also be given to the sizing of other CVCS and engineered safety features (ESF) components.

A study was conducted to determine the impact of the required boron concentration increase on the System $\mathbf{8 0}+$ design, and to evaluate the use of boric acid enriched in $B^{10}$ as the soluble poison. The use of enriched boric acid has been evaluated for commercial operating plants (References 2.1.1-8 and 2.1.1-9), and many potential benefits have been identified. These potential benefits include reduced waste water generation, improved coolant chemistry control, reduced corrosion potential, and the elimination of heat tracing. As part of its plutonium disposition study activities, ABBCE determined to evaluate the potential benefits of enriched boric acid for the System $80+$ design, and to establish the form of soluble boron (natural, or enriched, boric acid) to be applied in subsequent System $80+$ plutonium disposition design and analysis studies.

\section{Natural Boric Acid}

Utilization of commercial MOX fuel at the SGR and APR levels has been extensively studied for the System 80 design (References 2.1.1-1 through 2.1.1-5). These early design studies showed that certain modifications are required for PWR systems in order to accommodate large loadings of MOX fuel. In particular, the soluble boron worth, which is an inverse function of the core absorption cross section, is smaller in APR cores than in SGR and $\mathrm{UO}_{2}$ cores (see Table 2.1.1-8). The implications of this reduction are primarily related to the CVCS Boric Acid Storage Tank (BAST), which provides the normal source of reactivity control during core life, as well as shutdown margin for maintenance and refueling operations, and the Safety Injection System, which provides an auxiliary reactivity control system in the event of an accident. 
The reduced soluble boron worth necessitates maintenance of a higher concentration of boric acid in the various plant storage tanks, which in turn affects the sizing and design of certain components. For the System $\mathbf{8 0}$ design it was determined that the boron concentration in the various tanks would have to be increased from the 4000 to $4400 \mathrm{ppm}$ range for $\mathrm{UO}_{2}$ and SGR cores, to a 5800 to $6200 \mathrm{ppm}$ range for an APR core, in order to compensate for the reduced soluble boron worth. Since System $80+$ is based on the System 80 design, a similar increase in stored boron concentration would be necessary for the plutonium disposition plant(s) assuming the use of natural boric acid as the soluble poison. Consequently, an investigation was performed to identify those changes required to the System $80+$ design described in CESSAR-DC to accommodate this increase in stored boron concentration.

\section{Iemperature Requirements}

Table 2.1.1-9 presents solubility data for boric acid $\left(\mathrm{H}_{3} \mathrm{BO}_{3}\right)$ in water. The factor for converting boron concentrations in ppm to weight percent boric acid is roughly 1750 $\mathrm{ppm} / \mathrm{wt} \%$. Hence, the maximum concentration of $6200 \mathrm{ppm}$ boron required for APR operation (see above) is equivalent to a $3.54 \mathrm{wt} \%$ boric acid solution. From Table 2.1.1-9, the saturation temperature for such a solution is approximately $51^{\circ} \mathrm{F}$. To allow for typical instrument channel accuracy $\left( \pm 4^{\circ} \mathrm{F}\right)$, plus a margin for corrective actions, a minimum temperature of $60^{\circ} \mathrm{F}$ would be required for all piping and components containing concentrated boric acid solutions (5800-6200 ppm boron). For a System 80 + plutonium disposition plant using natural boric acid, this would include the Refueling and Spent Fuel Pools and associated cleanup/heat removal systems, the In-containment Refueling Water Storage Tank, the Safety Injection Tanks, and the CVCS Boric Acid Storage Tank and Holdup Tank.

Appendix 3.11A of CESSAR-DC specifies the environmental design data for normal, as well as accident, conditions for System $80+$ structures and components. Per Table 3.11 A-1 of the appendix, the containment vessel, nuclear annex/subsphere, and spent fuel pool area minimum temperatures are $60^{\circ} \mathrm{F}, 55^{\circ} \mathrm{F}$, and $40^{\circ} \mathrm{F}$, respectively. With the exception of the Boric Acid Storage Tank and the Holdup Tank, these three areas house all of the components and associated piping discussed above as requiring a minimum temperature of $60^{\circ} \mathrm{F}$ to avoid boric acid solubility concerns for a plutonium disposition plant. The Boric Acid Storage Tank and Holdup Tank are housed in the plant yard for System $80+$, and are presently designed to be maintained at a minimum temperature of $60^{\circ} \mathrm{F}$, and $40^{\circ} \mathrm{F}$, respectively (see CESSAR-DC Table 9.3.4-4).

While the presently-specified System $80+$ nuclear annex/subsphere, spent fuel pool area, and CVCS Holdup Tank minimum temperatures do not meet the $60^{\circ} \mathrm{F}$ requirement necessary for plutonium disposition, there should be no significant capital cost or operating expense increase as a result of implementing a minimum temperature requirement of $60^{\circ} \mathrm{F}$. Such a requirement would be placed on the various building ventilation systems, and the Holdup Tank recirculation line heat exchanger. Neither the heating coils for these HVAC systems, nor the Holdup Tank recirculation heat 
exchanger, have yet been specified or sized. However, since the areas served by these HVAC systems are normally occupied for maintenance/inspection activities, it is typical practice to size and operate the HVAC heating coils to ensure a $60^{\circ} \mathrm{F}$ minimum ambient temperature. Similarly, although a $60^{\circ} \mathrm{F}$ minimum temperature will result in a slightly larger Holdup Tank recirculation line heat exchanger than a $40^{\circ} \mathrm{F}$ requirement, the cost impact over the life of the plant is negligible since water pumped to the Holdup Tank is typically at a temperature much greater than $60^{\circ} \mathrm{F}$.

\section{Component Sizing Requirements}

Table 2.1.1-10 presents preliminary physics data for the plutonium disposition mission for the four-year cycle, and also for the suggested alternative equilibrium cycle. The data is based on recent studies, and updates information contained in the Phase I report (Reference 2.1.1-10). This data was used in conjunction with ABB-CE's computer code TANKSIZ to assess whether the CVCS tank volumes presently specified in CESSAR-DC are adequate for plutonium disposition. TANKSIZ is a computer program intended for use in determining the minimum storage requirements for the CVCS tanks in a PWR utilizing boric acid recycle.

Per Section 9.3.4.2.2 of CESSAR-DC, the System $80+$ CVCS tanks are sized as follows:

- The Boric Acid Storage Tank is sized to permit one back-to-back shutdown to cold shutdown (i.e., two consecutive shutdowns to Technical Specification Mode 5), at the most limiting time in core cycle, with the most reactive control rod withdrawn, followed by a boration to refueling conditions (Technical Specification Mode 6).

- The Holdup Tank is sized to store all recoverable reactor coolant generated by one back-to-back shutdown to cold shutdown, and subsequent startup, with the most reactive control rod withdrawn, at $90 \%$ core life.

- The Reactor Makeup Water Tank capacity is based on providing dilution to allow total recycle. The tank also provides dilution for a back-to-back shutdown and subsequent startup at $90 \%$ core life.

Utilizing the physics data of Table 2.1.1-10 and System 80+ parameters specified in CESSAR-DC as input, the ABB-CE proprietary computer code TANKSIZ was run to determine the minimum CVCS tank volumes necessary to meet the design basis criteria listed above for a plutonium disposition plant. Computer cases were run assuming the use of natural boric acid for both the four-year core, and equilibrium cycle fuel management schemes. The results of these runs indicated that while the Holdup Tank and Reactor Makeup Water Tank presently specified in CESSAR-DC are adequately sized for plutonium disposition assuming either a four-year core, or an equilibrium cycle, the presently specified Boric Acid Storage Tank is only adequately sized for a 
plutonium disposition plant utilizing an equilibrium cycle fuel management scheme. For the four-year core management scheme, the Boric Acid Storage Tank useful volume would need to be 325,000 gallons, an increase of $30 \%$ over the presently-specified volume.

In addition to determining the impact of the plutonium disposition mission on the CVCS tank sizes, an investigation was also conducted to determine the impact of a 6200 ppm boron solution on the trisodium phosphate (TSP) baskets in the Holdup Volume Tank (containment sump). For post-accident iodine control, as well as to minimize corrosion of stainless steel equipment inside containment, the pH of the recirculated containment spray solution must be maintained at a minimum value of 7.0 based on a reference temperature of $77^{\circ} \mathrm{F}$. This $\mathrm{pH}$ control is accomplished via granular TSP stored in baskets in the Holdup Volume Tank. These baskets become immersed in the recirculated containment spray solution which collects in the Holdup Volume Tank during a LOCA, thereby raising the $\mathrm{pH}$ of the recirculated solution.

Presently, a volume of 926 cubic feet of TSP is required in the Holdup Volume Tank for the System $80+$ plant. This volume is based on a maximum allowable boron concentration of $4400 \mathrm{ppm}$ in the containment spray solution, the maximum expected volume of containment spray solution (the combined IRWST, RCS, SIT and associated piping normal operating volumes), and a purchased TSP purity of $92 \%$. For margin, the basket volume in the Holdup Volume Tank has been increased to 1243 cubic feet. For the $6200 \mathrm{ppm}$ boron solution required for a plutonium disposition plant utilizing natural boric acid, a minimum TSP volume of 1534 cubic feet would be necessary, neglecting any design margin. Such a volume is beyond the capacity of the current TSP basket design; and, due to limited space in the Holdup Volume Tank, it is doubtful that a basket with adequate margin could be designed to accommodate such a volume.

\section{RCS Chemistry Requirements}

Finally, primary coolant chemistry-related issues were addressed. The natural acidity of the soluble poison, boric acid, is balanced by the addition of alkalinity in the form of lithium hydroxide. Using the critical boron concentration values of Table 2.1.1-10 in conjunction with the EPRI PWR primary coolant water chemistry recommendations for $\mathrm{pH}$ control (Reference 2.1.1-11), estimates were made of the RCS lithium concentrations at the beginning of cycle (BOL) for both of the two studied fuel management schemes. The EPRI primary chemistry guidelines recommend a minimum primary coolant pH of 6.9 , so long as the primary coolant lithium concentration does not exceed $2.2 \mathrm{ppm}$. Because of fuel cladding and Alloy 600 corrosion concerns, operation with lithium concentrations greater than $2.2 \mathrm{ppm}$ is recommended only after completion of a plant-specific fuel and materials review, as well as development of a fuel surveillance program.

The EPRI guidelines provide tables of required lithium concentration to achieve a specified $\mathrm{pH}$ given the RCS boron concentration and average coolant temperature. 
Table 4 reproduces the EPRI table applicable to the System 80 + design. Using Table 2.1.1-11 and the BOL critical boron concentrations from Table 2.1.1-10 for the two fuel management schemes, the following BOL lithium concentrations can be determined for a plutonium disposition plant utilizing natural boric acid:

(1) For a System 80 + plutonium disposition plant operating under the fouryear core fuel management scheme, the initial $(B O L)$ lithium concentration would need to be $>4.0 \mathrm{ppm}$ in order to achieve the minimum recommended pH of 6.9.

(2) For a System $80+$ plutonium disposition plant operating under the equilibrium cycle fuel management scheme, the initial (BOL) lithium concentration would need to be $\sim 2.8 \mathrm{ppm}$ in order to achieve the minimum recommended $\mathrm{pH}$ of 6.9 .

While both of these BOL lithium concentrations exceed the EPRI-recommended maximum of $2.2 \mathrm{ppm}$, the fuel cladding and Alloy 600 corrosion concerns associated with elevated lithium concentrations should be minimized for the System $80+$ plant. First, Alloy 600 has been replaced with Alloy 690 in most of the plant, and Alloy 690 has shown no susceptibility to the Alloy 600 corrosion concern (PWSCC) linked to elevated lithium concentrations. The second concern, accelerated fuel cladding corrosion, is thought to be caused by further concentrating conditions within the core region, such as thick oxide coverage or heavy crud deposits. Out-of-core tests indicate lithium concentrations of greater than $70 \mathrm{ppm}$ are necessary for accelerated cladding corrosion. Careful primary coolant chemistry control should minimize oxide coverage and crud deposition in the core region for a new plant, thereby eliminating conditions associated with lithium-induced fuel cladding corrosion. However, because of the limited operational data with greater than $2.2 \mathrm{ppm}$ lithium, the use of natural boric as the soluble poison would warrant careful corrosion monitoring during plutonium disposition plant operation.

\section{Enriched Boric Acid}

Given the potential problems associated with the use of natural boric acid as the soluble poison for the plutonium disposition plant (e.g., insufficient TSP basket volume, and elevated lithium concentrations for $\mathrm{pH}$ control), an investigation was performed to assess the mitigating effects of using enriched boric acid. This investigation focused, of course, on the System $80+$ design changes discussed above as necessary for plutonium disposition using natural boric acid. The results of this investigation are presented below. In addition, the enriched boric acid vendor (Eagle-Picher) was contacted in order to assess the cost differential associated with switching to enriched boric acid. This information is also presented below. 


\section{Temperature and TSP Basket Effects}

As noted in the discussion on natural boric acid, the present System $80+$ TSP basket design for $\mathrm{pH}$ control of the recirculated containment spray solution is based on a maximum stored boron concentration of $4400 \mathrm{ppm}$. If the total boron concentration in the plutonium disposition plant soluble poison storage tanks were reduced to 4400 ppm from the $6200 \mathrm{ppm}$ value required using natural boric acid, while maintaining the same reactivity control (i.e., same concentration of $B^{10}$ ), the presently sized TSP baskets would be adequate for the plutonium disposition mission. To achieve this reduction in total boron concentration (6200 to $4400 \mathrm{ppm}$ ) would require a boric acid enrichment to $\sim 30 \% B^{10}$. Enrichments to higher $B^{10}$ concentrations would result in lesser TSP volume requirements, and potential size reductions in the present TSP basket design.

An additional benefit of enriching the boric acid to 30 atom percent $B^{10}$ (maximum stored boron concentration of $4400 \mathrm{ppm}$ ) would be to eliminate the $60^{\circ} \mathrm{F}$ minimum temperature requirement for all piping and components containing concentrated boric acid solutions. Although the $60^{\circ} \mathrm{F}$ requirement is expected to have minimal cost impact on the present System $80+$ design if natural boric acid is utilized (see previous discussion), and additional considerations may even invoke a $60^{\circ} \mathrm{F}$ requirement (e.g., habitability and thermal transient concerns), elimination of this requirement from a boric acid solubility perspective places the System $80+\mathrm{UO}_{2}$ and plutonium disposition plants on an equal footing. The primary concern becomes equipment freeze protection, and not boric acid precipitation.

\section{BAST Sizing Effect}

For the four-year core fuel management scheme it was determined that the Boric Acid Storage Tank (BAST) useful volume would need to be increased by $30 \%$ to 325,000 gallons if natural boric acid were utilized in the plutonium disposition plant. The reason for this increase, as evidenced by Table 2.1.1-10, is the small difference between the estimated RCS refueling boron concentration (5710 ppm) and the BAST stored boron concentration (5800-6200 ppm). Since RCS boron concentration adjustments are accomplished by feed and bleed, this small difference results in a much greater volume of boric acid when borating the RCS to the refueling concentration.

The use of enriched boric acid by itself will not minimize the increase in required BAST volume. This is because any decrease in the required RCS refueling concentration through the use of enriched boric acid will be accompanied by a proportional decrease in the required BAST concentration. The result is that the two concentrations remain relatively equal, thereby requiring a large volume of boric acid to achieve the RCS refueling concentration. However, the use of boric acid enriched to $B^{10}$ concentrations of greater than 30 atom percent would permit storage of solutions in the BAST with more reactivity control (i.e., greater $B^{10}$ concentrations) than presently stored. Such storage could reduce the required BAST volume for the plutonium disposition plant, 
although ABB-CE has not yet investigated this issue. Potential areas of concern regarding such boric acid storage involve new operating transients which may require boric acid makeup system redesign and/or additional operational guidelines.

\section{RCS Chemistry Effect}

Table 2.1.1-11 indicates that in order to comply with present EPRI recommendations (Reference 2.1.1-9) regarding minimum $\mathrm{pH}(6.9)$ and maximum lithium concentration $(2.2 \mathrm{ppm})$, the RCS operating boron concentration must not exceed $\sim 1440 \mathrm{ppm}$. Table 3 specifies the BOL RCS operating boron concentration (assuming natural boric acid) as $2410 \mathrm{ppm}$ for the four-year core fuel management scheme, and $1775 \mathrm{ppm}$ for the equilibrium cycle fuel management scheme. To reduce these values to the $1440 \mathrm{ppm}$ maximum recommended by the EPRI guidelines, the boric acid would need to be enriched to approximately 25 atom percent B10 for the eqilibrium cycle plant, and approximately 35 atom percent B10 for the four-year core design. Selection of greater enrichments would permit operation at higher RCS pHs, potentially reducing primary system corrosion.

\section{Enrichment Costs}

Finally, as a means of addressing economic considerations, three enrichments covering the range between natural boric acid $\left(\sim 20\right.$ atom percent $\left.B^{10}\right)$ and fully enriched boric acid $\left(\sim 99\right.$ atom percent $\left.B^{10}\right)$ were selected for cost analysis. The specific enrichments selected were 30 atom percent $B^{10}(30 \%), 60$ atom percent $B^{10}(60 \%)$, and 95 atom percent $B^{10}(95 \%)$. Costs for these three enrichments have been estimated based on Eagle-Picher cost and technical data $\left(\$ 2.30\right.$ per gram of $B^{10}$ for $95 \%$ enriched boric acid, and $\$ 1.25$ per pound of natural boric acid), and are provided below.

\section{Boric Acid Enrichment}

Natural

$30 \%$

$60 \%$

$95 \%$

\section{Cost per Pound}

$\$ 1.25$

$\$ 23.13$

$\$ 87.33$

$\$ 162.15$

This cost data, however, presents a skewed picture of the true cost of enriched boric acid. Since the amount of boric acid required to achieve the same reactivity control decreases as the $B^{10}$ enrichment increases (i.e., the amount of acid is inversely proportional to the enrichment), a more appropriate comparison should focus on the total boric acid cost per plant. For simplicity, ABB-CE has calculated the cost on a per gallon basis. This is reasonable because the use of enriched boric acid has a negligible impact on the overall primary coolant volume (i.e., the RCS, CVCS, SIS and IRWST volumes are independent of the soluble poison form). The true boric acid cost data is therefore presented below. For calculational purposes, this data assumes a constant coolant $B^{10}$ concentration of $\sim 1225$ ppm. 
Boric Acid Enrichment

Natural

$30 \%$

$60 \%$

$95 \%$
Cost per Gallon Coolant

$\$ 0.38$

$\$ 4.67$

$\$ 8.91$

$\$ 10.70$

\section{Conclusions/Recommendations}

The use of natural boric acid as the soluble poison for plutonium disposition does not appear technically feasible. Neglecting the economic penalties associated with a minimum temperature increase for certain fluid-handling portions of the plant, and an increase in the required Boric Acid Storage Tank (BAST) volume, it is doubtful that adequate $\mathrm{pH}$ control of recirculated containment spray solution could be accomplished for a System $\mathbf{8 0}+$ plutonium disposition plant utilizing natural boric acid (containment spray solution of $6200 \mathrm{ppm}$ boron). In addition, utilization of natural boric acid would require plant operation at lithium concentrations greater than currently recommended by EPRI guidelines in order to achieve a minimum recommended RCS pH.

The use of enriched boric acid, however, while requiring a much larger capital expenditure (approximately $\$ 10 \mathrm{M}$ ), would eliminate most, if not all, of the problems associated with natural boric acid. Enrichments to 30 atom percent $B^{10}$ and greater will eliminate any minimum temperature requirements resulting from boric acid solubility concerns, as well as reduce the recirculated containment spray maximum boron concentration to an acceptable limit (4400 ppm) for $\mathrm{pH}$ control. In addition, enrichments to 30 atom percent $B^{10}$ and greater could reduce the required BAST volume through storage of solutions with more reactivity control (i.e., greater $B^{10}$ concentrations) than presently stored. Enrichments to 35 atom percent $B^{10}$ and greater will permit RCS operation within the chemistry limits recommended by the Electric Power Research Institute for the two plutonium disposition plant fuel management schemes studied by this report.

For the reasons discussed above, ABB-CE considers an enrichment to 35 atom percent $B^{10}$ to be a minimum acceptable requirement for the plutonium disposition plant boric acid. For conservatism, ABB-CE recommends an enrichment to 40 atom percent $B^{10}$, and will utilize this value in future plutonium disposition study activities.

\subsubsection{Plant Desion for 60-year Lifetime}

Observations of significant environmental degradation of the cyclic behavior of materials in LWR environments are primarily related to high strain ranges, slow strain rates, high oxygen contents of LWR primary water environments, high sulfur contents of carbon and low alloy steels, and low flow rate conditions. The absence of any one of these conditions is sufficient to preclude any significant environmental degradation 
of the fatigue behavior of materials exposed to typical PWR primary coolant environments.

Since System $80+$ components are not exposed to high oxygen content environments at elevated temperatures, and no carbon or low alloy steel is directly exposed to the primary coolant, no significant environmental degradation of the cyclic behavior of System $80+$ components will occur.

Therefore, the existing System $80+$ fatigue curves are applicable to the 60 year design life of System $80+$ components because:

1) the RCS, including all primary components, core support and internal structures, and pressurizer surge line, are either stainless steel clad materials or wrought stainless steel construction;

2) the primary system water chemistry controls require control of dissolved oxygen content in the primary system prior to operation above $150^{\circ} \mathrm{F}$; and

no carbon or low alloy steel materials are exposed to the primary coolant environment.

The System 80 + fatigue analysis concluded that a 60-year life was attainable, with adequate margin, and thus the extended life was included as a design feature.

The impact of the MOX core on the reactor vessel (RV) shift in the Reference NilDuctility Transition Temperature $\left(\mathbf{R T}_{\mathrm{NDT}}\right)$ is expected to be negligible. The predictions of the shift in $R T_{\text {NDT }}$ of the System $80+R V$ beltline materials are based on the procedures described in NRC Regulatory Guide 1.99. Based on these procedures the maximum calculated shift in RT NDT at $1 / 4$-thickness over a 60 -year design life is $77^{\circ} \mathrm{F}$ (including a conservative $50^{\circ} \mathrm{F}$ margin). The corresponding value for the beltline girth weld is $94^{\circ} \mathrm{F}$ (including a $56^{\circ} \mathrm{F}$ margin). The damage (fast, E> $1 \mathrm{MeV}$ ) fluence at the RV inner surface, assuming 60-year operation with a MOX core, is estimated to be approximately $4 \%$ greater than the System $80+\mathrm{UO}_{2}$ core. The calculated shift in $\mathrm{RT}_{\text {NDT }}$ is essentially the same as calculated for the $\mathrm{UO}_{2}$ core. The MOX core does present a slighly harder spectrum with, at most, $15 \%$ higher fraction of fast neutrons and $6 \%$ higher fraction of epithermal neutrons. These small differences are expected to have a negligible impact on the end-of-life $\mathrm{RT}_{\mathrm{NDT}}$ shift. Consequently, no lifetime impact on the RV due to the MOX core is anticipated.

\section{References}

2.1.1-1 "Assessment of PWR Plutonium Burners for Nuclear Energy Centers," Technical Information Center, US Energy and Research Development Administration, C000-2786, June 1976. 
2.1.1-2 A. J. Frankel, P.C. Rohr and N. L. Shapiro, "PWR Plutonium Burners for Nuclear Energy Centers," ABB Combustion Engineering, TIS-4847, ANS/CNA Joint Meeting, Toronto, June 1976.

2.1.1-3 R. L. Hellens, "Problems in Recycle of Plutonium in Pressurized Water Reactors," ABB Combustion Engineering, TIS-3283, ANS Winter Meeting, Miami, October 1971.

2.1.1-4 R. L. Hellens and N. L. Shapiro, "Plutonium Fuel Management Options in Large Pressurized Water Reactors," ABB Combustion Engineering TIS-3779, ANS Winter Meeting, San Francisco, November 1973.

2.1.1-5 C. K. Anderson and R. H. Klinetob, "Plutonium Burning Light Water Reactor Concept," TIS-7016, ANS Topical Meeting on Technical Bases for Nuclear Fuel Cycle Policy, September 1981.

2.1.1-6 "TRIGA LEU Shrouded Fuel Cluster Design", UZR-14A, IAEA TECDOC-233.

2.1.1-7 "Methodology for Core Designs Containing Erbium Burnable Absorbers," CENPD-383-P, October 1990, and CENPD-382-P, Supplement 1-P, February 1992.

2.1.1-8 J. A. Battaglia and J. Roesmer, "Utilization of Enriched Boric Acid in Pressurized Water Reactor Plants," Westinghouse Electric Corporation, EPRI PWR Primary Water Chemistry and Radiation Field Control Seminar, Berkeley, March 1988.

2.1.1-9 W. B. Rodill, "Feasibility Study on Enriched Boron for Surry Power Station, Units 1 and 2 (Revised)," Virginia Power, EPRI PWR Primary Water Chemistry and Radiation Field Control Seminar, Berkeley, March, 1988.

2.1.1-10 "DOE Plutonium Disposition Study, PU Comsumption in ALWRs," Contract No. DE-AC03-93 SF19682. A Final Report by ABB Combustion Engineering, Windsor, Connecticut, May 15, 1993.

2.1.1-11 "PWR Primary Water Chemistry Guidelines: Revision 2," Electric Power Research Institute, NP-7077, Palo Alto, California, November 1990. 
TABIE2.1.1-1

\section{APR MPACT ON PUR SYSTEM REOUIREMENTS}

\section{System or Componen}

Plant Cooling System

Chemical and Volume Control System (CVCS)

Safety Injection Systems

Control Element Assembly (CEA) Complement

Fresh Fuel Handling and Storage Facility

Spent Fuel Storage Facility

Radwaste System

\section{System Requirements Chanoes}

(1) Increased Core Decay Heat Removal Capacity for Plant Cooldown and Safety

(2) Accommodation of Increased Long Term Decay for Spent Mixed-Oxide Fuel

(1) Increased Maximum Soluble Boron Concentrations in Primary System and CVCS Components Increased Capacities for CVCS Processing and Waste Water Holdup

Increased Maximum Soluble Boron concentration in IRWST and Safety Injection Tanks

Increased Number of CEAs to Accommodate Reduced Individual CEA Worth

Shielding of Gamma and Neutron Sources from Fresh Mixed-Oxide Fuel

Increased Storage Capacity due to Lower Average Discharge Burnup and Potentially Longer Storage Time

Accommodation of Altered Reactivity

Characteristics of Mixed-Oxide Fuel in Conjunction of Uranium-Oxide Fuel

Addition of Tritium Removal System to Accommodate Higher Tritium Production Rate in Primary Coolant 


\section{MIXED-OXIDE FUEL CYCLE CHARACTERISTICS}

Cycle Length MWD/(MWd/t(metal))

Average $\mathrm{UO}_{2}$ Feed Enrichment

Average Mixed Oxide Feed Enrichment (w/o Fissile Pu)

Number of $\mathrm{UO}_{2}$ Assemblies

Number of Mixed Oxide Assemblies

Core Plutonium Inventory (Total Pu)

$$
\begin{aligned}
& \text { Beginning-of-Cycle } \\
& \text { End-of-Cycle }
\end{aligned}
$$

Core Plutonium Inventory (Fissile Pu)

Beginning-of-Cycle

End-of-Cycle
Equilibrium

Cycle $\mathrm{UO}_{2}$

11,400

3.29

-

241

0

$421.2 \mathrm{Kg}$

$740.0 \mathrm{Kg}$

$336.9 \mathrm{Kg}$

$561.8 \mathrm{Kg}$
Equilibrium

Cycle SGR

11,400

3.62

3.05

157

84

$2228.1 \mathrm{Kg}$

$2148.9 \mathrm{Kg}$

$1205.6 \mathrm{Kg}$

$1233.7 \mathrm{Kg}$
Equilibrium

Cycle APR

11,400

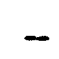

4.57

0

241

8439.1 Kg

$7824.4 \mathrm{Kg}$

$4279.9 \mathrm{Kg}$

$3829.0 \mathrm{Kg}$ 


\section{SAFETY RELATED PHYSICS CHARACTERISTICS FOR MIXED-OXIDE CYCLES}

Beginning of Cycle Reactivity (CEAs Withdrawn, No $\begin{array}{ll}\text { Equilibrium } & \text { Equilibrium } \\ \text { Cycle } \mathrm{UO}_{2} & \text { Cycle SGR }\end{array}$

Equilibrium Cycle APB

Dissolved Boron), $\rho$

Hot Standby

Full Power, No Xenon

Full Power, Equilibrium Xenon

Dissolved Boron Requirements

PPM Dissolved Boron for Criticality - CEAs Withdrawn

BOC Hot Standby

BOC Full Power, No Xenon

BOC Full Power, Equilibrium Xenon

Requirement for Refueling (5\% Subcritical)

Inverse Boron Worth (PPM/\% $\Delta \rho$ )

Full Power BOC

Full Power BOC

Moderator Temperature Coefficient $\left(10^{-4} \Delta \rho^{\circ} \mathrm{F}\right)$

Full Power BOC

Full Power EOC
0.137
0.121

0.122

0.101

0.103

0.081

0.083

0.064

0.055

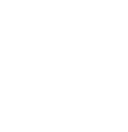

1589

1820

1400

1539

1170

1208

1955

2383

116

149

130

101

$-0.95$

$-3.73$ 
IABLE 2.1.1-3 (Cont'd)

SAFETY RELATED PHYSICS CHARACTERISTICS FOR MIXED-OXIDE CYCLES

Fuel Temperature Coefficient $\left(10^{-5} \Delta \rho^{\circ} \mathrm{F}\right)$

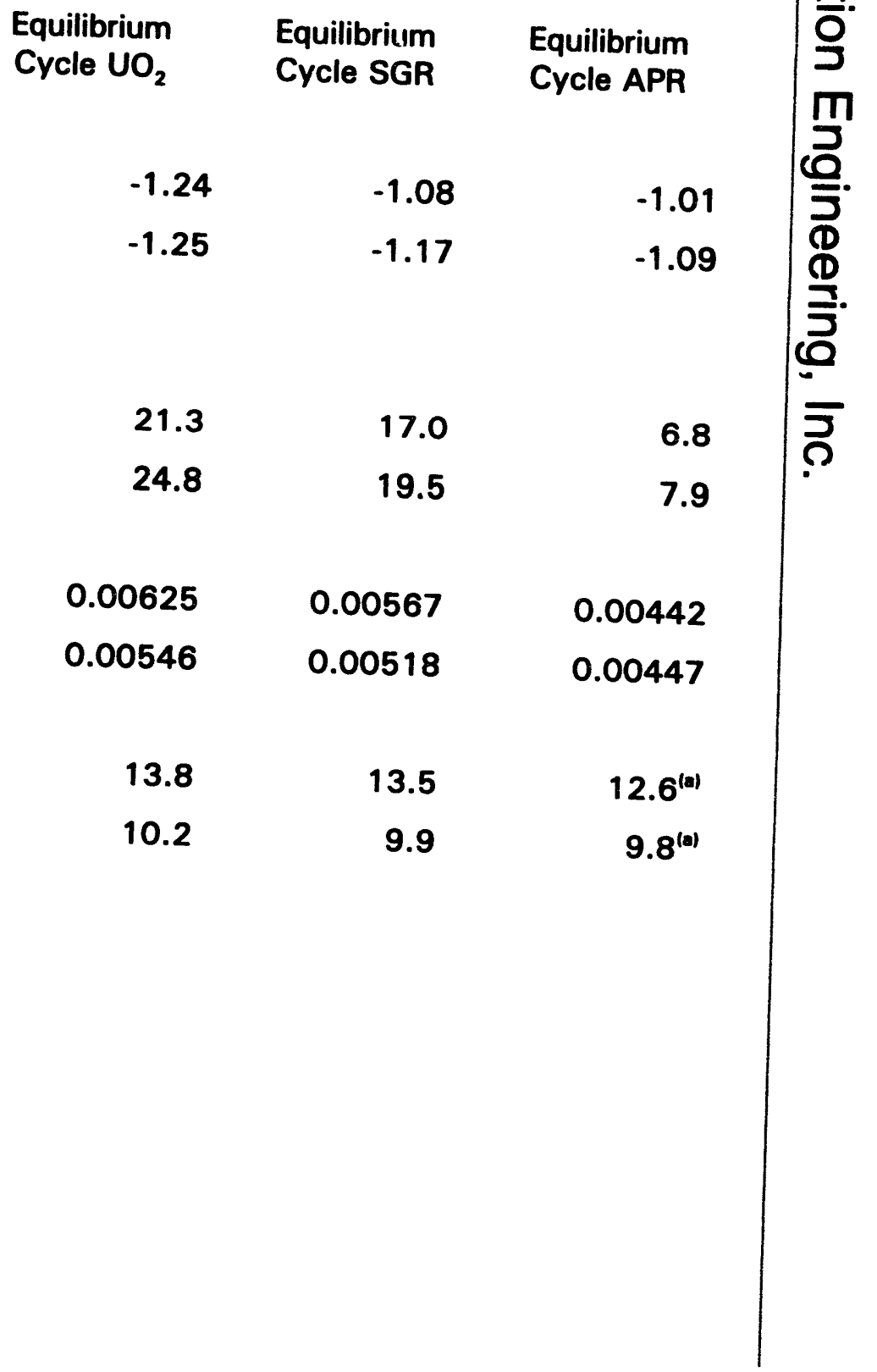

Full Power BOC

Full Power EOC

Neutron Kinetics Parameters

Prompt Neutron Lifetime (usec)

Beginning-of-Cycle

End-of-Cycle

Effective Delayed Neutron Fraction

Beginning-of-Cycle

End-of-Cycle

Available Control Rod Worth

Total $(\% \Delta \rho)$

Net $^{c}(\% \Delta p)$

(a) APR core with extended CEA complement 
IABLE 2.1.1-4

SYSTEM $80+\mathrm{UO}_{2}$ EOUILIBRIUM CYCLE

NSSS THERMAL RATED POWER

NUMBER OF FUEL ASSEMBLIES

FEED BATCH ASSEMBLIES

80

FEED ENRICHMENT, wt\%

4.20

FEED $U, M T U$

34.98

CYCLE LENGTH, months

CYCLE LENGTH, EFPD

476

AVERAGE CAPACITY FACTOR, \%

AVERAGE DISCHARGE BURNUP, GWD/T

47.8

DISCHARGE CHARACTERISTICS

$\mathrm{Pu}, \mathrm{kg}$

389.8

Pu238/Pu

0.018

Pu239/Pu

0.527

Pu240/Pu

0.232

$\mathrm{Pu} 241 / \mathrm{Pu}$

0.154

$\mathrm{Pu} 242 / \mathrm{Pu}$

0.070 
IABLE 2.1.1-5

\section{SYSTEM 80+ PU BURNER MOX CORE DESIGN CHARACTERISTICS}

Power Level

Core

Power Density

Average Linear Power ${ }^{(1)}$

Maximum Linear Power ${ }^{(1)}$

Core Dimensions

Active Core Length

Equivalent Core Diameter

Fuel Assemblies

Number

Dimensions

Array

0-Shim Assembly Number Fuel Rods

12-Shim Assembly Number Fuel Rods BPR Guide Tubes ${ }^{(2)}$

BPR Guide Tube ${ }^{(2)}$

Outside Diameter Thickness

Material

Fuel Rods

Outside Diameter

Cladding Thickness

Fuel Sintered Pellet Material

Cladding Material

Lumped Burnable Poison Rods (BPR)

Number per 12-Shim Assembly

BPR Outside Diameter

Cladding Thickness

BPR Absorber Material

BPR Cladding Material
$3800 \mathrm{MW}$ (th)

$95.5 \mathrm{~kW} / \mathrm{liter}$

$17.7 \mathrm{~kW} / \mathrm{m}(5.40 \mathrm{~kW} / \mathrm{ft})$

$41.7 \mathrm{~kW} / \mathrm{m}$ (12.7 kW/ft)

$3.81 \mathrm{~m}$ (150 in)

$3.65 \mathrm{~m}$ (143.6 in)

241

$202.7 \mathrm{~mm} \times 202.7 \mathrm{~mm}$

(7.972 in $\times 7.972$ in)

$16 \times 16$

236

224

12

$11.2 \mathrm{~mm}(0.440 \mathrm{in})$

$0.91 \mathrm{~mm}$ (0.032 in)

Zircaloy-4

$9.7 \mathrm{~mm}(0.382 \mathrm{in})$

$0.64 \mathrm{~mm}$ (0.025 in)

$\mathrm{UO}_{2}-\mathrm{PuO}_{2}-\mathrm{Er}_{2} \mathrm{O}_{3}$

Zircaloy-4

12

$8.7 \mathrm{~mm}$ (0.344 in)

$0.64 \mathrm{~mm}$ (0.025 in)

$\mathrm{Al}_{2} \mathrm{O}_{3}-\mathrm{B}_{4} \mathrm{C}$

Zircaloy-4

Based on 0.975 average energy deposition fraction in the fuel.

(2)

Non-structural guide tubes allow removal of BPRs for later cycles. 
IABLE 2.1.1-5 (Cont.)

SYSTEM $80+$ PU BURNER MOX CORE DESIGN CHARACTERISTICS

Control Element Assemblies (CEAs)

Number CEAs in Core $\quad 101$

- 12-element Assemblies 48

- 4-element Assemblies 53

CEA Rod Outside Diameter $\quad 20.7 \mathrm{~mm}$ (0.816 in)

Cladding Thickness

$0.89 \mathrm{~mm}$ (0.035 in)

CEA Absorber (all CEAs)

$\mathrm{B}_{4} \mathrm{C} /$ Feltmetal and Reduced

Cladding Material

Diameter $\mathrm{B}_{4} \mathrm{C}$

Inconel 625

Feed Fuel Batch

Number of Assemblies

0-Shim 81

12-Shim 160

Active Fuel Length

Number of Fuel Rods

$3.81 \mathrm{~m}$ (150 in)

Heavy Metal Feed

54956

Uranium (tails) Feed

98.75 MTHM

Plutonium Total Feed

92.08 MTU

Total Pu in HM

6.67 MTPu

Uranium (tails) Feed Isotopes

6.75 wt \%

Plutonium Feed Isotopes

$99.8 \%$ U-238, $0.2 \%$ U-235

Fissile Pu Feed

93.5\% Pu-239, 6.5\% Pu-240

Fissile $\mathrm{Pu}$ in $\mathrm{HM}$

$6.24 \mathrm{MTPu}$

$6.32 \mathrm{wt} \%$

Mixed-Oxide (MOX) Composition

Average Erbium in MOX

$\mathrm{UO}_{2}-\mathrm{PuO}_{2}-\mathrm{Er}_{2} \mathrm{O}_{3}$

$1.6 \mathrm{wt} \% \mathrm{Er}_{2} \mathrm{O}_{3}$ in MOX pellets

BPRs in Feed Fuel Batch

Number of Burnable Poison Rods

1920

Active Poison Length

$3.45 \mathrm{~m}$ (136 in)

Average B-10 Loading in Poison

$0.0102 \mathrm{~g} / \mathrm{cm}(0.026 \mathrm{~g} / \mathrm{in})$

Cycle Characteristics

Average Capacity Factor $\quad 0.75$

Cycle Length

12-months (274 EFPD)

Number of Irradiation Cycles

Average Discharge Burnup

Average Pu-240 in Discharge

4

42,200 MWD/MTHM

$23 \%$ of Total Pu Inventory 
IABLE 2.1.1-6

\section{SYSTEM $80+$ TRITIUM PRODUCTION CORE DESIGN CHARACTERISTICS}

Power Level

Core

Power Density

Average Linear Power ${ }^{(1)}$

Maximum Linear Power ${ }^{(1)}$

Core Dimensions

Active Core Length

Equivalent Core Diameter

Fuel Assemblies

Number

Dimensions

Array

32-Shim Assembly

Number Fuel Rods

TR Guide Tubes ${ }^{(2)}$

TR Guide Tube ${ }^{(2)}$

Outside Diameter

Thickness

Material

Fuel Rods

Outside Diameter

Cladding Thickness

Fuel Sintered Pellet Material

Cladding Material

Target Rods (TRs)

Number TRs in Core ${ }^{(3)}$

Number TRs per Assembly

Target Rod Outside Diameter
$3410 \mathrm{MW}$ (th)

$83.2 \mathrm{~kW} / \mathrm{liter}$

$17.75 \mathrm{~kW} / \mathrm{m}(5.41 \mathrm{~kW} / \mathrm{ft})$

$41.7 \mathrm{~kW} / \mathrm{m}(12.7 \mathrm{~kW} / \mathrm{ft})$

$3.81 \mathrm{~m}$ (150 in)

$3.65 \mathrm{~m}$ (143.6 in)

241

$202.7 \mathrm{~mm} \times 202.7 \mathrm{~mm}$

(7.972 in $\times 7.972$ in)

$16 \times 16$

204

32

$11.2 \mathrm{~mm}$ (0.440 in)

$0.91 \mathrm{~mm}$ (0.032 in)

Zircaloy-4

$9.7 \mathrm{~mm}(0.382 \mathrm{in})$

$0.64 \mathrm{~mm}(0.025 \mathrm{in})$

$\mathrm{UO}_{2}-\mathrm{PuO}_{2}-\mathrm{Er}_{2} \mathrm{O}_{3}$

Zircaloy-4

7712

32

$8.7 \mathrm{~mm}(0.344 \mathrm{in})$
(1)

(2)

(3)

Based on 0.975 average energy deposition fraction in the fuel.

Non-structural guide tubes allow insertion/removal of TRs.

Burnable Poison Rods (BPRs) can be substituted for TRs if fuel is not to be used for production in any cycle. 


\section{IABLE 2.1.1-6 (Cont.)}

\section{SYSTEM $80+$ TRITIUM PRODUCTION CORE DESIGN CHARACTERISTICS}

Control Element Assemblies (CEAs)

Number CEAs in Core 101

- 12-element Assemblies 48

- 4-element Assemblies 53

CEA Rod Outside Diameter $\quad 20.7 \mathrm{~mm}$ (0.816 in)

Cladding Thickness $\quad 0.89 \mathrm{~mm}$ (0.035 in)

CEA Absorber (all CEAs) $\quad \mathrm{B}_{4} \mathrm{C} /$ Feltmetal and Reduced

Cladding Material Inconel 625

Feed Fuel Batch

Number of Assemblies

241 (Full Core)

Active Fuel Length

Number of Fuel Rods

$3.81 \mathrm{~m}$ (150 in)

Heavy Metal Feed

49164

Uranium Metal Feed

89.04 MTHM

Plutonium Metal Feed

82.37 MTU

Uranium Feed Isotopes

6.67 MTPu

Plutonium Feed Isotopes

$99.8 \%$ U-238, $0.2 \%$ U-235

Pu-239 Concentration

93.5\% Pu-239, 6.5\% Pu-240

Mixed-Oxide (MOX) Composition $\quad \mathrm{UO}_{2}-\mathrm{PuO}_{2}-\mathrm{Er}_{2} \mathrm{O}_{3}$

Average Erbium in MOX

$1.2 \mathrm{wt} \% \mathrm{Er}_{2} \mathrm{O}_{3}$ in $\mathrm{MOX}$ pellets

Core Operating Cycles

Average Capacity Factor $\quad 0.75$

Cycle Length

12-months (274 EFPD)

Number of Cycles

$4^{(4)}$

Average Discharge Burnup

42,200 MWD/MTHM

Average Pu-240 in Discharge

$23 \%$ of Total Pu Inventory 


\section{IABLE 2.1.1-7}

\section{IHERMAL OUTPUT DATA FOR SYSTEM 80 + PLUTONIUM BURNER}

\begin{tabular}{|c|c|c|c|}
\hline Parameter & $\mathrm{UO}_{2}$ & Pu-Bnr & $H^{3}$-Prod \\
\hline $\begin{array}{l}\text { Core Thermal Output, MWth } \\
\text { NSSS Thermal Output, MWth } \\
\text { Percentage Reference NSSS Power }\end{array}$ & $\begin{array}{l}3914 \\
3931 \\
100 \%\end{array}$ & $\begin{array}{l}3800 \\
3817 \\
97.10 \%\end{array}$ & $\begin{array}{l}3410 \\
3427 \\
87.18 \%\end{array}$ \\
\hline $\begin{array}{l}\text { Hot Leg Temperature, }{ }^{\circ} \mathrm{F} \\
\text { Steam Pressure at SG outlet, psia } \\
\text { Total Steam Flow, Mlbm/hr } \\
\text { Minimum Steam Quality } \\
\text { Feedwater Temperature, }{ }^{\circ} \mathrm{F}\end{array}$ & $\begin{array}{l}616 . \\
1012 \\
17.66 \\
.9975 \\
450\end{array}$ & $\begin{array}{l}609.5 \\
1014 \\
17.08 \\
.9975 \\
447\end{array}$ & $\begin{array}{l}604 . \\
1023.4 \\
15.15 \\
.9975 \\
437\end{array}$ \\
\hline
\end{tabular}




\section{SAFETY RELATED PHYSICS CHARACTERISTICS FOR MIXED-OXIDE CYCLES}

Beginning of Cycle Reactivity (CEAs Withdrawn, No Dissolved Boron), $\rho$

Hot Standby

Full Power, No Xenon

Full Power, Equilibrium Xenon

$\begin{array}{lll}\text { Equilibrium } & \text { Equilibrium } & \text { Equilibrium } \\ \text { Cycle UO2 } & \text { Cycle SGR } & \text { Cycle APR }\end{array}$

$\begin{array}{lll}0.137 & 0.122 & 0.083\end{array}$

$\begin{array}{lll}0.121 & 0.103 & 0.064\end{array}$

$\begin{array}{lll}0.101 & 0.081 & 0.055\end{array}$

Dissolved Boron Requirements

PPM Dissolved Boron for Criticality - CEAs Withdrawn BOC Hot Standby

$\begin{array}{rrr}1589 & 1820 & 3189 \\ 1400 & 1539 & 2450 \\ 1170 & 1208 & 2100 \\ 1955 & 2383 & 4203 \\ 116 & 149 & 383 \\ 101 & 130 & 331 \\ -0.59 & -0.95 & -1.00 \\ -3.24 & -3.73 & -3.10\end{array}$

BOC Full Power, No Xenon

BOC Full Power, Equilibrium Xenon

Requirement for Refueling (5\% Subcritical)

Inverse Boron Worth (PPM/\% $\Delta$ p)

Full Power BOC

Full Power BOC

Moderator Temperature Coefficient $\left(10^{-4} \Delta \mathrm{p}\right)$

Full Power BOC

Full Power BOC

$-3.24$

$-3.73$

$-3.10$ 


\section{Combustion Engineering, Inc.}

\section{TABLE 2.1.1-9 \\ BORIC ACID \\ SOLUBILITY IN WATER}

\begin{tabular}{|c|c|c|c|c|}
\hline${ }^{\circ} \mathrm{C}$ & $\begin{array}{l}\text { Temperature } \\
\text { of }\end{array}$ & Wt. $\% \mathrm{H}_{3} \mathrm{BO}_{3}$ & $\begin{array}{c}\text { Parts } \mathrm{H}_{3} \mathrm{BO}_{3} \\
\text { per } 100 \text { Parts } \\
\mathrm{H}_{2} \mathrm{O} \text { by Weight }\end{array}$ & $\begin{array}{l}\text { Pounds Boric } \\
\text { Acid per U.S. } \\
\text { Gallon of Water }\end{array}$ \\
\hline 0.0 & 32.0 & 2.52 & 2.59 & 0.216 \\
\hline 5.0 & 41.0 & 2.98 & 3.07 & 0.256 \\
\hline 10.0 & 50.0 & 3.49 & 3.62 & 0.302 \\
\hline 15.0 & 59.0 & 4.08 & 4.25 & 0.355 \\
\hline 20.0 & 68.0 & 4.72 & 4.95 & 0.413 \\
\hline 25.0 & 77.0 & 5.46 & 5.78 & 0.481 \\
\hline 30.0 & 86.0 & 6.23 & 6.64 & 0.552 \\
\hline 35.0 & 95.0 & 7.12 & 7.67 & 0.636 \\
\hline 40.0 & 104.0 & 8.08 & 8.79 & 0.728 \\
\hline 45.0 & 113.0 & 9.12 & 10.02 & 0.830 \\
\hline 50.0 & 122.0 & 10.27 & 11.45 & 0.944 \\
\hline 55.0 & 131.0 & 11.55 & 13.06 & 1.074 \\
\hline 60.0 & 140.0 & 12.97 & 14.90 & 1.223 \\
\hline 65.0 & 149.0 & 14.42 & 16.85 & 1.379 \\
\hline 70.0 & 158.0 & 15.75 & 18.69 & 1.526 \\
\hline 75.0 & 167.0 & 17.41 & 21.08 & 1.715 \\
\hline 80.0 & 176.0 & 19.10 & 23.61 & 1.914 \\
\hline 85.0 & 185.0 & 21.01 & 26.60 & 2.151 \\
\hline 90.0 & 194.0 & 23.27 & 30.33 & 2.444 \\
\hline 95.0 & 203.0 & 25.22 & 33.73 & 2.707 \\
\hline 100.0 & 212.0 & 27.53 & 37.99 & 3.039 \\
\hline 103.3 & 217.9 & 29.27 & 41.38 & 3.301 \\
\hline
\end{tabular}




\section{PRELIMINARY PHYSICS DATA FOR PLUTONIUM DISPOSITION CORE}

\begin{abstract}
Cycle Length
$B O L$ no rods, equilibrium $X_{\theta}$

EOL no rods, equilibrium $X_{\theta}$

Cold, Critical Boron (ppm *)

BOL WRSO, no $X e, k=.95$

EOL WRSO, no $X e, k=.95$
\end{abstract}

4-Year Core

274 EDPD 10600 (MWD/T)

Hot Full Power Critical Boron (ppm)

2410

360

4120
Equilibrium Cycle

274 EFPD 10600 (MWD/T)

1775 1175

3220

Refueling Boron Concentration (ppm *)

BOL no rods, no $X_{e}, k=.95$

5710

4765

EOL no rods, no $X e, k=.95$

2770

3900

Core Exposure (MWD/T)

BOL

0

17345

EOL

44200

27945

$\left(p p m^{*}\right)=$ best estimate $+10 \%$

Note: This table assumes the use of natural boric acid. 
IABLE 2.1.1-11

LITHIUM CONCENTRATIONS (DPM) REOUIRED FOR COMBINATIONS OE BOBON AND PH AT RCS OPERATINC CONDITIONS

\begin{tabular}{|l||l|l|l|l|l|l|}
\hline \multicolumn{1}{|c||}{ pH } & 6.90 & \multicolumn{1}{c|}{7.00} & \multicolumn{1}{c|}{7.10} & 7.20 & 7.30 & 7.40 \\
\hline B,ppm & & & & & & \\
\hline 0 & 0.19 & 0.24 & 0.31 & 0.39 & 0.49 & 0.62 \\
50 & 0.25 & 0.31 & 0.39 & 0.50 & 0.63 & 0.80 \\
100 & 0.30 & 0.38 & 0.48 & 0.61 & 0.78 & 0.99 \\
150 & 0.36 & 0.45 & 0.58 & 0.73 & 0.93 & 1.18 \\
200 & 0.42 & 0.53 & 0.67 & 0.85 & 1.08 & 1.37 \\
250 & 0.48 & 0.60 & 0.76 & 0.97 & 1.23 & 1.56 \\
300 & 0.53 & 0.68 & 0.86 & 1.09 & 1.39 & 1.77 \\
400 & 0.66 & 0.83 & 1.06 & 1.35 & 1.71 & 2.18 \\
500 & 0.78 & 1.00 & 1.27 & 1.61 & 2.05 & 2.61 \\
600 & 0.92 & 1.16 & 1.48 & 1.88 & 2.40 & 3.06 \\
700 & 1.05 & 1.34 & 1.70 & 2.16 & 2.76 & 3.52 \\
800 & 1.19 & 1.51 & 1.93 & 2.46 & 3.13 & 4.01 \\
900 & 1.34 & 1.70 & 2.16 & 2.76 & 3.52 & 4.51 \\
1000 & 1.48 & 1.89 & 2.41 & 3.07 & 3.93 & 5.03 \\
1100 & 1.64 & 2.09 & 2.66 & 3.39 & 4.34 & 5.57 \\
1200 & 1.80 & 2.29 & 2.92 & 3.73 & 4.77 & 6.12 \\
1300 & 1.96 & 2.50 & 3.19 & 4.07 & 5.22 & 6.70 \\
1400 & 2.13 & 2.71 & 3.46 & 4.43 & 5.68 & 7.30 \\
1500 & 2.30 & 2.93 & 3.75 & 4.80 & 6.15 & 7.92 \\
1600 & 2.48 & 3.16 & 4.04 & 5.18 & 6.65 & 8.56 \\
1700 & 2.66 & 3.40 & 4.35 & 5.58 & 7.16 & 9.21 \\
1800 & 2.85 & 3.64 & 4.66 & 5.97 & 7.69 & 9.90 \\
1900 & 3.04 & 3.89 & 4.99 & 6.39 & 8.23 & 10.61 \\
2000 & 3.24 & 4.15 & 5.32 & 6.83 & 8.78 & 11.35 \\
\hline & & & & & & \\
\hline
\end{tabular}


Combustion Engineering, Inc.

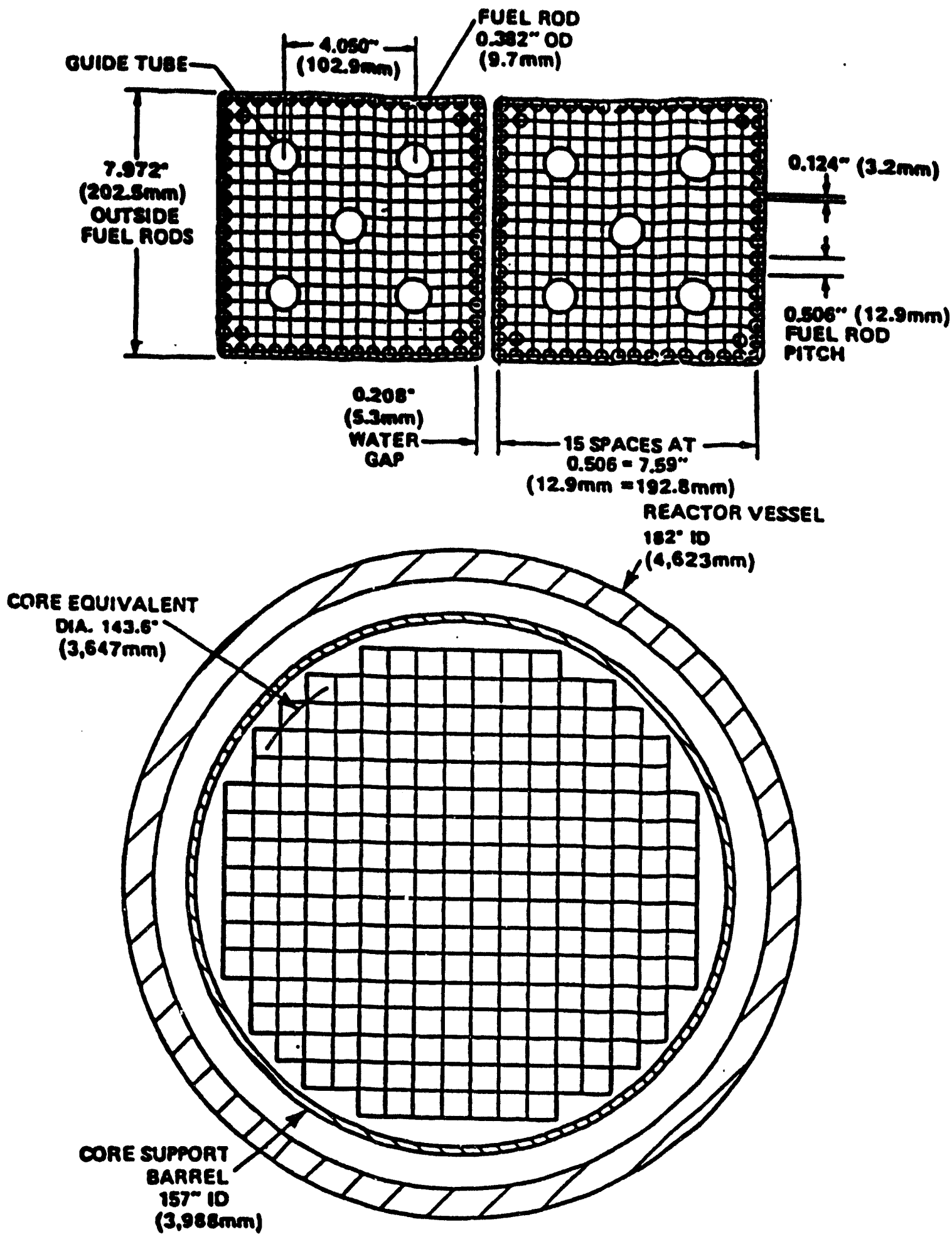

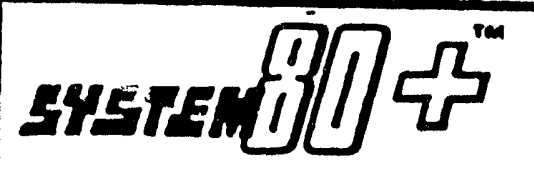

REACTOR CORE CROSS SECTION

FGURE 
Combustion Engineering, Inc.
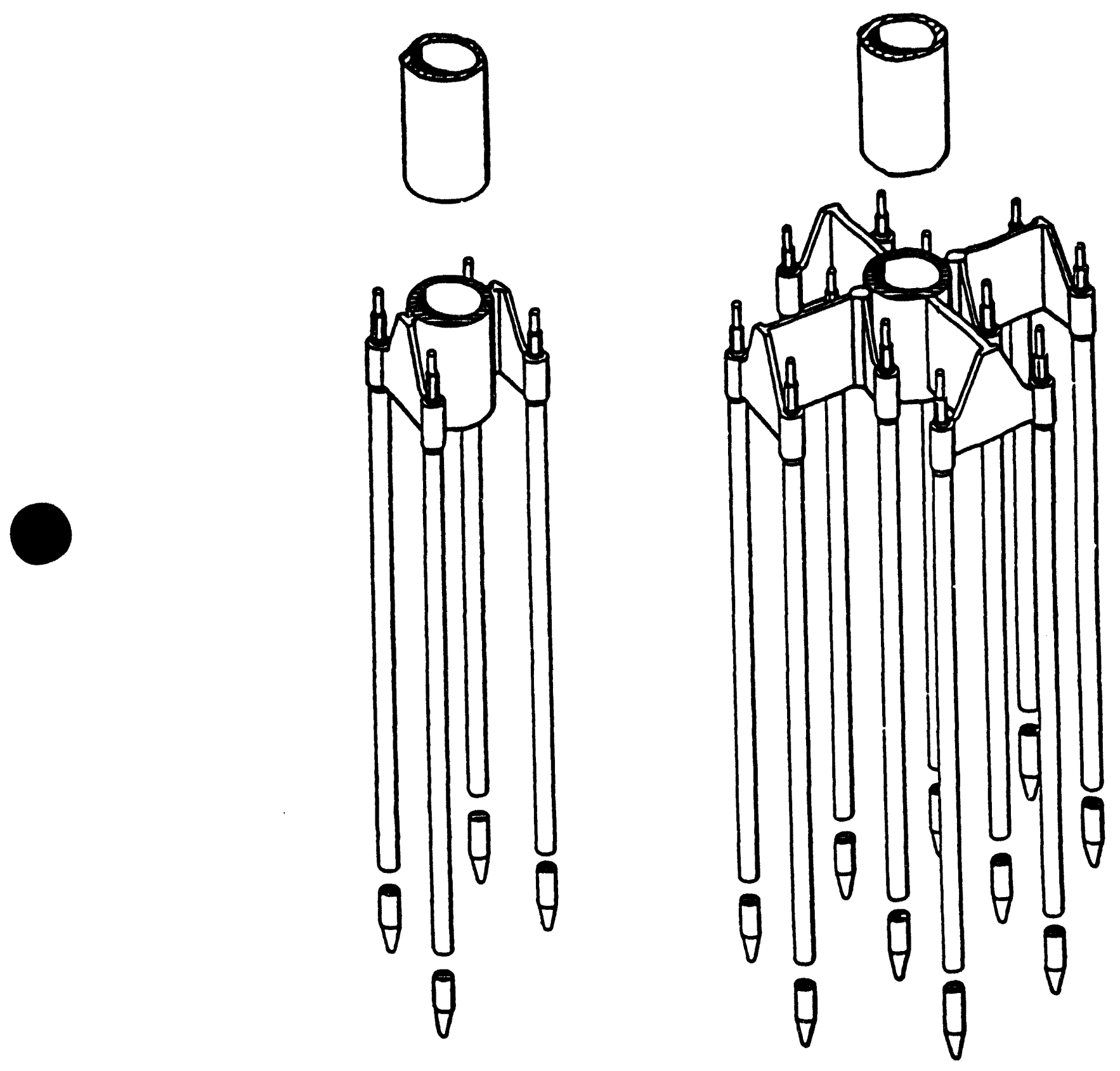

4 FWGER CEA

12 FWMGER CEA

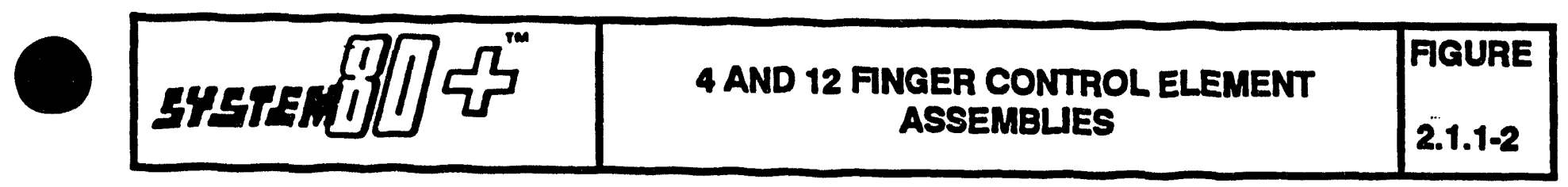


Combustion Engineering, Inc.
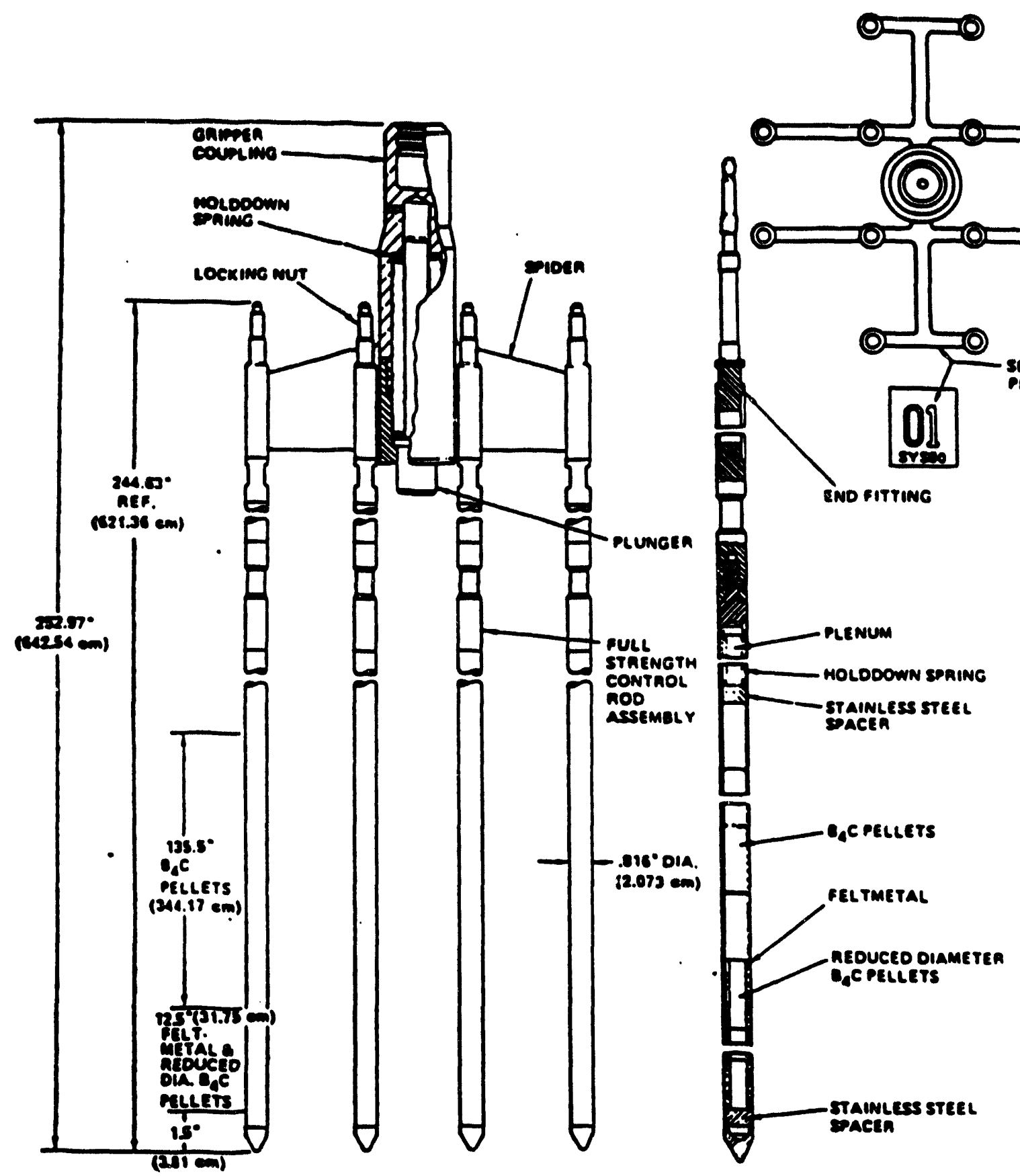
Combustion Engineering, Inc.

UPPER GUIDE STRUCTURE AND FUEL ASSEMBLY DETAILS OMITTED FOR VISUALIZATION PURPOSES

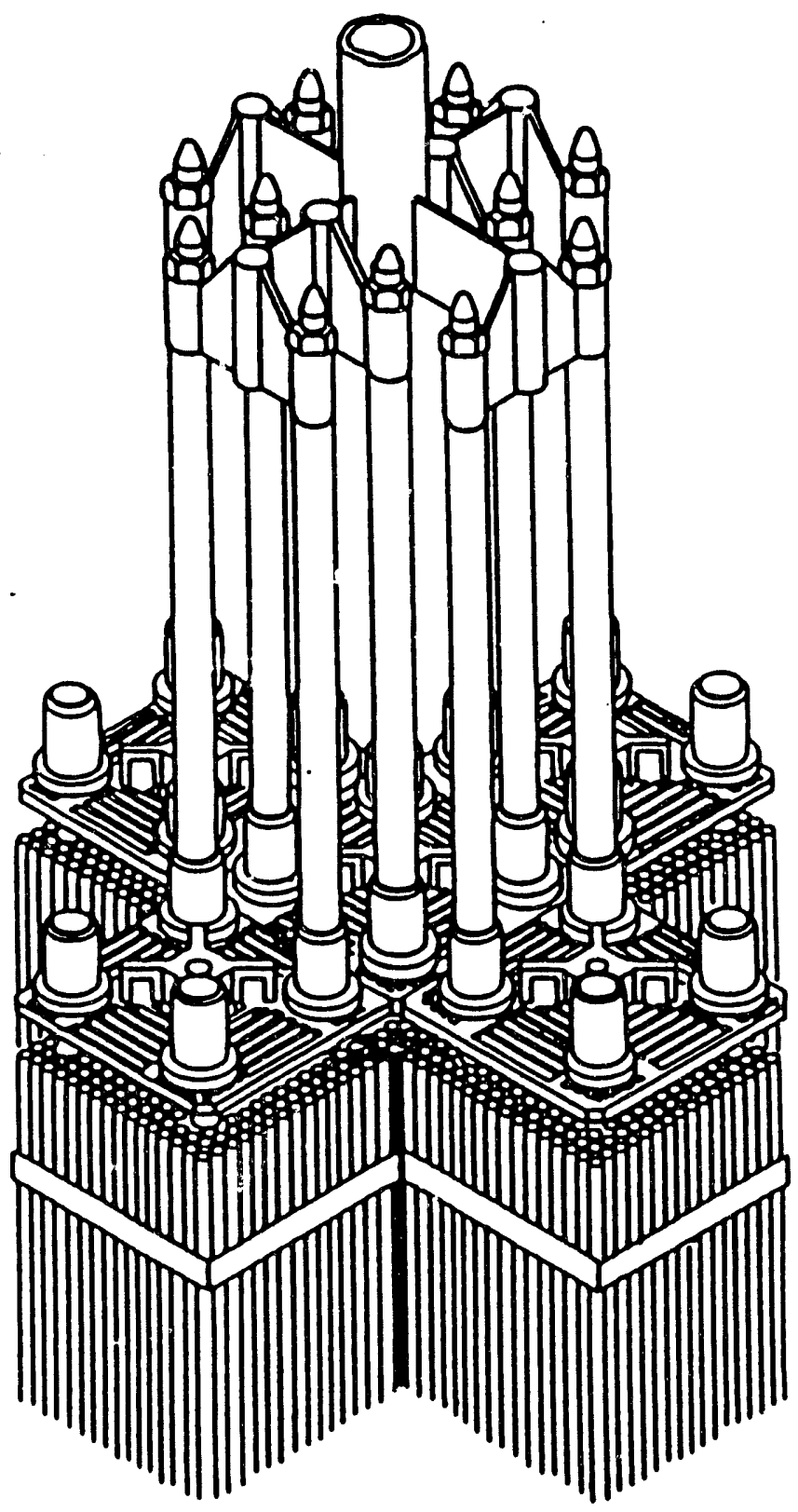




\section{Combustion Engineering, Inc.}

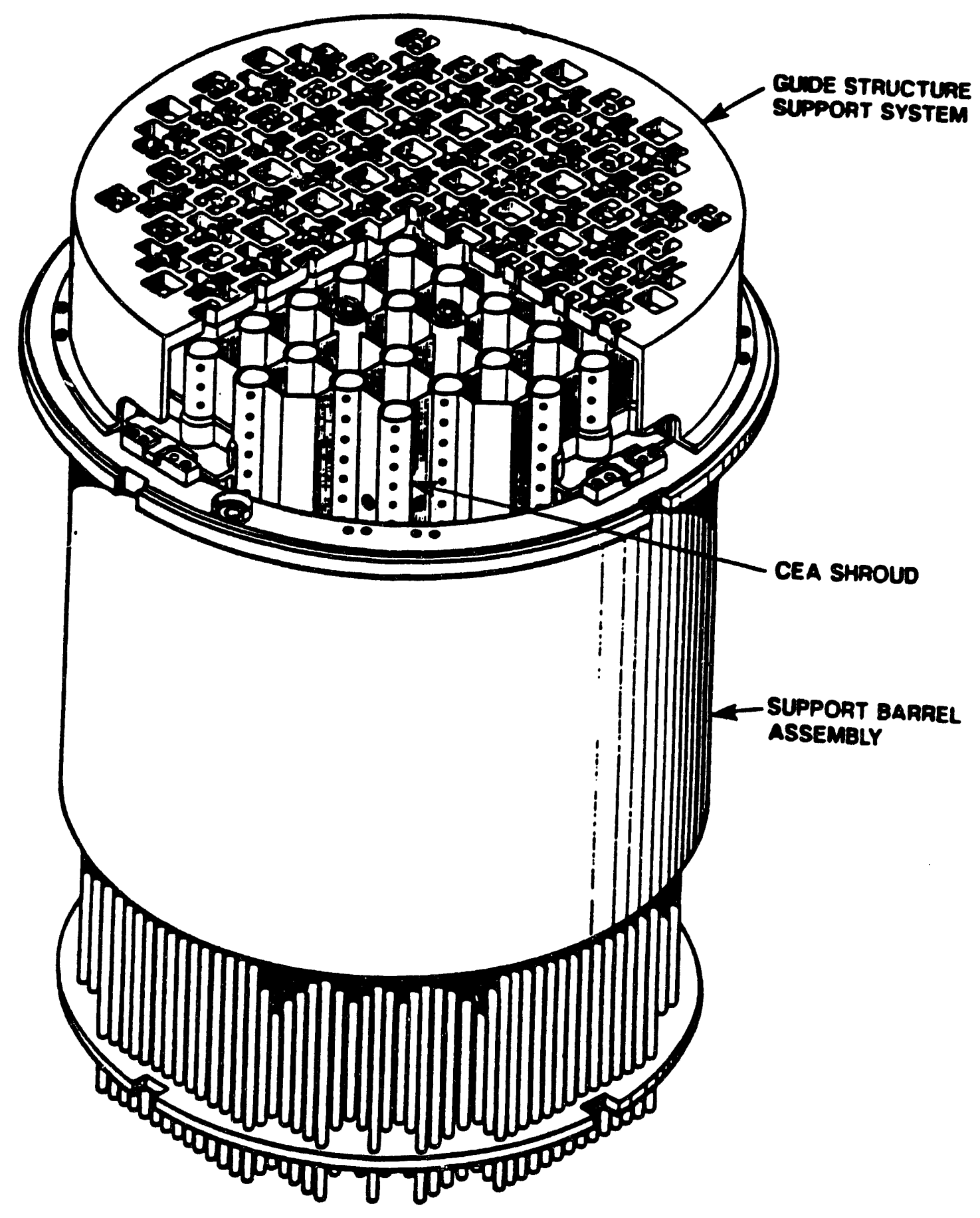



UPPER GUIDE STRUCTURE ASSEMBLY

FGURE 
Combustion Engineering, Inc.

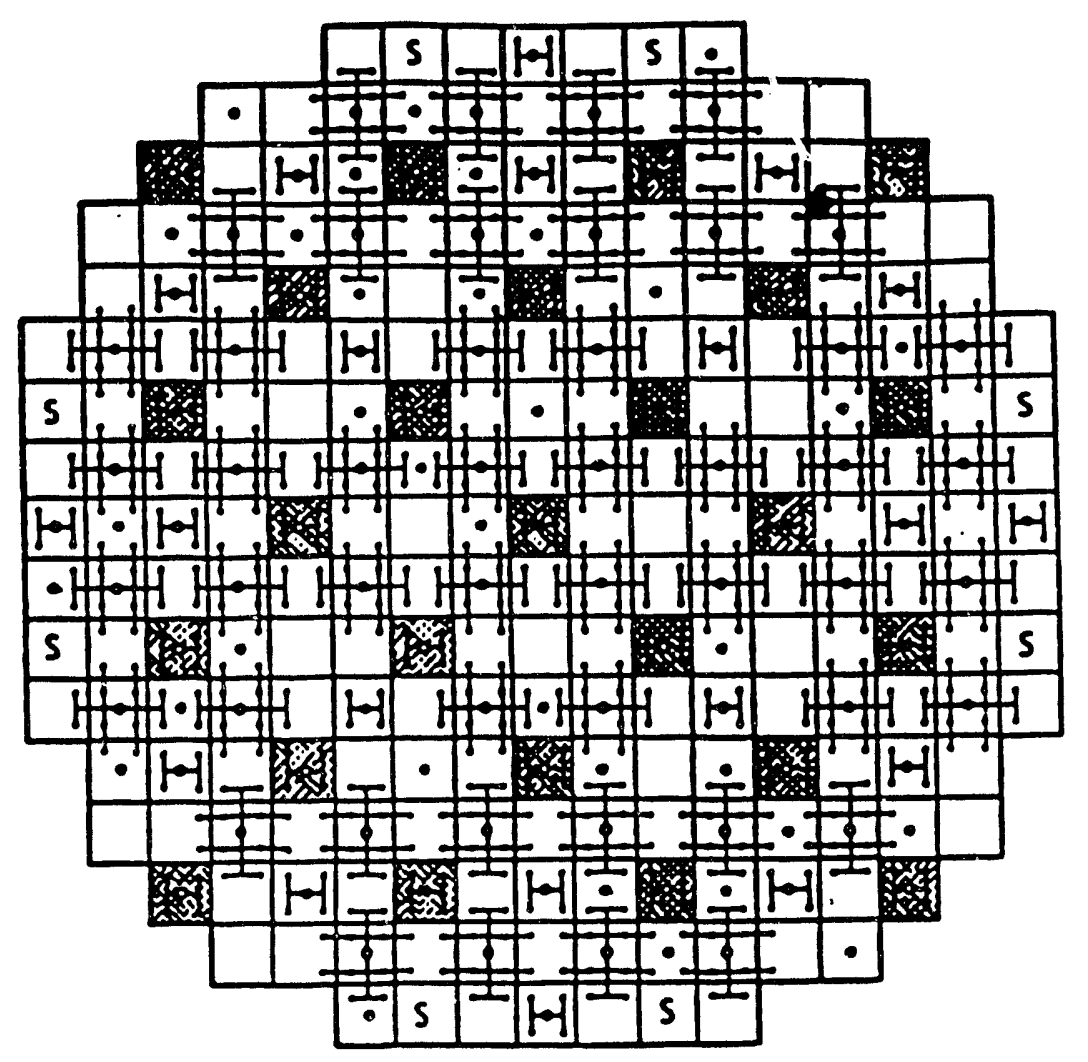

12 ELEMENT FULL STRENGTH CEA

A] alement full strength cea

㭚 a ELMENT PAAT STAENGTH CEA

5 oemotes spape cea locations FOR OPEN-MARKET PLUTONIUM RECYCLE

- DENOTES LOCATIONS OF FIXED AMOOIUN
W-CORE MEUTAON DETECTOR STRINGS AND IN-CORE INSTRUMENT LOCATIONS 


\section{Combustion Engineering, Inc.}

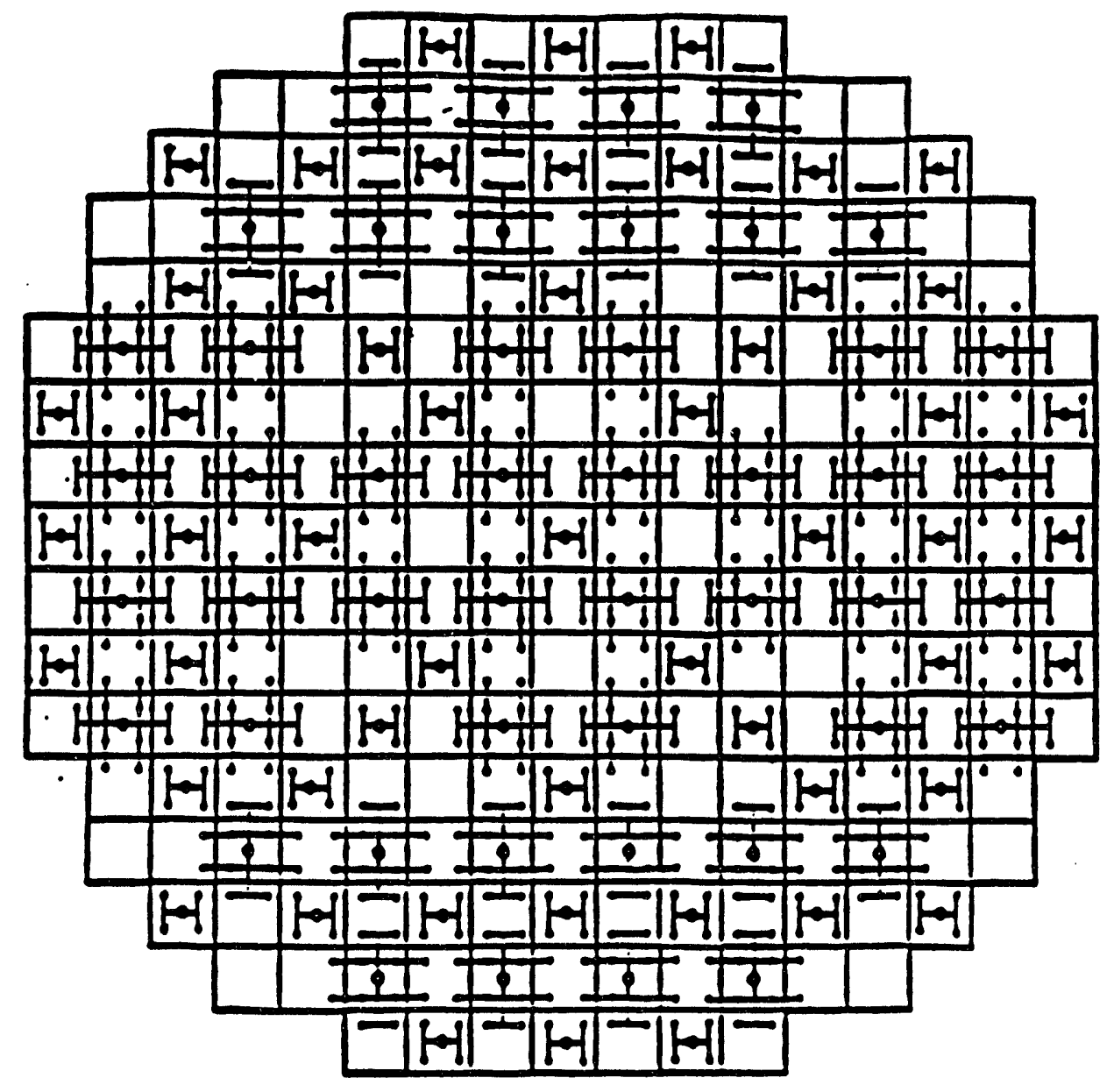

fid 12 ELEMENT FULL STRENGTH CEA (48)

[F] alEMENT FULL STRENGTH CEA (53) 
Combustion Engineering, Inc.

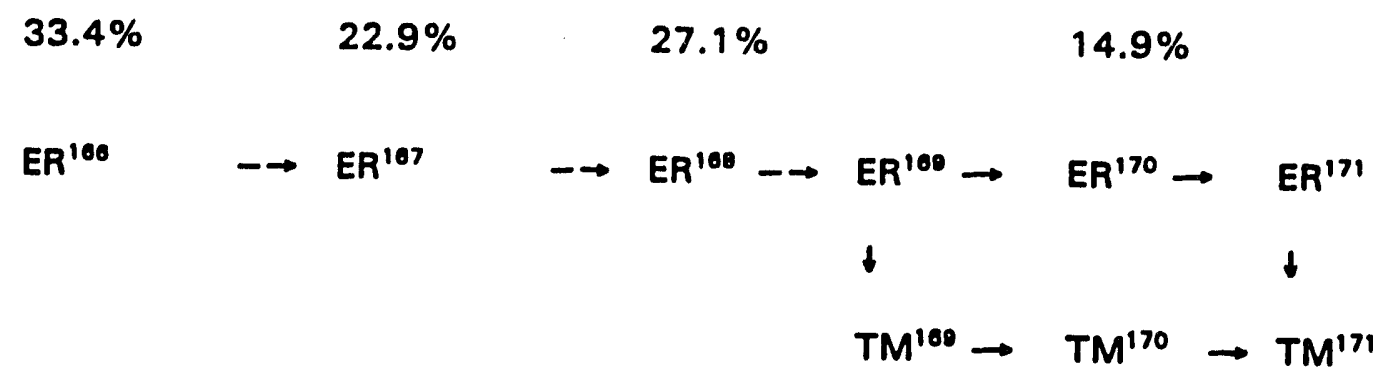




$$
\begin{gathered}
{ }_{84}^{238} \mathrm{Pu} \\
\sigma_{n_{0} \text { tot }}
\end{gathered}
$$

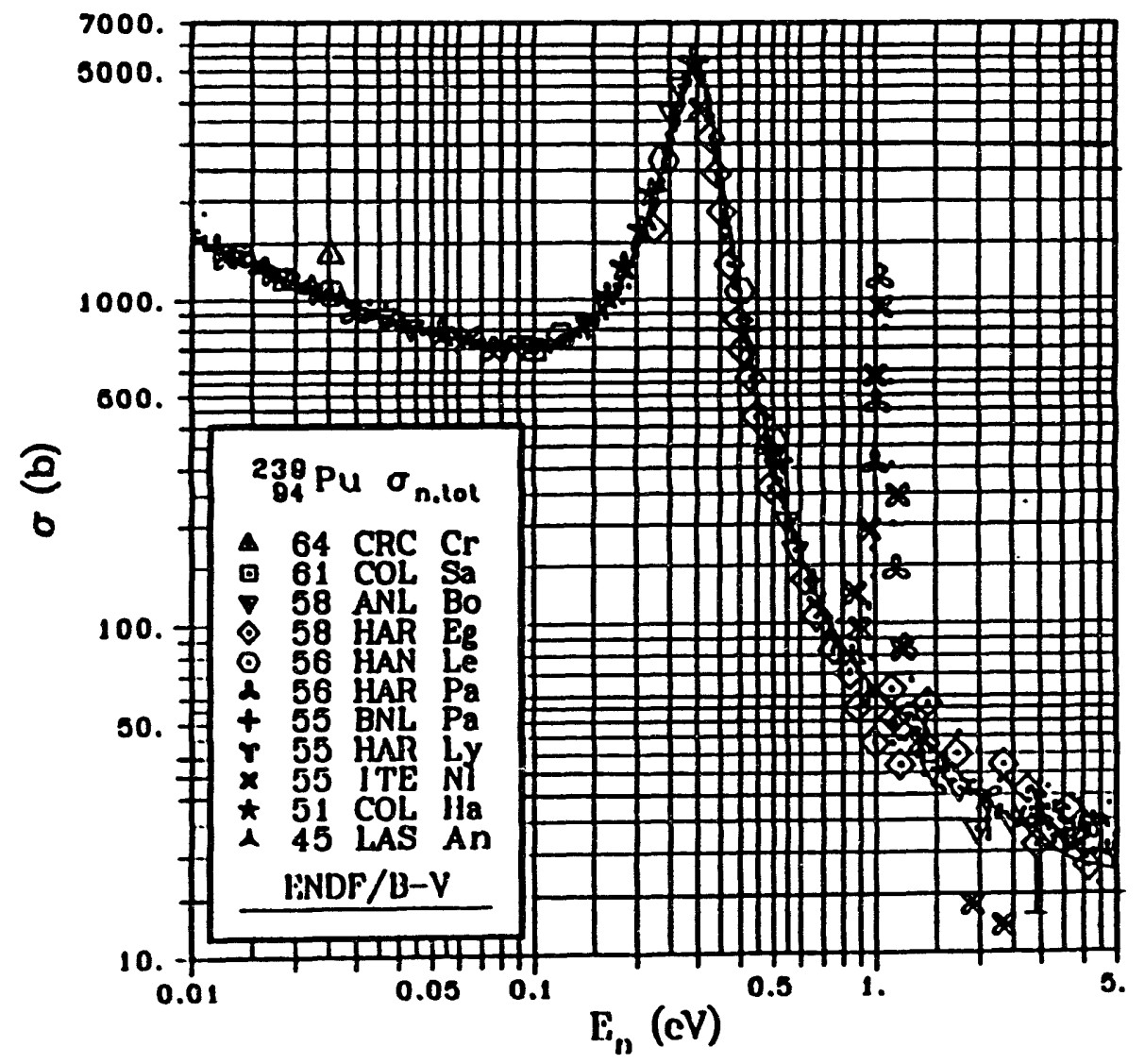

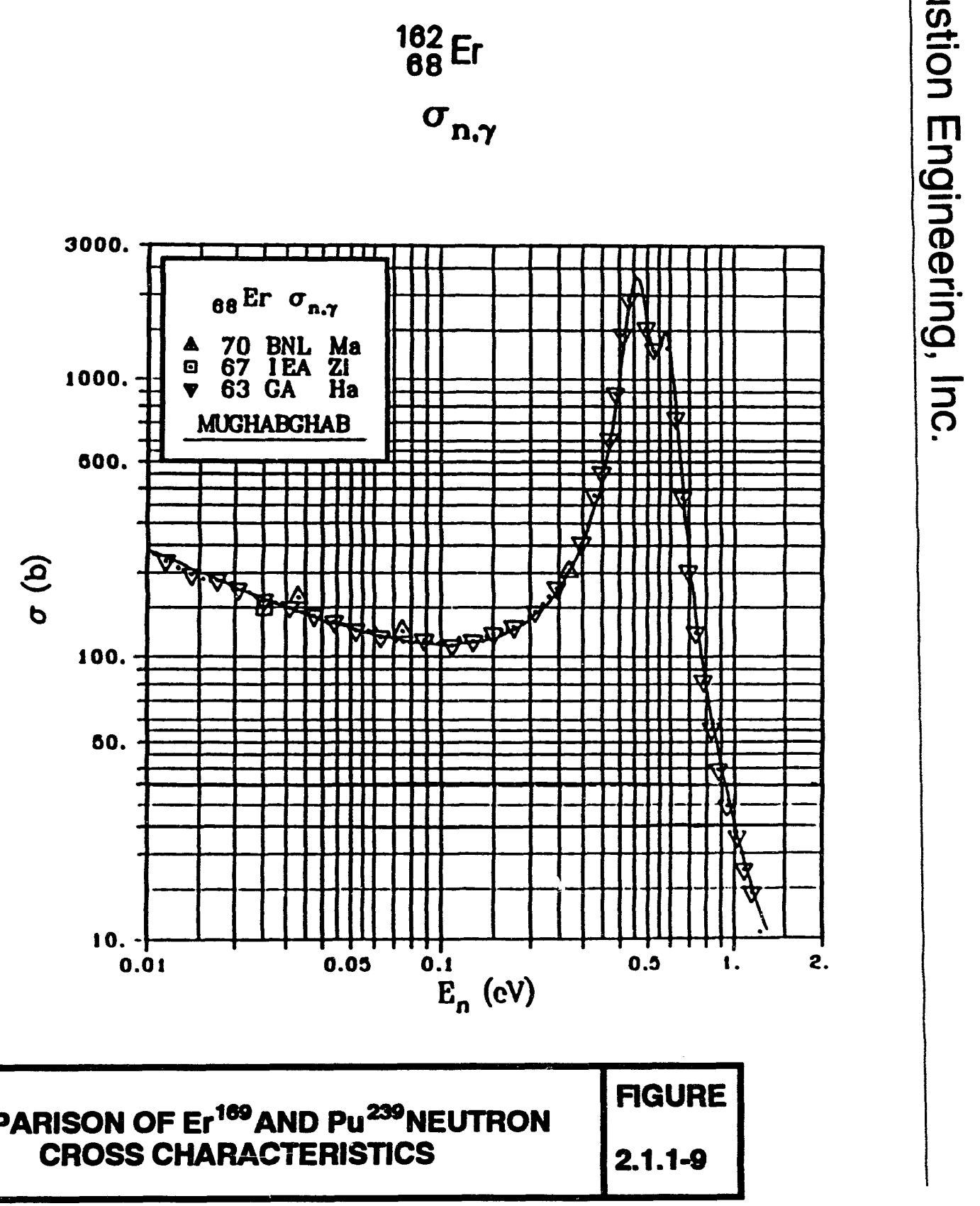




\section{Combustion Engineering, Inc.}

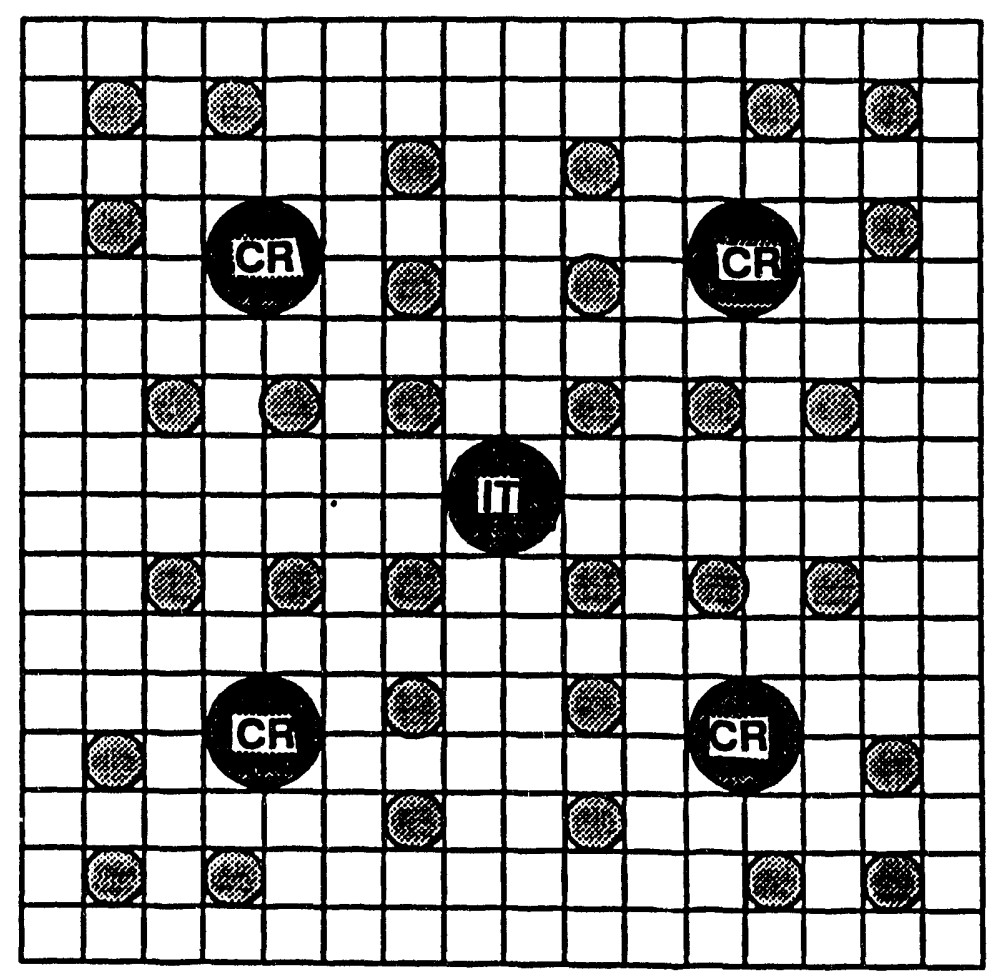

- Tritium Target

CR Control Rod

IT Instrument Tube 
Combustion Engineering, Inc.

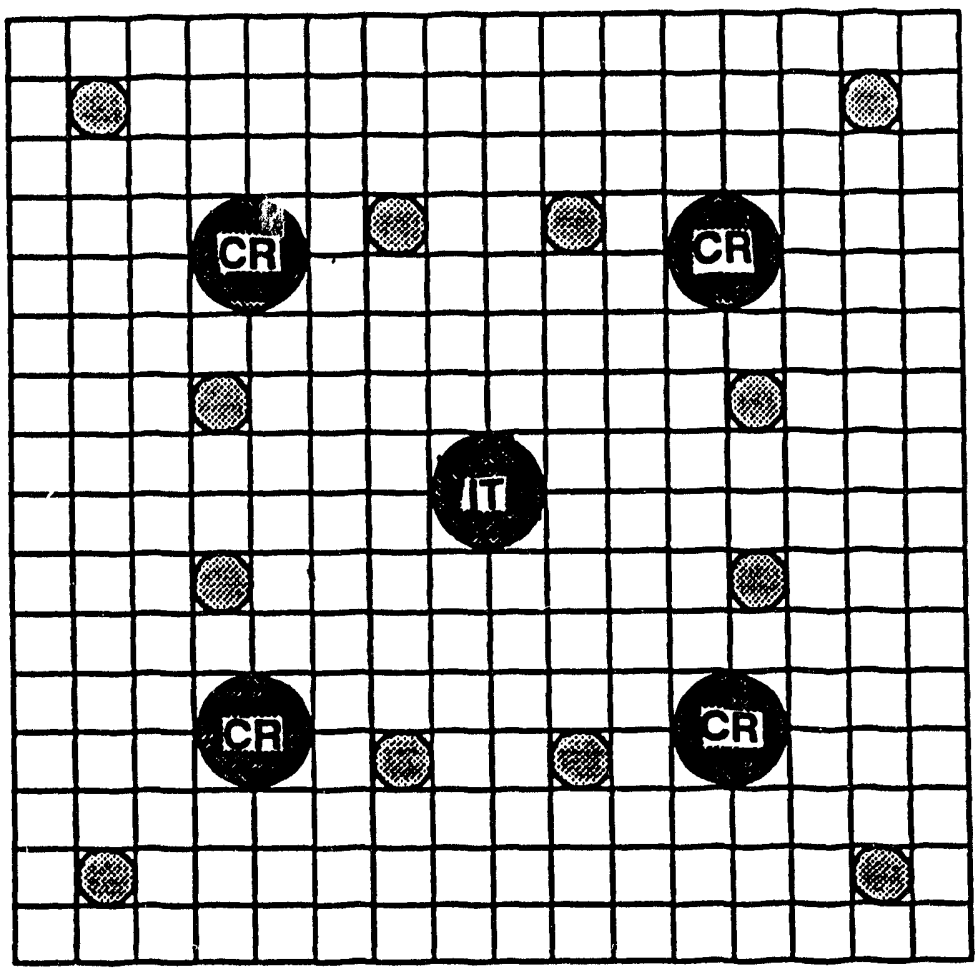
(1) Burnable Poison Rod
CR Control Rod
III Instrument Tube 


\subsubsection{Cooling Under Normal Operations, Desion Accidents}

\subsubsection{Introduction}

The following sections describe the System $80+$ Reactor Coolant System. This description would apply for either $\mathrm{UO}_{2}$ or MOX fuel operation.

The functions of the Reactor Coolant System (RCS) are:
A. To transfer energy from the reactor core to the steam generator where steam is produced for use in the turbine generator;
B. To serve as the secondary barrier to the release of fission products from the reactor core to the environment;
C. To provide sufficient cooling during all normal plant evolutions and expected transients to preclude significant fuel damage;
D. To circulate reactor coolant of the required chemistry to minimize corrosion and boron concentration for reactivity control.

The major safety role of the RCS is to act as a barrier against the release of fission products (Function B). High quality materials manufactured to withstand system design pressures coupled with stringent compliance to operating procedures help to ensure system integrity, thereby, preventing the release of fission products from the system.

\subsubsection{RCS Description}

\section{i. System Description}

The major components of the System 80 + Reactor Coolant System are a reactor vessel, two parallel heat transfer loops, each containing one steam generator and two reactor coolant pumps (RCPs) and a pressurizer connected to one of the reactor vessel hot legs. All components of the RCS are located inside the containme : building. The RCS also includes interconnecting piping to auxiliary systems and instrumentation necessary for operation and control.

The Reactor Coolant Pumps (RCPs) circulate water during normal operation through the reactor vessel and the steam generators. The reactor coolant is heated as it passes through the reactor vessel by energy produced from the fissioning fuel in the core and is cooled in the steam generators as it gives up heat to the secondary system. Feedwater ertering the shell side of the steam generators absorbs heat from the primary system forming steam. The reactor coolant also serves as a neutron moderator in the core and contains a soluble neutron absorber (boron) for reactivity control. Except for some local boiling in the hottest channels in the core, the reactor coolant is maintained in a subcooled condition by maintaining a high system pressure.

System pressure is controlled by the pressurizer where steam and water are maintained in thermal equilibrium. Steam is formed by energizing immersion heaters in the 
pressurizer, or is condensed by the pressurizer spray to limit the pressure variations caused by contractions or expansion of the reactor coolant.

The average temperature of the RCS varies with power level as the fluid expands and contracts, changing the pressurizer water level.

The charging pumps and letdown control valves in the Chemical and Volume Control System (CVCS) are used to maintain a programmed pressurizer water level. A continuous but variable letdown purification flow is maintained to keep the RCS chemistry within prescribed limits. A charging nozzle and a letdown nozzle are provided on the reactor coolant piping for this operation. The charging flow is also used to alter boron concentration or correct the chemical content of the reactor coolant.

Other RCS penetrations are the pressurizer surge line in one hot leg; the four direct vessel injection nozzles for the safety injection system; two return nozzles to the shutdown cooling system, one in each hot leg; two pressurizer spray nozzles; vent and drain connections; and sample and instrument connections.

Overpressure protection for the reactor coolant pressure boundary (RCPB) is provided by four spring-loaded ASME Code safety valves connected to the top of the pressurizer. These valves discharge to the in-containment refueling water storage tank (IRWST), where the steam is to be released under water and is condensed and cooled. Overpressure protection of the IRWST is provided by venting to the containment if there is a pressure buildup in the IRWST or by vacuum breakers should the IRWST pressure drops below atmospheric pressure. Overpressure protection for the secondary side of the steam generators is provided by spring loaded ASME code safety valves located in the main steam system upstream of the steam line isolation valves.

ii. Major Interfaces

The major interfaces of the RCS are:

A. Reactor and Core System

The reactor vessel in the RCS encloses the reactor and core system and provides support for the reactor core. The RCS also transfers heat from the reactor core through the steam generators to the secondary system.

B. Reactor Building, Containment, Containment Isolation System:

The RCS components are located inside the containment building. The containment heat removal system is designed to meet the RCS heat loads requirements during normal operation. Containment isolation valves associated with the RCS are closed for required design basis events (feedline break, LOCA, steam generator tube rupture). 
C. Shutdown Cooling System (Section 2.3)

The shutdown Cooling System (SCS) is used in conjunction with the main steam and main or emergency feedwater systems to reduce the temperature of the RCS in post shutdown periods from the hot shutdown operating temperature to the refueling temperature. Reactor coolant flows out of the SCS nozzles, located on the reactor vessel outlet (hot leg) pipes and is circulated through the SCS heat exchangers by the SCS pumps. The return to the RCS is through the Safety Injection System (SIS) direct vessel injection (DVI) nozzles.

D. Safety Injection System (SIS) (Section 2.3):

The SIS is designed to provide core cooling in the unlikely event of a lossof-coolant accident (LOCA). The borated safety injection water of the SIS is delivered to the core region (i.e., inside the reactor vessel) through four DVI nozzles located on the reactor vessel.

E. Safety Depressurization System (Section 2.3)

The Reactor Coolant Gas Vent System (RCGVS) function provides a safetygrade means of venting non-condensible gases from the pressurizer and reactor vessel upper head. The RCPVS is used for venting during system startup, shutdown or post accident operations. The Rapid Depressurization (RD) function, or bleed function, provides a manual safety-grade means of quickly depressurizing the RCS when normal and emergency feedwater are unavailable to remove decay heat through the steam generators.

F. Chemical and Volume Control System

The CVCS provides functions relating to the day-to-day operation of the RCS. The CVCS is designed as a non-safety-related system and as such is not required to perform any accident mitigation or safe shutdown function.

G. Main Steam Supply System:

The two steam generators in the RCS, using heat generated in the reactor core and carried by the primary coolant to each steam generator, produce steam which is supplied to the Main Steam Supply System.

H. Component Cooling Water System:

The CCWS provides cooling water to each reactor coolant pump (RCP) and pump motor. 
I. Sampling System:

The sampling system provides a means of obtaining remote liquid samples from the RCS for chemical and radiochemical laboratory analysis. Typical analysis preformed includes corrosion product activity levels, crud concentration, dissolved gas and corrosion product concentration, chloride concentration, coolant $\mathrm{pH}$, conductivity levels and boron concentration.

J. Control and Instrumentation:

The RCS has appropriate control and instrumentation capability to manually or automatically control the pressurizer level and fressurizer and RCS pressure. Process data from the RCS is provided to the Core Protection Calculators (CPCs) and the Reactor Regulating System (RRS).

K. Electric Power

The electric power system supplies electric power to the appropriate RCS components, i.e, the RCPs and motor operated valves. The electrical power system is composed of an offsite power system and an onsite power system.

\subsubsection{RCS Operation}

The following describes the RCS operation for relevant plant states:

A. Normal Operation

\section{BCS Startup}

The heat transfer loops and pressurizer are filled with water of the proper chemical composition and boron concentration. The steam generator secondary side is filled to the normal water level.

The RCS is pressurized above the minimum pressure required for RCP operation, but below the maximum pressure at which the low temperature overpressure protection (LTOP) relief valves may be aligned without opening; this is also the maximum pressure for alignment of the shutdown cooling system to the RCS. The value of this pressure may be impacted by the plutonium core if vessel embrittlement requires higher temperatures at low pressures. The RCS can be pressurized initially by using the charging pump and by controlling letdown backpressure. The pressurizer heaters are used to form a steam bubble and increase RCS pressure to a value that is sufficient for RCP operation. 
Venting is performed to remove air from the system. Vent connections to the RCGVS are provided on the reactor vessel upper head and the pressurizer. One or more RCP is operated for short periods of time to force air from the steam generator tubes.

If the RCS has been opened, e.g., for refueling operations, an RCS leak test is conducted.

The RCS is heated up by operating one or more reactor coolant pumps to provide heat input. During heatup, RCS pressure is manually controlled by operation of the pressurizer heaters and the letdown control system. The heatup rate is limited based on pressure/temperature (P/T) limit curves that are provided to guard against brittle fracture. When pressurizer pressure reaches the normal operating value the pressurizer level and pressure controls can be placed in the automatic mode. After normal operating pressure and temperature have been achieved, reactor power is increased by reducing the RCS boron concentration and/or withdrawing CEAs.

During low power operation (i.e., < 5\%), the NSSS control systems are generally in the manual mode of operation. Above $5 \%$ power the NSSS control systems will be placed in the automatic mode. Power escalation proceeds to $100 \%$ power.

\section{RCS Power Operation}

This operating mode of the NSSS is defined to be greater than $5 \%$ and less than or equal to $100 \%$ power. The reactor is critical and the primary system is at the normally prescribed operating temperature and pressure. The plant control systems are normally int he automatic mode of operation. Manual control system operation is allowed for short periods of time if the automatic systems are unavailable. The steam produced from reactor power by the steam generators flows through the turbine generator to produce electrical power. The turbine bypass valves are closed. The turbine-generator is connected to an electrical grid.

\section{RCS Shutdown}

The initial step in the transition from power operation to cold shutdown is to shutdown the reactor by manually inserting the control banks of CEAs and/or increasing the RCS boron concentration. Once the reactor is shutdown the RCS is borated to the cold shutdown boron concentration using the CVCS. The NSSS cooldown process consists of rejecting the NSSS stored energy and reactor decay heat to the steam generators. During these operations, the primary and secondary pressure and temperatures are controlled by bypassing steam to the main condenser. 
The RCS pressure is gradually reduced by de-energizing the pressurizer heaters and manually controlling the pressurizer spray valves. The reactor coolant pumps are operated, as necessary, to maintain a uniform temperature distribution in the primary loop and provide the necessary pressure differential for the pressurizer spray. The cooldown rate is administratively controlled so that it does not exceed the maximum specified rates.

Borated makeup water from the CVCS is added to maintain the pressurizer level as the primary coolant contracts during the cooldown process. When the reactor coolant temperature and the pressure is less than the plant specified values, the Shutdown Cooling System (SCS) can be placed in service.

After it becomes necessary to discontinue the operation of the reactor coolant pumps because of low system pressure, the auxiliary pressurizer spray (supplied by the CVCS charging pumps) is then used to continue the pressurizer cooldown.

After the RCS has been cooled down and depressurized, the pressurizer can be vented, as required, while the SCS remains in operation. This ensures that the RCS does not become pressurized because of the reactor decay heat generation.

B. Abnormal Operation

For abnormal operation where electrical power is lost to the RCPs, natural circulation provides adequate cooling of reactor core. The RCPs are not required to operate following any accident and are not required to perform a safety function. The RCPs are therefore not provided with emergency power. Each RCP is designed to coastdown at a rate such that core damage does not occur following a loss of offsite and onsite power. This is ensured by the inclusion of a flywheel on the RCP which provides additional inertia to extend the pump coastdown.

During accident conditions, a feed and bleed procedure can provide cooling for the core and RCS. The Safety Depressurization System is used to reduce primary pressure to enable the Safety Injection System to provide once through cooling flow.

\subsection{Infrastruature}

Infrastructure consists of the organizations, personnel, material resources, and facilities to develop, design, manufacture, and operate the plutonium disposition complex. DOE for this study has defined the infrastructure requirements to cover only facilities. 



\section{Centimeter}

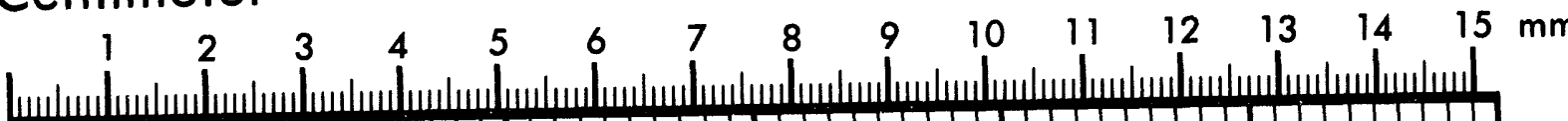

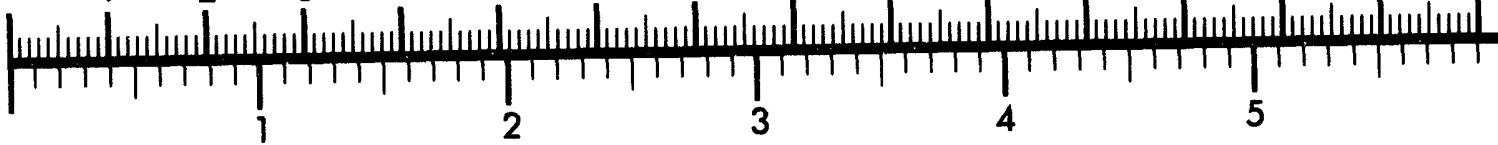
Inches
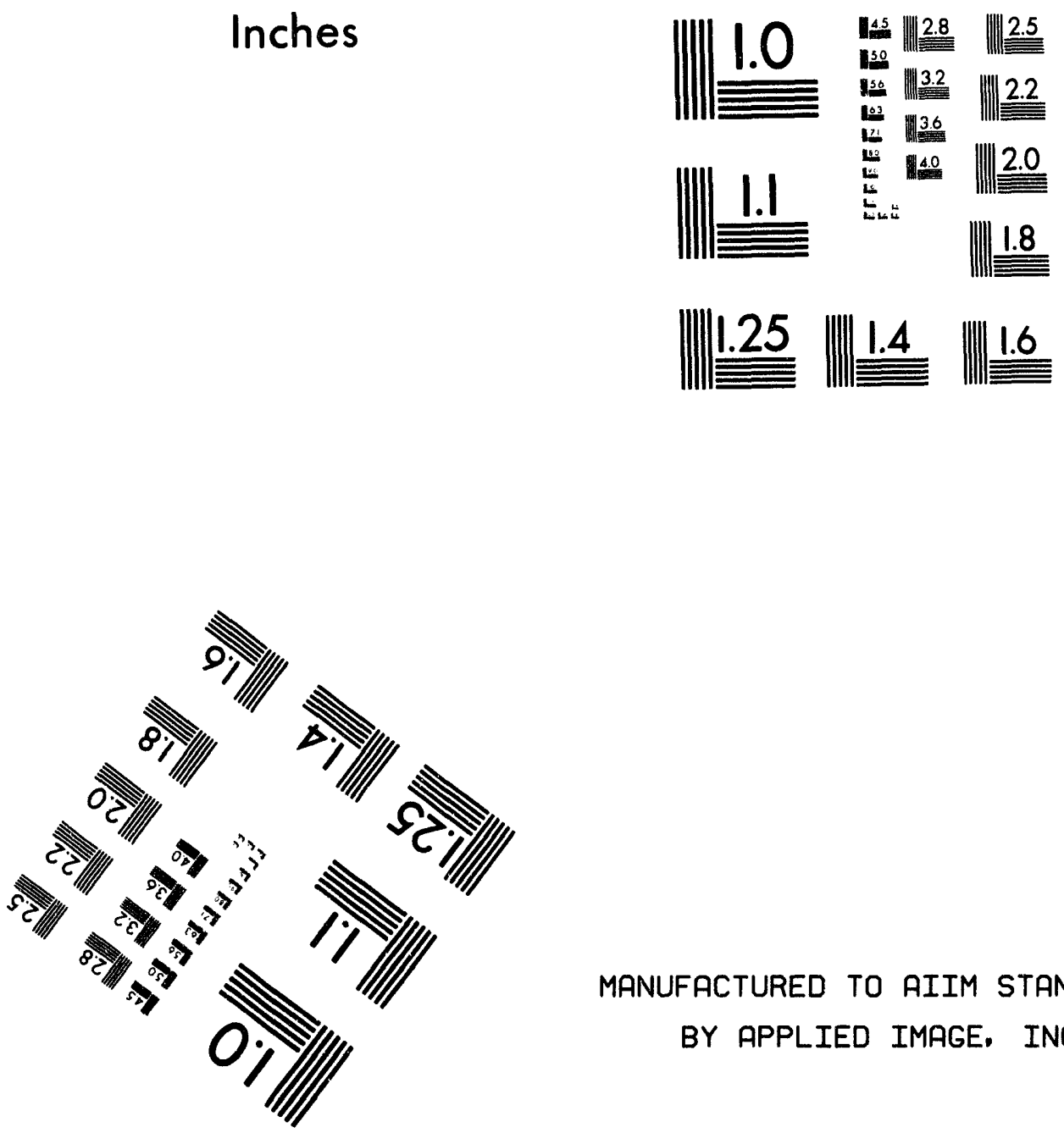

MANUFACTURED TO AIIM STANDARDS

BY APPLIED IMAGE, INC.





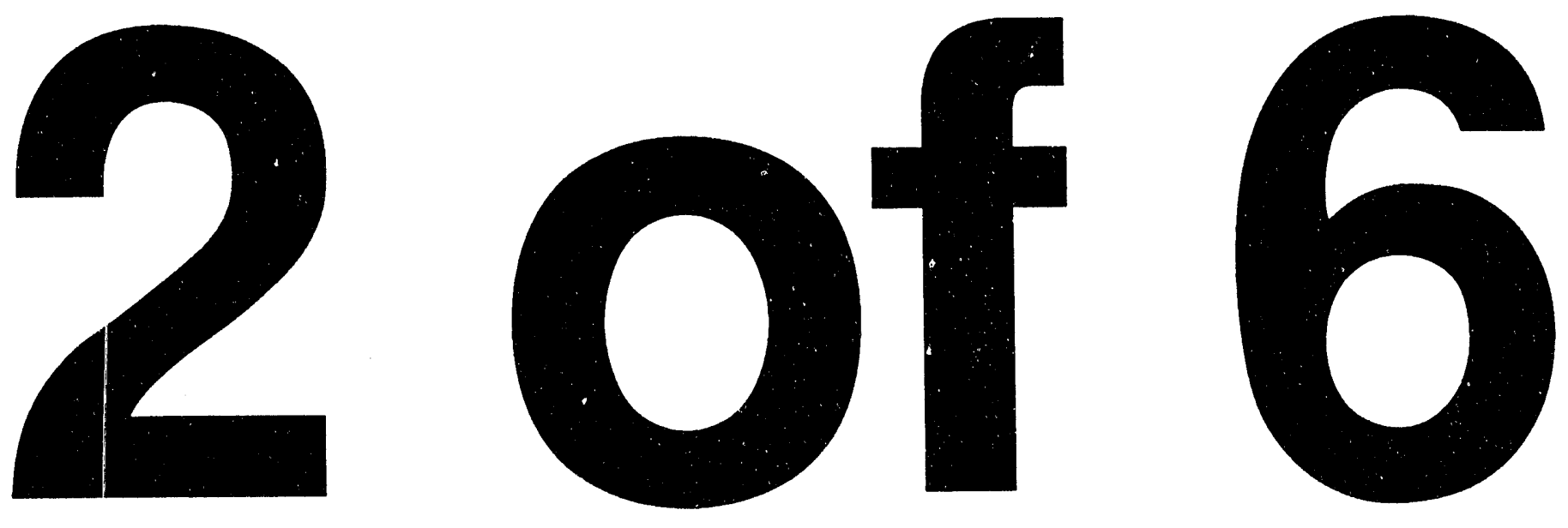
Outside the Reactor Complex, existing DOE facilities such as the TA-55 Area at Los Alamos and the Advanced Test Reactor at the Idaho National Engineering Laboratory can be directly applicable for the fuel qualification program. This program is discussed in Section 3.2.5. Other DOE facilities such as Pantex, TX and Yucca Mountain, NV are also key DOE facilities outside the Reactor Complex (and the scope of this study) which will provide fuel input, and, receive output from the Reactor Complex after sufficient cooling has taken place in the spent fuel pool. Depleted $\mathrm{UO}_{2}$ can be provided from the gaseous diffussion plant at Oak Ridge. Commercial facilities such as the ABB-CE Fuels Facility in Hemitite, Mo. can supply hardware, material, and burnable poisons. The world wide industrial base to support the Pu disposition mission is currently viable. An evaluation of the industrial base to support the New Production Reactor Program was completed in 1991. Recently, firm price contracts for the Taiwan Power Corp. Lungmen Project have been obtained. MOX fuel fabrication facilities have recently been completed or are in progress around the world.

Transportation Issues are described in Section 2.7.

The Reactor Complex is assumed to be located at a DOE site and will thereby benefit from the existing infrastructure such as trained personnel, security, roads, and office space to mention a few.

The MOX Fabrication Facility $\left(\mathrm{MF}^{2}\right)$ will be located within the Reactor Complex, and will include provisions for tritium target insertion. The $M^{2}$ is described in Section 2.4.

Spent fuel handling equipment and storage pools will accommodate the MOX fuel as described in Section 2.5.

The DOE will furnish the tritium target production, processing and recovery facilities. If the Reactor Complex is sited at Savannah River, the RTF and other tritium facilities can be modified and used as part of the tritium recovery process.

\section{$2.3 \quad$ Reactor Safety Systems}

This section describes the following System $80+$ principal safety systems:

- Shutdown Cooling System

- Emergency Feedwater (EFW) System

- Safety Injection System (SIS)

- Safety Depressurization System (SDS)

- Containment Spray System (CSS)

\section{Shutdown Cooling System}

The Shutdown Cooling System (SCS) is a safety-related system that is used in conjunction with the Main Steam and Main or Emergency Feedwater System to reduce 
the temperature of the Reactor Coolant System (RCS) in post-shutdown periods from the hot shutdown operating temperature to the refueling temperature. The initial phase of the cooldown is accomplished by heat rejection from the steam generator (SG) to the condenser or atmosphere. After the reactor coolant temperature and pressure have been reduced to approximately $350^{\circ} \mathrm{F}$ and $450 \mathrm{psia}$, the SCS is put into operation for normal shutdown cooling to reduce the RCS temperature to the refueling temperature $\left(120^{\circ} \mathrm{F}\right)$, and maintain this temperature during refueling or maintenance operations.

This system comprising two separate, redundant divisions utilizes two shutdown cooling pumps to circulate the reactor coolant, drawn from the SCS nozzles in the hot leg pipes between the reactor vessel and steam generator, through two shutdown cooling heat exchangers, returning it to the RCS via two direct injection nozzles. A schematic of one of the two divisions is shown in Figure 2.3-1. The component cooling water system supplies the cooling water for the shutdown cooling heat exchangers. During cooldown, the SCS suction side pressure and temperature follow the RCS conditions. The discharge side pressure is higher by an amount equal to the pump head. The temperature is lowered by the shutdown cooling heat exchanger.

The SCS divisions are designed to be independent, each receiving reactor coolant from a separate hot leg pipe and returning it through a separate nozzle on the RV. The design basis for normal cooldown with both divisions operating is to reduce the RCS temperature to $140^{\circ} \mathrm{F}$ within 24 hours after shutdown and to $120^{\circ} \mathrm{F}$ within 96 hours. The design basis allows the failure of a single active component, but at least one complete SCS cooling division can be brought on line from the control room. Under these conditions of a safety-grade cooldown, the RCS temperature is reduced to $200^{\circ} \mathrm{F}$ within 24 hours of shutdown.

The shutdown cooling heat exchangers are used to remove decay heat, RCS sensible lieat, and SCS pump heat during plant cooldown following initial cooldown and during safe cold shutdown conditions. The heat exchangers are sized to remove decay heat 96 hours after shutdown based on a reactor coolant water temperature of $120^{\circ} \mathrm{F}$, a component cooling water temperature of $100^{\circ} \mathrm{F}$, and a decay heat load corresponding to an average reactor core burnup of 2 years. The heat exchanger sizing should be verified against the larger decay heat load expected for the MOX core.

The SCS pumps have been selected to serve both the shutdown cooling function and the containment spray function. The pumps can provide the flow through the SCS heat exchangers for core cooldown. With appropriate valve actions, the SCS pump could supply the containment spray system (see Figure 2.3-1). In addition, the SCS loops are configured such that the pumps can be tested at design flow conditions with the reactor at power.

Additionally, the SCS is used in conjunction with the atmospheric dump valves and the emergency Feedwater System to cooldown the RCS following a small break Loss-ofCoolant Accident (LOCA). The SCS is also used subsequent to steam and feedwater line 
breaks and SG tube ruptures. The SCS is also designed to provide cooling to the Incontainment Refueling Water Storage Tank (IRWST) during post-accident feed and bleed operations (described below) utilizing the Safety Injection System and the Safety Depressurization System. The flow path for the operation is depicted in Figure 2.3-1, requiring valve operation to realign the system for this operation.

Details of SCS design, operation, and performance are provided in CESSAR-DC Section 5.4.7.

\section{Emergency Feedwater System}

The Emergency Feedwater (EFW) System provides an independent safety-related means of supplying secondary-side, quality feedwater to the steam generator(s) for removal of heat and prevention of reactor core uncovery during emergency phases of plant operation. The EFW System is a dedicated safety system which has no operating functions for normal plant operation.

The EFW System is designed to be automatically or manually initiated, supplying feedwater to the steam generators for any event that results in the loss of normal feedwater and requires heat removal through the steam generators, including the loss of normal onsite and normal offsite $A C$ power.

Following the event, the EFW System maintains adequate feedwater inventory in the steam generator(s) for residual heat removal and it is capable of maintaining hot standby and facilitating a plant cooldown (at the maximum administratively controlled rate of $75^{\circ} \mathrm{F} / \mathrm{hr}$ ) from hot standby to Shutdown Cooling System initiation. The Shutdown Cooling System becomes available for plant cooldown when the RCS temperature and pressure are reduced to $350^{\circ} \mathrm{F}$ and 450 psia, respectively.

The EFW System is designed to be initiated with operator action following a major loss of coolant accident to keep the steam generator tubes covered for the long term to enhance the closed system containment boundary. Covering the steam generator tubes post-LOCA minimizes potential containment bypass leakage, should pre-existing primaryto-secondary leakage be present.

The EFW System shown in Figure 2.3-2, is configured into two separate mechanical divisions. Each division is aligned to feed it $\mathrm{respective} \mathrm{steam} \mathrm{generator.} \mathrm{Each} \mathrm{division}$ consists of one Emergency Feedwater Storage Tank (EFWST), one $100 \%$ capacity motordriven pump subdivision, one $100 \%$ capacity steam-driven pump subdivision, valves, one cavitating venturi, and specified instrumentation. Each pump subdivision discharge header contains a pump discharge check valve, flow regulating valve, steam generator isolation valve and steam generator isolation check valve. The motor-driven subdivision and steam-driven subdivision are joined together inside containment to feed their respective steam generator through a common EFW header which connects to the steam generator downcomer feedwater line. Each common EFW header contains a cavitating 
venturi to restrict the maximum EFW flow rate to each steam generator. The cavitating venturi restricts the magnitude of the two pump flow as well as the magnitude of individual pump runout flow to the steam generator.

A cross-connection is provided between each EFWST so that either tank can supply either division of EFW. The two EFWSTs are safety grade tanks of seismic design in which each tank contains $100 \%$ of the total required volume of 350,000 gallons to achieve safe cold shutdown. A normally locked closed, local manually operated isolation valve is provided for each EFWST to provide separation. A line connected to a non-safety source of condensate is also provided with local manual isolation so that it can be manually aligned for gravity feed to either of the EFWSTs, should the EFWSTs reach low level before Shutdown Cooling System entry conditions are reached.

Pump discharge crossover piping is provided to enhance system versatility during longterm emergency modes, such that a single pump can feed both steam generators. Two normally locked closed, local manually operated isolation valves are provided for subdivision separation.

Details of the EFW System design operation and performance are provided in CESSAR-DC Section 10.4.9.

\section{Safety Injection System}

The Safety Injection System (SIS) is designed to provide core cooling in the unlikely event of a Loss-of-Coolant-Accident (LOCA). The SIS limits fuel damage to maintain a coolable core geometry, limits the cladding metal-water reaction, removes the energy generated in the core and maintains the core subcritical during the extended period of time following a LOCA. More specifically, the SIS assures that the criteria of 10 CFR 50.46 are met. In addition, the EPRI ALWR Requirements Document has been used to define a Safety Margin Design Basis for the SIS design. The Safety Margin Design Basis contains requirements which go beyond the minimum required by the Code of Federal Regulations, thereby providing additional safety assurance in the SIS design.

The SIS accomplishes these functional requirements by use of redundant active and passive injection subsystems. The active portion of the SIS consists of four mechanically separated trains, each consisting of a Safety Injection (SI) pump and associated valves. Each SI pump is provided with its own suction line from the In-containment Refueling Water Storage Tank (IRWST), and its own discharge line to a Direct Vessel Injection (DVI) nozzle on the reactor vessel. The passive portion consists of four identical pressurized Safety Injection Tanks (SITs). Two of the four trains are shown in Figure 2.3-3.

The SIS is designed such that for breaks larger than the size of a DVI nozzle, two SI pumps, in conjunction with the SITs, provides 100 percent of the minimum injection flow rate required to satisfy the LOCA performance requirements. For breaks equal to, or 
smaller than the size of a DVI nozzle, each SI pump, in conjunction with the SITs, has 100 percent of the capacity to satisfy LOCA performance requirements.

Four Safety Injection Tanks (SITs) are provided inside containment and as close to the DVI nozzles as possible. The bottom of the SIT is located above the centerline of the DVI nozzle, and the connecting piping is as direct as possible with a minimum of bends and elbows. The SITs automatically discharge their contents of borated water into the RCS if the RCS pressure drops below the SIT pressure of 610 psia as a result of a LOCA. Two check valves in the SIT discharge piping isolate the SITs from the RCS during normal plant operation. During startup, the operator pressurizes the SITs after the pressurizer pressure reaches 640 psia.

The primary function of the Safety Injection (SI) pumps is to inject borated water into the RCS if a break occurs in the Reactor Coolant Pressure Boundary (RCPB). For small break LOCAs, the RCS pressure remains high for a long period of time following the accident, and the SI pumps ensure that the injected flow is sufficient to meet the criteria given in 10CFR50.46. If necessary, SI pump flow is throttled to reduce RCS pressure to conditions that allow the initiation of shutdown cooling system operation for long term cooling. During shutdown cooling operations following a small break, the SI pumps continue injecting into the reactor vessel downcomer to provide makeup for spillage out the break.

Long-term cooling for large break LOCAs is accomplished by manually realigning the SIS for simultaneous hot leg and DVI nozzle injection. The alignment of SI pumps 1 and 2 is maintained to inject to the DVI nozzles; the discharge of SI pumps 3 and 4 is realigned to discharge to the RCS hot legs. Trains associated with pumps 1 and 3 are shown in Figure 2.3-3. This provides flushing flow and the ultimate subcooling of the core for those large break LOCAs that shutdown cooling cannot be used.

During normal operation, the SI pumps are isolated from the reactor coolant system by motor-operated valves. During safety injection, the SI pumps deliver water from the IRWST to the reactor vessel downcomer via DVI nozzles whenever RCS pressure falls below pump shutoff head. During the long-term mode of operation, the SI pumps continue to take suction from the IRWST.

The SI pumps are sized such that for breaks, up to a double-ended guillotine break, two SI pumps in conjunction with the SITs provide the required minimum injection flow rate to the core. The SI pumps are also sized such that, after consideration of spillage directly out through the break, one SI pump, in conjunction with the SITs, will supply adequate water to the core to match decay heat boiloff rates soon enough to minimize core uncovery and allow small break LOCAs to meet the performance criteria. The effectiveness of the SI pump during a steam line break is also analyzed to assure that the pumps are adequately sized. 
The SIS is capable of injecting borated water into the reactor vessel to mitigate accidents other than LOCAs. Safety injection would be initiated in the event of a Steam Generator Tube Rupture, Steam Line Break or a CEA Ejection incidents. The borated water injected by the SIS provides inventory and reactivity control for these events.

The SIS provides sufficient boron to maintain the reactor subcritical during safe cold shutdowns assuming that the most reactive control rod remains out of the core.

The SIS is capable of providing an alternate means of decay heat removal for those events beyond the licensing design basis in which the steam generators are not available. The SIS, in conjunction with the Safety Depressurization System is used to provide feed and bleed cooling of the RCS.

Details of the SIS design, operation, and performance are provided in CESSAR-DC Section 6.3

\section{Safety Depressurization System}

The Safety Depressurization System (SDS), shown schematically in Figure $2.3-4$, is designed to perform the following functions:

A. Venting of the Reactor Coolant System (RCS)

The Reactor Coolant Gas Vent (RCGV) function provides a safety-grade means of venting non-condensible gases and steam from the pressurizer and the reactor vessel upper head to the Reactor Drain Tank (RDT) during post-accident conditions for non-LOCA design basis events. In addition, the RCGV provides:

1. Safety-grade means to depressurize the RCS in the event that pressurizer Main Spray and Auxiliary Spray systems are unavailable.

2. Means of venting the pressurizer and reactor vessel upper head during prerefueling and post-refueling operations.

B. Rapid Depressurization (bleed process) of the RCS

The Rapid Depressurization (RD) function, or bleed function, provides a manual means of quickly depressurizing the RCS when normal and emergenisy feedwater (EFW) are unavailable for an extended time to remove core decay hea: through the steam generators. This function is achieved via remote manual oper ator control. When ever any event (e.g., a total loss of feedwater) results in high RCS pressure with a gradual loss of RCS liquid inventory, the SDS rapid depressurization or bleed valves may be opened by the operator, resulting in a controlled rapid depressurization of the RCS. As the RCS pressure decreases, the Safety Injection pumps start, initiating feed flow to the RCS and restoring the RCS liquid inventory. 
The RD function allows for both short and long-term decay heat removal.

In addition, the SDS piping transports the Pressurizer Safety Valve (PSV) discharge effluent and the Rapid Depressurization Valve (RDV) discharge from the pressurizer to the IRWST. This piping also transports the RCGV effluent from the pressurizer or the reactor vessel to either the IRWST or the RDT. The IRWST provides a water reservoir to condense the steam effluent and collect the RCS discharge.

As the PSV, RDV or RCGV discharge is mixed with the IRWST water, the IRWST water temperature is increased. The Shutdown Cooling System (SCS) or Containment Spray System (CSS) may be used to cool the IRWST should the IRWST liquid approach saturation. Cooling of the IRWST requires manual initiation by the operator. The realignment of the SCS or CSS by action of several valves can be seen in Figure 2.3-1.

Piping from each PSV nozzle is routed to a manifold which is part of the RCGV piping. This piping allows the operator to direct the RCGV discharge, through parallel valve divisions, to either the IRWST or the RDT.

A vent path is provided from the pressurizer steam space and the reactor vessel upper head to the Reactor Drain Tank (RDT). Redundant active components are provided such that no single active failure:

1. Prevents the establishment of a vent path between the pressurizer or the reactor vessel upper head to the RDT; or,

2. Prevents the isolation of the pressurizer from the reactor vessel upper head.

The piping layout is designed so there are no undrainable loops in the line. The piping is pitched downhill so that any fluid within the piping drains toward the RDT.

The RCGV piping and support arrangement on the reactor vessel upper head is designed to minimize the time required for disassembly and reassembly during refueling operations.

Tw o RD flow paths are provided from the pressurizer steam space to the IRWST. Two active valves are provided in each flow path such that no single active failure can prevent the establishment of a vent path from the pressurizer to the IRWST, nor can a single active failure prevent isolation of a vent path.

If normal or emergency $A C$ power sources are available, opening the rapid depressurization or bleed valves results in a rapid depressurization of the RCS which allows the SI pumps to be automatically started to refill the RCS and provide cooling of the core.

Core decay heat removal, using the RD function, is accomplished by a once-through cooling process in which water is injected directly into the reactor vessel downcomer via 
the Safety Injection System. Once in the reactor vessel, the cooling fluid passes through the vessel downcomer to the lower plenum, up through the core (where decay heat is removed) and out to the hot leg, through the surge line to the pressurizer and out through the rapid depressurization bleed valves to the piping sparger in the IRWST where quenching and cooling of the bleed flow is accomplished. The quench volume within the IRWST allows a feed and bleed operation to be maintained for about thirty minutes before external cooling of the IRWST should be initiated. IRWST cooling is provided by the safety grade Component Cooling Water System and the Shutdown Cooling System heat exchangers. In addition, the Containment Spray System heat exchangers may be used to cool the IRWST.

Bleed and feed and, therefore, core cooling can continue even without the initiation of flow through the Shutdown Cooling heat exchanger. Without IRWST cooling, the IRWST's vent system will relieve the steam formed in the tank to the containment. The discharged steam will be condensed by the containment cooling system and returned to the Holdup Volume Tank via the sump gravity drains.

For a Total Loss of Feedwater (TLOFW) event in which: (1) it is also assumed that feedwater is not restored to the steam generator secondary side; and (2) it is also assumed that early "feed" and "bleed" for once-through core cooling is not initiated, the Rapid Depressurization valves shall be opened no longer than 2.0 hours after the pressurizer safety valves first lift. This will allow the RCS pressure to be reduced from 2500 psia to 250 psia prior to reactor vessel melt-through for a severe accident scenario.

Details of the SDS design, operation, and performance are provided in CESSAR-DC Section 6.7.

\section{Containment Spray System}

The Containment Spray System (CSS) is a safety grade system designed to reduce containment pressure and temperature from a main steam line break or loss-of-coolantaccident and to remove fission products from the containment atmosphere following a loss of coolant accident. Fission product removal is required so that in the event of containment leakage, activity at the site boundary due to radioactive iodine will be reduced. No spray additives are required.

The CSS uses the In-Containment Refueling Water Storage Tank (IRWST) and has two independent divisions (two containment spray pumps, two containment spray heat exchangers, two independent spray headers, and associated piping valves and instrumentation). The system is shown in Figure 2.3-1. Post-accident pH control of the sprayed fluid is provided using trisodium phosphate dodecahydrate that is stored in the Holdup Volume Tank (HVT).

The CSS provides sprays of borated water to the containment atmosphere from the upper regions of the containment. The spray flow is provided by the containment spray pumps 
which take suction from the IRWST. The containment spray pumps start upon the receipt of a Safety Injection Actuation Signal (SIAS) or a Containment Spray Actuation Signal (CSAS). The pumps discharge through the containment spray heat exchangers and the spray header isolation valves to their respective spray nozzle headers, then into the containment atmosphere. Spray flow to the containment spray headers is not provided until a CSAS automatically opens the containment spray header isolation valves. The spray headers are located in the upper part of the containment building to allow the falling spray droplets time to approach thermal equilibrium with the steam-air atmosphere. Condensation of the steam by the falling spray results in a reduction in containment pressure and temperature.

The CS pumps are designed to be functionally interchangeable with the Shutdown Cooling System (SCS) pumps. Though not required for normal operation or accident mitigation, interchangeability of the pumps allows the CS pumps to back up the SCS pumps when the CS pumps are not needed for their requisite function, i.e., during refueling. In addition, the CS pumps and CS heat exchangers can be used as a backup to the SCS pumps and heat exchangers to provide cooling of the IRWST during postaccident feed and bleed operations when the steam generators are not available to cool the RCS.

The function of the CSS pumps is to provide flow through the CS headers and CSS heat exchangers to provide fission product control and containment atmosphere temperature and pressure control resulting from a plant accident.

Minimum flow orifices are installed in lines running from the pump discharge, returning back to the pump suction. These paths include a miniflow heat exchanger and ensure that the pumps are not deadheaded if they are inadvertently run against a closed system.

The CSS heat exchangers are used to remove heat from the containment atmosphere during and following an accident. The units are designed to reduce the containment atmosphere pressure 24 hours after an accident to a value that is one-half of the calculated peak pressure.

The CSS heat exchangers are used as a backup to the SCS heat exchangers for IRWST cooling during post-accident operations when the Safety Injection System and Safety Depressurization System are used for feed and bleed cooling of the RCS.

Details of the CSS design, operators, and performance are provided in CESSAR-DC Section 6.5. 
Combustion Engineering, Inc.

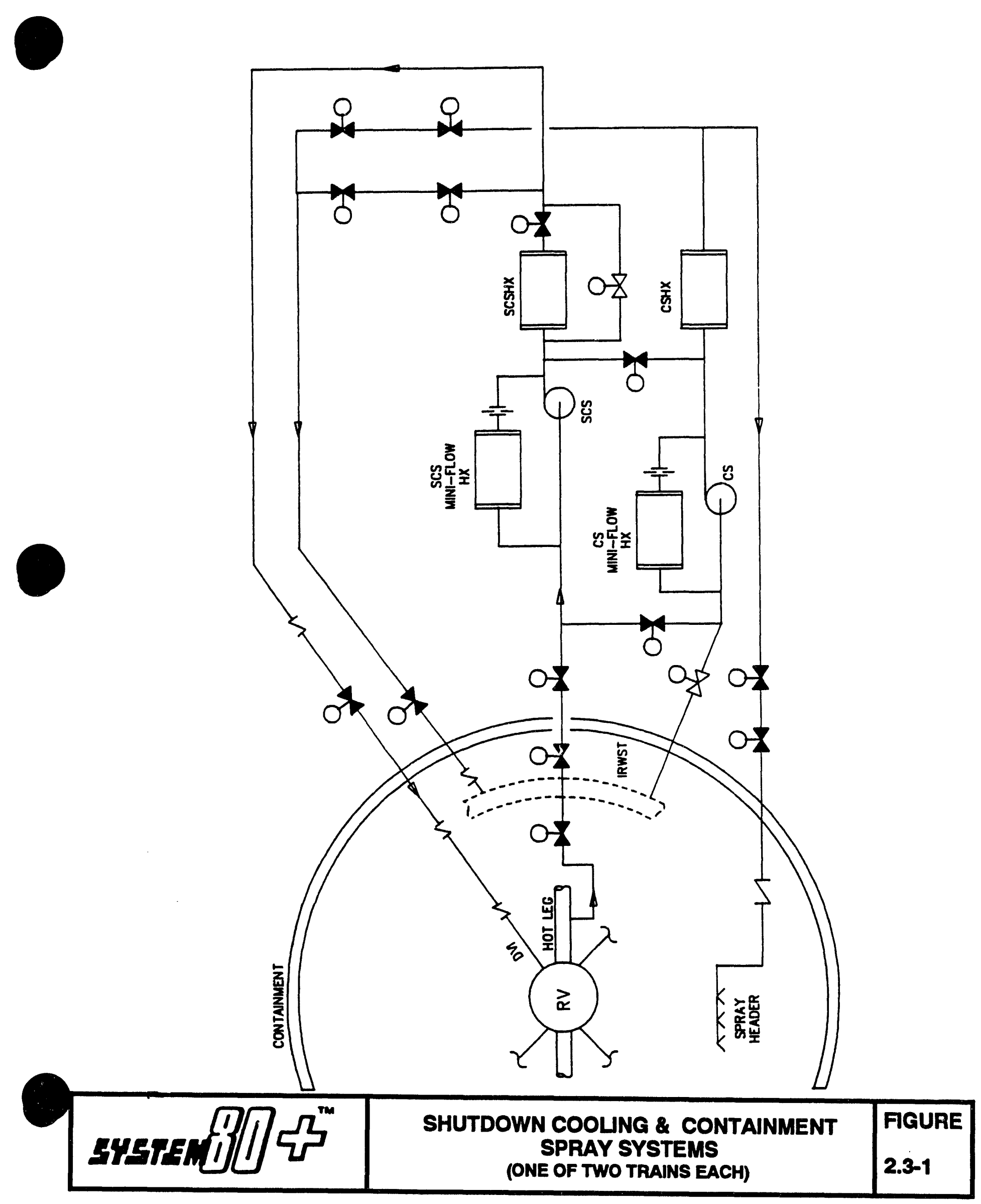




\section{Combustion Engineering, Inc.}

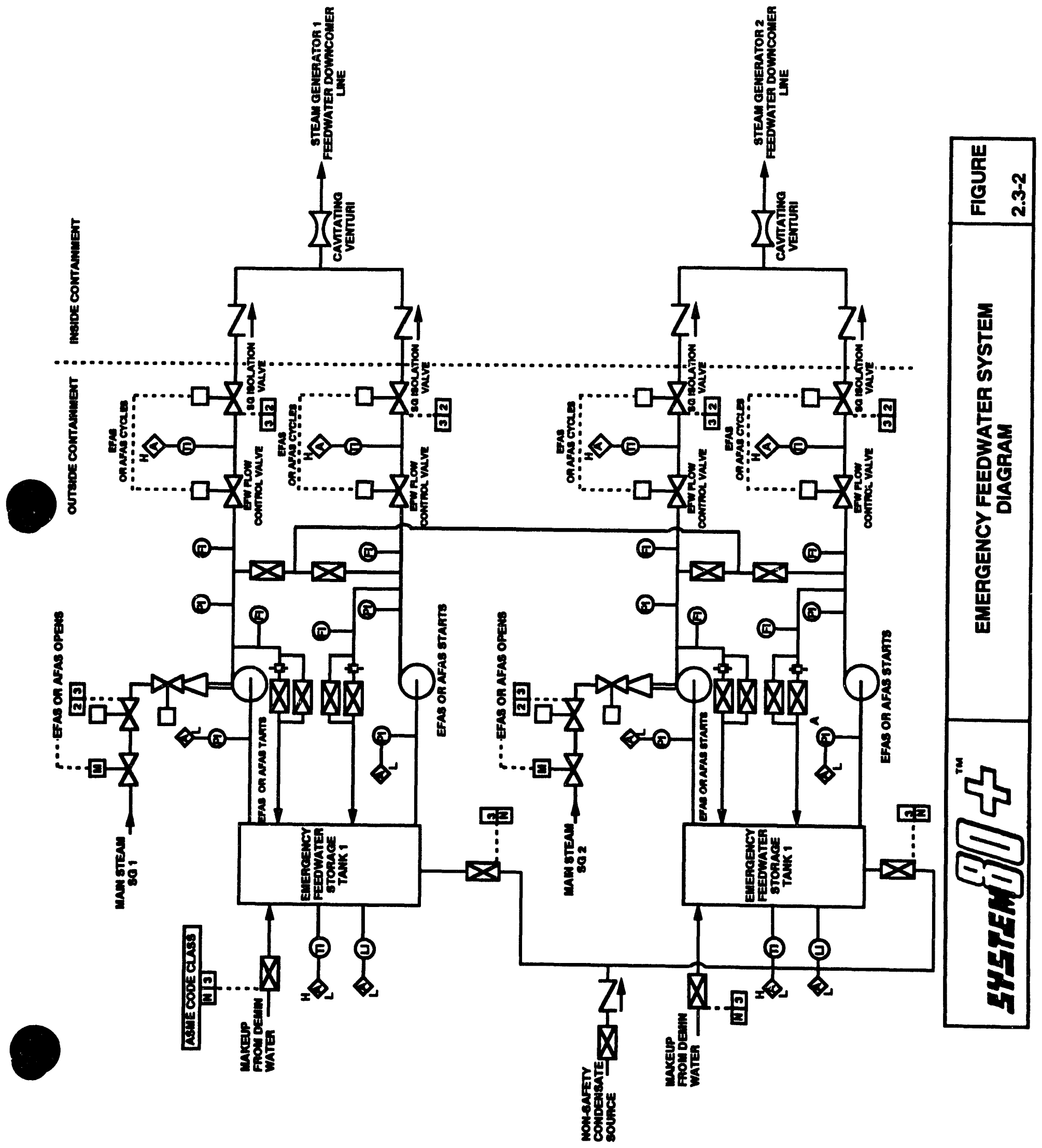


Combustion Engineering, Inc.

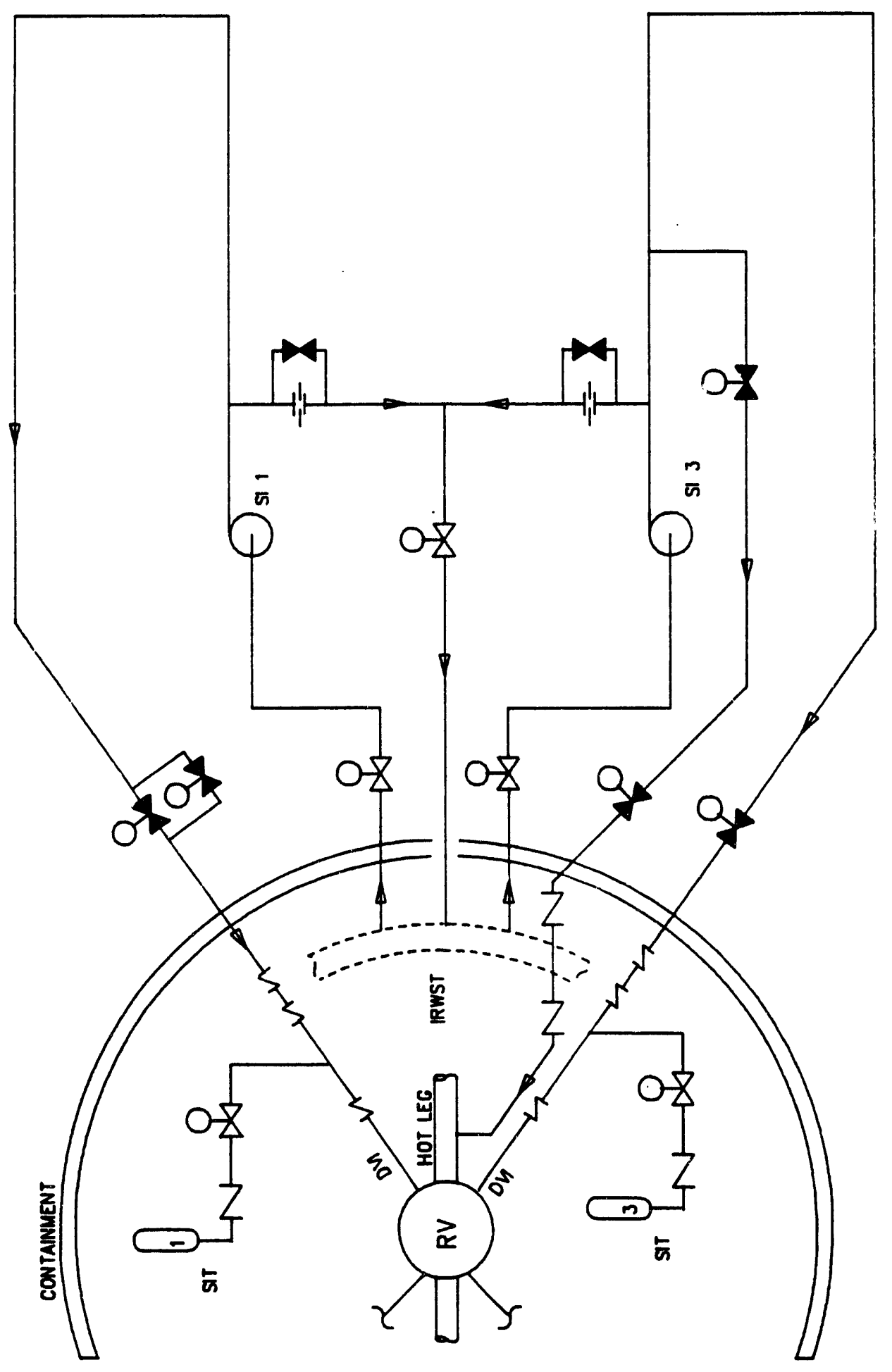


Combustion Engineering, Inc.



\subsection{MOX Fuel Facility $\left(M^{2}\right)$}

\subsubsection{Introduction}

The primary purpose of this section is to provide information on the technology, safety and costs of a Mixed Oxide (MOX) Fuel Facility $\left(\mathrm{MF}^{2}\right)$ which may be needed in converting weapons-grade plutonium to a suitable form for an indefinite storage after it is used as a reactor fuel.

The general design conditions of the $\mathrm{MF}^{2}$, described in this document, are based on well defined specific assumptions: (a) The MOX fuel fabrication facility assumes that the process feed material $\left(\mathrm{PuO}_{2}\right)$ meets Reference $2.4 .1-1$; (b) for the reference case, the MOX fuel fabrication plant should have an effective capacity of 50 Metric Tons of Heavy Metal (MTHM), which processes about 4 tons of plutonium per year. The 50 MTHM is sufficient to fuel two full ABB-CE System 80 + reactor cores which are replaced every four years. Two System $80+$ reactors will irradiate the 50 MT of weapons grade plutonium in less than 25 years.

The number of furnaces (for binder removal, sintering and outgassing in the main process area has been set at a level to process about 7 Metric Tons of plutonium per year. These extra furnaces are sufficient to satisfy DOE Alternative 1 (Disposal of 100 MT weapons plutonium within 25 years after project start); the DOE Alternative 2 (disposal of $50 \mathrm{MT}$ weapons plutonium over time from project start to end of plant life) and Alternative 3 (disposal of 100 MT weapons plutonium over time from project start to end of plant life) are less restrictive than the Reference Case and Alternative 1. System $80+$ plant life is assumed to be 60 years.

Fuel development for MOX fuel fabrication and irradiation has been essentially completed and demonstrated in previous commercial nuclear programs. In the USA, however, experience with a commercial plutonium based fuel fabrication facility is limited to pilot plants and/or to a laboratory scale. Also, the licensing process of a commercial mixed oxide fuel fabrication plant has not been recently tested in the USA. As a result, the fabrication of plutonium bearing fuels could be a schedule concern.

The information, presented in this report, provides the technical and commercial bases for future design regarding commissioning of such $\mathrm{MF}^{2}$. Work on MOX fuel fabrication, done in the past, has been reviewed and conceptually applied to this facility. Potential new guidelines and criteria were developed and utilized, where appropriate.

The design, presented in this report, represents the status of US technologies of the early 1970 's. This technological base will be reviewed in light of the European experience of binderless or short binderless processes. An effort is underway in obtaining state-of-theart information from European MOX fuel fabrication facilities. 


\subsection{2 $\mathrm{MF}^{2}$ Activities Identification and Effective Capacity}

\subsubsection{1 $\mathrm{MF}^{2}$ Activities}

All the activities associated with the mixed oxide fuel fabrication plant are shown in Figure 2.4.2-1. They include:

- Receipt, assay, and storage of special nuclear materials (SNM) powders

- Receipt, inspect and storage of structural material for fuel and target fabrication

- Accountability of SNM.

- Security of SNM and processes.

- Automated mixing and blending of oxide powders to appropriate specifications, and MOX powder storage. The feed powders may include recycled scrap.

- Precompaction-granulation of the mixed $\mathrm{UO}_{2}, \mathrm{PuO}_{2}$ and $\mathrm{Er}_{2} \mathrm{O}_{3}$ powders to prepare free-flowing MOX powder.

- Pelletizing to produce $\mathrm{UO}_{2}+\mathrm{PuO}_{2}+\mathrm{Er}_{2} \mathrm{O}_{3}$ green pellets.

- Presintering and sintering of green pellets to produce sintered mixed oxide pellets with a density between 10.1 and $10.6 \mathrm{~g} / \mathrm{cm}^{3}$.

- Centerless grinding of sintered pellets to produce pellets with diameters of specified limits.

- Pellet heat treatment to dry and/or to reduce the moisture and gas contents.

- Loading of fuel pellets into fuel rods (pins).

- Fabrication of lithium bearing target rods loptional for the case of tritium production).

- Assembly of fuel (and target) rods into fuel assemblies, and storage of fuel assemblies (Fuel and target assembly).

- Handling, packaging, and shipping of fuel assemblies.

- Confinement of all radioactive materials.

- $\quad$ Processing and minimizing of radioactive wastes. 
- Storage of wastes for ultimate disposal by the DOE.

- Preparation of radioactive wastes for off-site transportation and disposition by the DOE.

The main activities of the $\mathrm{MF}^{2}$ will be to produce $\mathrm{UO}_{2}-\mathrm{PuO}_{2}$ pellets, rods and fuel assemblies. The process starts from $\mathrm{PuO}_{2}$ powder, natural or depleted uranium oxide and structural materials required to prepare rods and fuel assemblies and ends with the shipment of fuel assemblies to a power plant for irradiation.

\subsection{Product Control Processes}

As a part of the quality assurance (QA) program, ana!yses, controls, tests and inspection procedures are made on feed materials, mixed powders, pellets, rods and fuel assemblies to assure final product conformity with the specifications. These QA controls are "Online" and "Off-line". The "On-line" controls are statistical non-destructive, made on part of the product to be controlled. The "Off-line" controls are statistical non-destructive and destructive, made on part or the product to be controlled. Most of the controls are made "on-line" to reduce Pu bearing material transfer, and non-destructive to limit the scrap and waste volume.

\subsection{Rejected Material}

Beside the main Fuel and Target Fabrication activities, auxiliary processes are used for the treatment of scraps and wastes produced during the fuel and target fabrication steps. The choice of the process depends on the nature and Pu content of the scraps and the wastes. The rejected material can be "clean" or "dirty".

Clean Rejected Oxide (CRO) Materials:

The CRO materials are defined as being the fraction of $\mathrm{Pu}, \mathrm{U}$ and $\mathrm{Er}$, mixed oxide powders, and/or pellets rejected during testing and inspection procedures associated with the quality assurance program. The CRO materials are clean and chemically uncontaminated. After crushing and milling, these materials are directly recycled into the main process (Figure 2.4.2-1).

Dirty Rejected Oxide (DRO) Materials:

The DRO materials are defined as being the fraction of $\mathrm{Pu}, U$ and $\mathrm{Er}$, mixed oxide powders, and/or pellets which will be chemically contaminated and which require chemical purification. These DRO materials are considered radwaste and sent to waste processing. 


\subsubsection{2 $\mathrm{MF}^{2}$ Capacity}

As in any manufacturing operation, some fractions of the material produced are found to be defective on inspection. Therefore, a fraction of the mixed oxide fuel will be rejected during testing and inspection procedures associated with the quality control program. As a consequence, the $\mathrm{MF}^{2}$ process operations have to be supplemented with other process operations to recover the maximum Pu quaritities from scraps and dispose of the wastes. As result of process control, material rejected and plant avairability play a major role to the $\mathrm{MF}^{2}$ sizing. To obtain an effective $50 \mathrm{MTHM}$ output per year, the $\mathrm{MF}^{2}$ should be designed for a theoretical (nominal) capacity of about 70 MTHM per year.

The theoretical $\mathrm{MF}^{2}$ capacity is estimated based on the requirements to support a nuclear program (effective capacity). It includes fuel fabrication losses and plant availability. Assumptions used to establish a nominal plant capacity are:

\begin{tabular}{|c|c|c|}
\hline $\begin{array}{l}\text { Effective capacity } \\
\text { CRO Materials } \\
\text { DRO Materials } \\
\text { Plant Availability }\end{array}$ & $\begin{array}{l}: \\
\vdots \\
:\end{array}$ & $\begin{array}{l}50 \text { MTHM per year } \\
7 \% \text { of the effective production capacity } \\
1 \% \text { of the effective production capacity } \\
70 \% \text { per year }\end{array}$ \\
\hline
\end{tabular}

The theoretical (nominal) capacity of this facility is then $[50 \times 1.07 \times 1.01 \div 0.7]=70$ MTHM/yr.

The capacity of the $\mathrm{MF}^{2}$ described in this document has a capacity equivalent to the treatment of about 7 MT Pu per year. The plant also allows an interim storage of powder, pellets, fuel rods and fabricated fuel assemblies. It is estimated that, during normal plant operation, more than $90 \%$ of the Pu will be located in storage areas $\left(\mathrm{PuO}_{2}\right.$ feed powder, MOX powder, CRO and DRO materials, sintered pellets, rods and fuel assembly storage areas). These storage areas are considered vital and are designed for maximum safety and security of the material.

\subsubsection{Eacility Layout}

The general lay-out of a 50 MTHM $\mathrm{MF}^{2}$ is shown in Figure 2.4.3-1. For physical protection reasons, the plant site is subdivided into four areas: the site area (SA), the protected area (PA), the controlled area (CA) and the vital area (VA).

The site is surrounded by an outer fence which constitutes a first physical barrier. The parking areas are located outside this fence. The administrative and technical service buildings are located inside the site area (SA) but outside the protected area (PA). A physical barrier, for which surveillance and intrusion detection are provided on a continuous basis, separates the protected area (PA) from the site area (SA). The access to the protected area (personnel and vehicles) is through a single controlled entrance. 
Inside the protected area are located the controlled area (CA) and the vital area (VA). These areas are provided for fuel processing and for storage of SNM at various stages of processing.

The access area (CA) to the manufacturing building provides for labs, meeting rooms, control rooms, personnel changing room, normal and emergency shower rooms, health physics and mechanical rooms. It is the sole normal entry lock to the fuel material manufacturing and handling areas.

The manufacturing building includes process and storage areas required to prepare mixed oxide powders, pellets, rods, fuel assemblies. It also provides space to process the clean rejected oxides (CRO) to be recycled into the main process. It is subdivided into several small and large rooms and halls the surface area of which depends on the plutonium materials to be treated and on the contamination risk. The process and control areas with relatively high contamination risk are surrounded by corridors in which are located most of the process control systems. Special physically protected areas (vital areas) are provided for storage of $\mathrm{PuO}_{2}$ powder, mixed oxide powder, sintered pellets, fuel rods and finished fuel assemblies. The storage facilities are located so that plutonium bearing material movements is minimized. The analytical laboratories for off-line controls are located near the manufacturing building to minimize transfers of contaminated materials.

For a 50 metric tons of heavy metal (MTHM) plant effective capacity, two fabrication lines are installed in the manufacturing building. Each fabrication line includes equipment such as blender, homogenizer, granulator, press, centerless grinding machine, rod filling and welding apparatus, storage device and on-line control equipment. Excess furnace capacity is added, however, to meet requirements imposed by the DOE on the weapon grade plutonium. All the process operations are mechanized. Manual operations are only envisaged for maintenance and for limited time. After the fuel pellets are sealed into fuel rods, hands-on operation is permissible. The fuel assemblies are prepared and controlled with techniques actually used to fabricate uranium fuel assemblies while taking into account possible fault conditions of MOX fuel.

The recycle of rejected material is within the manufacturing building. The area is equipped for the recovery of the plutonium, for the treatment and the conditioning of the solid and liquid wastes, and for the storage of the various plutonium bearing and contaminated materials before and after treatment. This area provides also special rooms for the depleted and natural $\mathrm{UO}_{2}$ power feed material, a small workshop and $\mathrm{UO}_{2}$ powder storage. The exhaust HEPA filters relating to this process and the equipment (pumps, tanks, etc.) required for the cooling of heating devices in the recycle processes are also provided in this area.

\subsubsection{Eacility Description}

The $\mathrm{MF}^{2}$ is designed and constructed for the production of mixed oxide $(U+\mathrm{Pu}) \mathrm{O}_{2}$ fuel assemblies, and for the fabrication of lithium bearing target rods. The facility is also 
designed for the recovery of plutoniurn from unirradiated scrap materials. It consists of various areas such as offices, laboratory, maintenance and manufacturing floor space, located in adjacent buildings. Auxiliary facilities include electrical substation, gas supply, cooling tower and effluent waste storage.

The exterior walls and roof of the buildings are designed to withstand wind and seismic loads of the selected site. All exterior and interior joints are caulked to make an air-tight structure.

The process building includes reinforced concrete storage areas and process areas. The storage areas are used for storage of Uranium, Erbium and Plutoniun powders, mixed oxide (MOX) powder, fuel pellets, fuel rods, and finished fuel and target assemblies. A basement is provided in the rejected material recycling area. It houses the dirty scrap recovery operation, and waste storage area and waste treatment area. The walls, ceilings and concrete floors of the building are coated to provide a smooth surface that can be easily decontaminated and cleaned.

Processing and movement of oxide powders and pellets witnin processing area is done remotely within shielded enclosures. In this report shielded enclosures are identified as Glove Boxes (GB).

In order to provide appropriate separation of functions and improve ventilation control, the plant is divided into work areas with each area subdivided into rooms in accordance with their respective functions, namely:

a. Office Area is considered a clean area and it is separated from all other facilities. It contains the security and surveillance area, the reception area, office area, lunchroori, and support facilities.

b. Service Area contains change rooms, shower facilities, laundry, health physics laboratories, and manufacturing support facilities.

c. Analytical Lab Area contains rooms for chemistry, metallurgical, radiological analyses, emission spectroscopy and mass spectroscopy, and support facilities.

d. Maintenance Area (mechanical/maintenance rooms) equipped with glove boxes for equipment maintenance is located near the central corridor and near the process area.

e. The Process Area is subdivided into dry blending, pellet fabrication and inspection, rod fabrication and inspection. All plutonium processing is done in glove boxes. After fuel pellets are sealed in the fuel pin (rod), contact operation (hands-on) may be permitted depending upon the activity level of the fuel rod. (Material recovery from rejected material and scrap is performed in a separated process areas.) 
f. Fuel Assembly Area is subdivided into areas for assembly of rod in fuel bundle, and for inspection and storage of assembled fuel bundles. This is a hands-on operation similar to commercial uranium fabrication operation.

Only one main personnel entrance is provided to the process areas; however there are many emergency "exit only" doors to the main coiridor. This corridor is shielded and serves as an escape route in an emergency. The emergency doors are sealed to prevent inflow/outflow of air. There is one unloading and loading dock. The unloading and loading dock (receiving and shipping) is provided with airlocks and security and surveillance systems. All emergency exits are alarmed and protected by the surveillance system.

The main characteristics of the MOX process ano fuel assembly areas are:

- Separation of the various process functions in different rooms with associated glove boxes (shield containers) for the powder and pellets handling and loading.

- Glove boxes made of stainless steel, since it is conducive to decontamination. Glove boxes can easily be disassembled.

- Minimization of Plexiglas used in a glove box design to reduce the decontamination effort.

- Minimization in using exposed concrete in high activity areas to reduce decontamination efforts.

- High efficient ventilation and filtration systems, separated by process areas.

- Waste minimization and stabilization systems to reduce liquid and solid radioactive wastes.

Safeguards and security systems at the exclusion area, entrance, exit doors and unloading/loading dock, and within the process areas.

Figure 2.4.2-1 Shows an overall MOX process. The processed material isotopic content, chemical composition and physical properties meet the ASTM C757-90 "Standard Specification for Nuclear Grade Plutonium Dioxide Powder, Sinterable".

Table 2.4.4-1 Shows process time and space requirements for a 50 metric



Figure 2.4.3-1 Shows a conceptual $\mathrm{MF}^{2}$ site plan.

Figure 2.4.4-1 Shows a conceptual $\mathrm{MF}^{2}$ floor plan. 
Figure 2.4.4-2 Shows the MOX fuel process areas and fuel assembly areas layout.

The production of fuel assemblies containing MOX sintered ceramic fuel pellets rods is a combination of chemical and mechanical operations. The facility described in this report only addresses the mechanical operations. The process starts with the receiving of Uranium, Plutonium and Erbium oxide powders and ends with the shipment of fuel assemblies. The chemical operation is limited the immobilization of the waste. (This operation is done in a separate building connected to the Main Processing Building). 
IABLE 2.4.4-1

PROCESS TIME AND SPACE REOUIREMENTS

EOR A 50 MTIYEAR MOX FUEL FACILITY

\begin{tabular}{|c|c|c|c|c|}
\hline \multirow[b]{2}{*}{ Processor Step } & \multirow[b]{2}{*}{$\begin{array}{l}\text { Principel } \\
\text { Equipment }\end{array}$} & \multirow[b]{2}{*}{ (Hours) } & \multicolumn{2}{|c|}{$50 \mathrm{MT} / \mathrm{Yr}$} \\
\hline & & & (Sq. Ft) & $\begin{array}{c}\text { * of } \\
\text { Stations }\end{array}$ \\
\hline \multicolumn{5}{|l|}{ BLENDING } \\
\hline Master Blend & Blender & 1 & 600 & 2 \\
\hline Final Blend & Blender & 1 & 600 & 2 \\
\hline Compaction & Press & 0.5 & 200 & 1 \\
\hline Granulation & $\begin{array}{l}\text { Hammer Mill Sieves } \\
\text { Blenders }\end{array}$ & 0.5 & 600 & 1 \\
\hline Oxide Powders $\left(\mathrm{UO}_{2}, \mathrm{PuO}_{2}\right.$, etc. $)$ & Storage & & 5000 & \\
\hline MOX Powders & Storage & & 5000 & \\
\hline TOTAL & & 3.0 & 12000 & \\
\hline \multicolumn{5}{|c|}{ PELLET PREPARATION AND RECYCLE } \\
\hline MOX Compaction and Binding & Press & 1 & 1200 & 2 \\
\hline Pelletizing & Press & 1 & 1200 & 2 \\
\hline Binder Removal (calciner) & Furnace & 4 & 3000 & 4 \\
\hline Sintering & Furnace & 16 & 1500 & 10 \\
\hline \multirow[t]{2}{*}{ Inspection } & $\begin{array}{l}\text { Centerless Grinder } \\
\text { Out-gassing Furnace } \\
\text { Inspection }\end{array}$ & $\begin{array}{l}1 \\
6\end{array}$ & $\begin{array}{l}400 \\
2000\end{array}$ & $\begin{array}{l}1 \\
4\end{array}$ \\
\hline & & 2 & 1000 & 2 \\
\hline \multirow{3}{*}{$\begin{array}{l}\text { Clean MOX Recycle and Waste } \\
\text { Processing }\end{array}$} & Crushers & 2 & 500 & 1 \\
\hline & Ball Mills & 4 & 500 & 1 \\
\hline & $\begin{array}{l}\text { Furnaces and Waste } \\
\text { Processing }\end{array}$ & 18 & $\begin{array}{c}800 \\
1000\end{array}$ & $\begin{array}{l}1 \\
1\end{array}$ \\
\hline Finished Pellet Inspection & & 1 & 1000 & 1 \\
\hline Finished Pellet Storage & & & 5000 & 1 \\
\hline TOTAL & & 55 & 40400 & \\
\hline TOTAL Dirty MOX Wasto Procese & & & 20000 & \\
\hline
\end{tabular}


TABLE 2.4.4-1 (Cont' d)

PROCESS TIME AND SPACE REQUIREMENTS

FOR A 50 MT/YEAR AND 100 MT/YEAR

MOX FUEL FABRICATION PLANT

\begin{tabular}{|c|c|c|c|c|}
\hline \multirow[b]{2}{*}{ Processor Step } & \multirow[b]{2}{*}{$\begin{array}{l}\text { Principlo } \\
\text { Equipment }\end{array}$} & \multirow[b]{2}{*}{ (Hours) } & \multicolumn{2}{|c|}{$50 \mathrm{MT} / \mathrm{rr}$} \\
\hline & & & (Sq. Ft.) & $\begin{array}{l}\text { \# of } \\
\text { Stations }\end{array}$ \\
\hline Tubing Inspection and Storage & & & 5000 & \\
\hline \multirow[t]{2}{*}{ Pin Loading } & Pin Makeup & 1 & 1000 & 2 \\
\hline & Pin Loader & 1 & 1000 & 2 \\
\hline Pin Woldir J & Welder & 1 & 1000 & 2 \\
\hline PIN LOADING TOTAL & & 3 & 8000 & \\
\hline Fuel Pin & Leak Detector & 1 & 500 & 1 \\
\hline Fuel Pin & X-Ray & 1 & 500 & 1 \\
\hline \multirow[t]{2}{*}{ Fuel Pin } & $\begin{array}{l}\text { Cleaning } \\
\text { Washing and Drying }\end{array}$ & $\begin{array}{l}1 \\
1\end{array}$ & $\begin{array}{c}500 \\
500 \\
5000\end{array}$ & $\begin{array}{l}1 \\
1\end{array}$ \\
\hline & $\begin{array}{l}\text { Inspection } \\
\text { Storage }\end{array}$ & & & \\
\hline Fuel Pin & $\begin{array}{l}\text { Assembly and In- } \\
\text { spection }\end{array}$ & 8 & 20000 & 8 \\
\hline Assembly & Storage & 4000 & 4000 & 400 \\
\hline FUEL ASSEMBLY TOTAL & & & 31000 & \\
\hline Hot Machine Shop & Work Area & & 3000 & \\
\hline Clean Machine Shop & Work Area & & 1000 & \\
\hline Health Physics, Showers, etc. & & & 2000 & \\
\hline TOTAL & & & 6000 & \\
\hline TOTAL PROCESS SPACE & & & 110,700 & \\
\hline \multicolumn{5}{|l|}{ SHIPPING AND RECEIVING } \\
\hline ANALYTICAL SERVICES & Labs and Offices & & 6000 & \\
\hline TOTAL & & & 9000 & \\
\hline GRAND TOTAL & & & 129,700 & \\
\hline
\end{tabular}

-AVERAGE TIME IN PROCESS STEP PER PRODUCTION UNIT, INCLUDING IN-PROGRESS STORAGE

NOTE:This facility can operate at $50 \mathrm{MTHM} / \mathrm{Nr}$ or $100 \mathrm{MTHM} / \mathrm{yr}$ effective capacity, depending on the number of furnaces that are kept on line and the number of shifts. For $50 \mathrm{MTHM} / \mathrm{yr}$, one shift is sufficient, while for the $100 \mathrm{MTHM} / \mathrm{yr}$, two shifts are required. 


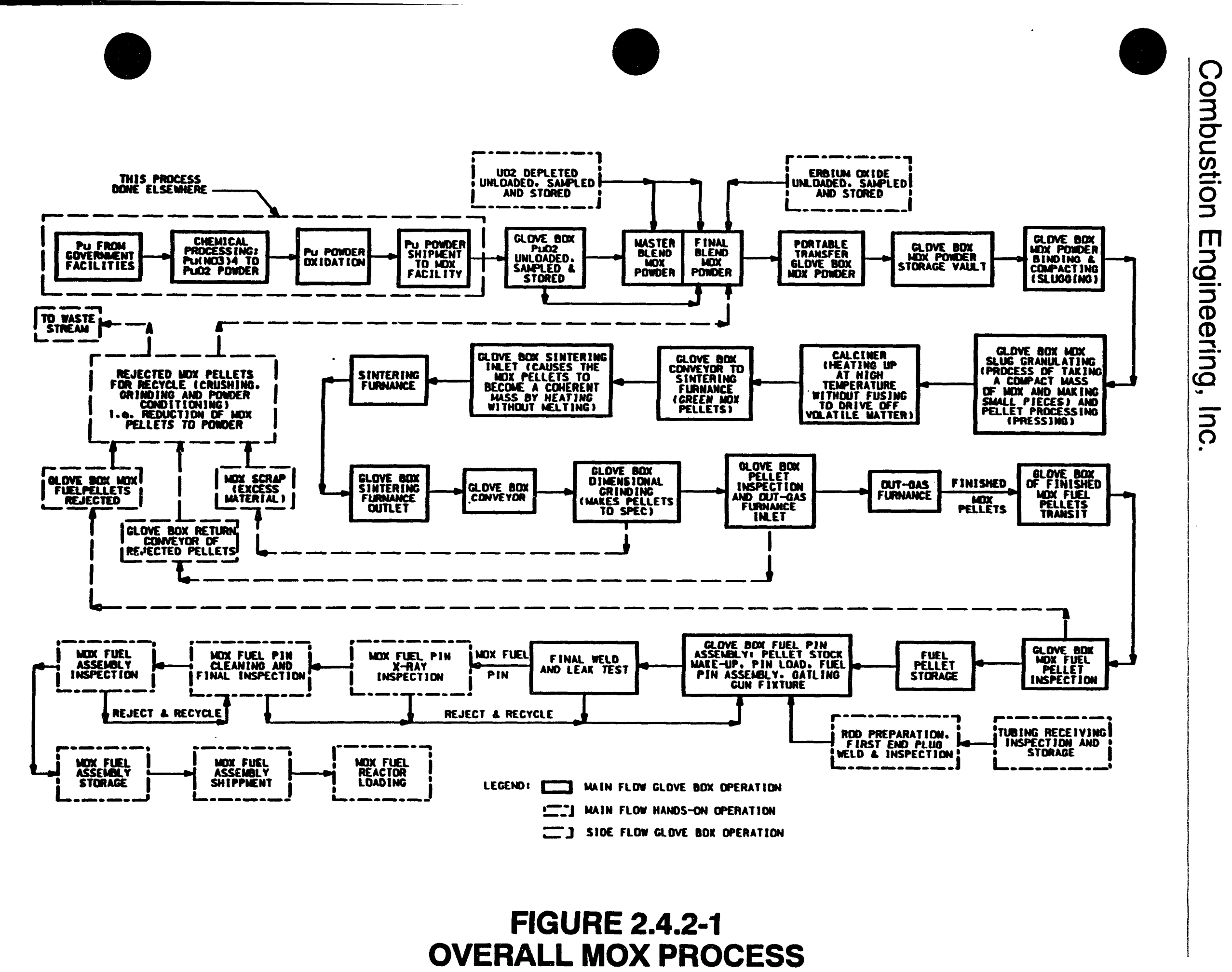




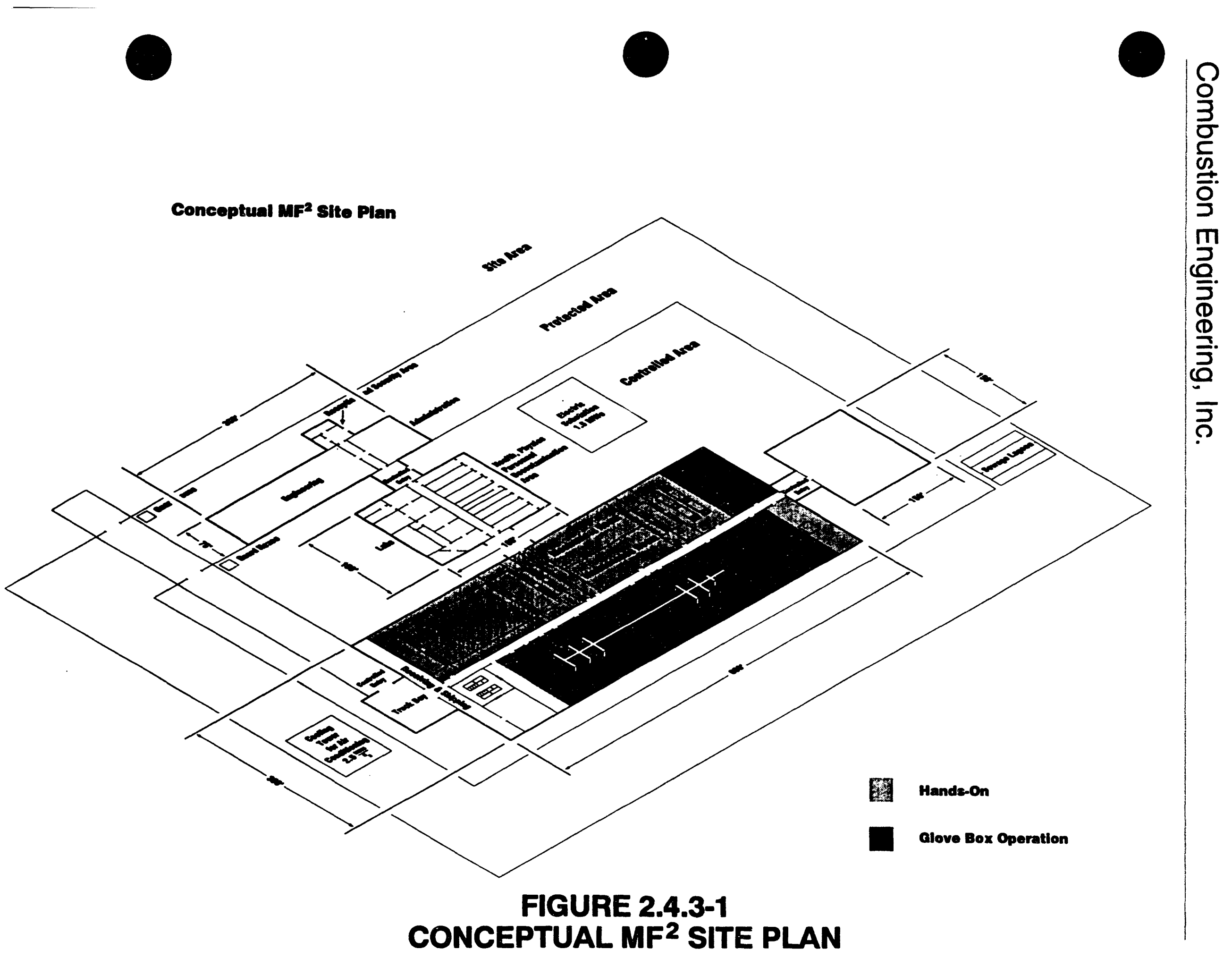




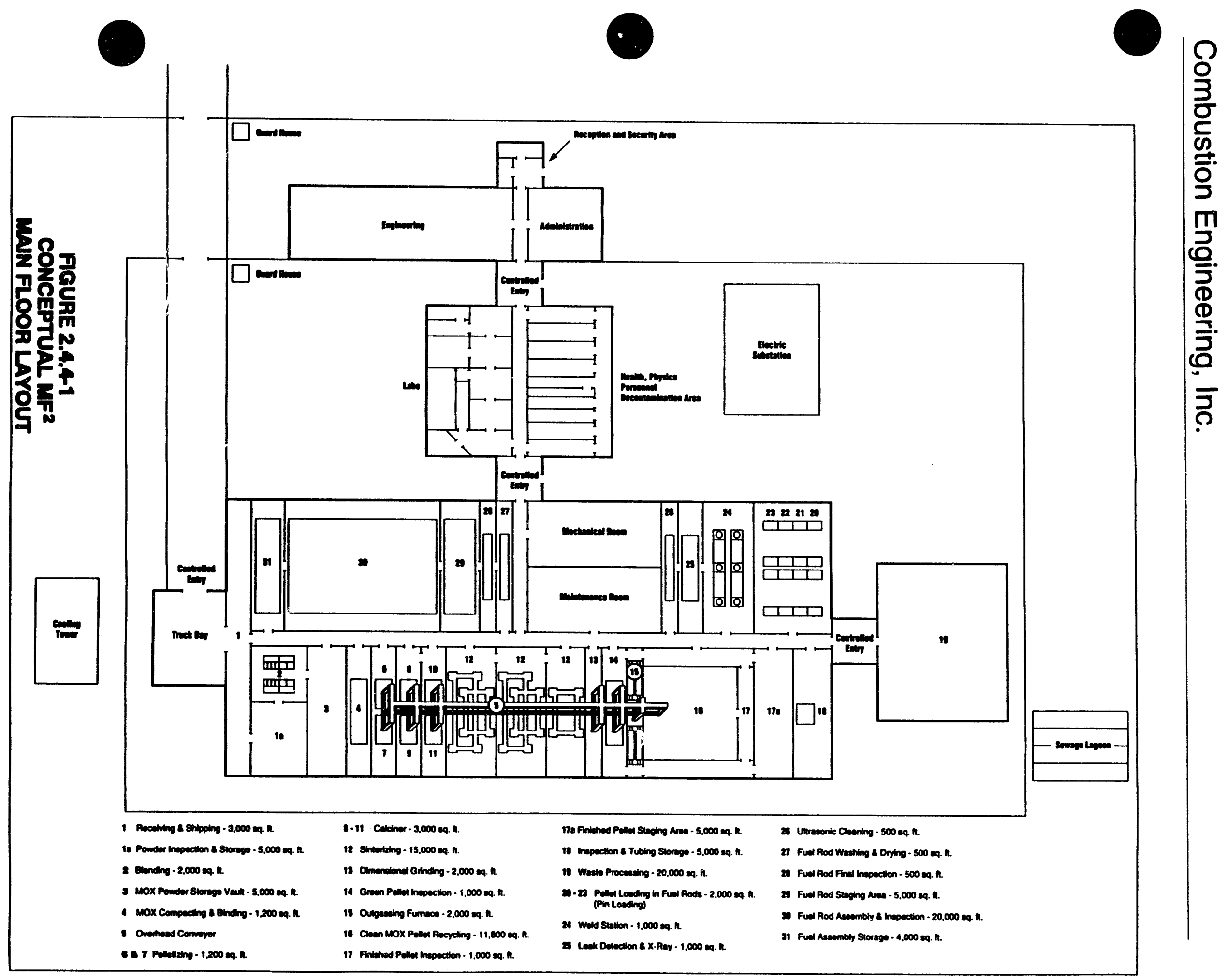




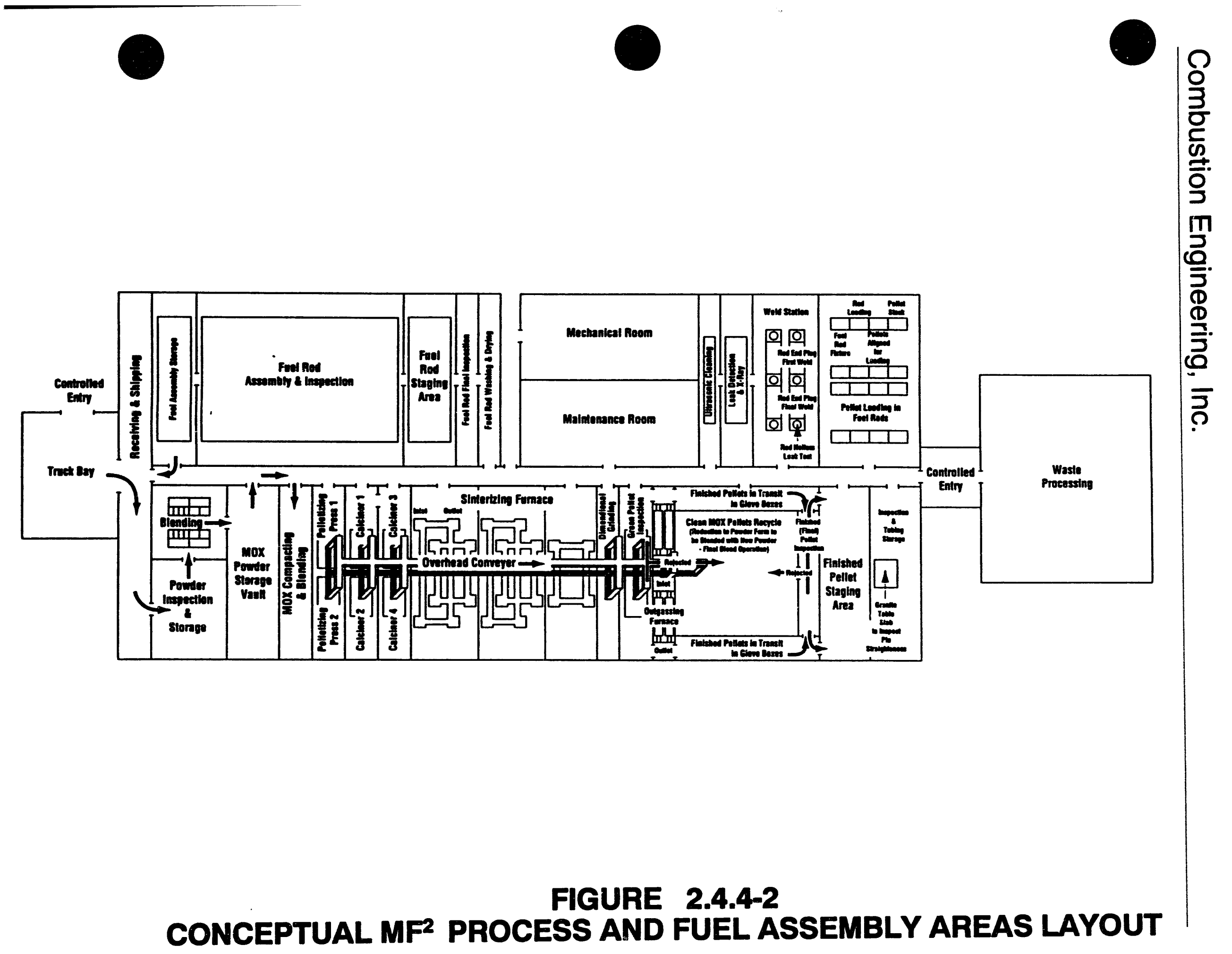




\subsection{5 $\mathrm{MF}^{2}$ Processing Areas}

The MOX fuel fabrication process for System $80+$ MOX fuel is similar to the process widely used to fabricate $\mathrm{UO}_{2}$ fuels for LWRs. The only exception is the glove box remote handling of the Plutonium and MOX powders, and MOX pellets. The process steps include receiving and storing $\mathrm{PuO}_{2}$ and depleted $\mathrm{UO}_{2}\left(0.2 \mathrm{w} / 0 \mathrm{U}^{235}\right.$ assay), blending these oxides and forming MOX fuel pellets, encapsulating the pellets into fuel pins, and assembling the pins into fuel bundles. All nuclear materials are supplied by the DOE. All non-nuclear materials, including erbium oxide, lithium aluminate (in the case of tritium target production) are acquired by the fuel fabricator from commercial sources. The $\mathrm{PuO}_{2}$ is mixed with depleted $\mathrm{UO}_{2}$ to a concentration of about seven weight-percent. A burnable poison, $\mathrm{Er}_{2} \mathrm{O}_{3}$, in the amount of about $2 \%$ is added to the mixture. The mixture is pressed into pellets that are sintered in a reducing atmosphere furnace. The sintered pellets are ground to size, inspected, and loaded into pins. The pins are assembled into fuel bundles which are transported to a System $\mathbf{8 0}+$ reactor for loading and irradiation.

The process assumes that plutonium will be provided by the DOE as $\mathrm{PuO}_{2}$ to purity and physical properties specifications of the fuel fabricator. If the plutonium is provided as metal, an additional step for conversion of the metal to $\mathrm{PuO}_{2}$ would be required. Costs for this conversion are not included in the estimate. The $\mathrm{PuO}_{2}$ is assumed to be provided in isotopically uniform batches subdivided into lots of $2 \mathrm{~kg}$ to avoid any criticality event. The $\mathrm{PuO}_{2}$ is further assumed to be provided as needed to meet fabrication schedules with an established inventory criteria at the fabrication plant. The uranium requirements are assumed to be provided by the DOE as depleted $\mathrm{UF}_{6}$ and converted to depleted $\mathrm{UO}_{2}$ in isotopically uniform batches to purity and physical properties specifications of the fuel fabricator by a commercial source.

\subsubsection{SNM Powders Receiving and Storage Area}

$\mathrm{PuO}_{2}$ powder is received in a double container batch of $100 \mathrm{~kg}$ subdivided in 50 lots of $2 \mathrm{~kg}$ each. The $2 \mathrm{~kg}$ limit on $\mathrm{PuO}_{2}$ is established by criticality considerations. A system of tags and seals will be used to verify content and composition of the sealed $\mathrm{PuO}_{2}$ containers. A robotics handling system will be used to receive, verify, identify, weigh, and place the $\mathrm{PuO}_{2}$ containers in the storage vault. The $\mathrm{PuO}_{2}$ container gross weight, net weight, serial number, and storage location will be automatically transmitted to the process control computer to maintain material balance.

Depleted $\mathrm{UO}_{2}$ is received in $\mathbf{5 5}$ gallon drums. The depleted $\mathrm{UF}_{\mathrm{B}}$ supplied by DOE, will be converted to $\mathrm{UO}_{2}$ according to specifications by a commercial fuel supplier. The identity and quantity of $\mathrm{UO}_{2}$ will be maintained by batch $\mathrm{UO}_{2}$ transferred into the MOX fabrication process will be recorded automatically. Samples will be taken from both the $\mathrm{PuO}_{2}$ and $\mathrm{UO}_{2}$ batches at the packaging sites to verify isotopic and chemical compositions and physical properties.

The Am-241 content of the weapons plutonium is expected to average about $2750 \mathrm{ppm}$, and to not exceed $4000 \mathrm{ppm}$. Compared to reactor-grade plutonium that is fabricated commercially into MOX fuel, the Am-241 content in the surplus plutonum is lower by about a factor of 2, and should not be a problem. The limit of theAm-241 content in 
foreign MOX fuel fabrication plants that use reactor-grade plutonium is currently about $8,000 \mathrm{ppm}$; however, some facricators have plans to extend that limit to about 20,000 $\mathrm{ppm}$. The shielding and automated handling equipment in the plutonium fabrication line should permit the surplus plutonium to be fabricated as-is, without requiring the removal of Am-241. The decay of Am-241 produces high gamma radiation levels, but the levels in the surplus plutonium are not expected to require extraordinary measures to reduce personnel radiation exposures or to limit the content of Am-241 during fuel fabrication.

Other potential impurities in the surplus plutonium will be gallium, calcium, magnesium, aluminum, fluorine, molybdenum, sodium, and copper. The limits on these impurities in the PuO2 will correspond to Reference 2.4.1-1, which covers all of the above impurities, with the exception of gallium and sodium. Specifications for gallium and sodium need to be developed. At this time it is expected that the low levels of gallium and sodium in the plutonium will be acceptable, and the plutonium will not require processing to remove these impurities. However, process development and testing will be required to confirm this point.

Erbium $\left(\mathrm{Er}_{2} \mathrm{O}_{3}\right)$ is received in small containers. It is sampled, weighed and stored. The erbium is loaded into trays, as needed for blending, and it is passed into the $\mathrm{PuO}_{2}$ final blend glove box.

For the dry process head-end, plutonium oxide, ursnium oxide and erbium oxide powders are received at the plant with a quality that nermits direct blending for fuel manufacture without the need for additional processing. The master and final blend operations are carried out remotely in glove boxes.

\subsubsection{SNM Powder Blending}

The $\mathrm{PuO}_{2}$ and $\mathrm{UO}_{2}$ will be withdrawn from storage as needed for processing. The expendable $\mathrm{PuO}_{2}$ containers will be opened in a glove box. The container identity and tare weight will be recorded in the process control computer. The $\mathrm{PuO}_{2}$ will be transferred to batching hoppers in the blending. The $\mathrm{UO}_{2}$ will be transferred into batching hoppers in the blending glove box. Erbium oxide, $\mathrm{Er}_{2} \mathrm{O}_{3}$, of the specified purity and physical properties will be transferred into the blending glove box.

The basic process is illustrated in Figure 2.4.7-1 The initial powder operation will prepare a master blend of $\mathrm{UO}_{2}$ containing approximately $20 \% \mathrm{PuO}_{2}$. The master blend will be thoroughly mixed using blenders and ball mills to insure homogeneity. All powders entering the blending operations, either at this step or subsequent steps, will have been precisely weighed, highly characterized, and controlled by lot.

The master blend will be subsequently diluted with $\mathrm{UO}_{2}$ to the final composition. Recycled MOX powders from dry scrap recycle operations will be included into this blend. Erbium oxide powder will be added also to this blend to meet the final composition specifications. This material will be blended and ball-milled to assure thorough mixing.

When a blend is to be made, the three oxides $\left(\mathrm{PuO}_{2}, \mathrm{UO}_{2}\right.$ and $\left.\mathrm{Er}_{2} \mathrm{O}_{3}\right)$ are metered from their respective feed storage areas into separate batch-weighing hoppers, and are then 
drained to a blender. The batch-weighing hoppers are controlled by an interlocking system that permits control of "Pu: $\mathrm{U}$ and $\mathrm{Pu}+\mathrm{U}$ : Er ratios" and blend size. Usually several subblends are made and then reblended to make a batch of about $26.66 \mathrm{~kg}$ MOX per hour (26.66 kg $\times 16$ hours/day $\times 245 \mathrm{day} / \mathrm{yr}=104.5 \mathrm{MT} / \mathrm{yr}$; overall process losses per year are: $140 \mathrm{gm} \times 16 \mathrm{hr} /$ day $\times 245$ days $/ \mathrm{yr}=550 \mathrm{~kg}$ ). After blending, the finished MOX is packed into critically safe stainless steel cylinder (2 liter container) and stored in a vault, until subsequent processing.

Small vessels are located in the glove boxes. The dimensions of these vessels are selected to prevent any criticality event. Operation is on a batch basis to avoid a criticality event and for material safeguards, security and accountability.

Various small tools are used within the glove box. They will facilitate unloading and transfer of mixed oxide. 


\section{Combustion Engineering, Inc.}

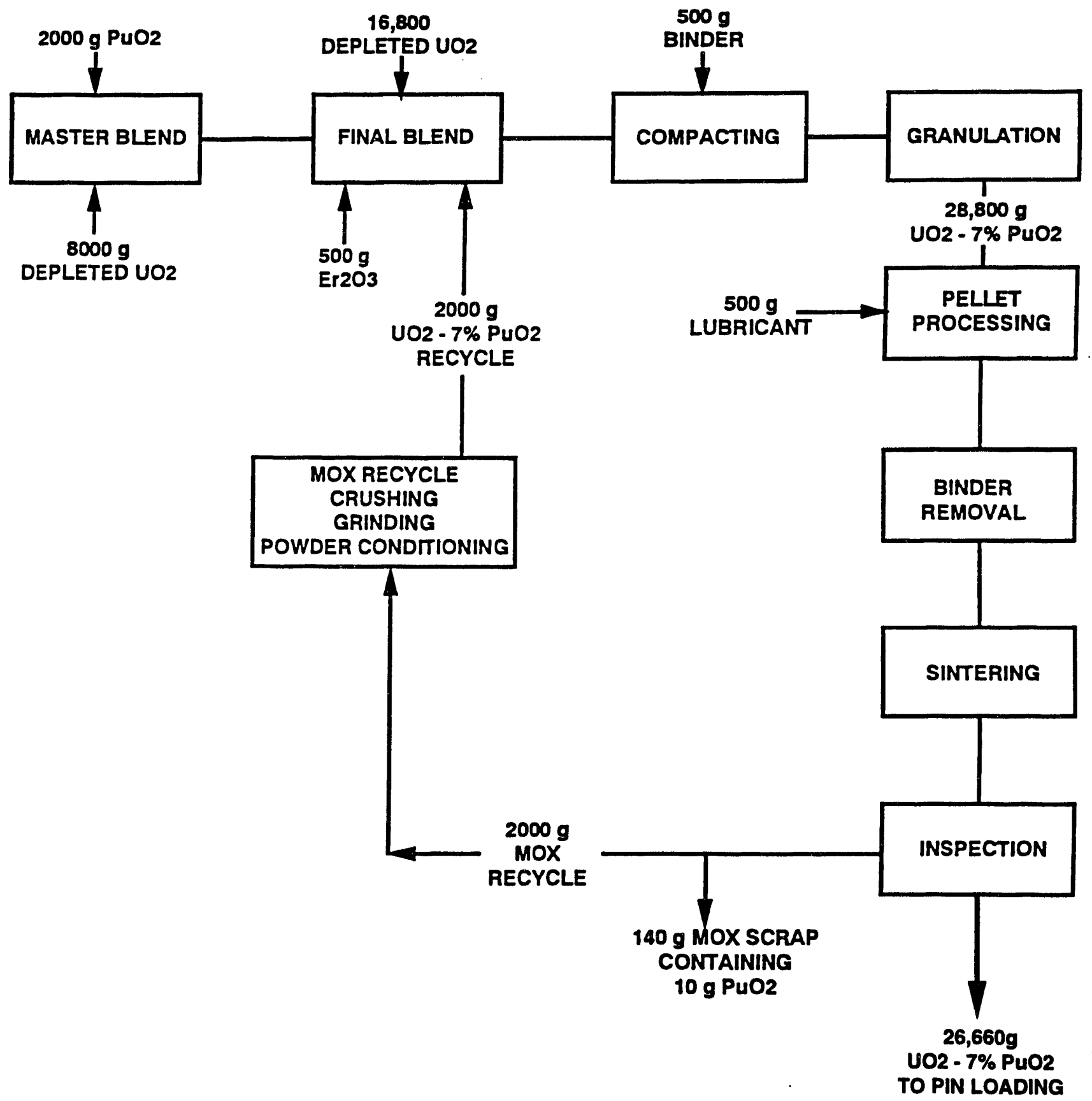




\subsubsection{MOX Powder Storage Vault}

After blending the MOX powder is drained from the blender in stainless steel cans to be transferred to the next operation or stored into the MOX vault storage room.

The vault has access from the main corridor. Small stainless steel containers for MOX storage are used. The dimensions of these cans are selected to prevent any criticality event. Safeguards and security and accountability procedures are fully implemented during powder handling.

\subsubsection{Rellet Processing Area}

This area includes: powder compacting, granulation, pellet processing, binder removal, sintering and pellets final inspection; it also includes MOX recycling after each inspection step. The area is equipped with glove boxes which provide access to presses, furnaces, grinders and other equipment used to convert mixed oxide powder into precisely dimensioned fuel pellets. The hydraulic systems and oil reservoirs for pellet presses and the control panels for the sintering furnace and the outgas furnace are also located in this area.

Typically in a MOX plant, dry ceramic oxide powder is batch transferred to the pellet process area. In the pellet process area the mixed oxide powder is loaded into the feed hopper of the slugging press. The blended material will be pressed into large diameter compacts. The compacts will be crushed in a hammer mill and the resulting granules will be sieved to obtain the required feed size for pellet pressing. The oversize and undersize granules will be returned to the compact press feed hopper.

The granulated pellet feed will be pressed into pellets using two hydraulically driven presses, operated in parallel. Sample pellets will be taken to verify proper green density. The pellets will then be loaded into sintering boats. Loaded boats will be weighed and automatically transferred to the binder removal furnace.

Green pellets loaded into containers (boats) are placed onto a belt conveyor and automatically inserted in a binder removal furnace. The organic binder will be removed in a remotely-operated, electrically-heated muffle furnace within the glove-box containment. Boats of pellets will be charged into, and removed from, the furnace through purge chambers to ensure retention of furnace gases and prevent introduction of outside objects into the furnace. The pellets will move through the furnace in a controlled flowing gas atmosphere. (Furnace exhaust gases will pass through a gas treatment system to remove vaporized organics and reduce the temperature before the gas is discharged through HEPA filters.) Upon exiting the furnace, pellets will be placed in the a storage area pending transfer to sintering. The pellets will be sintered to about $95 \%$ theoretical density in a high-temperature furnace. Sintering will employ a multizone, electrically-heated furnace containing a oxygen reducing atmosphere. Boats of pellets will be automatically conveyed into and out of the furnace through purge chambers to prevent introduction of objects into the furnace. The pellets are sintered at a temperature of 1600 to $1650^{\circ} \mathrm{C}$ in a reducing atmosphere. Sintered pellets are fed, one at a time, to a centerless grinder where they are ground to precise dimensional tolerances. 
Sintered pellets will be remotely transferred from the sintering furnace to a sampling station. Samples will be taken for chemical and physical analyses. Based on analytical results, the pellets will be rejected or accepted. Pellets meeting specifications will be unloaded from the sintering boats and stored. Rejected pellets will be crushed, ground, and recycled. The empty sintering boats will be cleaned and reused.

Accepted pellets are then loaded into a basket and transferred to vertical vacuum furnaces, where the pellets are first heated in flowing nitrogen and then outgassed at high vacuum at a temperature of 500 to $1000^{\circ} \mathrm{C}$. Outgassed pellets are removed from the furnace, allowed to cool, unloaded from the baskets in dry air, and transferred to an analytical sampling area.

\subsubsection{Euel Rod Fabrication Area}

Glove boxes and associated equipment are provided to enable final inspection of the finished fuel pellets, loading the pellets into cladding tube, welding of end caps to the tubes, machining of the welds, and leak testing of the finished fuel rods.

A mechanized process will load the pin components (fuel pellets and nonfuel components) into cladding tubes and decontaminate the cladding tube ends. A horizontal conveyor will move pellets from station to station. Primary containment will be a sealed housing over the conveyor and over each work station. The pin loadings steps are (1) Column makeup, where pellets are received from storage, stacked into specified columns, and weighed; and (2) Cold component makeup, where small nonfuel components are received from stock and manually loaded into the system via an airlock.

Zirconium cladding tubes, received at the MOX fuel fabrication plant, are inspected, ultrasonically cleaned and one end cap is welded in place with an automatic welder. The tubes will be equipped with a loading funnel and identified using a bottom end cap reader. When ready to be used, the tubes will be moved to handling trays. Each tube will be inserted through the loading station airlock and the loading funnel will be positioned against the loading sleeve.

A loaded pellet magazine will be positioned so that the fuel column is in front of the pin loader. A push rod equipped with force feedback will be used to push the pellets into the cladding. The nonfuel component magazine will then be indexed into place and the nonfuel components will be used to be pushed into the cladding. The loading funnel will then be removed from the cladding tube end and replaced with a plug. The pin will be withdrawn onto the transfer conveyor. The pin end will have alpha contamination that will be removed using a dry decontamination system prior to welding to the end plug to prevent contaminating the weld. At the welding station, the loaded fuel pins will be filled with helium and the end cap will be automatically positioned, welded in place and machined to the required profile.

\subsubsection{Euel Rod Inspection Area}

Welds for completed fuel rods are checked at a helium leak test station. The rods are then placed on a table with wheels. This table serves to transport the rods through an air 
locked corridor connecting the rod fabrication area with the final rod inspection area. Loose surface contamination is removed from the rods with damp wipes. An X-ray machine located in the connecting corridor is used to check the end cap welds and the rod loading.

In the final rod inspection area, the fuel rods are moved to a controlled process sink where the welds are scrubbed with cleanser and water to remove low-level surface contamination. The rods are then examined for compliance with the fuel specification. Rods that meet inspection requirements are then moved to the fuel assembly area. Rods that do not meet inspection requirements are returned to the rod fabrication area where the fuel pellets are removed, visually inspected, and inserted into new rods.

\subsubsection{Euel Rod Assembly Area}

The fuel and target assembly area consists of fuel storage, fuel rod pushing table, fuel assembly inspection platform, fuel assembly envelop station, fuel assembly storage racks, and packaging and shipping areas.

Fuel Rod Storage Cabinets - These cabinets can store completed fuel rods as they are waiting to be put into bundles (Fuel Assemblies).

Fuel Rod Pushing Table - The fuel rods are arranged on a preparation table (Pre-Table) in the way they will be in the completed assembly. Each row of rods from the prestack box is pulled out on the pre-table where they are checked one last time. The rods are then moved to the pushing half of the table where they are pushed into a grid cage on the tilt table. This process is repeated for each row until the fuel bundle is completed.

Fuel Assembly Inspection Platform - The full fuel assembly cage is taken to the inspection platform where the quality inspectors verify that it was properly assembled. At this point the upper end fitting is placed on the bundle (fuel assembly) to complete the assembly.

Fuel Assembly Envelope Station - The completed assembly is inspected for straightness by a small computer controlled measuring device that rides up the outside of the buncle. If the bundle is out of true it is adjusted and inspected again.

Fuel Assembly Storage Racks - The bundles are stored in the storage racks while they await packaging.

Packaging and Shipping - Two PWR fuel assemblies are packaged in a 5,000 lb steel shipping container to protect them as they are shipped to the reactor. The containers are designed to protect the fuel from damage that might occur during a truck wreck and the resulting fire including a plunge into a body of water. The fuel shipping containers are stored in the warehouse until they can be loaded for shipment to the reactor site via special transport vehicles. 


\subsubsection{Clean Sarap Recovery}

Clean scrap mixed oxide powder is recycled by direct addition to the final mixed oxide blend of the dry process head end. The scrap is loaded into a glove box where it is pulverized, weighed and transferred to the final blender. In this case the amount of $\mathrm{PuO}_{2,}$ $\mathrm{UO}_{2}$ and $\mathrm{Er}_{2} \mathrm{O}_{3}$ added to the blend is adjusted to maintain consistent composition.

\subsubsection{MF ${ }^{2}$ General Chemiatry Laboratories}

The General Chemistry Laboratory contains facilities for the chemical assay of powders containing plutonium and uranium. Most of the chemical analysis work is carried on inside glove box. The General Chemistry Laboratory also provides access to areas that contain specialized equipment for the analysis of plutonium- and uranium-bearing compounds.

\subsubsection{MF ${ }^{2}$ Other Laboratorias}

The $\mathrm{MF}^{2}$ houses a variety of specialized facilities for material accountability and analysis. These laboratories verify the chemical, mechanical and physical properties of the powders used in fuel pellet manufacture, and the fuel pellets themselves. Analysis methods for which special equipment is available include:

$\begin{array}{ll}\text { - } & \text { Metallography } \\ \text { - } & \text { Alphay analysis } \\ \text { - } & \text { Optical spectroscopy } \\ \text { - } & \text { Mass spectrometry } \\ \text { - } & \text { Gas analysis. }\end{array}$

\subsubsection{MF ${ }^{2}$ Health Physics}

A health physics area is provided at a convenient location in the plant. Access to the health physics area is from the process area, the laboratory area and the men's and women's locker rooms. The health physics area includes a personnel decontamination room, a first aid room and an instrument room.

\subsubsection{MF ${ }^{2}$ Equipment Maintenance Room}

The room is located off the main corridor across from the pellet processing area. A glove box fabricated from stainless steel is provided for maintenance and repair of contaminated equipment.

\subsubsection{8 $\mathrm{MF}^{2}$ Mechanical Room}

The Mechanical Room contains the compressed air system, low-pressure steam boiler, heat exchanger for hot water supply, chilled water loop, storage for tanks of oxygen and nitrogen, and the various motors, compressors and pumps needed for plant support. The room is not contaminated with plutonium or uranium. 


\subsubsection{MF² Piping and Duatwork}

Piping includes process piping, service piping, electrical conduit instrumentation lines, and the ventilation exhaust ductwork.

\subsubsection{MF² Sanitary Lageon}

The $\mathrm{MF}^{2}$ site includes a sanitary lagoon that is used for holding the discharge from the $M^{2}$ cold laundry, showers, sinks and toilets. The sanitary lagoon is a very low contamination area.

\subsubsection{OparationaL Parsonnel and Oraanization of the Plant}

\subsubsection{Oroanization}

The $\mathrm{MF}^{2}$ is designed, constructed, tested and operated following safety and quality assurance program conditions currently applied to commercial nuclear industry. The facility is engineered, designed, operated and maintained to:

- $\quad$ provide adequate confidence that structure, systems, components of the plant will satisfactorily perform their services.

- provide adequate confidence that the materials, produced in the plant, meet client specifications for its use.

The MOX fuel fabrication plant owner will implement a well defined organization to meet the safety and quality assurance criteria applicable to such a facility. To provide the adequate confidence, the plant has an independent safety and quality review team responsible for final verification of safety and quality-related activities.

\subsubsection{Rersonnel Required}

Qualified personnel are employed in the $\mathrm{MF}^{2}$. This means that the employees will receive appropriate training with particular emphasis on the matters for which their responsibility is involved. Their training will be oriented to safety and quality culture necessary for such an operation.

The plant operation is limited to one or two shifts with the exception of the furnaces which are operated in three shifts. The technical personnel required to operate the plant is estimated to be of the order of $\mathbf{3 5 0}$ for one shift. This personnel is distributed into various services such as:

- $\quad$ Fabrication (from feed powder up to fuel assembly):

200

- Testing, reject material recycling, waste treatment and conditioning: 
By utilizing the newer European technologies and automation, personnel requirements may be reduced by approximately $50 \%$.

\subsubsection{Desion Criteria}

\subsubsection{Quality Standarda}

Structures, systems, and components of the manufacturing facility important to safety shall be designed, fabricated, erected, and tested in accordance with NRC and DOE quality assurance criteria.

\subsubsection{Systems Important to Safety}

Systems important to safety in the MOX Plant shall be designed without the loss of capability to perform their safety functions in the absence of electric power with the control function designed to take the plant into a safe state. Systems important to safety shall be designed to withstand the effects of the most severe natural phenomena expected to occur at the site, including earthquakes, tornadoes, flooding, winds, without the loss of capability to perform their safety functions. These systems will also be appropriately protected against dynamic effects from missiles resulting from internal equipment failures and external causes.

\subsubsection{Nuclear Criticality and Safety}

The nuclear material in the form of powder, pellets or fuel assembly shall be stored or processed with a favorable geometry to prevent reaching a critical mass. In addition, neutron absorber material may be utilized, with provision for prevention of accidentally removal of the absorber in the storage location between the fuel containers. The fuel storage design considerations will include the fuel specifications (fuel enrichment, size and shape of containers, fuel quantity, security, shielding requirements etc.).

\subsubsection{SNM Accountability}

The incoming $\mathrm{UO}_{2}, \mathrm{PuO}_{2}$ and $\mathrm{Er}_{2} \mathrm{O}_{3}$ powders will be received in properly identified containers and accounted for. The assembled Mixed Oxide (MOX) fuel assembly shall be designed with proper identification for inventory control. (All special nuclear material shall be accounted for before it is shipped in the form of fuel assembly.) The scheme will utilize modern electronic and remotely operated identification methods.

\subsubsection{Physical Security}

The facility shall be designed to incorporate all the security requirements to prevent the intrusion of unauthorized personnel and/or prevent loss of fissile materials. The design shall follow the Security and Safeguards requirements stated in the DOE Orders and NRC Regulations for such a facility. Security will include barriers (fences, blockades, checkpoints), security lighting, intrusion detection systems, secure communications, and 
TV surveillance to control transport of the fuel material within the plant and outside within the perimeter of the facility.

\subsubsection{6 $\mathrm{MF}^{2}$ Layout}

a. The facility layout shall be designed with considerations of high security and safeguards, ease in cleaning and decontamination, maintenance, and inspection of the fuel material and fabricated fuel assembly.

b. The facility layout will be designed to physically separate the storage of fuel material and fabricated fuel assembly. The design will consider easy access for the transportation system to handle the material.

c. Doors and/or airlocks shall be designed for coordination with aisles to facilitate access to stored material for loading and unloading operations. The handling operations shall meet the security guidelines.

d. The handling equipment (cranes, hoists) for both fuel material and fabricated fuel assembly shall be designed to prevent potential damage to the building structure and the fuel itself during the operations.

e. Hazardous and secured areas at the facility shall be designed with warning signals, interlocks, annunciation in control room to prevent inadvertent entry.

f. The facility shall be designed with adequate radiation monitors to detect and warn about radiation levels in the various areas at all times and to provide access for personnel to exit from such location during emergency.

g. All combustible gas lines utilized for the furnaces in the sintering process shall be designed with double protection to prevent plutonium fires with the presence of $\mathrm{PuO}_{2} . \quad \mathrm{PuO}_{2}$ storage areas shall be designed to exclude combustible gas lines.

\subsubsection{Structural and Mechanical Desion Criteria}

Wind Loadings: The facility shall be designed to wind velocity in accordance with ANSI Standard 58.1 "Building Code Requirements for Minimum Design Loads in Buildings and other Structures"

Tornado Loadings: The facility shall be designed to the maximum tornado loadings applicable to the selected site. (Process, fuel assembly and emergency equipment areas must withstand a tornado event; no direct damage should be expected in areas containing dispersible plutonium.)

Flooding: The site drainage should be functional under all postulated conditions i.e., no floods can occur within the plant. 
Missile Protection: Process, Fuel Assembly, and emergency equipment areas must withstand external missile interactions. This includes external shells, doors, HVAC air intake and exhaust ducts. Internal missile should not be a problem since missiles generated by a tornado are considered the limiting ones.

Seismic Design Criteria: The earthquake intensities should be based on historical data for the selected site. The seismic criteria must be applied to all Seismic Category I and/or safety-related structures and equipment. The design basis events should satisfy this criteria.

Snow Loadings: The building roof shall be designed to withstand the maximum accumulation of snow loadings based on historical data.

Load Combinations:

a. Loads and load combinations for concrete structures shall be in accordance with ANSI/ACI Standard 349 "Code Requirements for Nuclear Safety related concrete Structures".

b. Load combinations and allowable stresses for steel in accordance with the American Institute of Steel Construction (AISC) Standard "Specification for design, fabrication and erection of structural steel for buildings"

c. Loads for piping shall be in accordance with ANSI Standard B.31.1 "Power Piping"

\subsubsection{General Safety Considerations}

There shall be a need of the general awareness of safety considerations in applying the design criteria through testing, operation and maintenance phases of the facility. Thus, it is necessary to consider:

a. Safety for manufacturing and chemical operations

b. Process and support material inventory capacities

c. Hazard types and magnitudes by locations

d. Source terms for shielding and dose calculations

e. Container and storage array dimensions

f. Process descriptions (production of pellets; production of rods; production of fuel assemblies; analysis and inspection of material)

g. Area/room activity assignments

h. Radiation control areas.

\subsubsection{Waste Management}

The radioactive waste and hazardous waste system shall be designed for proper collection, processing, packaging and disposal of the waste. The system shall be designed to meet the Federal, State and local regulations for waste handling. The waste system shall be designed with the concept of recycling a fraction of the total waste 
produced and thus reduce the total quantity of the waste produced by the facility for disposal (waste minimization). The radioactive waste system shall be designed to handle both solid and liquid wastes.

The waste system shall have provision for radioactive monitoring of the radioactive levels at all times. It must be instrumented in a manner to take suitable automatic action during an emergency.

\subsubsection{Confinement Areas/Zones}

Multiple barriers shall be used in the facility to limit uncontrolled release of plutonium and thus limit the release of radioactivity to the environment. The multiple barrier concept in the design will include series of structural barriers to form zones and utilize zoned ventilation system. In the restricted access areas (RAA) of the process building (such as handling plutonium) the design shall utilize shielded glove boxes for plutonium handling. Outside the RAA the layout design will provide area for operation and maintenance and designate it as a limited access area (LAA) thereby serving to contain any leakage from RAA. The building structure, i.e. walls, roof, and foundation, shall provide the final barrier for the release.

The ventilation system shall be designed to maintain a pressure differential between areas so that air flows from non-contaminated areas to areas of potentially higher contamination levels. The zoning of areas shall assist the design of the zoned ventilation system to provide for pressure differentials. The controlled zone ventilation system shall be designed with redundant, independent emergency power supplies with each individual system capable of fulfilling the design requirements. The exhaust of process air from the building shall be designed to pass through multiple filters and have monitoring systems to keep track of the total releases from the facility and thus ensure it is within the environmentally accepted limits.

Process equipment and storage containers shall provide primary confinements/barriers for MOX material and be qualified for earthquake events (Uniform Building Code Qualification shall be used for equipment and containers, such as process glove boxes, enclosures, ventilation ducts and storage containers). UBC qualification shall be provided to nearby or interfacing equipment whose failure could jeopardize confinement barriers.

The ventilation system shall be designed with provision for in-service inspection and testing.

\subsubsection{Radiation and Environment}

There shall be adequate shielding around high radioactive material and equipment to ensure the personnel exposure are within the stipulated limits. Administrative procedures shall be drafted and implemented as part of the operation to ensure that radiation limits are not violated. 


\section{Combustion Engineering, Inc.}

\subsubsection{Fire Protection}

Structures, systems, and components shall be designed to minimize the potential of fire, and/or the effects of fire and explosions. Each process aspect of the fabrication facility shall be enclosed within appropriate fire barriers and have fire detection and mitigation systems to detect a fire condition and prevent spread of any fire generated in a particular area. The type of structural barriers and fire mitigation systems shall be identified in the preliminary design of the facility in order to be properly integrated into the design of the building and building services systems.

\subsubsection{Electrical Power}

Offsite electric power system and onsite emergency electrical power system shall be designed such that systems important to safety at the facility can always function when it is required. The emergency power system shall be designed to be independent, reliable, testable and inspectable. The capacity of the emergency power system shall be adequate to meet the total electrical load requirements for achieving and maintaining the plant in a safe shutdown mode during any emergency.

\subsubsection{Instrumentation and Controls}

Instrumentation in the $\mathrm{MF}^{2}$ shall be provided to monitor system operations during normal operations, anticipated operational occurrences, and certain systems for accident conditions. The design shall provide for both automatic control with provision for manual override during emergencies. The instrumentation and controls shall be designed to maintain system functions within specified operating ranges and adequate response times to take appropriate actions during postulated off-normal events.

\subsubsection{Lighting and Communications}

The $M F^{2}$ facility shall be designed for adequate lighting and communications consistent with the requirements for a commercial fuel fabrication facility.

\subsubsection{Production and Reliability Goal}

The design of the facility shall be initiated by setting up a production goal for the facility. This would involve assigning a reliability goal for the facility and then dissect this value to provide a value for each system and each component associated with that system. Once a reliability goal is identified for a system, the design of the system shall proceed with the goal to meet it. Thus, Reliability, Availability, Maintainability and Inspectability (RAMI) limits shall be established for each system associated with the facility.

\subsubsection{Inspection and Maintenance}

The layout of the plant equipment shall consider the space needed for maintenance and inspection on a routine basis. 


\subsubsection{Reliability and Testabillty}

Systems of the $\mathrm{MF}^{2}$ necessary for the safe operation of the plant shall be designed for total functional reliability and in-service testability. These systems shall have provisions for redundancy and sufficient independence to prevent loss of their safety function in case of an accident. Also, they would ensure capability for safe shutdown of the plant operations.

\subsubsection{Decommissioning and Decontamination}

The Decommissioning criteria shall utilize the DOE Order 6430.1 Chapter XXI. It includes the following considerations:

a. Design of critical areas shall incorporate measures to simplify decontamination

b. Items such as service piping, conduits, and ductwork shall be kept at a minimum in operating areas and be arranged to facilitate decontamination

c. Walls, ceilings, and floors shall be finished with washable or strippable coverings or covered with metal liners, if required. All cracks, crevices and joints shall be caulked and finished smooth to prevent contamination of inaccessible areas. Painting of surfaces with smooth (gloss) finishes may also be done to improve decontamination ability.

d. Modular, separable enclosures shall be provided for radioactive materials to preclude contamination of fixed portions of the structure.

e. Glove box and enclosure design shall account for limitations on dimensions of packing crates or other containers accepted at transuranic disposal sites.

f. Localized liquid transfer systems shall be used to avoid long runs of contarninated piping. Emphasis shall be placed on localized waste batch solidification. Special provisions shall be made to ensure joint integrity in buried pipelines.

g. Exhaust filtration components shall be located to avoid long runs of contaminated duct work.

h. Effluent decontamination equipment shall preclude, to the extent practicable, the accumulation of radioactivity in relatively inaccessible natural soil columns.

i. A decontamination facility shall be provided to decontaminate equipment with chemical flushes, cut up metallic components, package waste materials, and load casks.

j. A hot repair area shall be provided to permit remote and hands-on repair of facility equipment.

k. All process cells shall be provided with metal liners that can be removed to facilitate decontamination and decommissioning.

I. Gloveboxes and process enclosures shall be designed with removable shielding, polished interior surfaces, and rounded corners and edges to facilitate decontamination. 


\subsection{Euel Handling and Storage Facilities}

Introduction

This report section contains a description and the design features of the proposed fuel handling and storage facility for plutonium burning plants.

The total capacity of the fuel storage buildings as described in this section is for 15 full core loads of MOX fuel assemblies. A standard fuel storage rack, designed and approved for System $80+\mathrm{UO}_{2}$ spent fuel, was incorporated. To avoid criticality concerns, the fuel rack will be modified so that MOX fuel assemblies can only be stored on a diagonal pitch: i.e., in every second location. This results in a very conservative design. A minimum configuration sized for four full core loads of MOX assemblies could be specified, provided there was adequate assurance that the discharged MOX fuel would be shipped to an offsite repository after a 10 year cooling period.

\section{Concept System Description}

The fuel handling and storage facilities are divided between two separate buildings (see Figure 2.5-1), that are connected through a fuel transfer tube. The first building (Building $1)$ is similar to the spent fuel building for the standard System $80+$ plant design. However, the pool storage capacity is increased to accommodate the storage requirements for plutonium disposition. This building is serviced by a fuel handling machine that is capable of transporting fuel to and from each of the designated storage stations within the pool. The areas covered by the fuel handling machine are the cask laydown area, the fuel storage racks, and each of the two fuel transfer mechanisms.

New fuel may be introduced into Building 1 by means of a transfer cask, which is offloaded from a transport vehicle by a cask handling crane at the loading/unloading area. The cask handling crane is part of the permanent equipment that is used to support activities in the fuel handling building. Fuel is removed from the cask with the fuel handling machine, inspected, and then placed into the fuel storage racks. When required, fuel may be placed in either of the two fuel transfer mechanisms, for underwater transfer to the containment building or the second fuel handling and storage building (Building 2 ).

In addition to fuel handling and storage capabilities, Building 1 is designed to permit underwater recovery of target rod assemblies (TRA) and burnable poison rod assemblies (BPRA) from activated plutonium fuel in the fuel inspection and rod recovery area. Equipment used for rod recovery operations is installed within the cask laydown pool.

Building 2 is similar in design to Building 1, except that it contains a larger segmented fuel storage pool. A gated partition divides the pool, giving it added strength and protection against accidental drainage. Like Building 1, provisions are included for cask handling an rod recovery. Similarly this building houses a fuel handling machine for fuel transport to the respective areas within the pool.

Fuel transfer between Buildings 1 and 2, may be performed using a dedicated fuel transfer mechanism. Transfer is accomplished by loading a fuel assembly into a vertical cavity in 
the transfer mechanism using the fuel handling machine. The cavity is then rotated to the horizontal position, and driven to the adjoining building. The fuel cavity is again rotated to the vertical position, and the fuel recovered using the second fuel handling machine.

During fuel transfer between the adjoining buildings, the fuel is conducted through a fuel transfer tube assembly, which connects the two pools. The fuel transfer tube is designed with a gate valve on each end. These valves facilitate pool segregation from either or both buildings. The transfer tube assembly is designed to accommodate relative motions between the two buildings due to settlement and design bases earthquakes. The assembly is also designed to prevent pool draindown during and after the occurrence of postulated design events.

\section{Design Features}

There are several design features afforded by the fuel handling and storage arrangement covered in this section. The duplicate facilities included in each of the two buildings allow reactor refueling and TRA/BPRA recovery operations to be conducted at the same time; though in different locations. This reduces the time to accomplish TRA/BPRA recovery operations. Also, since new fuel may be introduced through the cask handling facilities in either building, fuel receiving operations may be conducted in one building, without interrupting activities in the other building.

Underwater fuel transfer between the two adjacent storage pools, using the fuel transfer mechanism, provides a safe and secure means of conducting these operations. Fuel transfers conducted underwater in this fashion can be performed more rapidly than alternative methods, which may need to utilize an auxiliary fuel transfer cask shuttled between the two buildings. Also, since there are fewer handling maneuvers required when using the transfer mechanism, there is less chance for damaging the fuel. Another design feature of the direct fuel transfer is that the fuel does not have to leave the confines of either building enclosure. This provides additional protection against accidents or interference from outside agents. 


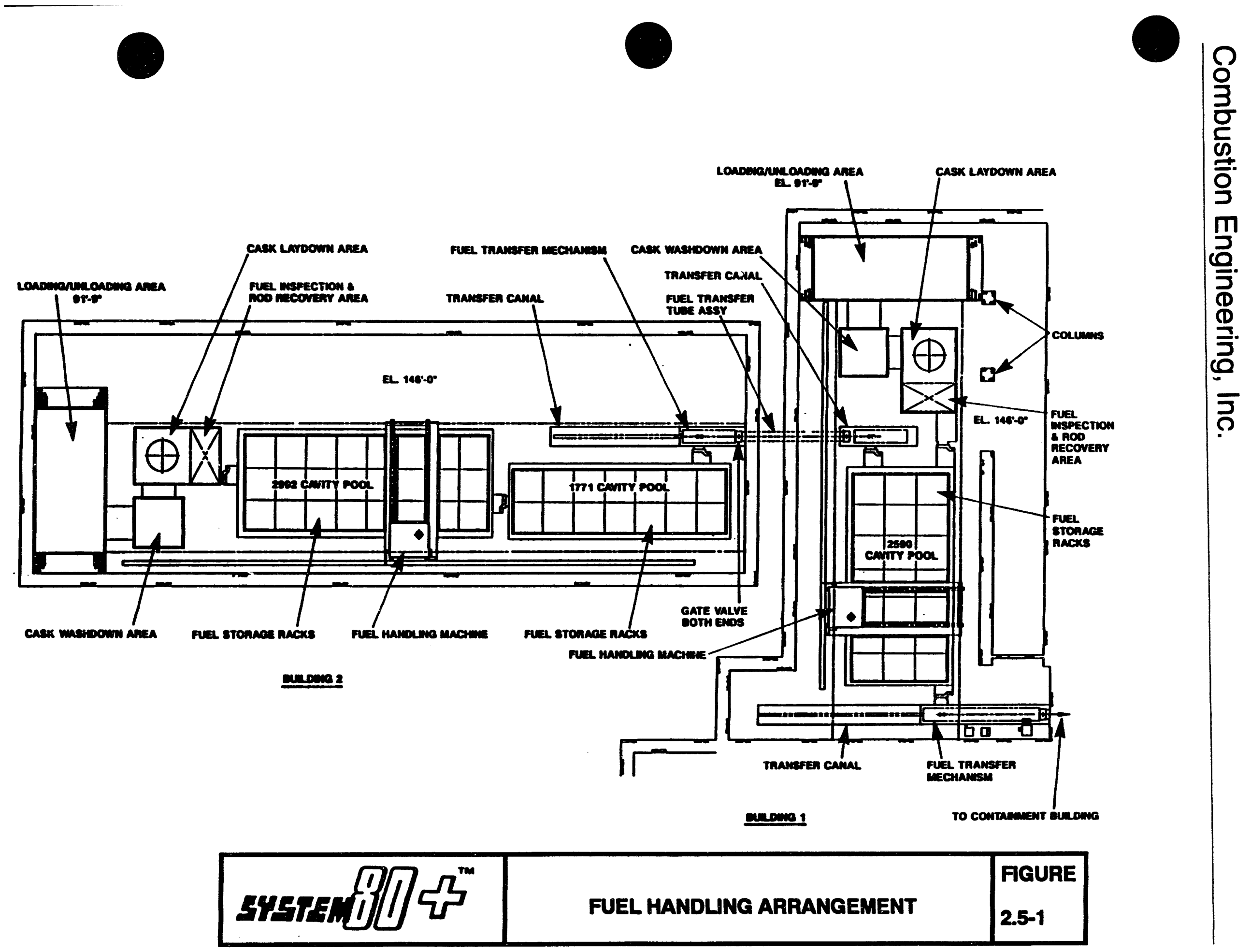




\subsection{Euel Management}

The System $80+$ reactor system as used for Plutonium disposition is designed for this base case to operate for four years with annual outages using a single core of fuel. This feature gives the flexibility to accommodate several types of missions with no change in the fuel specifications or in the fuel management. The first advantage is that the fuel management is the same for each cycle - whether it is the first, middle, or last. In addition, there is the flexibility to extend the cycle length for several months to generate additional energy, run a limited tritium production capability and/or spike the fuel to increase its diversion resistance.

Several other fuel managements approaches are possible to meet other mission requirements. While they are not discussed here, it is possible to design a three or four batch equilibrium cycle fuel management that produces less variations in system parameters during the cycle than those that occur for the four year core.

The characteristics for the MOX fuel design are discussed in Section 2.1.1 and are summarized in Table 2.6-1. Erbium is admixed with the fuel in every fuel pin in all assemblies. Two-thirds of the assemblies are designed with a lumped burnable absorber (LBA) cluster to give mission flexibility and to allow a mechanism to add reactivity to the fuel in later cycles.

A typical fuel management scheme is given in Figure 2.6-1 that has two types of fuel assemblies characterized by the number of LBAs - zero(0) and twelve (12). The assemblies with the LBA clusters have further flexibility with two different average erbium loadings.

The design objectives of Pu disposition and Pu-240 isotopic fraction typical of spent fuel from conventional LWRs are accomplished easily at the stated $75 \%$ capacity factor. The fuel management for this study was performed using the tablesets generated using standard libraries and techniques. In addition, the development, validation, and verification of the new ENDF/B-VI library for cross sections is being performed in parallel and is discussed in Section 3.1.7 and in Appendix B. When this verification and validation effort is complete, the safety parameters will be fine tuned with tablesets from the latest, evaluated cross sections.

The scoping study of the physics related safety parameters is summarized in Table 2.6-2 and compared with values calculated earlier for commercial $\mathrm{UO}_{2}$ and all-plutonium reactor (APR) studies for the System 80 plant in the 1970s. The results for the System $80+$ Plutonium Disposition operating in the spent fuel mode using weapons-grade plutonium fuel show that they are within the range of those for commercial APR.

\section{Physics Characteristics}

The basic cycle-dependent physics characteristics of the MOX fuel cycle concept evaluated for the spent fuel alternative are shown in the following figures:

- Figure 2.6-2 Critical Boron Concentration vs Exposure 
- Figure 2.6-3 Inverse Boron Worth vs Burnup

- Figure 2.6-4 Core Rod Worths vs Exposure

- Figure 2.6-5 Moderator Temperature Coefficient (MTC) vs Burnup

The magnitude and trend of the parameters shown for the MOX concept are similar to those of APR cycles based commercial-grade recycled plutonium, as were discussed in Section 2.1.1. In particular, the values of parameters near end-of-life (EOL) approach values characteristic of commercial $\mathrm{UO}_{2}$ cycles.

\section{Comparison of Parameters for MOX Concept}

Table 2.6-2 gives a comparison of physics parameters for the MOX and non-fertile concepts using weapons-grade plutonium and for commercial fuel cycles based on $\mathrm{UO}_{2}$ operation and APR plutonium recycle. Specific parameters are discussed below based on the comparisons provided.

a. Critical Boron Concentration (CBC)

Calculated values of CBC at full power over cycle are shown in Figure 2.6-2 for the MOX cycle. The values of inverse boron worth (IBW) are similarly shown in Figure 2.6-3.

For the MOX cycle, a relatively high CBC exists at BOL, consistent with the reduced soluble boron worth shown by the IBW. The CBC decreases over cycle, and indicates that a significant amount of excess reactivity remains at EOL (1096 EFPD). The excess reactivity shown at EOL is favorable from the viewpoint of providing flexibility for optimizing the design and cycle length of the MOX concept.

Critical boron concentrations for calculated operating conditions at BOL are compared in Table 2.6-2. The concentrations of natural soluble boron shown for the MOX cycle is consistent with the amount of excess reactivity at BOL. Since the overall excess reactivity of the MOX cycle is higher than required for cycle length, it is expected that the $\mathrm{CBC}$ values and the refueling boron concentration for an optimized design can be reduced to values near those for the commercial APR cycle.

b. Control Rod Worth

Calculated values of core reactivity worth of the control element assemblies (CEAs) over cycle are shown for hot-full-power conditions in Figure 2.6-4 for the MOX cycle. The CEA worth values are based on the extended CEA pattern for APR operation as described in Section ?.1. On the basis of the calculated results, the available CEA shutdown worth is sufficient for normal operations and safety-related requirements of the MOX cycle. The cycle-dependent behavior of CEA worth shows continuous increase in worth from BOL to EOL for the MOX case, consistent with the expected trend based on depletion of plutonium. 
c. Moderator Temperature Coefficient (MTC)

Calculated values of MTC over cycle are shown for in Figures 2.6-5 for the MOX cycle. These curves show the magnitude and trend of MTC at a constant soluble boron concentration.

For the MOX cycle, MTC is less negative at BOL and trends to a more negative value at EOL. Overall, the MTC characteristic for the MOX cycle is favorable relative to that of $\mathrm{UO}_{2}$ cycles. The high fissile plutonium content (supplemented by the effect of erbium) provides a more negative MTC at $\mathrm{BOL}$ than in $\mathrm{UO}_{2}$ fuel cycles. The MTC at EOL is similar in comparison to $\mathrm{UO}_{2}$ cycles due to depletion of plutonium. Calculations for full-power conditions and zero-power conditions, xenon-free conditions further show that MTC is negative for all critical conditions over the MOX cycle.

d. Fuel Temperature Coefficient (FTC)

Calculated values of FTC over cycle are shown in Table 2.6-2 for the MOX cycle. For the MOX cycle, the negative FTC magnitude is comparable to that of $\mathrm{UO}_{2}$ cycles, with little variation over cycle.

e. Delayed Neutron Fraction

Comparisons of delayed neutron fraction $\left(B_{\text {oft }}\right)$ and prompt neutron lifetime $\left(l^{\circ}\right)$ are given for BOL and EOL in Table 2.6-2. For the MOX cycle, the values of $B_{\text {eff }}$ are in the range of .003, which is lower than for the commercial APR due to the high $\mathrm{Pu}^{239}$ concentration in combination with $U^{238}$. Based on evaluations for commercial APR cycle, the lower $B_{\text {eff }}$ for the MOX concept is expected to be acceptable for safety-related performance (e.g., CEA ejection accident). 
TABLE 2.6-1

\section{SYSTEM $80+$ PU BURNER MOX CORE DESICN CHARACTERISTICS}

Power Level

Core

Power Density

Average Linear Power ${ }^{(1)}$

Maximum Linear Power'")

Core Dimensions

Active Core Length

Equivalent Core Diameter

Fuel Assemblies

Number

Dimensions

Array

0-Shim Assembly

Number Fuel Rods

12-Shim Assembly Number Fuel Rods BPR Guide Tubes ${ }^{(2)}$

BPR Guide Tube ${ }^{(2)}$

Outside Diameter

Thickness

Material

Fuel Rods

Outside Diameter

Cladding Thickness

Fuel Sintered Pellet Material

Cladding Material

Lumped Burnable Poison Rods (BPR)

Number per 12-Shim Assembly

BPR Outside Diameter

Cladding Thickness

BPR Absorber Material

BPR Cladding Material
$3800 \mathrm{MW}(\mathrm{th})$

$95.5 \mathrm{~kW} / \mathrm{liter}$

$17.7 \mathrm{~kW} / \mathrm{m}(5.40 \mathrm{~kW} / \mathrm{ft})$

$41.7 \mathrm{~kW} / \mathrm{m}(12.7 \mathrm{~kW} / \mathrm{ft})$

$3.81 \mathrm{~m}(150 \mathrm{in})$

$3.65 \mathrm{~m}$ (143.6 in)

241

$202.7 \mathrm{~mm} \times 202.7 \mathrm{~mm}$

$(7.972$ in $\times 7.98$ in)

$16 \times 16$

236

224

12

$11.2 \mathrm{~mm}$ (0.440 in)

$0.91 \mathrm{~mm}$ (0.032 in)

Zircaloy-4

$9.7 \mathrm{~mm}(0.382 \mathrm{in})$

$0.64 \mathrm{~mm}(0.025 \mathrm{in})$

$\mathrm{UO}_{2}-\mathrm{PuO}_{2}-\mathrm{Er}_{2} \mathrm{O}_{3}$

Zircaloy-4

12

$8.7 \mathrm{~mm}$ (0.344 in)

$0.64 \mathrm{~mm}$ (0.025 in)

$\mathrm{Al}_{2} \mathrm{O}_{3} \cdot \mathrm{B}_{4} \mathrm{C}$

Zircaloy-4

(11) Based on 0.975 average energy deposition fraction in the fuel.

(2) Non-structural guide tubes allow removal of BPRs for later cycles. 
TABLE 2.6-2

COMPARISON OF SAFETY RELATED PHYSICS PARAMEIERS

\begin{tabular}{|c|c|c|c|}
\hline PARAMETER & $\begin{array}{l}\text { COMMERCIAL } \\
\text { UO2 EQ. CYCLE } \\
\end{array}$ & $\begin{array}{l}\text { COMMERCIAL } \\
\text { APR EQ. CYCLE }\end{array}$ & $\begin{array}{c}\text { WEAPONS-GRADE } \\
\text { MOX APR }\end{array}$ \\
\hline $\begin{array}{l}\text { MTC (delta-rho/deg F) } \\
\text { Full Power, BOL } \\
\text { Full Power, EOL }\end{array}$ & $\begin{array}{l}-5.90 E-05 \\
-3.24 E-04\end{array}$ & $\begin{array}{l}-1.00 E-04 \\
-3.10 E-04\end{array}$ & $\begin{array}{l}-0.82 E-04 \\
-2.14 E-04\end{array}$ \\
\hline $\begin{array}{l}\text { FTC (delta-rho/deg F) } \\
\text { Full Power, BOL } \\
\text { Full Power, EOL }\end{array}$ & $\begin{array}{l}-1.24 E-05 \\
-1.25 E-05 \\
\end{array}$ & $\begin{array}{l}-1.01 E-05 \\
-1.09 E-05\end{array}$ & $\begin{array}{l}-1.54 E-05 \\
-1.57 E-05\end{array}$ \\
\hline $\begin{array}{l}\text { Dissolved Boron (ppm) } \\
\text { CBC at BOC, Unrodded } \\
\text { Hot Standby } \\
\text { Full Power, no Xe } \\
\text { Full Power, Eq. Xe } \\
\text { Refueling (5\% subcrit) }\end{array}$ & $\begin{array}{l}1589 \\
1400 \\
1170 \\
1955\end{array}$ & $\begin{array}{l}3189 \\
2450 \\
2100 \\
4203\end{array}$ & $\begin{array}{l}3359 \\
2839 \\
2409 \\
5190\end{array}$ \\
\hline $\begin{array}{l}\text { IBW (ppm/delt-rho) } \\
\text { Full Power, BOL } \\
\text { Full Power, EOL }\end{array}$ & $\begin{array}{l}116 \\
101\end{array}$ & $\begin{array}{l}383 \\
331\end{array}$ & $\begin{array}{l}403 \\
241\end{array}$ \\
\hline $\begin{array}{l}\text { CEA (\%delt-rho) } \\
\quad \text { Full Power, EOL }\end{array}$ & 13.8 & 12.6 & 13.4 \\
\hline $\begin{array}{l}\text { Eff. Delayed N. Fraction } \\
\text { BOL } \\
\text { EOL }\end{array}$ & $\begin{array}{l}0.00625 \\
0.00546 \\
\end{array}$ & $\begin{array}{l}0.00442 \\
0.00447\end{array}$ & $\begin{array}{l}0.00312 \\
0.00364\end{array}$ \\
\hline $\begin{array}{l}\text { Prompt N. Lifetime (sec) } \\
\text { BOL } \\
\text { EOL }\end{array}$ & $\begin{array}{l}2.13 E-05 \\
2.48 E-05\end{array}$ & $\begin{array}{l}6.80 E-06 \\
7.90 E-06\end{array}$ & $\begin{array}{r}6.42 E-06 \\
10.72 E-06\end{array}$ \\
\hline
\end{tabular}


LEGEND:

$\left[\begin{array}{lll}N & P \\ & B & \\ r & & F\end{array}\right]$

Loading Pattern-Typical

N = Quarter Core Box Number

P. Previous Cycle Location of Assembly

$F$ - Following Cycle Location of Asgambly

r- Clockwise Rotations from Box $N$ to F

$B$ = Batch_Identifier:

AA No BPRA

AL 12 BPRA, LO Er

AM 12 BPRA, AVEr

AH 12 BPRA. Hi Er

A Cycle 1 Fuel



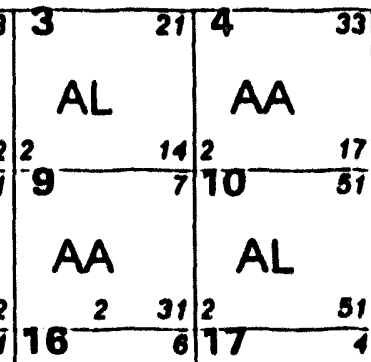

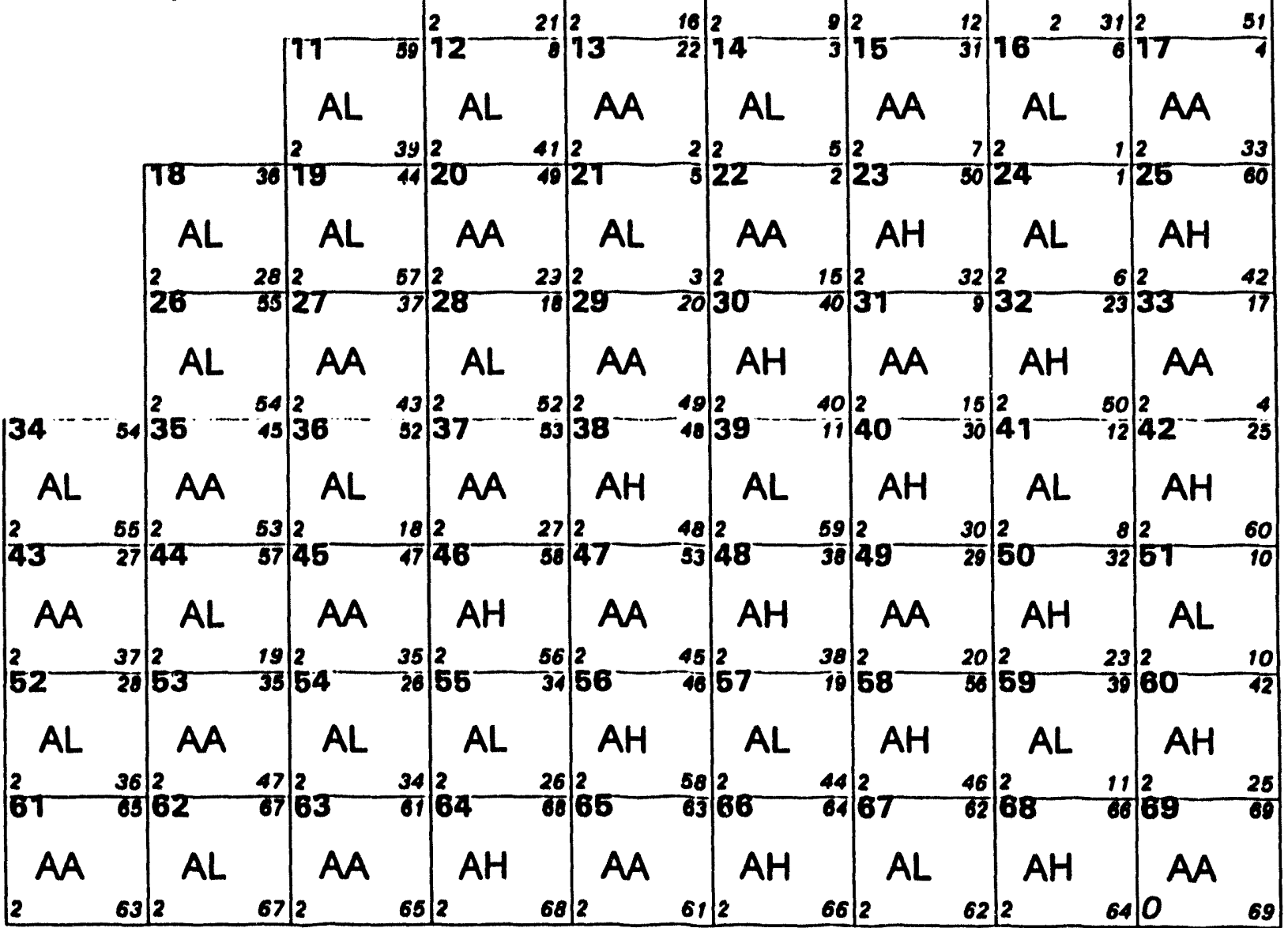




\section{Combustion Engineering, Inc.}

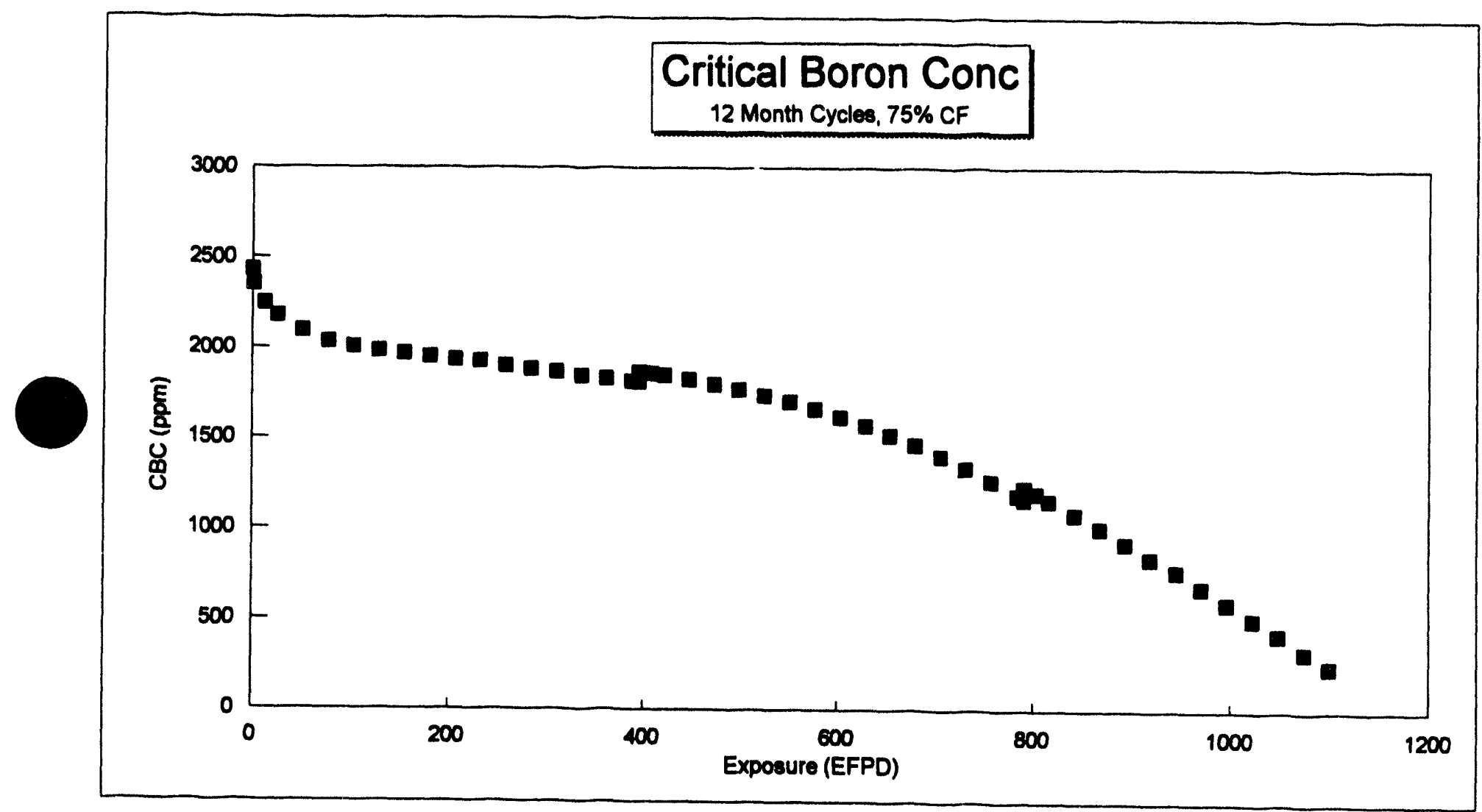

\begin{tabular}{|c|c|c|}
\hline GHERFA' & $\begin{array}{l}\text { CRITTCAL BORON CONCENTRATION VS } \\
\text { EXPOSURE }\end{array}$ & $\begin{array}{l}\text { FGUAE } \\
2.6-2\end{array}$ \\
\hline
\end{tabular}




\section{Combustion Engineering, Inc.}

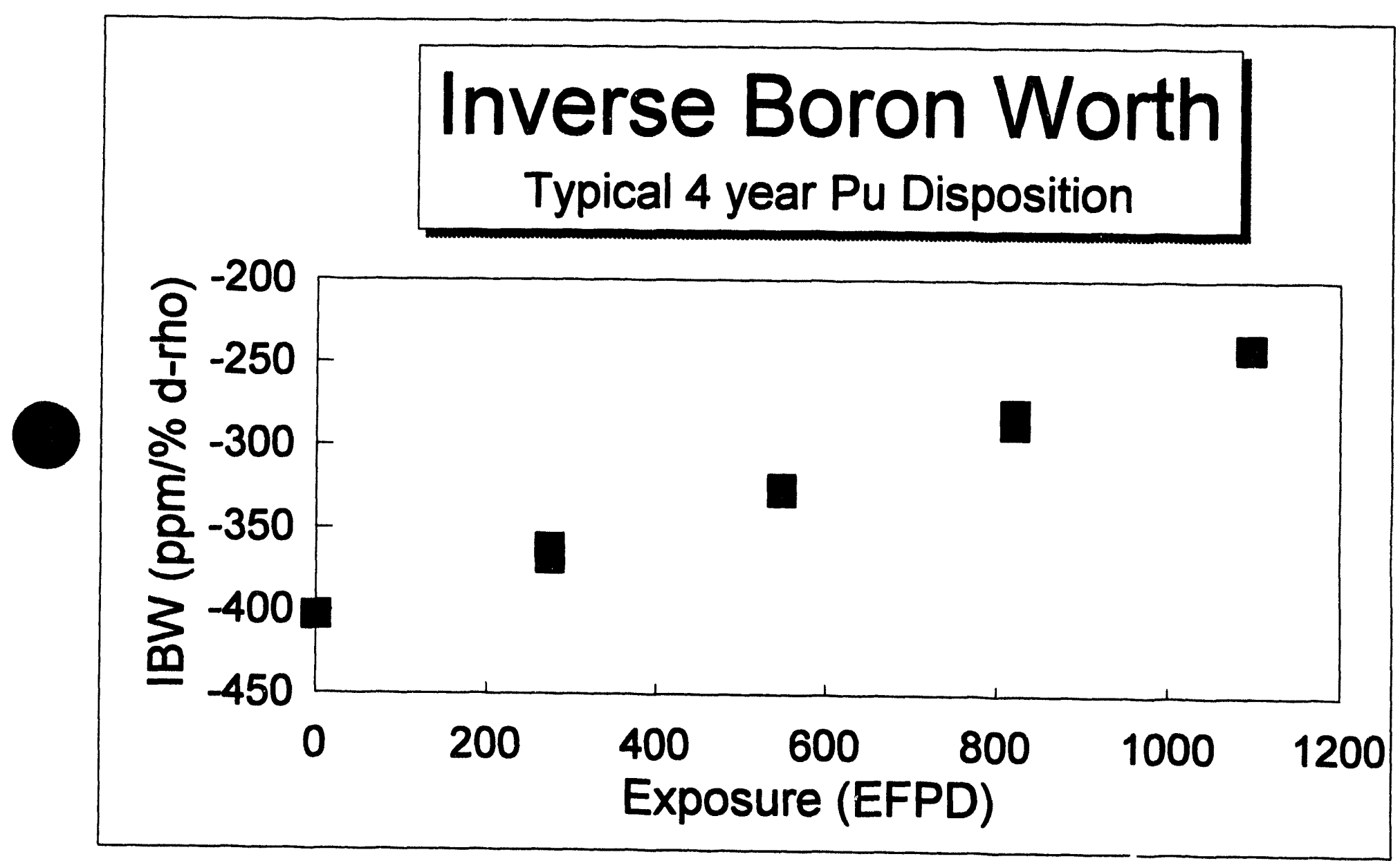


Combustion Engineering, Inc.

\section{Core Rod Worths vs Exposure} Typical 4 year Pu Disposition




Combustion Engineering, Inc.
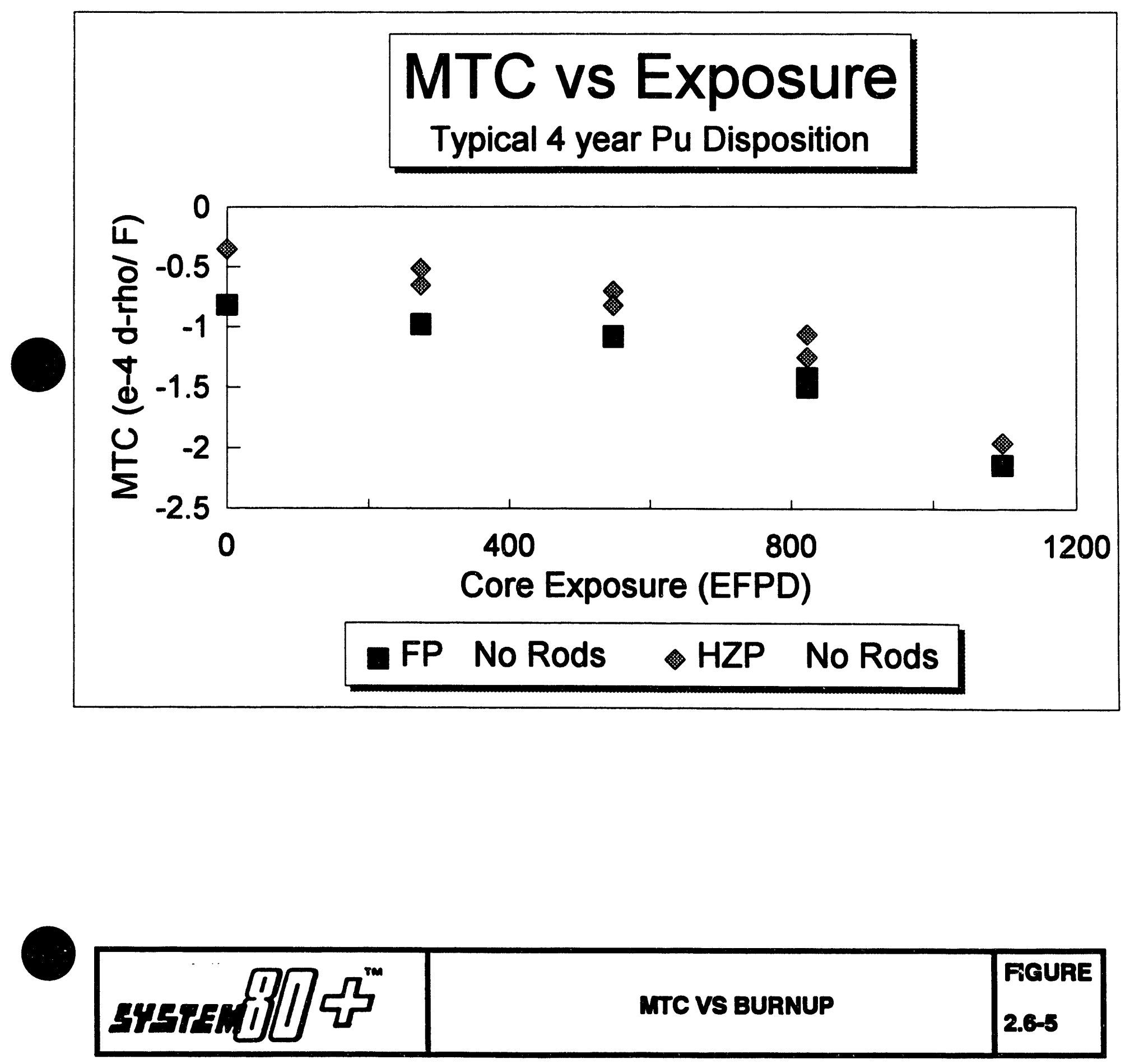


\subsubsection{Reactor Startup Plutonium Inventory and Discharge Rate}

As described in Section 2.6, the System $80+$ Plutonium burner reactor system is designed to operate for four years with annual outages using a single core of fuel for this base case. This means that the fuel management is the same for all cycles. The first cycle is the same as the middle or last cycles.

The characteristics for the MOX fuel design are discussed in Section 2.1.1 and are summarized in Table 2.6-1. This represents the plutonium startup inventory. The recharge rate for the four year core will require a 241 assembly core with the characteristics of Table 2.6-1 once every four years for each unit.

The four year core has no impact on fuel fabrication facility schedules. All concepts require a full load of fuel for the first cycle of operation. Once the four year core has been loaded and starts full power operation, there are four years before more fuel is needed for this plant. Other concepts would require one-quarter of this fuel to be delivered each year.

Table 2.6.1-1 illustrates the base case schedule for the startup and operation of a two unit site to dispose of 50 MT of Plutonium over a 25 year period from the start of the contract to build and operate this facility. Each of these System $80+$ reactor systems has a design life of 60 years. After completing the plutonium disposition mission, these plants have the power rating raised to $3941 \mathrm{MWt}$ and will burn commercially available fuel for the remaining 45 years of plant life. The base core requirement assumes a plant life of 40 years, which would put the commercial fuel operation to 25 years of the plant life defined as the reference case. 
IABLE 2.6.1-1

DEPLOYMENT STRATEGY

Base Case: $50 \mathrm{MT}$ in 25 Years

Schedule - Months Since Start of Contrat

Number of Reactor
Core Power Rating

Cycle Length

Cycle 1

Cycle 2

Cycle 3

Cycle 4

First Core Startup Test Per

Number of Feed Cores for Mission

Operating Cycles

Feed Core

1

Cycle

1

2

3

4

2

1

2

3

4

3

1

2

3

4

7

\section{1}

2

3

4

8

1

Months
12
12
12
12

\author{
2 \\ $3800 \mathrm{MWth}$
}

$\begin{array}{cc}\text { EFPD } & \text { Cap Factor } \\ 274 & 0.75 \\ 274 & 0.75 \\ 274 & 0.75 \\ 274 & 0.75\end{array}$

6 Months

8 Months $53.36 \quad$ MT Pu

Scheduled Start of cycle (Months)

Unit 1
74
92
104
116

Unit 2

Unit 3

Unit 4
98

110

122

134
128

140

152

164

224

236

248

260

2

3 


\subsubsection{Euel Cycle Characteristics}

As described in Section 2.6, the System $80+$ Plutonium burner reactor system is designed to operate for four years with annual outages using a single core of fuel for this base case. This means that the fuel management is the same for all cycles. A typical fuel management scheme is given in Figure 2.6-1. Minor variations on the fuel management scheme permit the flexibility necessary for various changes in mission requirements such as cycle length, capacity factor, or the need for a tritium generation mission. The first cycle is the same as the middle or last cycles.

As defined in the project definition, the base case is run with annual cycles and a $75 \%$ capacity factor. The startup of the first reactor unit in this complex has an additional 6 months during the first cycle to complete the additional startup and validation testing for this MOX fueled system. As shown in Table 2.6.1-1,the other unit on this site will commence operation two years after unit 1 and all cycles on this site (with the exception of Unit 1, cycle 11 will operate with annual cycles.

Each four year core in this base case study will operate for $4 \times 274$, or 1096, EFPD. This allows 90 days per annual cycle for refuelling, maintenance, and/or other operations that may be necessary for other plant missions. As discussed in Section 4.4, the System $80+$ reactor system is designed with operations and maintenance considerations. Conservative estimates show that one can easily operate this plant with considerably higher capacity factors and hence accomplish the plutonium disposition mission sooner and generate more energy and revenue for the project.

The recharging strategy is quite simple. Every four years a new core will be loaded with the same pattern as the initial core. For the three outages between new core loadings, the fuel management follows a strategy similar to that outlined in Figure 2.6-1.

\subsubsection{As-charged fuel actinide isotopic composition}

As described in Section 2.6, the System 80 + Plutonium burner reactor system is designed to operate for four years with annual outages using a single core of fuel for this base case. This means that the fuel management is the same for all cycles.

The recharging strategy is quite simple. Every four years a new core will be loaded with the same pattern as the initial core. The as charged fuel actinide isotopic composition is given in Table 2.6.3-1. The actinides are represented both as tonnes of heavy metal and as isotopic fractions.

Each feed core is composed of 241 assemblies loaded every four years. The heavy metal is composed of diluent as tails Uranium $(0.2 \mathrm{w} / \mathrm{o}$ of $\mathrm{U}-235)$ with weapons grade Plutonium (93.5 w/O Pu-239, 6.5 w/O Pu-240). $\mathrm{Er}_{2} \mathrm{O}_{3}$ is admixed with the $\mathrm{UO}_{2} / \mathrm{PuO}_{2}$ reactivity. 


\subsubsection{Discharged fuel actinide isotopic composition}

As described in Section 2.6, the System $80+$ Plutonium burner reactor system is designed to operate for four years with annual outages using a single core of fuel for this base case. This means that the fuel management is the same for all cycles.

As described above, every four years a new core will be loaded with the same pattern as the initial core. The discharged fuel actinide isotopic composition is given in Table 2.6.41. The actinides are represented both as tonnes of heavy metal and as isotopic fractions.

Each discharge core is composed of 241 assemblies off-loaded every four years. For the base case, there are four annual cycles of 274 EFPD with a capacity factor (CF) of 75 percent. This leads to an average discharge exposure of $42,400 \mathrm{MWD} / \mathrm{THM}$. 
IABLE 2.6.3-1

\section{AS-CHARGED FUEL. ACTINIDE ISOTOPIC COMPOSITION CORE TONNES}

\begin{tabular}{|c|c|}
\hline MWD/T & 0 \\
\hline U235 & 0.184137 \\
\hline U236 & 0 \\
\hline U237 & 0 \\
\hline U238 & 91.87906 \\
\hline NP237 & 0 \\
\hline PU238 & 0 \\
\hline PU239 & 6.236671 \\
\hline PU240 & 0.433558 \\
\hline PU241 & 0 \\
\hline PU242 & 0 \\
\hline AM241 & 0 \\
\hline AM243 & 0 \\
\hline CM242 & 0 \\
\hline CM244 & 0 \\
\hline TOTAL-HM & 98.73342 \\
\hline TOTAL U & 92.0632 \\
\hline TOTAL PU & 6.670229 \\
\hline TOTAL OTHER & 0 \\
\hline \multicolumn{2}{|c|}{ Pu Isotope Fraction } \\
\hline $\mathrm{Pu}-238 / \mathrm{Pu}$ & 0.000 \\
\hline $\mathrm{Pu}-239 / \mathrm{Pu}$ & 0.935 \\
\hline $\mathrm{Pu}-240 / \mathrm{Pu}$ & 0.065 \\
\hline $\mathrm{Pu}-241 / \mathrm{Pu}$ & 0.000 \\
\hline Pu-242/Pu & 0.000 \\
\hline
\end{tabular}


Combustion Engineering, Inc.

IABLE 2,6,4-1

DISCHARGED FUEL ACTINIDE ISOTOPIC COMPOSITION CORE TONNES

\begin{tabular}{|c|c|}
\hline Exposure & 42369.58 MWD/T \\
\hline U235 & 0.10395 \\
\hline U236 & 0.017788 \\
\hline U237 & 0.000032 \\
\hline U238 & 89.48765 \\
\hline NP237 & 0.001641 \\
\hline PU238 & 0.000275 \\
\hline PU239 & 3.063502 \\
\hline PU240 & 1.1021 \\
\hline PU241 & 0.610723 \\
\hline PU242 & 0.081952 \\
\hline AM241 & 0.029674 \\
\hline AM243 & 0.01992 \\
\hline CM242 & 0.013559 \\
\hline CM244 & 0.004515 \\
\hline TOTAL-HM & 94.53728 \\
\hline TOTAL U & 89.60942 \\
\hline TOTAL PU & 4.858552 \\
\hline TOTAL OTHER & 0.069309 \\
\hline \multicolumn{2}{|c|}{ Pu Isotope Fraction } \\
\hline $\mathrm{Pu}-238 / \mathrm{Pu}$ & 0.000 \\
\hline $\mathrm{Pu}-239 / \mathrm{Pu}$ & 0.631 \\
\hline $\mathrm{Pu}-240 / \mathrm{Pu}$ & 0.227 \\
\hline $\mathrm{Pu}-241 / \mathrm{Pu}$ & 0.126 \\
\hline $\mathrm{Pu}-242 / \mathrm{Pu}$ & 0.017 \\
\hline
\end{tabular}




\subsection{Nuclear Material Transporation}

\subsubsection{Eresh Fuel from fuel fabrication plant}

The System 80 + plutonium mission plant layout incorporates collocation of the fuel and reactor facilities in order to avoid shipment of fresh fuel from thefuel fabrication plant outside a controlled area. If the fabrication plantand the reactor plant are not collocated, the transport of the mixed oxide fuel rods to be transported from the fuel fabrication plant to the reactor can be accomplished in metal containers similar to the one utilized for the fresh $\mathrm{UO}_{2}$ fuel assemblies by the commercial nuclear industry. There is some radiation and therefore the packages will have to be modified slightly to include some shielding to meet the DOT requirements of external radiation dose levels for normal conditions of transport. The number of fuel assemblies will be established by the quantity of plutonium that can be transported in a single shipment.

The shipment can be accomplished via a truck. It is assumed that the shipment will require one day for a distance of travel equal to three hundred miles. The number of shipments to be made in a year depends on the production capacity of the MOX plant.

Each shipment will require special containers and a special security escort in view of the presence of plutonium in the fuel assemblies. During transport by road the vehicles may require armed escorts which provides additional security measure beside what is included in the container design and also be a communication link with the operation center during the transportation. Two drivers will accompany any shipment. The present practice of carrying six packages of PWR assemblies (12 assemblies) per truck can continue with the MOX assemblies except that each package may be heavier due to the extra shielding requirement. The handling of the packages at both the shipping and the receiving end could utilize the ones used by the commercial nuclear industry.

\subsubsection{Waste from fuel fabrication plant}

It is assumed that the solid wastes generated at the fuel fabrication plant would be placed in $\mathbf{5 5}$ gallon steel drums. These drums will be transported in the same manner as they are done for the $\mathrm{UO}_{2}$ fuel fabrication plant wastes. These drums would be placed in a steel cargo container or overpack and moved by rail or a truck. The quantity of waste and the characteristics of the waste depends on the fabrication process and the planned method of waste treatment used at the fuel fabrication plant.

The truck drivers may receive some radiation but will be limited to a value below that allowed by the regulation. The various accident that can occur during the transport will be analyzed and the necessary precautions taken to avoid release of radioactivity into the environment. 


\subsubsection{Waste from Beactor}

The waste from the reactor can be classified into high level and low level wastes. The low level wastes will be handled in the same manner as waste from fuel fabrication plant (see 2.7.2). The high level waste will be handled with care to prevent violation of ALARA limits. The wastes will be transported in casks similar to those used for irradiated or spent fuel assemblies. These shipments must meet the limits on size, weight, radiation level, and heat generation rate. The presently available spent fuel casks can be utilized for this operation. The number of shipments, distance to be travelled will be established after further study. The type of casks to be used depends on the mode of transport-- by rail or by truck. The wastes will have to be transported to a high level waste repository. The radiation level will be analyzed in a manner similar to the spent fuel assemblies. The present method for handling the casks can be utilized at both the shipping end and the receiving end.

\subsubsection{Spent Fual from the Reactor}

Spent fuel generated by the various Units will be stored on-site for a cooling period of ten (10) years from its core discharge date. Following the initial fuel accumulation delay period (which is be dependent on the fuel cycle chosen), spent fuel will be available for shipment on an annual basis to a Government specified permanent repository. Because of radiological considerations associated with spent fuel, special shipping casks are necessary to afford radiological protection during transport under both normal and accident conditions. Such shipping casks must meet Nuclear Regulatory Commission (NRC) requirements codified in 10 CFR 71, Packaging and Transportation of Radioactive Material. Casks which would serve a dual function of spent fuel storage must also satisfy NRC requirements codified in 10 CFR 72, Licensing Requirements for the Independent Storage of Spent Nuclear Fuel and High Level Radioactive Waste, Subpart L - Approval of Spent Fuel Storage Casks.

There are presently 7 types of spent fuel shipping casks that hold NRC Certificates of Compliance. The capacity of these casks varies between 1 and 7 PWR fuel assemblies. Clearly, cask choice is critical in that it affects the ultimate number of spent fuel shipments to the repository in order to transport an entire core of 241 fuel assemblies. It is desirable to minimize the number shipments required from radiological protection, security, and cost control perspectives.

Based upon the capacity of 1 assembly/cask, the number of shipments per year would be 120. Figure 2.7.4-1 shows the levelized schedule for shipping $\sim 120$ assemblies per year. Since the base case scenario uses a two unit site to dispose of the 50 MT of Plutonium, the actual shipping schedule could be 241 assemblies starting in year 2015 and 2017; but no shipments in 2016 and 2018. The levelized schedule allows shipments using fewer casks/year while having no impact on the fuel storage pool. 
Combustion Engineering, Inc.

\section{Assemblies Shipped per Year Base Case - 50 MT 25 years}

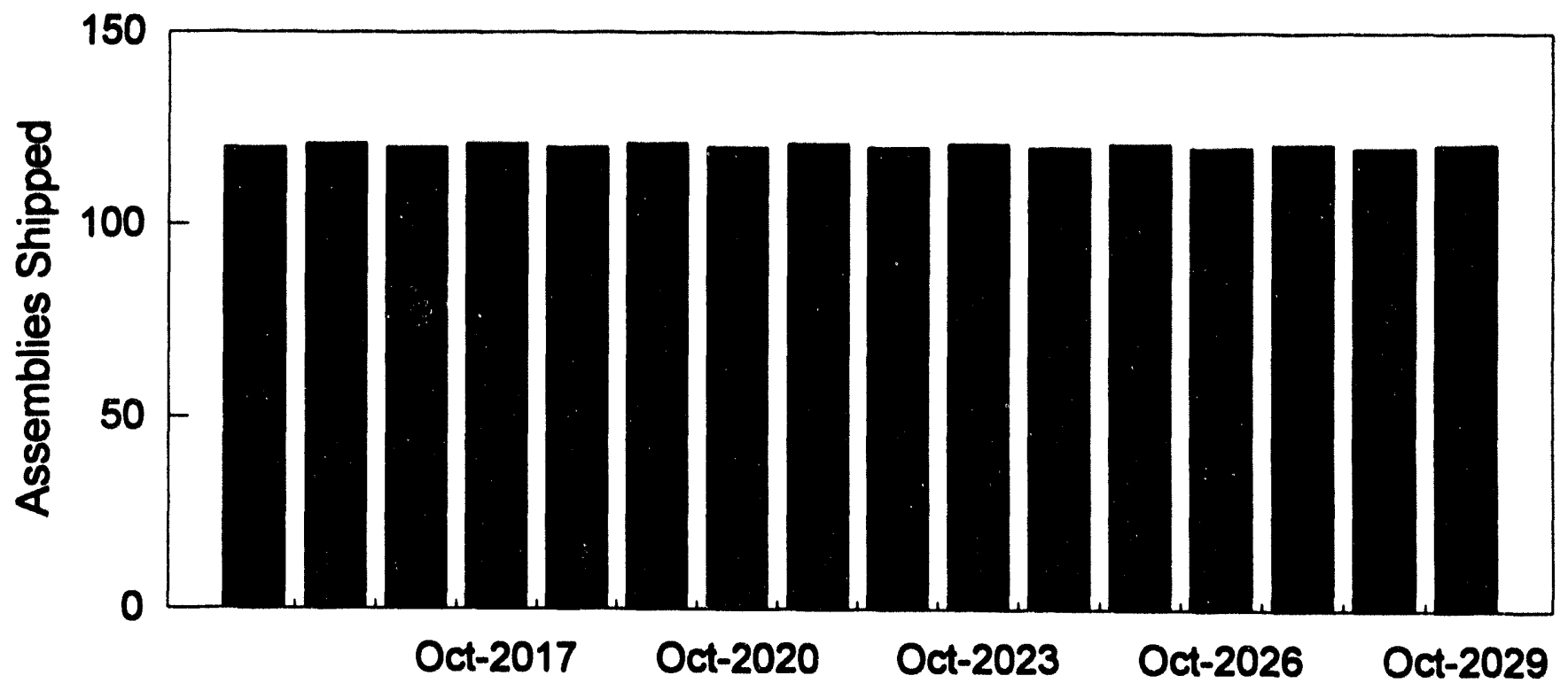

\begin{tabular}{|c|c|c|}
\hline 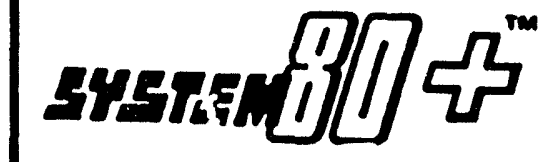 & $\begin{array}{l}\text { LEVELIZED SCHEDULE FOR SHIPPING } \\
\text { (BASE CASE) }\end{array}$ & $\begin{array}{l}\text { FQURE } \\
2.7 .4-1\end{array}$ \\
\hline
\end{tabular}




\subsection{TECHNOLOCY NEFDS}

The technology for System $80+$ is sufficiently developed and mature, through the implementation of PWRs and the development of the ALWR program in the US, that further development of the technology is unnecessary. On the basis of the Omberg and Walter scale, the Technology Readiness of System $80+$ is at Level 7, defined as follows:

"Level 7 This is the final level of technology readiness, at which a final design is approved or approval is pending with no outstanding issues of significance. An integrated system has been demonstrated on a scale relevant to the final application in the proper environment."

The backups for this assessment are the CESSAR System $80+$ Design Certification (FSER released by the NRC with no open items), and the three operating System 80 units at the Palo Verde Nuclear Generating Station.

For the plutonium disposition option, further development is in the form of validation of methods for the particular analysis, a revision of some specific calculations, and the safeguards and security aspects. The following sections outline the conformation work to be done in these areas.

\subsection{Benctor Technology Neads}

\subsubsection{Introduation and Summany}

System $80+$ is a mature Advanced Light Water Reactor (ALWR) design. The antecedents are System 80, which was brought to commercial operation at the Palo Verde Nuclear Generating Station, in Wintersberg, Arizona, in the early 1980's, and four units which are currently in construction in the Republic of Korea, which feature many of the System 80 + features, but in a smaller reactor size, commensurate with the customer's needs. Because of the degree of maturity of the design, there are no reactor technology needs. The remainder of this section will discuss the major design improvements featured in System $80+$ which have resulted from design and analysis experience as well as plant startup and operating experience. These are the "Technology Needs" that have already been met.

The experience input to the System $80+$ design process has been accrued through the organizations participating in the System $80+$ des jn team. This includes architect engineering organizations (Stone \& Webster Encjineering Corporation and Duke Engineering \& Services, Inc.) which have extensive experience in plant design and, in the case of Duke Engineering \& Services, actual plant operating experience. Architect engineering experience is reflected mainly in the plant layout, building design, control room, and the many "balance of plant" systems supporting the Nuclear Steam Supply System. This experience was brought to the System $80+$ design team by the 
engineers responsible for the design of specific structures and systems in currently operating plants and by actual plant operators who also participated in the design process. The ALWR Utility Requirements Document was also used in the design of System $80+$ and the design and operating experience of participating utilities reflected therein has been incorporated through the adoption of design requirements.

Experience related to the operation of the Nuclear Steam Supply System was brought to the System $80+$ design through the predecessor System 80 and earlier Nuclear Steam Supply System designs and through the years of experience of individual designers. This individual experience was developed through review of industry experience reflected in documents such as NRC Bulletins and Generic Letters, Unresolved and Generic Safety Issues, Institute for Nuclear Power Operations publications, and in the ABB-CE Corrective Actions Program. Their experience was also developed through participation on design teams for startup of plants with Nuclear Steam Supply Systems designed by ABB-CE.

Operating experience is reflected throughout the System $80+$ design described in this report, including shutdown risk improvements. The major improvements based on operating experience are summarized below.

\subsubsection{Integrated Desion Procens}

One organization, ABB-CE, is responsible for the design of structures, systems, and components of a plant which are important to safety (where design features depend on site-specific characteristics, interface requirements are provided), thus facilitating an integrated design process. The major considerations in this integrated design approach are as follows:

a. The Probabilistic Risk Assessment (PRA) is used to evaluate the design and to identify areas where significant improvement can be obtained. Although the end product of the PRA is a calculation of core damage frequency and offsite consequences, the PRA can also be used to gain design insights and identify improvements for handling more frequent transients and accidents.

b. Maintainability of the plant is being addressed by using equipment that minimizes the need for maintenance, by assuring that equipment can be easily accessed, and by assuring that maintenance actions will be as simple as possible (so as to avoid unplanned reactor trips and plant downtime). These same considerations apply to periodic testing and inspection of equipment.

c. In almost all cases for System $80+$, safety and non-safety functions have been separated. This will make the plant much simpler to operate and maintain. 
d. Human factors (i.e., the man-machine interface) are considered throughout the plant and especially in the control room.

e. As Low As Reasonably Achievable (ALARA) considerations affect the selection of materials and location of piping and equipment that carry radioactive coolant. For example, specifications for the reactor coolant system materials have been tightened to minimize transport of contamination. Improvements in the steam generator tubing material and access openings greatly reduce radiation exposures for maintenance, testing, and inspection. The overall goal is to maintain personnel exposure to less than 100 man-rems per year for each reactor.

f. Plant security (i.e., sabotage protection) and fire protection concerns have been directly addressed in determining layouts for plant safety systems.

\subsubsection{Increased Reactor Coolant System (RCS) Desion Margins and Improvements}

a. Reactor: The core operating margin has been increased by reducing the normal operating hot leg temperature and revising core parameter monitoring methods. The ability to change operating power level (i.e., maneuver) using control rods only (without adjusting boron concentration in the coolant syster()) has been provided, simplifying reactivity control during plant load changes and reducing liquid waste processing requirements.

b. Reactor Pressure Vessel: The reactor vessel is ring-forged with material specifications that result in a sixty year end-of-life RT $_{\text {NDT }}$ well below the current NRC screening criteria. This results in a significant reduction in the number of welds (with resulting reduction in inservice inspection) and eliminates concern for pressurized thermal shock.

c. Pressurizer: The pressurizer volume is increased to enhance the transient response of the RCS and to reduce unnecessary challenges to safety systems.

d. Steam Generators: The steam generators include Inconel 690 tubes, improved steam dryers, and a seventeen percent increase in overall heat transfer area, including a ten percent margin for potential tube plugging. The steam generators have a twenty-five percent larger secondary feedwater inventory to extend the "boil dry" time and improve response to upset conditions. Steam generator improvements also have been added to facilitate maintenance and long term integrity. These include larger and repositioned manways, a standby recirculation nozzle, and a redesigned flow distribution plate. 
e. Mechanical improvements based on System 80 startup and operating experience include strengthened reactor coolant pump impellers, redesigned reactor coolant temperature detector thermowells, strengthened reactor vessel upper guide structure, specification of antimony-free reactor coolant pump bearings, strengthened reactor coolant pump shafts, and redesigned steam generator economizer internals.

\subsubsection{Advanced Control Room Desion}

a. The Advanced Control Complex (Nuplex $80+$ ) for System $80+$ has been designed to meet demanding human factor, reliability, and licensing requirements, and is characterized by state-of-the-art advances, such as distributed digital processing, fiber optic data communications, and touch sensitive video displays.

b. Nuplex $80+$ is a total integration of plant-wide instrumentation and controls $(1 \& C)$ systems. The Advanced Control Complex includes the Main Control Room, the Technical Support Center, the Remote Shutdown Room, Computer Room; the Vital Instrumentation and Equipment Rooms, NonEssential Electrical Equipment Rooms and their respective control, protection, and monitoring systems.

c. Redundancy and diversity in all information processing and display ensures the correctness of information presentation and allows continued operation with equipment failures. Sufficient diversity is provided to ensure that the plant could be brought to a safe condition even with the loss of all safetyrelated digital instrumentation and controls. The integration of information from the former Safety Parameter Display System and the Post Accident Monitoring Instrumentation (PAMI) into normal operating displays allows the same displays to be used during all plant conditions.

d. Alarms are based on validated signal inputs with logic and setpoints that account for plant and equipment operating modes. Four levels of alarm presentation are employed. Individual and global alarm acknowledgement features ensure that all alarms are recognized without operator task overload. Alarm acknowledgement provides direct access to supporting displays.

\subsubsection{Highly Reliable Engineered Safequards Systems}

a. Chemical and Volume Control System (CVCS): The CVCS incorporates numerous significant improvements which include centrifugal charging pumps, a high pressure letdown heat exchanger, and simplified charging and auxiliary spray piping. A diverse positive-displacement charging pump has been added as a third source of cooling for the reactor coolant pump seals. 
Required safety functions previously performed by the CVCS are now delegated to other dedicated safety systems.

b. Safety Injection System (SIS): The SIS design has been improved to provide a simpler and more reliable system with increased redundancy. It has four mechanical trains for safety injection, direct-to-vessel injection connections, and an in-containment refueling water storage tank. The same size pumps and valves used in the original System 80 two train design are now used in all four trains. The trains are not interconnected by common headers and include provision for full flow, on-line testing to eliminate the need to extrapolate bypass-flow test results to demonstrate compliance to Technical Specifications.

c. In-Containment Refueling Water-Storage Tank (IRWST): The IRWST has been located in the containment building, in a torus-like configuration around the reactor vessel cavity. Containment water collection points empty into the IRWST. This means that the safety injection pumps always take water from the tank, eliminating the need to switch from tank to containment sump following a loss of coolant accident.

d. Safety Depressurization System (SDS): The SDS is a dedicated manuallyoperated system designed to permit depressurization of the Reactor Coolant System (RCS) when normal processes are not available. The SDS provides the capability to rapidly depressurize the RCS so that an operator can initiate primary system feed and bleed (using the safety injection pumps) to remove decay heat following a total loss of feedwater event. Manual control of motor operated valves enable discharge from the pressurizer to be directed to the IRWST, without the reliability concern that is associated with automatically operating valves.

e. Emergency Feedwater System (EFWS): The EFWS is a dedicated safety system intended for emergency use only. (The Main Feedwater System includes a startup pump and a full range control system for normal startup and shutdown operations).

The EFWS has two separate trains. Each consists of one emergency feedwater storage tank, one full capacity motor-driven pump, one full capacity non-condensing turbine-driven pump, and one cavitating venturi. The cavitating venturi minimizes excessive emergency feedwater flow to a steam generator with a ruptured feed or steam line. The EFWS therefore requires no provision for automatic isolation of emergency feedwater flow to a steam generator having a ruptured steam line or feed line.

f. Shutdown Cooling System (SCS): The SCS design pressure has been increased to $900 \mathrm{psig}$. This higher pressure provides greater operational 
flexibility and eliminates concern for system over-pressurization. The SCS is interconnected with the Containment Spray System, which uses identical pumps. The reliability of both systems is therefore increased, and each set of pumps can serve as a backup for the other.

\subsubsection{Plant Structures and Arrangements}

a. The containment for System $80+$ is a 200 -foot diameter steel sphere which maximizes space for equipment and maintenance while minimizing unusable volume in the upper part of the containment. The operating floor offers $75 \%$ more usable area than a cylindrical containment of equal volume.

b. Features for mitigating the consequences of postulated severe accidents include a reactor vessel cavity designed to improve the ability to resolidify molten core material on the cavity floor by cooling and retaining the molten core debris.

c. The spherical containment provides a lower annulus under the sphere which replaces a conventional safetygrade auxiliary building, and is an ideal location for safety systems. Placing of the safeguards equipment in the subsphere areas is an economically attractive approach to addressing numerous regulations associated with this equipment. Separation for internal flood mitigation, fire protection, security, and sabotage concerns are easily addressed without adverse affect on accessibility.

\subsubsection{Analytical Methods}

\subsubsection{Methods of Analysis}

The nuclear design analysis of low enrichment PWR cores is based on the twodimensional transport code DIT (Reference 3.1-1), which provides cross sections appropriately averaged over a few broad energy groups for the whole assembly or individual cells, and few group one-, two-, and three-dimensional diffusion theory calculations of integral and differential reactivity effects and power distributions. Differences between calculated and measured data for various nuclear parameters of interest in the nuclear design and safety analysis are presented in Section 3.1.7.2. The technology needs in analytical methods reflect the process that, as improvements in analytical procedures are developed, and improved data become available, they should be incorporated into the design procedures after validation by comparison with related experimental data. This section discusses the current status of these methods.

\subsection{Cross Section Generation}

Few group cross sections for coarse-mesh and fine-mesh diffusion theory codes are prepared by the DIT lattice code. These cross sections are used in ROCS (coarse- 
mesh, Section 3.1.7.1.2) and in MC (fine-mesh, Section 3.1.7.1.3). The ROCS/MCI/DIT code system is documented in an NRC-approved Topical Report (Reference 3.1-2).

The essential components of the DIT lattice code are:

1. Spectral calculations using discrete integral transport (DIT) theory in up to $\mathbf{1 9 0}$ energy groups with spectral coupling between cells over the entire assembly.

2. Few-group spatial calculations in exact assembly geometry followed by a leakage calculation to maintain a critical spectrum.

3. Isotopic depletion calculations for every cell in the assembly.

Thus the use of the two-dimensional DIT code ensures that the effects of lattice heterogeneities are explicitly treated. Few-group cross sections for coarse-mesh spatial calculations are obtained and include accurate weighting of the various types of fuel, absorber and water-hole cells.

Group condensation based on the specira calculated for all the different types of cells and subregions within them is performed to obtain few-group macroscopic cross sections that are passed on directly to the assembly calculations. Since the accuracy of the spectrum calculations is high, the group condensation can normally be performed with a standard four-group structure. In some cases, more groups can be (and are) used in the assembly calculation. For example, a seven-group condensation is typically used for gadolinia-bearing assemblies.

The assembly and spectrum calculations are performed by integral transport theory with multigroup interface currents used to couple adjacent cells.

This entire sequence of calculations is normally performed assuming that there is no net leakage from the assembly geometry. A correction for the influence of global leakage is made on the basis of a B1 calculation with the fine energy group structure for the homogenized assembly to maintain criticality of the assembly.

Reaction rates for use in the depletion stage of DIT are formed using the basic cross section library and the spectra calculated as described.

Spatial averages of microscopic and macroscopic cross sections are performed for editing purposes and are passed on to ROCS and MC.

The above calculations are performed in a single job step without manual intervention. Few-group coarse-mesh cross sections are prepared in the HARMONY format (Reference 3.1-3) for ROCS by the editing code CESAW, and fine-mesh cross sections are input to MC via the editing code MCXSEC. 
The DIT code utilizes a data library containing multigroup cross sections, fission spectra, fission product yields and other supplemental data. The source of data for the library is ENDF/B-VI. Two adjustments to the library data have been made to reflect recommendations by the Cross Section Evaluation Working Group. These adjustments include a very small reduction in the thermal capture of U-235 and epithermal capture of U-238.

The ENDF/B-VI files are processed with NJOY (Reference 3.1-4) and RABBLE (Reference 3.1-5).

Following the assembly spectrum calculation, a depletion time step takes place for each individual pin in the assembly and, when required, for sub-divisions of a pin. At the end of the depletion step, new isotopic compositions are defined for use in the spectrum calculation of the next time step. This process is extended over the expected life of the fuel assembly. Several improvements have been made to the DIT calculational methodology described in Reference 3.1-2. These improvements, described and approved in References 3.1-6 and 3.1-7, include the use of anisotropic scattering and higher-order interface currents.

\subsection{Coarse-Mesh Methods}

Static and depletion-dependent reactivities and nuclide concentrations, flux and power distributions in two- and three-dimensional representations of the core are determined by a diffusion-depletion program, ROCS-MC, which is described in Reference 3.1-2. The reactor operation and control simulator (ROCS) program was approved for use as a PWR core design and analysis code by the NRC in Reference 3.1-2. ROCS is designed to perform two- or three-dimensional coarse-mesh reactor core calculations based on a two-group nodal expansion method (NEM), with full-, half-, or quarter-core symmetric geometries. The mesh consists of rectangular parallelepiped "nodes" arranged contiguously in the $X-Y$ plane, with one or more axial meshes (or planes) in the $\mathbf{Z}$ direction. In most applications, only the active core region is represented, with albedo-like boundary conditions assigned to exterior nodes. A typical ROCS core geometry uses four nodes per assembly in the $X-Y$ plane and 20-30 axial planes depending upon core height and in-core instrument locations.

Improvements made to the ROCS methodology described in Reference 3.1-2 include the use of a predictor/corrector method for gadolinia-bearing fuel (described and approved for use in Reference 3.1-8) and the use of assembly discontinuity factors (described in Reference 3.1-6 and approved for use in Reference 3.1-7).

The nodal macroscopic group constants used in the neutronics calculation are constructed from detailed isotopic concentrations and microscopic cross sections processed by the code. The isotopes specified include fixed depletable isotopes and a lumped residual representing non-depletable isotopes. The depletable isotopes 
include fission chain isotopes, fission products and burnable absorbers. Control rods are represented by macroscopic cross sections specific to different rod banks.

The ROCS system performs coarse-mesh depletion calculations for each node in a twoor three-dimensional core configuration. The allowed depletion chains are internally modeled with fixed depletion equations so that beyond the input cross section data the user need supply only such data as initial concentrations, decay constants and fission yields for each depletion nuclide. These include the principal uranium and plutonium isotopes, a fuel exposure chain, xenon and samarium fission product chains, and boron, gadolinium, and erbium burnable absorber chains.

The fixed depletion equations used in the ROCS code are derived through the standard procedure of analytically integrating the coupled linear equations which represent each chain. The depletion equations are solved using the flux and microscopic cross section values based on the neutronics and thermal-hydraulic feedback calculations preceding the depletion time step. The initial flux and cross sections are assumed constant over the depletion time step.

Cross section information used in the ROCS system is derived from microscopic cross sections supplied by DIT for each nuclide in two energy groups. This information is utilized in two basic forms. First, two-group macroscopic cross sections are used in the basic flux and eigenvalue calculation. The microscopic contributions due to thermal-hydraulic feedbacks, xenon, soluble boron and control rods are added prior to the flux calculation. Second, two-group microscopic cross sections are used explicitly in the depletion and xenon short-term time-stepping calculations.

The two-group microscopic cross sections for each nuclide are supplied in tabular form. Represented for each nuclide and energy group are:

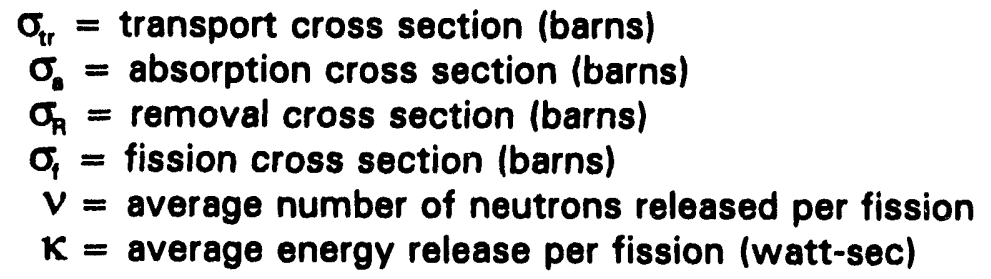

The tables represent the above values as nonlinear functions of important independent variables (e.g., exposure, initial enrichment, soluble boron concentration) evaluated for nominal thermal-hydraulic conditions. In addition, multipliers (called G-factors) may be included in the table for any of the cross sections. The G-factors may also be represented as functions of pertinent independent variables. Thus a typical crosssection table interpolation can be represented symbolically by:

$$
\sigma\left(B U, \varepsilon, P P M, \rho, T_{M}, T_{F}\right)=\sigma\left(N_{1}, N_{2}, N_{3}\right) G\left(N_{4}, N_{5}, N_{6}\right)
$$


where

BU, $\varepsilon, P P M, \rho, T_{M}, T_{F}=$ exposure, initial enrichment, soluble boron concentration, moderator density, moderator temperature and fuel temperature;

$N_{1}, \ldots, N_{6}=\quad$ independent variables for table interpolation.

The cross sections are assumed to vary with moderator temperature, moderator density, and the square root of the fuel temperature for small changes about the nominal. The dependence of the cross sections on the thermal-hydraulic parameters is usually approximated by the inclusion of the first derivative of the cross section, for example:

$$
\sigma\left(p, T_{M}, T_{F}\right)=\sigma\left(p_{0}, T_{M 0}, T_{F o}\right)+\frac{80}{8 p} \Delta p+\frac{80}{8 T_{M}}+\frac{80}{8\left(T_{F}\right)}\left(\Delta T_{F}\right)^{1 / 2}
$$

where

$$
\begin{array}{lll}
\Delta \rho=\rho-\rho_{0} & = & \text { change in density from nominal } \\
\Delta T_{M}=T_{M}-T_{M o} & = & \begin{array}{l}
\text { change in moderator temperature from } \\
\text { nominal }
\end{array} \\
\Delta\left(T_{F}\right)^{K}=\left(T_{F}\right)^{K}-\left(T_{F O}\right)^{K} & = & \begin{array}{l}
\text { change in square root of fuel temperature } \\
\text { from nominal }
\end{array}
\end{array}
$$

The ROCS neutronics calculation is linked to optional independent feedback calculations for thermal-hydraulic parameters (moderator density, moderator temperature, fuel temperature) and for equilibrium $\mathrm{I}^{135}$ and $\mathrm{Xe}^{135}$ distributions. (References 3.1-4,3.1-8) The thermal-hydraulic calculation is performed iteratively with the flux calculation when any combination of thermal-hydraulic feedbacks is specified. For each feedback variable specified, the macroscopic cross sections used in the flux calculation are updated through the appropriate feedback term. In the case of xenon, the macroscopic cross sections are updated each iteration cycle using calculated $I^{135}$ and $X e^{135}$ equilibrium concentrations based on the two-group flux distribution from the previous iteration. The number of feedback iterations is governed by independent convergence criteria for each feedback parameter, so that the final flux solution is obtained after all specified feedbacks have converged.

In addition to the above feedback models, the ROCS code contains optional eigenvalue search models for soluble boron concentration and axial power distribution. The search 
calculations employ numerical iteration techniques which update the specified control variable to obtain convergence on the search eigenvalue and/or axial power shape, and are generally used along with feedback calculations.

\subsection{Fine-Mesh Methods}

The MC code, which is described and approved in Reference 3.1-2, performs meshcentered pin peaking calculations for each node in two-dimensional core geometries. MC uses an embedded fine-mesh diffusion theory method for obtaining pin power distributions from coarse-mesh calculations.

A method has been developed for determining diffusion coefficients which, when combined with the finite difference formulation of $M C$, permits the inclusion of transport effects in a rigorous fashion. The diffusion coefficients have the property of conserving cell averaged fluxes, reaction rates, and partial currents across cell boundaries. Thus, MC has the capability to effectively reproduce DIT local power distributions.

Having determined diffusion coefficients that exactly reproduce average fluxes, reaction rates, and partial currents from transport theory for a particular geometry, it is then asserted that they are universally applicable independent of the size of the flux gradients seen in the core.

The nodal diffusion equations are solved as a boundary source problem for the embedded calculation. The partial in-currents on each nodal face and the global eigenvalue are supplied by the ROCS coarse-mesh calculation.

After completion of the fine-mesh embedded calculation, the fine-mesh power distribution is renormalized to the coarse-mesh power level to assure that coarse-mesh and fine-mesh node average powers and burnups will remain the same during depletion.

The MC embedded calculation uses a macroscopic cross section model based upon interpolation of multi-dimensional macroscopic tables. These tables are created by the MCXSEC code, which processes DIT results for all assembly types, and are typically burnup, enrichment, moderator and fuel temperature dependent for each fine-mesh pin cell type. Lagrange linear interpolations are performed to obtain the macroscopic cross sections. The interpolated absorption cross section is then corrected for soluble boron and xenon changes by using boron and xenon microscopic cross sections along with number densities obtained from the core soluble boron and local xenon equilibrium concentrations. In addition, axial leakage is represented by adding a $\mathrm{DB}^{2}$ term to the absorption cross section.

As the size of large power reactors increases, space-time effects during reactor transients become more important. In order not to penalize reactor performance unduly 
with overly conservative design methods, it is desirable to have the capability to perform detailed space-time neutronics calculations for both design and off-design transients.

The HERMITE (Reference 3.1-9) computer code has been developed to meet this objective. It solves the few-group, space and time-dependent neutron diffusion equation including feedback effects of fuel temperature, coolant temperature, coolant density and control rod motion. The neutronics equations in one, two, and three dimensions are solved by the fourth-order nodal expansion method. The fuel temperature model explicitly represents the pellet, gap and clad regions of the fuel pin, and the governing heat conduction equations are solved by a finite difference method. Continuity and energy conservation equations are solved in order to determine the coolant temperature and density. In the one-dimensional mode, HERMITE also has the option of finding the axially dependent poison distribution required to produce a particular user-specified axial power shape. This option is often used to produce conservative axial power shapes corresponding to the Limiting Conditions of Operation (LCO) limits on axial power shape from which simulations of core transients are subsequently initiated.

\subsubsection{Comparisons with Experiments}

The nuclear analytical design methods have been checked against a variety of critical experiments and operating power reactors. In the first type of analysis, reactivity and power distributions obtained from small zero power critical experiments lead to information concerning the validity of the basic fuel cell calculation. The second type of analysis consists of a core follow program for operating commercial PWR's in which power distributions, reactivity coefficients, reactivity depletion rate, and CEA worths are analyzed to provide a global verification of the nuclear design package.

The comparison between calculations and measurements serves not only to verify the calculational methodology, but also to provide a set of calculational biases and uncertainties that are applied to the calculational results to yield best estimate and 95/95 confidence limit predictions for use in the safety analysis. Verification of the basic methodology was demonstrated and approved in Reference 3.1-2. Biases and uncertainties were also documented and approved in Reference 3.1-2. Implementation of the improvements described in References 3.1-7 and 3.1-8 necessitated an update of the biases and uncertainties in order to assure that 95/95 confidence limits are maintained in all results used for licensing-related analyses. These updated biases and uncertainties appear in summary form in Reference 3.1-10. Reference 3.1-7, which was approved by the NRC in Reference 3.1-6, reported that the revised bias and uncertainty values were equivalent to those contained in Reference 3.1-2, and therefore did not require explicit NRC review. 


\subsection{Critical Experiments}

Selected critical experiments have been analyzed with the DIT code. Selection of criticals is based on the following criteria:

1. Applicability to C-E PWR fuel and assembly designs,

2. Self-consistency of measured parameters, and

3. Availability of adequate data to model the experiments.

Two groups of critical experiments have been employed in this evaluation. The first is a series of uniform lattices in cylindrical geometries with $\mathrm{UO}_{2}$ or $\mathrm{PuO}_{2}$ fuel, and the second is a set of experiments in which the lattice contains water holes to simulate the geometry of a PWR fuel assembly. The first set is analyzed to verify the reactivity of a uniform array of fuel rods, and the second set is analyzed to benchmark the power peaking factors in the vicinity of large water holes.

\section{Resulte of Analyses}

The uniform critical experiments were analyzed with the ENDF/B-VI cross section library. The results of the uranium lattices, described in References 3.1-11, 3.1-12, 3.1-13 and 3.1-14, are summarized in Table 3.1.7-1. This Table also provides the principal lattice characteristics and fuel enrichment. The average $k_{\text {eff }}$ is 1.00147 . The Plutonium lattices (References 3.1-15 and 3.1-16) are summarized in Table 3.1.7-2. The average $k_{\text {eff }}$ is 1.00185 . Thus the DIT code, in conjunction with ENDF/B-VI cross sections, exhibits very good predictive capabilities for pin cell reactivity level, for both uranium oxide and mixed plutonium-uranium oxide fuel. The plutonium lattices show a larger scatter in the reactivity level than the uranium lattices. This is due to the very large leakage of the former lattices, and to the uncertainties associated with the measured group-independent critical buckling.

The non-uniform critical experiments provided information on the pin-by-pin power distribution in fuel assemblies containing large water holes. The 95/95 confidence/tolerance range for pin power, irrespective of its location in the assembly, is $2.8 \%$.

\subsection{Power Reactors}

The accuracy of the calculational system in its entirety is assessed through the analysis of experimental data collected on operating power reactors. The data under investigation consist of critical conditions, reactivity coefficients, and rod worths measured during the startup period, and of critical conditions, power distributions, and reactivity coefficients measured throughout the various operating cycles. 


\section{Reactivity Level}

The ability of the calculational models to predict reactivity levels is assessed by compiling the calculated reactivities for a number of well defined measured critical conditions. This analysis has established a 95/95 confidence/tolerance interval of $\pm 0.25 \% \Delta$, irrespective of plant operating conditions or exposure.

\section{Isothermal Temperature Coefficient}

The Isothermal Temperature Coefficient (ITC) is the change in core reactivity resulting from a $1^{\circ} \mathrm{F}$ change in moderator and fuel temperatures.

The accuracy of the calculated ITC has been determined by comparing the isothermal temperature coefficients measured for a number of reactors and cycles, both at power and at zero power, and for a wide range of soluble boron concentrations, with threedimensional ROCS calculations performed at the same conditions as the measurements.

This analysis indicated that the best estimate ITC is known to within a 95/95 confidence/tolerance range of $0.16 * 10^{-4} \Delta p /{ }^{\circ} \mathrm{F}$. This uncertainty is applicable to all operating conditions, power levels and soluble boron concentrations.

\section{Control Rod Bank Worths}

The uncertainties in calculated CEA worths (Reference 3.1-10) were found to be $\pm 6.52 \%$ for total and net worths, and $\pm 15.5 \%$ for group or bank worths. The difference in uncertainties between total and group or bank worths is due to the fact that most of the bank worths were very small and hence the effects of measurement uncertainty resulted in greater relative errors.

\section{Dropped. Elected and Net Rod Worths}

Calculated reactivity worths of asymmetric rod configurations show biases and uncertainties similar to those observed for the CEA bank worths.

\section{Power Coefficient}

The power coefficient is the change in core reactivity resulting from a $1 \%$ change in core power, maintaining the core average moderator temperature constant. This coefficient can be determined with a $95 / 95$ confidence/tolerance range of $14 \%$.

\section{Assembly Power Distributions}

The uncertainty to be attribuidd to calculated fuel assembly power distributions is obtained by comparing detailed three-dimensional calculations of the assembly powers 
with those inferred from in-core messurements with the CECOR (Reference 3.1-17) system using fixed in-core rhodium detectors. The resulting differences are a reflection of both measurement and calculative errors. In order to determine the uncertainty to be attributed to the calculation, the measurement uncertainty is subtracted out from these difference distributions. The measurement uncertainty is from an evaluation of the uncertainty associated with the CECOR system (Reference 3.1-18).

Table 3.1.7-3 summarizes the calculational uncertainties.

\subsubsection{Code Benchmarking}

Battelle Pacific Northwest Laboratories (BPNL) provided the code benchmarks for DIT by using codes WIMS-E and MCNP at BPNL. The WIMS-E code uses the 69 group WIMS UK Nuclear Data Library which has been modified by BPNL to incorporate some of the appropriate erbium isotopes. The MCNP continuous energy Monte Carlo cross section library currently employed by BPNL consists primarily of ENDF/B-V data with a limited number of nuclides being represented by ENDF/B-VI data. ABB-CE has processed ENDF/B-VI data and has generated a 190 group cross section library (as well as a $\mathbf{8 9}$ group condensed library for design applications) for use with its DIT assembly lattice code. The unmodified library is based on ENDF/B-VI data. The modified library is also based on ENDF/B-VI data except reduction (of $3.4 \%$ ) of U-238 epithermal capture and reduction (of 1.36 barns) of U-235 thermal capture is applied.

ABB-CE provided the detailed benchmark specifications (Table 3.1.7-4), including geometry, MOX fuel composition $\left(\mathrm{UO}_{2}-\mathrm{Er}_{2} \mathrm{O}_{3}-\mathrm{PUO}_{2}\right)$ and loadings $\left(6.88 \mathrm{w} / \mathrm{O} \mathrm{PUO}_{2}, 2 \mathrm{w} / \mathrm{o}\right.$ $\mathrm{Er}_{2} \mathrm{O}_{3}$, and $\mathrm{UO}_{2}$ tails) to BPNL. Plutonium isotopics are $93.5 \mathrm{w} / 0$ and $6.5 \mathrm{w} / 0$ for 239 and 240 respectively. Benchmark runs were made in stages.

1. CE pin cell was run at room temperature using WIMS-E and MCNP at beginning of life (BOL). Results are compared with DIT and are presented in Table 3.1.7-5. Also a comparison of absorption and fission reaction rates (not shown in Table) was made for tha important nuclides 10-16, Er isotopes, U-235, U-238, Pu-239, $\mathrm{Pu}-240, \mathrm{~B}-10, \mathrm{Zr}, \mathrm{Fe}$, etc.) and the results are in general agreement.

2. Next, the CE pin cell was run at operating temperatures using WIMS-E, and MCNP, the three regions of the pin cell, fuel, clad and coolant being at $1200^{\circ} \mathrm{F}$, $633^{\circ} \mathrm{F}$, and $588^{\circ} \mathrm{F}$ respectively. Reactivity results are compared with DIT and are presented in Table 3.1.7-6 at BOL, $50 \mathrm{MWD} / \mathrm{T}$, and additional four depletion points at 10,600 MWD/T (274 Effective Full Power Days of operation which is one year with a $75 \%$ capacity factor), 21,200 MWD/T (two years of operation), $31,800 \mathrm{MWD} / \mathrm{T}$ (three years of operation), and 42,400 MWD/T (four years of operation). In addition, a detailed comparison was âlso made for reaction rates (absorption and fission) for the major nuclides at BOL (Table 3.1.7-7) as in the previous stage. 
As the depletion proceeds, the buildup of the fission products, creation of Tm169 (from the Er depletion chain in the fuel), creation of additional actinides was thoroughly studied. Tables 3.1.7-8 and 3.1.7-9 present the results for reaction rates at middle of life (MOL) and at end of life (EOL) respectively. The DIT and WIMS-E results agree reasonably well in most cases. However, in the WIMS-E data library all Er isotopes are not fully represented and there is no creation of Tm-169.

Table 3.1.7-10 presents the results for number densities for major nuclides (fission products, fuel constituents and the nuclides in the fuel decay chain as Tm-169 and additional actinides, etc) at end of life (EOL). From these number densities relative Pu discharge concentrations were calculated, and are presented in Table 3.1.7-11. Results, presented in Tables 3.1.7-10 and 3.1.7-11 for DIT and WIMS, agree reasonably well.

Knowing that the cross section data base for DIT, WIMS-E, and MCNP may be different, code benchmarking results are reasonable and acceptable. 


\section{REFERENCES}

3.1-1. A. Jonsson, J. R. Rec, U. N. Singh, "Verification of a Fuel Assembly Spectrum Code Based on Integral Transport Theory" Irans. Am. Nucl. Soc. 28, 778 (1978)

3.1-2. "The ROCS and DIT Computer Codes for Nuclear Design," CENPD-266-PA, C-E Proprietary Topical Report, April 1983.

3.1-3. Breen, R. J., et al., "HARMONY-System for Nuclear Reactor Depletion Computation," WAPD-TM-478, January 1965.

3.1-4. "NJOY89, A Code System for Producing Pointwise and Multigroup Neutron and Photon Cross Sections from ENDF/B Evaluated Nuclear Data". ORNL PSR-171. 1989.

3.1-5. U. Decher, "Users manual for RABBLE, DIT cross section library preparation", ABB CE Proprietary Report, NDP-032, Feb. 1994.

3.1-6. USNRC, "Safety Evaluation by the Office of Nuclear Reactor Regulation Related to Amendment No. 61 to Facility Operating License No. NPF-41. Arizona Public Service, et al., Palo Verde Nuclear Generating Station, Unit No. 1, Docket No. STN 50-528".

3.1-7. "Palo Verde Nuclear Generating Station (PVNGS) Unit 1 - Proposed Reload Technical Specification Changes - Unit 1 Cycle 4," File: 91-056-026: 91 005-419-5.

3.1-8. "CE Methodology for Core Design Containing Gadolinia-Urania Burnable Absorbers," CENPD-275-P Rev, 1-P-A, May 1988.

3.1-9. P. E. Rohan, S. G. Wagner, S. E. Ritterbusch: "HERMITE, A Multi-Dimensional Space-Time Kinetics Code for PWR Transients," Combustion Engineering Topical Report CENPD-188-A, July 1976.

3.1-10. CE-CES-129 Revision 2-P, "Methodology Manual - Physics Biases and Uncertainties," January 1993.

3.1-11. T. C. Engelder: "Spectral Shift Control Reactor, Basic Physics Program", BAW-1273, November 1963.

3.1-12. R. H. Clark: "Physics Verification Program - Final Report" BAW-3647-3, March 1967. 
3.1-13. P. W. Davison: "Yankee Critical Experiments". YAEC-94, April 1959.

3.1-14. F. J. Fayers: "An Evaluation of Some Uncertainties in the Comparison between Theory and Experiments for Regular Light Water Lattices". Brit. Nucl. Eng. Soc., April 1967.

3.1-15. E. G. Taylor: "Saxton Plutonium Program". WCAP-3385-54, December 1965.

3.1-16. R. D. Leamer: "PuO2-UO2 Fueled Critical Experiments". WCAP-3726-1, July 1967.

3.1-17. "A Method of Analyzing In-Core Detector Data in Power Reactor," CENPD-145, C-E Topical Report, April 1975.

3.1-18. A. Jonsson, W. B. Terney, M. W. Crump. "Evaluation of Uncertainty in the Nuclear Power Peaking Measured by the Self-Powered, Fixed In-Core Detectior System," CENPD-153, Rev. 1. May 1980. 
IABLE 3.1.7-1

CRITICAL EXPERINAENTS: UNIFORM UO ${ }_{2} \perp A T T I C E S$

\begin{tabular}{lcrrr}
\multicolumn{1}{c}{ Lattice } & Enrich & W/UO & PPM & ENDF/B6 \\
& W/O & Ratio & Boron & K-eff \\
BAW-1273-I & 4.02 & 1.137 & 0 & 1.00102 \\
BAW-1273-II & 4.02 & 1.137 & 3390 & 1.00000 \\
BAW-1273-X & 4.02 & 0.956 & 0 & 0.99765 \\
BAW-1273-XIII & 2.46 & 1.371 & 0 & 1.00378 \\
BAW-1273-XX & 2.46 & 1.371 & 1675 & 1.00363 \\
& & & & \\
BAW-3647-I & 2.46 & 1.846 & 0 & 1.00327 \\
BAW-3647-II & 2.46 & 1.846 & 864 & 1.00352 \\
BAW-3647-III & 2.46 & 1.846 & 1536 & 1.00461 \\
& & & & \\
YANKEE-1 & 2.70 & 1.048 & 0 & 0.99957 \\
YANKEE-2 & 2.70 & 1.405 & 0 & 1.00025 \\
YANKEE-3 & 2.70 & 1.853 & 0 & 1.00096 \\
YANKEE-4 & 2.70 & 2.166 & 0 & 1.00223 \\
YANKEE-8 & 2.70 & 1.199 & 0 & 1.00025 \\
WINFRITH-R1 & 3.003 & 1.001 & 0 & 1.00132 \\
WINFRITH-R1 & 3.003 & 1.001 & 0 & 0.99905 \\
WINFRITH-R2 & 3.003 & 3.164 & 0 & 1.00110 \\
WINFRITH-R3 & 3.003 & 0.779 & 0 & 1.00282
\end{tabular}

Avg $=1.00147$ 
IABLE 3.1.7-2

CRITICAL EXPERIMENTS: UNIFORM UO ${ }_{2}-$ PUO $_{2}$ LATTICES

\begin{tabular}{lrrrr}
\multicolumn{1}{c}{ Lattice } & $\begin{array}{r}\text { Enrich } \\
\text { w/o PuO }\end{array}$ & W/Fuel & PPM & ENDF/B6 \\
Saxton 01 & 6.6 & 1.681 & 0 & K-eff \\
Saxton 02 & 6.6 & 2.165 & 0 & 1.00384 \\
Saxton 03 & 6.6 & 2.165 & 0 & 1.01135 \\
Saxton 04 & 6.6 & 2.165 & 337 & 1.01379 \\
Saxton 05 & 6.6 & 4.699 & 0 & 1.00450 \\
Saxton 06 & 6.6 & 5.673 & 0 & 1.00658 \\
Saxton 07 & 6.6 & 10.754 & 0 & 1.00231 \\
& & & & \\
WREC 8\% Pu240 & 2.0 & 1.099 & 0 & 0.99283 \\
WREC 8\% Pu240 & 2.0 & 1.525 & 0 & 0.98977 \\
WREC 8\% Pu240 & 2.0 & 3.448 & 0 & 1.00421 \\
WREC 8\% Pu240 & 2.0 & 4.301 & 0 & 1.00727 \\
WREC 8\% Pu240 & 2.0 & 8.146 & 0 & 0.98972 \\
WREC 8\% Pu240 & 2.0 & 1.099 & 261 & 0.99828 \\
WREC 8\% Pu240 & 2.0 & 1.099 & 526 & 0.99628 \\
WREC 8\% Pu240 & 2.0 & 3.448 & 261 & 0.99982 \\
WREC 8\% Pu240 & 2.0 & 3.448 & 526 & 0.99745 \\
WREC 24\% Pu240 & 2.0 & 3.448 & 0 & 1.00940 \\
WREC 24\% Pu240 & 2.0 & 4.301 & 0 & 1.00791
\end{tabular}

Avg $=\quad 1.00185$ 
IABLE 3.1.7-3

\section{SUMMARY OF ROCS/DIT CALCULATIVE UNCERTAINTIES}

ROCS Calculational Uncertainty:

Absolute Standard Deviation. $S_{C}$

Degrees of Freedom.

$f_{c}$

Confidence Multiplier. $\quad k_{95 / 95}$

Percent Deviation, $s_{C}(\%)$

95/95 Confidence Interval _ $k S_{C}$
$E_{\mathbf{x y}}$

.0225

10

2.63

1.82

153

16

1.88

2.89

1.47

4.94

$\underline{5.25}$

3.44

$\mathbf{E}_{\mathbf{I}}$

2.34

147
0176 
TABLE 3.1.7.-4

ABB-CE PINCELL BENCHMARK

GEOMETRY

$\begin{array}{ll}\text { Pitch } & 1.2882 \mathrm{~cm} \\ \text { Fuel Radius } & 0.41275 \mathrm{~cm} \\ \text { Clad Radius } & 0.48605 \mathrm{~cm}\end{array}$

COMPOSITION

$\begin{array}{cll} & & \text { Number De } \\ \text { Fuel } & 0-16 & 4.5657 E-2 \\ & \text { Er-166 } & 2.1453 E-4 \\ & \text { Er-167 } & 1.4709 E-4 \\ & \text { Er-168 } & 1.7407 E-4 \\ & \text { Er-170 } & 9.5702 E-5 \\ & \text { U-235 } & 4.2052 E-5 \\ & \text { U-238 } & 2.0719 E-2 \\ & \text { Pu-239 } & 1.4273 E-3 \\ \text { Clad } & \text { Pu-240 } & 9.8807 E-5 \\ & \text { Zr } & 3.7036 E-2 \\ \text { Coolant } & \text { Fo } & 5.0067 E-4 \\ & \text { H-1 } & 4.7297 E-2 \\ & \text { B-10 } & 1.1714 E-5 \\ \text { B-11 } & 4.7449 E-5 \\ & \text { O-16 } & 2.3659 E-2\end{array}$

ROWER

$5.3248 \mathrm{~kW} / \mathrm{ft}$

IEMPERATURE

Fuel Clad Coolant

$1200 / 633 / 588^{\circ} \mathrm{F}$

BOL.

1500 pm (boron)

DEPLETION

1000 ppm constant (boron)

COMPARISON POINIS

$50,10600,21200,31800,42400 \mathrm{MWD} / \mathrm{T}$

EDITS

4 Groups

Group 1, $20 \mathrm{MeV}$ to $821 \mathrm{keV}$

Group 2, $821 \mathrm{keV}$ to $5.53 \mathrm{koV}$

Group 3, $5.63 \mathrm{koV}$ to $0.625 \mathrm{oV}$

Group 4, 0.625 oV to 0.0001 oV

for ko, absorption rate, fission rate (where applicable), etc.;

for Er isotopes, $U$ isotopes, Pu isotopes, etc. 


\section{IABLE 3.1.7-5}

\section{CE PIN CEIL}

$300^{\circ} \mathrm{K}$, Beginning of Life (BOL), 1500 PPM Boron

$\mathrm{UO}_{2}-\mathrm{Er}_{2} \mathrm{O}_{3}-\mathrm{PUO}_{2}$ Fuel (Weapons Grade Pu)

Method/Data

DIT (with ENDF/B-VI 89 group unmodified Library)

DIT (with ENDF/B-VI 89 group modified Library)

WIMS-E (with 69 group UK Nuclear Data Library)

MCNP4xe (with ENDF/B-V continuous energy cross section Library) $\mathrm{k} \infty \mathrm{OBOL})$

1.13412

1.13780

1.13637

1.13331 


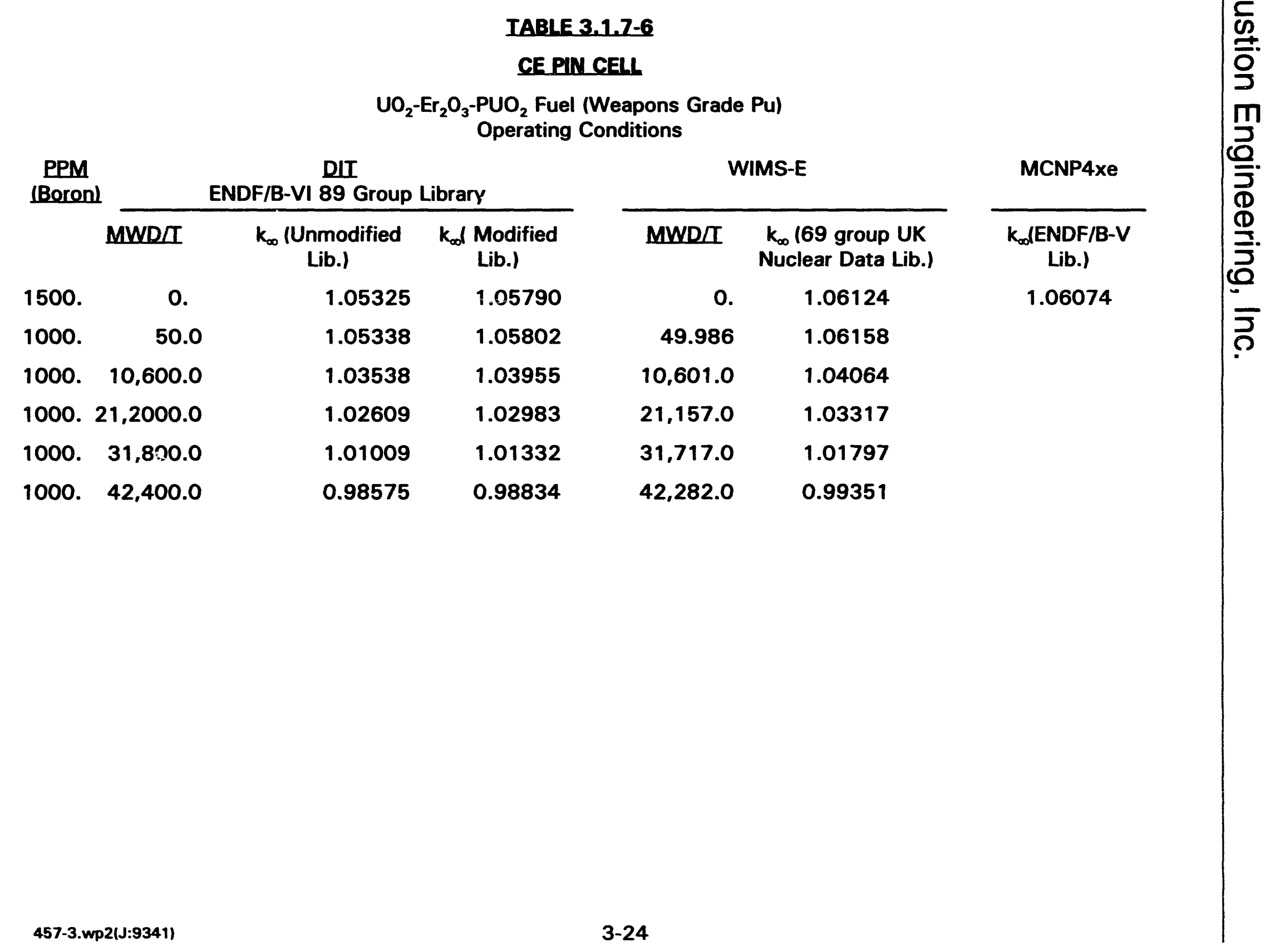




\section{IABLE 3.1.7-7 \\ CE PIN CELL}

$$
\begin{gathered}
\mathrm{UO}_{2}-\mathrm{Er}_{2} \mathrm{O}_{3}-\mathrm{PUO}_{2} \text { Fuel (Weapons Grade Pu) } \\
\text { Operating Conditions }
\end{gathered}
$$

Beginning of Life (BOL) Cell Averaged Reaction Rates

DIT

ENDF/B-VI 89 Group Library

Unmodified Lib. Modified Library
WIMS-E

69 Group UK Nuclear Data Library
MCNP4xe

ENDF/B-V Library

Fractional Absorption

$\begin{array}{lllll}\text { H-1 } & 8.6116 E-3 & 8.6570 \mathrm{E}-3 & 8.8522 \mathrm{E}-3 & 5.2893 \mathrm{E}-3 \\ \text { B-10 } & 2.4676 \mathrm{E}-2 & 2.4806 \mathrm{E}-2 & 2.5524 \mathrm{E}-2 & 1.5147 \mathrm{E}-2 \\ \text { O-16 } & 4.8995 \mathrm{E}-3 & 4.8999 \mathrm{E}-3 & 3.8800 \mathrm{E}-3 & 2.9256 \mathrm{E}-3 \\ \mathrm{Fe} & 1.6883 \mathrm{E}-4 & 1.6926 \mathrm{E}-4 & 1.7833 \mathrm{E}-4 & 4.6781 \mathrm{E}-4 \\ \mathrm{Zr} & 7.6233 \mathrm{E}-3 & 7.6417 \mathrm{E}-3 & 7.4021 \mathrm{E}-3 & 1.8220 \mathrm{E}-2 \\ \text { Er-166 } & 7.1593 \mathrm{E}-3 & 7.1902 \mathrm{E}-3 & 6.7248 \mathrm{E}-3 & 1.5913 \mathrm{E}-2 \\ \text { Er-167 } & 1.1556 \mathrm{E}-1 & 1.1617 \mathrm{E}-1 & 1.1459 \mathrm{E}-1 & 1.1593 \mathrm{E}-1 \\ \text { Er-168 } & 2.4970 \mathrm{E}-3 & 2.5064 \mathrm{E}-3 & 1.3256 \mathrm{E}-3 & \\ \text { Er-170 } & 1.5660 \mathrm{E}-3 & 1.5726 \mathrm{E}-3 & 1.4360 \mathrm{E}-3 & \\ \mathrm{U}-235 & 8.3900 \mathrm{E}-3 & 8.4242 \mathrm{E}-3 & 8.5161 \mathrm{E}-3 & \\ \text { U-238 } & 2.3963 \mathrm{E}-1 & 2.3587 \mathrm{E}-1 & 2.3814 \mathrm{E}-1 & \mathbf{8 . 6 5 6 6 \mathrm { E } - 3} \\ \text { Pu-239 } & 5.0785 \mathrm{E}-1 & 5.1034 \mathrm{E}-1 & 5.1915 \mathrm{E}-1 & 5.174 .4 \mathrm{E}-1 \\ \text { Pu-240 } & 7.1374 \mathrm{E}-2 & 7.1753 \mathrm{E}-2 & 6.4283 \mathrm{E}-2 & 6.4207 \mathrm{E}-2\end{array}$

Fractional Fission

$\begin{array}{lllll}\text { U-235 } & 6.2068 E-3 & 6.2357 E-3 & 6.2204 E-3 & 6.3481 E-3 \\ \text { U-238 } & 3.1456 E-2 & 3.1458 E-2 & 3.1082 E-2 & 3.0802 E-2 \\ \text { Pu-239 } & 3.2858 E-1 & 3.3017 E-1 & 3.3191 E-1 & 3.3217 E-1 \\ \text { Pu-240 } & 8.3094 E-4 & 8.3116 E-4 & 7.4023 E-4 & 8.0004 E-4\end{array}$




\begin{tabular}{|c|c|c|c|}
\hline & $\begin{array}{r}\mathrm{UO}_{2}-\mathrm{Er}_{2} \mathrm{O}_{3}-\mathrm{PUO}_{2} \text { Fuel } \\
\text { Operating } \mathrm{C} \\
\text { Middle of Life (MOL) Cell A }\end{array}$ & $\begin{array}{l}\text { apons Grade Pu) } \\
\text { itions } \\
\text { aged Reaction Rates }\end{array}$ & \\
\hline & $\begin{array}{r}\text { DIT } 1212 \\
\text { ENDF/B-VI } 8\end{array}$ & $\begin{array}{l}\text { MWD/T) } \\
\text { roup Library }\end{array}$ & WIMS-E (21157 MWD/T) \\
\hline & Unmodified Library & Modified Library & $\begin{array}{l}69 \text { Group UK } \\
\text { Nuclear Data Library }\end{array}$ \\
\hline Fractiona & & & \\
\hline$H-1$ & $9.1631 E-3$ & $9.2329 \mathrm{E}-3$ & 9.5789E-3 \\
\hline B-10 & $1.7503 E-2$ & $1.7636 \mathrm{E}-2$ & 1.8408E-2 \\
\hline $0-16$ & 4.9090E-3 & $4.9092 E-3$ & 3.9069E-3 \\
\hline $\mathrm{Zr}$ & 7.7149E-3 & 7.7371E-3 & 7.5303E-3 \\
\hline$X_{\theta-135}$ & 8.3393E-3 & 8.4107E-3 & $8.6272 E-3$ \\
\hline Cs-133 & 2.9927E-3 & $3.0099 E-3$ & \\
\hline $\mathrm{Nd}-143$ & $1.5055 E-3$ & 1.5171E-3 & \\
\hline $\mathrm{Nd}-145$ & $1.0815 E-3$ & $1.0877 \mathrm{E}-3$ & \\
\hline$P m-147$ & $2.9619 E-3$ & 2.9779E-3 & \\
\hline Sm-149 & $5.4097 E-3$ & $5.4364 E-3$ & $6.4192 E-3$ \\
\hline Sm-151 & $2.8646 E-3$ & 2.8827E-3 & $2.4186 E-3$ \\
\hline Sm-152 & 2.3249E-3 & 2.3388E-3 & $2.1211 E-3$ \\
\hline Eu-153 & $1.2584 \mathrm{E}-3$ & 1.2667E-3 & $1.1582 \mathrm{E}-3$ \\
\hline Er-166 & $6.9225 E-3$ & $6.9591 E-3$ & $6.7220 E-3$ \\
\hline Er-167 & $5.1418 E-2$ & $5.1691 E-2$ & $5.1558 E-2$ \\
\hline Er-168 & 3.9663E-3 & $3.9859 E-3$ & $2.0292 E-3$ \\
\hline Er-170 & $1.5602 E-3$ & $1.5681 E-3$ & $1.4587 E-3$ \\
\hline Tm-169 & $1.6545 E-3$ & $1.6653 E-3$ & \\
\hline U-235 & $6.8230 E-3$ & $6.8650 E-3$ & $6.9985 E-3$ \\
\hline U-238 & $2.3994 E-1$ & 2.3639E-1 & 2.3864E-1 \\
\hline Pu-239 & $4.4763 E-1$ & 4.4919E-1 & $4.5855 \mathrm{E}-1$ \\
\hline$P u-240$ & $1.0076 E-1$ & $1.0138 E-1$ & $9.7722 \mathrm{E}-2$ \\
\hline
\end{tabular}


TABLE 3.1.7-8 (Cont'd)

CE PIN CELLL

DIT (21200 MWD/T)

ENDF/B-VI 89 Group Library

Unmodified Library

Modified Library

4.0833E-1

1.9697E-3

$1.3471 \mathrm{E}-3$

Fractional Fission

U-235

U-236

$\mathrm{U}-238$

Np-239

Pu-239

Pu-240

Pu-241

Pu-242

Am-242M
$1.3363 E-3$

4.0460E-2

$1.9492 \mathrm{E}-3$

5.0864E-3

1.0050E-5

3.0912E-2

1.4683E-5

2.8826E-1

1.6810E-3

3.0913E-2

3.4664E-5

5.2107E-5
5.1122E-3

1.0054E-5

3.0921E-2

1.4377E-5

2.8924E-1

1.680OE-3

3.1194E-2

3.4804E-5

5.2688E-5
WIMS-E (21157 MWD/T)

69 Group UK

Nuclear Data Library

3.9620E-2

1.9207E-3

1.1689E-3

5.1585E-3

7.4040E-6

3.0824E-2

2.9172E-1

1.6402E-3

3.0022E-2

3.5188E-5 


\section{Combustion Engineering, Inc.}

\section{TABLE $3.1 .7-9$ \\ CE PIN CEIL}

$\mathrm{UO}_{2}-\mathrm{Er}_{2} \mathrm{O}_{3}-\mathrm{PUO}_{2}$ Fuel (Weapons Grade Pu)

Operating Conditions

End of Life (EOL) Cell Averaged Reaction Rates

DIT (42400 MWD/T)

ENDF/B-VI 89 Group Library

Unmodified

Library

Fractional Absorption

$\mathrm{H}-1$

B-10

$0-16$

$\mathrm{Zr}$

$x_{e-131}$

$X_{\theta}-135$

Cs-133

Cs-135

Nd-143

Nd-145

Pm-147

Sm-149

Sm-150

Sm-151

Sm-152

Eu-153

Eu-154

Eu-155

Er-166

Er-167
9.8032E-3

1.8725E-2

4.9199E-3

$7.7925 \mathrm{E}-3$

$6.5379 \mathrm{E}-3$

9.1827E-3

5.6050E-3

1.0989E-3

3.1788E-3

2.0560E-3

4.0086E-3

5.8393E-3

1.3073E-3

3.8707E-3

4.1732E-3

2.9808E-3

$1.6075 \mathrm{E}-3$

2.0420E-3

6.7276E-3

$1.9118 \mathrm{E}-2$
Modified

Library

$9.9121 \mathrm{E}-3 \quad 1.0402 \mathrm{E}-2$

$1.8933 \mathrm{E}-2 \quad 1.9985 \mathrm{E}-2$

$4.9201 \mathrm{E}-3 \quad 3.9338 \mathrm{E}-3$

$7.8189 \mathrm{E}-3 \quad 7.6556 \mathrm{E}-3$

6.5793E-3

$9.2954 \mathrm{E}-3$

9.6805E-3

5.6408E-3

$5.7743 \mathrm{E}-3$

$1.1036 \mathrm{E}-3$

3.2149E-3

2.7104E-3

2.0696E-3

$1.9623 \mathrm{E}-3$

4.0307E-3

2.5922E-3

$5.8703 \mathrm{E}-3$

$6.9241 E-3$

$1.3182 \mathrm{E}-3$

$1.3272 \mathrm{E}-3$

3.8977E-3

3.7847E-3

4.2024E-3

4.0790E-3

3.0049E-3

2.8680E-3

1.6287E-3

9.2578E-4

2.0640E-3

1.3526E-3

6.7702E-3

$6.6888 \mathrm{E}-3$

$1.9166 \mathrm{E}-2$

$1.8501 \mathrm{E}-2$ 
TABLE 3.1.7-9 (Cont'd) CEPIN CELL

DIT (42400 MWD/T)

ENDF/B-VI 89 Group Library

Unmodified

Library

Er-168

4.5648E-3

$1.5502 \mathrm{E}-3$

2.9608E-3

5.4506E-3

2.3946E-1

3.8695E-1

1.1396E-1

7.431OE-2

5.9919E-3

4.1317E-3

2.1816E-3

Am-243

Fractional Fission

U-235

U-238

Pu-239

Pu-240

Pu-241

Pu-242

Am-241

Am-242M

Am-243
4.1001E-3

3.0372E-2

2.4843E-1

2.1156E-3

5.6655E-2

1.1957E-4

8.4412E-5

2.4335E-4

2.9592E-5
Modified Library

4.5895E-3

1.5591E-3

2.9827E-3

5.4945E-3

2.3615E-1

3.8725E-1

1.1470E-1

7.5219E-2

6.0670E-3

4.1691E-3

2.2145E-3

2.3429E-3

1.475OE-3

69 Group UK
Nuclear Data Library

69 Group UK
Nuclear Data Library

WIMS-E(42282 MWD/T)

1.4750E-3

5.6141E-3

2.3875E-1

3.9496E-1

1.1456E-1

7.5873E-2

6.5974E-3

3.6865E-3

2.4784E-3

4.1385E-3 4.1845E-3

3.0389E-2 3.0546E-2

2.4859E-1 2.5033E-1

2.1093E-3 2.1330E-3

$5.7336 \mathrm{E}-2 \quad 5.7342 \mathrm{E}-2$

1.2036E-4 1.2477E-4

8.452OE-5 7.1327E-5

2.4654E-4

$2.9841 E-5 \quad 2.9783 E-5$ 


\section{IABLE 3.1.7-10}

CE PIN CELL

$\mathrm{UO}_{2}-\mathrm{Er}_{2} \mathrm{O}_{3}-\mathrm{PuO}_{2}$ Fuel (Weapons Grade Pu), Operating Conditions End of Life (EOL) Number Densities (Cell Averaged)

Nualide

DIT $142400 \mathrm{MWD} / \mathrm{TI}$ ENDF/B-VI 89 Group Library

Unmodified

$X e-131$

$X \theta-132$

$X_{\theta-136}$

Cs-133

Cs-135

Cs-137

La-139

$\mathrm{Ce}-142$

Pr-141

Nd-143

Nd-145

Pm-147

Sm-150

Sm-152

Eu-153

Gd-156

Er-166

Er-167

Er-168

Er-170

Tm-169

U-235
7.9114E-6

1.9349E-5

2.8494E-5

1.8497E-5

1.5341E-5

1.9256E-5

1.7234E-5

1.4884E-5

1.5076E-5

1.1986E-5

8.5295E-6

2.5468E-6

3.8662E-6

2.0678E-6

1.9073E-6

1.1580E-6

6.3220E-5

5.4211E-6

1.0083E-4

2.9522E-5

1.9109E-6

7.6905E-6
Modified

7.8989E-6

1.9351E-5

2.8521E-5

1.8484E-5

1.5301E-5

1.9251E-5

1.7230E-5

1.4880E-5

1.5071E-5

1.1976E-5

8.5244E-6

2.5421E-6

3.8682E-6

2.0681E-6

1.9082E-6

$1.1611 \mathrm{E}-6$

6.3211E-5

5.3771E-6

1.0088E-4

2.952OE-5

1.9104E-6

7.6781E-6
WIMS-E (42282 MWD/T)

69 Group UK Nuclear Data Lib.

8.4671E-6

1.8411E-5

1.4014E-5

1.3135E-5

8.9458E-6

1.2186E-6

4.6153E-6

1.9875E-6

1.8282E-6

6.3401E-5

4.9146E-6

1.0276E-4

2.9609E-5

7.535OE-6 
IABLE 3.1.7-10 (Cont'd) GE PIN CELL

$\mathrm{UO}_{2}-\mathrm{Er}_{2} \mathrm{O}_{3}-\mathrm{PuO}_{2}$ Fuel (Weapons Grade Pu), Operating Conditions End of Life (EOL) Number Densities (Cell Averaged)

Nuclide

DIT $142400 \mathrm{MWD} / \mathrm{TH}$ ENDF/B-VI 89 Group Library

Unmodified

Modified

U-236

U.238

Pu-239

Pu-240

Pu-241

Pu-242

Am-241

Am-243
1.3230E-6

$6.4754 \mathrm{E}-3$

2.5789E-4

8.1855E-5

4.6634E-5

6.0042E-6

2.6094E-6

$1.4439 \mathrm{E}-6$
1.3221E-6

6.4792E-3

2.5442E-4

8.1590E-5

4.6617E-5

6.0436E-6

2.6048E-6

$1.4551 \mathrm{E}-6$

WIMS-E (42282 MWDII)

69 Group UK Nuclear Data Lib.

1.3952E-6

$6.4765 E-3$

2.4646E-4

9.1425E-5

4.4666E-5

6.1369E-6

2.1870E-6

1.5754E-6 



Association for Information and Image Management

1100 Wayne Avenue, Suite 1100

Silver Spring, Maryland 20910

301/587-8202

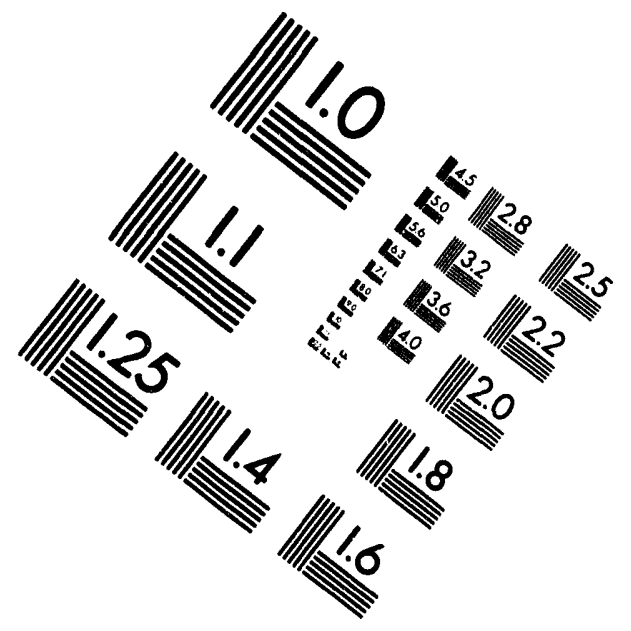

Centimeter

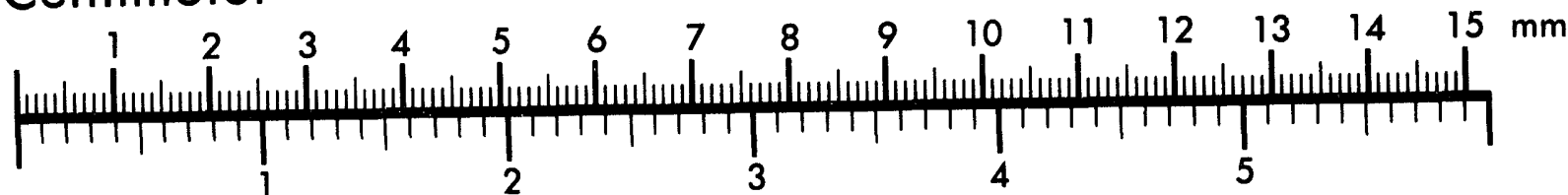
Inches
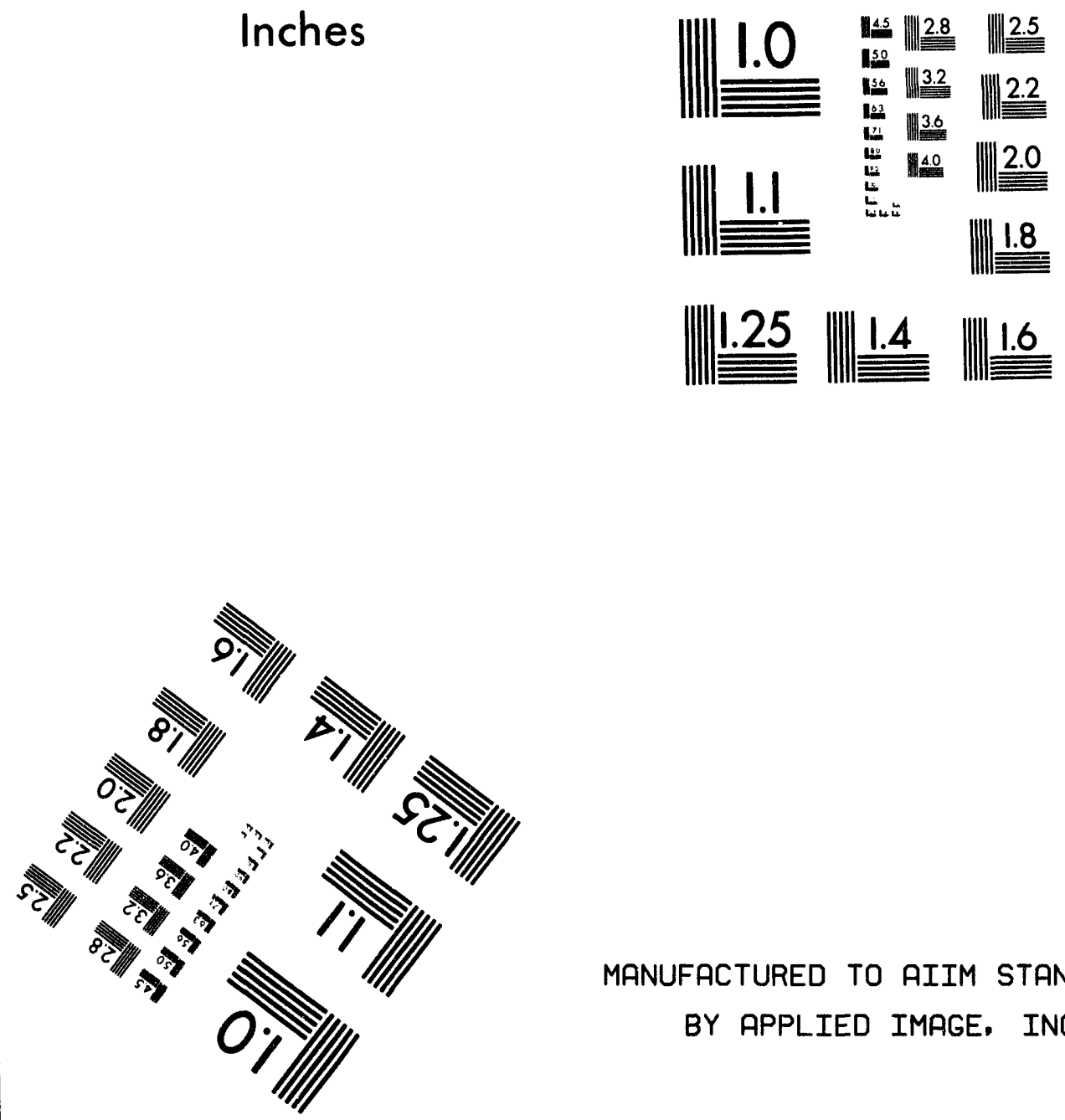

MANUFACTURED TO AIIM STANDARDS BY APPLIED IMAGE. INC.

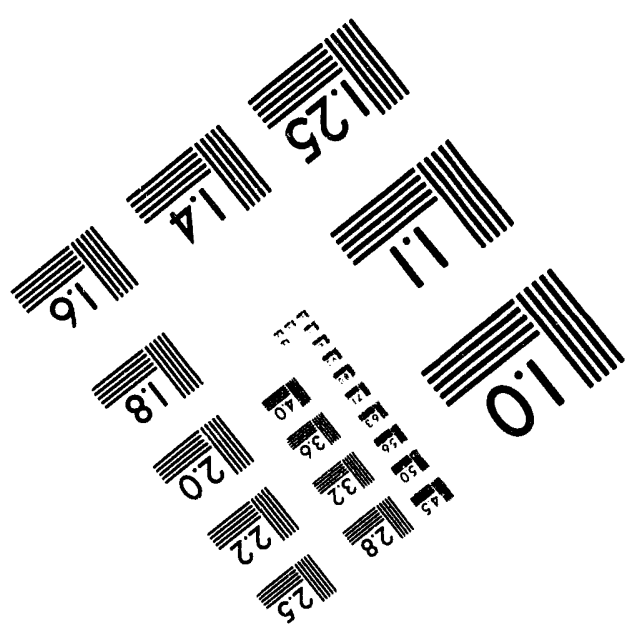



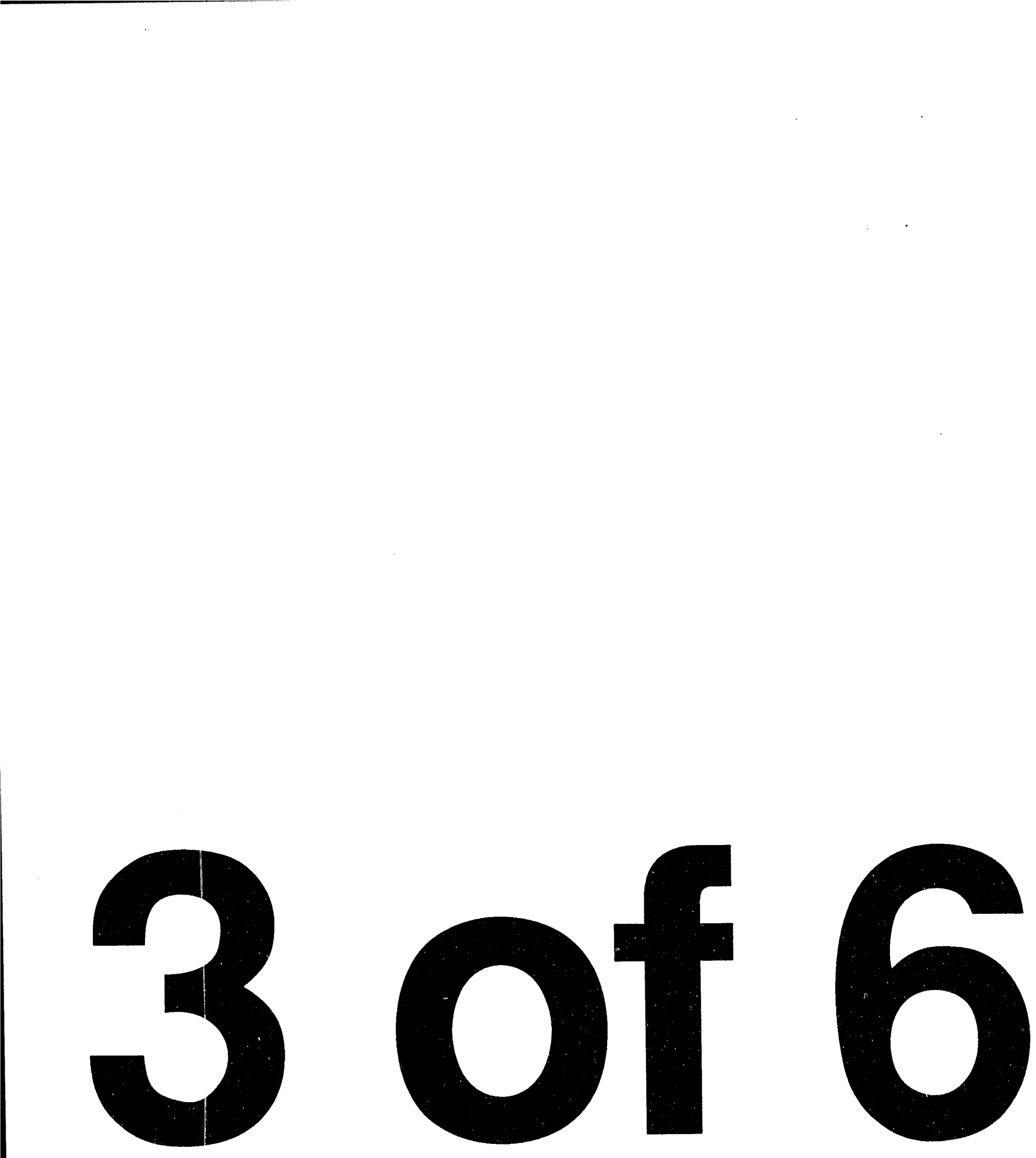
IABLE 3.1.7-11

CE PIN CELL

$\mathrm{UO}_{2}-\mathrm{Er}_{2} \mathrm{O}_{3}-\mathrm{PUO}_{2}$ (Weapons Grade $\mathrm{Pu}$ )

Operating Conditions

End of Life (EOL)

Relative Pu Discharge Concentrations

$\mathrm{DIT} 142400 \mathrm{MWD} / \mathrm{T}$ ENDF/B-VI 89 Group Library

Unmodified

Pu 238/Pu

$\mathrm{Pu} 239 / \mathrm{Pu}$

Pu 240/Pu

Pu 241/Pu

Pu 242/Pu
$0 \%$

$65.7 \%$

$20.9 \%$

$11.9 \%$

$1.5 \%$
WIMS-E $142282 \mathrm{MWD} / \mathrm{T})$

69 Group UK Nuclear Data Library

$0 \%$

$63.4 \%$

$23.5 \%$

$11.5 \%$

$1.6 \%$ 


\section{$3.2 \quad$ Euel}

\subsubsection{Introduction}

The proposed fuel design for use in the System $80+$ pressurized-water reactor (PWR) for disposition of plutonium is a uranium-plutonium mixed oxide (MOX) of approximately $\left.92 \% \mathrm{UO}_{2}-7 \% \mathrm{Pu}\right) \mathrm{O}_{2}\left[(\mathrm{U}, \mathrm{Pu}) \mathrm{O}_{2}\right]$, with up to $1.5 \% \mathrm{Er}_{2} \mathrm{O}_{3}$ as a burnable poison for reactivity control. (a) $^{(2)}$ The fuel rod cladding will be Zircaloy-4. In addition, the fuel may contain gallium (Ga) in concentrations up to $0.1 \%$ and ${ }^{241} \mathrm{Am}$ in concentrations up to $5000 \mathrm{ppm}$. Ga may be present because it was used as an alloying material with the original plutonium metal; $\mathrm{Ga}$ is of concern because potential interactions with the Zircaloy cladding have not been fully defined. The ${ }^{241} \mathrm{Am}$ will be present because it is a decay daughter of ${ }^{241} \mathrm{Pu}$. The proposed fabrication process is based on forming a master blend of $\mathrm{UO}_{2}-\mathrm{PuO}_{2}$ that is subsequently diluted to the final $\mathrm{PuO}_{2}$ composition by blending with depleted $\mathrm{UO}_{2}$ and $\mathrm{Er}_{2} \mathrm{O}_{3}{ }^{\left({ }^{(b)}\right.}$

The proposed $80+$ MOX fuel design is based on commercial LWR fuels experience; however, no data or irradiation experience exist for this specific $\mathrm{MOX} \mathrm{Er}_{2} \mathrm{O}_{3}-\mathrm{Ga}$ fuel. Therefore, it is necessary to review the available fuel data and experience that can be applied to the proposed $80+\mathrm{MOX}$ fuel. This review can then be used to define the technology development needs for the $80+\mathrm{MOX}$ fuel relative to the reference $\mathrm{UO}_{2}$ fuel currently accepted for use in light-water reactors (LWRs). In addition to an extensive data base on $\mathrm{UO}_{2}$, application of both $\mathrm{UO}_{2}-\mathrm{Gd}_{2} \mathrm{O}_{3}$ and $\mathrm{UO}_{2}-\mathrm{Er}_{2} \mathrm{O}_{3}$ for LWRs has been initiated (Ref. 3.2-10), MOX for LWR application (from spent $\mathrm{UO}_{2}$ recycle) was researched in the U.S. in the 1970s, MOX is/has been the reference fuel for liquid metal-cooled fast reactors (LMRs), and usage of MOX (from spent $\mathrm{UO}_{2}$ recycle) in LWRs has begun in Belgium, France, and Germany (Ref. 3.2-6, 3.2-7, 3.2-13). ${ }^{(c)}$ The Japanese are also planning LWR recycle of MOX and have been performing research le.g., Ref. 3.2-11.

The technology requirements that must be met by LWR fuels have been specified by the U.S. Nuclear Regulatory Commission (NRC). The NRC reviews fuel rod/assembly designs based on the licensing requirements identified in Section 4.2 of the Standard Review Plan (SRP) (Ref. 3.2-33). The objectives of the NRC review, as described in Section 4.2 of the SRP, are to provide assurance that:

(a) This fuel will be referred to as $80+$ MOX to differentiate it from other MOX variations; $\mathrm{MOX}$ alone will refer to $(\mathrm{U}, \mathrm{Pu}) \mathrm{O}_{2}$.

(b) The proposed process is similar to the MIMAS process used by Belgonucleaire (Ref. 3.2-13).

(c) The November 1993 issue of Nuclear News, page 68, notes that 30 European reactors have been licensed to use MOX fuel. 
- the fuel system is not damaged as a result of normal operation and anticipated operational occurrences

- fuel system damage is never so severe as to prevent control rod insertion when it is required

- the number of fuel rod failures is not underestimated for postulated accidents coolability is always maintained.

Section 4.2 of the SRP identifies a number of specific fuel models, behaviors, etc., that are reviewed; that list is repeated in Table 3.2-1.

Presented in the following sections of this report are 1) a brief summary of U.S. and foreign MOX experience; 21 a review identifying the applicable fuel material properties/models for evaluating fuel performance, the potential impact of using the proposed $80+\mathrm{MOX}$ fuel, and available relevant data; and 3) a summarizing discussion that includes needs for additional experimental data and model/code development, i.e., technology development needs, and recommendations.

\subsubsection{Experience with MOX}

\subsubsection{U.S. Experience}

Several programs were conducted in the United States during the 1960 s and 1970 s to investigate the use of recycle MOX as a LWR fuel. Those programs included:

- The Plutonium Utilization Program sponsored by the U.S. Atomic Energy Commission (AEC) and managed by Pacific Northwest Laboratory (PNL) (Ref. 3.2-15).

The Saxton Plutonium Project sponsored by the AEC and conducted by Westinghouse Electric Corporation (WEC) (Ref. 3.2-37).

- $\quad$ EEI-Westinghouse plutonium research (Ref. 3.2-20). This work began with the Plutonium Research Program and was followed by the Plutonium Recycle Demonstration Program for the San Onofre Reactor.

Electric Power Research Institute (EPRI) research into the use of MOX (Ref. 3.2-46).

Brief summaries of these programs and their results are provided in the following. It should be noted that all programs (LMR and LWR, U.S. and foreign) address the issue of using MOX formed from the recycling of plutonium from irradiated commercial fuel and not from weapons. 


\subsubsection{Plutonium Utilization Program}

The Plutonium Utilization Program was sponsored by the AEC and conducted by PNL; this program began in approximately 1960. Test irradiations of recycle MOX fuel designs, both pellet and vibrationally compacted (vi-pac) fuels, were conducted in the Plutonium Recycle Test Reactor (PRTR). The irradiation tests on the vi-pac fuel conducted in the PRTR were summarized by Freshley and Panisko (ref. 3.2-15). Additional irradiations on vi-prac MOX were conducted in the Materials Testing Reactor, Engineering Test Reactor, and experimental Boiling Water Reactor (ref. 3.2-4). Satisfactory performance of the vi-pac MOX was concluded by this program.

\subsubsection{Saxton Plutonium Project}

The Saxton Plutonium Project was conducted by WEC for the AEC and addressed plutonium recycle in LWRs; the program began in 1964 with Core II irradiations in the Saxton reactor running from December 1965 through October 1968 (refs. 3.2-37, 3.238, 3.2-34). Core III operated from December 1969 through May 1972 with peak rod burnups of $50 \mathrm{MWd} / \mathrm{kgM}$ and the overall performance of the MOX rods was determined to be satisfactory. Progressive changes in dimensions, fission gas release, fuel microstructure, etc., were consistent with LHGRs and increasing burnup levels. The changes were concluded to have no apparent adverse effects on the performance of the MOX fuel. Defects that did develop in some rods were apparently not related to any inherent limitation of the MOX fuel (ref. 3.2-38).

\subsection{EEI-Westinghouse Plutonium Research}

The EEI-Westinghouse Plutonium Utilization Program was principally an analytical feasibility study that addressed nuclear parameter studies, fuel fabrication studies, fuel cycle studies, physics methods development, and nuclear design studies (refs. 3.2-44, $3.2-20,3.2-34)$. The rods were to be irradiated in $14 \times 14$ assemblies to a burnup level of $30 \mathrm{MWd} / \mathrm{kgM}$. (ref. 3.2-21).

The EEI-Westinghouse Plutonium Recycle Demonstration Program was a follow-on program to the EEI-Westinghouse Plutonium Utilization Program completed in 1968. Whereas the Plutonium Utilization Program was an analytical feasibility study, the Plutonium Recycle Demonstration Program irradiated MOX rods in San Onofre 1 (refs. 3.2-20, 3.2-34). The San Onofre irradiations consisted of irradiating 720 rods for two cycles, ending in June 1973 (ref. 3.2-43). Postirradiation examination was planned during 1973, but concluding reports have not yet been located. 


\subsection{Electric Power Research In stitute (EPRI) Studies}

EPRI has sponsored a number of research projects on recycle MOX, as briefly summarized by Zolotar and Roberts (ref. 3.2-46). These projects included irradiations in Big Rock Point and Quad Cities, plus research into specific aspects of irradiation behavior. Zolotar and Roberts concluded that experience to-date indicated that MOX behavior was satisfactory and that there were no apparent performance limitations. Voll (ref. 3.2-42) described the irradiations at Big Rock Point and stated that the MOX fuels had performed as well as the $\mathrm{UO}_{2}$ rods. The San Onofre irradiations ranged from a few initial rods in 1969, to lead test assemblies through 1972, to a full reload of MOX assemblies in 1974. Plutonium enrichments ranged from less than 2 to $9 \mathrm{wt} \%$; burnups reached approximately $20 \mathrm{MWd} / \mathrm{kgM}$.

The EPRI Plutonia Fuel Study (RP 396) was conducted by BNWL to investigate the in-reactor densification characteristics of MOX fuel and determine the extent of thermal and irradiation-induced U,Pu homogenization in mechanically blended, MOX fuels for LWRs (refs. 3.2-17). It was concluded that there are many similarities in the densification behavior of $\mathrm{MOX}$ and $\mathrm{UO}_{2}$ and that the behavior of $\mathrm{MOX}$ was not affected by $\mathrm{PuO}_{2}$ concentrations up to $6 \mathrm{wt} \%$ or $\mathrm{PuO}_{2}$ particle sizes up to 500 um in diameter. In addition, significant $\mathrm{PuO}_{2}$ homogenization was found to occur at low burnups with temperatures greater than $1520^{\circ} \mathrm{C}$ or at temperatures as low as $520^{\circ} \mathrm{C}$ with a fission rate of $6 \times 10^{12}$ fissions $/ \mathrm{cm}^{3}$-sec.

\subsection{Testing in EBWR}

In the late 1960s, the final core loading for the Experimental Boiling Water Reactor (EBWR) at Argonne National Laboratory (ANL) included a central zone of $\mathrm{UO}_{2}-1.5 \mathrm{wt} \%$ $\mathrm{PuO}_{2}$ rods (ref. 3.2-26). The MOX fuel was of a vi-pac design rather than pellets. A planning report for this program, including preirradiation analysis, was prepared by-Liikala, Jenquin, and Reardon (ref. 3.2-24); however, concluding reports have not yet been located.

\subsubsection{U.S. Other Experiences}

United Nuclear provided MOX fuel fabricated by ALKEM to Dresden 1 in the early 1970 s. B\&W subsequentially examined discharged fuel at the reactor site.

\subsubsection{Eoreign Experience}

Major recycle MOX programs have been conducted by Belgium and France working together, and by Germany. 


\subsubsection{Belgium and France}

Belgonucleaire has been conducting extensive research into the use of recycle MOX for LWRs (refs. 3.2-6, 3.2-13). From this work, it has been concluded that the in-reactor behavior of $\mathrm{MOX}$ is very similar to that of $\mathrm{UO}_{2}$. This has included evaluations of thermal conductivity, fission gas release, melting temperature, thermal expansion, fuel creep, and integral fuel rod performance. Irradiations have been conducted in the BR-3, the Garigliano BWR (Italy 1968), the CNA PWR (France, 1974), and current French PWRs (ref. 3.2-7).

\subsubsection{Germany}

Recycling of plutonium in LWRs began in Germany in 1966 and up to twelve LWRs have now used recycle MOX (ref. 3.2-19). Examination of recycle MOX fuel irradiated to burnup levels exceeding $40 \mathrm{MWd} / \mathrm{kgM}$ has been conducted. Dimensional behavior has been found to be nearly identical to that of $\mathrm{UO}_{2}$; densification and swelling have been concluded to be controlled by the $\mathrm{UO}_{2}$ matrix. Little uranium-plutonium interdiffusion was observed in fuel irradiated at normal power levels, but substantial redistribution was found for fuel that had been transient tested. Fission gas release was found to be similar to that of $\mathrm{UO}_{2}$. Goll et al. also concluded that it could be justified from a technical point of view to use similar models for $\mathrm{UO}_{2}$ and $\mathrm{MOX}$ for design calculations.

Markl and Stehl (ref. 3.2-27) also discussed MOX experience in Germany. They concluded that fuel and core performance had been satisfactory and summarized the scope of KWU's MOX demonstration programs. Fuel specifications included $\mathrm{PuO}_{2}$ particle size less than $100 \mathrm{um}$; grain size greater than 5 um after sintering at $1700^{\circ} \mathrm{C}$; and thermal resintering densification of less than $15 \mathrm{~g} / \mathrm{cm}^{3}$. Plutonium contents in PWRs were in the range of 2.0 to $3.2 \mathrm{wt} \%$ fissile, while contents ranged from 0.7 to $3.1 \mathrm{wt} \%$ fissile in BWRs. Average burnups have reached $30 \mathrm{MWd} / \mathrm{kgM}$. Results of postirradiation examinations showed no significant differences in materials performance as compared to $\mathrm{UO}_{2}$. Higher fission gas release was observed, but this was attributed to lower initial fuel density. Slightly increased corrosion of the Zircaloy cladding inner surface was also observed.

\subsection{Italy}

MOX fuel assemblies have been irradiated in the Garigliano BWR, Trino Vercellese PWR, and in various other reactors (ref. 3.2-2). Burnups of the first assemblies reaclied in excess of $25 \mathrm{MWd} / \mathrm{kgM}$ for rods with plutonium contents of 3 to $6 \mathrm{wt} \%$. Postirradiation examinations have shown that the MOX rods behaved satisfactorily and that there was little plutonium redistribution. The only observed difference between $\mathrm{MOX}$ and $\mathrm{UO}_{2}$ rods was in the microstructure, but this apparently did not impact the performance of the rods. 
Some rods containing Gd were being irradiated in 1977 and examinations were planned (ref. 3.2-2).

\subsubsection{Other Relevant Irradiation Proarams}

The proposed $80+\mathrm{MOX}$ fuel incorporates $\mathrm{Er}_{2} \mathrm{O}_{3}$ as a burnable poison for criticality control. Use of $\mathrm{Er}_{2} \mathrm{O}_{3}$ in $\mathrm{UO}_{2}$ has begun (ref 3.2-10). In addition, the burnable poison $\mathrm{Gd}_{2} \mathrm{O}_{3}$ has been used with $\mathrm{UO}_{2}$ for a number of years, and in higher concentrations than have been proposed for $\mathrm{Er}_{2} \mathrm{O}_{3}$, with no significant problems. Because $\mathrm{Er}_{2} \mathrm{O}_{3}$ and $\mathrm{Gd}_{2} \mathrm{O}_{3}$ are highly similar physically and chemically (see, for example, refs. 3.2-39, 3.2-8), the case has been made that $\mathrm{UO}_{2}-\mathrm{Gd}_{2} \mathrm{O}_{3}$ data may be extrapolated to $\mathrm{UO}_{2}-\mathrm{Er}_{2} \mathrm{O}_{3}$. It is also reasonable to assume based on similarities in $\mathrm{UO}_{2}$ and $\mathrm{MOX}$ behavior that $\mathrm{UO}_{2}-\mathrm{Gd}_{2} \mathrm{O}_{3}$ and $\mathrm{UO}_{2}-\mathrm{Er}_{2} \mathrm{O}_{3}$ data may be extrapolated to $\mathrm{MOX}-\mathrm{Er}_{2} \mathrm{O}_{3}$.

\subsubsection{Summary}

None of the reviewed programs found any significant difficulties in using MOX fuel in LWRs. In fact, all work has generally concluded that, in LWRs, MOX behaves quite similar to $\mathrm{UO}_{2}$. Some observed fuel rod failures were attributed to internal cladding hydriding; these failures were not directly attributable to the use of MOX, but to residual moisture from fabrication.

Recent European applications of MOX for LWRs have focused on concentrations of generally $4 \mathrm{wt} \% \mathrm{PuO}_{2}$ or less. The early U.S. studies on LWR use of MOX investigated $\mathrm{PuO}_{2}$ concentrations of less than $7 \mathrm{wt} \%$. Therefore, these studies are applicable in terms of appropriate $\mathrm{PuO}_{2}$ concentration. However, no irradiation testing of $(\mathrm{U}, \mathrm{Pu}) \mathrm{O}_{2}-\mathrm{Er}_{2} \mathrm{O}_{3}$ - $\mathrm{Ga}$ has been performed.

\subsubsection{Euel Rod/Assembly Material Properties and Performance}

As presented in the previous section, test irradiations of recycle MOX rods in LWRs have not revealed any difficulties and, in fact, have concluded in general that the rervcle MOX behaved quite similarly to $\mathrm{UO}_{2}$. To support the good integral performance of the MOX rods, it is necessary to have models and codes, which are based on an understanding of the materials and behaviors during irradiation, to predict the thermal and mechanical performance of the rods. Table 3.2-1 provides a summary of the models that the NRC expects to find in fuel performance codes to predict the behavior of fuel rods and fuel assemblies, and comments on those models which may be impacted by the use of $80+$ MOX relative to $\mathrm{UO}_{2}$. The list in Table 3.2-1 has been reduced to that presented in Table 3.2-2, which emphasizes the fuel itself. The following sections discuss the data and models necessary to understand and predict fuel performance. 


\subsubsection{Cladding}

The planned cladding for the fuel rods is "standard" Zircaloy-4 for which an extensive data base and experience history exists. The use of $80+$ MOX will not affect basic cladding properties, although it may affect cladding behavior during irradiation by changing the neutron flux/fluence incident upon the cladding and the temperature at which the cladding operates. Therefore, existing cladding models need to be reviewed to determine if they appropriately account for the exposure conditions that will be encountered; i.e., temperature dependence, neutron fluence dependence, etc. Bariot et al. (ref. 3.2-5) have concluded that the use of MOX should have no impact on the fuel side of the cladding.

One factor that may need to be considered is the greater generation of tritium in MOX relative to $\mathrm{UO}_{2}$, and the subsequent uptake by the Zircaloy cladding (ref. 3.2-7). However, Deramaix, Haas, and Van de Velde (ref. 3.2-13) have noticed no difference in cladding hydriding between $\mathrm{MOX}$ and $\mathrm{UO}_{2}$ rods.

\subsubsection{Euel Assembly}

The situation for the fuel assembly is similar to that for the cladding; i.e., an extensive data base exists for the planned materials and design which will be standard ABB-CE practice. However, account will need to be taken for potentially different temperature and neutron flux/fluence histories. Another factor to consider will be if fuel rod elongation within the assembly will be different than for standard $\mathrm{UO}_{2}$-Zircaloy rods. Deramaix, Haas, and Van de Velde (ref. 3.2-13) report that total rod length change has not differed between $\mathrm{MOX}$ and $\mathrm{UO}_{2}$ rods; this is also the conclusion reached by Goll et al. (ref. 3.2-19).

\subsubsection{Euel}

A number of fuel properties and behaviors will likely be directly impacted (relative to $\mathrm{UO}_{2}$ ) by the use of $80+\mathrm{MOX}$. A brief summary of impacted properties/models, and expected impact, is provided below. It is important to note that Bariot and Deramaix (ref. 3.2-6) have concluded that for $\mathrm{MOX}$ with less than $10 \mathrm{wt} \% \mathrm{PuO}_{2}$, basic properties do not vary linearly with $\mathrm{PuO}_{2}$ content but are more similar to those of $\mathrm{UO}_{2}$ doped with Pu.

Relative to the inclusion of burnable poisons, the following general comments provide a preface to the more specific comments that will be provided in the following discussions.

Er and $\mathrm{Gd}$ are closely related rare earth elements which form oxides of the same structure. 
- $\quad$ ABB-CE has initiated a program to measure the physical properties of $\mathrm{UO}_{2}-\mathrm{Er}_{2} \mathrm{O}_{3}$ fuel pellets with up to $2.5 \mathrm{wt} \% \mathrm{Er}_{2} \mathrm{O}_{3}$ (refs. 3.2-10, 3.2-23). Results of these tests have indicated that the properties of $\mathrm{UO}_{2}-\mathrm{Gd}_{2} \mathrm{O}_{3}$ and $\mathrm{UO}_{2}-\mathrm{Er}_{2} \mathrm{O}_{3}$ are very similar.

- Values of specific heat and thermal expansion for $\mathrm{Gd}_{2} \mathrm{O}_{3}$ and $\mathrm{Er}_{2} \mathrm{O}_{3}$ are nearly identical (Ref. 3.2-39).

Based on the above, because $\mathrm{Er}_{2} \mathrm{O}_{3}$ and $\mathrm{Gd}_{2} \mathrm{O}_{3}$ are physically and chemically very similar, and because their effects upon addition to $\mathrm{UO}_{2}$ are likewise very similar, it may be concluded that the effects of adding $\mathrm{Gd}_{2} \mathrm{O}_{3}$ to $\mathrm{UO}_{2}$ may be extrapolated to $\mathrm{Er}_{2} \mathrm{O}_{3}$. Similarly, it may be preliminarily concluded that similar behavior will exist for $\mathrm{Er}_{2} \mathrm{O}_{3}$ additions to $(U, P u) O_{2}$; i.e., that any information on the effects of $\mathrm{Gd}_{2} \mathrm{O}_{3}$ in $\mathrm{MOX}$ may be extrapolated to $\mathrm{Er}_{2} \mathrm{O}_{3}$. Similarly, information on effects of $\mathrm{Er}_{2} \mathrm{O}_{3}$ on $\mathrm{UO}_{2}$ may be extrapolated to $\mathrm{MOX}-\mathrm{Er}_{2} \mathrm{O}_{3}$.

The following discussions will be separated into the effect of $\mathrm{MOX}\left[(\mathrm{U}, \mathrm{Pu})_{2} \mathrm{O}_{2}\right]$ versus $\mathrm{UO}_{2}$ and the effect of added burnable poisons. Determinable effects of $\mathrm{Ga}$ and $\mathrm{Am}$ will be discussed separately.

\subsubsection{Thermal Conductivity}

Thermal conductivity has a direct impact on fuel temperature and the value of this property for $80+$ MOX will be less than for $\mathrm{UO}_{2}$ (ref. 3.2-13). In addition to dependency on typical parameters such as temperature, density, and porosity, the thermal conductivity of MOX is also dependent on $\mathrm{O} / \mathrm{M}$ ratio, possibly on plutonium content for plutonium less than $15 \%$, and burnup because of the effect of solid fission products.

MOX versus $\mathrm{UO}_{2}$ The thermal conductivity of MOX has been found to be less than that of $\mathrm{UO}_{2}$. Philipponneau (ref. 3.2-35) has reviewed data for $\left(U_{0.8} P_{0.2}\right) \mathrm{O}_{2-x}$ and recommended a correlation that is dependent on temperature, porosity, $\mathrm{O} / \mathrm{M}$ ratio, and burnup; this correlation resulted in thermal conductivity values lower than those recommended by Martin (ref. 3.2-28)..$^{(0)}$ Philipponneau comments, first, that MOX thermal conductivity is independent of plutonium content within the range 15 to $30 \mathrm{wt} \%$ and, second, that data are very limited below $15 \%$ plutonium for extrapolation of this assumption. In comparison to the Lyons et al. (ref. 3.2-25) correlation for $\mathrm{UO}_{2}, \mathrm{MOX}$ with $20 \mathrm{wt} \% \mathrm{PuO}_{2}$ has a thermal conductivity approximately $30 \%$ lower at $500^{\circ} \mathrm{C}$, with the difference decreasing to zero at approximately $1700^{\circ} \mathrm{C}$. For concentrations of less than $10 \mathrm{wt} \% \mathrm{PuO}_{2}$, Deramaix, Haas, and Van de Velde (ref. 3.2-13) state that plutonium content has little effect on thermal conductivity relative to $\mathrm{UO}_{2}$. Beauvy (ref. 3.2-9) observed immediate decreases in thermal diffusivity upon initial addition of $\mathrm{Pu}$ to $\mathrm{UO}_{2}$, but then little change over the range of 2 to 10 at $\% \mathrm{Pu}$.

(d)

Martin's recommendation was essentially a constant $5 \%$ reduction in thermal conductivity independent of temperature. 
Yamamoto et al. (ref. 3.2.45) report little effect of burnup on thermal conductivity for samples up to $35 \mathrm{MWd} / \mathrm{kgM}$. In addition, their measurements of thermal conductivity on irradiated MOX indicate better agreement with the equation by Martin (ref. 3.2-28).

Effect of Burnable Poisons The addition of $\mathrm{Gd}_{2} \mathrm{O}_{3}$ to $\mathrm{UO}_{2}$ results in a slight reduction in thermal conductivity (ref. 3.2-30). An estimate of the effect for $1.5 \% \mathrm{Gd}_{2} \mathrm{O}_{3}$ would be a less than $10 \%$ decrease at $500^{\circ} \mathrm{C}$, with probably a minimal decrease in the integrated thermal conductivity for 500 to $1500^{\circ} \mathrm{C}$. No data were found on the effect of $\mathrm{Gd}_{2} \mathrm{O}_{3}$ added to MOX.

Summary It is estimated that the integrated effect of $80+\mathrm{MOX}$ relative to $\mathrm{UO}_{2}$ would be a decrease in the value of the thermal conductivity integral of less than $10 \%$. According to a recently published ANS paper (ref. 3.2-47) the integrated thermal conductivity decrease is $2.1 \%$ per $1 \% \mathrm{Er}_{2} \mathrm{O}_{3}$ for room temperature to the melting point. Open literature data are minimal for $\mathrm{PuO}_{2}$ concentrations less than $15 \%$, so experimental determination of thermal conductivity (and specific heat) would be advisable.

\subsection{Specific Heat}

Specific heat plays a role in defining thermal conductivity from thermal diffusivity data; thermal conductivity is inversely proportional to specific heat.

MOX versus $\mathrm{UO}_{2}$ Beauvy (ref. 3.2-9) observed a decrease of less than $10 \%$ in the specific heat of MOX for up to 5 at \% of $\mathrm{Pu}$, but then specific heat begins to increase and approach the value for $\mathrm{UO}_{2}$ at 15 at $\% \mathrm{Pu}$.

Effect of Burnable Poisons The addition of $\mathrm{Gd}_{2} \mathrm{O}_{3}$ to $\mathrm{UO}_{2}$ results in a slight increase in specific heat, as does that of $\mathrm{Er}_{2} \mathrm{O}_{3}$ additions. The estimated increase is less than $1 \%$ for the proposed $\mathrm{Er}_{2} \mathrm{O}_{3}$ concentrations. No data were found on the effect of $\mathrm{Gd}_{2} \mathrm{O}_{3}$ added to MOX.

Summary The integrated effect upon specific heat of $\mathrm{PuO}_{2}$ and $\mathrm{Er}_{2} \mathrm{O}_{3}$ additions to $\mathrm{UO}_{2}$, relative to $\mathrm{UO}_{2}$, is likely less than $10 \%$.

\subsection{Densification/Swelling}

Fuel densification and swelling affect the radial dimensions of the fuel and thus the size of the fuel-cladding gap and the heat transfer across the gap. Densification occurs early in life and results in an increased gap width while swelling (from fission products) occurs after an incubation period and results in a reduced gap width.

MOX versus $\mathrm{UO}_{2}$ Deramaix, Haas, and Van de Velde (ref. 3.2-9) state that MOX densification and swelling are controlled by the $\mathrm{UO}_{2}$ matrix, therefore $\mathrm{MOX}$ behavior is very similar to $\mathrm{UO}_{2}$. They also state that the in-reactor densification of MOX is typical of that observed for $\mathrm{UO}_{2}$; this is concurred with by Goll et al. (3.2-19). Freshley et al. 
(ref. 3.2-16) concluded that the densification behavior of MOX was dependent on the same parameters as $\mathrm{UO}_{2}$.

Dienst, Mueller-Lyda, and Zimmerman (ref. 3.2-14) concluded that $\mathrm{UO}_{2}$ and $\mathrm{MOX}$ swell at similar rates of approximately 1.2 vol\% per at\% burnup. Uematsu et al. (ref. 3.2-7) concluded that fuel column length change for MOX was $1-1.5 \%$ per at $\%$ burnup. Bariot et al. (ref. 3.2-7) have concluded that, based on fuel column length changes, that MOX swells less than $\mathrm{UO}_{2}$. Goll et al. (ref. 3.2-19) have measured similar fuel densities for $\mathrm{MOX}$ and $\mathrm{UO}_{2}$ at burnups at 40 to $50 \mathrm{MWd} / \mathrm{kgM}$.

Effect of Burnable Poisons The use of $\mathrm{Gd}_{2} \mathrm{O}_{3}$ in $\mathrm{UO}_{2}$ has not had apparently had any significant effects on-densification and swelling. No data were found on the effect of $\mathrm{Gd}_{2} \mathrm{O}_{3}$ added to MOX.

Summary The $80+$ MOX fuel should have densification and swelling behaviors very similar to standard $\mathrm{UO}_{2}$, assuming preirradiation microstructural characteristics that are very similar to that of standard $\mathrm{UO}_{2}$.

\subsection{Thermal Expansion}

Radial thermal expansion of the fuel affects the fuel-cladding gap width, thus affecting radial heat transfer and possible fuel-cladding mechanical interaction. If the fuel and cladding are in contact, axial thermal expansion of the fuel column can affect the length of the fuel rod.

MOX versus $\mathrm{UO}_{2}$ Deramaix, Haas, and Van de Velde (ref. 3.2-13) state that the linear thermal expansion coefficient for MOX is approximately $1 \%$ greater than that for $\mathrm{UO}_{2}$. However, Martin (ref. 3.2-29) concluded that there is little difference between stoichiometric MOX and $\mathrm{UO}_{2}$.

Effect of Burnable Poisons No significant differences on thermal expansion have been found between $\mathrm{UO}_{2}$ and $\mathrm{UO}_{2}-\mathrm{Gd}_{2} \mathrm{O}_{3}$. No data were found on the effect of $\mathrm{Gd}_{2} \mathrm{O}_{3}$ added to MOX.

Summary The difference in thermal expansion between $80+\mathrm{MOX}$ and $\mathrm{UO}_{2}$ would be expected to be minimal, less than $1 \%$.

\subsection{Fission Gas Production/Release}

The production of fission gas and its subsequent release to the open volumes of a fuel rod is of importance because of 1 ) its potential to degrade the heat transfer from the fuel to the cladding and thereby increase fuel temperatures, and 2) the potential for rod internal gas pressure to exceed coolant pressure and thereby cause outward creep of the cladding, increase the fuel-cladding gap, and increase fuel temperatures. 
MOX versus $\mathrm{UO}_{2}$ Goll et al. (ref. 3.2-19) conclude that fission product and fission gas release for MOX used in LWRs are comparable to $\mathrm{UO}_{2}$. Bariot and Deramaix (ref. 3.2-6) note that the generation of helium from transplutonium elements may provide a trend for higher fission gas release for $\mathrm{MOX}$ relative to $\mathrm{UO}_{2}$. This release may also affect the rod internal gas pressure (ref. 3.2-7). Also, it appears that the microstructure of the MOX fuel is more critical to fission gas release than the MOX itself (ref. 3.2-12). It should be noted that most MOX fission gas release data are from high linear heat generation rate, high temperature, and high fission gas release LMR MOX fuels.

Effect of Burnable Poisons Une and Kashibe (ref. 3.2-41) contend that the burst fission gas release bohavior of $\mathrm{UO}_{2}$ with $2 \mathrm{wt} \% \mathrm{Gd}_{2} \mathrm{O}_{3}$ has a temperature/burnup dependence similar to $100 \% \mathrm{UO}_{2}$. Although greater burst fission gas release was observed for $\mathrm{UO}_{2}-\mathrm{Gd}_{2} \mathrm{O}_{3}$, relative to $\mathrm{UO}_{2}$, it was attributed to a smaller grain size for the $\mathrm{UO}_{2}-\mathrm{Gd}_{2} \mathrm{O}_{3}$ fuel compared to the $\mathrm{UO}_{2}$ used in the tests (4 vs 9um); however, gas atoms per area of grain boundary were apparently the same for both fuel types. They also found a similar effective diffusion coefficient of ${ }^{85} \mathrm{Kr}$ at $1800^{\circ} \mathrm{C}$ for both $\mathrm{UO}_{2}$ and $\mathrm{UO}_{2}-2 \mathrm{wt} \% \mathrm{Gd}_{2} \mathrm{O}_{3}$, but with no systematic burnup dependence. Massih, Persson, and Weiss (ref. 3.2-30) found reduced fission gas diffuslon coefficients for $\mathrm{UO}_{2}-\mathrm{Gd}_{2} \mathrm{O}_{3}$ which would lead to low $\mathrm{Wr}$ fission gas release.

Although the presence of $\mathrm{Gd}_{2} \mathrm{O}_{3}$ may affect fission gas release rates, any specific effects may be "swamped out" by other factors such as grain size or by the temperature dependency of fission gas release. No data were found on the effect of $\mathrm{Gd}_{2} \mathrm{O}_{3}$ added to MOX.

Summary Fission gas release for the $80+$ MOX fuel would be expected to be similar to that of $\mathrm{UO}_{2}$ fuel for equivalent temperatures and microstructure.

\subsection{Creep/plasticity}

Creep and plasticity of the fuel may affect fuel-cladding mechanical interaction, with increased creep and plasticity reducing fuel-cladding mechanical interaction.

MOX versus $\mathrm{UO}_{2}$ Dienst, Mueller-Lyda, and Zimmerman (ref. 3.2-14) present data showing a higher creep rate for $\mathrm{MOX}$ relative to $\mathrm{UO}_{2}$. Bariot and Deramaix (ref. 3.2-6) also support higher creep rates and plasticity for MOX, thus reducing fuel-cladding mechanicat interaction. Measured cladding diametral changes have been similar for MOX and $\mathrm{UO}_{2}$ rods (ref. 3.2-19).

Effect of Burnable Poisons No data were found on the effect of $\mathrm{Gd}_{2} \mathrm{O}_{3}$ added to MOX.

Summary Increased creep and plasticity of the MOX fuel does not appear to be an issue, but in fact a point in favor of MOX because of reduced fuel-cladding mechanical interaction. 


\subsection{Fuel/Cladding Chemical Interaction}

Fuel-cladding chemical interaction (corrosion of cladding inner surface) is an issue for high temperature, high burnup MOX rods clad with stainless steel (clad T $>500^{\circ} \mathrm{C}$ ) (ref. 3.2-3).

MOX versus $\cup_{2}$ Goll et al. (ref. 3.2-19) conclude that for LWR application, the chemical states of fission products within the rods are similar for $\mathrm{MOX}$ and $\mathrm{UO}_{2}$. Deramaix, Haas, and Van de Velde (ref. 3.2-13) have observed no differences in cladding inner surface corrosion between $\mathrm{MOX}$ and $\mathrm{UO}_{2}$ fuels. Bagley et al. (ref. 3.2-3), looking at inner surface corrosion of stainless steel, noted the lack of corrosion in low heat rate, low cladding temperature MOX rods; this is likely also applicable to MOX-Zircaloy rods. It should also be noted that high burnup $\mathrm{UO}_{2}$ rods have a Pu concentration in excess of $1 \%$ at the fuel pellet edge and that no unusual fuel-cladding chemical interactions have been noted.

Effect of Burnable Poisons No data were found on the effect of $\mathrm{Gd}_{2} \mathrm{O}_{3}$ added to MOX.

Summary Initial indications are that fuel-cladding chemical interaction should not be an issue for the $80+$ MOX and Zircaloy fuel rods.

\subsection{Melting Temperature}

Prevention of fuel melting is a common limiting requirement for the normal operation of $\mathrm{UO}_{2}$ fuel rods.

MOX versus $\mathrm{UO}_{2}$ The melting temperature for $\mathrm{MOX}$ is affected by both $\mathrm{PuO}_{2}$ content and burnup. Yamamoto et al. (ref. 3.2-45) report that melting temperature decreases approximately $5^{\circ} \mathrm{C}$ per $10 \mathrm{MWd} / \mathrm{kgM}$ for $29 \mathrm{wt} \% \mathrm{PuO}_{2}$; however, they also report little effect of $\mathrm{PuO}_{2}$ for $\mathrm{MOX}$ used in LWR applications (i.e., lower $\mathrm{PuO}_{2}$ content and burnup to only $50 \mathrm{MWd} / \mathrm{kgM}$ ).

Effect of Burnable Poisons The addition of $\mathrm{Gd}_{2} \mathrm{O}_{3}$ to $\mathrm{UO}_{2}$ results in a slight reduction in the melting temperature. Fiero et al. (ref 3.2-47) report a reduction in melting temperature of $7 \mathrm{C}$ per $1 \mathrm{wt} \%$ addition of $\mathrm{Er}_{2} \mathrm{O}_{3}$. No data were found on the effect of $\mathrm{Gd}_{2} \mathrm{O}_{3}$ added to MOX.

Summary $80+$ MOX will have a lower fuel melting temperature which will need to be determined.

\subsection{Transient/Failure Behavior}

To date, all MOX rod failures have been attributed to factors other than the MOX fuel per se, e.g., hydriding failures (ref. 3.2-19). 
MOX versus $\mathrm{UQ}_{2}$ Abe et al. (ref. 3.2-1) conclude that the failure mechanism and the threshold of $\mathrm{MOX}$ fuel was consistent with that of $\mathrm{UO}_{2}$ fuel $(260 \mathrm{cal} / \mathrm{g})$. Influence of plutonium content is apparently low if the $\mathrm{PuO}_{2}$ content is low and well distributed. Goll et al. (ref. 3.2-19) also found similar transient behavior for $\mathrm{MOX}$ and $\mathrm{UO}_{2}$ rods. Freshley et ai. (ref. 3.2-18) investigated $\mathrm{PuO}_{2}$ particle size effects during transients and concluded that the presence of a single 550 um-diameter particle did not appear to affect the cladding failure threshold energy. Similarly, Meyer, Hann, and Lanning (ref. 3.2-31) also concluded that plutonium segregation was not an important phenomenon during transients.

Effect of Burnable Poisons No information on the impact of burnable poisons on the transient/failure behavior of MOX rods was located.

Summary The use of MOX does not appear to have a significant effect on the transient/failure behavior of fuel rods. Accounting will have to be made on changes in radial power profiles, possible transient histories, etc.

\subsection{Other Considerations}

- Bariot and Deramaix (ref. 3.2-6) postulate that the rim effect ${ }^{(\text {() }}$ for high burnup MOX fuel might extend deeper into the fuel than for $\mathrm{UO}_{2}$. However, this may not be of concern for the $80+$ MOX fuel because the planned burnup levels will be only approximately $40 \mathrm{MWd} / \mathrm{kgM}$, which is below the burnup level of significant consideration of the rim effect in $\mathrm{UO}_{2}$ fuel.

After irradiation, the MOX fuel has a higher neutron flux relative to irradiated $\mathrm{UO}_{2}$ and approximately $20 \%$ higher decay heat. This will affect handling operations including transportation (ref. 3.2-12).

While ${ }^{241}$ Am may not impact material properties, it will impact dose rates from the fuel and a level of $<10^{4} \mathrm{ppm}$ has been proposed by Bariot et al. (ref. 3.25). Actual levels in excess weapons-grade Pu are expected to be within this limit.

In several places in the literature, the importance of $O / M$ ratio has been commented on; this might be more important to some properties and behaviors than the plutonium content.

In a compilation of fuel assembly characteristics, Moore and Notz (ref. 3.2-32) note that the second reload of Dresden-1 used rods with $0.15 \% \mathrm{Er}_{2} \mathrm{O}_{3}$.

(e) The rim effect refers to the formation of a high porosity region at the outer edge of the fuel; see Cunningham, Freshley, and Lanning (Ref. 3.2-11). 


\subsubsection{Effect of Gallium and Americium}

Gallium

There is presently no specification for gallium. Gallium is an alloying element used to stabilize the delta phase of plutonium metal. The maximum $\mathrm{Ga}$ content in surplus plutonium is reported to be $1 \%$ by weight. Gallium oxidizes with plutonium such that the gallium content in the resulting $\mathrm{PuO}_{2}$ is the same as in the parent plutonium metal. However, when this $\mathrm{PuO}_{2}$ is diluted with $\mathrm{UO}_{2}$ to $7 \mathrm{wt} \% \mathrm{PuO}_{2}$ in the $\mathrm{MOX}$ fuel, the maximum $\mathrm{Ga}$ content in the MOX is reduced to about $620 \mathrm{ug} \mathrm{Ga} / \mathrm{g}$, which is equal 840 $\mathrm{Ga}_{2} \mathrm{O}_{3} / \mathrm{g}$; this level may be acceptable from sinterability and irradiation performance standpoints. Gallium oxide may be thermodynamically stable in MOX fuel, forming solid solutions or stable oxide compounds with $\mathrm{UO}_{2}$ and $\mathrm{PuO}_{2}$. The main concern is whether a possibility exists for allium oxide in $\mathrm{MOX}$ fuel to dissociate during sintering in a reducing atmosphere or during irradiation, forming metallic gallium that might migrate and attack the zirconium cladding. Experimental data may be required to determine the behavior of gallium under the expected rariye of operating conditions.

Gallium can be removed from Pu metal by electrolysis or other chemical separation methods. However, there are substantial incentives to avoid processing the plutonium to remove $\mathrm{Ga}$. These include reducing costs, minimizing waste generation, and reducing personnel exposures. since large amounts of surplus $\mathrm{Pu}$ are potentially available, an R\&D program may be warranted to determine the maximum permissible levels of $\mathrm{Ga}$ in the MOX fuel. Such a laboratory program can be conducted with $\mathrm{UO}_{2}$ initially, using cerium oxide as a stand-in for $\mathrm{PuO}_{2}$. The R\&D program would also determine the effects of erbium additions to fuel containing gallium impurities. The R\&D program may be extended later to MOX fuels, if required, to confirm the UO2 results.

\section{Americium}

The current specification on the maximum americium content calls for mutual agreement between the purchaser and seller. The Am-241 content of the weapons plutonium is expected to average about $2750 \mathrm{ug} / \mathrm{g}$ and to not exceed $4000 \mathrm{ug} / \mathrm{g}$. compared to reactor grade plutonium that is fabricated commercially into MOX fuel, the maximum Am-241 contents in the surplus plutonium is lower by about a factor to 2 . The limit on the Am-241 content in reactor grade plutonium used in foreign MOX fuel fabrication plants is currently about $8,000 \mathrm{ug} / \mathrm{g}$ (the restriction is that the Pu must be fabricated into fuel within two-years after separation); however, some fabricators have plans to extend that limit to about $20,000 \mathrm{ug} / \mathrm{g}$ (i.e. a 5 year restriction). The MOX fabrication line can be shielded and the handling equipment can be automated to reduce personnel exposures and permit the surplus plutonium to be fabricated as is without requiring the removal of Am-241. The decay of Am-241 produces high gamma radiation levels, but the Am levels in weapons-grade plutonium should not require extraordinary measures to reduce personnel radiation exposures or to limit the content of Am-241 during fuel fabrication. 
Americium can be removed from molten plutonium by sparging the melt with $\mathrm{Cl}$. Americium forms the chloride that floats to the surface; it can be removed by a calcium chloride flux. The separation of Am from Pu is nearly complete. The separated Am must be disposed of as transuranic waste. The trade-offs between separation of the Am and leaving it in the plutonium must be evaluated from cost ant effectiveness standpoints to the overall surplus plutonium disposal program such that costs, risks, ana benefits of all alternatives are considered over the long term. Risks include radiation exposure risks to operating personnel and the general population and diversion and proliferation risks. Costs considerations include shielding, automation, MOX fabrication, Am separation and packaging, and all waste storage and disposal costs.

Intermediate alternatives should be evaluated also in which Am is removed from plutonium when it exceeds specified levels, such as, for example, $3500 \mathrm{ug} / \mathrm{g}$. The potential advantage of this alternative is that in plutonium with a high Am content the initial Pu-241 content has decayed to a very low level, and thus, the subsequent buildup of Am in that Pu will be very low. This low Pu-241 plutonium could be blended with plutonium containing higher Am levels to reduce the overall level. This alternative requires that only a fraction of the plutonium be processed for Am separation, thus potentially minimizing wastes and costs compared to the total separation option and minimizing exposure risks compared to the no separation option.

\subsubsection{Summary/Recommendations}

The integral in-reactor performance of MOX used in LWRs is apparently very similar to that of $\mathrm{UO}_{2}$. This conclusion has been reached by Deramaix, Haas, and Van de Velde (ref. 3.2-13), Goll et al. (ref. 3.2-19), IAEA (3.2-22), and Reese et al. (ref. 3.2-36) among others. As a result, using similar models for design calculations can be justified from a technical point of view. Fuel centerline temperatures are expected to be similar to that for $\mathrm{UO}_{2}$ fuel when accounting for lower thermal conductivity, greater radial flux depression, and slightly higher fission gas release. MOX fuel apparently has lower pellet-cladding mechanical interaction because of a higher creep rate and plasticity. No differences in fuel rod length or diameter behavior have been observed between MOX and $\mathrm{UO}_{2}$ rods. For LWR application, no perceptible difference in cladding inner diameter corrosion or hydriding has been observed for MOX relative to $\mathrm{UO}_{2}$.

A consistent theme running through the literature is the impact of fabrication variables on the performance of $\mathrm{MOX}$, specifically $\mathrm{O} / \mathrm{M}$ ratio, $\mathrm{PuO}_{2}$ particle size and homogeneity, grain size, and the presence of impurities such as halogens and moisture. It was also consistent that manufacturing the $\mathrm{MOX}$ to current $\mathrm{UO}_{2}$ standards would result in the MOX behaving similar to $\mathrm{UO}_{2}$.

Considering that material properties do not vary linearly with $\mathrm{PuO}_{2}$ content (ref. 3.2-9), the limited quantity of data on $\mathrm{MOX}$ with the $\mathrm{PuO}_{2}$ content of interest $(-7 \%)$, the lack of data on MOX with burnable poisons (specifically $\mathrm{Er}_{2} \mathrm{O}_{3}$ ), and that the existing work was done using recycle $\mathrm{Pu}$ rather than weapons-grade $\mathrm{Pu}$, it appears to be prudent to do 
some experimental work in order to confirm the expected performance of the $80+\mathrm{MOX}$ fuel. It is specifically recommended that thermal conductivity, specific heat, heat capacity, and melting temperature be directly measured. These are of the most importance because 1) they are apparently the most directly impacted by Pu content, burnable poison content, and O/M ratio; 2) there are no direct data on the proposed $80+$ MOX fuel; and 3) quality models of these properties will be needed to accurately predict fuel rod thermal performance. The MOX Fuel Qualifications Program (Appendix D) is designed to obtain the necessary data, as well as qualify the fuel fabrication process.

A careful review of existing data, plus the use of additional specific data on $80+$ MOX, will be necessary in reviewing and revising existing fuel performance models and codes. Codes do exist to predict the performance of MOX fuels.

\subsubsection{Summary of MOX Fuel Qualification Plan}

This plan addresses the physical and chemical characterization and irradiation performance qualification of mixed oxide (MOX) fuel proposed for use in disposition of weapons-grade plutonium via operation in an ABB-Combustion Engineering (ABB-CE) System 80 + nuclear power plant. It is estimated that the program can be completed in six years at a cost within $\$ 30$ million. A detailed fuel qualification plan is contained in Appendix D of this report.

An integrated program of preirradiation characterization, test reactor irradiation, and postirradiation examinations is described, to demonstrate the expected performance similarities between the $80+\mathrm{MOX}$ fuel and conventional ABB-CE uranium dioxide fuel. It is proposed that the $80+$ MOX test rods be irradiated for a significant period (two years) in a pressurized water loop facility in the DOE-owned Advanced Test Reactor (ATR), located at the Idaho National Engineering Laboratory. Irradiation in an ATR water loop would provide the most prototypic available combination of test rod plutonium content, neutron spectrum, coolant temperatures and pressures, and bounding linear heat generation rates.

The use of other facilities, for example, the Halden facility in Norway, might be advantageous over the use of ATR for this purpose. These possibilities should be investigated in a later phase of this program. The safeguards and political complications, however, of conducting such a program outside the U.S. would have to be carefully considered.

The outline of the proposed program is as follows. First, the process for oxidizing weapons grade plutonium metal and producing sintered MOX pellets will be developed. The specifications and quality assurance tests for pellet purity, density, stoichiometry, and homogeneity will also be developed, and the materials properties of the sintered pellets will be determined. 
Second, pellets and test rods will be produced for an irradiation test. The loop test assembly would contain 20 test rods, each with a fuelled length of 4 feet. The rod design will be that for CE $16 \times 16$ fuel rods, which have an outer diameter of 0.385 inches. The MOX is expected to contain about $7 \mathrm{wt}$ \% plutonia and up to $2.5 \mathrm{wt} \%$ erbia. These rods will reflect to the extent possible all of the fabrication techniques and specifications that will be applied to the $80+$ MOX first-core fuel. The test rods will then be operated in near-prototypic (PWR) neutronic and coolant conditions, at normal power histories to significant burnup in a pressurized water loop facility in the ATR. An irradiation period of approximately two years is projected, to attain peak burnups of approximately $35 \mathrm{GWd} / \mathrm{MTM}$.

Fabrication of the MOX pellets and test rods is planned to be carried out at the Los Alamos TA-55 area facilities. Some modifications of these facilities would be required, but the basic processes are available and in commission. The processes for the prototypic MOX fuel Facility (see Section 2.4) are essentially the same used at TA-55.

Finally, the test rods will be discharged from the ATR and shipped to hot cell facilities for examination. The examinations will include both nondestructive and destructive tests, and will be used to confirm irradiation conditions and the end-of-life physical state of the rods. The nondestructive exams will include photography, length measurements, and axial gamma scanning. Destructive examinations will include puncture and plenum gas recovery/analysis for all rods, plus sectioning and detailed microscopic examinations on a limited number of rods. The detailed examinations will include pellet-average and radial distribution determinations for burnup and $\mathrm{U}, \mathrm{Pu}$, and $\mathrm{Er}$ isotopics, and fission product distributions, in addition to optical metallography, ceramography and electron microscopy.

Data reports will be issued at each stage of the program. A final program technical report will incorporate analysis of all the precharecterization, irradiation, and postirradiation examination data, which will form the basis for the performance projections for the $80+$ MOX first-core fuel.

Various DOE laboratories and contractors have declared willingness and capability to conduct various phases of this program. Los Alamos National Laboratory (LANL) is capable (with equipment upgrades) of oxidizing Pu metal, developing the MOX test fuel, and producing test rods. The appropriate irradiation facilities could be made available in the ATR, which is operated by EG\&G, Idaho, Inc.; and EG\&G would provide the technical support for test assembly design and operation. Both EG\&G and PNL have declared ability (with equipment upgrades) to conduct the postirradiation examinations.

The fuel fabrication and test assembly fabrication are projected to be completed in the first two years of the program. The test irradiation would proceed over the next two years, leaving the final two years for postirradiation examinations, data analysis, and reporting. The cost distribution among the major activities would be: approximately $\$ 3.5$ million for fuel development and test rod fabrication; $\$ 20$ million for irradiation (including 
test assembly fabrication); $\$ 2$ million for post irradiation examinations; $\$ 2$ million for analysis, administration, and reporting; and $\$ 2.5$ million for contingency.

It is assumed that the neutronics characteristics of the $80+$ MOX needed for the firstcore fuel will be gained from other test and analysis programs. This program may, however, provide neutronics code benchmark data from postirradiation examinations, and could be extended to provide the fuel rods critical experiments. 


\section{REFERENCES}

3.2-1 Abe, T., et al. 1992. "Failure Behavior of Plutonium-Uranium Mixed Oxide Fuel Under Reactivity-Initiated Accident Condition," Journal of Nuclear Materials, 188(1992)154-161.

3.2-2 Ariemma, A., et al. 1977. "Experience on Plutonium Recycle in Italy," in Proceedinge of the Typical Meeting on the Plutonium Fuel Cycle, Bal Harbour, Florida, May 2-4, 1977, pp. IV.3-1, American Nuclear Society, LaGrange, Illinois.

3.2-3 Bagley, K.Q., et al. 1979. "Fuel/Clad Reactions in Mixed Oxide Fuel Pins," in Proceedings of International Conference on Fast Breeder Beactor Fuel Performance, March 5-8, 1979, Monterey, CA, American Nuclear Society.

3.2-4 Bailey, W.J., and M.D. Freshley. 1967. Irradiation Properties of Hiah Eneray Bate Pneumatically Impacted $\cup_{2}-\mathrm{PuO}_{2}$ Fuels. BNWL-356. Pacific Northwest Laboratory, Richland, Washington.

3.2-5 Bariot, H., et al. 1991. " Foundations for the Definition of MOX Fuel Quality Requirements," Journal of Nuclear Materials, 178(1991)187-194.

3.2-6 Bariot, H., and P. Deramaix. 1992. "MOX Fuel Development: Yesterday, Today, and Tomorrow," Journal of Nuclear Materials, 188(1992)10-18.

3.2-7 Bariot, H., et al. 1986. "LWR MOX Fuel Experience in Belgium and France with Special Emphasis Placed on the Results Obtained in the BR3 PWR," in Proceedings of Improvements in Water Reactor Fuel Technology and Utilization, Stockholm, Sweden, September 15-19, 1986, IAEA, pp. 363-383).

3.2-7 Beals, R.J., J.H. Handwerk, and B.J. Wrona. 1969. "Behavior of Urania-Rare Earth Oxides at High Temperatures," Journal of American Ceramics Society, $52(1969) 578$.

3.2-9 Beauvy, M. 1992. "Nonideality of the Solid Solution in (U,Pu)02 Nuclear Fuels," Journal of Nuclear Materials, 188(1992)232-238.

3.2-10 Corsetti, L.V., S.C. Hatfield, and A. Jonsson. 1991. "Recent Advances in PWR Fuel Design at ABB-CE," in Proceedings Fuel for the 90's - International Topical Meeting on LWR Fuel Performance. Avignon, France, April 21-24, 1991, American Nuclear Society, pp. 113-121. 
3.2-11 Cunningham, M.E., M.D. Freshley, and D.D. Lanning. 1992. "Development and Characteristics of the Rim Region in High Burnup $\mathrm{UO}_{2}$ Fuel Pellets," Journal of Nuclear Materials, 188(1992)19-27.

3.2-12 Deramaix, P., and A. Charlier. 1986. "MOX Fuel Concepts for PWRs and BWRs," in Proceedings of Improvements in Water Beactor Fuel Technologx and Utilization, Stockholm, Sweden, September 15-19, 1986, IAEA, pp. 537-550).

3.2-13 Deramaix, P., D. Haas, and J. Van de Velde. 1993. "In-Pile Performance of Mixed-Oxide Fuel with Particular Emphasis on MIMAS Fuel," Nuclear Iechnologx, 102(1993)47-53.

3.2-14 Dienst, W., I. Mueller-Lyda, and H. Zimmermann. 1979. "Swelling, Densification and Creep of Oxide and Carbide Fuels Under Irradiation," in Proceedings of International Conference on Fast Breeder Reactor Fuel Performance, March 5-8, 1979, Monterey, CA, American Nuclear Society.

3.2-15 Freshley, M.D., and F.E. Panisko. 1967. The lrradiation Behavior of $\cup_{2}-P_{2} Q_{2}$ Euels in PRTB. BNWL-366. Pacific Northwest Laboratory, Richland, Washington.

3.2-16 Freshley, M.D., et al. 1979. "Irradiation-Induced Densification and $\mathrm{PuO}_{2}$ Particle Behavior in Mixed-Oxide Pellet Fuel," Journal of Nuclear Materials, 81(1979)63-92.

3.2-17 Freshley, M.D., et al. 1977. EPRL Plutonia_Fuel Study (RP396) - Final Summary Report. Prepared for the Electric Power Research Institute by Battelle, Pacific Northwest Laboratories.

3.2-18 Freshley, M.D., et al. 1972. "Behavior of Discrete Plutonium-Dioxide Particles in Mixed-Oxide Fuel During Rapid Power Transients," Nuclear Iechnology, 15(August 1972)239-248.

3.2-19 Goll, W., et al. 1993. "Irradiation Behavior of $\mathrm{UO}_{2} / \mathrm{PuO}_{2}$ Fuel in Light Water Reactors," Nuclear Technology, Vol. 102, pp. 29-46.

3.2-20 Haley, J. 1970. EEl-Westinghouse Plutonium Recycle Demonstration Program Progress Repert for the Period Ending April 1970. WCAP 4167-1. Westinghouse Electric Corporation, Pittsburgh, Pennsylvania.

3.2-21 Houston, D., et al. 1969. Review of Plutonium Recycle Demonstration to be Conducted in the San Onofre Reactor. Prepared for Southern California Edison Company by Battelle Memorial Institute, Columbus, Ohio. 
3.2-22 IAEA. 1990. Becvaling of Plutonium and Uranium in Water Reactor Fuels. IWGFPT/35, IAEA Technical Committee Meeting in Cadarache, France, November 1316, 1989.

3.2-23 Jonsson, A., et al. 1992. "Analysis of Critical Experiments with ErbiaUrania Fuel," Irans. American Nuclear-Society, 65(June 1992)415-416.

3.2-24 Liikala, R.C., U.P. Jenquin, and W.A. Reardon. 1965. The $\mathrm{PuO}_{2} \mathrm{UO}_{2}$ Experiment in the EBWB. BNWL-126. Pacific Northwest Laboratory, Richland, Washington.

3.2-25 Lyons, M.F., at al. 1964. UQ $\mathrm{U}_{2}$ Pellet Thermal Conductivity from Irradiation with Central Melting. GEAP-4624. General Electric Company.

3.2-26 Macherey, R.E. 1974. "History of EBWR Materials and Fuel Element Development," Iransactions American Nuclear Society, 18(1974)112-113.

3.2-27 Markl, H., and H. Stehle. 1977. "KWU Plutonium Recycle Fuel and Core Design, Performance and Experience," in Proceedings of the Topical Meeting on the Plutonium Fuel Cycle, Bal Harbour, Florida, May 2-4, 1977, pp. IV.2-1, American Nuclear Society, LaGrange, Illinois.

3.2-28 Martin, D.G. 1982. "A Re-Appraisal of the Thermal Conductivity of $\mathrm{UO}_{2}$ and Mixed (U,Pu) Oxide Fuels ," Jeurnal of Nuclear Materials, 110(1982)73-94.

3.2-29 Martin, D.G. 1988. "The Thermal Expansion of Solid $\mathrm{UO}_{2}$ and (U,Pu) Mixed Oxides - A Review and Recommendations," Journal of Nuclear Materials, 152(1988)94-101.

3.2-30 Massih, A.R., S. Persson, and Z. Weiss. 1992. "Modelling of (U,Gd) $\mathrm{O}_{2}$ Fuel Behavior in Boiling Water Reactors," Journal of Nuclear Materials, 188(1992)323-330.

3.2-31 Meyer, R.O., C.R. Hann, and D.D. Lanning. 1975. "Effects of Fissile Atom Segregation in Light Water Reactor Plutonium Recycle Fuels," Nuclear Iechnology, 27(November 1975)389-393.

3.2-32 Moore, R.S., and K.J. Notz. 1989. Physical Characteristics of GE BWR Fuel Assemblies. ORNL/TM-10902. Oak Ridge National Laboratory, Oak Ridge, Tennessee.

3.2-33 NRC. 1981. Standard Review Plan, Section 4.2. Fuel System Desion. NUREG-0800, U.S. Nuclear Regulatory Commission, Washington, D.C. 
3.2-34 Orr, W.L. 1977. "Westinghouse Pu Recycle Experience and Design," in Proceedings of the Topical Meeting on the Plutonium Fuel Cycle, Bal Harbour, Florina, May 2-4, 1977, pp. IV.4-1, American Nuclear Society, LaGrange, Illinois.

3.2-35 Philipponneau, Y. 1992. "Thermal Conductivity of (U,Pu) $\mathrm{O}_{2-x}$ Mixed Oxide Fuel," Jeurnal of Nuclear Materials, 188(1992)194 197.

3.2-36 Reese, A., et al. 1993. "Disposition of Weapons Plutonium Using the GE Advanced Boiling Water Reactor," in Proceedings of Future Nuclear Systems: Emerging Fuel Cycles and Waste Disposal Options. Global '93. Seattle, WA, September 12-17, 1993, American Nuclear Society, pp 825-832.

3.2-37 Small y, W.R. 1971. Saxton Core ll.FueL Performance Evaluation. Part Materials. WCAP-3385-56, Part I. Westinghouse Electric Corporation, Pittsburgh, Pennsylvania.

3.2-38 Smalley, W.R. 1974. Evaluation of Saxton Core Ill Fuel Materials Performance. WCAP-3385-57. Westinghouse Electric Corporation, Pittsburgh, Pennsylvania.

3.2-39 Touloukian, Y.S., editor. 1967. Thermephysical Properties of High Temperature Solid Materials, Vol. 4, The MacMillan Co., New York.

3.2-40 Uematsu, K., et al. 1979. "Irradiation Performance of Mixed Oxide Fuel Pins - Japanese Experience," in Proceedinos of International Conference on Fast Breeder Reactor Fuel Performance, March 5-8, 1979, Monterey, CA, American Nuclear Society.

3.2-41 Une, K., and S. Kashibe. 1992. "Fission Gas Release During Postirradiation Annealing of $\mathrm{UO}_{2}-2$ wt\% $\mathrm{Gd}_{2} \mathrm{O}_{3}$ Fuels," Journal of Nuclear Materials, 189(1992)210-216.

3.2-42 Voll, R.W. 1977. "Plutonium Recycle R\&D and Operating Experience at Big Rock Point," in Proceedings of the Topical Meeting on the Plutonium Fuel Cycle, Bal Harbour, Florida, May 2-4, 1977, pp. III.5-1, American Nuclear Society, LaGrange, Illinois.

3.2-43 Wallace, T.W. 1973. EEI-Westinghouse Plutonium Recycle Demenstration Program Progress Report for the Period April 1973-September 1973. WCAP 4167-6. Westinghouse Electric Corporation, Pittsburgh, Pennsylvania.

3.2-44 WEC. 1968. Economic Utilization of Plutonium in Pressurized Water Reactors. Final Report. WCAP-7160, Volumes 1 and 2. Westinghouse Electric Corporation, Pittsburgh, Pennsylvania. 
3.2.45 Yamamoto, K., et al. 1993. "Melting Temperature and Thermal Conductivity of Irradiated Mixed Oxide Fuel," Journal of Nuclear Materials, 204(1993)85-92.

3.2-46 Zolotar, B.A., and J.T.A. Roberts. 1976. "EPRI Plutonium Recycle Program," Iransactions American Nuclear Society, 23(1976)238-239.

3.2-47 Fiero, I.B. et al. 1994 "Staus of Erbium Burnable Absorber Development at ABB Combustion Engineering Nuclear Fuel," ANS International Topical Meeting on Light Water Reactor Fuel Performance, W. Palm Beach, FL, April 17-21, 1994. 
REVIEW ITEMS AS SPECIFIED IN SECTION 4.2 OF THE NRC SRP

\begin{tabular}{|c|c|}
\hline $\begin{array}{l}\text { Model/Behavior/etc. specifically } \\
\text { identified in SRP } 4.2\end{array}$ & Potential Impacts of Using $80+\mathrm{MOX}$ Relative to $\mathrm{UO}_{2}$. \\
\hline \multicolumn{2}{|l|}{ DAMAGE CRITERIA } \\
\hline $\begin{array}{l}\text { cladding/assembly stress/strain } \\
\text { limits }\end{array}$ & $\begin{array}{l}\text { secondary: changes in temperature or fluence affecting } \\
\text { properties }\end{array}$ \\
\hline cladding/assembly strain fatigue & $\begin{array}{l}\text { secondary: changes in temperature or fluence affecting } \\
\text { properties }\end{array}$ \\
\hline cladding/assembly fretting wear & $\begin{array}{l}\text { secondary: changes in temperature or fluence affecting } \\
\text { properties }\end{array}$ \\
\hline cladding/assembly oxidation/ & $\begin{array}{l}\text { secondary: changes in temperature or hydriding/ crud } \\
\text { buildup fluence affecting properties }\end{array}$ \\
\hline $\begin{array}{l}\text { cladding/assembly dimensional } \\
\text { changes }\end{array}$ & $\begin{array}{l}\text { secondary: changes in temperature or fluence affecting } \\
\text { properties }\end{array}$ \\
\hline fuel/burnable rod gas pressure & direct? changes in fuel, properties/behavior \\
\hline hydraulic loads & none? \\
\hline control rod reactivity & none \\
\hline \multicolumn{2}{|l|}{ DAMAGE CRITERIA } \\
\hline $\begin{array}{l}\text { cladding/assembly stress/strain } \\
\text { limits }\end{array}$ & $\begin{array}{l}\text { secondary: changes in temperature or fluence affecting } \\
\text { properties }\end{array}$ \\
\hline cladding/assembly strain fatigue & $\begin{array}{l}\text { secondary: changes in temperature or fluence affecting } \\
\text { properties }\end{array}$ \\
\hline cladding/assembly fretting wear & $\begin{array}{l}\text { secondary: changes in temperature or fluence affecting } \\
\text { properties }\end{array}$ \\
\hline $\begin{array}{l}\text { cladding/assembly } \\
\text { oxidation/hydriding }\end{array}$ & $\begin{array}{l}\text { secondary: changes in temperature or Crud/Buildup } \\
\text { fluence affecting properties }\end{array}$ \\
\hline $\begin{array}{l}\text { cladding/assembly dimensional } \\
\text { changes }\end{array}$ & $\begin{array}{l}\text { secondary: changes in temperature or fluence affecting } \\
\text { properties }\end{array}$ \\
\hline fuel/burnable rod gas pressure & direct? changes in fuel properties/behavior \\
\hline hydraulic loads & none? \\
\hline control rod reactivity & none \\
\hline
\end{tabular}


TABLE 3.2-1 (Cont'd)

REVIEW ITEMS AS SPECIFIED IN SECTION 4.2 OF THE NRC SRP

\begin{tabular}{|c|c|}
\hline FUEL ROD FAILURE & \\
\hline hydriding & direct? manufacturing process \\
\hline cladding collapse & $\begin{array}{l}\text { secondary: changes in temperature or fluence affecting } \\
\text { properties }\end{array}$ \\
\hline fretting & $\begin{array}{l}\text { secondary: changes in temperature or fluence affecting } \\
\text { properties }\end{array}$ \\
\hline sladding overheating & $\begin{array}{l}\text { secondary: changes in temperature or fluence affecting } \\
\text { properties }\end{array}$ \\
\hline fuel overheating & direct? changes in fuel thermal properties \\
\hline fuel enthalpy & none? \\
\hline $\mathbf{P C l}$ & direct? changes in fuel properties/behavior \\
\hline bursting & none? \\
\hline mechanical fracturing & $\begin{array}{l}\text { secondary: changes in temperature or fluence affecting } \\
\text { properties }\end{array}$ \\
\hline cladding embrittlement & $\begin{array}{l}\text { none? secondary?: changes in temperature or fluence } \\
\text { affecting properties }\end{array}$ \\
\hline violent expulsion of fuel & none? secondary? \\
\hline cladding melting & $\begin{array}{l}\text { secondary: changes in temperature or fluence affecting } \\
\text { properties }\end{array}$ \\
\hline fuel rod ballooning & $\begin{array}{l}\text { secondary: changes in temperature or fluence affecting } \\
\text { properties }\end{array}$ \\
\hline structural deformation & $\begin{array}{l}\text { secondary: changes in temperature or fluence affecting } \\
\text { properties }\end{array}$ \\
\hline \multicolumn{2}{|c|}{ ANALYTICAL PREDICTIONS } \\
\hline radial Dower distribution & secondary: change in spectrum/absorption \\
\hline $\begin{array}{l}\text { fuel and cladding temperature } \\
\text { distribution }\end{array}$ & $\begin{array}{l}\text { change in fuel thermal properties(?) and radial power } \\
\text { distribution(?) }\end{array}$ \\
\hline burnup distribution & secondary: change in spectrum/absorption \\
\hline $\begin{array}{l}\text { thermal conductivity of fuel, } \\
\text { cladding, }\end{array}$ & $\begin{array}{l}\text { change in fuel thermal conductivity?; crud oxidation } \\
\text { layers others need to be temperature dependent to } \\
\text { account for possible secondary effects of MOX }\end{array}$ \\
\hline
\end{tabular}


IABLE 3.2-1 (Cont'd)

REVIEW ITEMS AS SPECIFIED IN SECTION 4.2 OF THE NRC SRP

\begin{tabular}{|c|c|}
\hline fuel densification & yes? \\
\hline $\begin{array}{l}\text { thermal expansion of fuel and } \\
\text { cladding }\end{array}$ & $\begin{array}{l}\text { yes for fuel? cladding needs to be temperature } \\
\text { dependent }\end{array}$ \\
\hline fission gas production and release & $\begin{array}{l}\text { yes for fuel? production is fission/spectrum dependent. } \\
\text { release is temperature/fuel structure dependent }\end{array}$ \\
\hline $\begin{array}{l}\text { solid and gaseous fission product } \\
\text { swelling }\end{array}$ & yes? \\
\hline fuel restructuring and relocation & no for relocation? yes for restructuring? \\
\hline $\begin{array}{l}\text { fuel and cladding dimensional } \\
\text { changes }\end{array}$ & yes for fuel? only secondary for cladding? \\
\hline $\begin{array}{l}\text { fuel-cladding heat transfer } \\
\text { coefficient }\end{array}$ & maybe? \\
\hline thermal conductivity of gas mixture & no \\
\hline $\begin{array}{l}\text { thermal conductivity in the Knudsen } \\
\text { domain }\end{array}$ & no \\
\hline fuel-cladding contact pressure & yes? MOX mechanical properties \\
\hline heat capacity of fuel and cladding & yes for MOX, no for cladding \\
\hline growth and creep of cladding & $\begin{array}{l}\text { secondary: changes in temperature or fluence affecting } \\
\text { properties }\end{array}$ \\
\hline $\begin{array}{l}\text { rod internal gas pressure and } \\
\text { composition }\end{array}$ & no \\
\hline $\begin{array}{l}\text { sorption of helium and other fill } \\
\text { gases }\end{array}$ & no? \\
\hline $\begin{array}{l}\text { cladding oxidation and crud layer } \\
\text { thickness }\end{array}$ & $\begin{array}{l}\text { secondary: changes in temperature or fluence affecting } \\
\text { properties }\end{array}$ \\
\hline $\begin{array}{l}\text { cladding-coolant heat transfer } \\
\text { coefficient }\end{array}$ & no \\
\hline
\end{tabular}

(a)Specifically identified in the NRC's Standard Review Plan, Section 4.2 


\section{Combustion Engineering, Inc.}

TABLE 3.2-2.

FUEL ROD THERMAL/MECHANICAL PERFORMANCE MODELS

\begin{tabular}{|c|c|c|c|c|}
\hline Model & $\begin{array}{l}\text { Directly affected } \\
\text { by MOX? }\end{array}$ & $\begin{array}{l}\text { MOX data } \\
\text { avallable? }\end{array}$ & $\begin{array}{l}\text { MOX data } \\
\text { needed for LTA? }\end{array}$ & MOX date needed for licensing \\
\hline Radial Power & $?$ & $?$ & $?$ & \\
\hline temperature distribution & $\begin{array}{l}\text { yes - depends on } \\
\text { other models }\end{array}$ & & & \\
\hline Burnup distribution & yes? & & & \\
\hline Fuel thermal conductivity & yos & yes & possibly not & $\begin{array}{l}\text { probably yes } \\
- \text { Pu }<15 \% \text { and in renge planned } \\
-80+\mathrm{MOX}\end{array}$ \\
\hline Cladding thermal conductivity & no & & & \\
\hline crud/oxidation thermal conductivity & no & & & \\
\hline fuel densification & yes & $?$ & $?$ & \\
\hline Fuel thermal expansion & yes & $?$ & $?$ & \\
\hline flesion gas production/ralease & yes? & $?$ & $?$ & \\
\hline fission product swelling & $?$ & & & \\
\hline fuel relocation & $?$ & & & \\
\hline fuel restructuring & Yes & $?$ & $?$ & \\
\hline fuel dimensional changes & $?$ & & & \\
\hline cladding dimensional changes & no? & & & \\
\hline Fust-cladding hoat transfor & $?$ & & & \\
\hline ges thermal conductivity & no & & & \\
\hline Knudsen domain thermal conductivity & $?$ & & & \\
\hline fuel-cladding contact pressure & $?$ & & & \\
\hline fuel hoat capacity & yes & $?$ & $?$ & \\
\hline cladding heat capacity & yos & $?$ & $?$ & \\
\hline cladding growth & no & & & \\
\hline cladding creop & no & & & \\
\hline rod ges pressure/composition & no? & & & \\
\hline fill gas sorption & no? & & & \\
\hline oxide/crude layer thickness & no & & & \\
\hline cladding/ coolant heat transfor & no & & & \\
\hline
\end{tabular}


TABLE 3.2-3

SUMMARY LISTING OF MOX TYPES AND CONDITIONS DISCUSSED IN REFERENCES

\begin{tabular}{|c|c|c|c|c|c|c|}
\hline Reference & Number & $\begin{array}{l}\text { Fuel } \\
\text { Application }\end{array}$ & $\% \mathrm{Pu}$ & LHGR & Burnup & Comments \\
\hline Abe et al. 1992 & $3.2-1$ & LWR & $6-10$ & To failure & hear zero & transient testing \\
\hline $\begin{array}{l}\text { Bailey and Freshley } 1967 \\
\text { Freshley and Panisko } 1967\end{array}$ & $\begin{array}{l}3.2-4 \\
3.2-15\end{array}$ & LWR & $1-20 \mathrm{~kW} / \mathrm{m}$ & to $-65 \mathrm{KW} / \mathrm{m}$ & to $-20 \mathrm{MWd} / \mathrm{kgM}$ & vi-pac fuel \\
\hline Bariot and Beramaix 1992 & $3.2-6$ & LWR & $<10$ & & & generic discussion \\
\hline Bariot et al. 1986 & 3.2-7 & LWR & $4-11$ & & 30-50 MW/dkgM & \\
\hline Beauvy 1992 & 3.2-9 & LWR & $<20$ & & honirradiated & properties data \\
\hline Corsetti, Hatfield, and Jonsson 1991 & $3.2-10$ & LWR & 0 & & & $\mathrm{NO}_{2}-\mathrm{Er}_{2} \mathrm{O}_{3}$ \\
\hline $\begin{array}{l}\text { Deramiax, Haas, and Van de Velde } 1993 \\
\text { 3.2-13 }\end{array}$ & $3.2-13$ & LWR & low & $\begin{array}{l}<39 \mathrm{~kW} / \mathrm{m} \\
\text { maximum }\end{array}$ & $\begin{array}{l}50 \mathrm{MWd} / \mathrm{kgM} \text { peak } \\
\text { pellet }\end{array}$ & \\
\hline Dienst, Muller-Lyda, and zimmerman 1979 & $3.2-14$ & FBR & $\geq 20 \% ?$ & & & swelling and creep \\
\hline Deramiax, Haas, and Van de Velde 1993 & $3.2-13$ & LWR & low? & $39 \mathrm{KW} / \mathrm{m}$ & $50 \mathrm{MWd} / \mathrm{kgM}$ & \\
\hline $\begin{array}{l}\text { Freshley et al. } 1977 \\
\text { Freshloy ot al. } 1979\end{array}$ & $\begin{array}{l}3.2-17 \\
3.2-16\end{array}$ & LWR & $<6$ & $40 \mathrm{KW} / \mathrm{m}$ & $4.5 \mathrm{Mwd} / \mathrm{kgM}$ & \\
\hline Goll ot al. 1993 & $3.2-19$ & LWR & 3.5 & & $42 \mathrm{MWd} / \mathrm{kgM}$ & \\
\hline $\begin{array}{l}\text { Haley } 1970 \\
\text { Houston et al. } 1969\end{array}$ & $\begin{array}{l}3.2-20 \\
3.2-21\end{array}$ & LWR & 4.5 & & $30 \mathrm{MWd} / \mathrm{kgM}$ & \\
\hline Jonsson et al. $1992 \quad 3.2-23$ & $3.2-23$ & LWR & 0 & & & $\mathrm{NO}_{2}-\mathrm{Er}_{2} \mathrm{O}_{3}$ \\
\hline Macherey 1974 & $3.2-26$ & LWR & 1.5 & & & vi-pac loading \\
\hline Martin 1982 & $3.2-28$ & LWR/FBR & $15-30$ & & & thermal conductivity \\
\hline Phillipponneau 1992 & 3.2-35 & LWR & 15-30 & & hon-irradiated & thermal conductivity \\
\hline
\end{tabular}


IABLE 3.2-3 (Cont'd)

SUMMARY LISTING OF MOX TYPES AND CONDITIONS DISCUSSED IN REFERENCES

\begin{tabular}{|c|c|c|c|c|c|c|}
\hline Reference & Number & $\begin{array}{l}\text { Fuel } \\
\text { Application }\end{array}$ & $\% \mathrm{Pu}$ & LHGR & Burnup & Comments \\
\hline \begin{tabular}{|ll} 
Smalley & 1971 \\
Smalley & 1974
\end{tabular} & $\begin{array}{l}3.2-37 \\
3.2-38\end{array}$ & LWR & 6.6 & $\begin{array}{l}\text { peak pellet }-65 \\
\mathrm{KW} / \mathrm{m}\end{array}$ & to $51 \mathrm{MWd} / \mathrm{kgM}$ & \\
\hline Umeatsu et al. 1979 & $3.2-40$ & FBR & $>20$ & & & swelling \\
\hline Une and Kashibe 1992 & & LWR & o & & & $\mathrm{NO}_{2}-\mathrm{Gd}_{2} \mathrm{O}_{3}$ \\
\hline Voll 1977 & $3.2-42$ & LWR & $1.6-9.1$ & & $20 \mathrm{MWd} / \mathrm{kgM}$ & $\begin{array}{l}\text { test rods to a full core } \\
\text { reload }\end{array}$ \\
\hline Yamamota ot al. 1993 & $3.2-45$ & FBR & $\begin{array}{l}29 \% \text { for melting } \\
\text { temperature } \\
18 \% \text { for thermal } \\
\text { conductivity }\end{array}$ & $\begin{array}{l}\text { as appropriate } \\
18 \mathrm{KW} / \mathrm{m}\end{array}$ & $35 \mathrm{MWd} / \mathrm{kgM}$ & properties data \\
\hline
\end{tabular}




\subsection{Development lssues}

\subsubsection{Technical lssues}

Since the technology needs of System $80+$ have already been met, and the system is being offered commercially and has been through Design Certification licensing review, there are no development issues. The application of System $80+$ to the plutonium disposition revision involves a change in the fuel cycle and some changes in the operating characteristics of the reactor. Based on the earlier U.S. experience and the current world-wide experience with plutonium recycle, there are no developmenc issues identified with plutonium utilization. Confirming analysis and fuel qualification testing are straight forward processes and are expected to be issue-free.

\subsubsection{Development and Test Facilities}

No new development and test facilities are required to complete the planned fuel qualification propane.

Existing DOE facilities have been reviewed relative to their potential application to the fuel qualification propane. Sufficient base capability is available, but some preliminary work will be required to put facilities into operation.

The following paragraphs summarize the existing capabilities that have been reviewed:

\section{IA-55 at Los Alamos}

A complete glove box fabrication line is available and operational for making test reactor pins. There is a limit on the length of pin TA-55 can produce - about 6 to 8 feet long. Extending the final glove box to handle prototype-length fuel rods would not be difficult. The production and purification of Pu oxide powder can be done. Purification to remove Am-241 is relatively simple and can be done in combination with the reduction of the metal pit to oxide powder. Purification of the pit by the removal of gallium and the other trace impurities from the pit is available if required.

The bid disadvantage of TA-55 is its current limited throughout: about 4 tons of fuel a year without a major revamping of the facility. The infrastructure is available and quite good. If fabrication problems occur this is the ideal research facility in which to develop "fixes".

\section{SRS}

The Pu area is essentially deactivated. Equipment is still in the facility but the staff and supporting infrastructure are being deactivated. The equipment is not suited to fabrication of test reactor fuel pins. 


\section{Combustion Engineering, Inc.}

\section{EMEA}

Equipment for fabrication of fuel pins is present (both test reactor and prototypical fuel elements could be metal). However, the infrastructure is no longer viable.

\section{Agnes Reprocessing Plant}

The plant has been decommissioned and some of the equipment diverted to other uses. It is no longer viable for any use except possibly long term pool storage of spent fuel. 


\subsection{OPERATIONS}

\subsection{Government, Utility and Private Industry Interfaces}

\subsubsection{Introduction}

The use of System $80+$ for the Plutonium disposition mission would involve interactions between the U.S. Government, the utilities and private industry, depending upon the nature of the basic arrangements (plant ownership, electricity marketing, etc). Since System $80+$ is technologically mature, the relative attractiveness of private industry to take over the design, construction, ownership and operation of the plant, and the marketing of the electricity, under an irradiation services agreement with the government, is a potential option that should minimize government involvement and expenditures. This section outlines a program based on such an arrangement.

\subsubsection{Deployment Concept}

The organization of a privately funded consortium which would design, license, build, own, and operate the System $80+$ multipurpose plant is presumed. In the consideration of such an arrangement, it is noted that:

- The U.S. utility industry is presently in transition from its traditional mode of construction and operation of plants by utilities (with financial returns through a regulated rate base) to a mode in which peaking and intermediate plants are being built and operated by Independent Power Producers (IPPs), and more recently Exempt Wholesale Generating Companies (EWGs), which derive their financial returns from power purchase agreements with one or more of the utilities.

- A similar transition with respect to baseload plants (with much higher ratios of capital to operating cost) is impending, with the expected need for additions to baseload capacity early in the next century. Such capacity will require longer time horizons for planning than those contemplated by present IPPs and EWGs.

While some information is available as a result of ongoing experience with the first stage of the above transitions, the outlines of the second (baseload capacity) remain to be developed.

In order to obtain the required funding, the consortium would have to demonstrate its ability to earn a return on the investment. As envisioned in this plan, consortium revenues would come from two sources:

- $\quad$ Power purchase agreements for electricity. 
- An irradiation services agreement with the government (for disposition of plutonium and production of tritium or other isotopes).

Firm power purchase agreements that provide adequate rates of return and an irradiation services contract with the federal government will avoid the need for Government loan guarantees.

Certain features of the proposed System $80+$ multipurpose facility will reduce the required revenues of the project:

a. Final Design Approval of the System $80+$ standard design will be issued by NRC in August 1994 -- followed by Design Certification, due to be completed by December 1995. Besides eliminating a substantial early expense, this markedly reduces the regulatory risks for the deployment of the plant.

b. Siting on a government reservation at little or no cost to the consortium will reduce costs and simplify licensing of the facility.

c. The high throughput of plutonium (3.5 metric tons of weapons plutonium per year, with two System $80+$ units) can be achieved with the System $80+$ design; thus, minimizing the number of units to be constructed.

\subsubsection{Orasnization of the Consortium}

\subsubsection{The Exempt Wholesale Generator}

In 1992, Congress and the Administration developed and approved the Energy Policy Act. A key provision of the Act was reform of the Public Utilities Holding Company Act (PUHCA), to allow the formation of Exempt Wholesale Generators (EWGs). EWGs are a new class of Independent Power Producers that are free from corporate and geographic restrictions that existed in previous legislation. Prior to the 1992 Energy Policy Act (and the provision for EWGs), the ability to privately finance the System $80+$ multi-purpose facility could have only been accomplished by one or more utilities --- under the regulation of their public utility commissions.

It is now possible for un-regulated companies to generate and sell electricity -including reactor suppliers, architect/engineers, private investors, un-regulated subsidiaries of utilities, etc.

The 1992 Act also provides for wheeling of electrical power. Thus, an EWG can now rely upon neighboring utilities to provide access for wheeling electricity produced by the facility to other utilities. This provision is particularly important for a large generating plant (e.g., the System $80+$ facility) that will likely need to wheel power to several utilities over a broad region. 


\subsubsection{The Regional Ceneratina Company Concept}

One potential model for future nuclear plant ownership has been proposed (William S. Lee, Duke Power Company, "Atoms for Peace - Phase 2", Nuclear Energy Forum, Chicago, November, 1992), which recognizes the need to avoid rate shock by adding power supply to individual utilities in small increments, the need to spread risk, and at the same time the need to provide ownership and operation by companies with technical resources and depth of expertise.

Under this model, a plant would be owned and operated by a regional generating company whose stock is owned by several utilities which would share in the plant's output. Equity financing would be provided through the unregulated subsidiaries of the same utilities.

Since the electric output of the plant would be sold at wholesale rather than retail, local regulatory authorities would review only the power supply contracts between the regional company and the retail utilities -- not the operation of the plant.

Borrowing from this concept for the System $80+$ facility, it is envisioned that an EWG would include the unregulated subsidiaries of various utilities in the southeastern U.S. The EWG could also include investors that are not affiliated with regional utilities -e.g., the many IPPs that are currently participating in power projects around the country (and the world). It is expected that the major stakeholders in the EWG will be subsidiaries of utilities that are interested in purchasing the electricity from the facility at a competitive price.

\subsubsection{The role of the System $80+$ Team in the EWG}

Based upon lessons learned from the first generation of nuclear plants, it is expected that both the equity and the debt investors would require that at least the major participants of the System $80+$ Team also have an equity stake in the plant, sharing in both the risks and the rewards. While this stake may be smaller than the investments of the other participants, it would be large enough to assure effective performance during the design and construction phases.

\subsubsection{Risk Sharing among EWG Members}

As noted earlier, one of the principal reasons for multiple ownership of the plant is to spread risk. No single company can take the entire risk of construction and operation of a new nuclear power plant, or for that matter, any other project of comparable size and complexity. One of the most important lessons learned in the first generation of nuclear plants is that risks must be identified early and then apportioned (by contractual commitments) to the organization that can control the risk. 
The financing costs are strongly influenced by the perceived degree of risk. Under the program plan, actions will be taken, in addition to those already in hand, to limit specific risks. Some of these are as follows:

- Technical/regulatory risk. NRC Design Certification of System $80+$ is well advanced. A Final Safety Evaluation Report, with no open items, was issued in February 1994. The present schedule indicates that rule-making will be completed by December 1995, within the period of the Program Plan. Under the rule, new NRC requirements which might affect the design, the cost, or the schedule would be sharply limited, thus limiting the regulatory risk.

- Bisk of delay in plant operation. The System $80+$ plant would be built in accordance with the terms of the Design Certification and be licensed in a one-step licensing process (combined Construction and Operating License, COL), under 10CFR52. This would not, therefore, require a separate operating license proceeding, which was responsible for the delays experienced by many of the existing nuclear plants.

Rower cost risk. Because the cost of producing power from a nuclear power plant is dominated by the capital cost, the risk of variations in power generating costs during the life of the plant is much smaller than that with a plant in which the power cost is dominated by fuel costs. With a certified ALWR design and the lessons learned from the first generation of nuclear plants, the risks of major backfits (which have the effect of increasing the capital costs) and uncontrollable O\&M costs, after the plant is in operation, are much reduced. The prospect of long term price stability is expected to be an attractive feature of the power purchase agreements since that stability will balance against the presently low cost of alternative power sources generated by natural gas, but which also presents a significant risk of future fuel price increases.

Construction cost and schedule risk. Since the System $80+$ Team includes large companies with long experience in nuclear plant design and construction and with ample resources of qualified personnel, the internal cost and schedule risks are considered manageable. Experience gained from the recent System 80 + fixed-price bid to Taiwan Power Company provides a firm basis for understanding and quantifying the risks involved. In order to be able to present the project cost and schedule to prospective consortium members with assurance, additional detailed design, estimating, and schedule work will be accomplished under the program described in this plan. 
- Some licensing risks remain:

- The System 80 + Design Certification will be based on use of low enriched uranium fuel. An amendment permitting mixed oxide fuel (MOX) would be required. Since the reactor is already designed for MOX with $100 \%$ plutonium as the fissile component, the technical risk is low. The primary licensing impact should be limited to the reactor core design, along with demonstration that the safety analyses for the MOX core are bounded by the already approved analyses for the conventional uranium core. As a policy issue, it is expected that NRC approval of MOX fuel is readily achievable because this would be a one-time approval for a single facility on a government site using weapons plutonium in a once-through cycle. Under the program, the required licensing materials would be prepared during Phase C.

- A license would be required for the MOX fuel fabrication facility. Since BNFL (which has recently designed, built, and placed in service a MOX facilityl is a member of the System 80 + Team, with responsibility for the MOX process design, actual experience will be available for reference during licensing of the MOX facility, reducing the risk of needing extensive testing and validation. Design and licensing of the MOX facility will be addressed under the program.

- Environmental licensing and local permits will be required. Since the plant will be wholly contained within the Savannah River reservation, and will have the benefit of existing environmental data, these risks should be limited. Environmental licensing will also be addressed under the program (see Sections 5.3.4 and 6.7.1).

As other potential risks are identified during the period of the program, actions will be taken to define and limit them, with the purpose of reducing the risk premiums in the financing costs. This will control the capital charges and thus the amounts of the annual payments for radiation services from the government.

\subsubsection{Growing Availability of Capital for Investment}

The U.S. utility industry has worked off its backlog of capital intensive construction projects and is getting prepared to face a highly competitive marketplace for electricity sales. Most new capacity additions (which are to meet peaking needs) are natural gas units -- which are very low in capital costs. Moreover, if the capacity is being purchased from an IPP, there is no capital investment required from the utility. 
As a result, utilities, as a group, are expected to have cash available for investment in future generating projects. Competitive pressures in the marketplace, combined with deregulation, will prompt utilities to prefer higher yield investments that are not regulated by their public utility commissions. This, combined with a growing need for new baseload capacity, will likely be a major source of equity investment in the System $80+$ facility.

In addition to the utility industry, there are a growing number of other companies that are taking equity positions in IPP-based power generating projects. Such companies are likely to play a very substantial role in the future. However, to attract their participation, the nuclear EWG will need to offer a competitive rate-of-return and allocations of risks.

\subsubsection{Power Purahase Aoreements}

\subsubsection{Operation of an Aareement}

Under the Energy Policy Act of 1992, a consortium, including members of the System $80+$ Team, and unregulated utility subsidiaries could register with the Federal Energy Regulatory Commission (FERC) as an Exempt Wholesale Generator (EWG) to build and operate a System $80+$ plant for wholesale power generation.

The rates charged by an EWG for wholesale power are subject to FERC approval. Under the Act, the state's authority to review purchased power transactions with EWGs is significantly curtailed, although if a utility is both affiliated with (a participant in) the EWG and a purchaser of the EWG's power, the state may retain a veto power over the transaction under certain circumstances. Interpretation of the Act is still developing. There may also be a prudence risk for an affiliated utility which purchases power from an EWG if the power is not priced consistent with the utility's and the state's approved resource plans.

The Act offers a newly available structure and opportunity in which a nuclear EWG is feasible. In turn, however, the consortium must be able to provide accurate and competitive price estimates.

\subsubsection{Increased Competitiveness in the Utility Industry}

At the present time, utilities appear to favor a high degree of flexibility, characterized by limited capacity purchases over short time horizons, in order to maximize their own competitive positions. It is believed that this is at least partly because the utilities are still, in general, generating their own base load power and purchases are primarily to satisfy relatively volatile peaking requirements.

As utilities begin to extend their power purchases into the baseload regime, it is expected that long term price stability will become a more important factor. 


\subsubsection{Power Purchase from Nuclear Baseload Plants}

With load growth and concurrent aging of the present stock of baseload capacity, it is expected that early in the next century there will be a need for new baseload capacity in the southeastern U.S. which can primarily be best satisfied by "clean coal" or nuclear plants. Combined cycle natural gas plants may also play a major role in this market. The relative mix of these technologies, howeve?, will be strongly influenced by the future price of natural gas.

A nuclear plant, in which the cost of power is dominated by a "locked in" capital cost, and with the regulatory risk limited by Design Certification, should offer a desirable level of price stability. In addition, features such as generation diversity, Clean Air Act Amendments allowance credits, and lack of carbon emissions, will be considered desirable attributes for nuclear.

However, it is improbable that any single utility will want a major share of the total capacity of a nuclear plant, partly due to the need to increase capacity gradually to match load growth and partly due to the perceived risks of nuclear plants. Therefore, it is anticipated that the pattern will be a large number of power purchase agreements for relatively small blocks of capacity.

In order to develop such a market, extended discussions and negotiations with a large number of potential purchasers and utility commissions will be required. These will be conducted under the program.

\subsubsection{Financial Institutions}

\subsubsection{Overall Financing Plan}

The general financing plan consists of two phases and two general categories of financial instruments, as follows:

Construction financing. During the design and construction period, the consortium members would contribute equity and contract for short term debt. Due to the inherent uncertainties of the construction phase, the cost of the debt is expected to be relatively high during the construction period, which, therefore, needs to be as short as possible.

Permanent financing. At completion of construction, the total construction cost, including the accumulated interest during construction, would be converted to a combination of continued equity and long term debt. Since at this time, the construction and startup cost would have been successfully completed and the final power purchase and irradiation services agreements would be in existence, the cost of long term financing should be substantially lower. 


\begin{abstract}
Although the equity component in the construction period might be somewhat higher than in the long term financing, it is anticipated that debt ratios in the range of 70 to $80 \%$ should be feasible for both phases.
\end{abstract}

\title{
4.1.6 Role of the Government
}

Although the plant would be privately financed, designed, constructed, and operated, the government would have several important roles which contribute to project feasibility. These would be specifically defined, working with government representatives. Since the fees for irradiation services would be defined as the difference between the total revenue requirements and the electric revenues, it is to the government's advantage to adopt roles that reduce project costs where that can be done at minimal cost to the government.

\subsubsection{Site Lease}

The government would provide a suitable site on the Savannah River reservation at little or no cost to the consortium. This would include access, right-of-ways, use of existing infrastructure and provision of existing environmental and site characterization data.

\subsubsection{Disposition of Excess Plutonium}

As presently conceived, the government would make available, over an agreed upon period, plutonium and depleted uranium in oxide (powder) form. Conversion of this feed material to MOX fuel would be accomplished by the consortium.

If the government prefers to provide the excess plutonium in some other form, such as pits, conversion to oxide and MOX fuel could be accomplished by the consortium, but would have to be reflected in the charges for irradiation services.

\subsubsection{Disposition of Spent Fuel}

Spent MOX fuel would be technically similar to spent fuel from a commercial LWR reactor, and would be disposed of in the same way. The government would have to assure that there is adequate storage capacity at the High Level Waste Repository. The disposal fee (presently 1 mill per kilowatt hour) would be paid by the consortium and then passed through to the government.

\subsubsection{Bisk Sharing}

In addition to the risks assumed by the consortium and reflected in the financing costs, it seems appropriate for the government to share risks in those areas which it controls. At present, two such areas have been identified: 
- $\quad$ Risks associated with prior activities at the site. If environmental cleanup is required as a result of existing contamination, such cleanup should be the responsibility of the government, as it would have been if no System $80+$ plant were planned or built.

- Changes resulting from new or changed regulations issued by a government agency should be the responsibility of the government.

\subsubsection{Contractual Arrongements}

It is obvious from the above that the contractual structure of the Deployment Phase will be complex and interdependent. It is envisioned that there will be contracts:

between the EWG Consortium members, to formally establish the role of each member in the EWG;

between the EWG and the utilities agreeing to purchase or wheel electrical power;

between the EWG and financial institutions; and,

between the EWG and the federal government for site lease, plutonium supply, and irradiation services. 


\subsection{Checkout and Startup Tests}

Initial startup of a System $80+$ utilizing mixed-oxide (MOX) fuel would necessitate modification to the normal test program in three areas:

- Fuel storage and handling

- Boron management

- Core neutronics

The test program used for testing a System $80+$ is summarized in Tables 4.2-1 through 4.2-5. Tests that could potentially be impacted by utilizing MOX fuel are annotated. These are limited to 17 out of 230 tests. Most startup tests are unaffected by the presence of MOX fuel since they are primarily required to demonstrate the operability of plant equipment. In some cases, the components must be re-sized or re-designed but this would not impact the overall conduct of the testing program. 


\subsubsection{Euel Storage and Handling}

Initial fuel loadings for $\mathrm{UO}_{2}$ cores require minimal concern for the fuel's radiation levels. MOX fuel, on the other hand, is expected to have a significant inherent radioactive level due to the decay of plutonium and americium isotopes. This requires that the initial receipt and subsequent fuel storage be under water. MOX fuel must also be stored in more conservative fuel storage racks to assure sub-criticality. Subsequent initial core load will require that the fuel handling canal be flooded rather than dry as is the usual process for initial $\mathrm{UO}_{2}$ cores. This will not only change the initial testing procedures to reflect the presence of the water shielding, but will also require that prefuel load testing utilizing dummy fuel be more extensive than that normally carried out for $\mathrm{UO}_{2}$ since for the $\mathrm{UO}_{2}$ core final adjustment can be performed during the dry (fuel load canal) loading. All special fuel load equipment such as temporary neutron monitoring channels will have to be manipulated remotely rather than having the usual access to the top of the vessel.

\subsubsection{Boron Management}

Use of highly loaded (6.7\% weapons grade PU) MOX fuel requires a significantly larger (factors of 2 or 3 ) amount of soluble $B^{10}$ in the core for initial operation than does the normal low enrichment $\mathrm{UO}_{2}$. The increased $\mathrm{B}^{10}$ can either be achieved by increasing the concentration of the soluble boron or by utilizing boron enriched in the $B^{10}$ isotope.

Rather than accepting these operational problems for the MOX fuel burner, it has been proposed that boron enriched in the $B^{10}$ isotope be used instead of natural boron. $B y$ utilizing soluble boron of the appropriate enrichment, the soluble boron concentration can be quite similar to that used for $\mathrm{UO}_{2}$ cores, thus minimizing any changes to equipment or procedures. This is discussed more completely in Section 2.1.1.5.

Use of the enriched boron will impact testing and initial and subsequent operation in two ways:

- It will place a significantly higher importance on the boronometer as the only quick way that the relative $B^{10}$ content can be determined.

- Since enriched $B^{10}$ is more costly than natural boron, considerable emphasis will be placed on re-cycling the boron for subsequent re-introduction to the reactor.

The fact that the effectiveness of the soluble boron can no longer be determined by means of standard chemical techniques may require that redundant boronometers be installed and that a procedure for assuring their calibration be incorporated. Portable or remote boronometers may also be required to allow testing of boron prior to its introduction to the primary fluid system. 
Recycling of boron from cycle to cycle is done in the United States but usually there is a significant loss of boron during each cycle since the cost of natural boron is not that high as to require careful preservation of inventories. In Europe, boron recycling has been more assiduously pursued. This can result in the situation where neutron depletion of the $B^{10}$ must be considered and may require deliberate replacement of the enriched boron on a pre-determined schedule.

\subsubsection{Core Neutronics}

For the initial core, the largest impact is the result of the core neutronics. The physics of the MOX core is significantly different than that of a low enrichment $\mathrm{UO}_{2}$ core. Rod worths, peaking factors, temperature and power coefficients, and kinetic parameters are all different. These differences require that the first MOX core be treated as a first of a kind (expanded) core test program. Tables 4.2-6 and 4.2-7 compare a typical first of a kind (expanded) testing program to an Nth of a kind program.

In addition to the first of a kind testing, consideration was given to the impact of the physics differences on other operational and testing areas:

- Rod worth

- High inherent neutron background impact on startup, etc.

- MTC/power coefficient, etc.

- Spectral difference effect on excore and incore detectors impact of core spectrum on shape annealing matrix

- Xenon control

- Delayed neutron parameter differences

The tests carried out for low power physics will be quite similar to those performed for a normal $\mathrm{UO}_{2}$ core. The actual values of the parameters will differ but the technique for their measurement will not. Rod worths will be less. This may make it desirable to re-configure the rod patterns so as to assure relative group worth optimum for control and shutdown but change of rod drive speeds would not be required. From an operator perspective, the reduction in rod worths will be offset by Pu fuels' lesser value of $\beta$, plant response being proportional to $\Delta \varrho / \beta$ not $\Delta \varrho$. Temperature coefficients, boron worths, and critical borons would all change but not to the extent that would require changes in the measurement techniques.

The higher neutron background from the MOX fuel will require that greater care be given to selecting the power range for performing the Low Power Physics Tests (LPPT) measurements. The power range will be biased higher and the lower limit must be higher than that for a $\mathrm{UO}_{2}$ core in order to minimize the contaminating effect of the high neutron background. This requires running much closer to the point of adding nuclear heat. In addition, during rod worth measurements, much more attention will have to be paid to maintaining a constant temperature since the temperature coefficient for MOX fuel is more negative than that for $\mathrm{UO}_{2}$. This effect could be 
minimized by using a temperature corrected reactivity computer for the performance of this measurement.

Measurements associated with accurate knowledge of $B^{10}$ concentration such as boron worth and critical boron will require verification of isotopics as well as the usual chemistry analyses.

During power ascension testing, the response of the reactor to transients will be impacted by the changes in the reactivity coefficients, rod worths, and kinetic parameters. Although these changes will be significant to the safety analysis, they will not require changes in the test program.

The effect of core spectral differences has been considered for excore and incore neutron detector response and for the operation of the protective systems. The spectral effects will significantly change the relationship of detector signals to power level determination but this is primarily a matter of normalization. The impact on the reactor protective system parameters such as shape annealing factor (matrix) is not expected to be significant since the detectors are located in moderating media which reflect thermal neutrons coming from the core and monitor only those fast neutrons thermalized in the immediate vicinity of the detector. The signal observed should be larger for a MOX core but the effect should be well within the range that has been experienced in the various low and high leakage $\mathrm{UO}_{2}$ cores.

Demonstration of xenon control strategies will require a significant modification from that carried out for most previous System 80 + plants since for a $\mathrm{UO}_{2}$ core the xenon oscillations are usually controlled using part strength rods. For MOX cores, these have been replaced by full strength rods. This will require a test based on the use of full strength rods.

In summary, although there will be changes in the test program for the initial MOX core from that performed for a follow on $\mathrm{UO}_{2}$ plant, there are no areas that are expected to present a problem that cannot be addressed based on extension of current techniques. It is recommended that the test program be simulated using MOX core simulators so as to better quantify the differences. This is particularly true for the areas of shutdown margin determination and at power transient behavior.

\subsubsection{MF}

Checkout and startup tests will be developed as part of the detailed design process of the $\mathrm{MF}^{2}$. 
CESSAR-DC

Section

14.2.12.1.1

14.2.12.1.2

14.2.12.1.3

14.2.12.1.4

14.2.12.1.5

14.2.12.1.6

14.2.12.1.7

14.2.12.1.8

14.2.12.1.9

14.2.12.1.10

14.2.12.1.11

14.2.12.1.12

14.2.12.1.13 $3^{(2)}$

14.2.12.1.14

14.2.12.1.15

14.2.12.1.16

14.2.12.1.17

$14.2 .12 .1 .18^{(2)}$
TABLE 4.2-1(1)

(Sheet 1 of 8)

PREOPERATIONAL TESTS

Title

Reactor Coolant Pump Motor Initial Operation

Reactor Coolant System Test

Pressurizer Safety Valve Test

Pressurizer Pressure and Level Control Systems

CVCS Letdown Subsystem Test

CVCS Purification Subsystem Test

Volume Control Tank Subsystem Test

CVCS Charging Subsystem Test

Chemical Addition Subsystem Test

Reactor Drain Tank Subsystem Test

Equipment Drain Tank Subsystem Test

Boric Acid Batching Tank Subsystem Test

Concentrated Boric Acid Subsystem Test

Reactor Makeup Subsystem Test

Holdup Subsystem Test

Boric Acid Concentrator Subsystem Test

Gas Stripper Subsystem Test

Boronometer Subsystem Test

(1) The source of this listing is CESSAR-DC Table 14.2-1, Amendment T.

(2) The noted tests are part of the seventeen tests referred to in Section 4.2. 
CESSAR-DC

Section

14.2.12.1.19

14.2.12.1.20

14.2.12.1.21

14.2.12.1.22

14.2.12.1.23

14.2.12.1.24

14.2.12.1.25

14.2.12.1.26

14.2.12.1.27

14.2.12.1.28

14.2.12.1.29

14.1.12.1.30

14.2.12.1.31

14.2.12.1.32

14.2.12.1.33

14.2.12.1.34

$14.2 .12 .1 .35^{(2)}$
IABLE 4.2-1'(1)(Cont'd)

(Sheet $\mathbf{2}$ of $\mathbf{8}$ )

\section{PREOPERATIONAL TESTS}

Title

Process Radiation Monitor Subsystem Test

Gas Stripper Effluent Radiation Monitor Subsystem Test

Shutdown Cooling System Test

Safety Injection System Test

Safety Injection Tank Subsystem Test

Megawatt Demand Setter System Test

Engineered Safety Features - Component Control System Test

Plant Protection System Test

Ex-core Nuclear Instrumentation System Test

Fixed In-core Nuclear Signal Channel Test

Control Element Drive Mechanism Control System Test

Reactor Regulating System Test

Steam Bypass Control System Test

Feedwater Control system Test

Core Operating Limit Supervisory System Test

Reactor Power Cutback System Test

Fuel Handling \& Storage System Test

(11) The source of this listing is CESSAR-DC Table 14.2-1, Amendment E.

(2) The noted test is one of the seventeen tests referred to in Section 4.2. 
CESSAR-DC

Section

14.2.12.1.36

14.2.12.1.37

14.2.12.1.38

14.2.12.1.39

14.2.12.1.40

14.2.12.1.41

14.2.12.1.42

14.2.12.2.43

14.2.12.2.44

14.2.12.1.45

14.2.12.1.46

14.2.12.1.47

14.2.12.1.48

14.2.12.1.49

14.2.12.1.50

14.2.12.1.51

14.2.12.1.52

14.2.12.1.53
IABLF 4.2.1 (1) $($ Cont'd)

(Sheet 3 of 8 )

PREOPERATIONAL TESTS

Title

Emergency Feedwater System Test

Reactor Coolant System Hydrostatic Test

CEDM Cooling System Test

Safety Depressurization System Test

Containment Spray System Test

Integrated Engineered Safety Features/Loss of Power Test

In-containment Water Storage System Test

Internals Vibrations Monitoring System Test

Loose Parts Monitoring System Test

Acoustic Leak Monitoring System Test

Data Processing System and Discrete Indication and Alarm System Test

Critical Function Monitoring (CFM) System Test

Pre-core Hot Functional Test Controlling Document

Pre-core Instrument Correlation

Remote Shutdown Panel

Alternate Protection System Test

Pre-core Test Data Record

Pre-core Reactor Coolant System Expansion Measurements

(1) The source of this listing is CESSAR-DC Table 14.2-1, Amendment J. 


\section{IABLE 4.2-1"1) (Cont'd) \\ (Sheet 4 of 8 ) \\ PREOPERATIONAL TESTS}

CESSAR-DC

Section.

Title

14.2.12.1.54 Pre-core Reactor Coolant and Secondary Water Chemistry Data

14.2.12.1.55 Pre-Core Pressurizer Performance

14.2.12.1.56 Pre-Core Control Element Drive Mechanism Performance

14.2.12.1.57 Pre-core Reactor Coolant System Flow Measurements

14.2.12.1.58 Pre-core Reactor Coolant System Heat Loss

14.2.12.1.59 Pre-core Reactor Coolant System Leak Rate Measurement

14.2.12.1.60 Pre-core Chemical Volume Control System Integrated Test

14.2.12.1.61 Pre-core Safety Injection Check Valve Test

14.2.12.1.62 ${ }^{(2)}$ Pre-core Boration/Dilution Measurements

14.2.12.1.63 Downcomer Feedwater System Water hammer Test

14.2.12.1.64 Main Turbine Systems Test

14.2.12.1.65 Main Steam Safety Valve Test

14.2.12.1.66 Main Steam Isolation Valves (MSIVs) and MSIV Bypass Valves Test

14.2.12.1.67 Main Steam System Test

14.2.12.1.68 Steam Generator Blowdown System Test

14.2.12.1.69 Main Condenser and Air Removal Systems Test

14.2.12.1.70 Main Feedwater System Test

14.2.12.1.71 Condensate System Test

14.2.12.1.72 Turbine Gland Sealing System Test

14.1.12.1.73 Condenser Circulating Water System Test

(1) The source of this listing is CESSAR-DC Table 14.2-1, Amendment T.

(2) The noted test is one of the seventeen tests referred to in Section 4.2. 
CESSAR-DC

Seation.

14.2.12.1.74

14.2.12.1.75

14.2.12.1.76

14.2.12.1.77

14.2.12.1.78

14.2.12.1.79

14.2.12.1.80

14.2.12.1.81

14.2.12.1.82

14.2.12.1.83

14.2.12.1.84

14.2.12.1.85

14.2.12.1.86

14.2.12.1.87

14.2..12.188

14.2.12.1.89

14.2.12.1.90

14.2.12.1.91(2)

14.2.12.1.92
IABLE 4.2-1'" (Cont'd)

(Sheot 5 of 8)

PREOPERATIONAL TESTS

Title

Steam Generator Hydrostatic Test

Feedwater Heater and Drains System Test

Ultimate Heat Sink Test

Chilled Water System Test

Station Service Water System Test

Component Cooling Water System Test

Pool Cooling and Purification System Test

Turbine Building Cooling Water System Test

Condensate Storage System Test

Turbine Building Service Water System Test

Equipment and Floor Drainage System Test

Normal and Security Lighting Systems Test

Emergency Lighting System Test

Communications Systems Test

Compressed Air System Test

Compressed Gas System Test

Process Sampling System Test

Heat Tracing System Test

Fire Protection Systern Test

(11) The source of this listing is CESSAR-DC Table 14.2-1, Amendment T.

(2) The noted test is one of the seventeen tests referred to in Section 4.2. 
CEssaR-DC

Section

14.2.12.1.93

14.2.12.1.94

14.2.12.1.95

14.2.12.1.96

14.2.12.1.97

14.2.12.1.98

14.2.12.1.99

14.2.12.1.100

14.2.12.1.101

14.2.12.1.102

14.2.12.1.103

14.2.12.1.105

14.2.12.1.106

14.2.12.1.107

14.2.12.1.108

14.2.12.1.109

14.2.12.1.110

14.2.12.1.111

14.2.12.1.112

14.2.12.1.113
IABLE 4.2-1'1) (Cont'd)

(Shoot 6 of 8)

PREOPERATIONAL TESTS

Intle

Emergency Diesel Generator Mechanical System Test

Emergency Diesel Generator Electrical System Test

Emergency Diesel Generator Auxiliary Systems Test

Alternate AC Source System Test

Alternate AC Source Support Systems Test

Containment Polar Crane Test

Fuel Building Cranes Test

Turbine Building Crane Test

Containment Cooling and Ventilation System Test

Containment Purge Ventilation System Test

Control Complex Ventilation System Test

Turbine Building Ventilation System Test

Station Service Water Pump Structure Ventilation System Test

Diesel Building Ventilation System Test

Fuel Building Ventilation System Test

Annulus Ventilation System Test

Radwaste Building Ventilation System Test

Balance of Control Complex Ventilation System Test

Hydrogen Mitigation System (HMS) Test

Containment Hydrogen Recombiner System (CHRS) Test

(1) The source of this listing is CESSAR-DC Table 14.2-1, Amendment T. 
CESSAR-DC

Section

14.2.12.1.114

14.2.12.1.115

14.2.12.1.116

14.2.12.1.117

14.2.12.1.118

14.2.12.1.119

14.2.12.1.120

14.2.12.1.121

14.2.12.1.122

14.2.12.1.123

14.2.12.1.124

14.2.12.1.125

14.2.12.1.126

14.2.12.1.127

14.2.12.1.128

14.2.12.1.129

14.2.12.1.130

14.2.12.1.131

14.2.12.1.132

14.2.12.1.133

\section{TABLE 4.2-1"1) (Cont'd) \\ (Sheet 7 of 8) \\ PREOPERATIONAL TESTS}

Title

Liquid Waste Management System Test

Solid Waste Management System Test

Gaseous Waste Management System Test

Process and Effluent Radiological Monitoring System Test

Airborne and Area Radiation Monitoring System Test

4160 Volt Class $1 E$ Auxiliary Power System Test

480 Volt Class 1E Auxiliary Power System Test

Unit Main Power System Test

13800 Volt Normal Auxiliary Power System Test

4160 Volt Normal Auxiliary Power System Test

480 Volt Normal Auxiliary Power System Test

Non-Class 1E DC Power Systems Test

Class 1 E DC Power Systems Test

Offsite Power System Test

BOP Piping Thermal Expansion Measurement Test

BOP Piping Vibration Measurement Test

Containment Integrated Leak Rate Test and Structural Integrity Test

Fuel Transfer Tube Functional Test and Leak Test

Equipment Hatch Functional Test and Leak Test

Containment Personnel Airlock Functional Test and Leak Test

(1) The source of this listing is CESSAR-DC Table 14.2-1, Amendment T. 
CESSAR-DC

Section

14.2.12.1.134

14.2.12.1.135

14.2.12.1.136

14.2.12.1.137

14.2.12.1.138

14.2.12.1.139

14.2.12.1.140

14.2.12.1.141

14.2.12.1.142

14.2.12.1.143
TABLE 4.2-1 (11) (Cont'd)

(Sheot 8 of 8)

PREOPERATIONAL TESTS

Title

Containment Electrical Penetration Assemblies Test

Containment Isolation Valves Leakage Rate Test

Loss of Instrument Air Test

Mid-Loop Operations Verification Test

Seismic Monitoring Instrumentation Test

Auxiliary Steam System Test

Containment Isolation Valves Test

Post Accident Monitoring Instrumenttion (PAMI) Test

Component Cooling Water (CCW) Heat Exchanger

Structure(s) Ventilation Systems Test

Nuclear Annex Ventilation System Test

(1) The source of this listing is CESSAR-DC Table 14.2-1, Amendment $T$. 
CESSAR-DC

Section

14.2.12.2.1

14.2.12.2.2

14.2.12.2.3

14.2.12.2.4

$14.2 \cdot 12.2 .5^{(2)}$

14.2.12.2.6

14.2.12.2.7

$14.2 \cdot 12.2 .8^{(2)}$

14.2.12.2.9

14.2.12.2.10

14.2.12.2.1 $11^{(2)}$
TABLE 4.2-2(1)

POST-CORE HOT FUNCTIONAL TESTS

Title

Post-core Hot Functional Test Controlling Document

Loose Parts Monitoring System

Reactor Coolant System Flow Measurements

Post-core Control Element Drive Mechanism

Performance

Post-core Reactor Coolant and Secondary Water

Chemistry Data

Post-core Pressurizer Spray Valve and Control

Adjustments

Post-core Reactor Coolant System Leak Rate Measurement

Post-core In-Core Instrumentation

Post-core Instrument Correlation

Post-core Acoustic Leak Monitor System Test

Post-core Ex-core Nuclear Instrumentation

System Test

(1) The source of this listing is CESSAR-DC Table 14.2-2, Amendment J.

(2) The noted test are part of the seventeen tests referred to in Section 4.2. 
CESSAR-DC Section

14.2.12.3.1

$14.2 \cdot 13 \cdot 3.2^{(2)}$

$14 \cdot 2 \cdot 12 \cdot 3 \cdot 3^{(2)}$

$14 \cdot 2 \cdot 12 \cdot 3 \cdot 4^{(2)}$

14.2.12.3.5

IABLE $4.2-3^{(1)}$

\section{LOW POWER PHYSICS TESTS}

Title

Low Power Biological Shield Survey Test

Isothermal Temperature Coefficient Test

Shutdown and Regulating CEA Group Worth Test

Differential Boron Worth Test

Critical Boron Concentration Test

(1) The source of this listing is CESSAR-DC Table 14.2-3, Amendment E.

(2) The noted tests are part of the seventeen tests referred to in Section 4.2. 
IABLE 4.2-4 (1) $^{(1)}$

(Sheet 1 of 2)

CESSAR-DC

Section

14.2.12.4.1

14.2.12.4..$^{(2)}$

$14.2 .12 .4 .3^{(2)}$

14.2.12.4.4

14.2.12.4.5

$14.2 .12 .4 .6^{(2)}$

14.2.12.4.7

14.2.12.4.8

14.2.12.4.9

14.2.12.4.10

14.2.12.4.11

14.2.12.4.12

14.2.12.4.13

14.2.12.4.14

14.2.12.4.15

14.2.12.4.16

14.2.12.4.17
POWER ASCENSION TESTS

Title

Variable Tavg (Isothermal Temperature Coefficient \&

Power Coefficient) Test

Unit Load Transient Test

Control Systems Checkout Test

RCS and Secondary Chemistry and Radiochemistry Test

Turbine Trip Test

Unit Load Rejection Test

Shutdown From Outside the Control Room Test

Loss of Offsite Power Test

Biological Shield Survey Test

Steady-State Core Performance Test

Intercomparison of PPS, CPCs, DPS and DIAS Inputs

Verification of CPC Power Distribution Related Constants

Main and Emergency Feedwater System Test

CPC Verification

Steam Bypass Valve Test

In-core Detector Test

COLSS Verification

(1) The source of this listing is CESSAR-DC Table 14.2-4, Amendment E.

(2) The noted tests are part of the seventeen tests referred to in Section 4.2. 
CESSAR-DC

Section

14.2.12.4.18

14.2.12.4.19

14.2.12.4.20

14.2.12.4.21

14.2.12.4.22

$14 \cdot 2 \cdot 12 \cdot 4 \cdot 23^{(2)}$

14.2.12.4.24

14.2.12.4.25
IABLE 4.2-4 (1) $^{\text {(Cont' d) }}$

(Sheet 2 of 2)

POWER ASCENSION TESTS

Title

Baseline NSSS Integrity Monitoring

RPCS Test

Cooling Tower Acceptance Test

Penetration Temperature Survey Test

Ventilation Capability Test

Natural Circulation Test

Liquid Waste Management System Test

Gaseous Waste Management System Test

(1) The source of this listing is CESSAR-DC Table 14.2-4, Amendment E.

(2) The noted test is one of the seventeen tests referred to in Section 4.2. 


\section{IABLE 4.2-5 ${ }^{(1)}$}

(Sheet 1 of 2)

\section{POWER ASCENSION TESTS}

\section{Test Title}

Variable Tavg (Isothermal Temperature

Coefficient \& Power Coefficient) Test

Unit Load Transient Test

Control Systems Checkout Test

RCS and Secondary Chemistry and

Radiochemistry Test

Turbine Trip Test

Unit Load Rejection Test

Shutdown from Outside the Control Room Test

Loss of Offsite Power Test

Biological Shield Survey Test

Steady-State Core Performance Test

Intercomparison of PPS, CPC, DPS and DIAS Inputs

Verification of CPC Power

Distribution Related Constants

Main and Emergency Feedwater

CPC Verification
Plateau

$50,100 \%^{(2)}$

$50,100 \%$

$50,80 \%$

$20,50,80,100 \%$

$100 \%$

$100 \%$

$\geq 10 \%$

$\geq 10 \%$

$50,100 \%$

$20,50,80,100 \%$

$20,50,80,100 \%$

$20,50 \%$

$\geq 10 \%$

$20,50,80,100 \%$

(1) The source of this listing is CESSAR-DC Table 14.2-5, Amendment E.

(2) The temperature and power coefficient measurements are done as closely as possible to $100 \%$ at a level where CEA motion is practical accounting for margin considerations. 
IABLE 4.2-5 ${ }^{\text {(1) }}$ (Cont'd)

(Sheet 2 of 2)

\section{POWER ASCENSION TESTS}

Test Title

Steam Dump and Bypass Valve Capacity Test

Cooling Tower Acceptance Test

In-core Detector Test

COLSS Verification

Baseline NSSS Integrity Monitoring

Reactor Power Cutback System

Penetration Temperature Survey Test

Ventilation Capability Test

Natural Circulation Test

Liquid Waste Management System

Gaseous Waste Management System

\section{Plateau}

$\geq 15 \%$

$100 \%$

$20,50,80,100 \%$

$20,50,80,100 \%$

$20,50,80,100 \%$

$>50 \%$

$20,50,80,100 \%$

50,100

$>80 \%$

$>20 \%$

$>20 \%$

(1) The source of this listing is CESSAR-DC Table 14.2-5, Amendment U. 
IABLE 4.2-6 ${ }^{(1)}$

\section{LOWER POWER PHYSICS TEST PARAMETERS}

\begin{tabular}{|c|c|c|}
\hline Iest Title & Eirst of a Kind ${ }^{(2)}$ & Nth of a Kind ${ }^{(3)}$ \\
\hline $\begin{array}{l}\text { Low-Power Biological Shield Survey } \\
\text { Test }\end{array}$ & $\begin{array}{l}320^{\circ} \mathrm{F} / 565^{\circ} \mathrm{F} \\
\left(160^{\circ} \mathrm{C} / 296^{\circ} \mathrm{C}\right)\end{array}$ & $\begin{array}{l}565^{\circ} \mathrm{F} \\
\left(296^{\circ} \mathrm{C}\right)\end{array}$ \\
\hline CEA Symmetry Test & $\begin{array}{l}565^{\circ} \mathrm{F} \\
\left(296^{\circ} \mathrm{C}\right)\end{array}$ & $\begin{array}{l}565^{\circ} \mathrm{F} \\
\left(296^{\circ} \mathrm{C}\right)\end{array}$ \\
\hline $\begin{array}{l}\text { Isothermal Temperature Coefficient } \\
\text { Test }\end{array}$ & $\begin{array}{l}320^{\circ} \mathrm{F}-565^{\circ} \mathrm{F} \\
\left(160^{\circ} \mathrm{C}-296^{\circ} \mathrm{C}\right)\end{array}$ & $\begin{array}{l}565^{\circ} \mathrm{F} \\
\left(296^{\circ} \mathrm{C}\right)\end{array}$ \\
\hline Regulating CEA Group Worth Test & $\begin{array}{l}320^{\circ} \mathrm{F} \& 565^{\circ} \mathrm{F} \\
\left(160^{\circ} \mathrm{C} \& 296^{\circ} \mathrm{C}\right)\end{array}$ & $\begin{array}{l}565^{\circ} \mathrm{F} \\
\left(296^{\circ} \mathrm{C}\right)\end{array}$ \\
\hline Shutdown CEA Group Worth Test & $\begin{array}{l}320^{\circ} \mathrm{F} \\
\left(160^{\circ} \mathrm{C}\right)\end{array}$ & $\begin{array}{l}565^{\circ} \mathrm{F} \\
\left(296^{\circ} \mathrm{C}\right)\end{array}$ \\
\hline Differential Boron Worth Test & $\begin{array}{l}320^{\circ} \mathrm{F} \& 565^{\circ} \mathrm{F} \\
\left(160^{\circ} \mathrm{C} \& 296^{\circ} \mathrm{C}\right)\end{array}$ & $\begin{array}{l}565^{\circ} \mathrm{F} \\
\left(296^{\circ} \mathrm{C}\right)\end{array}$ \\
\hline Critical Boron Concentration Test & $\begin{array}{l}320^{\circ} \mathrm{F}-565^{\circ} \mathrm{F} \\
\left(160^{\circ} \mathrm{C}-296^{\circ} \mathrm{C}\right)\end{array}$ & $\begin{array}{l}565^{\circ} \mathrm{F} \\
\left(296^{\circ} \mathrm{C}\right)\end{array}$ \\
\hline $\begin{array}{l}\text { Pseudo Dropped and Ejected CEA } \\
\text { Worth Test }\end{array}$ & $\begin{array}{l}565^{\circ} \mathrm{F} \\
\left(296^{\circ} \mathrm{C}\right)\end{array}$ & NA \\
\hline
\end{tabular}

(1) The Source of this listing is the YGN 3\&4 FSAR, Table 14.2-6

(2) An expanded test program is conducted for the First of a Kind Units in order to validate the design, the design methods, and the safety analysis assumptions.

(3) Reduced testing is contingent upon the demonstration that the Nth Unit behaves in an identical manner as the First of a Kind Unit through conformance with the appropriate acceptance criteria. 
TABLE 4.2-7 (Sh. 1 of 2) (1) $^{(1)}$

\section{POWER ASCENSION TEST SEQUENCE}

\section{Test Title}

Natural Circulation Test

Variable Tavg (Isothermal Temperature ${ }^{(5)}$ Coefficient \& Power Coefficient) Test

Unit Load Transient Test

Control Systems Checkout Test

RCS and Secondary Chemistry and

Radiochemistry Test

Turbine Trip Test

Unit Load Rejection Test

Shutdown from Outside the Control Room

Test

Loss-of-Offsite Power Test

Biological Shield Survey Test

Xenon Oscillation Control Test
Eirst of a Kind ${ }^{(2)}$

$\geq 80 \%(4)$

$20,50,80,100 \% \quad 50 \& 100 \%$

$50,100 \%$

$50,100 \%$

$20,50,80,100 \%$

$20,50,80,100 \%$

$20,50,80,100 \%$

$20,50,80,100 \%$

$100 \%(6)$

$100 \%$

$100 \%^{(8)}$

$100 \%$

$\geq 10 \%$

$\geq 10 \%$

$\geq 10 \%$

$\geq 10 \%$

$20,50,80,100 \%$

$\geq 50 \%$
$20,50,80,100 \%$

N/A

(1) The source of this listing is the YGN 3\&4 FSAR, Table 14.2-7.

(2) An expanded test program is conducted for First of a Kind Units in order to validate the design, the design methods, and the safety analysis assumptions.

(3) Reduced testing is contingent upon the demonstration that the Nth Unit behaves in an identical manner as the First of a Kind Unit through conformance with the acceptance criteria.

(4) Initial Power Level

(5) The temperature and power coefficient measurements are done as closely as possible to $100 \%$ power at a level where CEA motion is practical, accounting for margin considerations.

(6) Post trip power defect and xenon worth test should be performed following either the load rejection or turbine trip. 
IABLE 4.2.7 (Sh. 2 of 2$)^{(1)}$

\section{POWER ASCENSION TEST SEOUENCE}

\begin{tabular}{|c|c|c|}
\hline Test Title & Eirat of a Kind ${ }^{(2)}$ & Nth of a Kind ${ }^{(3)}$ \\
\hline Dropped CEA Test & Post $80 \%$ & N/A \\
\hline "Ejected" CEA TEST & Post $80 \%$ & N/A \\
\hline Steady-State Core Performance Test & $20,50,80,100 \%$ & $20,50,80,100 \%$ \\
\hline $\begin{array}{l}\text { Intercomparison of PPS, CPCs, and } \\
\text { Process Computer Input }\end{array}$ & $20,50,80,100 \%$ & $20,50,80,100 \%$ \\
\hline $\begin{array}{l}\text { Verification of CPC Power Distribution } \\
\text { Related Constants }\end{array}$ & $20,50 \%$ & $20,50 \%$ \\
\hline Main and Auxiliary Feedwater & $\geq 10 \%^{(4)}$ & $\geq 10 \%$ \\
\hline CPC Verification & $20,50,80,100 \%$ & $20,50,80,100 \%$ \\
\hline $\begin{array}{l}\text { Steam Dump and Bypass Valve Capacity } \\
\text { Test }\end{array}$ & $\geq 15 \%$ & $\geq 15 \%$ \\
\hline Incore Detector Test & $20,50,80,100 \%$ & $20,50,80,100 \%$ \\
\hline COLSS Verification & $20,50,80,100 \%$ & $20,50,80,100 \%$ \\
\hline NSSS Integrity Monitoring System & $20,50,80,100 \%$ & $20,50,80,100 \%$ \\
\hline
\end{tabular}

(1) The source of this listing is the YGN $3 \& 4$ FSAR Table 14.2-7.

(2) An expanded test program is conducted for the First of a Kind Units in order to validate the design, the design methods, and the safety analysis assumptions.

(3) Reduced testing is contingent upon the demonstration that the Nth Unit behaves in an identical manner as the First of a Kind Unit through conformance with the acceptance criteria.

(4) Initial Power Level 


\subsection{Stantup and Initial Oparation}

\subsubsection{Beactor}

In-cycle and post reload testing of a MOX fueled PWR will require additional testing as compared to a standard $\mathrm{UO}_{2}$ fueled plant (see Table 4.3-1). This testing is primarily in the areas of:

- Boron Management

- Core Physics

Testing required in the boron management area will be associated with the necessity to assure the isotopics of the $B^{10}$. This would involve calibration and checkout of the boronometers and special offsite isotopic analysis of boron recycled from the previous cycle. If there is substantial replacement of boron through the cycle, as is the case in current $\mathrm{UO}_{2}$ plants, then verification of this recycled boron isotopic may not be necessary.

Testing in the core physics area will be primarily for validation of the applicability of time savings techniques (fast power ascension, rod swap, etc.) for applicability to MOX cores. In addition, benchmark tests are needed to reduce uncertainties in the core depletion behavior.

During the initial few cycles it will be important to perform an expanded core follow program in order to verify depletion behavior of reactivity coefficients, core peaking, and boron rundown.

During the first cycle, it will be desirable to validate post trip xenon build-in and xenon and power defect prediction. This will be addressed by a post trip fast return to critical and reactivity follow of xenon build-in and decay. In order to reduce the uncertainty associated with end of life rod worth and shutdown margin, it will be necessary to perform a test to measure shutdown margins for cold shutdown conditions.

\subsubsection{Euel Facility}

For the $\mathrm{MF}^{2}$, a review of the startup and initial operation philosophies of European MOX fuel facilities will be conducted for applicability to the finalized MF $^{2}$ design. 


\section{TABLE 4.3-1'11) \\ STANDARD UO 2 BEQUURED PHYSICS TEST PROCBAM}

Ient

1. Critical Boron

Concentration -

Control Rods

Withdrawn

2. Critical Boron

Concentration -

Control Rods

Inserted

3. Control Rod Group

Worths

Hot Zero Power

Hot Zero Power

Hot Zero Power

Core Conditions

Special Bequilemente

A control rod group or groups worth at least one (1) percent reactivity shall be fully in the core.

Two or more control rod groups shall be measured which are well distributed radially and represent a predicted total worth of at least three (3) percent.

4. Isothermal Temperature Coefficient

Hot Zero Power

5. Flux Symmetry

Between 0 and 30 Percent of Full Power

6. Power Distribution

Between 40 and 75 Per-

- Inter-mediate

Power

cent of Full Power

7. Power Distribution

Greater than 90 Percent

- Full Power

of Full Power

8. Critical Boron

Concentration -

Greater than 90 Percent

Full Power

of Full Power 


\subsection{Bolated Operntional Experience on Avalleblility. Capacity Factora}

\subsubsection{Plant Gapacity Factor Exponiance}

The average capacity factor in 1993 for all ABB-CE plants was $76 \%$. The experience with ABB-CE reactors on availability and capacity factor has shown considerable improvement over time. Partly, this is due to the trend in the industry towards longer fuel cycles of 18 months, the average capacity factor for ABB-CE plants was $75.4 \%$ for the former, and $81.4 \%$ for the latter.

The plant is designed to achieve high capacity factors. This is accomplished by incorporating advanced control system designs and where appropriate, redundant design features. To the extent possible, redundant active components are provided in both the nuclear and turbine islands to achieve and maintain full power capabilities.

Historically, a large fraction of unanticipated trips result from faults initiated in the main feed and steam systems. To minimize the impact on capacity factors, the design incorporates a Reactor Power Cutback System (RPCS) designed to accommodate full load rejections and a loss of one main feed pump without initiating a reactor trip and opening primary/secondary safety valves. The design also incorporates an Extended Range Feedwater Control System which allows for automatic steam generator water level control from zero to full power. The automatic control of steam generator levels at low power operation eliminates the difficulty in manually controlling levels, which has also resulted in numerous reactor trips. These advanced design features eliminate the need for automatic start of a standby component should a loss of component function occur that might result in a turbine/reactor trip.

As an example, the design can accommodate a fault in the main feed system with insignificant impact on plant capacity factor. A fault with a main feed pump and/or controls will result in the actuation of RPCS, which will automatically reduce reactor power by insertion of CEAs and initiate turbine cutback and runback to prevent a reactor trip on low secondary or primary pressure. Once the plant has been stabilized at approximately $60 \%$, the standby main feedwater pump can be placed in service and the plant can be quickly returned to full power operation. These design features have been demonstrated during testing and operations at PVNGS.

ABB-CE designed NSSS have consistently led the nuclear industry in the U.S. in performance, demonstrating the benefits of conservative plant design and prudent operation. For thirteen of the past fifteen years, ABB-CE designed NSSS units have let the USA nuclear industry in capacity factors. In fact, eleven ABB-CE designed NSSS plants established new records for energy generation or for continuous operation during the past four years. As examples, Fort Calhoun set a world record of 477 days for continuous energy generation by a light water reactor; Palo Verde 
Unit 3 set world records for annual energy generation and first cycle continuous energy production and St. Lucie Unit 2 established annual capacity factor records among all USA nuclear power plants.

The enviable capacity factor record achieved with the ABB-CE nuclear plant designs is certainly indicative of the careful design, manufacture, installation and operation considerations incorporated into each plant. The continued reduction in unanticipated trips each year as the utility operators experience base increases indicates that the fundamental plant design is very sound and supportive of the requirements for high availability.

For System $80+$ with the MOX fuel cycle, an everage annual capacity factor of 0.87 is believed to be achievable. The refueling and maintenance outage activities, covered in Section 4.4.2, support this claim.

\subsubsection{Bafuelling and Maintenance Qutage Schedules}

The experiences covered in Section 4.4.1 all are for a mix of plants of various vintages. Considerable improvement in the times for refueling, and the times for major maintenance outages, including steam generator inspection and BOP maintenance, have been engineered into the System $80+$ design. The System $80+$ Refueling System equipment, tools, and procedures; core design; reactor building and important nuclear annex arrangements; and plant systems incorporate the necessary features to ensure that the refueling outage can be accomplished within 17 days and a maintenance outage can be accomplished in 55 days. The most important design features that minimize the outage duration are described below.

- Multiple stud tensioner

The multiple stud tensioner allows the detensioning or tensioning of all the reactor vessel studs at one time. In addition, the multiple stud tensioner allows the simultaneous removal of all the reactor vessel studs from the work area to the storage area without additional stud handling and reliance on the polar crane.

- Bottom mounted in-core instrumentation

The bottom mounted design allows the withdrawal/insertion of the instrumentation in parallel with the reactor vessel head disassembly/reassembly operations rather than in series as is the case with top mounted instrumentation. 
- Penetration Sleove Quick Opening Closure

The closure design incorporates slide locks rather than bolts to permit the rapid, simultaneous unlocking/locking of all the fasteners by one person. A dedicated small hoist unir located directly above the closure allows the immediate removal of the closure from the penetration sleeve in the event the polar crane is not readily available. Pre-operational checkout of the fuel transfer system can proceed immediately upon removal of the closure.

Jib Cranes

Jib cranes are strategically located within the reactor building to perform the various light load handling tasks thus avoiding reliance on the polar crane and the potential attendant delays. The jib cranes allow movement of loads away from the reactor while fuel assemblies are being handled.

The CEAs are removed from the fuel assemblies within the core in parallel with the removal of the UGS from the reactor vessel. This operation eliminates the time consuming handling and exchange of CEAs during the fuel handling uperation. The CEAs are reinstalled into the core during the replacement of the UGS.

Refueling Machine Console and Spent Fuel Handling Machine Console Computer Control System.

The fuel handling machines incorporate computer control systems and preprogrammed software to efficiently plan and execute all machine movements and minimize operator reliance on paper manual instructions. Sequence operations are displayed on touch screen monitors as well as interlock function status, help menus, and other pertinent information to avoid potential delays.

Refueling Simulator

The simulator allows the fuel handling machine operators to be thoroughly trained under all normal and abnormal operations prior to the refueling outage. This training increases operator proficiency and minimizes fuel handling times. The simulator is also used to checkout the refueling machine console prior to the refueling outage. 
- ICI Replacement Operations

The $\mathrm{ICl}$ replacement operations are designed to be performed in parallel with the fuel handling operations. Although the design life of the $\mathrm{ICl}$ is such that replacement of the instrumentation may not occur as a normal outage function, the replacement system has been designed to avoid adverse impact on the outage when it does occur, during fuel handling operations.

- Head Area Cable Tray System (HACTS) with Integral Missile Shield

The HACTS design allows the simultaneous removal and replacement of all the CEDM, HJTC, and Mid Loop Monitoring System cabling to the reactor vessel head area. Incorporation of the missile shield eliminate the separate handling of the missile shield.

Permanent Pool Seal Assembly

The permanent pool seal design eliminates the requirement for handling and installing a large and heavy pool seal assembly for sealing the annulus between the reactor vessel flange and the refueling cavity floor.

\section{Building Arrangements}

The building arrangements provide improved personnel and equipment flow and staging for activities in the reactor building. Examples of these improvements are a large closed staging area outside the equipment hatch to improve material flow to support reactor building activities. Access to the reactor building operating floor can be gained through either the personnel lock or the equipment hatch. Both access points allow personnel traffic to the $\mathbf{3 6 0}$ degree hallway outside the crane wall. 


\section{Combustion Engineering, InC

\subsection{BEACTOR COMPLEX SAFETY AND LICENSING}

5.1 Reactor Transient and Accident Analysis

\subsubsection{Bases for Analyses}

\subsubsection{Event Categorization}

The bases for the transient and accident evaluations with the plutonium core are the analyses for the System 80 + Design Basis Events (DBEs) as reported in Chapters 6, 15, and 19 of CESSAR-DC. These analyses satisfy the U.S. NRC requirements for document content in 10 CFR 50.34 and demonstrate compliance with the General Design Criteria in 10 CFR 50 Appendix A. The format of the documentation follows Regulatory Guide 1.70 and the general methods for demonstrating compliance with criteria follow Standard Review Plan, NUREG-0800. These same analytical bases, methods and acceptance criteria are applied to the plutonium core.

The Design Basis Events are grouped into categories and the worst events from each category are reported in CESSAR-DC. Since the response of the System 80 + plant design with a plutonium core is similar to the response with a conventional enriched uranium core, the same categories and limiting events are evaluated here. The categories are:

- Design Basis Events

- Increase in secondary heat removal

- Decrease in secondary heat removal

- Decrease in reactor coolant flow

- Reactivity and power distribution anomalies

- Increase in RCS inventory

- Decrease in RCS inventory

- Radioactive release from a subsystem

- Beyond Design Basis Events

- Severe Accident Consideration

Within each event category, the severity of an event is determined in part by the assumptions postulated for the event scenario. The likelihood of the postulated assumptions occurring determines the frequency group for an event scenario. The frequency groups and the general assumptions applied to events in all the event categories are as follows: 
a. Moderate frequency events are expected to occur one or more times in a reactor year. Analytical assumptions for evaluating moderate frequency events include:

$\begin{array}{ll}- & \text { adverse initial conditions } \\ \text { - } & \text { worst stuck CEA } \\ \text { - } & \text { only safety grade systems are credited } \\ \text { - } & \text { no operator action for } 30 \text { minutes } \\ \text { - } & \text { loss of off-site power }\end{array}$

b. Infrequent events are expected to occur one or more times in the lifetime of the plant. Analytical assumptions include those for moderate frequency events and in addition include:

- worst single failure of a safety system (or control system if worse)

c. Accident events are not expected to occur but are postulated in order to judge the adequacy of protection systems. Analytical assumptionis for accidents include those for both moderate and infrequent events.

This grouping of event severity and frequency is directly applicable to a System $80+$ plant with a plutonium core. The general intent of the assumptions to assure conservatively biased analytical results is satisfied, although the magnitude of the plant response to a given assumption may differ. Detailed differences that may be expected are evaluated in the following sections for specific events.

\subsubsection{Acceptance Criteria}

Acceptance criteria for plant response to design basis events differ among the event categories depending on the nature of the event and differ within a category depending on the event frequency group. The acceptance criteria are specified in the Standard Review Plan, NUREG -0800, for each category or event. They include limits in three areas:

1. Fuel integrity criteria prevent release of fission products from the fuel or limit the extent of fuel damage during accidents.

2. Pressure criteria prevent over-pressure in the primary system, secondary system and containment.

3. Dose criteria limit the exposure of the public.

The applicability of these criteria to a System $80+$ plant design with a plutonium core is discussed in the following. 


\subsection{Fuel Acceptance Criteria}

Fuel integrity acceptance criteria refer to the integrity of the fuel cladding to contain fission products. It is quantified for most events by the value of the DNBR which is a function of the geometric configuration of the fuel rod and fuel assembly, the heat flux distribution and the coolant temperature, pressure and mass velocity. For the plutonium core, all these characteristics are essentially unchanged or, in the case of heat flux or power distribution, can be explicitly specified. In application of the DNBR limiting value to the System $80+$ safety analyses reported in CESSAR-DC, the uncertainties in fuel parameters that influence the DNBR are statistically combined. These uncertainties include experimental statistics related to the CE-1 critical heat flux empirical correlation and also statistics related to the physical characteristics of the fuel rod and fuel assembly. Fuel statistical parameters include fuel pellet diameter, density and enrichment (Pu content), clad diameter, and rod spacing and bow within the fuel assembly. For a developed fuel manufacturing process, historical inspection data provide the variations of these parameters and analytical advantage may be taken when variations are reliably smaller than manufacturing drawing tolerances would otherwise allow. Statistical fuel evaluations for the System $80+$ design result in a value of 1.24 for the DNBR Specified Acceptable Fuel Design Limit (SAFDL) including the effect of statistical variations. A new manufacturing process and/or facility for plutonium fuel fabrication may require reevaluation of the fuel statistics and an adjustment of the minimum DNBR criterion. The possibility of a change in DNBR margin available during transient events is acknowledged for new plutonium fuel, but is probably small and is typically overcome with small changes in the Limiting Conditions for Operation (LCO) maintained using the System 80 + Core Operating Limit Supervisory System (COLSS). Therefore, the value of the DNBR SAFDL used in CESSAR-DC is assumed in these preliminary plutonium core safety evaluations.

Another SAFDL applies to the maximum fuel rod linear heat rating that would assure no centerline melt. The value in CESSAR-DC is $21 \mathrm{kw} / \mathrm{ft}$. It is a function mostly of the pellet thermal conductivity which is dependent on burnup, but is also influenced by the fuel rod gap conductance and statistical factors mentioned above. For preliminary evaluations of the plutonium core, the CESSAR-DC value is assumed.

\subsection{Plant Acceptance Criteria}

Pressure acceptance criteria for the primary and secondary systems and the containment are specified in the Standard Review Plan and the ASME B\&PV code. The limit values are unchanged for a plant with a plutonium core.

\subsection{Dose Acceptance Criteria}

Dose acceptance criteria are established by 10 CFR 100 and by the Standard Review Plan for each event category and/or event frequency. The limiting values of dose in the acceptance criteria are unchanged for evaluations of the plutonium core. 
Dose values that are compared to the acceptance criteria are calculated for a given event and are a function of the characteristics of the dose source term and of the release pathway. The release pathways (e.g., steam safety valves, atmospheric dump valves, containment leakage, etc.) are determined by the overall plant and component design configuration and are unchanged with the plutonium core, although the magnitude of fluid release will change with changes in transient response.

The dose source term for non-LOCA events is dependent on the core characteristics that determine the isotopic spectrum of fission products that may be released from the fuel following postulated failure of fuel cladding or is established by Technical Specifications on allowable concentrations in the primary and secondary coolant during normal operation. The specifications that influence the dose calculated following events where there is no calculated fuel failure are the maximum iodine concentration (typically specified as micro-curies per gram equivalent $^{131}$ ) and the maximum total concentration of other radioactive isotopes in the coolant. These dose limit criteria are the same for uranium or plutonium cores since they are quantitative in radioactivity, independent of the type of core.

When fuel cladding is calculated to fail by DNB, the radioactivity in the gas gap is assumed released into the RCS coolant. The release is typically specified as a fraction of the fuel rod inventory of iodine and noble gases. Release fractions used in the safety analyses are specified by the Standard Review Plan and/or Draft NUREG-1465 and depend on the diffusion characteristics of the ceramic fuel pellet. Fission product inventory is calculated for each fissile loading and fuel cycle and differs for plutonium and uranium. The combination of different isotopic spectrum and possibly different release fractions may change the dose for events where fuel failure is calculated.

LOCA dose is also determined for the release pathways (that are unchanged from the CESSAR-DC design) and the assumed releases from the core. For the LOCA analyses, the radioactive release from the core is uncoupled from the event analysis. The U.S. NRC specifies the release fractions and the physical form for selected isotopes in a new Source Term prescribed in NUREG-1465 which is the basis for the CESSAR-DC LOCA doses. The applicability of the new NRC LOCA source term for the plutonium core has to be confirmed and the doses adjusted for the plutonium fission product inventory.

\subsubsection{Methods and Computer Codes for Safety Analysis}

The methods and computer codes employed in the safety analyses may be coarsely divided into three areas - nuclear core design, fuel rod performance and thermal hydraulic fluid systems performance. CESSAR-DC provides descriptions of the various codes employed in these areas and the codes are summarized elsewhere in this report.

Generally, the physical phenomena modeled by these analytical tools are the same for the uranium core evaluated in CESSAR-DC and for the plutonium core. In application, 


\section{Combustion Engineering, PLUTONIUM DISPOSITION STUDY \\ Combustion Engineering, InC. REACTOR COMPLEX SAFETY AND LICENSING}

input parameters to the codes will accommodate differences for a plutonium core, although some confirmation of the analytical models for use with plutonium may be required. For example, fuel pellet thermal expansion, swelling, cracking and fission gas release models should be confirmed for the plutonium loading. A significant data base on MOX fuel is available, and the carrying out of the MOX Fuel Qualification Program should provide confirming information. These fuel characteristics may affect the DNBR and fluid conditions during events. On the other hand, the thermal hydraulic systems performance codes should be directly applicable for plutonium cores. Potential sensitivity of safety analysis results to code models for plutonium are identified in the following event evaluations where significant.

\subsubsection{Initial Conditions for Safety Analyses}

Events evaluated here, and in Chapter 15 of CESSAR-DC, are analyzed over a range of initial values of the principal process variables. Analysis over a range of initial conditions is consistent with the monitoring function performed by the Core Operating Limit Supervisory System (COLSS) and the flexibility of plant operation which COLSS allows. This flexibility is produced by allowing parameter trade-offs by monitoring the principal process variables, synthesizing the margin to fuel thermal design limits and displaying to the reactor operator the core power operating limit. The range of values of each of the principal process variables considered in the event analyses is listed in Table 5.1-1. Flexibility afforded by the COLSS and margin inherent in the System $80+$ design may allow changes to the initial conditions to prevent event results from violating acceptance criteria.

\subsubsection{Input Parameter Values for Safety Analyses}

The parameters described here are consistent with the initial conditions for the process variables in Table 5.1-1 and represent the 4 year plutonium core. Values of these parameters are particularly sensitive to the core composition. Comparisons are given in the following with the parameter values calculated in the same manner for an all uranium core. The uranium values differ somewhat from values reported in CESSARDC because of standard analytical conservatisms applied there, but the relative differences between values for uranium and plutonium are applicable for the evaluations presented later in the event analysis sections. Section 2.6 provides discussions of MOX core safety parameters of interest.

\subsection{Fuel Temperature Coefficient}

Depending on the particular event, the most limiting value of the fuel temperature coefficient could be either the most negative or the least negative limit over a range of time in life, core conditions, conservative bias and calculational uncertainty. Events with a calculated power increase are analyzed with the least negative fuel temperature coefficient to conservatively maximize the power peak, while events with a calculated power decrease are analyzed with the most negative coefficient. Ranges calculated 
over core lifetime are given in Table 5.1-2. Values of fuel temperature coefficient for the 4 year plutonium core are slightly more negative than equivalent values for an all uranium core.

\subsection{Moderator Temperature Coefficient}

The moderator temperature coefficient is the net effect from the combination of the effect of temperature on the moderator density and the moderator nuclear temperature coefficient. Although the moderator density contribution is always positive in the operating range, the magnitude decreases as soluble boron level is increased, so the density contribution to moderator temperature coefficient might be expected to be less at the higher boron concentrations in the plutonium core.

The moderator nuclear temperature coefficient is the change in reactivity per unit change in core average temperature at constant moderator density. This nuclear reactivity effect is dependent on the spectral effects associated with the change in thermal scattering properties of water with temperature. The nuclear coefficient is also influenced by the changing neutron spectrum with fuel isotopic changes from beginning to end of cycle. For each event analysis, suitably conservative values are used representing the most limiting combinations of core conditions. Table 5.1-2 gives comparable values of the combined "Moderator Temperature Coefficient" for the 4 year plutonium core and an all uranium core.

\subsection{Reactivity Control}

Means for reactivity control include fixed burnable poison (erbia in fuel rods), soluble poison (boron) and control rods (Control Element Assemblies, CEAs). The reactivity effect on the plant response to design basis events will differ with the plutonium core. The increased inverse boron worth with plutonium that is indicated by Table 5.1-2 can be partially offset in its influence on safety response by employing enriched boron, so that a given volume of coolant carries equivalent reactivity worth, while the $50 \%$ greater decrease for inverse boron worth from BOL to EOL for plutonium will benefit cooldown events postulated at EOL.

Increasing the number of CEAs maintains about the same total rod worth in the plutonium core for events requiring reactor trip, while the individual rod worth is less, benefiting the rod transient events in both reduced total reactivity increment and in reduced local peaking.

The dynamic effects on reactivity are aggravated in the plutonium core by the smaller values for the effective delayed neutron faction and prompt neutron lifetime. While the decreases would appear to have an adverse effect upon short period transients such as a rod ejection, the overall consequence is mitigated by the lowered reactivity worth of the ejected rod and the reduced sensitivity of the core power distribution to the local reactivity perturbations. These mitigating effects on the plant response to transients 


\section{Combustion Engineering, Inc. REACTOR COMPLEX SAFETY AND LICENSING}

are a consequence of the strong thermal absorption properties which reduce the thermal diffusion length of the plutonium fuel lattice. 
IABLE 5.1-1

\section{RANGES OF INITIAL CONDITIONS FOR SAFETY ANALYSES}

Parameter

Core Power

Axial Shape Index

$0.3^{\prime \prime \prime}$
Reactor Vessel Inlet
Coolant Flow Rate
Pressurizer Water
Level

Core Inlet Coolant

Temperature

$<90 \%$ Power

90\%-100\% Power

Pressurizer Pressure

Steam Generator Water Level

Low

High
Units

\% of $3914 \mathrm{Mwt}$

--

$\%$ of $445600 \mathrm{gpm}$

\% distance between upper tap and lower tap above lower tap
Bange

$0-102$

$-0.3 \leq \mathrm{ASI} \leq+0.3$

$95-116$

26 to 60

$$
{ }^{\circ} \mathrm{F}
$$

$543-561$

${ }^{\circ} \mathrm{F}$

$550-561$

psia

$2175-2325$
\% Wide Range ${ }^{(2)}$

\% Narrow Range ${ }^{(3)}$
$33.7^{(4)}$

40.7

95.0
(1)

$$
\text { ASI }
$$

area under axial shape in lower half of core - area under axial shape in upper half of core total area under axial shape

(2) Percent of distance between the wide range instrument taps.

(3) Percent of distance between the narrow range instrument taps.

(4) For steam and feedwater line breaks only. 
TABLE 6.1-2

PARAMETERS FOR SAFETY ANALYSES COMMERCIAL URANIUM BEACTOR VERSUS PLUTONIUM BURNEB

\begin{tabular}{|c|c|c|}
\hline Parameter Unita & $\begin{array}{c}\text { Commorcial } \mathrm{UO}_{2} \text {, } \\
\text { Eq Cycle }\end{array}$ & $\begin{array}{l}\text { Pu Burner } \\
\text { 4-yr Core }\end{array}$ \\
\hline $\begin{array}{l}\text { Moderator Temperature Coef } \\
\left(10^{-4} \Delta \rho^{\prime} \mathrm{C}\right) \\
\text { Full Power BOL } \\
\text { Full Power EOL }\end{array}$ & $\begin{array}{r}-1.06 \\
-5.83\end{array}$ & $\begin{array}{l}-1.48 \\
-3.85\end{array}$ \\
\hline $\begin{array}{l}\text { Fuel Temperature Coef } \\
\left(10^{-6} \Delta p /{ }^{\circ} \mathrm{C}\right) \\
\text { Full Power BOL } \\
\text { Full Power EOL }\end{array}$ & $\begin{array}{l}-2.23 \\
-2.25 \\
\end{array}$ & $\begin{array}{r}-2.77 \\
-2.83 \\
\end{array}$ \\
\hline $\begin{array}{l}\text { Critical Bcron Conc } \\
\text { (BOC, unrodded ppm) } \\
\text { Hot Standby } \\
\text { Full Pwr,No } X_{\theta} \\
\text { Full Pwr, Eq } X_{\theta}\end{array}$ & $\begin{array}{l}1589 \\
1400 \\
1170 \\
\end{array}$ & $\begin{array}{l}3359 \\
2839 \\
2409 \\
\end{array}$ \\
\hline $\begin{array}{l}\text { Inverse Boron Worth } \\
\text { (ppm/\% } \% \text { (p) } \\
\text { Full Power BOL } \\
\text { Full Power EOL }\end{array}$ & $\begin{array}{l}116.0 \\
101.0\end{array}$ & $\begin{array}{l}402.6 \\
241.1\end{array}$ \\
\hline $\begin{array}{l}\text { CEA Worth Full Power EOL } \\
\text { (\% \% } \\
\text { Total } \\
\text { Net (with WSR) } \\
\text { Worst Stuck Rod } \\
\text { Number of CEA Drives }\end{array}$ & $\begin{array}{l}13.80 \\
10.20 \\
3.80 \\
89\end{array}$ & $\begin{array}{l}13.43 \\
10.36 \\
1.98 \\
101 \\
\end{array}$ \\
\hline $\begin{array}{l}\text { Eff Delayed Neut Frac } \\
\text { Full Power BOL } \\
\text { Full Power EOL } \\
\end{array}$ & $\begin{array}{l}0.00625 \\
0.00546 \\
\end{array}$ & $\begin{array}{l}0.00312 \\
0.00363 \\
\end{array}$ \\
\hline $\begin{array}{l}\text { Prompt Neutron Lifetime } \\
\left(10^{-8} \text { seconds }\right) \\
\text { Full Power BOL } \\
\text { Full Power EOL }\end{array}$ & $\begin{array}{l}21.3 \\
24.8\end{array}$ & $\begin{array}{c}6.42 \\
10.72\end{array}$ \\
\hline
\end{tabular}


TABLE 5.1-3

DESIGN BASIS EVENTS FOR SAFETY AMALYSES

\begin{tabular}{|c|c|c|c|c|c|c|c|c|}
\hline $\begin{array}{l}\text { Event } \\
\text { Frequency } \\
\text { of Occur. }\end{array}$ & $\begin{array}{l}\text { Inc. Sec. } \\
\text { Sys. Heat } \\
\text { Removel }\end{array}$ & $\begin{array}{l}\text { Dec. Sec. } \\
\text { Sys. Heat } \\
\text { Removel }\end{array}$ & $\begin{array}{l}\text { Dec. RCS } \\
\text { Flow }\end{array}$ & $\begin{array}{l}\text { Reactivity } \\
\text { \& Power } \\
\text { Dist. } \\
\text { Anomolies }\end{array}$ & $\begin{array}{l}\text { Inc. RCS } \\
\text { Inventory }\end{array}$ & $\begin{array}{l}\text { Dec. RCS } \\
\text { Inventory }\end{array}$ & $\begin{array}{l}\text { Rad. } \\
\text { Rolease } \\
\text { from } \\
\text { Subeys or } \\
\text { Comp. }\end{array}$ & $\begin{array}{l}\text { Beyond } \\
\text { Deaign } \\
\text { Basis } \\
\text { Events }\end{array}$ \\
\hline $\begin{array}{l}\text { Moderate } \\
\text { Frequency } \\
\text { Events }\end{array}$ & $\begin{array}{l}\text { - Inc. Feed. } \\
\text { Flow } \\
\text { - Dec. Feed. } \\
\text { Temp. } \\
\text { - Inc. Main } \\
\text { Steam } \\
\text { Flow } \\
\text { - Inadvert. } \\
\text { ADV } \\
\text { Opening }\end{array}$ & $\begin{array}{l}\text { - Loss of } \\
\text { External } \\
\text { Load } \\
\text { - Turbine } \\
\text { Trip } \\
\text { - Loss of } \\
\text { Cond. Vac. } \\
\text { - MSIV } \\
\text { Closure } \\
\text { - Loss of } \\
\text { Normal } \\
\text { Feed. Flow } \\
\text { - Loss of } \\
\text { Non-Emerg } \\
\text { AC Power } \\
\text { to Station } \\
\text { Auxliaries }\end{array}$ & $\begin{array}{l}\text { Total Loss } \\
\text { of RCS } \\
\text { Flow }\end{array}$ & $\begin{array}{l}\text { - Uncontrolle } \\
\text { d CEA } \\
\text { Withdrawal } \\
\text { from } \\
\text { Subcrit or } \\
\text { low power } \\
\text { - Uncontrolle } \\
\text { d CEA } \\
\text { Withdrawal } \\
\text { at power } \\
\text { - Single CEA } \\
\text { drop } \\
\text { - Inadvertant } \\
\text { Deboration } \\
\text { - Startup } \\
\text { Inactive } \\
\text { RCP }\end{array}$ & $\begin{array}{l}\text { - Inadvertant } \\
\text { Oper. of } \\
\text { ECCS } \\
\text { - CVCS } \\
\text { Malfunctio } \\
\text { n-PLCS } \\
\text { w/LOOP }\end{array}$ & None & None & None \\
\hline
\end{tabular}


DESIGN BASIS EVENTS FOR SAFETY ANALYSES

\begin{tabular}{|c|c|c|c|c|c|c|c|c|}
\hline $\begin{array}{l}\text { Event } \\
\text { Frequency } \\
\text { of Occur. }\end{array}$ & $\begin{array}{l}\text { Inc. Sec. } \\
\text { Sys. Heat } \\
\text { Removal }\end{array}$ & $\begin{array}{l}\text { Dec. Sec. } \\
\text { Sys. Heat } \\
\text { Remove: }\end{array}$ & $\begin{array}{l}\text { Dec. RCS } \\
\text { Flow }\end{array}$ & $\begin{array}{l}\text { Reactivity } 8 \\
\text { Power Dist. } \\
\text { Anomolies }\end{array}$ & $\begin{array}{l}\text { Inc. RCs } \\
\text { Inventory }\end{array}$ & $\begin{array}{l}\text { Dec. RCS } \\
\text { Inventory }\end{array}$ & $\begin{array}{l}\text { Rad. } \\
\text { Release } \\
\text { from } \\
\text { Subeys or } \\
\text { Comp. }\end{array}$ & $\begin{array}{l}\text { Bayond } \\
\text { Deaign } \\
\text { Basis } \\
\text { Events }\end{array}$ \\
\hline $\begin{array}{l}\text { Infrequent } \\
\text { Events }\end{array}$ & $\begin{array}{l}\text { Same as Mod. } \\
\text { Freq. but with } \\
\text { a single failure }\end{array}$ & $\begin{array}{l}\text { Same as } \\
\text { Mod. Freq. } \\
\text { but with a } \\
\text { single failure }\end{array}$ & $\begin{array}{l}\text { Same as Mod. } \\
\text { Freq. but with a } \\
\text { single failure }\end{array}$ & $\begin{array}{l}\text { - Inadvertant } \\
\text { Loading of } \\
\text { Fuel Ass. into } \\
\text { Improper } \\
\text { position } \\
\text { - Inadvertant } \\
\text { Deboration } \\
\text { with a Single } \\
\text { Failure } \\
\text { - Startup of } \\
\text { Inactive RCP } \\
\text { with a Single } \\
\text { Failure }\end{array}$ & $\begin{array}{l}\text { Same as } \\
\text { Mod. } \\
\text { Freq. but } \\
\text { with a } \\
\text { single } \\
\text { failure }\end{array}$ & None & $\begin{array}{l}\text { - Fuel } \\
\text { Handing } \\
\text { Accident } \\
\text { - Spent } \\
\text { Fuel Cask } \\
\text { Drop } \\
\text { Accidents }\end{array}$ & None \\
\hline Accidents & $\begin{array}{l}\text { Steam Sys. } \\
\text { Piping } \\
\text { failures } \\
\text { Inside \& } \\
\text { Outside } \\
\text { Containment }\end{array}$ & $\begin{array}{l}\text { Feed. Sys. } \\
\text { Pipe } \\
\text { Breaks }\end{array}$ & $\begin{array}{l}\text { Single RCP } \\
\text { Rotor Seizure } \\
\text { w/LOOP (RS) } \\
\text { - RCP Shaft } \\
\text { Break w/LOOP } \\
\text { (SB) }\end{array}$ & - CEA Ejection & None & $\begin{array}{l}\text { - LOCAs } \\
\text { - DE Break of } \\
\text { Letdown } \\
\text { Line } \\
\text { Outside } \\
\text { Cont. } \\
\text { - SGTR } \\
\text { - SGTR } \\
\text { w/LOOP } \\
\text { - SGTR } \\
\text { w/LOOP \& } \\
\text { stuck open } \\
\text { ADV }\end{array}$ & $\begin{array}{l}\text { Postulate } \\
\text { d Rad. } \\
\text { Releases } \\
\text { due to } \\
\text { liquid } \\
\text { tank } \\
\text { failures }\end{array}$ & $\begin{array}{l}\text { S8O } \\
\cdot \text { ATWS } \\
\text {. TLOFW }\end{array}$ \\
\hline
\end{tabular}




\section{Combustion Engineering, Inc. REACTOR COMPLEX SAFETY AND LICENSING}

\section{TABLE $5.1-4$ \\ SINCLE FALLURES ASSUMED FOR SAFETY ANALYSES}

\section{A. STEAM BYPASS CONTROL SYSTEM}

1. Failure to Modulate Open

2. Failure to Quick Open

3. One Bypass Valve Fails to Quick Close

4. Excessive Steam Bypass Flow

5. Failure to Generate Automatic Withdrawal Prohibit Signal During Steam Bypass Operation

6. Failure to Generate the Reactor Power Cutback Signal

B. REACTIVITY CONTROL SYSTEMS

7. Regulating Group(s) Fail(s) to Insert or Withdraw

8. A Single CEA Stuck *

9. A CEA Subgroup Stuck *

10. Failure to Initiate or Execute the Reactor Power Cutback

11. CEAs Withdraw upon Automatic Withdrawal Prohibit and/or CEA Withdrawal Prohibit

C. FEEDWATER CONTROL SYSTEM

12. Failure of Reactor Trip Override

13. Failure of High Level Override

D. TURBINE-GENERATOR CONTROL SYSTEM

14. Setback w/o Cutback

15. Failure to Modulate the Turbine Control Valves

16. Failure to Setback Given a Cutback

$(100 \% \geq$ Initial Power $\geq 75 \%$ )

17. Failure to Setback

$175 \% \geq$ Initial Power $\geq 60 \%)$

18. Failure to Runback

160\% > Initial Power)

19. Failure to Trip the Turbine

* Control Element Drive Mechanism does not respond to control signal. Release of CEA(s) on trip is not inhibited. 
TABLFS $5.1-4$ (Cont'd)

SINGLE FAILURES ASSUMED FOR SAFETY ANALYSES

E. PRESSURIZER PRESSURE CONTROL SYSTEM (PPCS)

20. Failure of Spray Control Valves to Open

21. Failure of Spray Control Valves to Close

22. Failure of Backup Heaters to Turn On

23. Failure of Backup Heaters to Turn Off

24. Failure of Proportional Heaters to Turn Off

F. PRESSURIZER LEVEL CONTROL SYSTEM

25. Charging Flow Control Valve Fails to Open

26. Charging Flow Control Valve Fails to Close

27. Letdown Flow Control Valve Fails to Close

28. Letdown Flow Control Valve Fails to Open

G. MAIN FEEDWATER SYSTEM

29. One MFIV Fails to Close

30. One Back-flow Check Valve Fails to Close

H. MAIN STEAM SYSTEM

31. One MSIV Fails to Close

32. One Atmospheric Dump Valve Fails to Open

33. One MSSV Closes Below Blowdown Pressure

34. One Atmospheric Dump Valve Fails to Reclose

I. EMERGENCY FEEDWATER SYSTEM

35. Failure of Any One Emergency Feed Pump to Start

J. SAFETY INJECTION SYSTEM

36. Failure of One SI Pump

K. ELECTRICAL POWER SOURCES

37. Failure of One Emergency Generator to Start, Run, or Load (Two SI pumps are powered from one Emergency Generator.)

L. INTERACTIVE CONTROL SYSTEM FAILURES

38. Loss of CEDMC Reactor Tripped Signal 


\subsubsection{Event Analyses}

\subsubsection{The fault Schedule}

Categories of events that are analyzed in the plant safety analyses are identified in Section 5.1.1 and a summary listing of the categories, events and event frequency are given in Table 5.1-3. In this section, the event from each category and frequency that most closely challenges the applicable acceptance criteria is evaluated. Analytical results reported in Chapters 6 and 15 are the reference point for these evaluations. The objective is to estimate if, when the initial conditions and plant parameters identified in Section 5.1.1 for the plutonium 4 year core are substituted for the System $80+$ design parameters for a conventional uranium plant, the consequences of the postulated events satisfy the acceptance criteria.

These evaluations employ the same perspective as generally used to establish bounding conditions and methods that assure the physical consequences of the postulated event are no worse than the analytical results. In other words, the direction of trends for parameters and consequences from a reference condition can predict acceptable results without performing analyses on the plutonium 4-year plant design at this time. Similarly, the direction of trends can identify the need for specific event analyses with the plutonium 4-year plant design.

To assure completeness of the evaluation process, a comprehensive listing is made of the event categories, the event frequency group and the individual events considered in each. Table 5.1-3 lists the events that were considered in the System $80+$ design evaluations reported in CESSAR-DC Chapters 6 and 15. Analyses are reported in CESSAR-DC for the most limiting event from each category and frequency group. These same events are evaluated in the following sections.

The evaluations consider the effect of plutonium on the plant transients and the response of available protection, detection and mitigation systems. Plant response is considered according to the Safety Functions that are exercised during each event and the systems and actuation parameters available to initiate and provide each safety function. Only safety grade systems are assumed to mitigate the events for design basis events, and the worst single failure of those systems lor a non-safety grade system if it yields worse results) may be assumed. Table 5.1-4 lists the single failures from which the worst is selected for each event.

Detection of abnormal events and actuation of systems is dependent on the instrumentation response. Uncertainties are assumed in the response of protection and safety systems. Uncertainties account for normal instrument behavior, response in a harsh environment and the effect on response of the particular event, for example, a particularly rapid transient effect on the indicated value. There are no identified effects of the plutonium core relative to an all uranium core for the instrument responses that are required to indicate or mitigate the Design Basis Events. 


\subsection{Increase in Heat Removal by the Secondary System Events}

The events occurring in this event category are characterized by decreasing RCS temperature and pressure with the potential for an increase in reactor power caused by reactivity feedback due to the cooldown. Subsequent degradation in DNBR results. Large steam line ruptures are included in this group. These faults have the tendency to result in a core damage sequence due to the occurrence of DNB.

The causes of events within this category can be related to either feedwater system or the steam system malfunctions. Feedwater control system malfunctions can result in increased feedwater flows, while loss of a feedwater heater can cause a reduction in feedwater temperature. Steam system malfunctions can result from the inadvertent opening of valves or from pipe ruptures. The feedwater system malfunctions and steam system failures due to valve misoperation are moderate frequency faults. However, when coupled with an additional failure, these faults fall into the infrequent fault category. The steam piping ruptures are classified as limiting faults.

Detection of events within this group is by RCS and Steam Generator low pressure alarms, steam generator water level alarms, and the high power alarm. Trips include the core protection calculator trips on low DNBR or high local power density, low steam generator pressure, variable overpower, steam generator water level, manual, low RCS pressure, and high containment pressure.

The events within this group are characterized by decreasing primary and secondary pressure and in the case of steam line break, increasing containment pressure. Subsequent to reactor trip there is the potential for actuating the main steam safety valves (unaffected steam generator), main steam and feedwater isolation systems, emergency feedwater system, safety injection system, containment isolation system, containment spray system and the atmospheric dump valve system. Eventual operator assisted cooldown following the initiating fault will lead to operator initiation of shutdown cooling. Once in shutdown cooling, the plant can be maintained in a stable condition indefinitely.

The limiting moderate frequency and infrequent events for this category are the Inadvertent Opening of a Steam generator Atmospheric Dump Valve (IOSGADV) and the same event combined with a Single Failure (SF). The major parameter of concern is the minimum hot channel DNBR. This parameter establishes whether a fuel design limit has been violated and thus whether fuel cladding degradation might be anticipated. Those factors which cause a decrease in local DNBR are:

(a) Increasing coolant temperature

(b) Decreasing coolant pressure

(c) Increasing local heat flux (including radial and axial power distribution effects)

(d) Decreasing coolant flow 
For these events, the secondary cooldown causes a primary temperature and pressure decrease and a heat flux increase, resulting in a net decrease DNBR. The Core Protection Calculators (CPC) in the Reactor Protection System will trip the reactor on low DNBR, so the worst single failure is selected to yield the greatest decrease in DNBR after reactor trip and is combined with initial conditions that give the greatest pre-trip decrease in DNBR. Conservative initial conditions include the time in life with the most negative moderator temperature coe'fficient and with the highest worth stuck rod. Both conditions occur at EOL in the plutonium core, but the total rod worth is also greater at EOL so detailed analyses will deternine the worst time in life.

Because the CPC provides reactor trip production for the event, the differences in moderator coefficient and stuck rod worth in the plutonium core can be accommodated, if necessary, without violating the minimum DNBR criterion. Specific transient analyses for the plutonium core will establish the plant response. These events can probably be accommodated with, at most, a reduction in the minimum pretrip DNBR which can be achieved by selective reduction in the range of initial conditions allowed within the Core Operating Limit Supervisory System (COLSS).

In other words, the consequences of these moderate frequency and infrequent events can be maintained the same as on the System $80+$ design by adjusting the operating parameter space if it becomes necessary.

The limiting accident in the category of increased heat removal events is the Steam Line Break (SLB). Typically, a series of postulated conditions are analyzed in order to determine the worst initial conditions. One set of initial conditions is selected to maximize the post-trip return to power. In the CESSAR-DC analyses, no post-trip return to power occurs. The second set of initial conditions is selected to maximize pre-trip potential for fuel failure by DNB. The CESSAR-DC analyses reported no fuel failure for these conditions, but conservatively assumed 0.5 percent failed fuel as a bounding limit to show offsite radiological dose is within the 10CFR 100 acceptance criterion.

The important plant characteristics that change for the SLB analyses on the plutonium core are the negative moderator and fuel temperature coefficients, the net control rod worth with one stuck rod, the consequent post-trip three-dimensional core peaking factor and the negative reactivity worth of the borated safety injection flow. Counteracting core reactivity effects and interacting plant fluid dynamics make a conclusive statement on the direction of the net result of the SLB analyses on a plutonium core difficult without specific analyses. The moderator temperature coefficient is favorably less negative at EOL but the fuel coefficient is unfavorably more negative.

The EOL rod worth is favorably greater and the local peaking disturbance with a stuck rod upon a return to power is favorably smaller with the 4 year plutonium core. The 
inverse boron worth is less favorable but that may be overcome by increasing the safety injection boron concentration and/or the boron-10 isotopic enrichment.

In conclusion, the predicted trend for the consequences from a SLB accident with the 4 year plutonium core relative to the consequences reported in CESSAR-DC for the System $80+$ core is uncertain at this time. However, the consequences reported in CESSAR-DC are limiting, conservative values for radiological dose. Although no fuel failure is predicted, the radiological dose is bounded by assuming that 0.5 percent of the fuel rods fail in DNB. Hence, there is margin between the transient analysis results in CESSAR-DC and results with potentially less favorable characteristics of the 4 year plutonium core with respect to calculation of acceptable consequences.

\subsection{Decrease in Heat Removal by the Secondary System Events}

The events occurring in this category are characterized by increasing RCS temperature and pressure. The increasing pressure during these events results in a DNBR which also tends to increase. Feedwater line breaks are included in this group. These faults result in consequences which approach the safety limit on RCS pressure of $186.6 \mathrm{bar}$ (2750 psia).

The causes of events within this category include malfunctions in the turbine/generator system, condenser, main steam isolation system, offsite power system, and feedwater system. The feedwater system malfunctions include pipe breaks. Condenser malfunctions occur due to failure of the circulating water system to supply cooling water, failure of the main condenser evacuation system to remove non-condensible gases, or excessive in-leakage of air to the condenser. Malfunctions of the main steam isolation system result from a spurious closure signal. The malfunctions in the offsite power system result from grid instabilities or electrical faults resulting in grid collapse. The feedwater system malfunctions result from loss of the main feedwater pumps or a spurious signal generated by the feedwater control system which results in closure of the feedwater control valves.

Events occurring within this category are classified as either moderate frequency, infrequent, or limiting faults. The turbine/generator, condenser, and main steam isolation system malfunctions are moderate frequency faults. However, when coupled with an additional failure, these faults fall into the infrequent fault category. Feedwater system malfunctions also fall into the above two categories, although pipe breaks are classified as limiting faults.

Detection of events within this group is by the RCS pressure high alarm. Reactor trip will occur on high pressurizer pressure, CPC low DNBR, steam generator water level low and/or high containment pressure.

The events within this group are characterized by increasing primary and secondary pressure and containment pressure for the case of pipe breaks inside containment. 
Subsequent to reactor trip, there is the potential for lifting the pressurizer and main steam safety valves (unaffected steam generator) and actuating the main steam and feedwater isolation systems, emergency feedwater system, containment isolation system, containment spray system and the atmospheric dump valve system. Eventual operator assisted cooldown following the initiating fault will lead to operator initiation of shutdown cooling. Once in shutdown cooling, the plant can be maintained in a stable condition indefinitely.

The limiting moderate frequency and infrequent events for this category are the Loss of Condenser Vacuum (LOCV) events without or combined with a single failure. These events challenge the primary and secondary pressure limits and the DNBR limit, depending on the initial conditions selected. Conservative assumptions regarding the plant response bound the magnitude of reduction in primary-to-secondary heat transfer and of secondary heat removal, resulting in maximum pressures occurring within 10 seconds. These fluid system transients are conveniently bounded by assuming a zero moderator temperature coefficient which yields an upper limit of positive reactivity feedback. Hence, there are no anticipated adverse effects expected with core characteristics for the 4 year plutonium core to make the pressure transients worse. Separate analyses that minimize DNBR yield no worse results than those for the complete loss of flow event resulting from a loss of power, for which the initial core margin combined with the available low flow and CPC reactor trips provide protection that can be extended to the plutonium core.

The most limiting accident events in this event category are the feedwater system pipe break events. The Feedwater Line Break (FLB) event is initiated by a break in the main feedwater system (MFS) piping. Depending on the break size and location and the response of the MFS, the effects of a break can vary from a rapid heatup to a rapid cooldown of the Nuclear Steam Supply System (NSSS). Because the cooldown associated with SLB event is more severe than with the FLB event, it bounds the consequences of a cooldown associated with the FLB so only the FLB heatup event is considered here.

The loss of subcooled feedwater flow to both steam generators causes increasing steam generator temperatures and decreasing liquid inventories and water levels. The rising secondary temperatures reduce the primary-to-secondary heat transfer and force a heatup and pressurization of the RCS. The heatup becomes more severe as the ruptured steam generator experiences a further reduction in its heat transfer capability due to insufficient liquid inventory as the break discharge continues. This initial sequence of events culminates with a reactor trip on high pressurizer pressure, low steam generator water level or high containment pressure. RCS heatup can continue after trip due to a total loss of heat transfer in the ruptured steam generator as it empties. Eventually the decreasing core power following reactor trip reduces the core heat rate to the heat removal capacity of the intact steam generator. 
Because of the various interacting physical phenomena, a number of limit conditions are analyzed for this event. The significant assumptions are break size, loss of offsite power or not, and conditions to minimize DNBR. In these analyses, the core characteristics for fuel and moderator temperature coefficients and fuel rod heat transfer are appropriately biased to maximize RCS pressure, secondary pressure or radiological dose. For the maximum pressure analyses in CESSAR-DC, there is no significant core power transient, so the fluid system responses are the dominant features that establish acceptable consequences. Decay heat influences the longer time results for the radiological dose from secondary fluid releases. For the minimum DNBR analyses, both core transient and heat transfer characteristics as well as the fluid system responses, at least up until the time of minimum DNBR, may influence the results. However, even with the 0.22 percent failed fuel calculated for the minimum DNBR analyses, the more significant dose is calculated for the steam releases in the maximum pressure analyses, for which no failed fuel is calculated.

In conclusion, the plutonium core characteristics might influence the DNBR results for the feedwater line break event, but might not increase its dose above the dose with the high pressure analyses. Specific analyses with plutonium core characteristics will confirm the worst situation.

\subsection{Decrease in Reactor Coolant Flow Rate Events}

The events occurring in this event category are initiated by a decrease in reactor coolant flow. The flow decrease results in increasing RCS temperature and pressure with subsequent degradation in DNBR. Upon reactor and turbine trip the secondary pressure increases. The events within this group result from a loss of offsite power or a mechanical defect in an individual RCP resulting in seizure or a break in the RCP shaft.

Events within this group are classified as either moderate frequency, infrequent or limiting faults. Faults initiated by a loss of offsite power are classified as a moderate frequency fault. When a single failure is included, the fault is classified as an infrequent fault. Faults initiated by RCP mechanical failures are classified as limiting faults.

Detection of events within this category is by alarms on high pressurizer pressure and low thermal margin. Within seconds of event initiation, reactor trips occur on CPC low DNBR or on low reactor coolant flow rate.

These events are characterized by decreasing reactor coolant flow, increasing RCS temperature and pressure, and increasing steam generator pressure in at least one steam generator. Subsequent to reactor trip, there is a potential for lifting the pressurizer and main steam safety valves and actuating the emergency feedwater system and the atmospheric dump valve system. Eventual operator assisted cooldown 
following the initiating fault will lead to operator initiation of shutdown cooling. Once in shutdown cooling, the plant can be maintained in a stable condition indefinitely.

A complete loss of forced reactor coolant flow will result from the simultaneous loss of electrical power to all reactor coolant pumps. The only credible failure which can result in a simultaneous loss of power is a complete loss of offsite power which is assumed to result in a turbine trip rendering the steam dump and bypass system function unavailable. For this event, the minimum DNBR is the major concern and it occurs within the first few seconds. There are no single failure assumptions that can significantly effect the DNBR on such a short time scale. Hence, this event scenario is the limiting moderate frequency and infrequent event.

The consequences, i.e., minimum DNBR, are determined by the competition between the decreasing DNBR caused by decreasing flow and the increasing DNBR caused by decreasing heat flux after reactor trip. Decreasing flow is almost entirely a fluid system process related to primary system flow resistance and stored energy in the pump flywheel. These characteristics are unchanged with the plutonium core. Increasing DNBR is determined by the interrelationships between the local and core wide power decrease as the control rods drop into the core and the thermal response of the fuel rod and resultant surface heat flux. All of these characteristics vary with the 4 year plutonium core.

Typically, bounding values of the reactivity temperature coefficients are employed in the analyses, i.e., the least negative moderator coefficient and Doppler coefficient. Even with bounding values the moderator temperature effect is small and the time scale is short for Doppler effects from the thermal response of the fuel to the changing coolant temperature. Details of the thermal transient related to differences in fuel pellet, gap and cladding thermal/mechanical behavior could affect the decreasing transient heat flux during this event, but they are believed small. The dominant mitigating effect is the negative reactivity transient by the CEAs dropping into the core. There are no differences in the rod motion transient and nearly the same net rod worth (see Table 5.1-2). In conclusion, there may be small differences in the results of the loss of flow transient with the plutonium core that should be overcome with specific analyses and/or by adjusting the initial DNBR margin that is monitored by the COLSS.

The most limiting accident in the flow decrease event category is the single reactor coolant pump rotor seizure combined with loss of offsite power. A single reactor coolant pump rotor seizure can be caused by seizure of the upper or lower thrustjournal bearings. Loss of offsite power subsequent to turbine generator trip may be caused by a complete loss of the external electrical grid triggered by the turbine generator trip. The onsite loads will subsequently lose power and the plant will experience a simultaneous loss of feedwater flow, condenser inoperability, and a coastdown of all reactor coolant pumps. 
The increasing temperature of the secondary system leads to a reduction of the primary to secondary heat transfer. Concurrently, the failed reactor coolant pump and the three reactor coolant pumps coasting down result in a lower RCS flow which further reduces the heat transfer capability of the RCS. This decrease in heat removal from the RCS leads to an increase in the core coolant temperatures, a corresponding reduction in the margin to DNB, and an increase in the primary system pressure, caused by the thermal expansion of the RCS fluid. The core coolant temperature peaks shortly after reactor trip. The increase in RCS temperature leads to an increase in RCS pressure, which reaches a maximum at 5 seconds. After this time, the RCS pressure decreases rapidly due to the declining core heat flux, in combination with the opening of the main steam safety valves. At $\mathbf{3 0}$ minutes, the operator is assumed to use the atmospheric dump valves to begin cooldown.

Analyses for this event determine the maximum offsite radiological dose resulting from fuel failure by DNB, primary to secondary leakage and eventually steam releases via the secondary safety and atmospheric dump valves. Analyses also determine the peak primary pressure. Initial conditions for the radiological dose analyses are selected to maximize core power, minimize DNBR and maximize secondary pressure. The fluid system parameters and plant response characteristics are unchanged for the plutonium core. The radial peaking, reactivity coefficients and net rod worth will vary with the plutonium core and will affect the minimum DNBR and amount of fuel failure predicted and may affect the power/pressure transient.

The differences related to the core reactivity and peaking transients are similar to those discussed above for the complete loss of flow events. If the net effect is unfavorable, restrictions on normal Limiting conditions for Operation (LCOs) that increase the initial core thermal margin may accommodate them. These differences affect the radiological dose predicted from fuel failures resulting from DNB.

Radiological dose from the activity initially in the primary coolant, from iodine spiking during the event and from activity initially in the secondary resulting from postulated steam generator tube leakage might not increase because of the conservatism in the CESSAR-DC analyses. The conservative analyses assume a stuck open atmospheric dump valve after operator action at 1800 seconds which causes a cooldown rate greater than the allowable rate and causes attainment of shutdown entry conditions sooner than if the operator limited the cooldown rate to the maximum allowable value. Entry into shutdown cooling removes the steam generator release pathway and stops offsite releases. To avoid this limit on release, the analyses conservatively assume that the radiological release is prolonged while the operator properly limits the cooldown rate to the allowable limit by manually cycling the atmospheric dump valves. Even if the primary and secondary pressure transients driving the steam release were aggravated by the plutonium core characteristics, the system related releases may not become worse than the releases calculated with the conservative analytical assumptions employed in the CESSAR-DC analyses. In conclusion, a specific analysis 
for the plutonium core would demonstrate any differences, which should be small because of the conservatisms in the analytical method.

\subsection{Reactivity and Power Distribution Anomalles Events}

The events occurring in this fault group are characterized by either an increase in core power or a resultant perturbation in core power distribution. The events resulting in an increase in core power subsequently result in increases in primary temperatures and pressures and degradation in DNBR. The CEA ejection accident included within this group has the tendency to result in a core damage sequence due to the occurrence of DNB.

CEA withdrawal events are caused by a single failure in either the control element drive mechanism, control element drive mechanism control system, or reactor regulating system or by operator error. The drop of a single CEA is caused by holding coil failure or loss of power to a coil. Inadvertent deboration is caused by improper operator actions or a failure in the boric acid makeup flow path. The ejection of a CEA is caused by the rupture of a control element drive mechanism housing.

Events occurring within this group are classified as either moderate frequency, infrequent or limiting events. The faults within this group which are classified as infrequent faults are the inadvertent loading of a fuel assembly into the improper position and the inadvertent deborationand startup of an inactive RCP coupled with a single failure. The only fault within this group classified as a limiting fault is the CEA ejection.

Detection of events within this group is by a high average coolant temperature alarm or a high neutron flux alarm (Modes 3-6 only). Trips also provide a means for detection. Trips occurring during faults of this group are high logarithmic power level variable overpower, and CPC low DNBR.

For events within this group characterized by either an increase in core power or resultant perturbation in core power distribution, the resulting increase in pressure is accommodated by lifting the primary and secondary safety valves. For certain events initiated from shutdown modes when low temperature overpressure protection is in service, the shutdown cooling relief valves provide overpressure protection. The resulting responses may actuate the emergency feedwater system and require cooldown utilizing the atmospheric dump valve system. Eventual operator assisted cooldown following the initiating fault will lead to operator initiation of shutdown cooling. Once in shutdown cooling, the plant can be maintained in a stable condition indefinitely.

The sequential CEA withdrawal events from subcritical or low power and from full power are similar. They cause a positive reactivity transient that increases core power and that challenges the fuel limits for minimum DNBR and maximum fuel rod linear heat 
generation rate. The significant core parameter is the rate of reactivity addition as the regulating rod banks are withdrawn. Individual rod worth is less for the plutonium core, which will reduce the reactivity insertion rate, but the assignment of regulating rod banks and the total sequential bank reactivity insertion rates are not yet known in detail for the plutonium core. The significant mitigating response is the reactor trip from the ex-core neutron detectors of the reactor protection system. The instrument response should be the same for the plutonium core.

Within the core, the event is influenced by the local power distribution and by the reactivity feedback from moderator and fuel temperature. Conservatively large peaking factors are typically assumed in analyses of this event, for event initiation from low power or from full power. Neutron slowing down and diffusion characteristics of the plutonium fuel lattice suggest that there may be less effect on the local power distribution from perturbations of the control rod patterns so transient peaking factors may not be adversely different from the values assumed in CESSAR-DC. Fuel and moderator reactivity temperature coefficients are taken at BOL when they are less negative and provide less favorable feedback to counteract the increasing core power. However, in the plutonium core, control rod worth, and presumably reactivity insertion rates, is greater at EOL so it is not apparent which time in life will yield the more limiting consequences for this event. The CESSAR-DC analyses show margin to the limiting values of DNBR and rod linear heat rate that would be available to offset potential unfavorable trends of the rod withdrawal event consequences in the plutonium core.

The single CEA drop event may not cause a reactor trip but will cause a decrease in DNBR. Negative reactivity inserted by the dropped CEA causes an initial power decrease that is overcome by negative moderator and fuel temperature coefficients. The power returns to its initial value while the core radial peak increases as a result of the perturbation from the dropped rod, causing an increase in local heat flux and a decrease in the DNBR.

The reactivity coefficients for fuel and moderator are both more negative at EOL, when the fuel coefficient is slightly worse than the CESSAR-DC value and the moderator coefficient is more favorable for this event. The net effect is probably small. Because of the neutron characteristics of the plutonium core as discussed above, the worth of the dropped rod and the purtubation in radial peak from the inserted rod are probably smaller in the plutonium core. Hence, consequences of the control rod drop event are probably not significantly different or worse in the plutonium core.

The startup of an inactive reactor coolant pump event is necessarily initiated from a shutdown mode, since all pumps are required for critical operation. The principal effect is a cold water surge the results in a positive reactivity insertion via the negative temperature coefficients. Values of the coefficients in the plutonium core are not significantly worse for this event. The event pressure rise is accommodated by the 
safety valves and the minimum DNBR is not challenged. Hence, there is no significant difference in the consequences from those reported in CESSAR-DC.

The inadvertent deboration event may be caused by equipment failure or by improper operator action that results in charging flow with boron concentration below the concentration in the reactor coolant. The limiting situation occurs during cold shutdown when the reactor coolant volume has been drained down. The design objective is to provide reliable automatic indication to the operator in time for action before the boron dilution leads to criticality.

The indication in the shutdown modes is from the neutron flux alarm on the startup flux channel of the reactor protection system. The alarm occurs on the ratio of the signal value at any time to the reference value initially present. Hence, the response and sensitivity of the instrument is relative, so potential changes in instrument sensitivity with neutron spectra and/or normal boron cuncentrations in the plutonium core should not invalidate the effectiveness of the boron dilution alarm.

The rate of reactivity insertion by dilution determines the time available for operator action. Thirty minutes is the minimum allowable dilution interval following the alarm. The inverse boron worth is greater for the plutonium core, but the critical boron concentration is also greater. The appropriate comparison between cores is made for the reactivity change caused by a given fractional change in the RCS boron concentration. Current estimates (see Table 5.1-2) show that the reactivity change per fractional change in concentration as unborated water is added to the RCS is smaller for the plutonium core. Therefore, for a given charging flow rate of unborated water, there is a longer time interval available before reaching criticality. This favorable conclusion must be verified when more nearly complete boron worth calculations are available.

The CEA ejection event is the limiting accident in the reactivity anomaly event category. It results from a circumferential rupture of the control element drive mechanism housing of the CEDM nozzle. Ejection of the CEA causes the core power to increase rapidly due to the almost instantaneous addition of positive reactivity. Smaller rod worths in the plutonium core make the reactivity addition smaller. The rapid power increase is terminated by a combination of Doppler and delayed neutron effects. The Doppler coefficient is slightly more negative for the plutonium core, tending to decrease the power rise, but both the delayed neutron fraction and the neutron lifetime are smaller, tending to increase the peak transient power and the rate of power rise. A reduced sensitivity of the core power distribution to local removal of the control rod reduces the increase in local peaking.

There are three acceptance criteria for the CEA ejection event. The first is the maximum primary pressure. It is calculated conservatively assuming there is no break in the primary pressure boundary. The peak pressure occurs within 5 seconds and is strongly dependent on the magnitude of the power peak. For the CEA ejection analysis 


\section{Combustion Engineering, Inc.

reported in CESSAR-DC, the calculated peak pressure is about $110 \%$ of design pressure. The allowable pressure in the SRP is higher, so there is margin to the specified limits for this event.

The second acceptance criterion is that the maximum radial average fuel enthalpy shall be less than $280 \mathrm{cal} / \mathrm{gm}$ to avoid fuel dispersion in the coolant. The calculated value is directly dependent on the magnitude of the power spike and the increase in local peaking. The net effect on these results is uncertain until specific analyses with specific values of core parameters are available. The limit value of $280 \mathrm{cal} / \mathrm{gm}$ for fuel pellets with all uranium is assumed applicable for pellets with plutonium and uranium.

The third acceptance criterion is for radiological dose, which is the sum of two contributions. One contribution is the radioactivity in the coolant initially and that is released via secondary safety valves. This should not change significantly for plutonium since the initial concentration is assumed the same, at the Technical Specification operational limit. The other dose contributor is from activity in the fuel rod gas gap that is assumed to be released instantaneously when the Specified Acceptable Fuel Design Limit on DNBR is violated. The analyses in CESSAR-DC Chapter 15 estimate less than $6.8 \%$ of the fuel rods experience DNB. Again, specific analyses with the plutonium core parameter values are needed to determine the net effect on local rod power and DNBR. Dose results reported have significant margin to the acceptable limits of 10CFR100.

In conclusion, specific analyses are required for the CEA ejection event. While the net plutonium effect could yield results that are worse than reported in CESSAR-DC, there is margin available to the acceptance criteria.

\subsection{Incresese in RCS Inventory Events}

The events occurring in this fault group are characterized by increasing RCS inventory with subsequent RCS pressurization. Due to the pressurization the DNBR increases. Causes include operator error, spurious signals causing inadvertent actuation of the safety injection system, and a failure in the pressurizer level control system resulting in excess charging flow to the RCS. These faults are categorized as moderate frequency or, when combined with an additional failure, as infrequent. Detection is by the pressurizer high level alarm or high pressurizer pressure alarms. The only trip required is the high pressurizer pressure trip.

The faults within this group are characterized by increasing RCS inventory and pressure and increasing steam generator pressure following trip. The pressurization of the RCS is accommodated by the primary safety valves or the shutdown cooling relief valves if low temperature overpressure protection is in service. The secondary pressurization is accommodated by the main steam safety valves. For certain events, actuation of the emergency feedwater and atmospheric dump valve system may be required. 
Eventual operator assisted cooldown following the initiating fault will lead to operator initiation of shutdown cooling. Once in shutdown cooling, the plant can be maintained in a stable condition indefinitely.

The inadvertent operation of the ECCS event does not impact normal operation at normal full pressure because the shutoff head of the SI pumps is below RCS operating pressure. Inadvertent SIS operation at lower pressure and temperature could result in low temperature pressurization up to the SI pump shutoff pressure. While this scenario does not violate RCS pressure or brittle fracture limits in the System 80 + design with a uranium core, the event should be evaluated if core loadings with plutonium decrease the margins to reactor vessel enbrittlement at low temperature.

A malfunction in the CVCS may cause an event where the charging pump operates at maximum flow rate, causing the reactor pressure to increase. When the initiating event is combined with a loss of power and consequent loss of flow, the reduction in primary-to-secondary heat transfer increases the primary pressure rise. These effects are plant system effects which do not change with plutonium. The plutonium core affects the positive reactivity response caused by the lowered temperature of the excess charging flow. A more negative moderator temperature coefficient would be worse, but the temperature effect on the power and pressure is relatively small compared to the effect from increasing inventory. In conclusion, the plutonium rore should have only a small effect on the peak pressure consequences of this event and no adverse effect on minimum DNBR.

\subsection{1.6 Decrease in Reactor Coolant Syatem Inventory Events}

The events occurring in this fault group are characterized by decreasing RCS pressure, reduced RCS inventory and an approach to fuel design limits. Reactor coolant pipe breaks are included in this fault group. For in containment breaks a resultant pressurization of the containment occurs.

The causes of the events within this group are in most cases due to a pipe rupture. However, the inadvertent opening of a pressurizer safety/relief valve is a result of mechanical valve failure or operator error. Events within this group are classified as limiting faults.

The inside containment breaks will be detected by means of the low pressurizer pressure and level alarms. For outside containment breaks, in addition to the pressurizer alarms, the operator will be alerted by the regenerative heat exchanger high exit temperature alarm, the letdown line low pressure alarm, the auxiliary building high radiation, temperature, humidity, and sump level alarms, and the volume control tank low level alarm. Reactor trips required are low pressurizer pressure, manual, high steam generator water level, and margin to subcooling. 
The faults within this group are characterized by decreasing primary pressure and reduced RCS inventory. Upon reactor trip steam generator pressure will increase. For in containment pipe breaks, containment pressure limits may be challenged. Secondary pressurization is accommodated by the main steam safety valves. For certain cases emergency feedwater actuation and use of the atmospheric dump valve system is required. In order to mitigate events resulting in a loss of RCS inventory, safety injection pump flow is required and in some cases safety injection tank flow is required. The reactor coolant gas vent system is required to mitigate the consequences of the steam generator tube rupture accident. In order to mitigate the containment pressure transient and offsite dose release for inside containment loss of coolant accidents the containment spray and isolation systems are required. In addition, in order to mitigate the offsite dose due to loss of coolant accidents the containment annulus, subsphere and control room ventilation systems are required. Eventual operator assisted cooldown following the initiating fault may lead to operator initiation of shutdown cooling. Once in shutdown cooling, the plant can be maintained in a stable condition indefinitely.

The letdown line break event, outside containment, releases primary cooiant to the atmosphere. Analyses of this event assume no operator action or automatic mitigating function for 30 minutes. Since there is no credited reactor trip and since there is no significant variation in core power or coolant temperature, there are no reactivity effects. Hence, the analytical response is based upon normal plant functions that would conservatively maximize the break flow rate and these functions do not vary with the plutonium core.

It is assumed that the design ranges for CVCS charging and letdown flow rates are unchanged. This assumption implies that the increased soluble boron requirements for the plutonium core can be accommodated with enriched boron. When the boron design requirements are established, the safety related design basis events that are influenced by charging and letdown flow capacities should be evaluated. For the letdown line break event, the primary parameters are the maximum break flow rate, determined by orifices in the letdown line, and the maximum break flow temperature, determined by the combination of flow rate and heat transfer capacities of the letdown and regenerative heat exchangers. The break flow temperature influences radiological dose because it determines the fraction of break flow that evaporates into the atmosphere. There is about 10 percent margin between the most limiting dose reported in CESSAR-DC for this event and the dose acceptance criteria in the SRP, but there is believed to be additional margin in the conservatism of the analytical methods that could be utilized if needed. In conclusion, this event should be reanalyzed for the plutonium core CVCS detailed design.

The steam generator tube rupture event is characterized by the radiological release of primary coolant via the pathway through the ruptured tube to secondary steam, thence, to the atmosphere. Prior to reactor trip, the RCS temperature does not vary significantly so there are no reactivity feedback effects that would make the core 

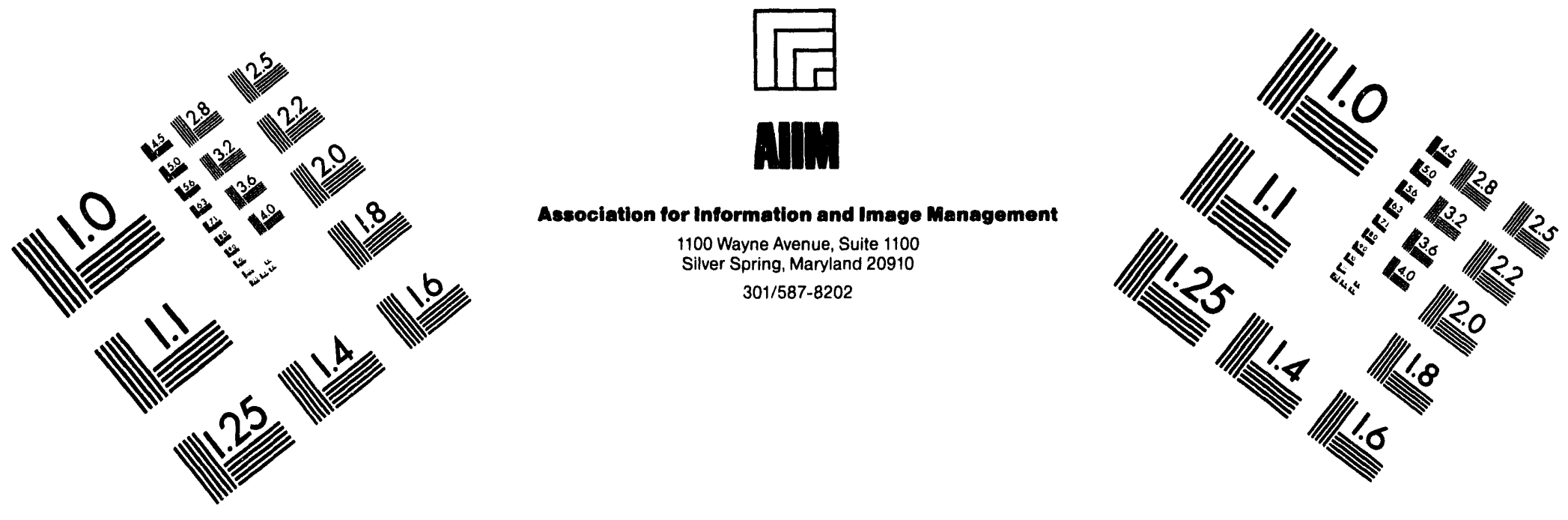

\section{Centimeter}

$\begin{array}{llllllllllllllll}1 & 2 & 3 & 4 & 5 & 6 & 7 & 8 & 9 & 10 & 11 & 12 & 13 & 14 & 15 & \mathrm{~mm}\end{array}$ Lm.

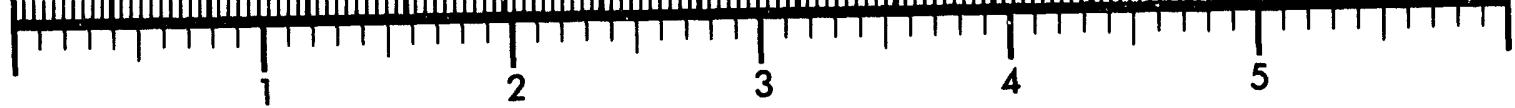
Inches
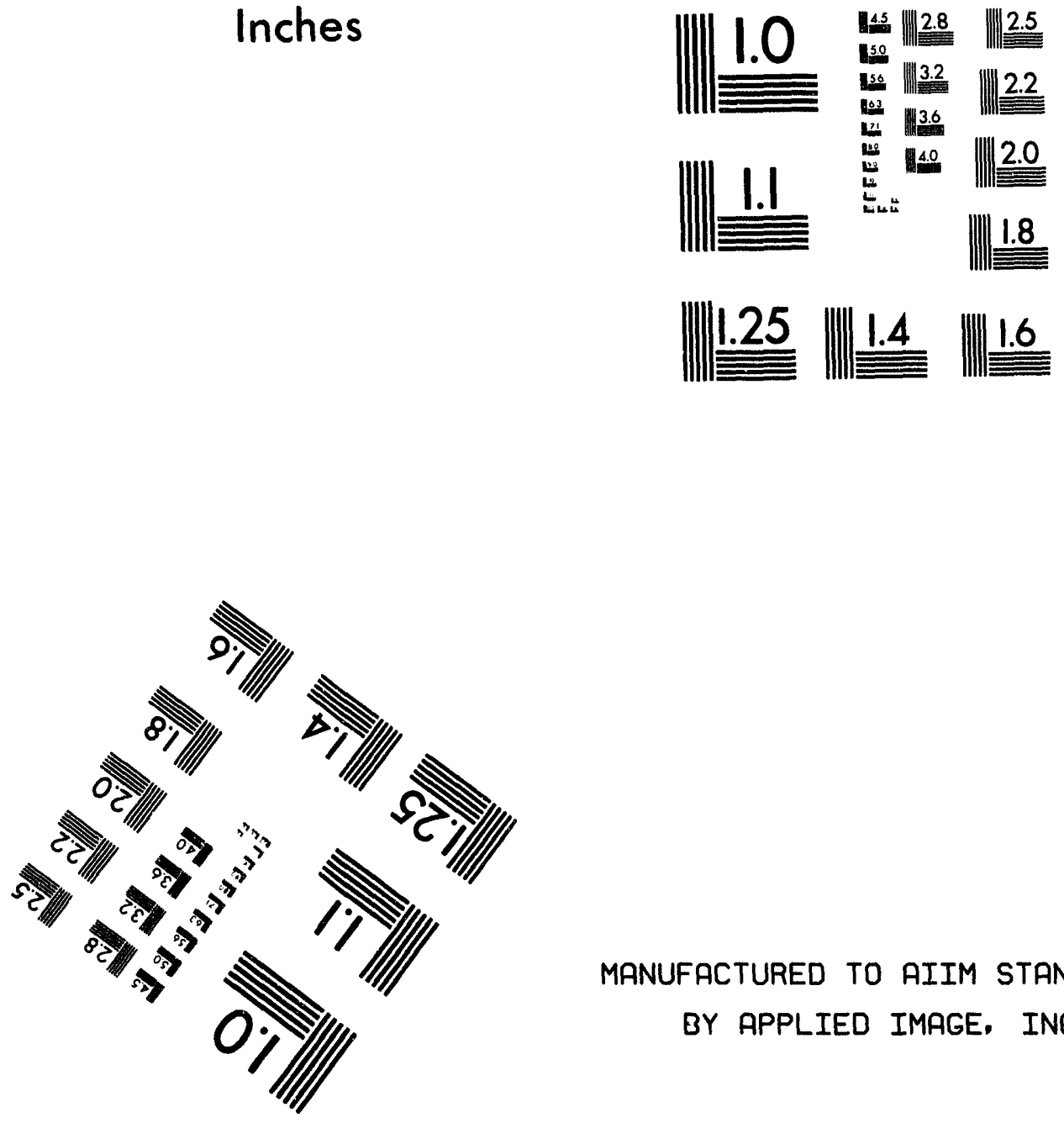

MANUFACTURED TO AIIM STANDARDS BY APPLIED IMAGE, INC.

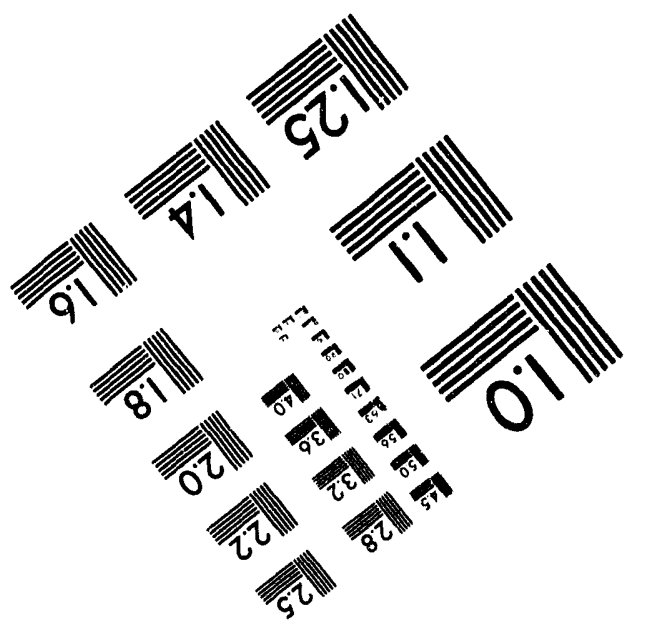



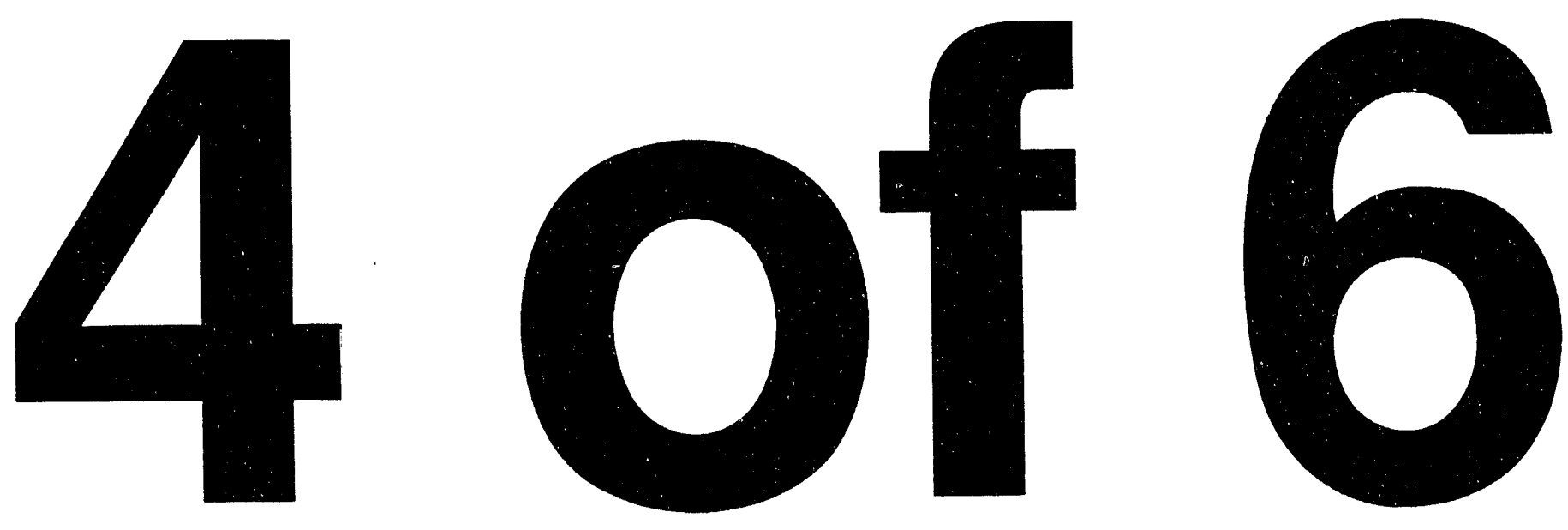
response different with a plutonium core. Other influences on the radiological release are essentially dependent upon the plant responses which are unchanged for the System $\mathbf{8 0}+$ design when a plutonium core is substituted. Decay heat is a significant factor, but the decay heat for the first two to eight hours is no higher with the plutonium core so the magnitude of steam release is no larger. In conclusion, the plutonium core should have no significant effect on the CESSAR-DC plant response to a SGTR event.

The LOCA event is unique in that the U.S. NRC prescribes one set of assumptions and analytical models for evaluations to show that large scale core damage is avoided and another set for radiological dose evaluations that essentially assumes extensive core damage. Evaluations for these two conditions are analytically decoupled, so each is discussed separately here.

In the core damage evaluation, acceptance criteria are imposed for peak clad temperature, clad oxidation and long term cooling. Physical changes for the plutonium core that may influence the calculated results are outlined. Changes to the fuel pellet conductivity and gap conductance will affect the adiabatic heatup portion of the Large Break LOCA event. For example, the previous change from uranium fuel with separate poison rods to uranium fuel with erbia absorber in the fuel for the System $80+$ design, reduced the conductivity of the fuel pellet and resulted in an increase for the calculated fuel temperature. Similar conductivity changes may occur with the change from all uranium to plutonium, but the changes are believed small.

Thermal radiation from the hot rod to the neighboring rod array beneficially reduces the hot rod temperature, so a flatter local rod power distribution yields worse results. Shorter neutron slowing down and diffusion lengths in the plutonium core will influence the local rod power distribution, but the direction of the result for the hottest rod array is not known. Thermal radiation is evaluated at two times during the LBLOCA. During refill, before the coolant level rises to the bottom of the fuel, cooling is by thermal radiation, but the duration is short and the temperatures are too low for appreciable radiation. During reflood, after the reflood rate falls below one inch per second and the hot rod has ruptured, the analytical model differentiates between cooling below the ballooned rupture elevation and above. Changes to the assumed steam-plus-thermal radiation cooling above the ruptured elevation could switch the hottest location to above the ruptured elevation, with associated incremental changes in peak clad temperature. Another effect of the local power distribution involves the net amount of gama and beta radiation interchange between the hot rod and surrounding rods. In a flatter distribution, there is less net power transferred out of the hot rod by nuclear radiation. The effects of local power distribution changes require detailed evaluations for the plutonium core.

Reactivity effects are generally small for LOCA evaluations. The LBLOCA depressurizes the RCS so rapidly that the voiding effect overwhelms temperature effects, and rod insertion is not credited. The Small Break LOCA evaluation models the control rods 
and a small power rise occurs before the reactor trips on low pressure, but the void reactivity negates $i t$, even before the rod insertion has significant effect. In conclusion, differences in reactivity effects should not be significant in LOCA evaluations of the plutonium core.

Decay heat influences the LOCA event throughout, but estimates of decay heat with the plutonium core shows no increase above that for the uranium core until after the typical period of concern about core temperature. Initial boron concentration and worth has some adverse reactivity effect early in the SBLOCA depressurization before reactor trip, but it is small. Injected boron concentration is significant in the LBLOCA during the long term cooling period. Then, the combination of decay heat, which determines the boiloff rate, and boron concentration determines the length of time available before the reactor operator must divert some of the SI coolant from a direct vessel injection nozzle to the hot leg. The time when the boron concentration in the core approaches precipitation is shorter for higher decay heat and for higher injected boron concentrations. Preliminary evaluation with a $20 \%$ increase in decay heat and with $6200 \mathrm{ppm}$ boron, relative to the evaluation in CESSAR-DC with $4400 \mathrm{ppm}$, decreases the time available before required operator action to avoid boron precipitation in the core from about 3 hours to about 1-1/2 hours. The shorter time is still acceptable, so these long term cooling requirements are satisfied with the plutonium core. Even so, the use of enriched boric acid in the coolant will mitigate this situation.

Actuation of the engineered safeguards is essential to satisfy the ECCS acceptance criteria, and there are no changes to that part of the System $80+$ design with a plutonium core. In conclusion, the LOCA evaluation with a plutonium core should yield results that are close to those reported in CESSAR-DC, but several differences in core details will cause differences in peak clad temperature and clad oxidation and the direction of the trend is uncertain at this time.

The second area of LOCA evaluation, after core damage evaluation, is radiological dose. A review of Section 15.6.5 CESSAR-DC identifies the plant parameters that influence the calculation of dose. Calculations of the containment pressure trunsient yield some values of time when the containment purge, spray and annulus systems become operable and these will not change, but mostly the NRC prescribes the assumptions in the radiological dose analyses. One of the primary assumptions involves the fractions of the core radioactive isotope inventories that are released. Since the fuel material for both a uranium core and for the proposed plutonium 4 year core is more than 90 percent uranium, it is assumed that the fraction isotopic releases and their physical forms are the same as employed in CESSAR-DC and as prescribed in NUREG-1465. The isotopic quantities will change when plutonium is the fissile material but this is accounted for by detailed depletion calculations for specific plutonium configurations and burnup cycles. 
A significant dose parameter that is not specific to the System $80+$ plant design, but that determines the offsite dose for the LOCA event as well as for all other events with an offsite release, is the atmospheric dispersion of released radioactivity. In CESSARDC, values of dispersion are assumed that encompass $95 \%$ of the available commercial sites in the USA. When the actual site atmospheric conditions are bounded by the values assumed, this aspect of dose evaluation for the plutonium core is satisfied.

In conclusion, the radiological dose from a postulated LOCA in a System $80+$ plant design with a plutonium core is dependent on the core inventory, to be calculated, and its acceptability is dependent on the combination with specific site parameters.

\subsection{Radioactive Material Release from a Subsystem or Component Events}

The events occurring in this fault group result in ex-core release sequences. The types of faults involve radwaste system failure and the drop of a fuel assembly and spent fuel cask. The cause of the radwaste system failure is the rupture of a tank. The cause of the dropping of a fuel assembly or a spent fuel cask is mechanical failure of the lifting equipment. The tank rupture is classified as a limiting fault. The dropping of a fuel assembly or the spent fuel cask is classified as an infrequent fault. There are no reactor trips associated with these faults. The only means of detecting the tank failure and the spent fuel cask drop is by visual inspection. The occurrence of a fuel assembly drop will result in a high radiation alarms in the containment or the fuel building wherever the fault occurs. Upon dropping a fuel assembly in the containment, the resultant discharge of radionuclides will result in a containment isolation signal, thus isolating the containment. Prior to this, isolation radioisotopes will be filtered by the refueling purge system. Upon dropping a fuel assembly in the fuel building, the fuel building ventilation system will raposition its dampers to ensure filtration of the activity released prior to the releases reaching the dampers. The dropped cask event is eliminated by procedures and design.

The release of radioactive liquid from the Boric Acid Storage Tank (BAST) was the most limiting radioactive tank failure for the System 80 + design reported in CESSARDC. The event is characterized by a rapid release of the BAST contents to the environment. In order to dilute the radioactive concentration to allowable levels, the minimum dilution that the site conditions must provide is calculated. The result establishes site acceptance criteria for the minimum dilution flow to the nearest potable water source.

Dilution required is dependent upon tank volume and radioactive isotope concentrations. These are dependent upon the plutonium core isotopic inventory, the operating boron concentration and the CVCS design capacities. Higher boron concentrations may increase the required BAST size, unless use of enriched boron reduces the concentrations with the plutonium core to the System $80+$ values reported in CESSAR-DC. Alternatively, for the period of plant life that the plant is loaded with plutonium, the liberal design allowances in the System $80+$ design for 
repeated heatup/cooldown cycles could be tightened so as to reduce needed tank size and processing capacity.

In conclusion, the acceptance criteria for the tank release event are dependent on the site and the plant parameters can be varied somewhat to meet the needs of the site.

The fuel handling event con'sequences are directly dependent upon the quantity of fission product iodine and fission gases in the fuel gap that are assumed released when a fuel assembly is damaged in hanidiling. The NRC specifies assumptions in Regulatory Guide 1.25 and in Draft NUREG-1465. These assumptions are assumed valid for plutonium fuel assemblies. The most sigrificant are the fractions of core inventory of iodine, noble gases, rubidium and cesium that are in the fuel rod gap and are released upon fuel clad damage. Specific evaluations of the plutonium fuel assembly inventory are needed. Variations in the inventory, and therefore dose, from that reported in CESSAR-DC may be accommodated, if needed, by the margin to the applicable dose acceptance criteria.

\subsubsection{Beyond Design Basis Events}

The events in this group are characterized by a sequence of failures with a low frequency. Three events are considered - total loss of feedwater (TLOFW), station blackout (SBO) and anticipated transient without trip (ATWT). These events lead to high primary pressures that may prevent safety injection, and result in core damage.

The causes of faults within this group are the following: ATWT initiators include all non-LOCA and non-secondary break initiators for which the basic plant response is a reactor trip. These initiators in combination with a failed reactor trip system result in an ATWT event. The TLOFW fault initiator is the loss of main feedwater coupled with a loss of all emergency feedwater. The SBO initiating fault is the loss of offsite power coupled with the failure of onsite emergency $A C$ power (diesel generators).

Faults occurring within this group are classified as limiting faults since they are not expected to occur during the lifetime of a plant. They are postulated since they can potentially result in core damage or release of radioactive material.

Detection of faults within this group is accomplished as follows: The TLOFW fault would be detected by a resulting high pressurizer pressure or low steam generator water level trip. The most adverse ATWT initiator is the loss of main feedwater. This causes steam generator secondary level to decrease. The ATWT fault would be detected by a low steam generator level alarm and other alarm actuations that exist in the System $80+$ design. SBO is detected by the loss of offsite power leading to reactor coolant pump (RCP) coastdown and a core protection calculator (CPC) trip on low RCP shaft speed. 
The plant response to the TLOFW fault is a reactor trip followed by lifting of the primary safety valves. Decay heat removal is accomplished by a feed and bleed process utilizing the safety injection and the safety depressurization systems. The plant response to an ATWT is a substantial increase in primary pressure. The only available heat sink for reducing the pressure is the automatically actuated emergency feedwater. Plant response to a SBO fault is a hot standby condition with the atmospheric dump system and steam turbine driven emergency feedwater pumps operational. In addition, the alternate gas turbine driven standby power source handles permanent non-safety loads and one train of safety loads to continue plant cooldown.

An anticipated transient without trip (ATWT) is a plant event which is accompanied by a failure of the Plant Protective System (PPS) to trip the reactor when required. The ATWT scenario shown to have the most significant consequences begins with the loss of normal feedwater which causes a reduction in the steam generator inventory and reduces the secondary heat sink. The loss of main feedwater and the failure of the reactor turbine to trip increases the primary temperatures which causes a rapid increase in pressurizer pressure. The maximum RCS pressure, which occurs in the cold leg discharge piping, must be below the pressure that would yield the ASME B\&PV code Level C service stress limit. Void formation in the core because of inability to transfer the heat produced and the primary safety valve discharge and subsequent blowdown further reduces reactor power via the negative reactivity feedback. The combined effects reduce reactor power to below the secondary heat sink capacity and result in a coodlown of the RCS. The cooldown causes a reduction in the pressurizer pressure and level and results in the automatic actuation of the SIS. A relatively small steam void forms in the reactor vessel upper head but is quickly collapsed by the SIS flow that is injected directly into the reactor vessel. The reactor core remains covered during the entire transient. The inventory addition by the SIS rapidly restores pressurizer level and provides reactivity control. The emergency feedwater restores steam generator level and provides a sufficient heat sink to remove decay heat.

The initial temperature rise provides a negative reactivity via the net effects from moderator and doppler coefficients. Analyses show a significant increase of the resulting peak primary pressure as the moderator temperature coefficient becomes less negative, i.e., as it approaches zero from larger negative values. A more negative value at $B O L$ in the plutonium core is an advantage in the ATWT event.

Eventual reactivity control and cooldown is accomplished by operator action with boration, via the CVCS (if available) or via the safety injection system after primary pressure has been lowered below the SI pumps' shutoff head by depressurizing with the Safety Depressurization System. The rate of negative reactivity insertion by boration is dependent on the inverse boron worth of the injected coolant. Inverse boron worth (ppm/\% delta rho) is more than twice as large for the plutonium core when natural boron is used. Use of enriched boron would reduce the inverse worth, but the negative reactivity insertion rate by the SI pumps still may not be as large for the plutonium core. The conclusion is that the ATWT can be accommodated by more 
the favorable moderator temperature coefficient at BOL and by appropriate boron concentrations and/or boron 10 enrichment for the safety injection coolant in the IRWST. Confirmatory analyses at various conditions should be performed for the plutonium core and boron concentrations.

A station blackout (SBO) is an event which involves the loss of offsite power concurrent with turbine trip and failure of the onsite emergency $A C$ power system. Station batteries, through inverters and an alternate $A C$ source, i.e., gas turbine generator, are available to mitigate to consequences of a SBO event.

The loss of forced coolant flow following loss of power to the RCPs leads to a reactor trip on low DNBR. The loss of secondary heat sink due to the loss of main feedwater results in a reduction in RCS heat removal. Both primary and secondary pressure will increase. The primary and secondary safety valves will lift to control primary and secondary pressure respectively. Concurrently, steam generator level will be decreasing due to void collapse, and emergency feedwater, supplied by the steam driven pumps, will be actuated on a low steam generator level. Secondary heat removal via the emergency feedwater and the secondary safety valves is thus reestablished and primary pressure and temperature will begin to decrease. At this time, the Atmospheric Dump Valves (ADVs) can be opened to continue cooling and depressurizing the RCS. When sufficient energy has been removed from the RCS, the shutdown cooling system, powered by the alternate $A C$ source is activated and directs the plant to a safe shutdown condition.

For the station blackout event, the major area of concern is the maintenance of the secondary side heat sink so as to remove residual heat from the RCS. To this end, the major objectives of the operator are to establish a source of electrical AC power from the alternate $A C$ combustion turbine and to maintain single phase natural circulation of the RCS. Because a reactor trip on low flow occurs very early in the event, and because the secondary system is employed to remove decay heat, there is essentially no difference in the plant response with a plutonium core beyond those discussed for the loss of flow event. Those differences relate to details of the transient heat flux and DNB on the hot rod and are considered small.

The total loss of feedwater event (TLOFW) is defined as the total loss of feedwater to both steam generators. Following the loss of feedwater flow, steam generator level decreases and the steam generator pressure increases. This, in turn, forces the reactor coolant to heat up and expand, raising the pressurizer level and pressure. These trends will continue until a reactor trip is generated on either low steam generator level or high pressurizer pressure condition. After the reactor/turbine trip, pressurizer level and pressure and RCS temperatures will decrease. Since emergency feedwater is not available, the secondary inventory continues to deplete resulting in further degradation in primary to secondary heat transfer. As a result, the primary system pressure again begins to increase. Once the steam generators begin to dry out, the primary pressure increases rapidly until the pressurizer pressure reaches the primary safety valves lift 
setpoint. Upon steam generator dry out, the only means of rejecting heat is via primary safety valve discharge which is not sufficient to depressurize the RCS to the safety injection pump shutoff pressure. The safety depressurization valves are sized to provide the additional capacity. Once the valves are opened, the RCS and pressurizer pressures decrease to the point where safety injection flow is delivered to the RCS.

The initial period of this event, prior to reactor trip, is similar to the response discussed above for the ATWT. Reactor trip for the TLOFW event reduces power, but lack of secondary cooling subsequently makes the primary heatup more significant. A plutonium core would differ for the same reasons for the TLOFW; moderator temperature reactivity feedback is beneficial while SI flow is needed only for cooldown, not for reactivity control at temperature. In conclusion, the TLOFW event should not be more adverse with the plutonium core.

\subsubsection{Severe Accident Considerations}

System $80+$ is currently being certified by the NRC for construction in the United States. In pursuit of this goal, System $80+$ has been the first evolutionary PWR to comprehensively address severe accident issues within the licensing forum. Specifically, System 80 + has addressed severe accident issues associated with SECY90-016, SECY-93-087 and 10CFR50.34(f) "Post TMI Requirements". These regulations require that several aspects of severe accident performance be considered in the plant design both deterministically and probabilistically. The thrust of these requirements is to ensure the plant has an acceptably low probability of early containment failure, and smaller than $10 \%$ conditional failure probability of a large environmental radiation release following a core damage event.

In order to establish the ability of System $80+$ to meet the general guidelines identified above several specific deterministic and probabilistic assessments were required. These included deterministic assessments of:

- Core-Concrete Interaction Phenomena

- Containment Overpressure Failure Process

- Post Severe Accident Equipment Survivability

and probabilistic risk assessments to demonstrate that:

- The conditional probability of a large radiation release following a core damage event was below or in the proximity of the desired NRC goal of 0.10

- The frequency of a large radiation release $1>25$ rem at 0.5 miles from the reactor site) was below $10^{-6}$ per reactor year. 


\section{Combustion Engineering, Inc. REACTOR COMPLEX SAFETY AND LICENSING}

A preliminary assessment of the potential for meeting the above criteria for a Pu fueled System 80 + PWR operated at 3800 Mwt is discussed below.

\section{Core Concrete Interaction (CCII Phenomena}

SECY-90-016 and SECY-93-087 require that the evolutionary plant design be equipped with a means of cooling corium (a molten mixture of fuel, fission products, steel and concrete) within the reactor cavity. To this end the System $80+$ design includes a cavity flood system. As a limiting demonstration of the robustness of the containment design, it was further required by NRC staff that corium progression into the cavity basemat, to the embedded segment of the containment steel shell, requires a minimum of 24 hours and that crust formation limiting upward decay heat removal to the overlying pool be considered. That this requirement could be met was demonstrated for System $80+$ using a version of the CORCON (CORe-CONcrete interaction) program. The core-concrete interaction process is driven by the decay heat contribution of non-volatile fission products and actinides and is significantly affected by the melting temperature of the corium debris and the thermal properties of its crust.

A preliminary comparison of the $\mathrm{Pu}$ and $\mathrm{U}$ fuelled cores suggest that the concrete erosion behavior of both cores would be similar. Table 1 lists the decay thermal power produced by both cores. This table shows that, over the first $24 \mathrm{hrs}$ after shutdown, both "cores" will generate similar levels of decay power and both systems have similar thermal and mechanical properties. Thus, while details of the analysis will vary there is a high degree of confidence that the overall penetration timing will be consistent with the NRC guidelines.

\section{Containment Overpressure Failure Process}

The System $80+$ design includes a large $(3.4$ million cubic feet) containment. This feature results in a plant design that is relatively robust with respect to containment pressurization challenges. In the present System $80+$ design, given a severe accident with loss of containment heat removal and without implementation of any recovery process, overpressure failure of the containment will be averted for at least two days. This failure time is primarily determined by the core decay power which vaporizes the water in the flooded reactor cavity.

While the containment failure modes would be the same for the $\mathrm{Pu}$ and $\mathrm{U}$ fuelled cores, differences in timing could arise as a result of differences in the amount of decay heat produced by the two types of cores. Table 5.1-5 compares the decay powers of the $\mathrm{Pu}$ and $U$ based cores at various times after shutdown for up to $96 \mathrm{hrs}$. Inspection of this table reveals that the $U$ core thermal power exceeds that of the Pu core by about $13 \%$ immediately after shutdown. As the Pu core decay power decreases at a slower rate (due to the presence of a higher concentration of longer lived fission products and actinides), the decay heat produced by the Pu fuelled core vill begin to exceed that of the $U$ core between 24 and 48 hours after shutdown. The net difference in the 


\section{Combustion Engineering, Inc.}

integrated decay power for both cores is small, i.e., the integrated decay heat of both cores is within about $5 \%$ of each other at the time that the decay heat curves cross. This information implies that the containment over-pressure failure timing for a $\mathrm{Pu}$ fuelled core plant should not vary significantly from that of the $U$ core design.

\section{Equipment Survivability}

Equipment survivability issues are defined in SECY-90-016,SECY-93-087, and 10 CFR50.34(f). These guides and regulations require that equipment required to establish and maintain a safe stable state following a severe accident be able to survive the associated thermodynamic environment. Thermal aspects of equipment survivability are expected to be similar for both designs. However, due to detailed changes in the cores isotopic distribution, the radiation environment experienced by the safety related equipment will be different. Since the Pu core is biased in the directed of longer lived fission product isotopes, most equipment will be subjected to a lower integrated dose. However, the Pu core results in the production of approximately $30 \%$ more of the $\mathrm{Cs}^{136}$ isotope. Cesium is soluble in water and will collect (along with lodine) in the containment sumps and be transported throughout various safety systems (including the containment sprays). The $\mathrm{Cs}^{136}$ isotope in particular emits a high energy gamma, which upwardly biases ("hardens") the gamma energy spectrum and may result in the need for locally increased shielding or extended equipment qualification for a limited number of safety systems.

\section{Probabilistic Risk Goal and Aversion of Large Radiation Release}

For the purpose of plant design, the containment performance goal was to ensure the conditional probability of containment failure resulting in a large radiological release was less than 0.10 . In addition, it is also an NRC goal that the frequency of a radiation release exceeding 25 Rem at a position one half mile from the reactor centerline be less than $10^{-6}$ per reactor year. Since the integrated decay heat to the time of containment failure is generally equal for both fuel deigns, the overall plant thermodynamic response will be similar. Thus, the conditional containment failure probability for both the $\mathrm{Pu}$ and $U$ fuelled cores are expected to be similar. However, a review of the discharge isotope inventories for the Pu fueled and $U$ fueled cores (see Table 5.1-6 and 5.1-7) shows that on the average the net fission product activity is initially lower for the $\mathrm{Pu}$ core than for the $U$ fuelled core. Furthermore, the distribution of elements between volatile and non-volatile elements/compounds results in a lower expected concentration of airborne contaminants for the Pu core and consequently lower expected offsite doses. These assertions should be confirmed in the next stage of the Pu burner design. 


\section{IHERMAL POWER OF A SINGLE FUEL ASSEMBLY FOR PU AND U CORES}

\begin{tabular}{|c|c|c|c|}
\hline \multirow{2}{*}{$\begin{array}{l}\text { Time After } \\
\text { Shutdown }\end{array}$} & \multirow{2}{*}{ Elements } & \multicolumn{2}{|c|}{$\begin{array}{c}\text { Single Assembly Decay Power } \\
\text { (Watts) }\end{array}$} \\
\hline & & Pu Core & U Core \\
\hline \multirow{3}{*}{ Discharge } & Actinide & $2.612 E+4$ & $4.733 E+4$ \\
\hline & Fission & $7.800 E+5$ & $8.639 E+5$ \\
\hline & Total & $8.061 E+5$ & $9.112 E+5$ \\
\hline \multirow{3}{*}{3 hours } & Actinide & $2.555 E+4$ & $2.338 E+4$ \\
\hline & Fission & $1.138 E+5$ & $1.246 E+5$ \\
\hline & Total & $1.394 E+5$ & $1.480 E+5$ \\
\hline \multirow{3}{*}{24 hours } & Actinide & $2.209 E+4$ & $1.818 E+4$ \\
\hline & Fission & $6.503 E+4$ & $6.912 E+4$ \\
\hline & Total & $8.712 E+4$ & $8.730 E+4$ \\
\hline \multirow{3}{*}{48 hours } & Actinide & $1.908 E+4$ & $1.391 E+4$ \\
\hline & Fission & $+5.387 E+4$ & $5.711 E+4$ \\
\hline & Total & $7.295 E+4$ & $7.102 E+4$ \\
\hline \multirow{3}{*}{72 hours } & Actinide & $1.683 E+4$ & $1.072 E+4$ \\
\hline & Fission & $4.833 E+4$ & $5.125 E+4$ \\
\hline & Total & $6.516 E+4$ & $6.197 E+4$ \\
\hline \multirow{3}{*}{96 hours } & Actinide & $1.514 E+4$ & $8.337 E+3$ \\
\hline & Fission & $4.466 E+4$ & $4.740 E+4$ \\
\hline & Total & $5.980 E+4$ & $5.574 E+4$ \\
\hline
\end{tabular}


IABLE 5.1-6

COMPABISON OF FISSION PRODUCT ACTIVITY AT DISCHARGE

\begin{tabular}{||l|c|c||}
\hline ELEMENT & $\begin{array}{c}\text { PU FUELLED CORE } \\
\text { (CURIES PER ASSEMBLY) }\end{array}$ & $\begin{array}{c}\text { U FUELLED CORE } \\
\text { (CURIES PER ASSEMBLY) }\end{array}$ \\
\hline OODINE & $4.71 E+6$ & $4.96 \mathrm{E}+6$ \\
\hline BARIUM & $3.65 E+6$ & $4.11 \mathrm{E}+6$ \\
\hline CERIUM & $2.92 \mathrm{E}+6$ & $3.30 \mathrm{E}+6$ \\
\hline CESIUM & $2.96 \mathrm{E}+6$ & $3.36 \mathrm{E}+6$ \\
\hline KRYPTON & $0.95 \mathrm{E}+6$ & $1.66 \mathrm{E}+6$ \\
\hline RUTHENIUM & $2.97 \mathrm{E}+6$ & $2.14 \mathrm{E}+6$ \\
\hline STRONTIUM & $2.59 \mathrm{E}+6$ & $3.64 \mathrm{E}+6$ \\
\hline TELLURIUM & $3.09 \mathrm{E}+6$ & $3.33 \mathrm{E}+6$ \\
\hline XENON & $3.57 \mathrm{E}+6$ & $3.68 \mathrm{E}+6$ \\
\hline
\end{tabular}

Based on a Pu core run at $3800 \mathrm{MW}$ with a heavy metal loading of $98.75 \mathrm{MT}$, a $U$ core run at $3914 \mathrm{MW}$ with a heavy metal loading of $105.7 \mathrm{MT}$ and both cores with a total burn-up of $45830 \mathrm{MWD} / \mathrm{MT}$. 


\section{Combustion Engineering, Inc. REACTOR COMPLEX SAFETY AND LICENSING}

IABLE 5.1-7

COMPARISON OF ACTIVITIES BY ELEMENT AT DISCHARGE AND 96 HOURS AFTER SHUTDOWN

\begin{tabular}{||c||c|c|c|c|c|c||}
\hline \multirow{2}{*}{ Element } & \multicolumn{3}{|c|}{ Discharge Curies } & \multicolumn{3}{c|}{96 Hour Curies } \\
\cline { 2 - 7 } & Pu Core & U Core & Ratio Pu/U & Pu Core & U Core & Ratio Pu/U \\
\hline \hline lodine & $4.71 E+6$ & $4.964 E+6$ & 0.950 & $6.057 E+5$ & $6.009 E+5$ & 1.008 \\
\hline Uranium & $5.847 E+6$ & $9.064 E+6$ & .645 & $3.394 E+4$ & $3.340 E+5$ & 0.102 \\
\hline Barium & $3.649 E+6$ & $4.114 E+6$ & 0.887 & $5.887 E+5$ & $6.397 E+5$ & 0.920 \\
\hline Cerium & $2.915 E+6$ & $3.304 E+6$ & 0.882 & $1.114 E+6$ & $1.304 E+6$ & 0.855 \\
\hline Cesium & $2.962 E+6$ & $3.363 E+6$ & 0.880 & $1.647 E+5$ & $1.875 E+5$ & 0.878 \\
\hline Erbium & $1.913 E+00$ & $2.296 E+0$ & 0.833 & $1.334 E-01$ & $1.231 E-01$ & 1.084 \\
\hline Krypton & $9.465 E+5$ & $1.666 E+5$ & 0.568 & $3.057 E+3$ & $5.763 E+3$ & 0.530 \\
\hline Lanthanum & $3.586 E+6$ & $4.075 E+6$ & 0.880 & $5.911 E+5$ & $6.492 E+5$ & 0.911 \\
\hline Plutonium & $4.488 E+5$ & $2.477 E+5$ & 1.811 & $2.497 E+5$ & $6.482 E+4$ & 3.852 \\
\hline Radon & $1.509 E-4$ & $7.988 E-4$ & 0.189 & $1.512 E-4$ & $8.015 E-4$ & 0.189 \\
\hline Ruthenium & $2.974 E+6$ & $2.146 E+6$ & 1.386 & $1.248 E+6$ & $9.073 E+5$ & 1.367 \\
\hline Strontium & $2.593 E+6$ & $3.637 E+6$ & 0.713 & $2.205 E+5$ & $3.983 E+5$ & 0.554 \\
\hline Tellurium & $3.093 E+6$ & $3.326 E+6$ & 0.930 & $3.416 E+5$ & $3.290 E+5$ & 1.038 \\
\hline Xenon & $6.833 E+7$ & $7.295 E+7$ & 0.937 & $1.036 E+7$ & $1.085 E+7$ & 0.955 \\
\hline \hline
\end{tabular}

Based on a Pu core run at $3800 \mathrm{MW}$ with a heavy metal loading of $98.75 \mathrm{MT}$, a $\mathrm{U}$ core run at $3914 \mathrm{MW}$ with a heavy metal loading of $105.7 \mathrm{MT}$ and both cores with a total burn-up of $45830 \mathrm{MWD} / \mathrm{MT}$. 


\section{Combustion Engineering, Inc.}

\subsection{Licensing the Reactor Facility}

The policy embodied in the System $80+$ plutonium-disposition reactor is that safety and protection of the public and environment have the highest priority in accomplishing the mission of designing, constructing, and operating the reactor and associated support facilities. The reactor facility will be designed, constructed, and operated in compliance with all applicable Federal, State, and local statues and regulations. Among all required permits and licenses, two of them are more prominent than the others. One is obtaining NRC approval of the System $80+$ Standard Design for the missions of plutonium disposition. The other is getting the environment report relating to the construction, operation, and decommissioning of the System $80+$ plutoniumdisposition facility approved in accordance with the National Environmental Policy Act. A preliminary listing of typical licenses and permits required for the facility is given in Table 5.2-1.

Most PWR systems require design modifications to accommodate large loadings of mixed-oxide (MOX) fuel. These modifications include additional control rods to maintain required shutdown margin, equipment modifications to accommodate higher soluble boron concentrations, core and spent fuel cooling equipment sized to accommodate the higher decay heat loads associated with irradiated MOX fuel, design of the reactor vessel and internals to tolerate a greater flux of high energy neutrons than arises in uranium fuelc $t^{\prime}$ operation, modifications to the radwaste systems to accommodate higher tritium activity in the primary coolant, and design of fuel storage and fuel handling facilities to safely accommodate MOX fuel.

The System $80+$ Standard Design, however, was specifically developed to accommodate MOX fuel loadings up to and including an All Plutonium Reactor (APR). Consequently, design requirements for APR operation are incorporated in the basic systems of the System $80+$ design, or design provision is made which facilitate modifications for APR operation. For this reason, the primary licensing impact of APR operation on the Systern $80+$ design is limited to modifying the analyses and revising applicable sections of CESSAR-DC to address APR operation. These revisions will have to be reviewed and approved by the NRC based on the fact that these revisions will include, among other things, certain changes to the Technical Specifications. However, the technical review by the NRC on these revisions to CESSAR-DC should be straight forward in that they should not involve any unreviewed safety questions since the revisions would not depart substantially from the reference System $80+$ Design which has been reviewed by the NRC.

The CESSAR-DC sections dealing with the following systems and subject matters will have to be reviewed for potential revisions to address plutonium fuel loadings:

* Shutdown Cooling System (CESSAR-DC Section 5.4.7)

The System $80+$ Shutdown Cooling System is designed to handle higher long-term decay heat generation rates associated with MOX fuel. Therefore, only a confirmatory 
analysis is required to verify that the higher decay heat load can be accommodated while still maintaining a high margin of safety.

* Spent Fuel Pool Cooling System (CESSAR-DC Section 9.1.2)

The System 80 + Spent Fuel Pool Cooling System is designed to handle increased long-term decay of spent MOX fuel without any hardware changes to the system. Therefore, only a confirmatory analysis is required to verify that the increased longterm decay of spent MOX fuel can be accommodated while still maintaining a high margin of safety.

* Component Cooling Water System (CESSAR-DC Section 9.2.2)

The System $80+$ Component Cooling Water System is designed to handle higher long-term decay heat generation rates associated with MOX fuel. Therefore, only a confirmatory analysis is required to verify that the higher decay heat load can be accommodated while still maintaining a high margin of safety.

* Safety Injection System (CESSAR-DC Section 6.3)

The increased maximum soluble boron concentration required for APR operation in the Safety Injection Tanks needs to be analyzed to determine the new concentration required to maintain adequate shutdown margin and to assess the impact due to a malfunction of equipment important to safety compared to that previously evaluated with a lower soluble boron concentration for the reference System $80+$ Design. The increased concentration can be handled by the use of enriched boron, as discussed in Section 2.1.1.5.

* Chemical and Volume Control System (CESSAR-DC Section 9.3.4)

The System $80+$ Chemical and Volume Control System is designed to handle higher soluble boron concentration in the Reactor Coolant System associated with APR operation. Therefore, only a confirmatory analysis is required to verify that the system can in fact handle the higher soluble boron concentration associated with APR operation.

* In-containment Refueling Water Storage Tank (CESSAR-DC Section 6.8) The increased maximum soluble boron concentration required for APR operation in the In-containment Refueling Water Storage Tank will be analyzed to determine the new concentration required to maintain adequate shutdown margin and to assess the impact due to a malfunction of equipment important to safety compared to that previously evaluated with a lower soluble boron concentration for the reference System $80+$ Design.

* Radioactive Waste Management System (CESSAR-DC Chapter 11) The liquid and gaseous radwaste systems will be reviewed to determine whether the systems can handle the higher tritium levels. 
* Reactor Internals (CESSAR-DC Sections 3.9 \& 4.5)

The System 80 + reactor vessel and reactor internals are designed to tolerate the higher neutron fluence levels and the higher heating rates associated with APR operation. Therefore, only a confirmatory analysis is required to verify that the higher neutron fluence levels and the higher heating rates can be accommodated without significantly reducing the margin of safety.

* Core Design (CESSAR-DC Chapter 4)

A detailed thermal hydraulic analysis and fuel performance analysis of the reference Pu core design will be performed using NRC approved design methodology. The thermal hydraulic performance of the reference Pu burning core requires evaluation for all performance-related and safety-related design basis. Additionally, a detailed neutronics evaluation of the reference Pu burning core design including depletion isotopics, reactivity coefficients, control worths, and power distributions as a function of burnup. Detailed design is based on the NRC approved methods. Analyses are performed for core stability and power distribution control.

* Accident Analyses (CESSAR-DC Chapters 6 \& 15)

The LOCA and non-LOCA safety analyses will be evaluated using NRC approved licensing methodology consistent with the applications for CESSAR-DC which have been reviewed and approved by the NRC staff. The analyses performed will include small-break and large-break LOCA events, steam generator tube rupture, control rod misoperation and inadvertent withdrawal events, control rod ejection events, and steam line break, in order to demonstrate the reactor aid safety systems designed with MOX fuel still meet licensing basis safety criteria.

* Severe Accident Evaluation (CESSAR-DC Chapter 19)

Postulated severe accidents will be evaluated, including use of deterministic methodologies, and survey of relevant physical and experiment data, in order to assess the significance of the plutonium core on severe accident phenomenology, and to assess the mitigation features of the System $80+$ for this application. The potential for recriticality following a severe accident and the consequences or mitigation of such recriticality will be addressed. If necessary, the System $80+$ features for severe accident mitigation will be evaluated.

* Radiation Protection (CESSAR-DC Chapter 12)

Radioactive decay of plutonium isotopes in fresh MOX fuel requires provision of shielding in the fuel receipt, handling and inspection area. Accordingly, a minor design change in the area of shielding design as well as changes to CESSAR-DC may be required.

* Technical Specifications (CESSAR-DC Chapter 16) The technical specifications will be revised to reflect plant operations with the plutonium burning core. The changes may include certain core physics parameters. 
During the initial phase of this projecr, a plan will be developed to identify and document all applicable Federal and State permits, and the lead time and schedule required for each permit, to operate the System $80+$ ALWR as a plutonium-disposition facility. Special permit conditions applicable to the plutonium-disposition facility will be documented, on a schedule that will permit application, review and approval by controlling authorities, and implementation of permit coriditions consistent with the dates needed to support plant construction and operation. The plan will be developed in cooperation with the DOE to take advan iage of review activities performed by the NRC while defining the role of the NRC and DOE in reviewing the plutonium-disposition plant design. The plan will define all permitting, both Federal and State, for the System $80+$ ALWR-based complex for the missions of plutonium disposition and electric power generation. Compliance with safety and environmental requirements will be demonstrated, as will licensability under NRC regulations. The plan will also be integrated with the safeguards and security plans, to ensure licensing coverage, as appropriate, of these measures. 


\section{TABLE 5.2-1 \\ IYPICAL REGULATORY AND ENVIRONMENTAL PERMITS AND LICENSES FOR. PLUTONIUM-DISPOSITION FACILITY}

\author{
Permit or License \\ National Emission \\ Standards for Hazardous \\ Air Pollutants [NESHAP] \\ Construction \\ permit/Operating license
}

Prevention of Significant Deterioration [PSD] of Air Quality

Air Quality

Erosion Control Plan

National Pollutant Discharge Elimination System [NPDES]

Wetlands

Domestic [potable] water

Sanitary Waste water Treatment

Transportation

Solid Waste Disposal

Federal Aviation Agency

Navigable Waters

\section{Requirements}

Radiological source term Calculations. EPA approval prior tc NESHAP application. Detailed procurement activities schedule required prior to start of construction. Applicability to specific facilities to be identified. Compliance with State requirements to be determined.

NRC approval of the System $80+$ standard plant. Approval of mixed-oxide fuel. Approval of the tritium target and tritium recovery facility.

PSD permit process is independent of NESHAP. Controlled by State of residence for facility. Approval required prior to start of construction for facility that will emit regulated pollutants.

Diesel generators and concrete batch plant will be only source of air pollutants other than radionuclides. Limited diesel operating time per year may exclude need for permit.

Governs impact on terrain due to timber harvest, altering groundwater flow patterns, and storm water erosion control.

Governs effluent quality and quantity for all liquid discharges from facility. Storm water and process waste water control. An approved erosion control plan may be required.

Impact on protected wetlands.

Drilling of wells and water treatment systems.

NPDES requires discharge characteristics, anticipated manpower loading [utilization] and schedule. Discharge paths must be identified. Permit required for the construction of the waste water treatment plant.

Safeguards for shipment of plutonium, mixed-oxide fuel, tritium.

Identify non-hazardous, non-radioactive waste disposal by type and rate.

Tall structures or cranes over 200 feet above ground level.

Modification to navigable water. 


\section{IABLE 5.2-1 (CONT'D) \\ IYPICAL REGULATORY AND ENVIRONMENTAL PERMITS AND ULCENSES FOR PLUTONIUM-DISPOSITION FACILITY}

\section{Permit or License}

Timber Harvest

National Historic

Preservation Act [NHPA]

American Religious

Freedom Act

Fish and Wildlife

Coordination Act

\section{Requirements}

Forest management plan, if appropriate, to be developed.

Survey of artifacts or discovery of archaeological items in any area of disturbance during facility construction.

Disturbance of areas considered "sacred" to Indian cultures.

Endangered species and migratory bird impact. 


\subsubsection{Safety Analysis and Impact on the Environment}

The success of the MOX fuel cycle depends on its performance, safety record and public acceptance. Public acceptance can only be achieved by demonstrating safety in all phases of the MOX fuel cycle, reliability in its performance and safe disposal of generated wastes. To provide reasonable assurance that the MOX fuel fabrication plant can be operated without undue risk to the health and safety of employees and the public, and to the environment, such plant must be located, designed, constructed, tested and operated according to well defined criteria of safety. Also, physical security and SNM accountability and protection must be assured. The main safety problems associated with the mixed oxide fuel fabrication industry is the occupational exposure and the release of Pu bearing material into the environment. The safe operation of the facility and its impact on the environment have to be evaluated for normal operation and for accidental events.

\subsubsection{Normal Operation}

During plant normal operation, the occupational exposure and the radioactive releases are kept as low as possible by using the highest design standards and then performing and implementing periodic safety, inspection and maintenance programs. Occupational exposure and the Pu releases during plant normal operation are low enough to avoid any deleterious effect. The occupational exposure, the amount of airborne plutonium released to the atmosphere, the Pu concentration in effluents disposed of as liquids, and the Pu solid wastes are in accordance with and meet all the local, state and federal laws and regulations.

\subsubsection{Accidental Events}

The accidental radiation exposure and release are normally produced by a sequence of events which ultimately result in an exposure to or a release of radioactive material. Considering the risks associated with postulated accidents, the probability of occurrence of the accidents and the severity of cheir consequences must be taken into account. The plant design provides high reliability or redundant systems in order to assure low and acceptable risks.

The plant events which have to be considered for the design to assure low risks for the environment are: fire, explosion, criticality and loss of confinement. The MOX fuel fabrication plant is designed and operated to assure very low risks for such accidents. Also the plant design will minimize the effect of natural phenomena (such as earthquake, flood, tornado, airplane crashes).

The risks of such events to the environment is evaluated, taking into account the plant site characteristics and the associated plant design. Plant design criteria are based on the premise that the plant location represents a reasonable balance between the advantages and limitations inherent in the size of the exclusion area (distance to nearest site boundary), the population density and other demographic data, the physical characteristics (meteorology, geology, hydrology and background radiation) and the accessibility and communication. 
The present knowledge and the expected results of future technological developments concerning commercial plant design and operation are such that the risks associated with such events could be predicted and could be reduced to acceptable risks.

\subsubsection{Licensina. DOE Orders, Desion Codes and Procedures}

\subsubsection{Licensing}

Applicable NRC Regulatory Guide Divisions include:

Reg. Guide 3 - Fuels and Materials Facilities

Reg. Guide 4 - Environmental and Siting

Reg. Guide 5 - Materials and Plant Protection

Reg. Guide 7 - Transportation

Reg. Guide 8 - Occupational Health

Plutonium recycle in light water reactors (LWRs) is defined as the use of plutonium-uranium mixed oxide fuels in which plutonium obtained from weapons replaces some portion of the $\mathrm{U}^{235}$ normally used for fueling the LWRs. The US NRC has in the past determined that the applicant planning to construct a MOX fuel fabrication facility must submit an application for a Special Nuclear Material facility under 10 CFR 70.

Mixed oxide fuel must be fabricated in specially designed fuel fabrication plant. The general rules utilized to license a LWR fuel fabrication plant may be applicable, however, with the presence of plutonium NRC will certainly take a more conservative approach and impose certain additional requirements to a MOX fuel fabrication facility.

There are three key aspects in the licensing process for the mixed oxide fuet fabrication facility which have an impact on the schedule. These are: 1) Design of facility 2) Environmental assessment, and 3) Construction. The three aspects are discussed in some detail to better understand the MOX reference schedule and justify the time associated with the activities in the schedule spread sheet (see Section 6.0).

The granting of a license by NRC will require a complete assessment of the safety of the facility. This would involve addressing the requirements specified in 10 CFR 70 for special nuclear materials and submitting an application. The application can be prepared with guidance from the regulatory guides. Some of these specifically applicable for a fuel fabrication plant are identified below:

Reg. Guide 3.3-

Reg. Guide 3.4-

Reg. Guide 3.7 -
Quality Assurance Program requirements for FTFG Nuclear Criticality and Safety considerations in operation with fissioriable materials.

Monitoring of combustible gases and vapors in plutonium processing and fuel fabrication plants. 
Reg. Guide 3.12 -

Reg. Guide 3.14 -

Reg. Guide 3.16 -

Reg. Guide 3.35 -

Reg. Guide 3.39 -

Reg. Guide 3.40 -

Reg. Guide 3.42

Reg. Guide 5.30

Reg. Guide 5.52 -
General design guide for Ventilation systems of plutonium processing and fuel fabrication plants

Seismic Design Classification for plutonium processing and fuel fabrication plants

General Fire protection guide for plutonium processing and fuel fabrication plants

Assumptions used for evaluating the potential radiological cor.sequences of accidental nuclear criticality in a plutonium processing and fuel fabrication plants.

Standard format and content of license applications for plutonium Processing and fuel fabrication plants.

Design basis floods for fuel reprocessing plants and for plutonium and fuel fabrication plant.

Emergency planning for fuel cycle facilities and plants licensed under 10CFR Parts 50 and 70.

Materials protection contingency measures for unranium and plutonium fuel manufacturing plants.

Standard format and content of a license physical protection plan for strategic special nuclear material at fixed sites.

\subsubsection{Environmental Assessment}

In the past (November 1975), NRC required the preparation of a Generic Environmental Statement on the use of Recycle Plutonium in Mixed Oxide fuel and it is certain that a similar requirement will be imposed now. Thus an environmental assessment will have to be completed in parallel with the plant SAR prior to the start of construction of the facility. The environmental study and assessment will have to satisfy the requirements specified in 10 CFR 51. This assessment will culminate in the submission of an Environmental Report (ER) to NRC by the applicant to obtain a permit/license for the plant. The ER shall contain a description of the proposed action, namely building, a statement of its purpose and the description of environment effected. The report shall include an analysis which considers and balances the environmental effects of the proposed action (production of radioactive waste, use of water for the facility, release of radioactivity into the air, etc) and the alternatives available for reducing or avoiding adverse environmental impacts. The analysis shall be able to quantify the various factors considered. This involves collection of data on water, air, amount of material handled and obtain permits for water, air, etc which become part of the ER. A number of regulatory guides under Division 4 - Environmental and Siting - should be considered while preparing the ER.

\subsubsection{Construction}

The location of the Fuel Fabrication and Target Facility has to satisfy the requirements of 10 CFR 100. Although this regulation is specifically applicable to a nuclear power plant, certain activities at the Fuel Facility are similar and one can assume NRC will apply the same criteria. The construction of the facility can start only after completion of the following 
efforts: site approval, obtain air permits, obtain water permits, submission of the Application, submission of ER, and obtaining a Safety Evaluation Report (SER) and a Final Environmental Impact Statement (FEIS) from the NRC.

\subsubsection{Uncertainties}

This is the first MOX facility to be built in USA and therefore one has to consider a number of unknowns which could impact the schedule in a significant manner.

- The facility is being built for the DOE with the facility licensed by NRC. It is assumed that the NRC would take the lead on licesning. In addition, a draft bill, ${ }^{4}$ presently undergoing hearings, would require all new DOE nuc:ear facilities to be licensed by the NRC. This includes any radioactive waste management facilities as well as production or research reactors. It appears that NOE and NRC officials are amenable to the draft bill, although NRC Chairman Selin has some reservations with the bill's broad language and lack of additional NRC funding to cover the additional oversight responsibilities. ${ }^{5,6,7,8}$

4

H.R. 3920, sponsored by House Natural Resources Committee Chairman George Miller (D-California), House Natural Resources Subcommittee on Energy and Mineral Resources Chairman Richard Lehman (D-California), House Energy and Commerce Subcommittee on Energy and Power Retiring Chairman Philip Sharp (D-Indiana) and Representative Peter DeFazio (D-Oregon).

5

Nucleonics Week article, "Miller Plans to Regulate New, Existing DOE Facilities," Vol. 34, No. 51, December 23, 1993.

Nucleonics Week article, "Bill to Regulate New, Existing DOE Facilities to be Introduced," Vol. 35, No. 7, February 17, 1994.

7

Inside NRC article, "Bill Would Give NRC Oversight Over Any New DOE Nuclear Facility," Vol. 16, No. 5, March 7, 1994.

8

The Energy Daily article, "Selin Says No Thanks To Broader Regulatory Role," Vol. 22, No. 45, March 9, 1994. 
It is assumed that MOX fuel assemblies will be licensed soon and be available for conducting fuel tests. Fuel containing plutonium have not been licensed by NRC to date and it is not known that process will be used to license one.

One needs to know if the SAR on the $\mathrm{MF}^{2}$ should address the issue of severe accidents, for example, MOX fuel melting during its fabrication.

\subsubsection{DOE Orders}

1. DOE Order 5480.1A "Environmental protection, safety, and health protection program for DOE operation"
a. Chapter V "Safety of Nuclear Facilities"
b. Chapt or VII "Industrial Fire Protection"
c. Chapter X "Industrial Hygiene Program"
d. Chapter XI "Standards of Radiation Protection"

2. DOE Order 5480.4 "Environmental Protection, Safety, and Health Protection Standards"

3. DOE Order 6430.1 "General Design Criteria Manual"
a. Chapter I "Criteria Purpose and Application, the Planning and Design Process, and Fundamental Design Requirements"
b. Chapter IV "Architectural and Structural"
c. Chapter V "Mechanical Systems"
d. Chapter VI "Interior Electrical Systems"
e. Chapter VII "Interior Telecommunications and Alarm Systems"
f. Chapter $X$ "Fire Protection"
g. Chapter XII "Water Pollution Control"
h. Chapter $X X \mid$ "Plutonium Facilities"
i. Chapter XXIII "Un-irradiated Enriched Uranium Storage Facilities"

4. DOE Order 5630.2 "Control and Accountability of Nuclear Materials, Basic Principles"

5. DOE Order 5630.3 "Documentation of Transactions"

6. DOE Order 5630.6 "Nuclear Materials Management and Safeguards System Data Processing Procedures"

7. DOE Order 5632.1 "Physical Protection of Classified Matter"

8. DOE Order 5632.2 "Physical Protection of Special Nuclear Materials" 
9. DOE Order 5700.6A "Quality Assurance"

\subsubsection{Desion Codes}

1. UBC: Uniform Building Code

2. AISC: American Institute of Steel Construction

3. NFPA: National Fire Protection Association

4. ASME: American Society of Mechanical Engineers, Boiler and Pressure Vessel Code Section VIII, "Pressure Vessels"

5. OSHA: Occupational Safety and Health Administration Bulletins

6. Code of Federal Requirements, Title 10 100, "Reactor Site Criteria", USNRC

\subsubsection{PROCEDURES}

The ABB-CE Team will implement the internal design procedures which include:

1. Management Procedures

2. Radiation Protection Procedures

3. Waste Management and Recycle Procedures

4. Quality Assurance Manual

5. Crane and Hoist Safety Manual

6. New Facility Shield Design Criteria

7. Seismic qualification of Category I Structures, Systems and Components

8. Criteria for Criticality Safety limits and controls

\subsection{Environmental Impact Review Process}

With respect to the environmental report associated with a plutonium-disposition facility using the System $80+$ Standard Design, a study of the NRC's review history on GESMO, the Generic Environmental Statement on Mixed Oxide Fuel, indicates that NRC review will not involve major contentious issues. The NRC was in the final draft stages of review on GESMO and all technical issues had been adequately addressed, when a government policy directive canceled the option for spent fuel reprocessing, utilization of open-cycle plutonium fuel, or mixed-oxide cores. Based on the review and evaluation of plutonium utilization at the time, the NRC found no objection to the use of mixed-oxide fuel. Therefore, NRC approval of a plutonium-disposition facility at a single site may be facilitated.

Compliance with the National Environmental Policy Act is the cornerstone for developing the environmental report for the facility. An Environmental Report will be developed and submitted to the NRC in accordance with 10 CFR Part 51 "Environmental Protection Regulations for Domestic Licensing and Related Regulatory Functions." The Environmental Report will include detailed information concerning the following:

\section{- $\quad$ Purpose of the Proposed Facility}




\section{Combustion Engineering, Inc. REACTOR COMPLEX SAFETY AND LICENSING}

- The Site and Environmental Interfaces with the Surrounding Region, including:

- Geography and Demographics

- Ecology

- Meteorology

- Hydrology

- Geology

- Regional Historical, Scenic, Cultural and Natural Features

- Description of the Plant, including source terms and effluent treatment systems

- Environmental Effects of Site Preparation, Plant Construction, and Transmission Facilities Construction

- Environmental Effects of Plant Operations

- Effluent and Environmental Measurements and Monitoring Programs

- Environmental Effects of Accidents

- Economic and Social Effects of Plant Construction and Operation

- $\quad$ Alternative Energy Sources and Sites

- Plant Design Alternatives

- Sumınary Cost-Benefit Analysis

- Environmental Approvals and Consultation

The content and format of the Environmental Report will be consistent with Regulatory Guide 4.2, "Preparation of Environmental Reports for Nuclear Power Stations."

This information will allow the Nuclear Regulatory Commission to develop and prepare an Environmental Impact Statement ("EIS"). The EIS will demonstrate that the facility will not have significant negative environmental impact on the region surrounding the facility. 


\subsection{ESTIMATED COST AND SCHEDULE}

\subsection{Summary Life Cycle Cost}

Life Cycle Cost (LCC) Analysis for various deployments of System $80+$ for plutonium disposition using the spent fuel option have been prepared. Consistent with DOE requirements, the following cases at the East/West Central "green field" were assessed:

Reference - Dispose $\mathbf{5 0} \mathrm{mt}$ of Plutonium in 25 years

A-1 - Dispose $100 \mathrm{mt}$ of Plutonium in 25 years

A-2 - Dispose $50 \mathrm{mt}$ of Plutonium over life of plant

A-3 - Dispose $100 \mathrm{mt}$ of Plutonium over life of plant

In accordance with the cost estimating guidelines and supplemental instructions a plant life of $\mathbf{4 0}$ years and a capacity factor of $\mathbf{7 5 \%}$ were used for the above cases.

In addition to the base cases, LCC analyses have been prepared for East/West Central "green field" site deployments to more accurately reflect and utilize the full capability of System $\mathbf{8 0}+$ to complete the plutonium disposition mission. These options are as follows:

Rc - Dispose $50 \mathrm{mt}$ of Plutonium in 25 years; $87 \%$ capacity

A21 - Dispcse $50 \mathrm{mt}$ of Plutonium over life of plant (60 years);

A2cl - Dispose $50 \mathrm{mt}$ of Plutonium over life of plant (60 years);

A31 - Dispose $100 \mathrm{mt}$ of Plutonium over life of plant (60 years):

A3c - Dispose $100 \mathrm{mt}$ of Plutonium over life of plant (40 years);

$\mathrm{A} 3 \mathrm{cl}$ - Dispose $100 \mathrm{mt}$ of Plutonium over life of plant (60 years);

$75 \%$ capacity

$87 \%$ capacity

$75 \%$ capacity

$87 \%$ capacity

$87 \%$ capacity

As indicated, for the East/West Central "green field" site options we have varied the capacity from $75 \%$ to $87 \%$ and the plant life from 40 years to 60 years. A discussion of the higher capacity factor can be found in Section 4.4. The extended plant life is addressed in Section 2.1.1.6.

Table 6.1-1 summarizes the various cost elements of the deployments assessed including base cases and options. Capital cost details by EEDB account are depicted in Tables 5.1-2 through 6.1-6. The Life Cycle Cost analyses presented in Table 6.1-7 were based on the cash flow forecasts shown in Tables 6.1-8 through 6.1-12 and a discount rate of $4 \%$. 
We have also included an analysis of System $80+$ deployments at the Savannah River site as follows:

A2s - Dispose $50 \mathrm{mt}$ of Plutonium over life of plant (60 years);

A2sf - Dispose $50 \mathrm{mt}$ of Plutonium over life of plant (60 years);

$87 \%$ capacity

A3s - Dispose $100 \mathrm{mt}$ of Plutonium over life of plant (60 years);

$87 \%$ capacity

A3sf - Dispose $100 \mathrm{mt}$ of Plutonium over life of plant (60 years);

$87 \%$ capacity

A3'sf

- Dispose $100 \mathrm{mt}$ of Plutonium over life of plant (60 years);

$87 \%$ capacity

$87 \%$ capacity

As indicated, siting the single reactor facility at Savannah River results in a substantial capital cost savings, as can be seen in Table 6.1-1, compared to the East/West Central site. This reduction is the result of productivity and labor rate differences.

In addition to the mission requirements, the various cases presented reflect changes to plant life (I), capacity (c), siting (s) and firmness factor (f).

Detailed discussion and analysis of the alternative deployments is presented in Section 10. 
TABLE 6.1-1

CAPITAL AND OPERATING COSTS

SYSTEM 80+ PLUTONIUM DISPOSITION PLANTS

All in 1993 s (millions), except as noted.

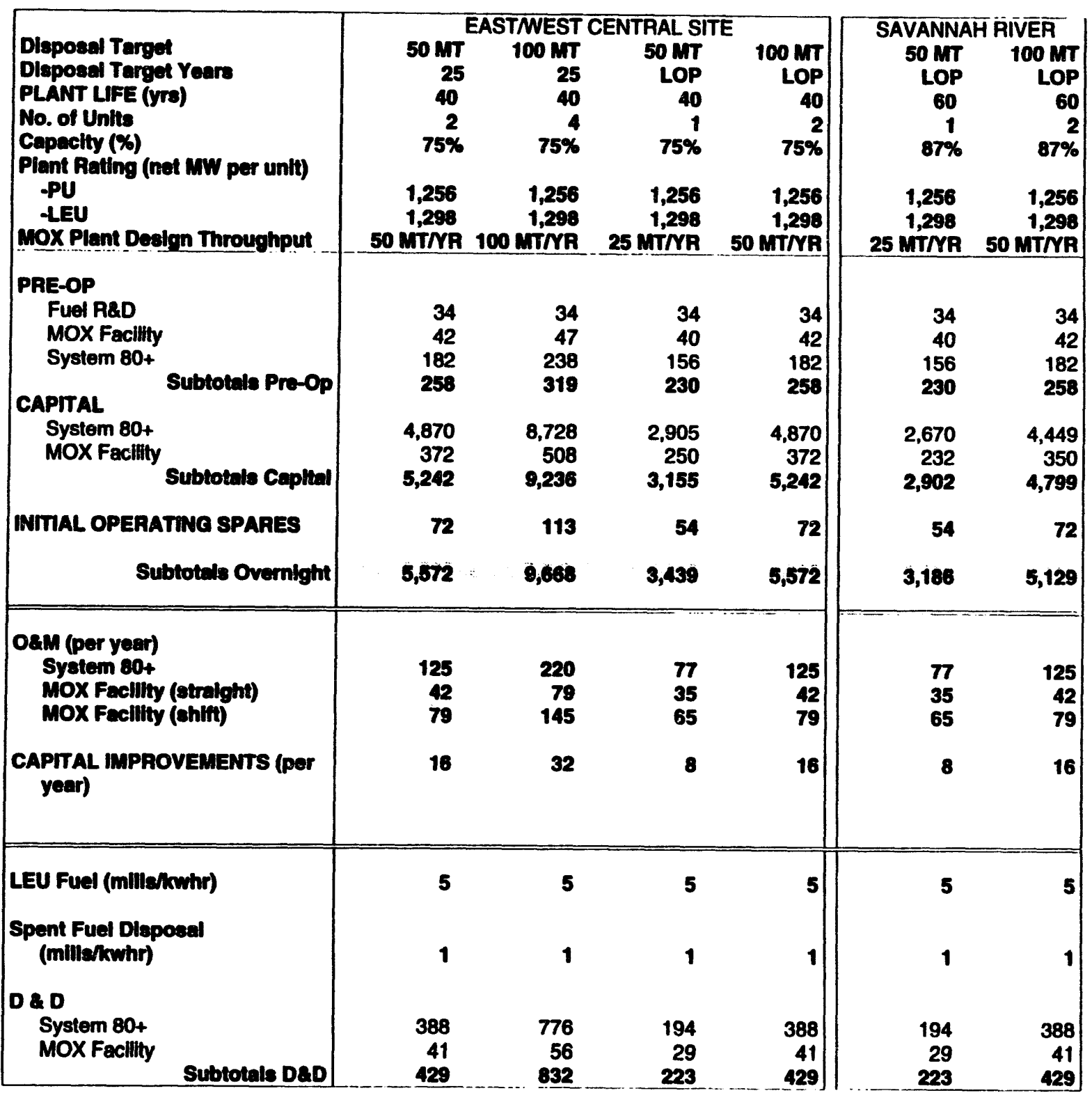


TABLE 6.1-2

CAPITAL COST ESTIMATE BY EEDB COST ACCOUNT

1 UNIT

$25 \mathrm{mt} / \mathrm{Yr}$ MOX FACILITY

EASTMEST CENTRAL SITE

THOUSANDS OF JANUARY, 1993 DOLLARS

\begin{tabular}{|c|c|c|c|c|c|c|}
\hline \multirow{2}{*}{$\begin{array}{c}\text { EEDB ACC̄T. } \\
\text { NUMBER }\end{array}$} & \multicolumn{6}{|c|}{ THOUSANDS OF JANUAAY, 1993 DOLLARS } \\
\hline & ACCT. DESCAIPTION & $\begin{array}{l}\text { FACTORY } \\
\text { EQUIPMENT }\end{array}$ & $\begin{array}{c}\text { SITE LABOR } \\
\text { HOURS }\end{array}$ & $\begin{array}{c}\text { SITE } \\
\text { LABOR }\end{array}$ & $\begin{array}{c}\text { SITE } \\
\text { MATERIAL }\end{array}$ & TOTAL \$ \\
\hline 211 & YARDWOAK INCL. LAND COSTS & & 602,154 & $\$ 16,102$ & $\$ 1,522$ & $\$ 17,624$ \\
\hline 212 & REACTOR BUILDING & $\$ 3,298$ & $2,643,856$ & $\$ 76,048$ & $\$ 46,945$ & $\$ 126,291$ \\
\hline 213 & TÜRBINE BUILDING & $\$ 766$ & 844,230 & $\$ 24,919$ & $\$ 22,013$ & $\$ 47,698$ \\
\hline 214 & SECUAITY BUILDING AND GATE HOUSE & $\$ 15$ & 43,452 & $\$ 1,290$ & $\$ 671$ & $\$ 1,976$ \\
\hline 215 & AUXILIARY BUILDING & $\$ 11,687$ & $5,506,578$ & $\$ 155,964$ & $\$ 57,262$ & $\$ 224, \overline{913}$ \\
\hline 216 & RADWASTE FACILITY & $\$ 617$ & 658,591 & $\$ 18,945$ & $\$ 7,502$ & $\$ 27,064$ \\
\hline $218 B$ & ADMINISTRATION AND SERVICE BUILDING & $\$ 669$ & 75,343 & $\$ 2,249$ & $\$ 1,942$ & $\$ 4,860$ \\
\hline 218C & ONSITE STANDBY AC POWER GENEAĀTION & $\$ 599$ & 368,329 & $\$ 10,354$ & $\$ 4,080$ & $\$ 15,033$ \\
\hline $218 D$ & FIRE PUMPHOUSE & $\$ 30$ & 2,737 & $\$ 77$ & $\$ 40$ & $\$ 147$ \\
\hline $218 K$ & PIPE \& ELECTRIC TUNNELS & & 386,860 & $\$ 10,703$ & $\$ 3,954$ & $\$ 14, \overline{657}$ \\
\hline 218R & AUXILIARY BOILEA BUILDING & & 937 & $\$ 28$ & $\$ 75$ & $\$ 103$ \\
\hline $218 \mathrm{~T}$ & ULTIMATE HEAT SINK STRUCTURE & & 788,976 & $\$ 22,027$ & $\$ 13,586$ & $\$ 35,613$ \\
\hline $218 Z$ & OTHER MISC. STRUCTURES & $\$ 344$ & 123,811 & $\$ 3,482$ & $\$ 1,722$ & $\$ 5,548$ \\
\hline 21 & STRUCTUAES \& IMPOVEMENTS & $\$ 18,025$ & $12,045,854$ & $\$ 342,188$ & $\$ 161,314$ & $\$ 521,527$ \\
\hline 222 & MAIN HEAT TRANSPOAT SYSTEM & $\$ 371,002$ & 356,803 & $\$ 10,458$ & $\$ 14,856$ & $\$ 396,316$ \\
\hline 223 & SAFEGUAADS SYSTEM & $\$ 3,211$ & 236,090 & $\$ 6,891$ & $\$ 3,968$ & $\$ 14,070$ \\
\hline 224 & RADWASTE PROCESSING & $\$ 2,435$ & 100,509 & $\$ 2,957$ & $\$ 1,841$ & $\$ 7,233$ \\
\hline 225 & FUEL HANDLING \& STORAGE & $\$ 3,237$ & 144,483 & $\$ 4,253$ & $\$ 3,374$ & $\$ 10,864$ \\
\hline 226 & OTHER REACTOR PLANT EQUIPMENT & $\$ 4,854$ & $1,608,258$ & $\$ 46,947$ & $\$ 23,760$ & $\$ 75,561$ \\
\hline 227 & REACTOR PLANT INSTRUMENTATION \& CONTROL & $\$ 620$ & 21,792 & $\$ 662$ & $\$ 872$ & $\$ 2,154$ \\
\hline 228 & PLANT SIMULATOR & $\$ 27,172$ & 17,000 & $\$ 517$ & & $\$ 27,689$ \\
\hline 22 & AEACTOR PLANT EQUIPMENT & $\$ 412,5 ; 1$ & $2,484,935$ & $\$ 72,685$ & $\$ 48,671$ & $\$ 533,887$ \\
\hline 231 & TUABINE GENERATOR & $\$ 117,05 i$ & 344,786 & $\$ 10,089$ & $\$ 7,421$ & $\$ 134,567$ \\
\hline $23 \overline{3}$ & CONDENSING SYSTEM & $\$ 29,347$ & 133,537 & $\$ 3,957$ & $\$ 2,343$ & $\$ 35,647$ \\
\hline 234 & FEED HEATING SYSTEM & $\$ 21,397$ & 230,522 & $\$ 6,746$ & $\$ 5,809$ & $\$ \overline{33}, 952$ \\
\hline 235 & OTHER TURBINE PLANT EQUIPMENT & $\$ 1,513$ & 291,432 & $\$ 8,619$ & $\$ 5,873$ & $\$ 16,005$ \\
\hline 237 & TUABINE PLANT MISC. ITEMS & $\$ 223$ & 34,673 & $\$ 1,010$ & $\$ 769$ & $\$ 2,002$ \\
\hline 23 & TURBINE PLANT EQUIPMENT & $\$ 169,537$ & $1,034,950$ & $\$ 30,421$ & $\$ 22,215$ & $\$ 222,173$ \\
\hline
\end{tabular}

filename>C:WOBSIPUBURMKENOSHAISF125MT1UN_EEDB.WK3 
TABLE 6.1-2 (continued)

CAPITAL COST ESTIMATE BY EEDB COST ACCOUNT

1 UNIT

$25 \mathrm{mt} / \mathrm{yr}$ MOX FACILITY

EASTMEST CENTRAL SITE

THOUSANDS OF JANUARY, 1993 DOLLARS

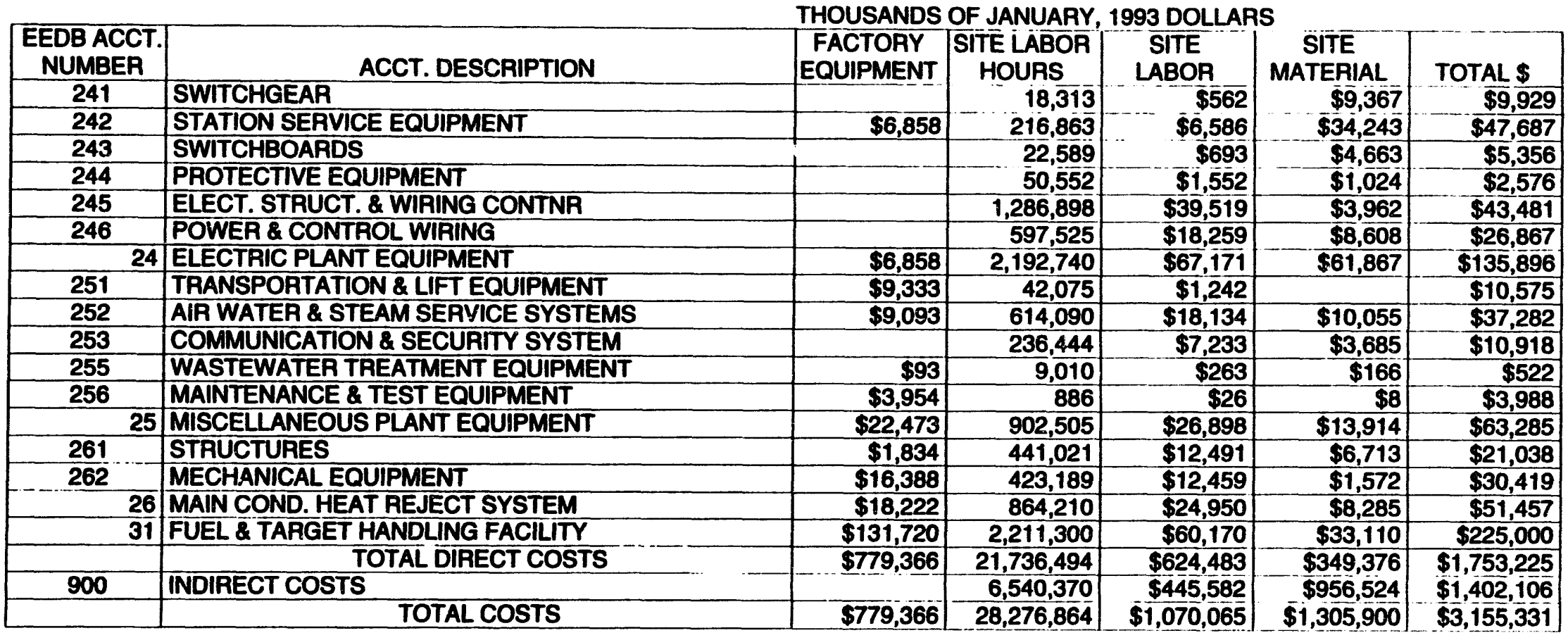


TABLE 6.1-3

CAPITAL COST ESTIMATE BY EEDB COST ACCOUNT 2 UNIT

$50 \mathrm{mt} / \mathrm{yr}$ MOX FACILITY

EASTMEST CENTRAL SITE

THOUSANDS OF JANUARY 1993 DOLLARS

\begin{tabular}{|c|c|c|c|c|c|c|}
\hline $\begin{array}{l}\text { EEDB ACCT. } \\
\text { NUMBER }\end{array}$ & ACCT. DESCAIPTION & $\begin{array}{l}\text { FACTORY } \\
\text { EQUIPMENT }\end{array}$ & $\begin{array}{c}\text { SITE LABOR } \\
\text { HOURS }\end{array}$ & $\begin{array}{c}\text { SITE } \\
\text { LABOR }\end{array}$ & $\begin{array}{c}\text { SITE } \\
\text { MATERIAL }\end{array}$ & TOTAL \$ \\
\hline 211 & YARDWOAK INCL. LAND COSTS & & $1,186,255$ & $\$ 31,721$ & $\$ 2,95 \overline{3}$ & $\$ 34,674$ \\
\hline 212 & REACTOR BUILDING & $\$ 6,399$ & $5,370,892$ & $\$ 154,255$ & $\$ 94,264$ & $\$ 254,918$ \\
\hline 213 & TUABINE BUILDING & $\$ 1,486$ & $1,663,217$ & $\$ 49,093$ & $\$ 42,710$ & $\$ 93,289$ \\
\hline 214 & SECURITY BUILDING AND GATE HOUSE & $\$ 30$ & 85,619 & $\$ 2,542$ & $\$ 1,302$ & $\$ 3,874$ \\
\hline 215 & AUXILIARY BUILDING & $\$ 21,103$ & $7,968,337$ & $\$ 225,007$ & $\$ 78,178$ & $\$ 324,288$ \\
\hline 216 & RADWASTE FACILITY & $\$ 1,197$ & $1,298,201$ & $\$ 37,346$ & $\$ 14,556$ & $\$ 53,099$ \\
\hline $218 B$ & ADMINISTRATION AND SERVICE BUILDING & $\$ 1,298$ & 148,479 & $\$ 4,431$ & $\$ 3,769$ & $\$ 9,498$ \\
\hline $218 \mathrm{C}$ & ONSITE STANDBY AC POWER GENERATION & $\$ 1,163$ & 725,651 & $\$ 20,398$ & $\$ 7,913$ & $\$ 29,474$ \\
\hline 218D & FIRE PUMPHOUSE & $\$ 59$ & 5,392 & $\$ 152$ & $\$ 78$ & $\$ 289$ \\
\hline 218K & PIPE \& ELECTRIC TUNNELS & & 762,411 & $\$ 21,093$ & $\$ 7,669$ & $\$ 28,762$ \\
\hline $218 \mathrm{~A}$ & AUXILIAAY BOILEA BUILDING & & 1,846 & $\$ 56$ & $\$ 145$ & $\$ 201$ \\
\hline $218 \mathrm{~T}$ & ULTIMATE HEAT SINK STRUCTURE & & $1,554,618$ & $\$ 43,403$ & $\$ 26,351$ & $\$ 69,754$ \\
\hline $218 Z$ & OTHER MISC. STRUCTURES & $\$ 668$ & 243,996 & $\$ 6,862$ & $\$ 3,340$ & $\$ 10,870$ \\
\hline 21 & STRUCTURES \& IMPOVEMENTS & $\$ 33,403$ & $21,014,914$ & $\$ 596,359$ & $\$ 283,228$ & $\$ 912,990$ \\
\hline 222 & MAIN HEAT TRANSPORT SYSTEM & $\$ 685,770$ & 702,895 & $\$ 20,602$ & $\$ 28,821$ & $\$ 735,193$ \\
\hline 223 & SAFEGUARDS SYSTEM & $\$ 5,928$ & 461,449 & $\$ 13,468$ & $\$ 7,651$ & $\$ 27,047$ \\
\hline 224 & AADWASTE PAOCESSING & $\$ 4,720$ & 194,962 & $\$ 5,7 \overline{3}$ & $\$ 3,538$ & $\$ 13,995$ \\
\hline 225 & FUEL HANDLING \& STOAAGE & $\$ 6,088$ & 193,914 & $\$ 5,705$ & $\$ 4,622$ & $\$ 16,415$ \\
\hline 226 & OTHER REACTOR PLANT EQUIPMENT & $\$ 9,366$ & $3,004,978$ & $\$ 87,725$ & $\$ 44,210$ & $\$ 141,301$ \\
\hline 227 & REACTOR PLANT INSTRUMENTATION \& CONTROL & $\$ 1,203$ & 42,774 & $\$ 1,298$ & $\$ 1,620$ & $\$ 4,121$ \\
\hline 228 & PLANT SIMULATOR & $\$ 27,172$ & 17,000 & $\$ 517$ & & $\$ 27,689$ \\
\hline 22 & REACTOA PLANT EQUIPMENT & $\$ 740,247$ & $4,617,972$ & $\$ 135,052$ & $\$ 90,462$ & $\$ 965,761$ \\
\hline 231 & TURBINE GENERATOA & $\$ 227,091$ & 679,231 & $\$ 19,876$ & $\$ 14,397$ & $\$ 261,364$ \\
\hline 233 & CONDENSING SYSTEM & $\$ 56,933$ & 263,054 & $\$ 7,796$ & $\$ 4,545$ & $\$ 69,274$ \\
\hline 234 & FEED HEATING SYSTEM & $\$ 41,509$ & 454,136 & $\$ 13,290$ & $\$ 11,270$ & $\$ 66,069$ \\
\hline 235 & OTHER TURBINE PLANT EQUIPMENT & $\$ 2,935$ & 572,184 & $\$ 16,923$ & $\$ 11,376$ & $\$ 31,234$ \\
\hline 237 & TURBINE PLANT MISC. ITEMS & $\$ 433$ & 63,698 & $\$ 1,856$ & $\$ 1,430$ & $\$ 3,719$ \\
\hline 23 & TURBINE PLANT EQUIPMENT & $\$ 328,901$ & $2,032,303$ & $\$ 59,741$ & $\$ 43,018$ & $\$ 431,660$ \\
\hline
\end{tabular}

filename $C$ :WOBSIPUBURMKENOSHAISF25OMTLUN_EEDB.WK3 
TABLE 6.1-3 (continued)

CAPITAL COST ESTIMATE BY EEDB COST ACCOUNT

2 UNIT

$50 \mathrm{mt} / \mathrm{yr}$ MOX FACILITY

EASTMEST CENTRAL SITE

\begin{tabular}{|c|c|c|c|c|c|c|}
\hline \multicolumn{7}{|c|}{ THOUSANDS OF JANUARY, 1993 DOLLARS } \\
\hline $\begin{array}{c}\text { EEDB ACCT. } \\
\text { NUMBER }\end{array}$ & ACCT. DESCRIPTION & $\begin{array}{c}\text { FACTOAY } \\
\text { EQUIPMENT }\end{array}$ & $\begin{array}{c}\text { SITE LABOA } \\
\text { HOUAS }\end{array}$ & $\begin{array}{c}\text { SITE } \\
\text { LABOR }\end{array}$ & $\begin{array}{c}\text { SITE } \\
\text { MATERIAL }\end{array}$ & TOTAL $\$$ \\
\hline 241 & SWITCHGEAR & & 36,078 & $\$ 1,108$ & $\$ 18,172$ & $\$ 19,280$ \\
\hline 242 & STATION SEAVICE EQUIPMENT & $\$ 13,305$ & 427,353 & $\$ 12,978$ & $\$ 66,436$ & $\$ 92,719$ \\
\hline 243 & SWITCHBOARDS & & 42,779 & $\$ 1,313$ & $\$ 8,706$ & $\$ 10,019$ \\
\hline 244 & PAOTECTIVE EQUIPMENT & & 99,233 & $\$ 3,047$ & $\$ 1,972$ & $\$ 5,019$ \\
\hline 245 & ELECT. STRUCT. \& WIAING CONTNA & & $2,510,302$ & $\$ 77,088$ & $\$ 7,603$ & $\$ 84,691$ \\
\hline 246 & POWEA \& CONTROL WIRING & & $1,172,003$ & $\$ 35,814$ & $\$ 16,559$ & $\$ 52,373$ \\
\hline 24 & ELECTRIC PLANT EQUIPMENT & $\$ 13,305$ & $4,287,748$ & $\$ 131,348$ & $\$ 119,448$ & $\$ 264,101$ \\
\hline 251 & TAANSPOATATION \& LIFT EQUIPMENT & $\$ 16,783$ & 73,339 & $\$ 2,164$ & & $\$ 18,947$ \\
\hline 252 & AIR WATER \& STEAM SERVICE SYSTEMS & $\$ 17,593$ & $1,189,712$ & $\$ 35,138$ & $\$ 19,129$ & $\$ 71,860$ \\
\hline 253 & COMMUNICATION \& SECUAITY SYSTEM & & 465,795 & $\$ 14,248$ & $\$ 7,149$ & $\$ 21,397$ \\
\hline 255 & WASTEWATER TREATMENT EQUIPMENT & $\$ 180$ & 17,749 & $\$ 518$ & $\$ 323$ & $\$ 1,021$ \\
\hline 256 & MAINTENANCE \& TEST EQUIPMENT & $\$ 7,670$ & 1,744 & $\$ 49$ & $\$ 16$ & $\$ 7,735$ \\
\hline 25 & MISCELLANEOUS PLANT EQUIPMENT & $\$ 42,226$ & $1,748,339$ & $\$ 52,117$ & $\$ 26,617$ & $\$ 120,960$ \\
\hline 261 & STRUCTUAES & $\$ 3,559$ & 868,934 & $\$ 24,611$ & $\$ 13,023$ & $\$ 41,193$ \\
\hline 262 & MECHANICAL EQUIPMENT & $\$ 31,793$ & 833,679 & $\$ 24,544$ & $\$ 3,049$ & $\$ 59,386$ \\
\hline 26 & MAIN COND. HEAT REJECT SYSTEM & $\$ 35,352$ & $1,702,613$ & $\$ 49,155$ & $\$ 16,072$ & $\$ 100,579$ \\
\hline 31 & FUEL \& TARGET HANDLING FACILITY & $\$ 203,811$ & $2,790,500$ & $\$ 75,929$ & $\$ 67,260$ & $\$ 347,000$ \\
\hline & TOTAL DIRECT COSTS & $\$ 1,397,245$ & $38,194,389$ & $\$ 1,099,701$ & $\$ 646,105$ & $\$ 3,143,051$ \\
\hline 900 & INDIRECT COSTS & & $11,199,234$ & $\$ 815,157$ & $\$ 1,283,700$ & $\$ 2,098,857$ \\
\hline & TOTAL COSTS & $\$ 1,397,245$ & $49,393,623$ & $\$ 1,914,858$ & $\$ 1,929,805$ & $\$ 5,241,908$ \\
\hline
\end{tabular}


TABLE 6.1-4

CAPITAL COST ESTIMATE BY EEDB COST ACCOUNT

4 UNIT

$100 \mathrm{mt} / \mathrm{yr}$ MOX FACILITY

EASTMEST CENTRAL SITE

\begin{tabular}{|c|c|c|c|c|c|c|}
\hline $\begin{array}{c}\text { EEDB ACCT. } \\
\text { NUMBER }\end{array}$ & ACCT. DESCRIPTION & $\begin{array}{c}\text { FACTORY } \\
\text { EQUIPMENT }\end{array}$ & $\begin{array}{c}\text { SITE LABOR } \\
\text { HOURS }\end{array}$ & $\begin{array}{c}\text { SITE } \\
\text { LABOR }\end{array}$ & $\begin{array}{c}\text { SITE } \\
\text { MATERIAL }\end{array}$ & TOTAL \$ \\
\hline 211 & YARDWORK INCL. LAND COSTS & & $2,302,711$ & $\$ 61,575$ & $\$ 5,562$ & $\$ \overline{67,137}$ \\
\hline 212 & REACTOR BUILDING & $\$ 12,053$ & $10,424,670$ & $\$ 299,405$ & $\$ 177,540$ & $\$ 488,998$ \\
\hline 213 & TURBINE BUILDING & $\$ 2,798$ & $3,228,509$ & $\$ 95,296$ & $\$ 80,476$ & $\$ 178,570$ \\
\hline 214 & SECUAITY BUILDING AND GATE HOUSE & $\$ 57$ & 166,261 & $\$ 4, \overline{935}$ & $\$ 2,4 \overline{53}$ & $\$ 7,445$ \\
\hline 215 & AUXILIAAY BUILDING & $\$ 39,750$ & $15,464,433$ & $\$ 436,687$ & $\$ 147,240$ & $\$ 623,677$ \\
\hline 216 & RADWASTE FACILITY & $\$ 2,255$ & $2,522,242$ & $\$ 72,563$ & $\$ 27,452$ & $\$ 102,270$ \\
\hline $218 \bar{B}$ & ADMINISTRATION AND SERVICE BUILDING & $\$ 2,445$ & 288,425 & $\$ 8,607$ & $\$ 7,103$ & $\$ 18,155$ \\
\hline $218 \mathrm{C}$ & ONSITE STANDBY AC POWER GENERATION & $\$ 2,190$ & $1,408,356$ & $\$ 39,590$ & $\$ 14,904$ & $\$ 56,684$ \\
\hline 2180 & FIRE PUMPHOUSE & $\$ 111$ & 10,472 & $\$ 295$ & $\$ 147$ & $\$ 553$ \\
\hline 218K & PIPE \& ELECTRIC TUNNELS & & $1,480,144$ & $\$ 40,952$ & $\$ 14,455$ & $\$ 55,407$ \\
\hline 218A & AUXILIARY BOILER BUILDING & & 3,582 & $\$ 109$ & $\$ 272$ & $\$ 381$ \\
\hline 218T & ULTIMATE HEAT SINK STRUCTUAE & & $3,018,350$ & $\$ 84,270$ & $\$ 49,642$ & $\$ 133,912$ \\
\hline $218 Z$ & OTHER MISC. STRUCTUAES & $\$ 1,258$ & 473,760 & $\$ 13,324$ & $\$ 6,294$ & $\$ 20,876$ \\
\hline 21 & STRUCTURES \& IMPOVEMENTS & $\$ 62,917$ & $40,791,915$ & $\$ 1,157,608$ & $\$ 533,540$ & $\$ 1,754,065$ \\
\hline 222 & MAIN HEAT TRANSPORT SYSTEM & $\$ 1,259,783$ & $1,364,249$ & $\$ 39,986$ & $\$ 54,288$ & $\$ 1,354,057$ \\
\hline 223 & SAFEGUARDS SYSTEM & $\$ 11,165$ & 895,634 & $\$ 26,140$ & $\$ 14,412$ & $\$ 51,717$ \\
\hline 224 & RADWASTE PROCESSING & $\$ 8,891$ & 378,404 & $\$ 11,135$ & $\$ 6,664$ & $\$ 26,690$ \\
\hline 225 & FUEL HANOLING \& STORAGE & $\$ 11,468$ & 376,367 & $\$ 11,073$ & $\$ 8,706$ & $\$ 31,247$ \\
\hline 226 & OTHER REACTOR PLANT EQUIPMENT & $\$ 17,641$ & $5,832,452$ & $\$ 170,270$ & $\$ 83,276$ & $\$ 271,187$ \\
\hline 227 & REACTOA PLANT INSTRUMENTATION \& CONTROL & $\$ 2,267$ & 83,021 & $\$ 2,520$ & $\$ 3,051$ & $\$ 7,838$ \\
\hline 228 & PLANT SIMULATOA & $\$ 50,280$ & 31,450 & $\$ 956$ & & $\$ 51,236$ \\
\hline 22 & REACTOR PLANT EQUIPMENT & $\$ 1,361,495$ & $8,961,577$ & $\$ 262,080$ & $\$ 170,397$ & $\$ 1,793,972$ \\
\hline 231 & TURBINE GENEAATOA & $\$ 427,748$ & $1,318,326$ & $\$ 38,577$ & $\$ 27,119$ & $\$ 493,444$ \\
\hline 233 & CONDENSING SYSTEM & $\$ 107,240$ & 510,564 & $\$ 15,132$ & $\$ 8,561$ & $\$ 130,933$ \\
\hline 234 & FEED HEATING SYSTEM & $\$ 78,187$ & 881,456 & $\$ 25,794$ & $\$ 21,228$ & $\$ 125,209$ \\
\hline 235 & OTHER TURBINE PLANT EQUIPMENT & $\$ 5,529$ & $1,110,532$ & $\$ 32,847$ & $\$ 21,427$ & $\$ 59,803$ \\
\hline 237 & TURBINE PLANT MISC. ITEMS & $\$ 815$ & 123,634 & $\$ 3,602$ & $\$ 2,693$ & $\$ 7.110$ \\
\hline 23 & TURBINE PLANT EQUIPMENT & 6619,519 & $3,944,512$ & $\$ 115,952$ & $\$ 81,028$ & $\$ 816,499$ \\
\hline
\end{tabular}


TABLE 6.1-4 (contiued)

CAPITAL COST ESTIMATE BY EEDB COST ACCOUNT

4 UNIT

$100 \mathrm{mt} / \mathrm{yr}$ MOX FACILITY

EASTMEST CENTRAL SITE

THOUSANDS OF JANUARY, 1993 DOLLARS

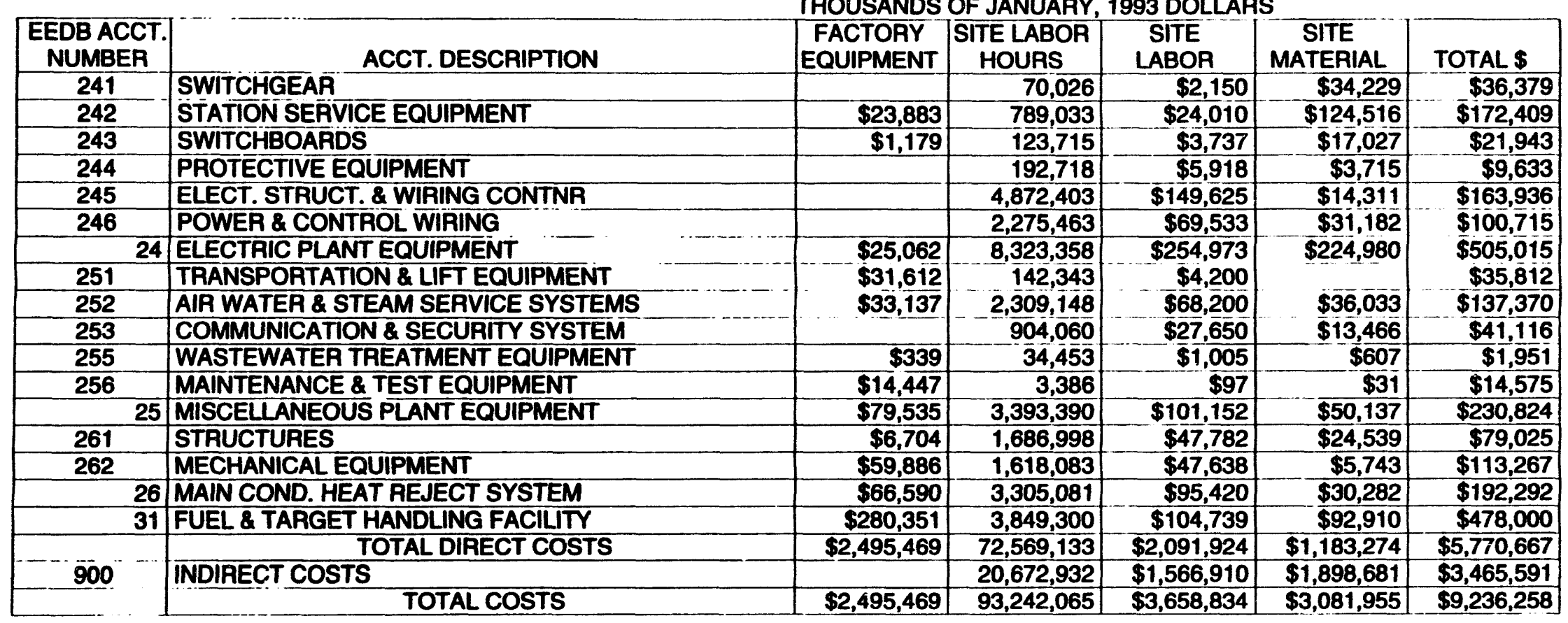


TABLE 6.1-5

CAPITAL COST ESTIMATE BY EEDB COST ACCOUNT

1 UNIT

$25 \mathrm{mt} / \mathrm{yr}$ MOX FACILITY

SAVANNAH RIVER SITE

\begin{tabular}{|c|c|c|c|c|c|c|}
\hline \multirow{2}{*}{$\begin{array}{c}\text { EEDB ACCT. } \\
\text { NUMBER }\end{array}$} & \multicolumn{6}{|c|}{ THOUSANDS OF JANUARY, 1993 DOLLLARS } \\
\hline & ACCT.DESCAIPTION & $\begin{array}{l}\text { FACTOAYY } \\
\text { EQUIPMENT }\end{array}$ & {$\left[\begin{array}{c}\text { SSTE LĀBOR } \\
\text { HOURS }\end{array}\right.$} & $\begin{array}{l}\text { SITE } \\
\text { LABOR }\end{array}$ & $\begin{array}{c}\text { SITE } \\
\text { MATERIAL }\end{array}$ & TOTAL \$ \\
\hline 211 & YARDWOAK INCL. LAND COSTS & & 573,532 & $\$ 8,775$ & $\$ 1,522$ & $\$ 10,297$ \\
\hline 212 & REACTOR BUILDING & $\$ 3,298$ & $2,518,449$ & $\$ 48,805$ & $\$ 46,945$ & $\$ 99,048$ \\
\hline 213 & TURBINE BUILDING & $\$ 766$ & 804,004 & $\$ 16,299$ & $\$ 22,013$ & $\$ 39,078$ \\
\hline 214 & SECURITY BUILDING AND GATE HOUSE & $\$ 15$ & 41,373 & $\$ 841$ & $\$ 671$ & $\$ 1,527$ \\
\hline 215 & AUXILIARY BUILDING & $\$ 11,687$ & $5,245,374$ & $\$ 99,605$ & $\$ 57,262$ & $\$ 168,554$ \\
\hline 216 & RADWASTE FACILITY & $\$ 617$ & 626,803 & $\$ 12,186$ & $\$ 7,502$ & $\$ 20,305$ \\
\hline 218B & ADMINISTRATION AND SERVICE BUILDING & $\$ 669$ & 71,694 & $\$ 1,525$ & $\$ 1,942$ & $\$ 4,136$ \\
\hline $218 \mathrm{C}$ & ONSITE STANDBY AC POWEA GENERATION & $\$ 599$ & 350,866 & $\$ 6,579$ & $\$ 4,080$ & $\$ 11,258$ \\
\hline 218D & FIRE PUMPHOUSE & $\$ 30$ & 2,606 & $\$ 50$ & $\$ 40$ & $\$ 120$ \\
\hline 218K & PIPE \& ELECTRIC TUNNELS & & 368,296 & $\$ 6,616$ & $\$ 3,954$ & $\$ 10,570$ \\
\hline 218R & AUXILIARY BOILER BUILDING & & 892 & $\$ 21$ & $\$ 75$ & $\$ 96$ \\
\hline $218 \mathrm{~T}$ & ULTIMATE HEAT SINK STRUCTURE & & 751,512 & $\$ 13,859$ & $\$ 13,586$ & $\$ 27,445$ \\
\hline $218 Z$ & OTHER MISC. STRUCTURES & $\$ 344$ & 117,894 & $\$ 2,249$ & $\$ 1,722$ & $\$ 4,315$ \\
\hline 21 & STRUCTUAES \& IMPOVEMENTS & $\$ 18,025$ & $11,473,295$ & $\$ 217,410$ & $\$ 161,314$ & $\$ 396,749$ \\
\hline 222 & MAIN HEAT TRANSPPOAT SYSTEM & $\$ 371,002$ & 339,798 & $\$ 7,731$ & $\$ 14,856$ & $\$ 393,589$ \\
\hline 223 & SAFEGUARDS SYSTEM & $\$ 3,211$ & 224,836 & $\$ 5,113$ & $\$ 3,968$ & $\$ 12,292$ \\
\hline 224 & RADWASTE PROCESSING & $\$ 2,435$ & 95,726 & $\$ 2,195$ & $\$ 1,841$ & $\$ 6,471$ \\
\hline 225 & FUEL HANDLING \& STORAGE & $\$ 3,237$ & 137,599 & $\$ 3,134$ & $\$ 3,374$ & $\$ 9,745$ \\
\hline 226 & OTHEA REACTOR PLANT EQUIPMENT & $\$ 4,854$ & $1,531,640$ & $\$ 34,911$ & $\$ 23,760$ & $\$ 63,525$ \\
\hline 227 & REACTOR PLANT INSTRUMENTATION \& CONTAOL & $\$ 620$ & 20,751 & $\$ 490$ & $\$ 872$ & $\$ 1,982$ \\
\hline 228 & PLANT SIMULATOR & $\$ 27,172$ & 16,190 & $\$ 383$ & & $\$ 27,555$ \\
\hline 22 & REACTOR PLANT EQUIPMENT & $\$ 412,531$ & $2,366,540$ & $\$ 53,957$ & $\$ 48,671$ & $\$ 515,159$ \\
\hline 231 & TURBINE GENERATOA & $\$ 117,057$ & 328,370 & $\$ 7,463$ & $\$ 7,421$ & $\$ 131,941$ \\
\hline 233 & CONDENSING SYSTEM & $\$ 29,347$ & 127,177 & $\$ 2,928$ & $\$ 2,343$ & $\$ 34,618$ \\
\hline 234 & FEED HEATING SYSTEM & $\$ 21,397$ & 219,542 & $\$ 5,009$ & $\$ 5,809$ & $\$ 32,215$ \\
\hline 235 & OTHER TURBINE PLANT EQUIPMENT & $\$ 1,513$ & 277,549 & $\$ 6,404$ & $\$ 5,873$ & $\$ 13,790$ \\
\hline 237 & TURBINE PLANT MISC. ITEMS & $\$ 223$ & 33,022 & $\$ 751$ & $\$ 769$ & $\$ 1,743$ \\
\hline 23 & TURBINE PLANT EQUIPMENT & $\$ 169,537$ & 985,660 & $\$ 22,555$ & $\$ 22,215$ & $\$ 214,307$ \\
\hline
\end{tabular}


TABLE 6.1-5 (continued)

CAPITAL COST ESTIMATE BY EEDB COST ACCOUNT 1 UNIT

25mtyr MOX FACILITY

SAVANNAH RIVER SITE

THOUSANDS OF JANUARY, 1993 DOULARS

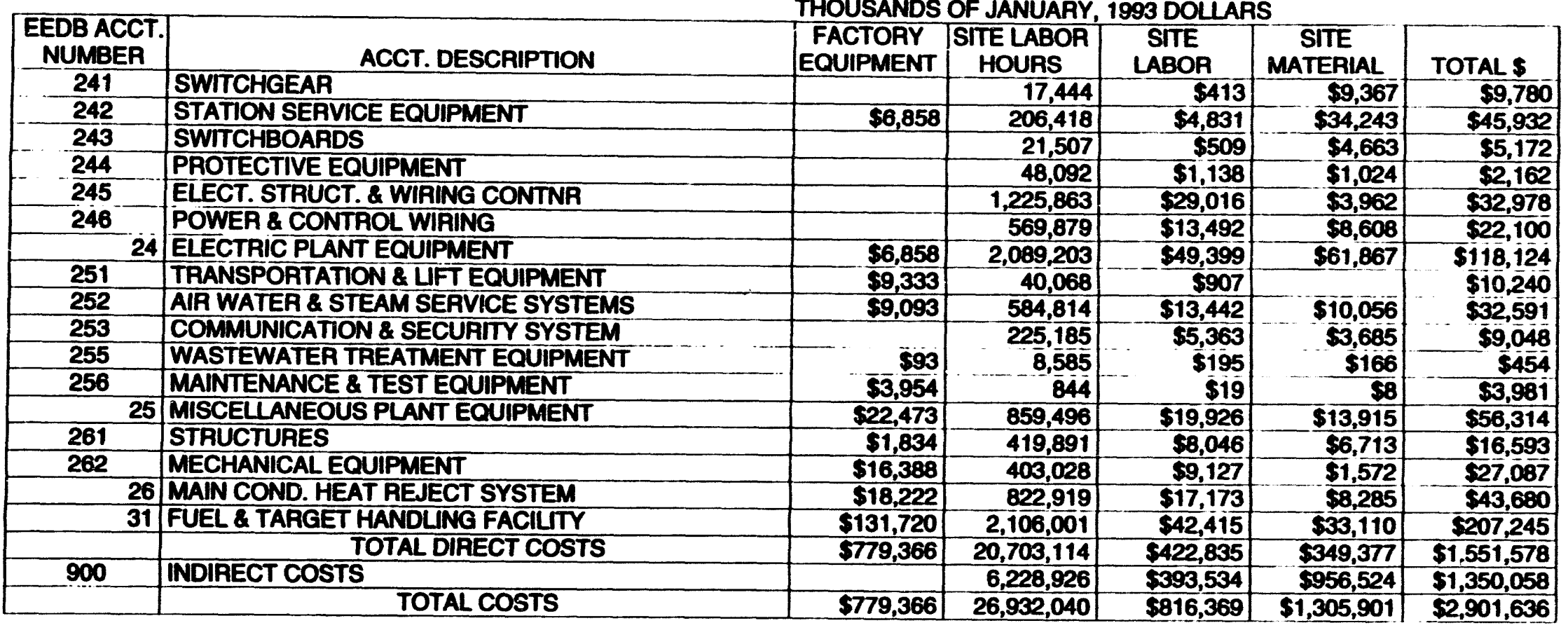




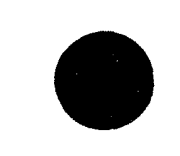

TABLE 6.1-6

CAPITAL COST ESTIMATE BY EEDB COST ACCOUNT 2 UNIT

$50 \mathrm{mt}$ Yr MOX FACILITY

SAVANNAH RIVER SITE

\begin{tabular}{|c|c|c|c|c|c|c|}
\hline \multirow{2}{*}{$\begin{array}{c}\text { EEDB ACCT. } \\
\text { NUMBER }\end{array}$} & \multicolumn{6}{|l|}{ in } \\
\hline & ACCT. DESCRIPTION & $\begin{array}{l}\text { FACTOATY } \\
\text { EQUIPMENT }\end{array}$ & $\begin{array}{l}\text { STTE LABOA } \\
\text { HOUAS }\end{array}$ & $\begin{array}{l}\text { SITE } \\
\text { LABOR }\end{array}$ & $\begin{array}{l}\text { SITE } \\
\text { MATERLAL }\end{array}$ & TOTALS \\
\hline 211 & YARDWOAK INCL LAND COSTS & & $1,129, \overline{639}$ & $\$ 17,283$ & $\longdiv { 2 , 9 5 3 }$ & $\frac{101 \mathrm{LL} \$}{\$ 20.236}$ \\
\hline 212 & REACTOA BUILDING & $\$ 6,399$ & $5,115,882$ & $\$ 98,901$ & $\$ 94,264$ & $\$ 199,564$ \\
\hline 213 & TUABINE BUILDING & $\$ 1,486$ & $1,583,607$ & $\$ 32,108$ & $\$ 42,710$ & $\$ 76,304$ \\
\hline 214 & SECURITY BUILDING AND GATE HOUSE & $\$ 30$ & 81,503 & $\$ 1,656$ & $\$ 1,302$ & $\$ 2,988$ \\
\hline 215 & AUXILIARY BUILDING & $\$ 21,103$ & $7,590,180$ & $\$ 143,690$ & $\$ 78,178$ & $\$ 242,971$ \\
\hline 216 & RADWASTE FACILITY & $\$ 1,197$ & $1,235,505$ & $\$ 24,021$ & $\$ 14,556$ & $\$ 39,774$ \\
\hline $218 B$ & ADMINISTRATION AND SERVICE BUILDING & $\$ 1,298$ & 141,328 & $\$ 3,006$ & $\$ 3,769$ & $\$ 8,073$ \\
\hline $218 C$ & ONSITE STANOBY AC POWER GENERATION & $\$ 1,163$ & 691,217 & $\$ 12,902$ & $\$ 7,913$ & $\$ 22,038$ \\
\hline 2180 & FIRE PUMPHOUSE & $\$ 59$ & 5,133 & 598 & $\$ 78$ & $\$ 235$ \\
\hline $218 K$ & PIPE \& ELECTAIC TUNNELS & & 725,921 & $\$ 13,040$ & $\$ 7,669$ & $\$ 20,709$ \\
\hline 218R & AUXILIARY BOILER BUILDING & & 1,757 & $\$ 42$ & $\$ 145$ & $\$ 187$ \\
\hline $218 T$ & ULTIMATE HEAT SINK STRUCTURE & & $1,480,802$ & $\$ 27,309$ & $\$ 26,351$ & $\$ 53,660$ \\
\hline $218 Z$ & OTHEA MISC. STAUCTUAES & $\$ 668$ & 232,353 & $\$ 4,432$ & $\$ 3,340$ & $\$ 8,440$ \\
\hline 21 & STRUCTUAES \& IMPOVEMENTS & $\$ 33,403$ & $20,015,027$ & $\$ 378,548$ & $\$ 283,228$ & $\$ 695,179$ \\
\hline 222 & MAIN HEAT TRANSPOAT SYSTEM & $\$ 685,770$ & 669,404 & $\$ 15,228$ & $\$ 28,821$ & $\$ 729,819$ \\
\hline 223 & SAFEGUARDS SYSTEM & $\$ 5,928$ & 439,471 & $\$ 9,995$ & $\$ 7,651$ & $\$ 23,574$ \\
\hline 224 & RADWASTE PAOCESSING & $\$ 4,720$ & 185,677 & $\$ 4,258$ & $\mathbf{3 , 5 3 8}$ & $\$ 12,516$ \\
\hline 225 & FUEL HANDLING \& STORAGE & $\$ 6,088$ & 184,683 & $\$ 4,200$ & $\$ 4,622$ & $\$ 14,910$ \\
\hline 226 & OTHER REACTOR PLANT EQUUIPNENT & $\$ 9,366$ & $2,861,802$ & $\$ 65,238$ & $\$ 44,210$ & 5118,814 \\
\hline 227 & REACTOA PLANT INSTRUMENTATION \& CONTROL & $\$ 1,203$ & 40,734 & $\$ 963$ & $\$ 1,620$ & $\$ 3,786$ \\
\hline 228 & PLANT SIMULATOA & $\$ 27,172$ & 16,190 & $\$ 383$ & & $\$ 27,555$ \\
\hline 22 & REACTOR PLANT EQUIPMENT & $\$ 740,247$ & $4,397,961$ & $\$ 100,265$ & $\$ 90,462$ & $\$ 930,974$ \\
\hline 231 & TURBINE GENERATOR & $\$ 227,091$ & 646,880 & $\$ 14,702$ & $\$ 14,397$ & $\$ 256,190$ \\
\hline 233 & CONDENSING SYSTEM & $\$ 56,933$ & 250,530 & $\$ 5,768$ & $\$ 4,545$ & $\$ 67,246$ \\
\hline 234 & FEED HEATING SYSTEM & $\$ 41,509$ & 432,511 & $\$ 9,868$ & $\$ 11,270$ & $\$ 62,647$ \\
\hline 235 & OTHER TURBINE PLANT EQUIPMENT & $\$ 2,935$ & 544,929 & $\$ 12,574$ & $\$ 11,376$ & $\$ 26,885$ \\
\hline 237 & TUABINE PLANT MISC. ITEMS & $\$ 433$ & 60,663 & $\$ 1,381$ & $\$ 1,430$ & $\$ 3,244$ \\
\hline 23 & TURBINE PLANT EQUIPNENT & $\$ 328,901$ & $1,935,513$ & $\$ 44,293$ & $\$ 43,018$ & $\$ 416,212$ \\
\hline
\end{tabular}


TABLE 6.1-6 (continued)

CAPITAL COST ESTIMATE BY EEDB COST ACCOUNT

2 UNIT

$50 \mathrm{mt} / \mathrm{yr}$ MOX FACILITY

SAVANNAH RIVER SITE

THOUSANDS OF JANUARY, 1993 DOLLARS

\begin{tabular}{|c|c|c|c|c|c|c|}
\hline $\begin{array}{c}\text { EEDB ACCT. } \\
\text { NUMBER }\end{array}$ & ACCT. DESCAIPTION & $\begin{array}{l}\text { FACTORY } \\
\text { EOUIPMENT }\end{array}$ & $\begin{array}{c}\text { SITE LABŌ } \\
\text { HOURS }\end{array}$ & $\begin{array}{l}\text { SITE } \\
\text { LABOR }\end{array}$ & $\begin{array}{c}\text { SITE } \\
\text { MATERIAL }\end{array}$ & TOTAL \$ \\
\hline 241 & SWITCHGEAR & & 34,362 & $\$ 813$ & $\$ 18,172$ & $\$ 18,985$ \\
\hline 242 & STATION SERVICE EQUIPMENT & $\$ 13,305$ & 406,757 & $\$ 9,520$ & $\$ 66,436$ & $\$ 89,261$ \\
\hline 243 & SWITCHBOAADS & & 40,738 & $\$ 964$ & $\$ 8,706$ & $\$ 9,670$ \\
\hline 244 & PROTECTIVE EQUIPMENT & & 94,559 & $\$ 2,238$ & $\$ 1,972$ & $\$ 4,210$ \\
\hline 245 & ELECT. STRUCT. \& WIRING CONTNA & & $2,390,994$ & $\$ 56,595$ & $\$ 7,603$ & $\$ 64,198$ \\
\hline 246 & POWEA \& CONTROL WIAING & & $1,117,329$ & $\$ 26,453$ & $\$ 16,559$ & $\$ 43,012$ \\
\hline 24 & ELECTRIC PLANT EQUIPMENT & $\$ 13,305$ & $4,084,739$ & $\$ 96,583$ & $\$ 119,448$ & $\$ 229,336$ \\
\hline 251 & TAANSPOATATIOON \& LIFT EQUIPMENT & $\$ 16,783$ & 69,844 & $\$ 1,580$ & & $\$ 18,363$ \\
\hline 252 & AIR WATER \& STEAM SERVICE SYSTEMS & $\$ 17,593$ & $1,133,030$ & $\$ 26,048$ & $\$ 19, \overline{129}$ & $\$ 62,770$ \\
\hline 253 & COMMUNICATION \& SECUAITY SYSTEM & & 443,614 & $\$ 10,564$ & $\$ 7,149$ & $\$ 17,713$ \\
\hline 255 & WASTEWATER TREATMENT EQUIPMENT & $\$ 180$ & 16,912 & $\$ 384$ & $\$ 323$ & $\$ 887$ \\
\hline 256 & MAINTENANCE \& TEST EQUIPMENT & $\$ 7,670$ & 1,663 & $\$ 37$ & $\$ 16$ & $\$ 7,723$ \\
\hline 25 & MISCELLANEOUS PLANT EQUIPMENT & $\$ 42,226$ & $1,665,063$ & $\$ 38,613$ & $\$ 26,617$ & $\$ 107,456$ \\
\hline 261 & STRUCTURES & $\$ 3,559$ & 827,219 & $\$ 15,850$ & $\$ 13,023$ & $\$ 32,432$ \\
\hline 262 & MECHANICAL EQUIPMENT & $\$ 31,793$ & 793,972 & $\$ 17,980$ & $\$ 3,049$ & $\$ 52,822$ \\
\hline 26 & MAIN COND. HEAT REJECT SYSTEM & $\$ 35,352$ & $1,621,191$ & $\$ 33,830$ & $\$ 16,072$ & $\$ 85,254$ \\
\hline 31 & FUEL \& TARGET HANDLING FACILITY & $\$ 203,811$ & $2,657,619$ & $\$ 53,524$ & $\$ 67,260$ & $\$ 324,595$ \\
\hline & TOTAL DIRECT COSTS & $\$ 1,397,245$ & $36,377,113$ & $\$ 745,656$ & $\$ 646,105$ & $\$ 2,789,006$ \\
\hline 900 & INDIRECT COSTS & & $10,665,937$ & $\$ 726,155$ & $\$ 1,283,700$ & $\$ 2,009,855$ \\
\hline & TOTAL COSTS & $\$ 1,397,245$ & $47,043,050$ & $\$ 1,471,811$ & $\$ 1,929,805$ & $\$ 4,798,861$ \\
\hline
\end{tabular}




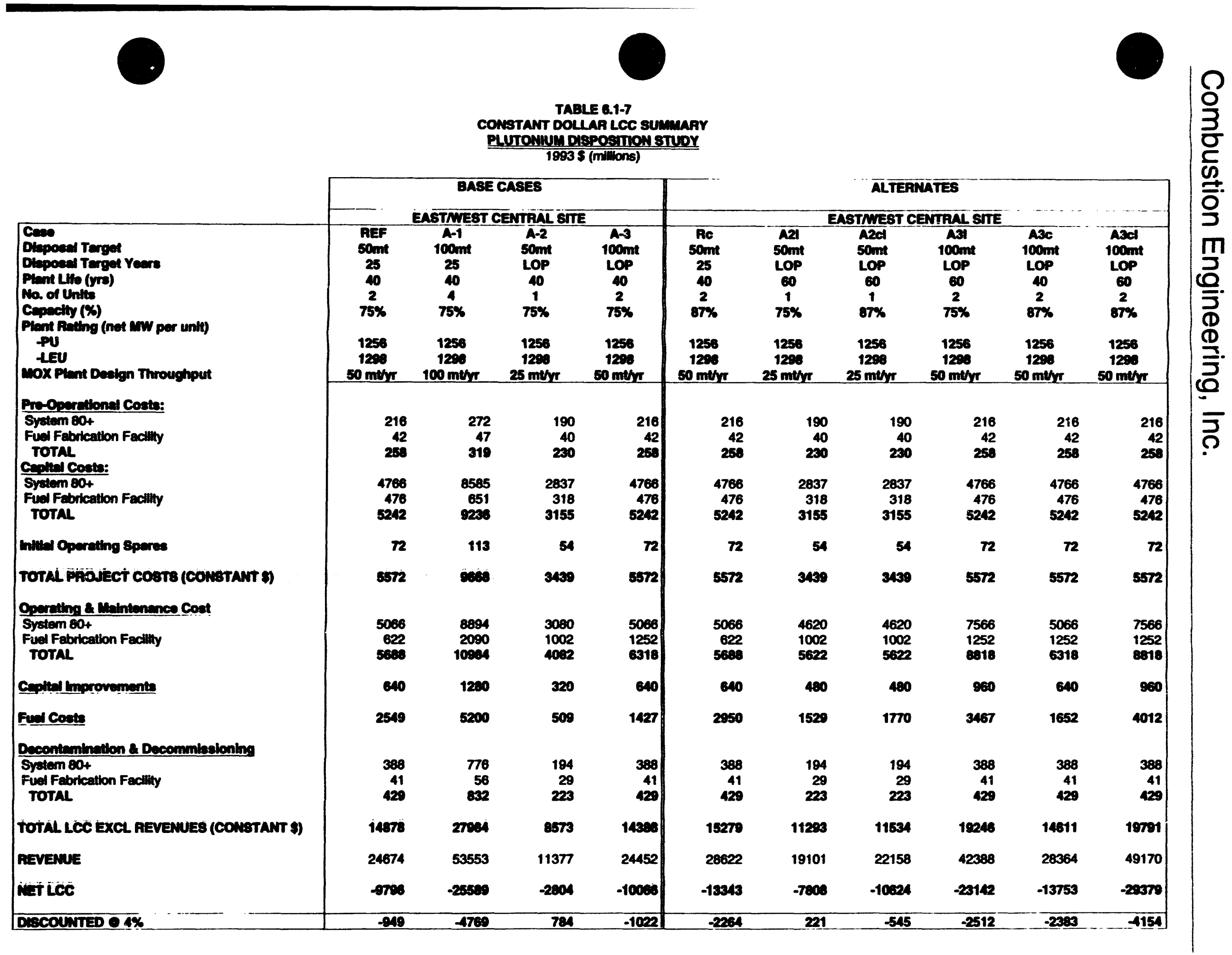




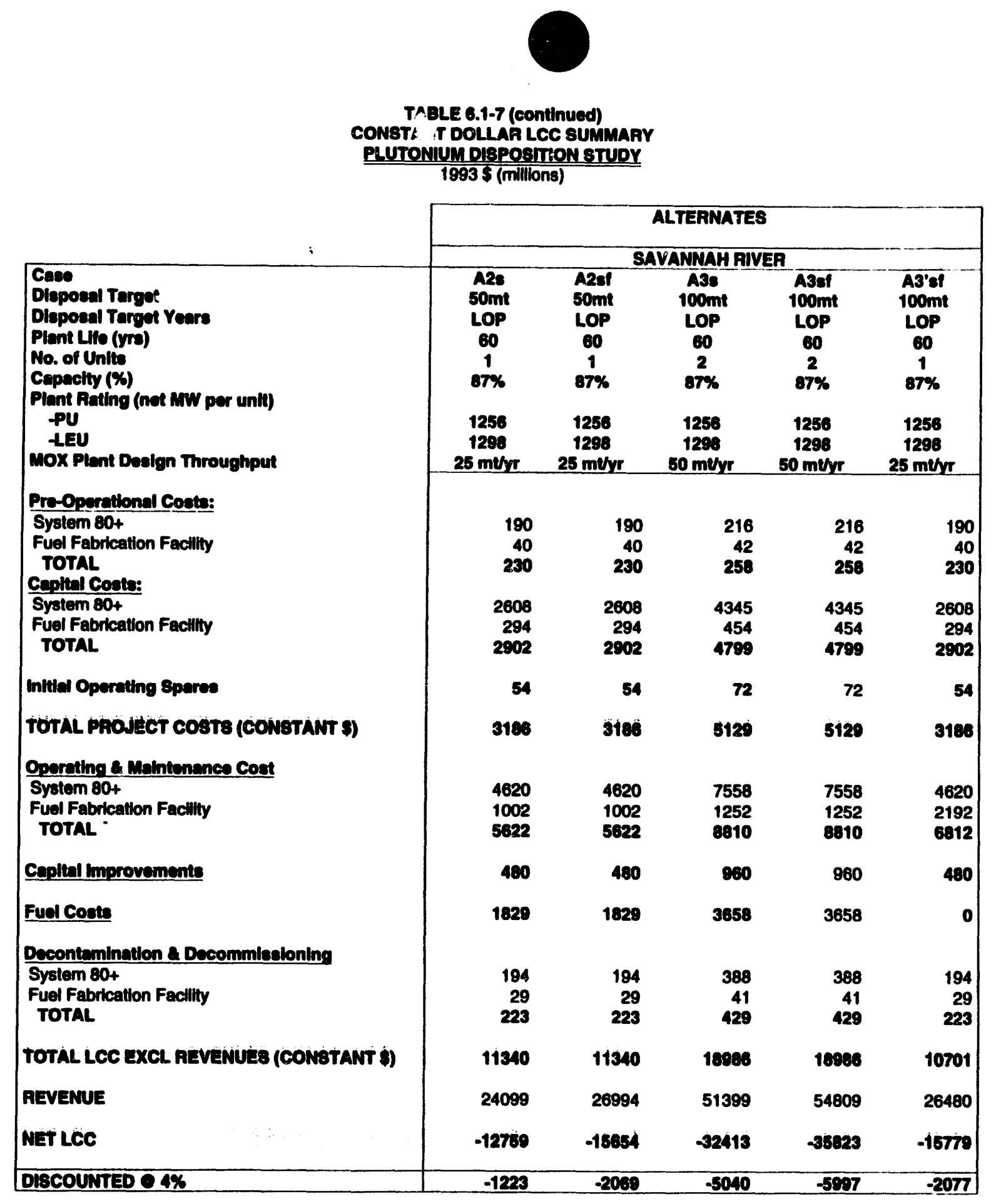


Combustion Engineering, Inc.

TABLE 6.1-8

CONSTANT DOLLAR CAPITAL COST FORECAST

PLUTONIUM DISPOSITION STUDY

1993 \$ (millions)

CONSTRUCTION CASH FLOW

FOR ONE UNIT

AT THE EAST/WEST CENTRAL SITE

QUARTER FIRST UNIT

127

$2 \quad 54$

$3 \quad 81$

$4 \quad 110$

$5 \quad 117$

$6 \quad 125$

$7 \quad 131$

8133

$9 \quad 160$

$10 \quad 165$

$11 \quad 173$

$12 \quad 209$

$13 \quad 228$

$14 \quad 232$

$15 \quad 242$

$16 \quad 259$

$17 \quad 187$

$18 \quad 145$

191130

20113

$21 \quad 94$

$22 \quad 94$

$23 \quad 79$

$24 \quad 61$

$25 \quad 23$

$26 \quad 67$

$27 \quad 0$

$28 \quad 0$

$29 \quad 0$

$30 \quad 0$

$31 \quad 0$

$32 \quad 0$

$33 \quad 0$

$34 \quad 0$

TOTAL $\quad 3,439$ 
Combustion Engineering, Inc.

TABLE 6.1-9

CONSTANT DOLLAR CAPITAL COST FORECAST

PLUTONIUM DISPOSITION STUDY

1993 \$ (millions)

CONSTRUCTION CASH FLOW

FOR TWO UNITS

AT THE EAST/WEST CENTRAL SITE

\begin{tabular}{|c|c|c|c|}
\hline QUARTER & FIRST UNIT & SECOND UNIT & TOTAL \\
\hline 1 & 27 & 0 & 27 \\
\hline 2 & 54 & 0 & 54 \\
\hline 3 & 81 & 0 & 81 \\
\hline 4 & 110 & 0 & 110 \\
\hline 5 & 117 & 0 & 117 \\
\hline 6 & 131 & 0 & 131 \\
\hline 7 & 140 & 0 & 140 \\
\hline 8 & 144 & 1 & 145 \\
\hline 9 & 171 & 5 & 176 \\
\hline 10 & 177 & 13 & 190 \\
\hline 11 & 187 & 21 & 208 \\
\hline 12 & 223 & 29 & 252 \\
\hline 13 & 244 & 29 & 273 \\
\hline 14 & 238 & 32 & 270 \\
\hline 15 & 248 & 32 & 280 \\
\hline 16 & 265 & 42 & 307 \\
\hline 17 & 192 & 84 & 276 \\
\hline 18 & 148 & 99 & 247 \\
\hline 19 & 133 & 102 & 235 \\
\hline 20 & 113 & 132 & 245 \\
\hline 21 & 94 & 144 & 238 \\
\hline 22 & 94 & 159 & 253 \\
\hline 23 & 79 & 160 & 239 \\
\hline 24 & 61 & 185 & 246 \\
\hline 25 & 23 & 133 & 156 \\
\hline 26 & 67 & 111 & 178 \\
\hline 27 & 0 & 100 & 100 \\
\hline 28 & 0 & 93 & 93 \\
\hline 29 & 0 & 78 & 78 \\
\hline 30 & 0 & 68 & 68 \\
\hline 31 & 0 & 54 & 54 \\
\hline 32 & 0 & 40 & 40 \\
\hline 33 & 0 & 13 & 13 \\
\hline 34 & 0 & 52 & 52 \\
\hline TOTAL & 3,561 & 2,011 & 5,572 \\
\hline
\end{tabular}

filename>A:2FOREE_W.WK3 


\section{TABLE 6.1-10}

CONSTANT DOLLAR CAPITAL COST FORECAST

PLUTONIUM DISPOSITION STUDY

1993 \$ (millions)

\section{CONSTRUCTION CASH FLOW \\ FOR FOUR UNITS \\ AT THE EAST/WEST CENTRAL SITE}

\begin{tabular}{|c|c|c|c|c|c|}
\hline QUARTER & FIRST UNIT & SECOND UNIT & THIRD UNIT & FOURTH UNIT & TOTAL \\
\hline 1 & 27 & 0 & 0 & 0 & 27 \\
\hline 2 & 54 & 0 & 0 & 0 & 54 \\
\hline 3 & 81 & 0 & 0 & 0 & 81 \\
\hline 4 & 111 & 0 & 0 & 0 & 111 \\
\hline 5 & 118 & 6 & 0 & 0 & 124 \\
\hline 6 & 138 & 12 & 2 & 0 & 152 \\
\hline 7 & 151 & 17 & 4 & 0 & 172 \\
\hline 8 & 155 & 24 & 4 & 1 & 184 \\
\hline 9 & 182 & 25 & 9 & 2 & 218 \\
\hline 10 & 191 & 28 & 14 & 2 & 235 \\
\hline 11 & 201 & 31 & 18 & $\overline{7}$ & 257 \\
\hline 12 & 238 & 37 & 28 & 8 & 311 \\
\hline 13 & 261 & 61 & 28 & 9 & 359 \\
\hline 14 & 246 & 102 & 27 & 17 & 392 \\
\hline 15 & 257 & 107 & 28 & 21 & 413 \\
\hline 16 & 274 & 147 & 29 & 29 & 479 \\
\hline 17 & 199 & 152 & 50 & 30 & 431 \\
\hline 18 & 155 & 164 & 90 & 32 & 441 \\
\hline 19 & 134 & 164 & 97 & 32 & 427 \\
\hline 20 & 113 & 186 & 136 & 35 & 470 \\
\hline 21 & 94 & 175 & 146 & 43 & 458 \\
\hline 22 & 94 & 107 & 164 & 82 & 447 \\
\hline 23 & 79 & 107 & 163 & 91 & 440 \\
\hline 24 & 61 & 89 & 183 & 127 & 460 \\
\hline 25 & 23 & 78 & 165 & 133 & 399 \\
\hline 26 & 67 & 68 & 103 & 151 & 389 \\
\hline 27 & 0 & 60 & 103 & 155 & 318 \\
\hline 28 & 0 & 45 & 86 & 175 & 306 \\
\hline 29 & 0 & 15 & 75 & 159 & 249 \\
\hline 30 & 0 & 54 & 66 & 100 & 220 \\
\hline 31 & 0 & 0 & 59 & 102 & 161 \\
\hline 32 & 0 & 0 & 42 & 82 & 124 \\
\hline 33 & 0 & 0 & 15 & 70 & 85 \\
\hline 34 & 0 & 0 & 55 & 62 & 117 \\
\hline 35 & 0 & 0 & 0 & 54 & 54 \\
\hline 36 & 0 & 0 & 0 & 37 & 37 \\
\hline 37 & 0 & 0 & 0 & 14 & 14 \\
\hline 38 & 0 & 0 & 0 & 52 & 52 \\
\hline OTAL & 3,704 & 2,061 & 1,989 & 1,914 & 9,668 \\
\hline
\end{tabular}


Combustion Engineering, Inc.

TABLE 6.1-11

CONSTANT DOLLAR CAPITAL COST FORECAST

PLUTONIUM DISPOSITION STUDY

1993 \$ (millions)

CONSTRUCTION CASH FLOW

FOR ONE UNIT

AT THE SAVANNAH RIVER SITE

QUARTER FIRST UNIT

1

2

27

54

3

81

110

117

125

131

128

152

156

161

191

204

203

212

232

161

127

115

102

20

92

21

87

23

73

58

24

21

26

66

27

28

29

30

31

32

33

34

0

0

0

0

0

0

0

TOTAL

0

3,186

filename>A:1FORESAV.WK3 
Combustion Engineering, Inc.

TABLE 6.1-12

CONSTANT DOLLAR CAPITAL COST FORECAST

PLUTONIUM DISPOSITION STUDY

1993 \$ (millions)

CONSTRUCTION CASH FLOW

FOR TWO UNITS

AT THE SAVANNAH RIVER SITE

\begin{tabular}{|c|c|c|c|}
\hline QUARTER & FIRST UNIT & SECOND UNIT & TOTAL \\
\hline 1 & 27 & 0 & 27 \\
\hline 2 & 54 & 0 & 54 \\
\hline 3 & 81 & 0 & 81 \\
\hline 4 & 110 & 0 & 110 \\
\hline 5 & 117 & 0 & 117 \\
\hline 6 & 131 & 0 & 131 \\
\hline 7 & 140 & 0 & 140 \\
\hline 8 & 138 & 0 & 138 \\
\hline 9 & 163 & 5 & 168 \\
\hline 10 & 168 & 13 & 181 \\
\hline 11 & 175 & 22 & 197 \\
\hline 12 & 204 & 29 & 233 \\
\hline 13 & 220 & 34 & 254 \\
\hline 14 & 208 & 33 & 241 \\
\hline 15 & 217 & 33 & 250 \\
\hline 16 & 237 & 37 & 274 \\
\hline 17 & 166 & 80 & 246 \\
\hline 18 & 130 & 93 & 223 \\
\hline 19 & 118 & 96 & 214 \\
\hline 20 & 102 & 120 & 222 \\
\hline 21 & 92 & 126 & 218 \\
\hline 22 & 87 & 139 & 226 \\
\hline 23 & 73 & 142 & 215 \\
\hline 24 & 58 & 161 & 219 \\
\hline 25 & 21 & 117 & 138 \\
\hline 26 & 66 & 99 & 165 \\
\hline 27 & 0 & 89 & 89 \\
\hline 28 & 0 & 82 & 82 \\
\hline 29 & 0 & 70 & 70 \\
\hline 30 & 0 & 61 & 61 \\
\hline 31 & 0 & 49 & 49 \\
\hline 32 & 0 & 34 & 34 \\
\hline 33 & 0 & 11 & 11 \\
\hline 34 & 0 & 51 & 51 \\
\hline TAL & 3,303 & 1,826 & 5,129 \\
\hline
\end{tabular}

filename>A:2FORESAV.WK3 


\subsection{Cost Fatimate Detail}

The scope of work included within the capital cost estimate includes all engineering, design, materials, commodities, equipment, installation, erection, testing and facilities necessary for an operating System $80+$ nuclear power plant and MOX Fuel Facility. Pre-Operational costs are included for both complexes.

The estimated were developed based on the May 1993 Cost Estimate Guidelines for Advanced Nuclear Power Iechnologies as supplemented by draft Letter Report on Guidelines for Cost Estimating dated January 19, 1994. The estimates reflect a January 1993 overnight cost.

\section{Pre-Operational Costs}

Pre-Operational costs have been included which consist of the following cost elements:

- Research and Development

- Pre-Title I Engineering

- Regulatory, Safety and Environmental

- Start-up and Testing

Research and Development activities for the project are directed at fuel fabrication issues which include development and irradiation of assemblies for MOX fuel qualification. The other area of significance is the analysis of fuel performance characteristics. Successful completion of these activities will provide the basis for plant safety analysis.

\section{System 80 t}

The Capital Cost Estimate was developed based upon the System $80+$ Standard Nuclear Power Plant design accomplished to date under the USNRC Design Certification Program. Significant estimating activities have taken place as part of the System 80 + development and application process. The capital cost estimates for the Plutonium Disposition mission were developed based on these initiatives. The following outlines the basis of estimates for the Pu mission.

\section{Quantity Development}

Individual components, including material commodities and bulks within the scope of supply, were quantified by computerized material takeoffs of drawings and diagrams, by manual takeoffs, and by adjusting quantities from previous nuclear power plant experience. Computer based systems were used for those areas and commodities which are significant contributors to the total capital cost. 
Because the structural quantities in the nuclear island and turbine island represent a significant portion of the capital cost, they were completely modeled in 3-dimensional CAD. Concrete and steel were quantified utilizing the computer resource and used directly in the estimate, providing what we consider to be highly accurate scope definition.

Piping, including hangers and supports, which is another major contributor to total capital cost was partially quantified by 3D computer, as a function of the existing plant design detail.

Valves, which are also a contributor to total plant costs were quantified using computer takeoff, based upon system P\&IDs.

\section{Mini-Specifications}

In order to facilitate a comprehensive, high confidence level survey of component and equipment suppliers in a short period of time, component specific "mini-specifications" were developed from full scope vendor-specific specifications used in previous procurements and distributed to potential suppliers.

Equipment costs per the mini-specifications were assembled based on quotations. Cost estimates for erection contracts were based on quotations. Since the scope of work is accurately expressed in the mini-specifications and supply and erection is based on budgetary quotations, these estimates reflect a significantly high confidence level.

\section{Major Equipment}

Pricing for the following equipment was based on vendor quotations.

\section{$\bullet$}

\section{NSSS}

The entire NSSS scope of supply, including the reactor vessel, steam generators, pressurizer, reactor coolant pumps and piping, shutdown cooling, CVCS, safety injection, and containment spray systems, along with related instruments and controls for the reactor protection system and the NUPLEX 80 + Control Complex. 
The turbine generator scope of supply including turbines, generator, auxiliary equipment such as reheaters, moisture separator, lube oil equipment, hydrogen cooling, and the condenser; conceptual design including preliminary heat balances has been accomplished in order to properly size the equipment.

\section{Maior Equipment Erection}

A mechanical erection contractor estimated the hours and costs to erect the NSSS. A contractor also estimated the hours for the turbine generator, condenser and feedwater heater erection. The balance of major equipment erection scope was estimated using previous construction experience.

\section{Bulk Material and Labor}

Bulk material quantities were developed based on computer aided design, manual takeoffs and adjustment for comparable nuclear plant data. Reference was made to historical information where appropriate to test the reasonableness of the information developed.

Bulk material costs were developed based on the Cost Estimating Guidelines.

\section{Crew Labor Rates}

The labor rates used in the estimate were those specified by DOE. Table 6.2-1 reflects hours by craft for a single System $80+$ deployment.

\section{Indirect Cost}

Indirect costs are costs required to support the construction effort but not identifiable to a specific end use account. The indirect costs for this construction effort were developed based on historical information, adjusted, where necessary for the scope and complexity of the project. A non-manual staffing profile was developed consistent with the project manual labor supervisory requirements, the project schedule, and the type of work anticipated. In addition, the associated support staff requirements were evaluated. Experienced construction personnel assessed the temporary facility requirements, as well as the construction equipment needs required for the identified construction methodologies. 
The Indirect Costs include support for both the System $80+$ complex and the MOX Fuel Facility. Should these facilities not be collocated an adjustment to the Indirect Costs would be required.

\section{Project Management and Engineering}

The engineering costs were developed by each engineering discipline based upon the specific engineering products and efforts required. In addition, the engineering resources required to support procurement and construction activities were assessed and included.

Project Management costs have been included. Costs for administration support services within the project organization have been included. These services include cost and scheduling, construction liaison, procurement, and othor support services.

For multiple System $80+$ applications, the estimates reflect reductions to engineering costs due to the completion of first of a kind engineering with the first unit.

\section{MOX Fual Fabriantion Facility $\left(\mathrm{MF}^{2}\right)$}

$\mathrm{MF}^{2}$ estimates for the $50 \mathrm{MT} / \mathrm{yr}$ facility have been included. This same facility can bes upgraded to $100 \mathrm{MT} / \mathrm{yr}$ by two - shift operation. Only minimal engineering activities have taken place regarding defining the commodities and equipment details of $\mathrm{MF}^{2}$. As a result, the estimates developed were based on an engineering assessment of previous studies and a review of applicable published information coupled with scaling to arrive at estimates for the required capacities. Decontamination and decommissioning of the $\mathrm{MF}^{2}$ have been estimated at $10 \%$ of the capital cost and included.

Cost estimates for the $\mathrm{MF}^{2}$ were derived from various sources, but mainly from work done under this and other DOE contracts by the Team Members. The estimates are being checked against available European data on MOX facilities under construction and in operation.

The $\mathrm{MF}^{2}$ cost estimate for a typical facility (1994 dollars) is as follows:

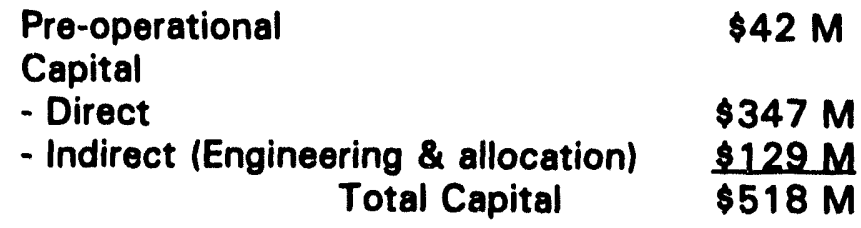

Annual Operation \& Maintenance $\$ 42 \mathrm{M}$

For purposes of comparison, a MOX facility cost estimate for Savannah River site, of equivalent capacity, was found in the literature (Ref. 6.2.1). The numbers, in 1992 dollars, are as follows: 
Capital

- Conversion of $\mathrm{UF}_{6}$ to $\mathrm{UO}_{2}$

$\$ 100 \mathrm{M}$

- Conversion of $\mathrm{Pu}$ to $\mathrm{PuO}_{2}$ $\$ 205 M$

- Blending, Pelletizing , Assembly \$375 M Total

$\$ 680 M$

Annual Operating \& Maintenance

$\$ 30 \mathrm{M}$

European cost estimates tend to be somewhat lower. The Seismic $120 \mathrm{MT} / \mathrm{yr}$. plant at Hanau was built at a cost of $\$ 500 \mathrm{M}$. BNFL is contracting a $100 \mathrm{MT} / \mathrm{yr}$. plant at a cost of $\$ 400 \mathrm{M}$. The conclusion is that the costs estimated for the System $80+\mathrm{Pu}$ disposition mission, although in need of considerable refinement, are not unrealistic.

\section{Electric Revenue Calculation}

Electric revenues are calculated using the above assumptions for capacity factor and net electric generation and electric revenue prices supplied by ORNL. The results are shown on Table 6.1-7.

\section{Reference:}

6.2-1 WSRC-RP-98-1004, October, 1992 "Strategies for Denaturing the Weapons Grade Plutonium Stockpile." 
TABLE 6.2-1

MANUAL MANHOURS BY CRAFT

\begin{tabular}{|c|c|c|c|c|c|}
\hline CRA & $\begin{array}{c}\text { EASTWEST } \\
\text { CENTRAL SITE } \\
1 \text { UNIT } \\
25 \mathrm{mt} / \mathrm{yr} \text { MOX }\end{array}$ & $\begin{array}{c}\text { EASTMEST } \\
\text { CENTRAL SITE } \\
2 \text { UNIT } \\
50 \mathrm{~m} / \mathrm{yr} \text { MOX } \\
\end{array}$ & $\begin{array}{c}\text { EASTWEST } \\
\text { CENTRAL SITE } \\
4 \text { UNIT } \\
100 \mathrm{~m} \text { tyr MOX }\end{array}$ & $\begin{array}{c}\text { SAVANNAH } \\
\text { RIVER SITE } \\
1 \text { UNIT } \\
25 \text { mtyT MOX }\end{array}$ & $\begin{array}{c}\text { SAVANNAH } \\
\text { RIVER SITE } \\
2 \text { UNIT } \\
50 \mathrm{mt} / \mathrm{yr} \text { MOX }\end{array}$ \\
\hline BOILERMAKER & 199,449 & 377,534 & 732,754 & 189,949 & \\
\hline CARPENTER & 349 & 7,25 & & & \\
\hline E & & 6,5 & & 3 & 6, \\
\hline IRON WORKER & & & & & \\
\hline LAB & & 6,6 & & & \\
\hline MILLWRIGHT & & & & & \\
\hline OPERATING EI & 39 & 0,1 & 9,7 & 271 & 4,9 \\
\hline PIPEFITTER & & & & & \\
\hline & & & & & \\
\hline & & & & & \\
\hline TOTAL & $28,276,864$ & $4 \overline{49,393}$ & $93,242,065$ & $26,932,0401$ & $\mathbf{1 7 , 0}$ \\
\hline
\end{tabular}




\subsection{Oparntione and Maintenanae Cont Dotell}

The DOE Plutonium Disposition Study (PDS), Phase 1, resulted in a Final Report, Plutonium Consumption in ALWRs, on May 15, 1993. The Operations and Maintenance (O\&M) cost estimates of Section VI of that report were based, in part, on an initial estimate of the staffing required for a Plutonium Disposition Reactor (PDR).

Since that time, the O\&M cost estimates have been improved. Particular attention has been given to the underlying staffing estimates for the PDR, since labor costs are traditionally the largest single component of reactor O\&M costs. The following section discusses the revised staffing estimate, including the methodology used, associated assumptions and organization. The subsequent section then discusses the elements of O\&M cost as provided in DOE guidance. The numerical results are then presented in the tables and figures of this section.

\subsubsection{Staffing}

The revised estimates required careful development and assessment of more detailed staffing assumptions, more detailed consideration of the impact of the advanced design features of System $80+$, and an explicit organization with assigned functional responsibilities. In addition, to the extent possible, information has been taken into account from a variety of sources such as the progress of nuclear utilities in controlling O\&M of current operating plants, the applicability of standardization information from the Advanced Reactor Corporation (ARC), and guidance from the Institute of Nuclear Power Operations (INPO). Information such as the draft ALWR Guiding Principles and Underlying Considerations for Organizing and Staffing a Family of Standard Nuclear Plants by INPO was used in confirming these revised staffing estimates.

As in the Phase 1 report staffing estimate, the System $80+$ staffing levels were adjusted to meet the unique mission of the PDR. Expected requirements for this mission increased the staffing for certain groups (e.g., security, site management, etc.) somewhat over that which would be required for a commercial unit.

The revised staffing estimates benefit from further, in-depth examination of the functions required for the operation, maintenance and overall support of the plant with an emphasis on assumptions and related information. As an evolutionary Advanced Light Water Reactor, numerous design features have been incorporated into the System $80+$ to improve the operational capabilities, improve the capacity factor, and reduce the staffing levels below that of the latest generation of operating plants. Credit has been taken for these features in the current estimate, which was not possible in the initial staffing estimate. 


\section{Assumptions}

More detailed assumptions have been developed for this revised estimate, some of which evolved directly from those used for the initial staffing estimate for the PDR. Fundamental assumptions used for the initial staffing estimates included compliance with proposed Technical Specifications and INPO guidance, such as Guidelines for the Organization and Administration of Nuclear Power Plants, INPO 86-009, Rev. 01. Other assumptions were made consistent with the overall operating philosophy. A more detailed source of information on operations and maintenance practices and associated design features is provided in Appendix $\mathrm{C}$ of this report.

The revised assumptions also benefit from work previously performed by ABB-CE and DE\&S on an Operational Support Information (OSI) Plan in support of CESSAR-DC. Useful information from that effort resulted from the review of numerous NUREGs and INPO documents dealing with qualifications, conduct of programs, and other programmatic issues. OSI information was available for the areas of construction, startup, operations, training, security, and maintenance and provided useful background information and insights for developing and validating the assumptions used in this study.

The revised assumptions not only include more detail in the areas previously identified, but also include new assumptions regarding the physical layout of the facility, especially those considerations that may be determined by the owner/operator. These assumptions define how the infrastructure needed to operate the facility is provided. Obviously, the facility will be operated within the bounds of regulations selected at the time. But, these assumptions are critical since how the support is provided and how the owner/operator chooses to meet those regulations significantly influences the resources required. As demonstrated by the commercial industry today, the staff and organization can vary greatly and still satisfy regulatory requirements and industry standards. These assumptions provide the detailed information necessary to support the staffing estimates for the PDS.

The more complete set of assumptions specifically developed and employed in the process of assuring all the required functions were satisfied define the basis for the staffing estimate. They are presented in following sections and categorized into four groups: Off-site Support Assumptions, Conduct of Operations Assumptions, Administrative Assumptions, and Facilities Assumptions. These assumptions are presented in Table 6.3.1-1, Staffing Assumptions.

\section{Eunctions}

A functional organizational chart was developed that listed the major functions (not resources) required to support the mission of the plant down to the individual group level. The approach avoided simple adoption of previous organizational structures so that different, more innovative and/or more efficient alternatives could be considered. 
The organizational structure was gradually refined as a result of the process for assigning staffing (resources) to the required functions. Input was obtained from the quality improvement teams of an operating utility that have been deeply involved in reorganizations and related efforts to reduce O\&M costs. This provided insight into the approach to optimizing staffing. For example, information obtained included identification for the functions required via work breakdowns for the maintenance and work control areas.

The organizational structure that was developed as part of the revised staffing estimate is provided in Figure 6.3.1-1, Organization Structure. A concise functional description for the major organization groups that describes functions and responsibilities for each group is provided in the following sections.

The Executive Management group consists of the Chief Operating Officer and four support sections. The support sections are Nuclear Operations, Nuclear Oversight, Staff, and Nuclear Financial. These sections are headed by a Vice President and report directly to the Chief Operating Officer. The Nuclear Operations section is responsible for following the day to day operations of the site and monitoring their performance during operation and outages. This section has the lead for ensuring standardization is maintained within the site where multiple units are involved. The Nuclear Oversight section has responsibility for the quality and regulatory oversight of the site. They act as a liaison between government and industry agencies at the corporate level. This section arranges for audits and inspections of the site. The Staff section provides the clerical support and technical expertise to the section Vice Presidents. The Nuclear Financial section compiles and reports information for the corporate entity as well as government and industry agencies, and is responsible for the budget process.

The Site Management group consists of the Site Manager, Staff, Assistant Manager, an Engineering/Design section, and the Plant Staff. Each group within the site has a manager that reports directly to the Site Manager. The Staff section provides the clerical support for the group. The Assistant Manager is responsible for administrative and special operations duties as directed by the Site Manager and acts as the Site Manager in his absence. The Engineering/Design section is the liaison between the site and the NSSS vendor. This section will also be the point of contact for the DOE in the case of the PDR. The Engineering/Design section reports directly to the Site Manager but will interface with the System Engineering group to resolve generic regulatory and operability issues. For a multiple unit site, each Assistant Manager assumes Site Manager responsibilities applicable to each respective unit. Groups for that unit report directly to the Assistant Manager. The Site Manager retains responsibility for support groups common to the site (e.g., Administration, Security, etc.) and ensures standardization is maintained between multiple units.

The Operations group is responsible for the integrated operation of the plant equipment. Other groups may "own" equipment that directly affects their tasks, but Operations is responsible for the operation of the plant as a whole. The Operations 
group consists of the Staff, Shift Support, Operations Support, and Surveillance sections. The Staff sections provides the clerical support for the group. The Shift Support section provides the functions of the training coordinator for licensed and nonlicensed training, an operating compliance position to monitor Technical Specification surveillance completion and procedure adherence, and Shift Supervisor relief. This section includes all personnel assigned to shifts. The Operations Support section provides procedure enhancement, and work control support for the Work Control group. The Surveillance section has the responsibility of Technical Specification, Design Basis, and other required surveillance testing. This group will provide the technical expertise and manpower for all testing within Operations. The concept is for "system experts" that routinely perform the same tests to ensure the familiarity and reduce errors.

The Maintenance group performs all routine and assorted outage maintenance activities for mechanical, electrical and instrumentation disciplines. The five sections within maintenance are Staff, Mechanical/Electrical, Instrument \& Control, Work Planning, and QA/Materials. The Staff section provides the clerical and Document Control function for the group. The Mechanical/Electrical section is discipline combined to gain the advantage of a crew approach for work. The crews will have mechanical and electrical leads, but all personnel within the crew will be able to perform most tasks required of a specialized crew. The crews are divided into the major work areas: pumps, valves, diesel generator (D/G) and combustion turbine (CT), general maintenance, and support (such as tool rooms, labs, etc.). The Instrumentation \& Control (I\&C) section is responsible for all process instrumentation in the plant, calibration labs, and related valve work. Both the Mechanical/Electrical and I\&C sections have personnel on shift. The shift supervision for these personnel may be from either section and reports to the supervision over that section. The Work Planning section provides for work order preparation, procurement of items for repair, and work tracking for the maintenance of the site. The QA/materials section is responsible for the receiving, inventory, and inspection of all items received on site. The QA portion of this section will perform all nuclear safety related tasks for materials and also provide technical support to the crafts. Reliance is placed on self checking of work with minimal QA support.

The Security group has the responsibility of nuclear and industrial security for the site. The four sections within Security are the Staff, Access/Records, Compliance and Training sections. The Staff section provides clerical support for the Security group, a Day Supervisor and Officers assigned to day shift. The Shift Lieutenants and shift personnel report to the Day Supervisor. The Access/Records section has the responsibility for site access screening and issuance of security badging. The Training section coordinates and provides regulatory and first responder training as well as drills for Security. The Compliance section answers concerns related to the security plan and handles any implementation infractions.

The Radiation Protection group has five sections: the ALARA, RP Support, Staff, Count Room, and Decontamination (Decon) sections. The ALARA section supports the work 
order process from a radiological aspect and tracks doses at the site. The effectiveness of practices and dose reduction initiatives are monitored by this section for improvements. The RP Support section provides coverage for task performance by all groups at the site to ensure all requirements set by the ALARA group are followed. A Day Supervisor manages day shift technicians. The RP supervisors for each shift may be drawn from any section and report to the Day Supervisor. The Staff section provides for clerical, records and dosimetry issuance functions. These personnel report directly to the Radiation Protection Manager. The Count Room section analyzes samples and prepares effluent release packages for the site. The Decon section has the responsibility for the decontamination of site areas, equipment and tooling if required for work, and also operates the contaminated clothing laundry for the site.

The Chemistry group has four sections within the group. The sections include Staff, Environmental, Chemists, and Radwaste functions. The Staff section provides the clerical and records support for the group. The Environmental section has the responsibility of environmental monitoring and reporting. This section also provides operators for the water treatment facility at the site. The Chemists section obtains and analyzes samples for monitoring operation and ensuring Technical Specification surveillance. The Radwaste section operates all equipment that is in the solid, liquid and gaseous effluent release process. The Chemistry group has shift personnel from the Environmental, Chemists and Radwaste sections. They may be supervised by an individual from either of the sections.

The Work Control group has the responsibility of scheduling and tracking all maintenance and testing performed at the site, both routine and outage related. The group consists of three sections, Schedule, Staff and Shifts. The Schedule section will establish routine and outage schedules, and implement the Preventive Maintenance Program. The Staff section provides the clerical support, computer support and provides a relief Shift Manager for the group. The Shift section reports directly to the Work Control Manager and provides for the actual implementation, tracking and conflict resolution of the schedule as developed by the Schedule section on a 24 hour basis.

The Safety group consists of the Medical, Fire Protection, Staff, Training and Industrial Hygiene sections. The Medical section provides for all pre-employment and continuous testing, Fitness for Duty testing, and provides medical response to accidents when required. The Fire Protection section has the responsibility of testing fire protection (not detection) equipment. This group also develops and evaluates the drill scenarios for the certification of the site Fire Brigade. The Staff section provides clerical support for the group. The Training section updates of policies and standards used by the site and provides general safety training on these and other topics to ensure OSSA compliance. The Industrial Compliance section provides for the routine monitoring and sampling of work spaces and atmospheres for all groups at the site. This section also performs accident investigations, and ensures records are provided to the proper agencies as required. 
The Training group provides the site with the resources for all employee technical training. The sections in the Training group are General Employee Training (GET), Operator, Staff, Maintenance, and Technical Services. The GET section provides training of initial and requalification required for general access to the site. The Operator section provides systems, initial and requalification NRC license, and simulator training. The Staff section provides clerical and records support for the Training group. The Maintenance section provides classroom and lab instruction for the Mechanical / Electrical and Instrument \& Control sections of the Maintenance group. The Technical Services section provides general systems and continuing engineering training, radiation protection and chemistry subjects for these groups.

The Administrative group consists of five sections which includes Support Services, Purchasing/Contracts, Staff, Regulatory Compliance, and Emergency Planning. The Support Services section provides the human resources assistance for the site personnel and the accounting resources necessary for the site. The Purchasing/Contracts section maintains contracts and purchasing agreements for the required site services. The Staff section provides the clerical support for the group. Regulatory compliance is the point of contact for the site specific licensing issues and NRC responses, along with INPO coordination. The Emergency Planning section is responsible for Emergency Plan development and the continuing scenario development, evaluation, and training to ensure compliance with NRC regulations.

The System Engineering Group has seven sections that previously were aligned under other groups. The System Engineering organizational approach allows for more thorough expertise in all facets of particular system operation, maintenance, and testing by using resources in a "team" concept. These personnel will have the knowledge and experience for system troubleshooting and problem resolution to support the Operations and Maintenance groups. By using the "team concept," personnel can provide backups to other members of the team to be utilized more efficiently in peak workloads.

The System Engineering group has responsibility for major programs such as implementation of the Maintenance Rule, actions required to respond to Generic Letter 89-10, Integrated Leak-Rate Testing (ILRT), In-service Testing of Pumps and Valves, and similar functions. Other responsibilities include Root Cause Analysis and LER responses for their systems or components.

The seven sections are Primary Systems, Secondary Systems, Electrical Systems, Instrument \& Control (1\&C) Systems, Reactor Engineering, Information Management System (IMS) Support, And Staff. The Primary Systems group is responsible for plant systems such as the Emergency Core Cooling System (ECCS), Emergency Feedwater System, the Steam Generators, and Heating, Ventilation and Air Conditioning (HVAC) systems. The Secondary Systems group is responsible for plant systems that include the turbine-generator and all support systems, the feedwater system, and feedwater heaters plus thermal performance monitoring. The Electrical Systems section is 
responsible for the Diesel Generators, Combustion Turbines, and all low, medium and high voltage equipment. The $1 \& \mathrm{C}$ section provides the expertise required for the plant process and reactor protection components. The Reactor Engineering section provides the resources for core analysis, fuel handling operations, and plant transient monitoring. The IMS Support section is responsible for the computer processes utilized at the site and provides validation \& verification (V\&V) for new software, as appropriate, in the evolutionary process of maintaining the IMS near state of the art during plant life. The Staff section provides the clerical and document control resources to support the group.

\section{Resources}

From the organizational structure, the resources to perform the identified functions were estimated. These resources include both administrative and technical personnel. The revised single unit estimates assign each organizational group a manager and appropriate administrative support. Sufficient supervision is provided for required functions and all supervisors report directly to a manager. Estimates for the required technical/craft personnel are based on industry standards for completing work in a timely manner while taking into account the System $80+$ design improvements that directly benefit the PDR. Estimates of the number of required support personnel incorporate assumptions for the Information Management System (IMS) and the technology available to the plant staff. The revised estimates also assume efficient management practices such as self-directed work teams and working supervisors.

The staffing estimates for multiple units were developed from the one-unit estimate. While craft functions tend to increase in direct proportion to the number of units, the increase for personnel fulfilling support functions are not directly proportional. For example, additional technicians can reasonably be assigned to an existing supervisor when a second unit is added. However, additional supervisors are provided when additional crews are added for the second unit. Appropriate employee to supervisor ratios for the crews are based, in part, on current industry ratios for the work being performed. Clearly, some crews can be more self-directed than others, depending on the work function. This approach was used for individual review of each function to assure that the staff was increased as needed; a general multiplier approach was not used.

The revised estimate is outlined below.

$\begin{array}{cccc}\text { Category } & \text { One Unit } & \text { Iwe Units } & \text { Eour Units } \\ \text { On-site Staff } & 645 & 1045 & 1842 \\ \text { Executive Staff } & 15 & 20 & 29 \\ \text { Total Staff } & 660 & 1065 & 1871\end{array}$


Figure 6.3.1-2, Staffing Assumptions, shows the relationship between the Total Staff and the Staff per Unit. As expected, there are clear advantages for a multiple unit site on the basis of staff required per unit. The major benefit is for the increase from one unit to two units. As the number of units increases from two to four, the incremental benefit is less.

The experience gained from developing the initial PDS staffing estimates suggested that it would be beneficial to clearly define where all personnel in the organizational structure were included in the labor cost calculations (an "accounting" presentation). DOE's guidance on the "accounting" breakdown of staffing and associated salaries was provided in Table 4.4 of "Cost Estimate Guidelines for Advanced Nuclear Power Technologies," March 1993, by ORNL. It was also important to assure that there was no inadvertent duplication of personnel. In the original estimates, it was difficult to assure that all personnel in the organization were indeed included in the accounting presentation and that excess personnel are not being required for certain categories. For example, the "accounting" estimate lists staffing for the Administrative \& General, Non-Nuclear Site, and Engineering/Design functions. Organizationally, these personnel are not a separate group but are distributed in a variety of groups. This need has been addressed in the revised estimates by providing a staffing matrix. [Refer to Table 6.3.1.2] 
TABLE 6.3.1-1

STAFFING ASSUMPTIONS

\section{OFF-SITE SUPPORT}

These assumptions principally relate to the corporate support available for routine and outage services.

- An equivalent of a corporate or executive staff is required. This is considered in the Executive Management staffing category.

-

Outage services are provided by a vendor leither the NSSS vendor or another engineering and services company) for the scope of steam generator inspection and repair, reactor vessel inspection, refueling support, turbine inspection and repair and major valve work.

- An Engineering/Design position exists at the site to coordinate any generic licensing/design concerns that may arise. For a single unit site, this position is the liaison between the NSSS vendor and the owner/operator. For a multiple unit site, the responsibilities of this position include coordination between the NSSS vendor and the site's engineering staff. In all cases, this position reports to executive management to ensure that decisions are uniform (e.g., reflect a standard approach among units).

- For a multiple unit site, an assistant manager replaces the site manager as the individual with overall responsibility for unit operation.

\section{CONDUCT OF OPERATIONS}

These assumptions principally relate to the operating philosophy at the plant, availability of materials for the performance of tasks, and the allocation of responsibilities within the organizational structure.

- All procedures (operating, emergency, administrative, maintenance, etc.) have been previously developed or else guides are available to support adaptation of specific plant information to appropriate procedures and formats.

- Changes to procedures are limited le.g., only required due to minor modifications or in response to industry events) such that the procedures enhance plant performance and/or the margin of safety. Changes do not result in unreviewed safety questions or require the performance of safety evaluations. 


\section{IABLE 6.3.1-1 (Cont'd) STAFFING ASSUMPTIONS}

-

-

$\bullet$

-

$\bullet$

$\bullet$

Training guides and lesson plans are established. The instructors need only present the lesson plans and add operational experience items to enhance the lessons and comply with operational experience requirements by NRC, INPO, etc.

Rotating shifts are used which consist of Operations (OPS), Security (SEC), Chemistry (CHM), Radiation Protection (RP), Work Control (WC), and Electrical, Mechanical and I\&C Maintenance (EM, MM and I\&C).

Fire brigade responsibilities are provided by Operations with support by other groups which are on rotating shifts.

Regulatory Compliance is staffed with a Compliance Manager supported by individual representatives from each station group to perform the compliance/safety oversight function. This group responds to regulatory concerns and performs audit functions.

Chemistry (CHM) has the responsibility for the operation of radwaste systems, water treatment systems, and environmental compliance monitoring.

Support groups (e.g., CHM, RP, and $18 \mathrm{C}$ ) "own" equipment they routinely operate for the purpose of supporting plant operation, or for their use in laboratories, shops, etc. Operation of equipment that affects plant operation is coordinated with OPS.

Only modifications needed to replace components with similar specification components are necessary. The only evaluation required is to assure compatibility with the Design Certification Design Control Document (e.g., specifications).

Quality Assurance places relatively greater reliance on "self-checking" by the workers than on the formal QA/QC process typical of current operating plants. (It is recognized that some current operating plants are already taking this approach and the implementation of ISO 9000 standards may advance this approach more generally.l

The plant operates on a 12-month fuel cycle, has one refueling and maintenance outage per year with a length between 45 to 55 days, and has one forced outage per year lasting three days. This yields an average capacity factor of $85 \%$. 


\section{TABLE 6.3.1-1 (Cont'd) STAFFING ASSUMPTIONS}

\section{ADMINISTRATIVE}

These assumptions principally relate to the organizational structure needed to comply with efficient management practices, facility usage, and items to enhance the flow of information.

- Rotating shift personnel work a 5-shift, 12-hour per day rotation with the hours with an average cycle consisting of $\sim 44$ hours per week. The shift cycle is a combination of days, nights, and training.

- $\quad$ Training is $-20 \%$ of the cycle, and mainly addresses topics needed to satisfy NRC operator requalification requirements. Operations is in formal training essentially $100 \%$ of their training week. Other groups may spend less time in training. Specifically, security is in formal training $~-70 \%$ of their training week with the additional resources supporting the day shift staff.

- Personnel not required to attend training are assigned to support the day shift staff. That time is also utilized for unproductive uses such as vacation. Since most vacation is taken while on day-shift rotation, this limits the number of additional personnel required.

- All training for rotating shift personnel is performed within their assigned training time. This includes annual training requirements, annual physicals, updated training, etc. Training is not to be performed on shift unless absolutely required.

- Managers, clerks and other support personnel for each group are provided in the group estimate. There is no separate "pool" of clerical personnel.

$\bullet$

The Information Management System (IMS) enhances the work functions to provide an almost "paperless" system. The IMS will be used for items such as document control, procedure writing, payroll, injury reports, problem investigation reports, work order request, work order preparation, scheduling, log keeping, etc. Details of IMS and its assumed benefits to the respective groups include the following: 


\section{IABLE 6,3,1-1 (Cont'd) \\ STAFFING ASSUMPTIONS}

- Maintenance: Technical manuals and drawings will be on a computerized system to allow easy access and cross referencing of information for troubleshooting and repair of equipment. Work history on equipment will be retrievable for use in the Reliability Centered Maintenance (RCM) program. All work package information will be integrated through a work management system to allow more efficient work package preparation, scheduling and tracking.

- Warehousing/Purchasing: A direct link exists between the warehouse and purchasing. The IMS allows planners to designate parts and materials from inventory before they are actually needed to perform a task. With a direct link to purchasing, specifications and other pertinent information are available to allow the suppliers to better serve the plant personnel. "Just in time" material inventory delivery is adopted.

- Badiation Protection: A radiation monitoring query system exists for the Radiation Protection (RP) group. This system allows the RP group to track doses by their plant workers almost instantaneously while in the field, and stores this data for future use by ALARA personnel. This is also integrated through the work management system to allow work planners in maintenance to access ALARA reviews on repetitive tasks.

All oroups: The IMS database contains all revisions to procedures and updates them as necessary. Procedures revisions are electronically routed for review. The safety review process is streamlined with the use of a cross reference system on the IMS. The procedure use process is enhanced by having the latest copy of the procedure on file. This eliminates the task of reviewing handwritten changes and virtually eliminates the potential error of using an outdated procedure. The procedure user simply obtains the latest copy on record.

Security: For a multiple unit facility all security information will be available through the IMS. Access control will be streamlined by having records information available before the personnel arrive onsite. Proper controls assure limited access to safeguards information. 


\section{TABLE, 6,3.1-1 (Cont'd) \\ STAFFINC ASSUMPTIONS}

- Iraining: Computer Based Training (CBT) is used extensively to train and test personnel at the facility. Individuals are trained and tested without heavy reliance on classroom instructors, especially for low technical lovel topics such as General Employee Training (GET).

- Document Centrol: The IMS transfers the document control function from paper based information to an electronic format. This process will be enhanced by the use of appropriate technology (e.g., scanners, etc.) in order to be readily available for retrieval in a timely fashion.

- Work Control: The entire plant will operate under one master scheduling process. Efficiency will increase as a consequence of the identification and advance notification of tasks which rely on the other groups support. The integrated schedule will address both normal operation and outage periods. The entire site will have access to the schedule for planning and execution purposes. Schedule development, reviews, and approvals will be IMS based.

- Irending and analysis by all oroups: Individual work-stations provide access to the relational database containing all documents. The logs and trending information from all groups are available via the IMS. This provides up to date information for the System Engineering group and others to ensure optimum plant performance. The information is also be available in an time series (historical mode) for troubleshooting and compliance functions.

Labor arrangements at the plant (either non-union or union with appropriate working agreements) allow and support cross-training and working outside narrowly defined "normal disciplines".

- Training is performed on-site for all initial and requalification purposes and is provided by the normal training staff. Limited exceptions include specialty training which may either be given off-site or on-site with vendor instructors.

$\bullet$

Schedule changes or overtime is expected for situations such as critical path evolutions during planned outages, supporting forced outages, preventive or corrective maintenance of plant equipment affecting plant reliability or safety. This overtime, as well as that incurred through the normal shift rotation is accounted for in the "On-site Staff - Overtime, Supplemental" category of the O\&M estimate. 


\section{TABLFE.3.1-1 (Cont'd) STAEFINC ASBUMPTIONS}

-

-

$\bullet$

-

\section{FACILITIES}

These assumptions principally relate to the physical layout of the plant. These assumptions are necessary due to the state of the NRC Design Certification or because certain portions of the design are left to the option of the owner/operator.

- $\quad$ Fire protection is independent for each unit of a multiple unit site.

- One central warehouse location exists for either single or multiple unit sites. Satellite warehouses will be utilized, if necessary.

-

Machine shop and test equipment facilities will be shared for a multiple unit site. However, the tool rooms and inventories for normal maintenance will be separated for the units. Special maintenance tooling will be shared to the extent possible. INote: The Hot Machine Shop, Equipment Decontamination room, Instrumentation Calibration Shop, and Hot Tool Cribs are located in the Nuclear Annex of each unit.]

○

One full scope simulator is provided for one or two unit sites. Two simulators are provided for a four unit site. 


\section{TABLE 6.3.1-1 (Cont'd)}

\section{STAFFINC ASBUMPTIONS}

- A single security area is used for one and two unit sites. For a four units site, individual security fences separate the units and a common perimeter fence surrounds the site.

-

-

-

0

-

○

-

Advanced access control devices result in minimal failures and minimal compensatory measures for Security.

Individual security zones are established for spent and new fuel storage.

Each unit has separate lab facilities for Chemistry and Radiation Protection, except for common functions such as environmental, water treatment, etc. INote: Primary chemistry laboratories, the Counting Room, and Radiation Access Control Area are located in the Nuclear Annex of each unit.]

Each unit has separate Radwaste systems.

Each unit will have a separate control complex including the Control Room, Technical Support Center, and similar support areas.

Grounds and facility housekeeping and maintenance is contracted. This contract is accounted for under the "Supplies and Expenses-Fixed" category of the O\&M estimate.

Plant arrangement reduces the number of security doors and the reliance on locked doors. Also, improved security doors and video surveillance equipment is integrated into the design to reduce security staff.

New and spent fuel storage is contained in the nuclear annex. Additional security access will be required for this area. Security surveillance and access control is performed by on-site staff. No additional operations or maintenance personnel are required. 
Combustion Engineering, Inc.

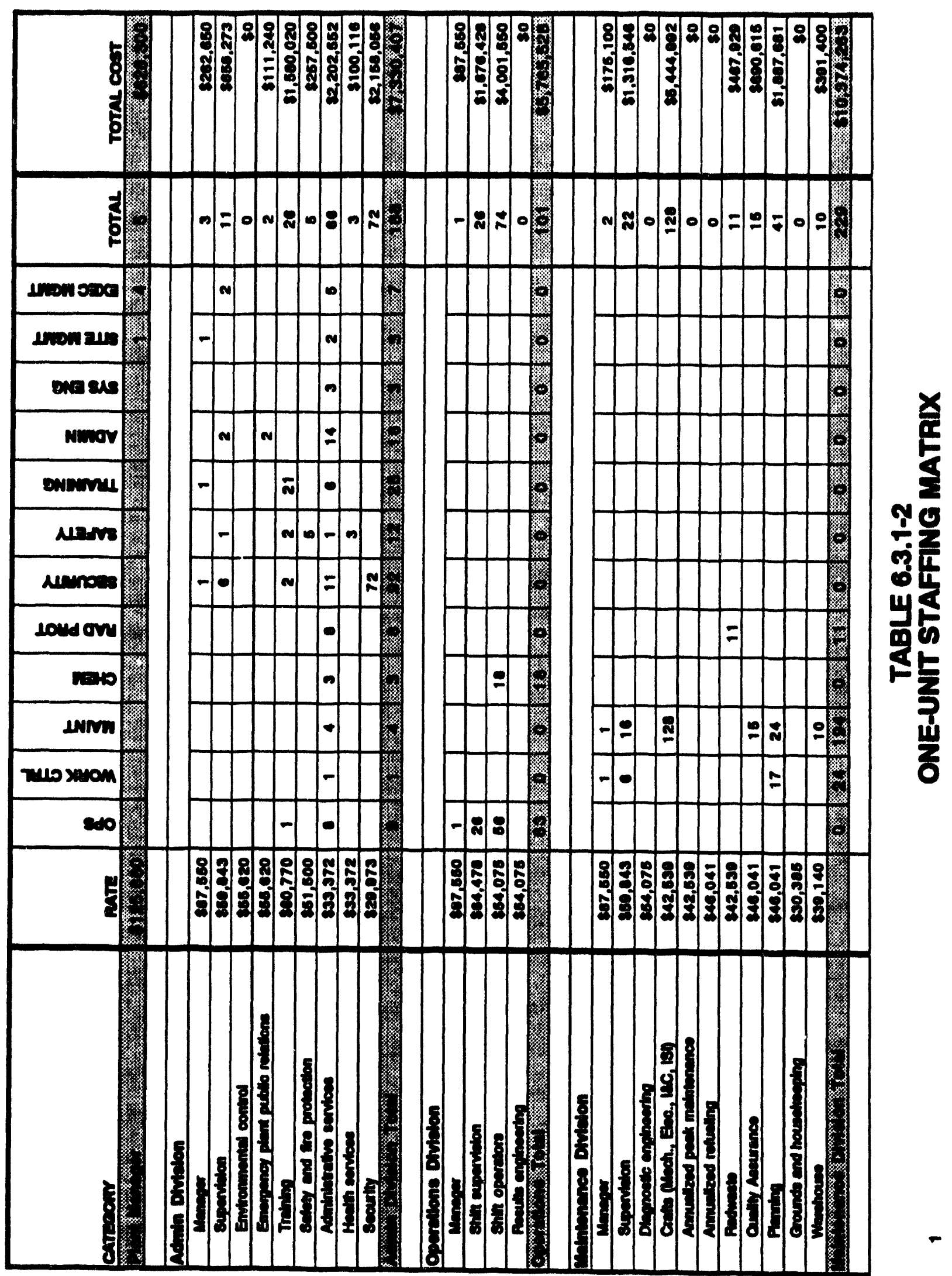




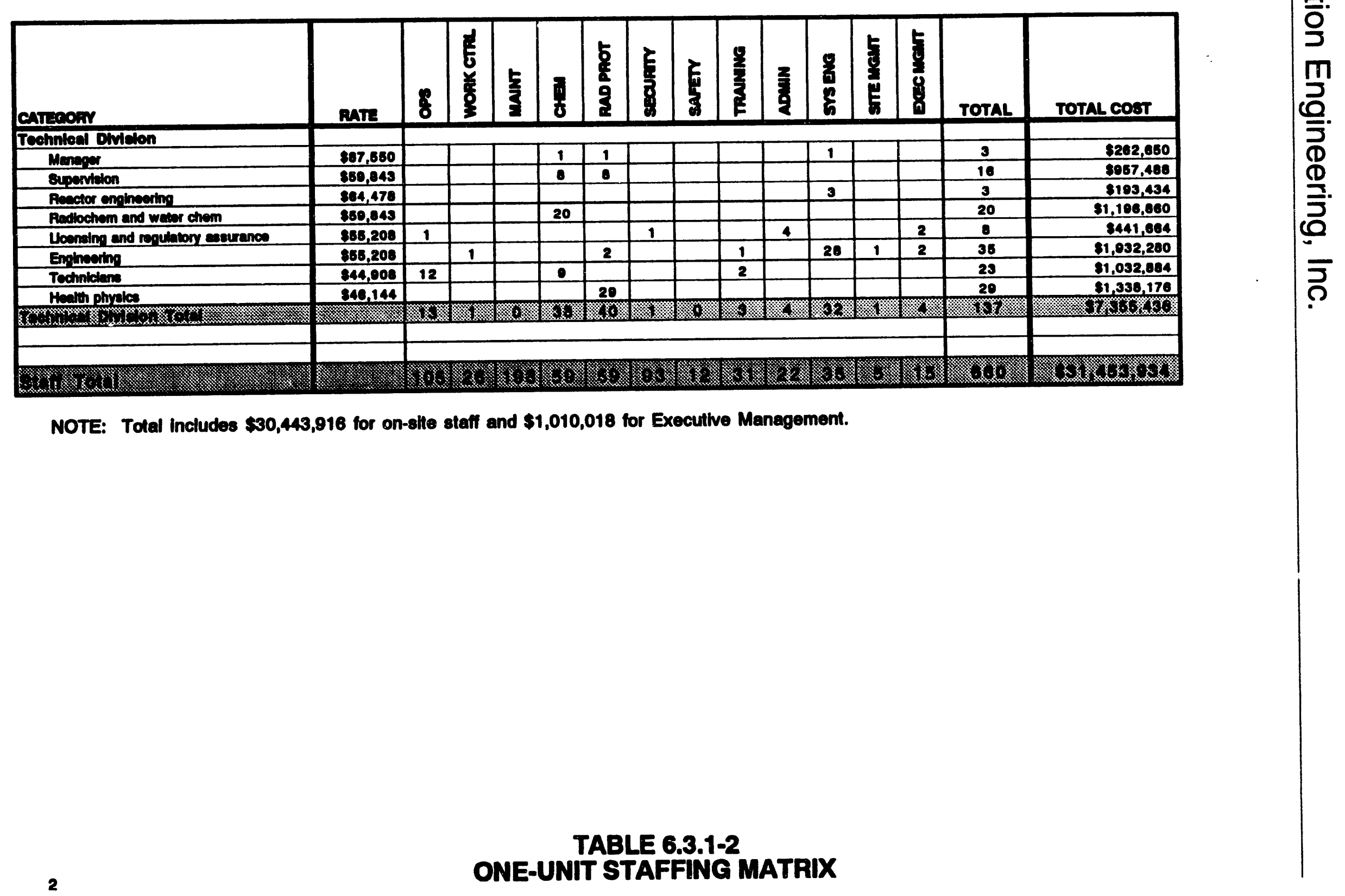


Combustion Engineering, Inc.

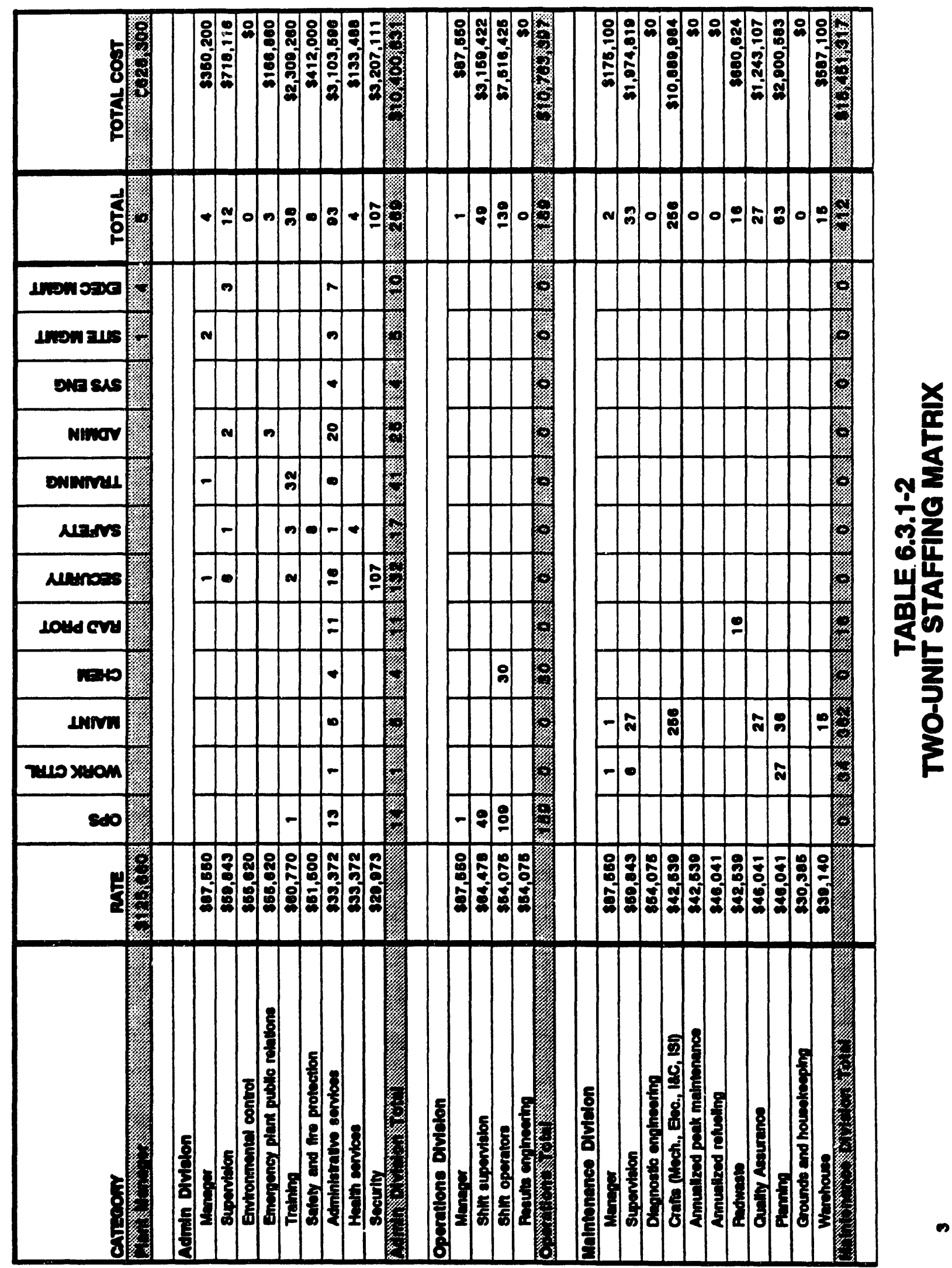




\begin{tabular}{|c|c|c|c|c|c|c|c|c|c|c|c|c|c|c|c|}
\hline call-somill & maTe & 8 & $\begin{array}{l}1 \\
\frac{1}{6} \\
\frac{1}{0} \\
0 \\
3\end{array}$ & $\frac{5}{3}$ & 8 & $\begin{array}{l}5 \\
\frac{5}{2} \\
9 \\
2\end{array}$ & $\frac{8}{8}$ & $\frac{5}{3}$ & 是 & $\frac{z}{\bar{z}}$ & $\begin{array}{l}0 \\
5 \\
5 \\
0\end{array}$ & $\frac{5}{5}$ & $\begin{array}{l}5 \\
\frac{5}{8} \\
8 \\
8 \\
8\end{array}$ & TOTAL & TOTAL COST \\
\hline \multicolumn{16}{|l|}{ Teetinleal Didcion } \\
\hline Maneres & 807.580 & & & & 1 & 1 & & & & & 1 & & & 3 & $\$ 262,650$ \\
\hline Superdition & 850,843 & & & & - & 2 & & & & & & & & 17 & $31,017,391$ \\
\hline Acector enpitreetions & 864,470 & & & & & & & & & & 4 & & & 4 & $\$ 257,012$ \\
\hline Redlochem and wefor chem & 350,049 & & & & 27 & & & & & & & & & 27 & $\$ 1,816,701$ \\
\hline Leeneler and ropratory coperences & 896,200 & 1 & & & & & 1 & & & 8 & & & 3 & 10 & 3582,000 \\
\hline Engheoeng & 865,200 & & 2 & & & 3 & & & 1 & & 42 & 1 & 3 & 82 & $\$ 2,070,018$ \\
\hline Tochniclene & 344,000 & 10 & & & 11 & & & & 2 & & & & & 31 & $\$ 1,302,140$ \\
\hline Heath phritas & 846,144 & & & & & 46 & & & & & & & & 48 & $\$ 2,122,624$ \\
\hline 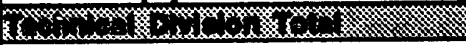 & $x$ & 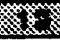 & -2 & 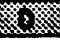 & 28 & Yry & 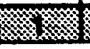 & $\$ 0$ & s & 䋞 & 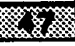 & 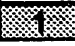 & ras & KTo & 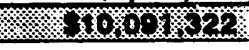 \\
\hline & & & & & & & & & & & & & & & \\
\hline $3 . .1$ & & $\$$ & 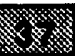 & $1 \%$ & $\therefore$ &. & 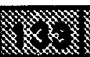 & 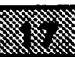 & $1 \leqslant$ & -3 & 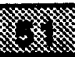 & 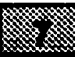 & (2) &  & $(1 \cdot 2 \times 1 \times 1)$ \\
\hline
\end{tabular}

NOTE: Total includes \$49,087,946 for on-site staff and \$1,247,021 for Executive Management. 







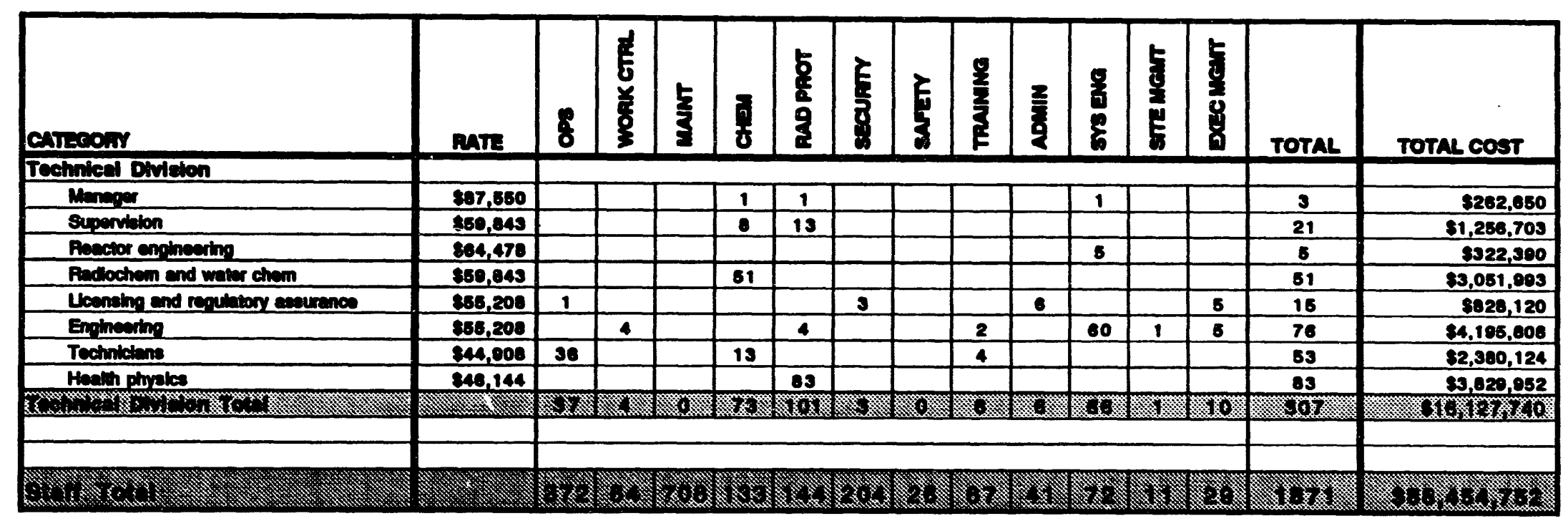

NOTE: Total inctudes \$86,767,097 for on-she staff and \$1,687,655 for Executive Management. 
Combustion Engineering, Inc.

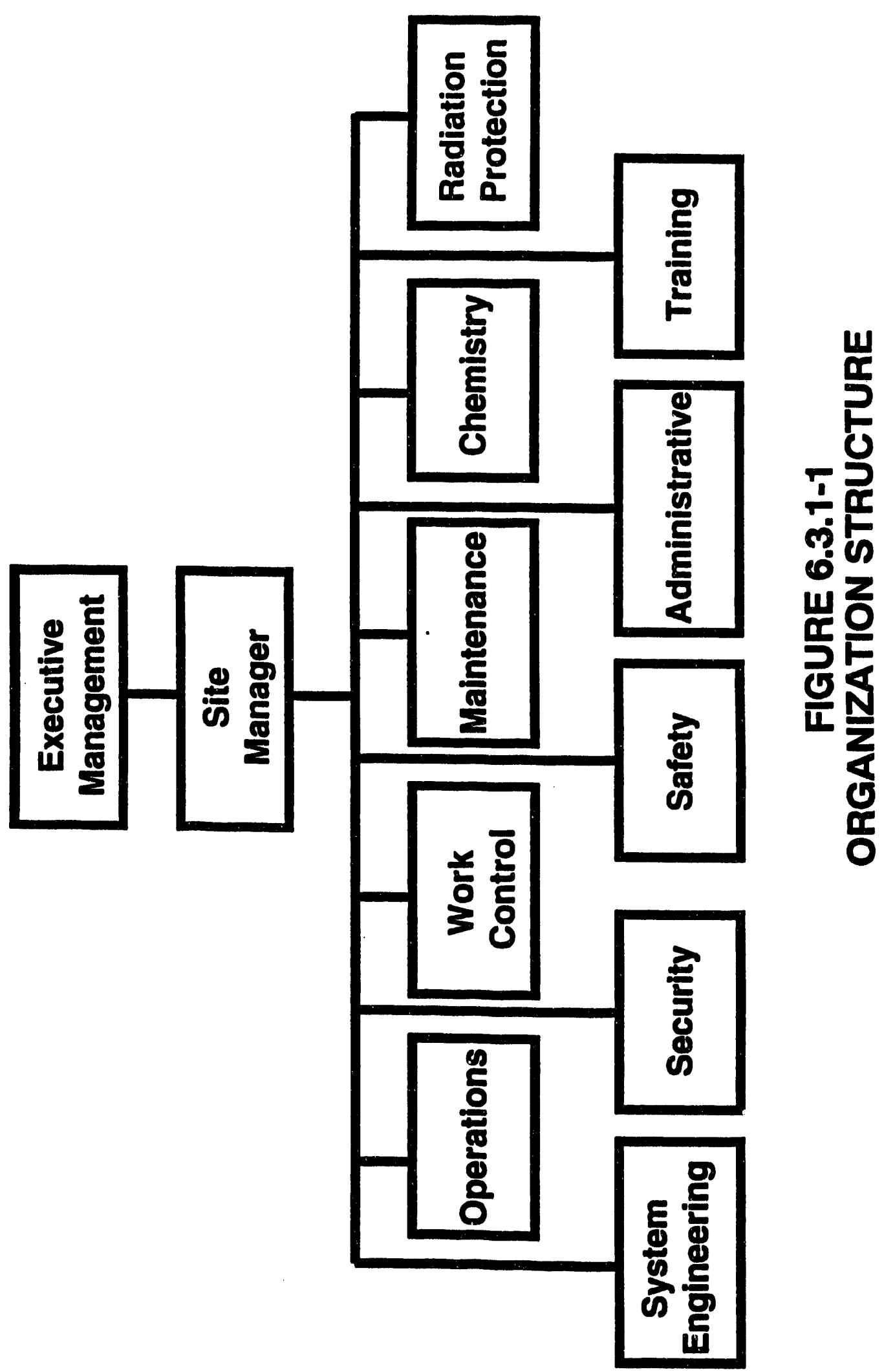




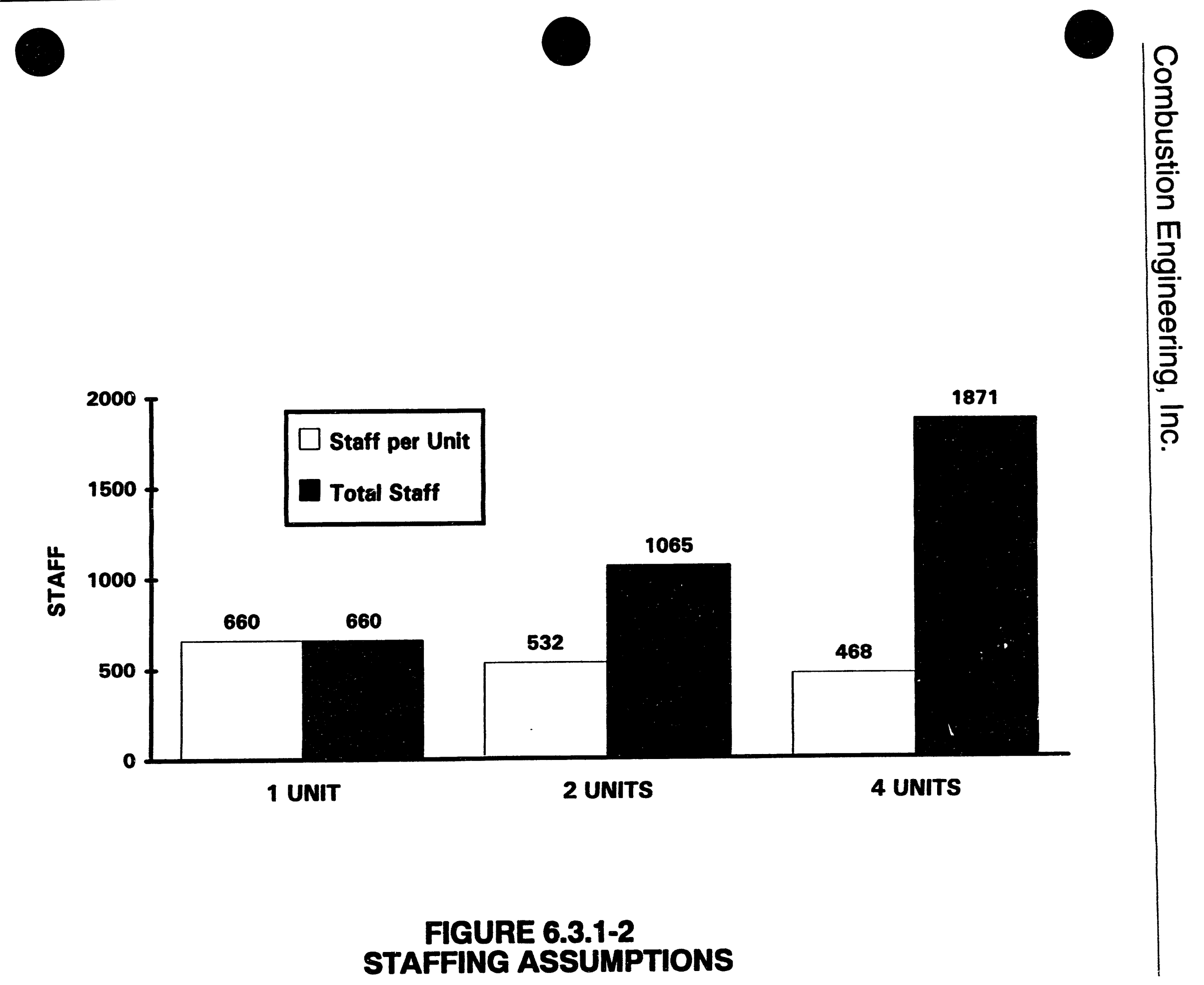




\subsubsection{Elements of O8M Cost}

Operating and Maintenance Costs (O\&M) are defined as the costs to operate and maintain the complex. This section of the report addresses power production from the Plutonium Disposition Reactor (PDR). The Requirements Document, Section 4.0, Information Requirements, Sections 4.5 and 4.5.1.3 identify the information requested for the Operating and Maintenance Cost portion of the Study.

The annual O\&M costs were developed using the Cost Estimate Guidelines for Advanced Reactors (CEG), May 1993 incorporating 1994 labor rates as per 1/20/94 revision. The annual O\&M cost estimates are shown on Table 6.3.2-1. Fuel costs are excluded from the O\&M estimates. Contract services costs (both outage and nonoutage related) are included in the annual O\&M estimate as described below.

Outage related costs (both contract and in-house labor, and outage related maintenance materials and supplies and expenses) are included in the annual O\&M estimate. The incremental (above the base level of effort) outage related costs are $\$ 3.73$ million per unit. These costs are associated with a defined (and limited) scope of outage work for turbine maintenance, head removal and assembly, valve maintenance, and steam generator inspection. All other routine outage related maintenance and testing activities are performed by the in-house staff.

Given a defined, limited scope of outage activities, the incremental outage costs will not increase if the outage duration increases. In fact, incremental outage costs may be decreased if the outage is extended without an increased work scope, since overtime labor costs could be reduced. However, since the objective is short outage durations and maximum electrical generation, overtime is accounted for in the estimate. Obviously, long outages would cause the production costs (\$/MWHR) to be worse (higher) due to less annual net electrical generation produced.

\section{On-site Staff}

The on-site staffing described in Section 6.3.1 was compared to the CEG position descriptions and salaries. The matrix shown on Table 6.3.1-2 was used to develop annual labor costs. An additional $10 \%$ was added for overtime, supplemental pay, etc., and an additional 10\% was added for social security tax and unemployment insurance premiums. More than half of the $10 \%$ assumed for overtime is incurred during the outage. The remaining overtime is incurred during normal operation which is consistent with current industry averages. Outage costs associated with on-site labor overtime are $\$ 1.76$ million per unit and are included in the $10 \%$ added for overtime.

\section{Maintenance Materials}

Maintenance materials are defined as material that is used in normal maintenance of the plant. Maintenance materials can either be variable or fixed costs. Fixed costs are 
costs or expenses that remain basically constant and do not vary with the level of output or operation over a short period. Variable costs are costs or expenses that increase or decrease along with increases in each station's level of output or operation. Fixed and variable costs are categorized by FERC accounts.

The fixed cost portion was estimated as $7 \%$ of on-site base salaries and the variable cost portion was estimated as $3 \%$ of on-site base salaries based on industry experience. The variable portion also includes outage related costs equal to $\$ 0.47$ million per unit.

\section{Supplies and Expenses}

Supplies and expenses consist of consumable material and other unrecoverable items such as make-up fluids, chemicals, gases, lubricants, office and personnel supplies and monitoring and record supplies, costs for on-site radioactive and non-radioactive waste management activities, and the cost for disposal of absorbers and other replaceable reflector or shield assemblies.

This category includes direct purchases, contracts, and employee expenses. Supplies and expenses can be either variable or fixed costs. Fixed costs are costs or expenses that remain basically constant and do not vary with the level of output or operation over a short period. Variable costs are costs or expenses that increase or decrease along with increases in each station's level of output or operation. Fixed and variable costs are categorized by FERC accounts.

The fixed cost portion was estimated as $28 \%$ of on-site base salaries and the variable cost portion was estimated as $14 \%$ of on-site base salaries. This methodology was based on industry experience. The variable portion also includes outage related contract services costs equal to $\$ 1.5$ million per unit.

\section{Off-site Technical Support}

Off-site technical support are activities by personnel not assigned full time to the plant site. Examples include safety reviews, off-site training, environmental monitoring, meteorological surveys, power planning, fuel studies, and other owner home office or contracted activities that directly support the plant.

The cost estimates for off-site technical support were calculated using the Executive Management base salaries plus $10 \%$ for overtime, supplemental pay, etc., and an additional $10 \%$ was added for social security and unemployment insurance premiums, as was done for the on-site labor calculation. This category also includes $\$ 0.66$ million per unit for miscellaneous contract support. 


\section{Nuclear Regulatory Fees}

Nuclear Regulatory Fees are NRC annual fees and review costs as well as other routine safety, environmental, and health physics inspections. Annual nuclear regulatory fees are estimated to be $\$ \mathbf{2 . 8}$ million per unit.

\section{Pensions and Benefits}

The total Administrative and General costs were also developed using the CEG. The pension and benefits account which includes workman's compensation insurance was estimated at $25 \%$ of the sum of on-site base salaries and off-site technical support (Executive Management) base salaries.

\section{Nuclear Insurance Premiums}

These costs are for commercial and government liability insurance, property damage insurance, and replacement power insurance. Estimates for annual premiums for nuclear plant insurance for advanced nuclear plants are based on estimates provided in Table 4.5 of the CEG.

\section{Other A\&G Expenses}

Other administrative and general expenses were estimated at $15 \%$ of the sum of onsite salaries and adders, maintenance materials, supplies and expenses, and off-site technical support costs (O\&M sub-total) as outlined in the CEG.

\section{Decontamination and Decommissioning (D\&.D)}

The estimation of D\&D costs has been and will likely to continue to be a subject of considerable uncertainty. Although the U.S. nuclear industry is striving for better estimates, the range of possible costs remains wide and is sensitive to numerous factors such as the regional costs for disposal of low-level wastes, site restoration and various state and local requirements.

In October 1993, the Nuclear Regulatory Commission issued NUREG/CR-5884, Vol. 1 and 2, Revised Analysis of Decommissioning for the Reference Pressurized Water Reactor Power Station, and a companion marual, NUREG/CR-6054, Estimating Pressurized Water Reactor Decommissioning Costs. The methodology of these documents requires a detailed and comprehensive set of input data in order to provide the cost estimate. Also, the degree of applicability to advanced LWR designs is not clear. In any case, the data requirements and level of detail ir not available to provide an estimate per the methodology NUREG/CR-6054.

It is important to note, as previous industry studies and publications have indicated, that commercial electricity prices are relatively insensitive even to large variations in 
D\&D costs. While the D\&D costs are significant, the overall PDR life costs should be relatively little affected by the realistic range of estimate. Therefore, for the purposes of this report, the ORNL CEG methodology has been used as described below.

The cost of decontamination utilized in this analysis was considered to be included in the decommissioning cost. The funding requirements were based on the CEG INRCbased equations) as shown below:

D\&D Cost (Millions \$) $=150+0.02(P-1200)$

where: $P=$ Unit Thermal power $(\mathrm{MWt})$ with a maximum value of $3400 \mathrm{MWt}$

$D \& D$ Cost $=150+0.02(3400-1200)$

D\&D Cost $=\$ 194$ Million per unit

The estimated cost of $\$ 194$ million for this methodology is thought to be conservative (i.e., the upper end of the range of realistic estimates).

\section{Operating Spares}

An effective maintenance program requires timely availability of parts, materials and services. The procurement process for each of the cases will ensure that parts, materials, and services are available when needed. In the development of the dollar values for component replacement and operating spares, the following aspects were considered:

Standardization of equipment to minimize inventory levels

Vendor recommended spare parts list

Spare parts lead time on a "just in time" delivery concept

Spare parts shelf life

Spare parts pricing

Potential development of cooperative stocking programs with vendors and other users

Utilization of industry standard equipment

The cost analysis was based on a recent ABB-CE study, industry data, and an assessment of the NSSS and turbine generator spare parts.

\section{Production Costs}

Production costs (\$/MWHR) were calculated using the Total Annual O\&M Costs described above, a net electrical generation of $1256 \mathrm{MWe}$ for the MOX reactor, and $1294 \mathrm{MWe}$ for the $\mathrm{UO}_{2}$ case, and a capacity factor of $75 \%$ for the base case and $87 \%$ 
for an additional case. The results of the calculation are shown in Table 6.3.2-2 below and in Figure 6.3.2-1.

\begin{tabular}{||l|l|l|l||}
\hline \multicolumn{4}{|c|}{ PRODUCTION COSTS (\$/MWH) } \\
\hline CF & 1 Unit & 2 Unit & 4 Unit \\
\hline $75 \%$ & $\$ 9.35$ & $\$ 7.54$ & $\$ 6.65$ \\
\hline $87 \%$ & $\$ 8.06$ & $\$ 6.50$ & $\$ 5.74$ \\
\hline
\end{tabular}

TABLE 6.3.2-2 
Combustion Engineering, Inc.

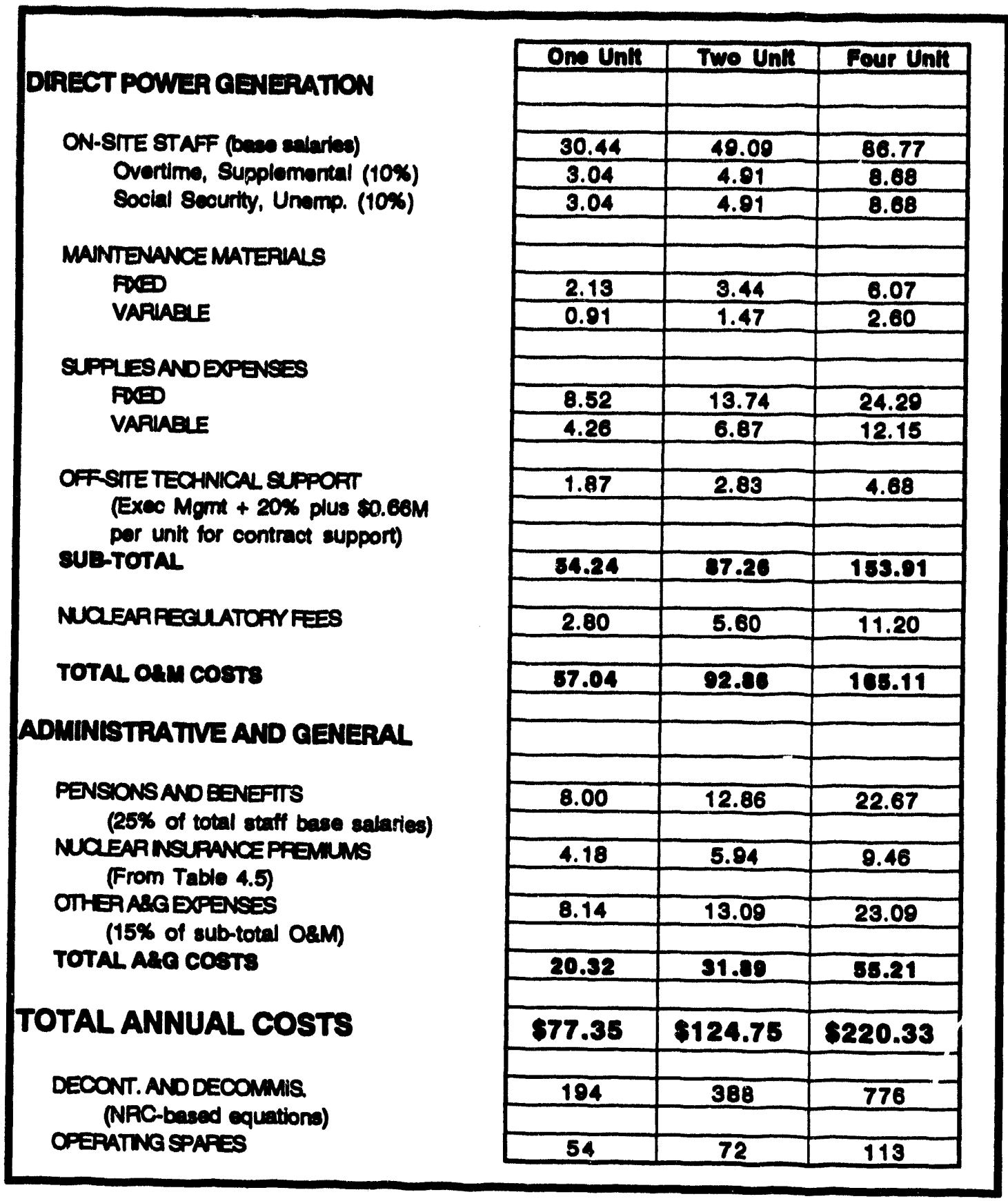






FIGURE 6.3.2-1

PRODUCTION COSTS (\$/ MWHR) VS CAPACITY FACTOR 


\subsection{Other Life Cycle Cost Detail}

\section{Revenue}

\section{Decontamination and Decommissioning}

Decontamination and decommissioning costs have been included. These costs were calculated based on $10 \%$ of capital costs.

\section{Capital linprovements.}

The estimate includes $\$ 8$ million per year per System $80+$ complex for Capital Improvements. This estimate reflects an engineering assessment of anticipated costs and is based on the assumption the no significant plant modifications will be required.

\section{Euel Costs}

The initial operation of the complex will utilize fuel fabricated by the MOX plant. During this period of operation only MOX plant operating and maintenance costs will be experienced. However, due to the extended life of the System $80+$ complex and the capability to dispose of plutonium in a relatively short period of time, plant life extends beyond the plutonium disposition mission. At the conclusion of that mission a switch to LEU fuel will take place for the remainder of the plant life. LEU fuel costs have been included at 6 mills per kwhr which includes 1 mill per kwhr for ultimate spent fuel disposal.

\section{Sensitivity}

As part of the System 80 + estimating effort an assessment of selected life cycle cost components in terms of cost sensitivity was conducted. The cost components assessed were as follows:

- Plant Capacity

- Capital Costs

- Operating \& Maintenance Costs

- Life of Plant

The sensitivity analysis was on a constant dollar basis and was conducted by varying the value of the different cost components and determining the resulting impact on plant life cycle costs. The components of cost selected were those having the most significant impact which can be controlled. It is recognized that other elements could have significant cost impacts. However, since they are typically subject to outside influences they were not assessed. Those cost components would include the following: 


\section{Combustion Engineering, Inc.}

- Construction Schedule

- LEU Fuel Costs

- Discount Rate

Figure 6.4-1 reflects the sensitivity of the specified cost components relative to plant life cycle costs. As indicated, capacity has the most significant effect of costs. Capacity is followed by plant life, capital costs and finally, O\&M costs. The relatively low sensitivity of O\&M costs is attributable to the discounting that takes place over the life of the plant. 


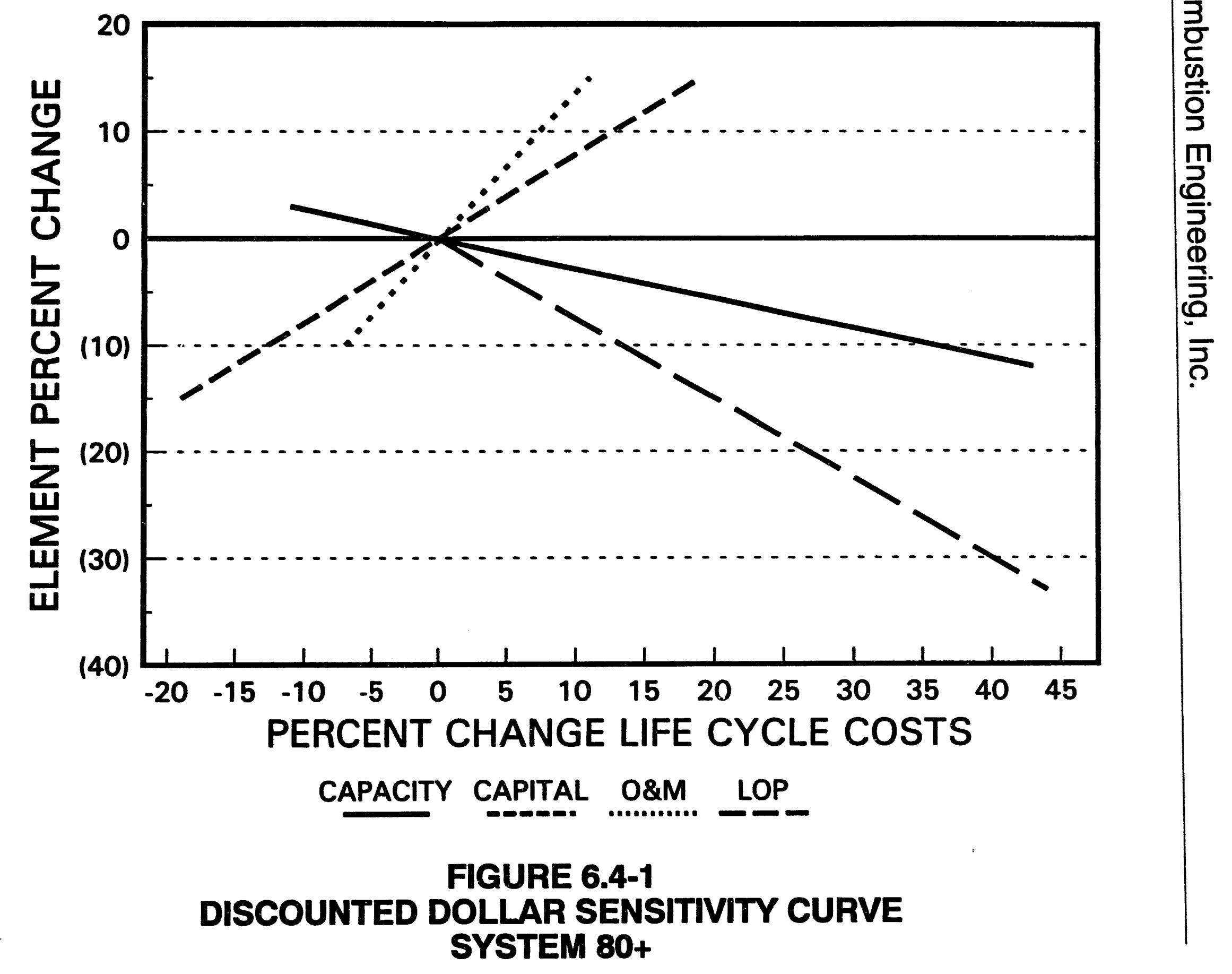




\subsection{Anticipated Cost Risks}

\section{MOX FueL Facility $\left(\mathrm{ME}^{2}\right)$}

The capital cost of the $\mathrm{MF}^{2}$ reflected in the various deployment options was based on a combination of escalating previous studies, review of the literature of non-US plants, and scaling for the required capacity. At this time only limited engineering has been accomplished in defining the scope and complexity of the facility. The estimates presented are considered sufficiently accurate for purposes of the plutonium disposition mission and reasonably portray cost comparisons. However, the estimates would be further detailed as the scope of the Fuel Fabrication Facility was further defined.

\section{Decontamination and Decommissioning}

Allowances for decontamination and decommissioning of both the System $80+$ complex and $\mathrm{MF}^{2}$ have been included in our assessments. Since only limited decontamination and decommissioning actual cost information is available, our estimates were based on parametric studies.. These estimates would be further defined as a project decommissioning plan was developed.

It should be noted that System $80+$ was designed with decommissioning being considered. The design minimizes such costs by minimizing radiation hazards through either improved decontamination or easier disassembly, additional remotely operated machinery or movable shielding and reduced demolition effort. Key features considered in the design to support decommissioning include the following:

- Low Leakage Fuel

- Accessibility

- Surface Finishes and Material Selection

- Improved Documentation

\subsection{Base Schedule}

The Project Summary Network (PSN) for a "green field" deployment option is presented as Figure 6.6-1. The PSN is a schedule of major activities at the total project level that displays the significant project stages and interdependencies, and identifies key events and milestones. The main work groups of Licensing, Engineering and Procurement, Construction and Fuel Fabrication Facility are depicted.

The Project Summary Network is not site specific but representative of a generic site. Requirements for a specific site would appear on detailed schedules but would not impact the total project duration.

In the case of System $80+$, the Project Summary Network is supported by detailed schedules prepared for other initiatives. Detailed activities reflected on those schedules 
have been vertically integrated with the PSN. Engineering activities are scheduled such that design and procurements are accomplished in sufficient time to support construction. Construction has a duration of $\mathbf{4 8}$ months from first concrete to fuel load. The schedule allows six months for initial operations prior to commercial operation. Although aggressive, the schedule is achievable and consistent with a recently submitted proposal.

The critical path flows through the nuclear island, sphere and reactor shield building. However, a second critical path exists through the Fuel Fabrication Facility.

The PSN shows a total project duration of $\mathbf{8 0}$ months from authorization to first unit operation. Subsequent units are placed in operation at 12 month intervals for the four-unit case, and for the two-unit case, a two year delay between the units is planned. This should provide a levelizing of the construction force requirements while fulfilling the appropriate mission.

The MOX Fuel Facility $\left(\mathrm{MF}^{2}\right)$ schedule reflects 57 months from contract initiation to the start of fuel fabrication. This allows 18 months for SAR submittal, 9 months for NRC review, and 36 months for construction. 


\section{Combustion Engineering, Inc.}

THE FIGURE LISTED BELOW, AS CALLED OUT WITHIN PARAGRAPH 6.6, IS OVERSIZED AND IS PACKAGED IN A SEPARATE ENVELOPE ELSEWHERE IN THE REPORT

FIGURE 6.6-1

PROJECT SUMMARY NETWORK 


\section{Combustion Engineering, Inc.}

\subsection{Anticipated Schedule Risks}

\subsubsection{MOX Fuel Facility}

Since 10 CFR 70.21 (f) requires that an application for a fuel fabrication license be filed at least 9 months prior to commencement of construction, 9 months was used for the time between application submittal and construction start.

Therefore, if licensing extends past 9 months, there is a possibility of impacting the fuel load dates. However, since the government policy on using MOX fuel would have been settled outside the licensing process, the risk to exceeding the 9 months is considered low.

\subsection{Incremental Tritium Related Cost}

If a tritium production mission is desired, incremental development, capital, and operating costs will be incurred to DOE for this mission. These costs are associated with the completion of the Tritium Target Development Program (TTDP) and siting, construction, and operation of target fabrication and tritium extraction facilities.

The costs of completing the TTDP are estimated in detail in Section 9.1. The completion of the TTDP would include target qualification as well as extraction facility development work. The estimated cost of completion is approximately $\$ 53 \mathrm{M}$.

The additional costs for the construction and operation of the target fabrication and tritium extraction facilities are also detailed in Section 9.1. Costs include capital costs as well as manpower estimates for operation of the facilities, however, the information in Section 9.1 assumes the use of existing facilities. For new facilities, the total capital cost is estimated to be $\$ 245 \mathrm{M}$. Operating cost of the facility will approach $\$ 10 \mathrm{M}$ per year.

\subsection{Other Deployments}

\subsubsection{Plutonium Fabrication Capability Currently Available}

In order to provide fuel from the MOX fuel qualification program, it will be necessary to fabricate some prototypical fuel pins before the availability of the onsite MFF. An investigation was conducted to locate a plutonium oxide capability that could:

a) Reduce the metal pits to oxide powder.

b) Purify the Pu as required.

c) Make mixed oxide fuel pellets to specification.

d) Assemble the pellets into 4-foot long fuel pins using clad and welding equipment supplied by the ABB-CE factory at Hematite, MO. 
A visit was made to Hematite to determine their support for the test fuel. Battelle supplied descriptions of the FMEF at Hanford and their knowledge of this facility obviated the need to inspect it. We visited the TA-55 Area at Los Alamos. The Reactor and Pu Areas at Savannah River Site (SRS) (also the Tritium Area) and the Agnes Reprocessing Plant. The following paragraphs summarize the existing capabilities.

\section{IA-55 at Los Alamos}

A complete glove box fabrication live is available and operational for making test reactor pins. There is a limit on the length of pin TA-55 can produce - about 6 to 8 feet long. Extending the final glove box to handle Lead Test Assembly Pins would not be difficult. The production and purification of $\mathrm{Pu}$ oxide powder can be done. Purification to remove Am-241 is relatively simple and can be done in combination with the reduction of the metal pit to oxide powder. Purification of the pit by the removal of gallium and the other trace impurities from the pit is available if required.

The big disadvantage of TA-55 is its current limited throughput, about 4 tons of fuel a year without a major revamping of the facility. The infrastructure is available and quite good. If fabrication problems occur this is the ideal research facility in which to develop "fixes".

\section{SRS}

The Pu area is essentially deactivated. Equipment is still in the facility but the staff and supporting infrastructure are being deactivated. The equipment is not suited to fabrication of test reactor fuel pins.

\section{EMEA}

Equipment for fabrication of fuel pins is present (both test reactor and prototypical fuel elements could be made). However, the infrastructure is no longer viable.

\section{Agnes Reprocessing Plant}

The plant has been decommissioned and some of the equipment diverted to other uses. It is no longer viable for any use except possibly long term pool storage of spent fuel.

\subsubsection{Develepment Recommendations}

Based on our initial assessments, the opportunity to use existing U.S. facilities for MOX fuel fabrication is extremely limited. The SRS, FMEF, and AGNS facilities are not considered to be viable for this application. There is a potential at the TA-55 area at Los Alamos, based on an existing process and a currently operating facility. Major facility modifications would be required, however, to meet the Pu disposition mission 
requirements. The expansion of this facility is not likely to be economically justified when compared to the cost of a new facility, dedicated to the mission.

\subsubsection{Test Program}

To form a reasonable estimate of the annual throughput requirement for an onsite $\mathrm{MF}^{2}$ plant, several assumptions were made to enable a specific quantity estimate. These assumptions are composed of schedule and fuel element test program postulates based on the combined experience of CE, BMI, and Ebasco. They are presented here as the framework of the fuel program strategy prepared in detail by BMI.

1. Before the NRC can issue a construction permit for the reactor site, they will require some experimental proof that the MOX fuel process will yield a fuel pin mixture of oxides of Pu, $U$, and Er clad in the System 80 + cladding, will survive an in-service exposure of design life with acceptable integrity.

2. To produce this experimental evidence, there must be a facility in which to make $\mathrm{Pu}$ fuel pins prior to the site facility becoming available.

3. A detailed investigation of sites available was made using the following selection criteria:

a. It must be a DOE owned facility located at a national laboratory having a current or recently terminated Pu authorization.

In arriving at this criteria, the CE fuel fabrication facility at Hematite MO was ruled out. Hematite can supply much of the material required for experimental pin fabrication but they cannot operate with $\mathrm{Pu}$ under their current license. Hematite is considered as the source of depleted $\mathrm{UO}_{2}$ and $\mathrm{E}_{2} \mathrm{O}_{2}$ powders, System $80+$ fuel pin cladding and welding equipment and fuel pin specifications for the MOX fuel. Our visit and discussio was fully supportive of a fuel pin design capable of use with MOX being produced with these input elements.

b. It must be capable of producing test fuel pins and/or lead test assemblies with existing equipment and infrastructure.

c. It must have a demonstrated history of operation with Pu materials.

d. It must have an availability that corresponds with the proposed fuel testing schedule.

e. It must have a throughput capacity of producing the initial core loading in a reasonable time period. 
f. It must have an infrastructure available for Pu operation that will not burden the fabrication cost with an unreasonable high overhead.

g. It must have a Quality Assurance Pro, ram in place that is capable of servicing the fuel fabrication program.

h. It must have a staff qualified to produce experimental fuel pins and assemblies.

A list of potential facilities was developed and evaluated against these criteria both by inspection of documents, conversations with the site personnel and visics by the team to the most promising locations after their initial screening. The sites selected for evaluation were:

1. The FMEF at Hanford

2. The Pu fabrication area at SRP

3. The TA-55 area at Los Alamos

4. The Hematite, MO, Fuel Factory of ABB-CE

5. The Fuel Restoration Facility at INEL

6. The Pu fabrication facilities at Lawrence-Livermore

7. The Agnes facility at Barnwell

The result of this evaluation is that the test reactor fuel pins should be made in the TA55 glove boxes at Los Alamos. Metal pits will be converted to Pu oxide. The oxide powder will then be blended with depleted uranium oxide and erbium oxide supplied by the ABB-CE plant at Hematite. This mixture will be made into pellets using a specification supplied by BMI and ABB-CE. The pellets will encapsulate using fuel cladding and welding equipment from Hematite. The existing radio-logical support and quality assurance staff will support this effort. The existing hot cell facilities can furnish fuel pins suitable for ATR testing both in length and quantity lless than 4 feed in length and an estimated 20 pins).

Production of Lead Test Assembly (LTA) and the production of a first core cannot be done at Los Alamos with the existing equipment. The choice for doing this work is between a modification of TA-55 where the staff, technology and infrastructure is in place but equipment would require augmentation and the FMEF at Hanford where the equipment is still in place but the infrastructure no longer exists. 


\subsection{SAFEGUARDS AND SECURITY}

The safeguards and security requirements for the fuel fabrication, nuclear reactor and new fuel storage facility being considered under the Plutonium Disposition Study will be different from the existing commercial light water reactor facilities. Most of these requirements will impact the fuel fabrication facility, where the presence of small quantities of materials containing weapons-grade plutonium may be considered as a threat to diversion. The use of weapons grade plutonium in the reactor fuel adds a number of new safeguards and security requirements as well as the additional safety requirements to protect the workers due to the toxicity of the plutonium. The amount of special nuclear material (SNM) required to qualify the material as category 1 , per DOE order 5633.3A is six kilograms of weapons grade plutonium 239 in comparison to the 20 kilograms for uranium 235 for oxide type materials. This will require tighter material controls and a proven accountability methods to prevent theft or diversion of the category 1 material.

Since any facility that will be used for plutonium disposition is expected to be licensed by the Nuclear Regulatory Commission (NRC), the facility will have to meet the applicable safeguards and security portions of 10 CFR 70, 72, 73, 74 and possibly 75 and 95. Facilities that are used for plutonium will be DOE facilities, and will also have the meet the requirements of DOE orders 5633 and the 5632 series. Where these two sets of requirements conflict, the most restrictive requirement will be used. This will ensure that all minimum safeguards and security requirements are met.

\subsection{Security}

Physical protection will be designed to protect the $\mathrm{MF}^{2}$ and System $80+$ plant from both insider and outsider threats to the fullest extent possible. Systems will provide protection from sabotage (both industrial and radiological), espionage, theft or diversion of SNM, loss or theft of classified material or government property, and other hostile acts. The physical security system to be installed at the site includes technological detection, control, and containment measures as well as protection methodologies and procedures, that apply to the protective forces and security programs.

Procedures and protective measures regarding emergency situations, i.e., fires, contamination, or other emergencies, are not considered part of this physical protection system. These requirements are addressed in emergency management procedures and operations.

All matters concerning physical protection will be handled according to the Site Safeguards and Security Plan (SSSP).

The physical protection system consists of a series of sub-sysizms (i.e., access control, barrier denial, isolation zone, intrusion dietection, assessment, communication, 
SNM detection, x-ray, security posts and response forcel. To ensure the concept of "defense-in-depth" the sub-systems will provide concentric lines of defense.

The main and auxiliary power sources will be located in secure buildings which preclude easy access. Computer facilities will be protected through a series of security systems and procedures.

\subsubsection{Deley and Denial Systems}

Physical barriers will be used to deny or delay unauthorized access to security areas. The barrier used will facilitaie effective and economical use of protective personnel and direct the flow of personnel and vehicular traffic through designated portals in a manner which permits efficient operation of personnel identification and control systems.

Delay and denial pertaining to key security interests at the facility will be accomplished through a system of barriers and access control points to deter and neutralize sabotage and contain thefts. The facility will use a variety of passive and active barriers that will include fences, buildings with locked doors, vaults, secure repositories, expanded metal cages, and cold smoke or other obscurants.

A vulnerabilicy analysis will be conducted. This analysis will identify any weak points in denying or delaying an adversarial attempt to reach their target. The analysis will also provide supplemental information regarding DOE threats, used to complement the Physical Protection Plan, and mitigate identified vulnerabilities.

\subsubsection{Delay Time}

The DOE Site Operations Office and the Site Guard Force (SGF) will determine the delay time to be provided by physical barriers and other delay mechanisms. The delay time is determined by considering the actions adversaries would have to perform to complete their mission. In determining the delay provided by the barriers, all credible modes of penetration available to a threat guidance level adversary force should be considered. A spectrum of adversary scenarios is considered to assure that barriers provide adequate delay to all credible modes of attack. Actions that a well-placed insider could take to circumvent delay barriers are considered. The delay time calculated for the barriers starts at the first reliable layer of detection. For containment strategies, the time required to locate and obtain the target SNM is considered, including the time for any special actions the adversaries would have to perform to accomplish their mission. For sabotage targets, the time required for adversaries to perform any special actions inside the security area is considered. For each potential target, it must be clear whether a denial or containment strategy is appropriate. 


\subsubsection{Entry Control Syatems (ECS)}

The ECS will consist of badge readers, automated entry control, search procedures, metal detectors, SNM detectors, $x$-ray machines and explosive detectors. Personnel ECS will use a combination of credentials, biometrics, and coded devices. The ECS will provide for emergency safeguards, and communications between security personnel, vehicles and posts.

\subsubsection{Protegtive Force Support}

The protective force for the PBRF is expected to be supplied by the site. Contingency response plans will provide actions to be taken in the event of a security or other emergency-related incident. These plans will include the support of local law enforcement agencies in any areas of shared responsibility.

\subsubsection{Detection and Assessment Systems}

The SGF will provide detection and assessment capability for all security boundaries and areas required by DOE Orders. The Intrusion Detection System (IDS) provides assurance that: 1) breaches of security boundaries are detected; 2) there is timely detection of unauthorized access attempts; and 3) information regarding adversary movement toward the target is provided to the SGF, where appropriate.

\subsubsection{Intrusion Detection System}

The Intrusion Detection System will have an uninterruptible power supply (UPS), and consist of guards, electronic intrusion alarms with exterior perimeter sensors, interior sensors, tamper protection, balanced magnetic switches, and alarm processing and display equipment, CCTV cameras and monitors, and perimeter lighting. CCTV cameras and alarm coverage will provide coverage of the yard between fences and be capable of detecting persons tampering with external equipment valves, ducts, etc., and an assessment of outside doors.

Exterior sensors provide assurance that a person crossing the perimeter will be detected at any point in the detection zone. Sensor systems will cover the entire perimeter. The IDS will detect any barrier penetration attempts at locations other than the designated entry point.

Any intrusion will activate the alarms and the situation will be assessed by the SGF using CCTV which will automatically display and record events. The assessment will expedite an appropriate response by the SGF. The Intrusion Detection System will be operated and maintained so the false alarm rate does not result in a degraded response. 
Doors to vaults and vault-type rooms used to store Category I or II quantities of SNM will be protected with a DOE approved intrusion alarm systems sufficient to defect unauthorized intrusion.

Unoccupied rooms or buildings within a Vital Area containing vital equipment will be equipped with a DOE approved intrusion alarm system or other equally effective means of detection approved by the DOE Field Office.

\subsubsection{Acases Control System}

Access will be controlled by using a distribution system operated by the SGF. All screening operations and access will be controlled by a microcomputer located near the controlled door. If communication with the central computer is lost, the microcomputer can control the door in a degraded mode using its memory, permitting operation to continue. Most routine portal control transactions will be automatic and will not involve the SGF operator.

The central computer can produce a printout of transactions to assist in investigation of personnel movements, providing a deterrent to covert activity. Software will be available to operate all types of security doors in use at the facility. Additional types of doors can be accommodated by providing more software modules, provided the input/output capabilities are respected. For some type of security doors, different levels of locking can be readily programmed for operation during "normal mode" security status.

\subsubsection{Closed Cirauit Television System (CCTV)}

The Perimeter Intrusion Detection and Assessment System (PIDAS) will be equipped with a fixed camera on a pole or tower for each view required to cover each detection zone individually. When detection sensors are stimulated, the camera view assessing the vicinity of those sensors will be automatically displayed and a period of view time starting immediately will be electronically recorded for playback as required by the SGF operator. The operator can review this recording of happenings which occurred before he could concentrate on the live view. Several additional camera views can be selected manually for display on additional monitors.

Lighting at the PIDAS will be designed to meet DOE requirements for CCTV cameras with infrared capabilities, will be partially backed up by UPS (battery) and totally backed up by the dedicated emergency generator. Controlled doors, egress only doors, and spaces of particular interest will be covered by CCTV cameras. 

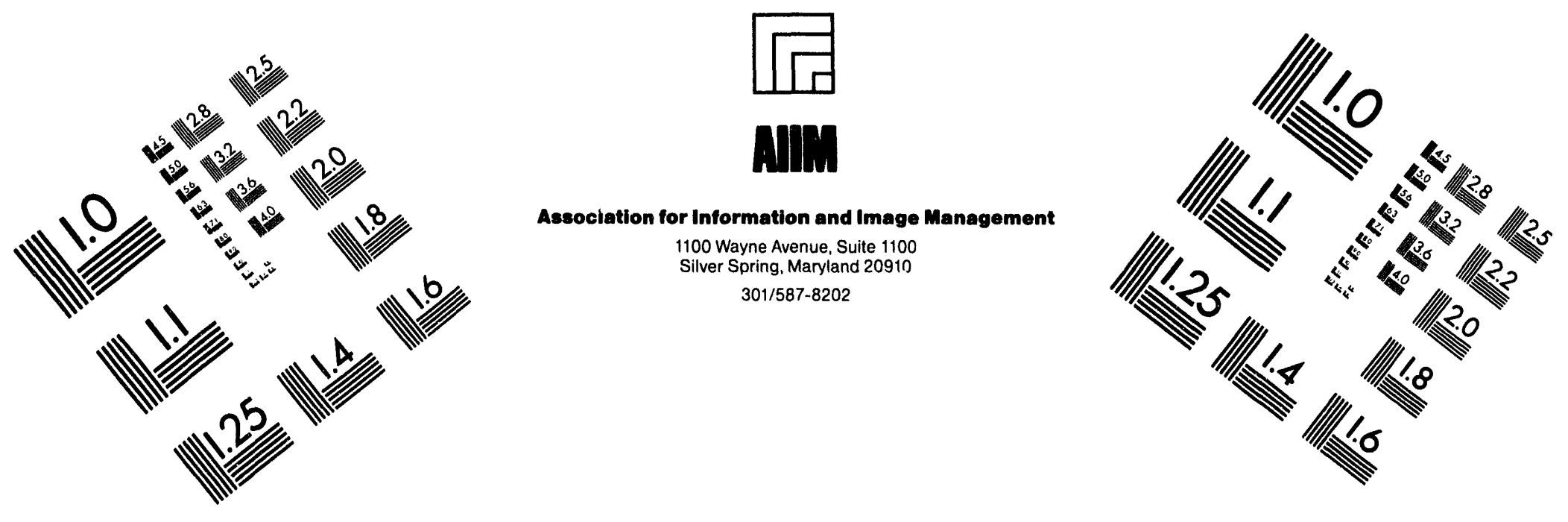

\section{Centimeter}

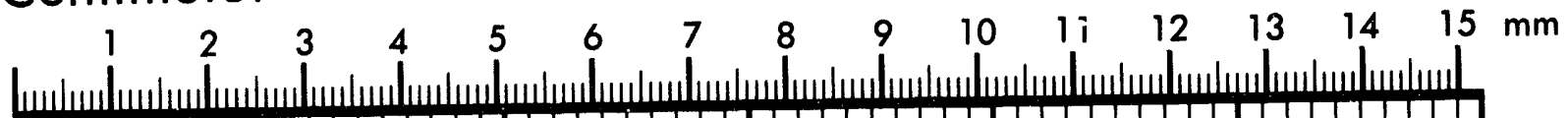

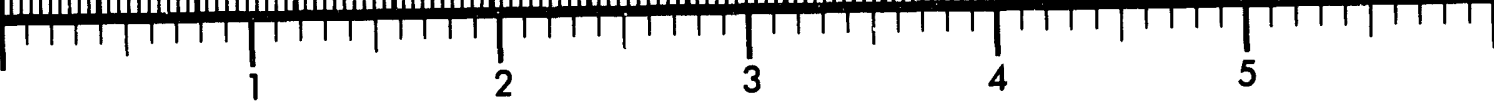
Inches

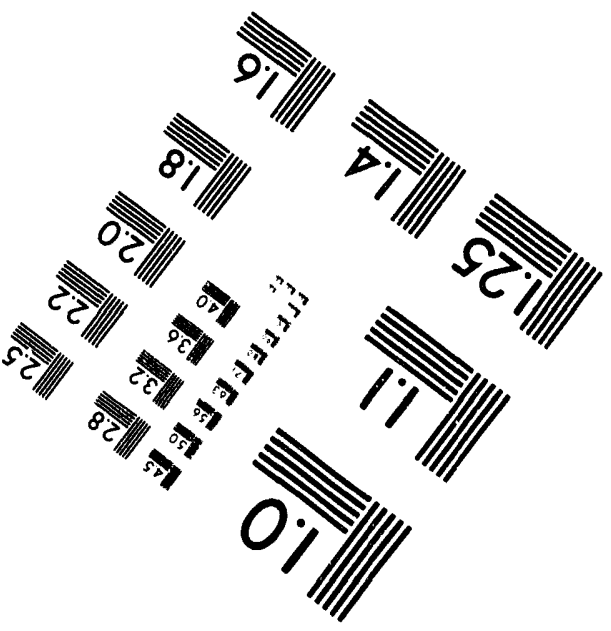

MANUFACTURED TO AIIM STANDARDS

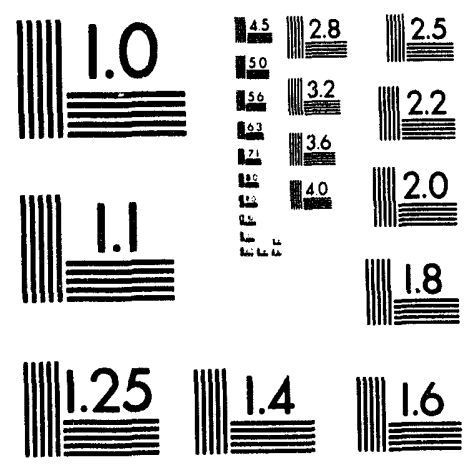

BY APPLIED IMAGE. INC.

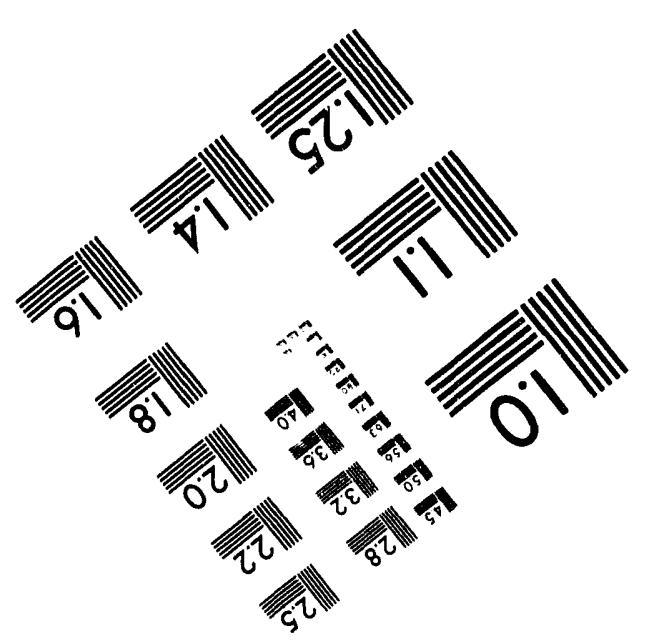



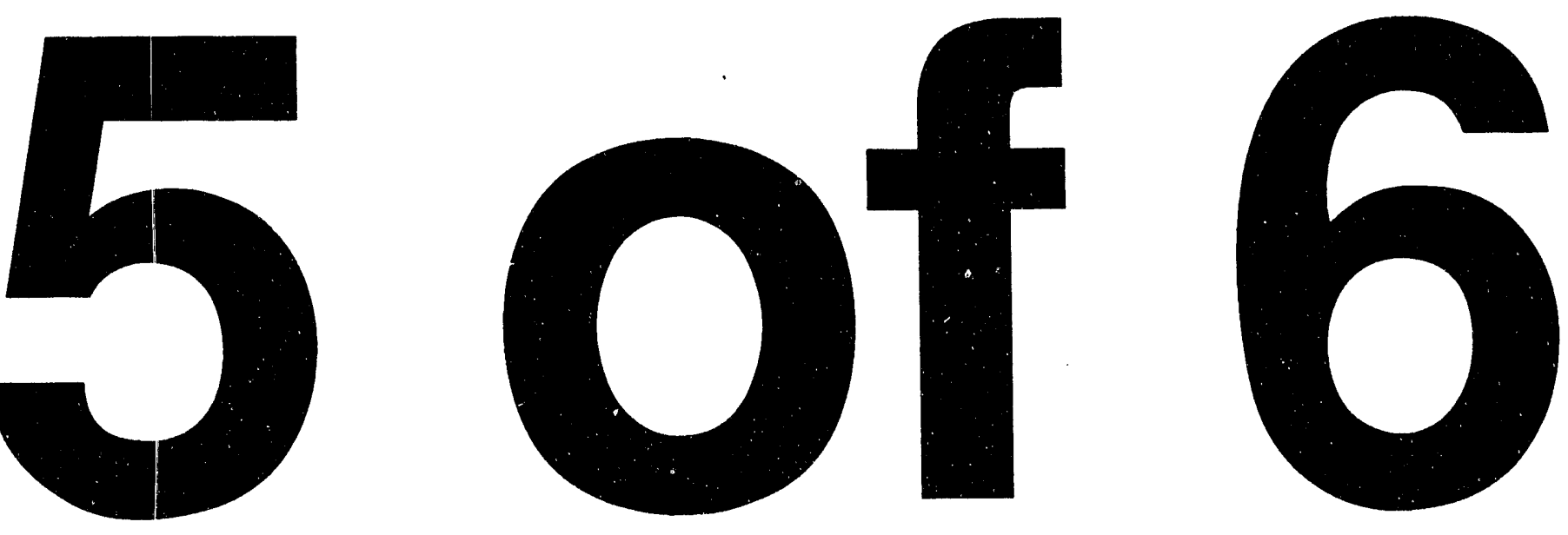
A camera interface panel (CIP) will convert electronic signals from one or two nearby cameras to fiber optic light signals for transmission to the CAS. Other important system components will be an electronic video switcher and the electronic instant replay VCR. The CCTV system will have tamper alarms and loss of video alarms in the CAS.

\subsubsection{Communications System}

The communications system must allow rapid, reliable, and protected information exchange between on-site protective forces and the CAS/SAS, and between the CAS/SAS and local law enforcement agencies. SGF at fixed posts will have both normal telephone services and two-way communications with alternate positions from which backup forces can be dispatched. Security personnel at mobile and fixed posts will be provided with duress capabilities. All security personnel must be able to communicate directly with all other security personnel, posts, and vehicles, whether inside or outside of PBRF buildings. Special Response Teams will be provided with voice privacy or digital encryption two-way radio communications which meet the requirements of DOE Order 5300.3B, Telecommunications: Communications Security. Communications systems will be tested daily.

\subsubsection{Portal Control Unit}

A Portal Control Unit will control doors or groups of doors called a portal. Each portal configuration is called a "Portal Type" and will be supported by software specific to that type. This control device, located on the protected side of the door or in another hardened area, can act alone in a degraded mode if necessary.

\subsubsection{Security Areas}

\subsubsection{Limited Areas (LA)}

The LA will be surrounded by chain-link security fence capable of deterring access to the PBRF. Entrances and exits will be controlled by the SGF. Only appropriately badged persons will be allowed access, and random searches will be performed on persons entering and exiting the area. Radiation detection monitors will be available for emergency procedures. No civilian vehicles will be allowed in the LA, except under approved conditions. Procedures for emergency vehicles are written by the Emergency Management Office and the SGF.

\subsubsection{Protected Areas (PA)}

The PBRF PA will be encompassed by chain-link security fence with extended barb-wire outriggers. Isolation zones will be established at the outer boundary of the PA. A clearance of at least 30 feet will be maintained between the isolation zone fence lines. A minimum of 20 feet will separate the inner fence line and any adjacent areas that 
could conceal intruders. An IDS will be located in the isolation zone between the two fence lines. A minimum of two (2) diverse/complementary IDS, each covering $100 \%$ of the perimeter, will be installed and each will be tied into an uninterruptable power supply (UPS) backup power source. In addition, a taut-wire system or fiber optic system will be provided on the PA (inner) fence to detect any climbing and/or cutting of the PA fence. Various field sensor technologies will be integrated throughout the PBRF to provide graded probability of detection. Barriers will meet the requirements of DOE Order 6430.1A-O and 10 CFR 73.46. Explosive and metal detectors, $x$-ray capabilities, radiation monitors, and SNM detectors will be employed at the PA portals.

Alarm assessment will be by fixed CCTV cameras with some PTZ and infrared capabilities, SGF response, or both. CCTV cameras will also be provide with automatic recording.

Access will be granted only to appropriately cleared and badged personnel through access control points manned by the SGF. An ACS (badge reader, etc.) will be used to control ingress and egress from the PA. The ACS will meet the requirements of DOE Order 5632.9. Personnel access points to the PA will be equipped with metal and explosive detection devices, radiation monitors, SNM detectors and $x$-ray capabilities.

Within the PA there will be other barriers enclosing the Material Access Areas (MAA) and the Vital Areas. The inner barriers will be designed to delay unauthorized entry until the SGF arrives to aid in the prevention of intrusion. These inner areas within the PA will also have one controlled entry point to ensure only authorized personnel enter. The entry points will have equipment to detect unauthorized entry of personnel, explosives, and weapons. The PA will have lighted MAA access locations.

\subsubsection{VitalAreas}

A vulnerability analysis will be used to identify the vital areas. All Vital Areas will be contained within PAs and will have clearly defined perimeters. Access to a Vital Area will be controlled so entry is limited to appropriately cleared or escorted individuals who require admission to perform their official duties. An approved access list will be kept current. Records will be maintained of all persons admitted to Vital Area who are not employed directly in operations that involve access to the Vital Area. Escorts, when required, will be cleared and authorized persons knowledgeable of facility operations including safeguards and security procedures.

\subsubsection{Vehicle Entrance and Trans-ship Facility}

Vehicle entrance will be limited to emergency vehicles. These vehicles will be followed into the PA by the SGF as a way of preventing contraband and unauthorized personnel from being introduced into the PA during an emergency. To preclude vehicles entering the PA on a routine bases, a tranship facility will be used. Materials and supplies necessary for operation of the facility will be brought to the outer side of the transship 
facility and unloaded. The material will then be inspected and passed through the barrier into the PA, where the material is either stored until needed or picked up and delivered to the job site.

\subsubsection{Entry Control Facility (ECF)}

The ECF will be isolated within a bullet-resistant structure, and the SGF staffing the facility will be responsible for final access control to the PA. The PBRF security personnel will be able to visually identify persons obtaining and presenting badges.

The ECF will be provided with metal and explosive detection devices for both personnel, and containers or briefcases, etc., radiation monitors, SNM detectors, $x$-ray machines, CCTV, hand-geometry units, and floor to ceiling turnstiles with solenoid release. An Access Control System (badge reader, etc.) for controlling ingress and egress will be used. A separate area for visitor and escort badge pickup will be designated. A handicapped access/exit portal will be provided with the same protection features as listed above. The ECS will interface with other security measures and facility resources (barriers, IDS, power, and testing and maintenance).

The NRC is permitting the use of a new entry control facility that requires a reduced number of the SGF. The system uses state-of-the-art readers plus a biometrics unit. If favorable operating experience is obtained, and the required degree of security is reached, this type of ECF will be considered for the PBRF.

\subsubsection{Fuel Fabrication Building $\left(\mathrm{MF}^{2}\right)$}

The $\mathrm{MF}^{2}$ will be located within the PA and will either be designated a MAA or will have an MAA designated within the building if only partial use is made of an existing facility. Entry and exit will be controlled, and a tamper detection system will provide intrusion detection for access locations not routinely used. Radiation detection scanning equipment, and $x$-ray equipment will be employed to detect unauthorized removal of SNM from the MF².

Remote control CCTV cameras will be monitored by the SGF to observe the receiving area, the incoming material vault-type storage area, the fabrication areas, the assembly area and the fuel assembly storage area. Emergency lighting will ensure illumination in case of a power failure.

The incoming plutonium is expected to arrive in a nonclassified form, (e.g., a "button") which should minimize classification requirements for the facility, unless the isotopic make up of the plutonium is classified. A transportation plan will be required to ship the plutonium from the storage location to the $\mathrm{MF}^{2}$. The shipments will be conducted to meet DOE requirements utilizing the DOE Transportation Safeguard Division (TSD). We expect these shipments of plutonium will be handled similar to the past shipments from the DOE site at Rocky Flats, $\mathrm{CO}$ to the Pantex facility in Texas. Assuming a plant 
throughput of 50 Metric tons of mixed oxide fuel per year, with an enrichment of 6.7 $\% \mathrm{Pu}$, the plant will use about 3.2 tons of plutonium a year or about $270 \mathrm{~kg}$ per month. This use rate will probably require more than one shipment per month. Additional SGF personnel will be used when shipments arrive, until the material is received and stored in the vault.

The security requirements for the front end of the fabrication line, from the receiving area through the blending step : where the plutonium oxide is mixed with uranium oxide, will be the highest level for the facility. The plutonium in this portion of the fuel fabrication will have an Attractiveness Value of $B$ as defined in DOE order 5633.3A, and will be the most likely target for theft or diversion.

\subsubsection{Reactor Building Complex}

The reactor buildings will include the Reactor Containment Building, the Auxiliary Building, with the control room, and the Turbine Building. These buildings will all be located inside the PA. The primary entry and exit to this complex will be one controlled area, and a tamper detection system will provide intrusion detection for access lccations not routinely used. Radiation detection scanning equipment, and $x$-ray equipment will be employed to detect the unauthorized removal of SNM.

Remote control CCTV cameras will be monitored by the CAS-SGF to observe the new fuel receiving area, the fuel assembly storage area and the refueling canal area where the new fuel is laid down in preparation for moving into the containment building during refueling. Emergency lighting will ensure illumination in case of a power failure.

The primary security concern for the reactor complex will be sabotage, either industrial or radiological. Design considerations, that will reduce the affects of sabotage, will include: 1) compartmentalization of the auxiliary building so the loss of any safety system will not prevent the safe shutdown and cooldown of the reactor, 2) limited access to the control room, 3) an auxiliary shutdown panel where the reactor can be shutdown if the control room is lost, and 4) defendable station for controlling access to the containment building. Theft or diversion can not be ruled out, however, a single fuel element weighes in excess of 1000 pounds and is about 14 feet long. Also, except when the reactor is in the refueling operation mode, access to the fuel would involve shutting down the reactor, cooldown, depressurization, head and internals removal, and operation of a refueling machine hoist to remove the highly radioactive fuel assemblies. This increases the difficulty of completing a theft scenario.

\subsubsection{Spent Fuel Storage Facility (SFSF)}

The SFSF will be located in the PA, and the entrance and exit controlled by badge readers. The SFSF will be attached to the reactor containment building with a water canal running between them allowing the spent fuel to be moved from containment to 
the storage water pool without exposing the element to the air. New fuel is moved from the water storage pool into containment by the reverse process.

Entry and exit will be controlled and restricted to personnel for authorized work only. Intrusion detection and alarm devices will be employed to detect unauthorized access. CAS personnel will monitor the new fuel receiving area, the new fuel storage area and the spent fuel storage area with remote controlled CCTV equipment at all times. Emergency lighting will be provided. Radiation detection equipment and $x$-ray equipment will scan personnel and containers to detect unauthorized removal of SNM from the area. Alarmed sensors will be used to detect the removal of SNM or the inadvertent spreading of contamination.

\subsubsection{Material_Access Areas (MAA)}

Each MAA located in the MF ${ }^{2}$, SFSF and the Reactor Containment Building, will be defined by physical barriers and will be contained within the PA. Security will comply with DOE Order 5632.2A requirements. MAA zoned areas will have ingress and egress control devices. Rooms, buildings, or portions of a building within an MAA containing unattended Category I quantities of in-process SNM, will be equipped with IDS and/or other equally effective means of detection.

MAA Access Control Systems will limit entry to appropriately cleared or escorted personnel who require admittance to perform their official duties. Access to MAAs will be through doors or hatches of substantial construction and installation that will be lockable or otherwise secured to offer penetration resistance and impede both surreptitious and forced entry.

SNM entering the MAA will be identified and logged into the MC\&A System. An SNM monitor will be located at exit areas, and CAS-monitored CCTV cameras will provide visual observation within the MAA. A metal and SNM detector will be located at the MAA egress and ingress area. Emergency lighting will provide illumination during power interruptions.

\subsubsection{Material Balance Area (MBA)}

MBAs will be located in the FFB, the SFSF and the RBC in appropriate locations to aid in the control and accounting of SNM.

\subsubsection{Central Alarm Station and Secondary Alarm Station}

The CAS, located within the PA and considered a Vital Area, will be the central point for all physical protection of the facility. It will operate as the terminal point for all security systems information and will interface with the Material Control and Accountability (MC\&A) systems for safeguards and security. The CAS will have bulletresistant walls, doors, ceiling, floor, and windows, and will be on the same level near 
the Control Room. The CAS interior will not be visible from the perimeter of the PA. Security personnel will man the CAS 24 hours a day. No operational activities that will interfere with the execution of the alarm response function will be contained in the CAS. On-site secondary power supply systems for the alarm annunciator equipment and non-portable communications equipment, with an independent power source in the event of the loss of normal power, will be located within the CAS.

Should one AMS computer system or peripheral fail, a second Hot backup computer system with redundant capabilities and associated peripherals will be available for use. The Hot backup system will be available immediately upon failure of the primary system.

\subsubsection{Physical Access Control}

Access to locations protected by the Intrusion Detection System (IDS) will be made by authorized personnel only. Alarm protection will not be reduced or removed from any area without specific authorization from Site Safeguards and Security personnel.

Keys providing access to security areas or portions of security areas will be issued only to authorized individuals. The loss of a sensitive key will result in re-keying of the affected area. The security badge system will be used to ensure only authorized personnel enter or leave the security areas.

At the point of personnel access into the facility, all hand-carried packages will be inspected by $x$-ray and/or metal detector devices, for firearms, explosives, incendiary devices, or other items that could be used for sabotage. Any hand-carried item too large to pass the $x$-ray machine will be inspected manually by security personnel. All packages being delivered into the facility will be inspected. To the extent practicable, all vehicles will be unloaded in the Trans-ship Facility. Cargo will be checked for items of contraband or those that could be used for sabotage purposes before entry into the facility.

Any unmanned exits (e.g., emergency doors or gates) will operate only from the inside. Access control points and emergency exits in each inner physical barrier are alarmed and provided with tamper-indicating device (TID) seals. Emergency exits in the exterior of the facility will be alarmed and provided with TID seals. To comply with reactor safety requirements, unmanned secured exits will be capable of being operated from the outside with a $k e y(s)$. Control of the $k e y(s)$ will be determined by appropiriate DOE operation office, safeguards, and security personnel and the Plant Manager.

SNM-handling activities at the facility will use the two-person rule to preclude individual access to available Category I SNM. These controls will be applied administratively and with access control systems. All strategic quantities of SNM handled outside the facility will be escorted by the site SGF. Exit inspection/searches of all personnel, and hand-carried items, including packages, briefcases, handbags, and 
lunch containers, will be conducted to prevent unauthorized removal of SNM, classified matter, or government property. In addition to the inspection, SNM hand-held and portal monitors will be used to detect the removal of SNM.

\subsubsection{Other Site-Wide Protection Systems}

The PBRF protection programs discussed below will be compatible with the existing site protection programs. Appropriate interfaces and coordination will be made to ensure program continuity.

\subsubsection{Personnel Security}

The Personnel Security Program at the facility will implement the policy, responsibilities, and authorities for DOE's Personnel Security Program. The provisions of this program and its DOE Orders will apply to all DOE employees, contractors, subcontractors, and any other individuals who require access to DOE classified information or SNM. The program will support the provisions of the Atomic Energy Act of 1954, as amended; Executive Orders 10450 and 12356; and Federal Personnel Manual Chapter 732.

The Personnel Security Program's objective will be to assure that access to classified or sensitive information, or to Category I quantities of SNM, is granted only to individuals whose access to these items has been determined by DOE not to constitute a threat to the common defense and security.

\subsubsection{Personnel Security Assurance Proaram (PSAP)}

The PSAP will be implemented in full compliance with DOE Order 5631.6A, which establishes the PSAP requirements listed below.

The PSAP will be approved by the DOE Field Element Manager. All positions to be included in the PSAP will be identified by DOE and its contractors. Training sessions will be prepared for these positions.

Where necessary, procedures will be developed for establishing and maintaining acceptable standards of reliability for employees. The procedures will also aid in identifying employees who are unfit for their assigned duties as a result of substance abuse, or physical or psychological conditions, and provide for the removal of those affected individuals from such duty. These procedures are expected to be incorporated into the PSAP.

Employees found to be in violation of DOE's Fitness-For-Duty policy will be subject to disciplinary action up to and including termination of employment and possible criminal charges. 


\subsubsection{Classified-Matter Security}

Most information used or generated by this project is expected to be uncla isified, however since some information may still be classified and a classification program will be required. The purpose of the classification program is to ensure that proper security will be afforded classified matter requiring protection in the interest of the security of the United States, and to identify classified matter (documents and materials) that contain such information to ensure its protection. The facility will have a Classification Officer who will be approved by DOE-HQ, and who will be responsible for administering the classification program within the facility.

\subsubsection{Computer Security and Automatic Data Processing}

The security system will have a dual computer system and dual multiplex loops so no single failure or line break will cause a system failure. These electronic systems will be supplied from a UPS system. Automatic Data Processing (ADP) of classified information is governed by implementation of DOE Order 5639.6, "Automated Information Security Systems Program," and other DOE national and local directives. These orders and directives implement policy to prevent unauthorized personnel from accessing and/or exploiting classified systems. The processing of classified information on non-accredited systems is prohibited. Internal procedures will be generated which further define and identify policies, responsibilities, and procedures for managing and controlling classified ADP.

\subsubsection{Operation Security (OPSEC)}

OPSEC is a "countermeasures program designed to disrupt or defeat the ability of foreign intelligence, or other adversaries, to exploit sensitive departmental activities or information, and to secure against the inadvertent release of information outside established control procedures." OPSEC techniques and measures will be identified and employed to ensure that PBRF classified and sensitive/unclassified information is not inadvertently made available to an adversary. Countermeasures will be implemented to secure information against hostile intelligence efforts.

\subsubsection{Property Control}

The operating contractor has the responsibility to manage government property in its custody in accordance with sound industrial practices, accepted accounting principles, and compliance with federal statutes and regulations and will develop procedures to carry out this responsibility.

\subsubsection{Site-Wide Systems Performance Validation}

At least annually, the facility will conduct a self-survey and self-inspection of the DOE security interests and their effectiveness in complying with policies and procedures. 
These assessments will include UPS testing (and necessary maintenance) to ensure usability of the equipment and all batteries whether in use or in storage. No periodic tests or maintenance of the protection system components will interfere with normal operations.

Security IDS will be functionally tested on a weekly basis, and the results documented and verified by security. Schedules will be coordinated with appropriate security offices.

\subsection{Material Control and Accountability}

The purpose of this write-up is to identify the MC\&A requirements and to provide information that is needed to design the safeguards and security system for the PBRF.

The facility is being studied for the U.S. Department of Energy (DOE) for the destruction of weapons grade plutonium by using the material as a fuel in a commercial type reactor. For the purposes of this preliminary study, it is assumed that the facility will be built at a DOE Site and the MC\&A system will be an integral part of the existing Safeguards and Security System at that site. However, the MC\&A system will be capable of being adapted to any location selected for the facility. Any MC\&A system developed for this project will need to be periodically reviewed and updated as necessary to meet or exceed the requirements delineated in relevant DOE Orders, and pertinent U.S. Nuclear Regulatory Commission (NRC) regulations.

The following write-up is a general description of the system that will be implemented for controlling and accounting for all nuclear materials located at the facility.

\subsubsection{Purpose}

The MC\&A system, in combination with the physical protection system, has three major purposes: 1) to provide assurance that nuclear materials are present in correct amounts and location in the facility, 2) to detect and deter unauthorized movements of nuclear material within the facility or unauthorized removals of nuclear materials from security areas of the facility, and 3) to deter radiological sabotage resulting from adversarial acts involving the unirradiated and irradiated fuel materials.

\subsubsection{Scope}

The MC\&A system will be a major element of the integrated safeguards system to be implemented at the facility. Its role is to control and account for all nuclear materials at the facility through programs for material measurements, accounting, surveillance, and containment of the nuclear materials.

The safeguards and security system will provide protection against the Design Bases Threat Policy for DOE Facilities (July 1993); (CNSI) and facility site-specific threats to 
be identified in the Site Safeguards and Security Plan (SSSP), for all applicable categories of potential insider adversaries, outsider adversaries, or combinations of insiders and outsiders. It will be a requirement of the operator of the facility to protect and safeguard pursuant to the Atomic Energy Act of 1954, as amended, all source, special, and other nuclear materials stored and used at the facility.

An MC\&A plan will be prepared describing the program used at the facility to comply with the requirements in DOE Order 5633.3A and other relevant DOE orders. The plan will reflect the requirements specific to the facility, including MC\&A program planning and management, threat considerations, performance criteria, reporting requirements, the accounting system, physical inventories, measurements and measurement control, control limits, loss detection elements, detection and assessment capabilities, access control, material containment, material surveillance, and MC:\&A capabilities during emergencies.

\subsubsection{Eacilities}

Special nuclear materials (SNM) will be located in three areas at the PBRF: the Fuel Fabrication Building $\left(\mathrm{MF}^{2}\right)$, the Reactor Building Complex (RBC), and the Spent Fuel Storage Facility (SFSF). Category I quantities of SNM will be stored and used only within the Material Access Areas (MAA) to be defined within the facility (e.g., the FFB, RBC, and the SFSF). All areas will be located within the Protected Area (PA).

\subsubsection{Euel Fabrication Building}

The $\mathrm{MF}^{2}$ will be the receiving point for the plutonium metal, from their storage facility, the fabrication facility for mixed oxide fuel assemblies and the shipping point for the fuel assemblies to the reactor. It was assumed, for this study, that the plutonium will arrive in an unclassified form, (e.g. "buttons"). This will remove the requirement to have the front end of the fabrication line and storage area a classified area. Having the plutonium arrive in an unclassified form would permit opening the entire facility for IAEA inspections.

The plutonium will be received, identified, analyzed, entered into the accounting records, and stored in this area. The area will contain a storage vault where the plutonium will be stored until conversion to the oxide form and blending with depleted uranium. The blended material will then be fabricated into fuel pellets and assembled into fuel elements, which will then be assembled into fuel assemblies and shipped to the reactor. This area is designated as a MAA because Category I quantities of SNM will be handled and stored here.

\subsubsection{Spent Fuel Storage Facility}

The SFSF contains underwater compartments for storing irradiated fuel assemblies and control rods. Fuel handling facilities are available for loading the shipping casks. This 
facility also contains the receiving and storage area for new fuel. The SFSF is adjacent to the Reactor Containment Building and is connected to the RCB by a water channel. This water channel is used to pass spent fuel from the reactor, during refueling, into the spent fuel storage pool and to pass the new fuel into the containment building for insertion into the reactor.

\subsubsection{Reactor Building Complex}

The RBC includes the Reactor Containment Building, the Auxiliary Building and the Turbine Building. The Reactor Containment Building houses the reactor vessel and has work space for handling fuel assemblies, inserting the assemblies into the reactor vessel, and removing the assemblies from the reactor vessel.

\subsubsection{Categorization}

Under the MC\&A program, the nuclear materials will be protected by a graded safeguards system in which the greatest control and effort will be applied to the materials of greatest attractiveness (i.e., those materials that can be most effectively used in constructing an improvised nuclear explosive device) and the category, based on the amount of material present. The nuclear materials in the facility will include depleted or natural uranium and plutonium. The plutonium is expected to arrive in the form of a metallic "buttons", which were formed by melting down the "pits" after they were removed from dismantled weapons; plutonium oxide, after the "buttons" are converted; or a mixed oxide, after the plutonium oxide is blended with depleted uranium.

The category of a Material Balance Area (MBA) is based on both the amounts of materials and their attractiveness levels. Specific procedures are given in DOE Order 5633.3A, Chapter I.2. Some key points are:

Uranium and plutonium are not combined for category determination, category is determined for each and the more restrictive category applies.

- If several attractiveness levels of materials are present, the amounts are "weighted" based on the attractiveness prior to summing the weights of the materials.

In determining the category of an area, it is necessary to consider the maximum amounts of materials that could be present. Both the total amount of material and its distribution among attractiveness levels may vary during processing. The category for an area will be the most restrictive expected for normal operations. Once the category level is determined, administrative and other controls must be implemented that will prevent the area from exceeding the permissible amounts. 
Table 7.2.4-1 lists the nuclear materials and the safeguards categories and attractiveness levels that are expected to be present in each of the three known MBAs in the facility.

IABLE 7.2,4-1

Categories and Attractiveness of Nuclear Materials (1)

Attractiveness Nuclear Material

\section{Category}

Level

\section{Euel Fabrication Blda}

Plutonium Buttons

Plutonium Oxide

Mixed Oxide (Pu - U)

Low-Enriched or Natural U

$\begin{array}{rr}\text { I } & \text { B } \\ \text { II } & \text { C } \\ \text { IV } & \text { D }\end{array}$

Reactor Building Complex

Mixed Oxide (Pu - U)

II

D

Mixed Oxide (Pu - U)

in Irradiated Fuel

$\mathrm{Pu}$ in Irradiated Fuel

IV

IV

E

E

\section{Spent Fuel Storage Facility}

Mixed Oxide (Pu - U)

in Irradiated Fuel

$\mathrm{Pu}$ in Irradiated Fuel
IV

IV
B
C
D
E

C

E




\subsubsection{General}

Nuclear material accounting at the facility will conform to the requirements specified in DOE 5633.3A, Chapter II. The system will provide for tracking nuclear material inventories; documenting nuclear material transactions; issuing periodic reports; and verifying, detecting, and evaluating loss detection elements.

The nuclear material content in the reactor and the SFSF will be based on accountability measurements made at the fuel fabrication facility. Reactor burnup of ${ }^{239} \mathrm{Pu}$, will be calculated using operating data.

Because the fuel elements and fuel assemblies have the characteristics of sealed sources, attempts to remove SNM would leave obvious evidence. The material tracking and inventory systems as well as the accounting function at the facility will rely on item control accounting strategies and methods, destructive and nondestructive analysis for the plutonium metal, oxide, fuel elements and fuel assemblies. Weights and analytical measurement techniques coupled with statistical sampling and nondestructive analysis will be required to account for the plutonium from the time it is received, converted to oxide and is assembled, as fuel pellets, into fuel elements. Very reliable and durable processes will be required for uniquely identifying the fuel assemblies. The identifying markings will have to remain legible after intense irradiation in the reactor vessel and long-term storage in the SFSF. The legibility will also have to survive corrosion and scale buildup resulting from long-term contact with water and heavy water.

Nondestructive analysis will be used to obtain a "fingerprint" of the plutonium before the material leaves the storage facility. This "fingerprint" will be used to track the material until it is assembled into fuel elements and is given a unique number identification.

The irradiated fuel assemblies will be stored in the SFSF in water basins. The fuel assemblies will be highly radioactive and can be considered to be self-protecting.

\subsubsection{Accounting System}

Nuclear material accounting at the facility will be accomplished with a near-real-time computer-based system that will track all nuclear material transfers into and out of the facility, and maintain records of nuclear material inventories including location changes, amount, and identity.

The facility accounting system will be a subsystem of the Site MC\&A system. The facility computer and the central MC\&A computers will be interconnected by a secure interface to enable accounting system data transfers. All transactions posted to the MBA system will also be automatically posted to the central accounting system. 
To meet the near-real-time requirement, the accounting data base will be updated to reflect nuclear material transactions when the transactions are made or as soon after the transaction as is practical but no later than the end of the current work shift. This will enable the system to generate a book inventory listing within 3 hours, which is required for all SNM. Data entry will be performed at remote work stations by authorized MC\&A or operations personnel.

Access limitations to the MC\&A computer data system will be implemented to ensure that only authorized persons make adjustments to the accountability data base. Adjustments to the accounts will be reviewed and approved by an authorized person in the MC\&A organization. Where operations personnel enter MC\&A-related data at remote work stations, overchecks will be implemented to detect any attempt at data falsification.

\subsubsection{Material Balance Areas}

The facility presently has three MBAs identified that will be employed to provide physical and administrative control of the nuclear materials. Each of the MBAs will consist of a physical area with well-defined boundaries. The boundaries will be selected to facilitate material control and accounting, and in accordance with the requirements specified in DOE Order 5633.3A, III,4(b) and 10 CFR 70.58(d).

The selection of the MBA was based on the:

flow and types of nuclear materials at the facility

capability to establish controls on transfers in and out of the MBA

processes and functions in each MBA

frequency of physical inventories required for the material category and attractiveness in the MBA.

Internal transfers of nuclear materials will require prior authorization. Unauthorized movements will result in an alarm requiring assessment. The amount of nuclear materials moved in or out of the MBA will be based on weighted measurements in the front end of fuel fabrication building, and item identity, item count, and verification of the physical integrity of the individual items in the assembly area of the fuel fabrication, reactor complex and spent fuel storage . (The quantity of nuclear material in each item will be based on previously measured values.)

Primary administrative control and custodial responsibility for the nuclear materials in each MBA will be assigned to the nuclear material custodian for that MBA. 


\subsubsection{Material Control Indicaturs}

A program for assessing the material control indicators will be implemented in accordance with the requirements of DOE Order 5633.3A,II,6.

\section{Shipper/Receiver Differences}

Procedures will be written for evaluation, investigation, and reporting of significant shipper/receiver differences.

\section{Inventory Differences}

Accountability measurements for nuclear materials at the facility are made at the fuel fabrication facility. Verification measurements will be made in the fuel fabrication area. The remainder of the facility will deal with fuel assemblies, therefore, inventory differences can only result from missinc or mislocated items. All such anomalies must be resolved by locating the missing item(s) or determining they have been removed from the facility. The discrepancies must be investigated and reported to DOE in accordance with DOE Order 5000.3B

\subsubsection{Measurements and Measurement Control}

The measurements made at the facility will include accountability, verification, and confirmatory measurements. A measurement cont o! program will be implemented to ensure high-quality measurement data. The measurements will be made with the best systems available consistent with the graded safeguards requirements. Verification measurements will include quantitative analyses to verify accountability data and may include destructive or NDA methods. Confirmatory measurements will measure at least one attribute of the nuclear material and may include mass determinations by NDA.

The overall responsibility for the MC\&A measurement and measurement control functions will be organizationally independent of operations. This includes the responsibility for measurement system selection, measurement procedures review and approval, performance test design, calibrations, and statistical analyses.

MC\&A measurement systems will be selected, tested, qualified and approved, installed, and documented to ensure the desired levels of precision and accuracy are maintained for the type of confirmatory tests needed.

\subsubsection{Material Transfers}

The MC\&A program includes procedures, authorizations, documentation, tracking and verification of nuclear material transfers that meet the requirements stated in DOE 5633.3A,Il.5. The purpose of transfer controls is to ensure nuclear material is 
transferred only with the knowledge and concurrence of proper authorities, to provide necessary information on the location and disposition of nuclear materials, and to implement checks to verify the completion of transfers.

Material transfers pertaining to the facility will be: 1 ) received from off site, 2) within the DOE Site, and 3) sent offsite when the spent fuel is moved to permanent storage. They include transfers of plutonium metal for a [.OE storage to the $\mathrm{MF}^{2}$ site, transfers of fuel assemblies from the $\mathrm{MF}^{2}$ to the reactor, transfers of fuel assemblies to the SFSF. and the shipment of spent fuel assemblies from the SFSF to permanent storage.

\subsubsection{Nuclear Material Control}

The overall purpose of the nuclear material control program for the facility is to ensure the status and physical location of all nuclear materials in the inventory are known and are protected consistent with the graded safeguards concept. The program has four functional areas: access controls, material surveillance, material containment, and detection/assessment.

The nuclear material control program has elements in common with the physical security system. Elements of the program that are primarily the responsibility of MC\&A are TID administration, waste monitoring, daily administrative checks, and custodial responsibilities. Elements that are primarily the responsibility of physical security are intrusion alarm system design, surveillance system design and operation, identification systems, and locks. Elements that are applicable to both MC\&A and physical security are material surveillance procedures, access authorization lists, portal monitoring (SNM detectors), material transfer operations and surveillance, storage area entry controls, MAA access procedures, PA access procedures, and CCTV surveillance. In general, the hardware design and operation aspects of the above-noted elements (not including MC\&A computers and instrumentation) are the responsibility of the physical security system, whereas procedural aspects are the responsibility of the MC\&A system.

\subsubsection{Protected Area}

The PA Entry Control Facilities will provide controlled access to the PA. The physical security system will control entry to and exit from the PA. Individual access will be limited to persons having the necessary security clearance and having work activities in the PA or to escorted persons who require admittance for performance of official functions.

\section{Access Controls}

The purpose of personnel access controls is to ensure only authorized persons have access to the protected areas in the facility containing nuclear materials, MC\&A data, MC\&A data-generating equipment (including measurement systems), and data- 
processing systems. This controlled access reduces the potential for theft and diversion of nuclear materials.

The physical security system will provide personnel access control at several levels for protecting nuclear materials at the facility. These levels include the boundaries of the Protected Areas, and the Material Access Areas. In addition, access controls within the MAA will be placed on the plutonium storage location.

All nuclear materials at the facility will be used and stored within the PA. Category I quantities of SNM are used and stored only within the MAA.

\section{Detection and Assessment}

The MC\&A system will provide the capability to detect and assess acts involving unauthorized removal of nuclear materials from the protected area consistent with the graded safeguards concept. In conjunction with the physical protection system, the system will detect and respond to removal of SNM from the protected area.

\subsubsection{Material Access Area}

An MAA will be established in the facility that will enclose the area in which Category I quantities of SNM are located. The area will include either the entire $M^{2}$ or the portion of an existing building dedicated to fuel fabrication.

The boundaries of the MAA will be defined by a physical structure. The personnel ingress/egress points will be limited to the minimum number required for efficient operations and personnel safety. Access will be limited to properly cleared, authorized persons having work activities in the MAA and to escorted persons needed to perform official functions.

\section{Access Controls}

The purpose of personnel access controls is to ensure that only authorized persons have access to the MAA. This controlled access reduces the potential for theft and diversion of nuclear materials. The physical security system will provide the personnel access control. In addition, access controls within the MAA will be placed on the plutonium storage location.

All category I quantities of SNM are used and stored only within the MAA.

Material Surveillance

A graded program for monitoring the nuclear materials in the facility to detect unauthorized movements or activities will be implemented. The objective of material surveillance is to provide knowledge on a timely basis that all nuclear materials are in 
their authorized locations. For unirradiated fuel material, the performance requirement for the system is to detect unauthorized material movements.

The material-tracking system in the PBRF will provide near-real-time knowledge of the location of plutonium metal from the time it arrives at the FFB until the conversion to plutonium oxide, and the plutonium oxide and assembled into fuel elements and fuel assemblies until they are shipped to the storage sites.

\section{Material Containment}

The MC\&A system will include a program to provide controls for nuclear material operations relative to the MAA, MBA, storage repositories, in-process areas, and in the use of tamper indicating devices. The program will be formally documented, including written procedures, and conform to the graded safeguards concept for MC\&A.

The facility will have MBA that will provide physical and administrative control of the nuclear materials. Each of the MBAs will consist of a physical area with well-defined boundaries. The boundaries will be selected to facilitate material control and accounting.

Primary administrative control and custodial responsibility for the nuclear materials in each MBA will be assigned to the nuclear material custodian for that MBA.

\section{Detection and Assessment}

The MC\&A system will provide the capability to detect and assess acts involving unauthorized removal or diversion of nuclear materials consistent with the graded safeguards concept. In conjunction with the physical protection system, the system will detect and respond to the removal of SNM from its authorized location in the facility.

\section{Daily Administrative Checks}

MBAs that contain Category I quantities of nuclear materials will require the implementation of a program of daily administrative checks. This program is intended to detect obvious abnormalities or missing items and evidence of tampering, and to provide assurance that theft or diversion of Category I nuclear material is promptly detected.

The MBA custodian will be responsible for overseeing the performance of the daily administrative checks. A record of daily administrative checks will be maintained by the MBA custodian or designee with a check sheet(s) indicating the completion of each check initialed by the individual who performed it. The daily administrative check will be made using the two-person rule. 
If an anomaly is discovered during the daily administrative check, atternpts will be made to resolve it. If not resolved within a designated time from the discovery, the MC\&A Manager and cognizant PBRF management will be notified and an investigation will be initiated.

Use of Tamper-Indicating-Devices (TIDs)

TIDs are devices that can be attached to properly designed containers, portals, and vault compartments providing positive indications of penetration or attempted penetration. The TID program will be documented and will address control of TIDs from receipt to destruction to ensure TIDs are used, to the extent possible, to detect violation of container integrity. The facility will implement and maintain a TID program in compliance with the DOE Order and with guidance in the Safeguards Seal Reference Manual (DOE 1991c).

\section{MAA Search Point}

Personnel and material will be searched to detect attempts of unauthorized removal of nuclear materials from the MAA and the PA. Searches can be accomplished using electronic equipment capable of detecting shielded or unshielded plutonium of a specific quantity.

Procedures will be implemented for testing and calibrating the portal monitors. Provisions will be made for storing calibration standards in a secure repository to reduce the potential tampering. The monitors will be protected with TIDs to detect tampering.

\section{Waste Monitors}

All wastes leaving the MAA will be monitored to ensure SNM does not leave the facility via waste streams. State-of-the-art counting equipment will be used to survey the waste.

Solid waste will be removed from the inventory only after written authorization is obtained from the MC\&A organization and after all other operations approvals have been obtained.

\subsubsection{Material in Storage}

The storage locations in the $\mathrm{MF}^{2}$ will be treated as special control areas. Administrative controls will be established to detect unauthorized activities within the storage locations. The two-person rule will be enforced during all activities, including transfers in or out, physical inventory, and maintenance and repair of equipment. 
Plutonium metal will be received continuously to meet the fuel fabrication schedule and will be stored in vault-type rooms that meet Category I requirements until the material is converted to oxide and blended with depleted uranium. After the plutonium has been blended the mixed oxide, fuel pellets and fuel assemblies will be stored in areas of the $\mathrm{MF}^{2}$ designed to meet the requirements for vaults or vault-type rooms that ineet the Category II requirements. In addition, procedures will be implemented to control and validate material movements into and out of the storage locations.

Irradiated fuel assemblies will be stored in underwater storage areas in the SFSF. Because of the intense radiation associated with these materials, the nuclear materials are considered to be self-protecting from the standpoint of theft or diversion. However, due to the potential for radiological sabotage, access controls will be established at the entry points to the building. The building will be equipped with an intrusion alarm system. When the building is unoccupied, it will be locked and the intrusion detection system will be in operation and monitored at the central alarm station.

Surveillance measures for Category I material in the storage locations consist of examining the storage location access $\log$ to determine if the records indicate any anomalous entries, verifying the integrity of the TIDs to ensure that no unauthorized attempts were made to access the material in the storage location, and confirming the storage location intrusion alarm record indicates no unresolved alarms have occurred since the last check.

\subsubsection{Material in Process}

Controls for materials in process will be documented. All authorized locations for nuclear materials in each of the MBA will be defined in operating procedures and will be contained in the nuclear material tracking system data base. All location changes will be logged in the tracking system. Any attempt to make an unauthorized location change (e.g., from one process area to another) will be detected by the nuclear material tracking system and will result in a material control alarm.

Process activities involving non-irradiated fuel materials will be done under the twoperson rule. All process areas in the $\mathrm{MF}^{2}$ will be under electronic surveillance (CCTV). When any enclosed area is unattended, the CCTV system will be in operation.

Special security provisions will be implemented in the RCB during refueling, while unirradiated fuel materials are in the building, and will be continued until the reactor head has been replaced and sealed.

All process operations involving plutonium metal, unblended plutonium oxide and unirradiated fuel assemblies will be done under the two-person rule. All transfers within the PBRF involving unirradiated fuel material are to be performed under the twoperson rule, which also applies to reactor vessel loading operations. 
Category I material must be in authorized storage locations when unattended. Category I material can be in process locations if access in controlled and material surveillance procedure have been implemented.

When operations in the RBC and the SFSF involve only Category IV quantities, the twoperson rule requirement does not apply. However when new fuel is stored in the SFSF (e.g., prior to refueling) and compensatory measures are in place the two man rule will be used. Material surveillance measures in this MBA require the MBA custodian to compare operating logs with the nuclear material tracking system to ensure there are no anomalies.

\subsection{International Atomic Enerov Association (IAEA) Safequards}

\subsubsection{IAEA Safeguards}

The safeguards efforts of the IAEA was designed to reduce the proliferation risks posed by plutonium and enriched uranium in the international nuclear community. Their inspections were directed towards ensuring that fissile materials planned for civilian use was not diverted by the country to nonpeaceful uses. The PBRF will required to maintain material control and accountability that meets the present requirements, however the records and facility will be available for IAEA inspections. The "timely detection" of a "significant quantity" as defined for the IAEA is 8 kilograms. This amount is greater than the DOE requirement, therefore the controls and surveillances to meet the U.S. requirements will be adequate for the IAEA.

The physical security of the nuclear plants is currently entirely a national effort. Therefore, the physical security of the plant will still have to meet the U.S. DOE or NRC requirements.

\subsubsection{Iransparency}

The facility will be considered to be placed under IAEA safeguards inspections. This will permit the U.S. to set an example for and to provide transparency, to the remaining countries that have nuclear weapons, on our method of disposing of the weapons grade plutonium. The transparency provided by the unilateral placement of the U.S. excess weapons grade plutonium under IAEA inspections can be used to encourage other nations to provide for similar inspections.

\subsubsection{Classified "Pits"}

The plutonium "pits" that are removed from dismantled weapons are assumed to have classified characteristics e.g. specific design, exact dimensions, or materials. If the facility is to receive the unaltered "pits" and will be required to dismantle them and then convert the plutonium to oxide for blending, this portion of the fuel fabrication facility will have to be a classified facility. IAEA inspections of this portion of the MF" 


\section{Combustion Engineering, Inc.}

with foreign nationals would not appear to be possible. The remainder of the $\mathrm{MF}^{2}$, after the "pits" have been altered to a nonclassified configuration, will be accessible the IAEA inspectors.

One option which would allow the IAEA inspectors into the entire facility is to convert the plutonium "pits" into a nonclassified form e.g. metallic "buttons" at some other location. This could be done by placing a facility near the DOE plutonium storage location. The "pits" would be disassembled there and converted to a nonclassified form e.g. "buttons". The "buttons" will still be category I B, pure products, with the shipping and receiving requirements. 


\subsection{ENVIRONMENT, SAFETY AND HEALTH}

\subsection{Nuclear Material Transpertation}

\subsubsection{Introduction}

One of the tasks that has to be undertaken to successfully close the program on qualifying the mixed oxide fuel for use in a reactor is to examine the transportation requirements for various conditions. These are:

- Shipment of fresh mixed oxide fuel assemblies from the mixed oxide fuel fabricatiun plant to the reactor site for irradiation.

- Shipment of alpha wastes from the mixed oxide fuel fabrication plant to the Federal waste disposal site.

- Shipment of both high and low level radioactive waste from the reactor

- Shipment of irradiated fuel (spent fuel) from the reactor to a storage location.

The existing shipping containers utilized for transportation by the commercial nuclear industry will be investigated. It is not the intention of the program to develop a new cask or container for transportation of mixed fuel assemblies. Thus, the task is to evaluate the existing casks having certificate of compliance for the utilization of transportation of mixed fuel assemblies from the plant where it is manufactured to the site where it will be irradiated and thereafter transported as spent fuel to the permanent storage.

The packaging and transportation of the fuel assemblies is a very specialized effort and there are many considerations that helps to finalize the one suitable for the particular type of shipping. Each of these will be discussed separately.

\section{Regulatory Requirements}

Commercial packaging and transport of radioactive materials are regulated at the Federal level by the Nuclear Regulatory Commission (NRC), the Department of Transportation (DOT), and the U.S.Postal Service. The packaging and criteria are found in the regulation of NRC (10 CFR Part 71) and regulation of DOT (49 CFR Parts 170 through 179). Certain aspects-- such as limitation on gross weight of trucks and transportation not subject to DOT, NRC or the Postal Service regulations-- are regulated by the States. Most states have adopted regulations which require the shipper to conform to the packaging, labeling, and marking requirements of the DOT to the same extent as if the transportation were subject to the rules and regulation of that agency. Most shipments of radioactive material move in the routine commerce and conventional 
transportation equipment. Shipments are subject to the same transportation environments, including accidents, as nonradioactive cargo. Although a shipper may impose some conditions on the carriage of his shipment, such as speed limitation and the provision of an escort, most of the conditions to which his shipment is subjected are not under his control. Protection of public and workers from radiation during the shipment of the radioactive material is achieved through adherence to the regulation promulgated by NRC through a combination on the limitation of the contents according to the quantities and type of radioactivity, and standards and criteria for package design. These will be discussed for each type of shipment separately.

\section{Handling Requirements}

The loading and unloading operations are often taken for granted, but they are actually technically complex, requiring prevention of damage during transfers, avoiding excessive radiation dosage to the operators involved. The handling requirements become more complex with the handling of spent fuel. The general approach should be to minimize the number of shipments, reduce the complexity in the handling operations and reduce the time for each operation, thereby reducing the radiation dose to the operator.

\subsubsection{Fresh Fuel from Fuel Fabrication Plant}

With the recommended location of the fuel fabrication plant and the reactor at the same site, the environment, safety, and health concerns for transportation of fresh fuel from the fabrication plant to the reactor are minimal. The following discussion deals with the situation that arises if the fuel fabrication is off-site.

The mixed oxide fuel rods to be transported from the fuel fabrication plant to the reactor can be accomplished in metal containers similar to the one utilized for the fresh $\mathrm{UO}_{2}$ fuel assemblies by the commercial nuclear industry. There is some radiation and therefore the packages will have to be modified slightly to include some shielding to meet the DOT requirements of external radiation dose levels for normal conditions of transport. The number of fuel assemblies will be established by the quantity of plutonium that can be transported in a single shipment, which in turn is controlled by safeguards and security regulations.

Each shipment will require a special vehicle and a special security escort in view of the presence of plutonium in the fuel assemblies. During transport by road the vehicles may require armed escorts which provides additional security measure beside what is included in the container design and also be a communication link with the operation center during the transportation. Two drivers will accompany any shipment. The present practice of carrying six packages of PWR assemblies (12 assemblies) per truck can continue with the MOX assemblies except that each package may be heavier due to the extra shielding requirement. The handling of the packages at both the shipping and the receiving end could utilize the ones used by the commercial nuclear industry. 


\subsubsection{Waste from fuel fabrication plant}

It is assumed that the solid wastes generated at the fuel fabrication plant would be placed in $\mathbf{5 5}$ gallon steel drums. These drums will be transported in a similar manner as the $\mathrm{UO}_{2}$ fuel fabrication plant wastes. These drums would be placed in a steel cargo container or overpack and moved by rail or a truck. The quantity of waste and the characteristics of the waste depends on the fabrication process and the planned method of waste treatment used at the fuel fabrication plant.

\subsubsection{Waste from the Reactor}

The waste from the reactor can be classified into high level and low level wastes. The low level wastes will be handled in the same manner as waste from fuel fabrication plant (see 8.1.3). The waste will be handled with care to prevent violation of ALARA limits. The wastes will be transported in casks similar to those used for irradiated or spent fuel assemblies. These shipments must meet the limits on size, weight, radiation level, and heat generation rate. The presently available spent fuel casks can be utilized for this operation. The number of shipments, distance to be travelled will be established after further study. The type of casks to be used depends on the mode of transport-- by rail or by truck. The wastes will have to be transported to a high level waste repository. The radiation level will be analyzed in a manner similar to the spent fuel assemblies. The present method for handling the casks can be utilized at both the shipping end and the receiving end. 


\subsection{Fuel Activities}

\subsubsection{Confinement and Ventilation}

\subsubsection{Confinement}

During the fabrication of MOX fuel, there is a significant exposure risk to particle inhalation. The risk for particle dispersion in the environment can be reduced, however, by increasing the number of confinements.

As a general principle, the Mixed Oxide Fabrication Facility $\left(\mathrm{MF}^{2}\right)$ process is carried out in various rooms and in multiple confinements, depending on the plutonium product being treated and the contamination risk. Where plutonium powders are processed, the first confinement is provided by the equipment itself. The enclosures containing the equipment provide supplementary sealed enclosures to avoid spread of contamination in the event of seal failure of the primary containment. Also, to limit the operating personnel radiation exposures, the MOX oxide processing and handling operations are carried out, using remotely controlled and automated equipment located inside the process enclosures shielded for radiation control. Once the fuel pellets are sealed in fuel rods, hands-on operation can be conducted, as in a commercial uranium fuel fabrication plant.

The process described in Section 2.4 in this report has the function of preventing the spread of radiation and avoiding (minimizing) any criticality event. The technology presented is somewhat old, however it serves the purpose of identifying the major steps for a MOX fuel fabrication and isolation of the various operations. Further work with more advanced and proven technologies from European MOX fuel fabrication facilities will refine and update the process.

\subsubsection{Ventilation}

The release and dispersal of plutonium materials is the principal risk of a MOX fuel fabrication plant. The plant ventilation and confinement systems minimize the potential for uncontrolled release. The system consists of fresh air supply, process ventilation and exhaust air systems, together with associated air heating units, filters, fans, dampers, ducts, firefighting devices, and control instrumentation devices.

Air is supplied through an intake system that provides for dust filtration, heating or cooling. It is distributed to the various rooms (or areas) of the buildings. The intake system is located on the second floor of each building. Different and independent heating and air conditio ing systems are provided. They are separated from one other depending on their function and contamination levels of the areas they serve. The air supply system draws in, conditions fresh air and distributes it throughout the processing arca st a rate allowing appropriate degree of volume renewal per hour. A portion of air supply enters the process ventilation system through process enclosures 
and other components. It is removed together with other plant air through fire-resistant HEPA filters and discharged to the environs through a stack. The stack allows adequate dispersion of radioactive material, even in the event of an accident. The ventilation system serves also as principal confinement barriers between building confinement zones, and between the building confinement zones and the outside atmosphere.

Air in the fuel process area is supplied to individual rooms through ducts and diffusers located in the ceiling. Room air is exhausted through a roughing filter, followed by a high efficiency particulate air (HEPA) filter installed in the floor of each room. The air then enters in a ductwork system and is filtered by a final HEPA filter system before exhausts from the plant stack. Room air entering a glove box is filtered by roughing and HEPA filters. Air leaving a glove box is filtered first by roughing and HEPA filters at the glove box and then a second HEPA filter located in each room for all glove boxes in the room. The air then enters a central air ductwork system and is filtered by a third HEPA filter system before being exhausted from the plant stack. The flow of air in the fuel process area is controlled so that air moves from clean areas to areas with successively higher contaminated air and finally to the glove box enclosures containing process equipment, where ventilation system becomes effectively a gaseous radioactive effluent treatment system.

\subsubsection{Radioactivity Control in the Plant}

The mixed oxide fuel fabrication facility is designed, constructed, tested and operated under rigid a safety quality assurance program. This assures that workers are not exposed to internal and external radiation. This means that the design is such that the radiation levels in all accessible areas are maintained below the recommended levels, to support access requirements that assure ALARA, per 10 CFR 20.

\subsection{Prevention}

To avoid any spread of the radioactivity, the mixed oxide handling and processing operations are performance inside equipment located within process enclosures. In turn a process enclosure is maintained at a negative pressure relative to the adjacent areas. Furthermore, any suspected or slightly contaminated material is treated or controlled in ventilated hoods. Outside the process enclosures, the plutonium bearing materials or small amounts of liquids are stored and/or transferred according to well defined procedures and using leaktight devices (glove boxes, pipes or special designed tanks).

The protection of the operating people in the process areas mainly consists of remote or semi remote handling of the MOX material. Operating personnel are protected from alpha, gamma and neutron irradiations by biological shields (glove boxes). 


\subsection{Plant ambient monitoring}

\subsection{Alpha Contamination}

The surface contamination monitoring consists of routine checks (or special checks in the event of an incident). These routine and special checks are made using appropriate detectors such as alpha-scintilation counters.

In zones occupied or to be occupied by workers, the atmospheric contamination is continuously monitored and compared with the applicable control level to assure that workers are not exposed to concentrations exceeding those considered safe. for this control, a large number of air sampling devices are installed along the process enclosures at well defined locations. The number and locations of the sampling points are chosen in keeping with the risks expectec' and the rate of presence of the workers at these places. At each sampling point, a known flow of air is passed through a filter. The contamination, if any, is retained on the filter and can therefore be continuously, and/or intermittently monitored.

\subsection{Beta Irradiation}

The ambient beta-irradiation is practically negligible because the material is always handled behind shielding (glove box), strong enough to permit the radiation flux to be disregarded in most cases.

\subsection{Gamma Irradiation}

The gamma -irradiation is the prominent factor in the ambient irradiations. Its level is measured instantaneously during special and routine checks with portable radiation meters, and as a mean level over fairly long periods by means of dosimetry films placed in selected locations that are particularly critical.

\subsection{Neutron Irradiation}

The neutron irradiation may, in certain cases, become as important as the gamma irradiation. Neutrons originate both from spontaneous fission reactions (Pu 238 and Pu 240 ) and from (alpha, $n$ ) reactions on oxygen. Measurements are made with appropriate measuring devices.

\subsection{Operating Personnel Monitoring}

\subsection{Alpha Contamination}

For personnel external contamination, each process area is provided with portable alpha scintillation counters, made available to the personnel to routinely check the presence of any alpha contamination on their clothes, hands or feet. 
Internal contamination of the personnel is routinely controlled. The frequency of these analyses depends on the kind of work carried out by the personnel. The greater the plutonium airborne inhalation risk, higher the control frequency will be. In case of a contamination incident, measurements can be made to define the inhalation danger for the personnel involved in the incident and eventual internal contamination can be controlled.

\subsection{External Radiation}

The personnel whether directly employed or not, wear a film badge from which at least the total radiation doses to the whole body can be assessed. Direct reading pocket dosimeters for gamma and Xray radiations are also used for quick and continuous controls.

The operators in the process building are equipped with special gamma-dosimeters. These dosimeters adapted to the operator tasks are periodically monitored. The monitoring frequency depending on the potential irradiation level.

\subsubsection{Radioactivity Control for the Environment}

\subsection{Control of Plant Airborne and Gasesus Effluents}

\subsection{Confinement and Filtration}

The $\mathrm{MF}^{2}$ is maintained at negative pressure relative to the outside. The MOX handling operations are carried out inside equipment located within process enclosures maintained at negative pressure relative to the adjacent areas of the process building. The pressure differentials are maintained so that air is flowing from non-contaminated areas into areas of potential higher contamination levels. The exhausted air from process enclosures and process areas is filtered through high efficiency particulate air filters (HEPA filters) and discharged to the environs through a stack. The stack will allow dispersion of plutonium as a function of atmospheric conditions. The stack will reduce, in the event of an accident, the concentration of plutonium to the surrounding area.

\subsection{Radiplogical Controls in the Plant}

The effluents are radiologically controlled by monitors, measuring continuously the total alpha activity collected on filters through which a well known air flow is derived from the release duct, before release through the stack.

An alarm is set off when the integrated release exceeds the permissible level. This permissible release depends on the design of the ventilation system, the meteorological conditions, the neighborhood and the Pu specific activity. In practice, the alarm is set at a lower release level in order to allow a time delay to interrupt the release. 


\subsection{Radiological Controls in the Neighborhood}

Site control stations are erected in the neighborhood of the MOX fuel fabrication plant. The stations are provided with:

- $\quad$ equipment to monitor activity of the dust in the air. Alarms associated with these measurement are set to levels slightly above the observed natural activities of these radionuclides in the air;

- $\quad$ equipment to monitor the ambient dose rate. The alarms are set to levels above the maximum natural activities observed.

\subsection{Control of Liquid Effluents}

The potentially contaminated liquids which include cold laboratory wastes, floor scrubbing liquids, and hot shower wastes are analyzed to determine whether they must be processed or whether they can be disposed of as liquids. For the analysis, samples are taken from potentially contaminated liquids and measured for the plutonium and uranium content. Based on the results of the analysis, the liquid could be discharged to the environment or processed further.

\subsubsection{Protection Against Fire}

In a MOX fuel fabrication plant, the main health and safety risk is the release and dispersal of the plutonium materials due to a fire or explosion. The fire protection system prevents, detects, extinguishes, limits and controls fires and explosions and their resulting hazards and damaging effects.

\subsection{Prevention}

\subsection{Plant Area}

The plant area is isolated and protected from the surroundings to limit any damage resulting from a fire originating outside the area. On the plant site, physical barriers are created to avoid any transmission of a fire occurring in the environs.

\subsection{Building Construction}

In general, heat resistant and non-combustible materials are used throughout the MOX process areas, vital areas, and plant control areas.

The structural shells, their supporting members and the penetration in these shells, where MOX is handled and processed, are designed to withstand and continue to act as a confinement structure during a well defined time delay in case of failure of the fire suppression system. 
Interconnected areas or buildings are equipped on each end with fire resistant doors.

\subsection{Isolation of Process Enclosures}

The MOX material is processed through interconnected enclosures which are located in several rooms (areas). To avoid fire transmission to adjacent process areas, the process enclosures located in the intermediate walls of the room are equipped with fireproof locks which are open only to allow material transfers.

\subsection{Gas Handling Equipment and Flammable Materials}

Flammable materials are not introduced in the MOX process area unless specifically required for process reasons. Solvents and other flammable liquids are stored outside the process building. Special control is exercised over the handling of flammable in MOX material process areas and the process enclosures.

The hydrogen, required in the process, is stored in tanks outside. It is diluted to a nonflammable percentage with inert gas prior to its introduction in the process building. If the process requires pure hydrogen or a concentration exceeding the nonflammable limit, the process enclosures will be equipped with special devices to control the potential hazard.

\subsection{Exhaust Filter Protection}

Room exhaust filters are protected by a spark arrestor flame trap and a fire-resisting prefilter. These filters and the HEPA filters installed in the MOX process building and process enclosures ventilation systems withstand high temperatures over a well defined time delay without any loss of efficiency.

\subsection{Fire Detection and Alarm Systems}

The fire detection and alarm systems consisting of fire detectors, signaling devices and audible and visual indicators in a constantly attended location as well as in appropriate locations throughout the plant. The type of fire detectors is chosen as a function of the fire types. The fire detectors are connected to the plant-wide fire detection, signal and alarm systems. Manual fire alarm stations, connected to the plant-wide fire detection systems, are installed throughout the plant at accessible places.

\subsection{Fire Suppression Agent and Techniquess}

Depending on the localization, the type and the hazard of the fire which could break out, different fire-fighting techniques, products and equipment are used in the MOX fuel fabrication plants. Fire hydrants or connection points for hydrants are strategically located around a water distribution loop encircling the buildings site. Conventional automatic sprinklers are used in non-process areas of the facility. 
For the process areas, automatic water sprinkler systems can be used; the sprinkler system selected will minimize the quantity of water used. The spread of contamination by water and possibility of a criticality event will also be controlled. An automatic fire extinguishing system is provided in the process enclosures where it is too risky for fire fighters to enter.

As a supplementary caution, portable fire extinguishers filled with various fire suppression agents are distributed throughout the plant.

\subsection{2 $\mathrm{MF}^{2}$ Thermal Wastes}

Mixed oxide fuel fabrication is not an energy intensive process. Essentially, all electrical energy used in the model MOX plant site is discharged as heat via the cooling tower(s), either as evaporative loss or in the blowdown. In addition, showers, sinks, and laundry wastes can contain heated water. It is estimated that the $\mathrm{MF}^{2}$ plant will release about $2,200,000 \mathrm{Btu} / \mathrm{hr}$ to the biosphere.

\subsubsection{Safety Analysis and Impact on the Environment}

The success of the MOX fuel cycle depends on its performance, safety record and public acceptance. Public acceptance can only be achieved by demonstrating safety in all phases of the MOX fuel cycle, reliability in its performance and safe disposal of generated wastes. To provide reasonable assurance that the $\mathrm{MF}^{2}$ can be operated without undue risk to the health and safety of employees and the public, and to the environment, such as plant must be located, designed, constructed, tested and operated according to well defined criteria of safety. Also, physical security and SNM accountability and protection must be assured. The main safety problems associated with the mixed oxide fuel fabrication industry is the occupational exposure and the release of Pu bearing material into the environment. The safe operation of the facility and its impact on t'ne environment have to be evaluated for normal opeation and for accidental events.

\subsubsection{Normal operation}

During plant normal operation, the occupational exposure and the radioactive releases are kept as low as possible by using the highest design standards and then performing and implementing periodic safety, inspection and maintenance programs. Occupational exposure and the Pu releases during plant normal operation are low enough to avoid any deleteriouos effect. The occupational exposure, the amount of airborne plutonium released to the atmosphere, the Pu concentration in effluents disposed of liquids, and the Pu solid wastes are in accordance with and meet all the local, state and federal laws and regulations. 


\subsubsection{Accidental Events}

The accidental radiation exposure and release are normally produced by a sequence of events which ultimately result in an exposure to or a release of radioactive material. Considering the risks associated with postulated accidents, the probability of occurrence of the accidents and the severity of their consequences must be taken into account. The plant design provides high reliability or redundant systems in order to assure low and acceptable risks.

The plant events which have to be considered for the design to assure low risks for the environment are: fire, explosion, criticality and loss of confinement. The $\mathrm{MF}^{2}$ is designed and operated to assure very low risks for such accidents. Also the plant design will minimize the effect of natural phenomena (such as earthquake, flood, tornado, airplan crashes).

The risks of such events of the environment is evaluated, taking into account the plant site characteristics and the associated plant design. Plant design criteria are based on the premise that the plant location represents a reasonable balance between the advantages and limitations inherent in the size of the exclusion area (distance to nearest site boundary), the population density and other demographic data, the physical characteristics (meterology, geology, hydrology and background radiation) and the accessibility and communication.

The present knowledge and the expected results of future technological developments concerning commercial plant design and operation are such that the risks associated with such events cuuld be predicted and could be reduced to acceptable risks.

\subsubsection{Spent Fuel}

The spent fuel operations for the MOX fuels are essentially identical to those that apply to spent $\mathrm{UO}_{2}$ fuel. After discharge from the reactor, the spent fuel assemblies will be transferred to the reactor storage pool. The spent fuel handling machine will remove the poison pins. The poison pins will be packaged in canisters and stored in the storage pool. The spent fuel assemblies will be transferred to storage locations in the pool. After cooling, the spent fuel assemblies will be packaged into canisters that will serve as repository disposal packages. The canisters will be loaded into casks for shipment to the repository. All packaging operations will take place under water in the reactor storage pool. Cask shipment to the repository will be by truck, rail, or dedicated train. The fuel transfer and loading operations must be performed carefully in order to avoid breaking or dropping fuel assemblies that might lead to fission gas release and spent fuel contamination in the pool.

The disposal of spent MOX fuel assemblies presents no significant increase in safety or environmental risks compared to $\mathrm{UO}_{2}$ fuels based on the fact that their spent fuel operations are similar. However, licensing amendments and procedures specific to the 
MOX fuel are required to cover handling, storage, packaging, shipment, and disposal. The licensing amendments must consider, among other things, the potential impacts of the spent MOX fuels on criticality and operating safety.

\subsubsection{Spent Fuel from the Reactor}

The irradiated mixed oxide fuel assemblies are expected to be similar to the irradiated uranium oxide fuel assemblies and thus casks used for the latter can be utilized for the mixed oxide assemblies. The only constraints may be the weight limitations imposed by the DOT regulations. The shipping/transportation casks developed and approved by US NRC are described in the report by Oak Ridge National Laboratory ORNL/TM11005 Dated November 1988. As per this report, there are 4 casks approved for shipment by road and two casks for shipment by rail. These existing approved casks can be used for the System $80+$ fuel assemblies containing mixed oxide fuels.

The parameters associated with these casks are shown in Table 8.2.4-1. The irradiated mixed oxide fuel assemblies will have an average heat generation rate about $20 \%$ higher than the $\mathrm{UO}_{2}$ fuel assemblies for the same amount of fuel burnup. Also, the neutron radiation level of a spent mixed fuel assembly is slightly higher and thus will require some additional shielding, thereby reducing the maximum number of assemblies per shipment. These factors have to be considered in utilizing the existing casks for the shipment. Due to the increased weight one can expect that most of the shipment may be done by rail. If the reactor site is not accessible to rail service, the lighter cask for shipment by truck can be utilized only increasing the number of shipments. These casks are designed to handle various type of accidents and one need not consider any additional ones for the transport of mixed oxide spent fuel assemblies. The need for escorts and other safeguards and securities factors will be the same as that applied for the present transportation of commercial spent $\mathrm{UO}_{2}$ fuel assemblies.

\subsubsection{Euel Qualification Testing}

The fuel assemblies fabricated for the testing program will not be the same size as the one planned for use in the reactor. Thus, the transportation requirements for these assemblies will have to be modified to a certain extent. The fresh MOX test fuel assemblies transported to the irradiation facility can use the metal container planned for utilization with fresh assemblies and discussed in Section 8.1.2. The irradiated fuel assemblies can be transported in the shipping casks identified for use with irradiated MOX fuel assemblies in Section 8.2.4.1.

Table 8.2.4-2 shows the shipment means, number of shipment for each type, distance travelled, etc. This information will be developed as part of the project development. 


\section{TABLE 8.2.4-1}

\section{SHIPPING CASK EVALUATION PARAMETERS}

The existing shipping cask for truck and rail transport have to be evaluated for its capability to handle the System $80+$ MOX fuel assemblies. The key parameters to be examined include:

a. Number of fuel assemblies that can be transported

b. Maximum weight of cask including fuel assemblies

c. Maximum heat rejection capacity (spent fuel requirement)

d. Geometrical shape of the cask interior for its compatibility with the MOX fuel assemblies

e. Overall dimension including the cavity dimension to load the MOX fuel assemblies

f. Material of construction

g. Type of cooling required during the transport

h. Temperature and pressure conditions to be maintained during the transport

i. The cask surface dose

j. Type of atmosphere to be maintained in the cask interior cavity

k. Licensing status for MOX fuel

I. The type of approved transportation vehicle

The review of these parameters will enable one to envelope the System $80+$ MOX fuel assemblies and identify a specific cask which meet with the needs of the fuel qualifying program. 


\begin{tabular}{|c|c|c|c|c|c|c|}
\hline \multicolumn{7}{|c|}{$\begin{array}{l}\text { TABLE } 8.2 .4-2 \\
\text { NEW AND SPENT FUEL SHIPMENT }\end{array}$} \\
\hline $\begin{array}{l}\text { Nuclear Material } \\
\text { Shipped }\end{array}$ & Shipment Mode & Packaging Type & $\begin{array}{l}\text { No. of } \\
\text { Shipments } \\
\text { Per Yoar }\end{array}$ & $\begin{array}{l}\text { Distance } \\
\text { of Travel }\end{array}$ & $\begin{array}{l}\text { Escort/ } \\
\text { Security }\end{array}$ & Remarks \\
\hline Fresh MOX Fuel & By Truck & Metal Containers & & & & \\
\hline $\begin{array}{l}\text { Waste from } \\
\text { MOX } \\
\text { Fabrication Plant }\end{array}$ & $\begin{array}{l}\text { By Truck to Nevada } \\
\text { Site }\end{array}$ & Drums (55 Gallons) & & & $\begin{array}{l}\text { Not } \\
\text { Required }\end{array}$ & \\
\hline $\begin{array}{l}\text { Reactor } \\
\text { Produced } \\
\text { Waste } \\
\text { Low Level } \\
\text { High Level }\end{array}$ & $\begin{array}{l}\text { By Truck } \\
\text { Truck/Rail }\end{array}$ & $\begin{array}{l}\text { Drums (55 Gallons) } \\
\text { Shipment Cask }\end{array}$ & & & Not Requred & \\
\hline $\begin{array}{l}\text { Spent MOX Fuel } \\
\text { Assemblies }\end{array}$ & Truck/Rail & $\begin{array}{l}\text { Shipping Cask } \\
\text { (approved for use } \\
\text { for spent } \mathrm{UO}_{2} \text { fuel } \\
\text { Assemblies) }\end{array}$ & & & Yes & $\begin{array}{l}\text { No. of } \\
\text { assemblies/cask } \\
\text { will be decreased } \\
\text { to accommodate } \\
\text { extra shielding. }\end{array}$ \\
\hline $\begin{array}{l}\text { Test Assemblies } \\
\text { Fresh } \\
\text { Irradiated }\end{array}$ & $\begin{array}{l}\text { Truck } \\
\text { Truck }\end{array}$ & $\begin{array}{l}\text { Metal Containers } \\
\text { Shipping Cask }\end{array}$ & $\begin{array}{l}\text { XNA } \\
\text { XNA }\end{array}$ & & $\begin{array}{l}\text { Yes } \\
\text { Yes }\end{array}$ & \\
\hline
\end{tabular}

Note: Blank spaces to be completed on obtaining more information on size of fuel fab plant reactor site location; no. of reactors, etc. 


\subsection{Wante Straams}

It is not anticipated that a large difference in waste streams will result from MOX as compared to $\mathrm{UO}_{2}$. However, the waste streams to be considered regarding environment, health, and safety (ES\&H) issues from reactor disposition of plutonium includes the fuel cycle leading to fuel fabrication and subsequent reactor operations, with particular attention being given to the plutonium contained in any waste streams. Within each of the following sections on waste minimization and plutonium carryover, the aspects pertinent to the fuel cycle, fuel fabrication facility and reactor operations are discussed.

\subsubsection{Waste Minimization Measures}

The Atomic Energy Commission performed a study of the uranium fuel cycle to assess the environmental effects of LWRs. The study, with consideration of input from the public, is reported in "Environmental Survey of the Uranium Fuel Cycle," US AEC Report WASH-1248, April 1974. That report indicates that the environmental burdens associated with waste management are small with respect to other phases of the cycle. The study is cast in terms of the annual impacts resulting from operation of a model 1000 MWe LWR operating at $80 \%$ capacity factor, and concludes that the environmental impacts of the uranium fuel cycle are small.

\subsubsection{Eual Crale}

Essentially all of the environmental impact of the uranium fuel cycle per the WASH1248 report results from the mining, milling, conversion to $U F_{6}$ and enrichment (M,M,C,E) phases of the cycle. The use of a reactor to dispose of excess weapons plutonium while producing electricity avoids these phases. The environmental impact of producing the weapons plutonium can properly be considered as a "sunk environmental effect." Clearly then, the $M, M, C, E$ environmental effects are less than those considered in WASH-1248 to be small.

Environmental data derived from Table S-3A in WASH-1248 are summarized below in Table 8.3.1-1. An additional entry, the amount of enrichment tails, has been included in this summary. Impacts associated with reprocessing, although small, have been subtracted from the "Total" fuel cycle impacts and no credit has been taken for recycled uranium (which had been assumed in the study).

-

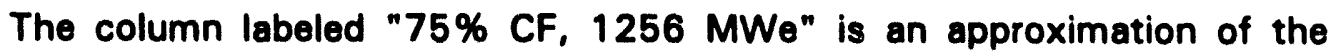
annual environmental effects that are relieved by reactor disposition of plutonium. It is determined by multiplying the "Total" column by the product of two ratios. The first is the ratio of capacity factors; the base case required by DOE of $75 \%$ divided by $80 \%$., The second is the ratio of power levels; $1256 \mathrm{MWe}$ divided by $1000 \mathrm{MWe}$. 
- The column labeled "\% Present (M, M,C,E)" indicates the percentage of total uranium fuel cycle amounts that are present in the cycle(s) to be used in plutonium disposition operations.

\subsubsection{Euel Fabrication Facillity Waste Stream}

During the operation of the MOX facility, processing of liquid and solid radioactive material will produce contaminated effluents. These effluents are treated so that releases to the environment of reactivity are maintained as low as reasonably achievable (ALARA). This means that the treatment operation takes a broad spectrum of primary waste materials and convert them to a few secondary waste types in forms suitable for interim storage at the plant site and ultimate disposal off-site.

Waste Streams in the MOX facility are generated by the following operations:

- $\quad$ Processing and/or handling of scrap (clean and dirty scrap)

- Decontamination operation

- $\quad$ Process off-gas cleanup

- Miscellaneous liquid waste generating activities (laundry and personnel showers)

Clean Scrap (rejected fuel pellets, grinding fines) will be recycled in a dry process at site to recuperate mixed oxide powder as previously discussed.

The dirty scrap will be processed as rad waste.

HVAC (HEPA) Filters are volume reduced, packed and shipped offsite for low-level waste (LLW) disposal.

Sanitary Wastes from non-radioactive laundry, showers and sinks are sampled for possible Pu content and discharged to a sanitary lagoon.

Waste from hot laundry are collected to sample for Pu content and either discharged to a sanitary lagoon or processed, and residue solidified for offsite LLW disposal. Table 8.3.1-2 summarizes typical parameters and radwaste produced in a mixed oxide fuel fabrication facility, using as a guide the "Final Generic Environmental Statement on the Use of Recycled Plutonium in Mixed Oxide Fuel in Light Water Cooled Reactor" (NUREG-0002, Table IVD-7, dated August 1976). For the MOX Fabrication Facility 150 MT/year), contaminated effluents have been assumed to be $15 \%$ of the values presented in NUREG-0002. 


\subsection{Liquid Waste Treatment}

The liquid waste treatment system accepts all discard streams that could be potentially contaminated from the main process, scrap recovery, and support areas.

Plant liquid effluents include:

- The cold laboratory wastes, floor scrubbing liquids, cooling water for process equipment, hot shower wastes, all of which may be potentially contaminated.

- The sanitary wastes, cooling tower blowdown and all the other liquid effluents coming from non-radioactive areas.

- The potentially contaminated liquids are analyzed to determine whether they must be sent to auxiliary process systems or whether they can be disposed off as liquids. The decision is made based on the lower overall environmental impact.

- The non-radiological effluents, coming from sanitary, cooling tower blowdown and non-radioactive areas are discharged as liquid effluents. The potentially contaminated liquid stream is diluted with non-radiological effluents and discharged to the environment.

Processing of this waste include:

- Evaporation of trace contaminated liquids to reduce volume

- Processing of liquid waste streams from processes to recover and recycle chemical reagents and water

- Processing of off-gas from the recycle processes to scrub out chemical pollutants

- Collection, sampling, and release of potentially contaminated liquids that meet 10 CFR 20 levels into the sanitary waste water system.

The design of the liquid waste treatment system is directed toward minimizing the volume of waste sent to waste packaging and reducing the volatile chemical pollutants released from the plant.

\subsection{Solid Waste Treatment}

It is expected that the solid wastes produced during the fuel fabrication operations will be treated to recover plutonium to the maximum practicable extent and/or to reduce their volume. The volume of the collected wastes, after treatment, is in a form suitable 
for ultimate disposal. It is expected that the average plutonium concentration in the solid wastes conditioned for ultimate disposal will be less than $0.10 \%$ of the total amount of Pu treated.

The solid waste treatment system accepts discarded solid residue from the main process and scrap recovery areas, and salt residues from the liquid waste treatment system. Solid wastes are compacted to minimize volume, and the liquid waste residues are treated and immobilized in a solid matrix (concrete, bitumen, plastic or glass).

\subsection{Waste Packaging}

The solid waste and solidified liquid waste are packaged in accordance with transportation regulations, normally in 55-gallon drums. They are assayed by a nondestructive method for accountability purposes and to ensure control of transuranium elements released to offsite shipment.

\subsection{MF² Airborne Effluents}

Small-quantities of various airborne effluents are released from the mixed oxide manufacturing processes. The radioactive airborne effluents are plutonium and uranium isotopes, and their progeny.

The radiological and gaseous effluents are limited to plutonium and uranium isotopes and their daughters. The air ventilation streams are filtered through high efficiency particulate air filters (HEPA filters) and discharged through a stack to the environment. The effluents are radiologically controlled by monitors measuring continuously the total alpha-activity.

Mixed oxide fuel fabrication may give rise to the release of non-radioactive gaseous effluents such as hydrogen, argon, helium, and nitrogen. With the exception of hydrogen, all of these gases are normal constituents of the atmosphere. Chemicals, which may be released as vapor from process operations (hydrogen fluoride, $\mathrm{NO}_{\mathrm{x}}$ and ammonia) will be passed through scrubbers and will not lead to significant polluting consequences.

\section{- Radioactive Airborne Effluents}

Industrial experience indicates that a small fraction (approximately $10^{-9}$ ) of the material that is processed through a plant is dispersed to the atmosphere via the filtered exhaust system.

On the basis of a 50-MT/yr plant with this release factor, the gaseous effluents are calculated to contain $0.050 \mathrm{gm} \mathrm{HM}\left[(50 \mathrm{MT} / \mathrm{yr})\left(10^{-9}\right)\right]$ of mixed oxide or $0.003 \mathrm{gm} \mathrm{Pu}$. 


\section{Combustion Engineering, Inc.}

The total activity for $100 \mathrm{mg}$ MOX Fuel Fabrication Plant is estimated as follows:

\begin{tabular}{lrrr} 
ISOTOPE & HALF-LIFE (yr) & WEIGHT $(\mathbf{g m})$ & \multicolumn{1}{c}{ ACTIVITY (Ci) } \\
\hline & & & \\
Ra-226 & 1600 & 1 & 1 \\
P-239 & 24131 & 0.003 & $1.88 \times 10^{-4}$ \\
U-238 & $4.5 \times 10^{9}$ & 0.047 & $1.6 \times 10^{-8}$
\end{tabular}

\section{ACTIVITY}

PU-239

$1600 / 24131 * 226 / 239=0.062698 \mathrm{Ci}$ per gram or $1.88 \times 10^{-4} \mathrm{Ci}$ per $0.003 \mathrm{gm}$

$\mathrm{U}-238$

$1600 / 4.46810^{9} * 226 / 238=3.4 \times 10^{-7} \mathrm{Ci}$ per gram or $1.6 \times 10^{-8} \mathrm{Ci}$ per $0.047 \mathrm{gm}$

\section{ALPHA EMISSION}

$1 \mathrm{Ci}$ yields $3.7 \times 10^{10}$ alpha emissions per sec. In the case of $0.003 \mathrm{gm}$ of Pu-239


sec; for $0.047 \mathrm{gm}$ of $U-238$, the alpha emission rate is $6 \times 10^{2}$ alphas per sec. The total alpha emission is approx $7 \times 10^{6}$ alphas per sec. 


\section{- Nonradiological Process Effluents}

Mixed oxide fuel fabrication operations may give rise to the release of non-radioactive gaseous effluents such as nitrogen, hydrogen, argon, helium and oxides of nitrogen $\left(\mathrm{NO}_{x}\right)$, hydrogen fluoride, and ammcnia. Very small amounts of solvent vapors will result from hardware cleaning work outside the manufacturing building.

Nitrogen-hydrogen gas mixtures, below the explosive limit, are used to provide a reducing atmosphere both in pellet sintering furnaces and for treating clean recycle scrap powder and pellets. Argon and helium are used in welding and in fuel rod leaktesting procedures. No atmospheric pollution problem will result from the use of these gases.

Chemicals used in waste treatment operations, however, may be released in the vapor phase and are potential atmospheric pollutants. These are hydrogen fluoride (HF), oxides of nitrogen $\left(\mathrm{NO}_{x}\right)$, and ammonia $\left(\mathrm{NH}_{3}\right)$.

-

\section{Nonradiological Utility Effluents}

The heating, ventilating, and air-conditioning systems for the MOX plant will be electrically operated. The amount of $\mathrm{NO}_{x}$ released from the operation of a diesel powered emergency generator may require air permits depending upon diesel generator capacity and testing requirements.

\subsubsection{5 $M F^{2}$ Liquid Effluents}

Plant liquid effluents include both uncontaminated and potentially contaminated liquids. The latter includes laundry water, laboratory sink drainage, floor scrub liquids, regular shower water, fire water, and distillate from the general purpose evaporator. The uncontaminated liquid effluents are primarily sanitary waste water and cooling tower blowdown. Table 8.3.1-2 summarizes the volume of liquid effluents released from the MOX plant.

\section{- Radioactive Liquid Effluents}

Potentially contaminated liquids are kept in a holdup tank until analysis determines whether they must be sent to the radwaste system or disposed of as uncontaminated liquid waste. The decision for its transfer to the liquid radwaste processing or release is made on a case-by-case basis, considering which route will result in the lower overall environmental impact. It should be noted that the potentially contaminated liquid effluent stream is diluted by the sanitary waste and cooling tower blowdown. Also, dilution by surface water will further reduce the liquid waste concentration. 


\section{- Nonradiological Liquid Effluents}

The chemical and sanitary liquid effluent flows, the cooling tower blowdown and uncontaminated laboratory waste and scrub water are discharged together to the environment. It is estimated that small amounts of phosphate $(<0.5 \mathrm{lb} /$ day $)$ and nitrate $(<10 \mathrm{lb} /$ day $)$ are present in this discharge stream.

\subsection{MF² Solid Radioactive Wastes}

Solid waste generation has been estimated as approximately 1,600 cu ft per year containing about $3.4 \mathrm{~kg}$ of $\mathrm{PuO}_{2}$. The waste consists of $115 \mathrm{cu} \mathrm{ft}$ from used HEPA filters, $305 \mathrm{cu} \mathrm{ft}$ from solidified liquid wastes, $805 \mathrm{cu} \mathrm{ft}$ from general process waste, and $400 \mathrm{cu}$ ft from discarded major process components. Solid waste will be packaged in approved shipping containers for transfer to a Federal waste repository. Table 8.3.1-2 summarizes the volumes and contents of solid wastes.

\subsubsection{Reactor Waste Streams}

Waste minimization has received tremendous attention by the commercial nuclear industry since the time of the WASH-1248 report. This has been the result of numerous factors, including ALARA programs, improved technical capability for waste management, elimination of the sources of waste streams, etc. For example, the experience of the industry reflects a small failed fuel fraction (less than $0.015 \%$ ). Thus, the source of waste streams originating from reactor operations is small. Similar results are expected for MOX fuel.

The System $80+$ design has also benefitted directly from the commercial nuclear industry experience by incorporating approaches and design features in compliance with the EPRI ALWR Utility Requirements Document, which was developed from the vast commercial nuclear industry experience. This should enable a System $80+$ based reactor to limit personnel exposures and wastes to level less than attainable by comparable current generation reactors.

Low level wastes resulting from reactor operations may include sludge, ion exchange resins, evaporator bottoms, aqueous filters, dry filters, contaminated rags, cleaning materials, disposable protective clothing, plastic containers and other materials that require disposal, not classified as either spent fuel or as by-product thereof.

The System $80+$ design already includes features that will minimize waste. For example, floor drains are strategically located near the component and equipment drains. This better provides for segregation and reduces the potential for contaminating the area. This results in both a reduction of liquid and solid wastes.

The design emphasizes waste segregation. Waste segregation and hard piping of drains enables effective processing. Segregation by chemical and radiological characteristics 
decreases the quantity of water that must be treated due to unknown or suspected characteristics. Dedicated drains minimizes the use of floor drains and further reduces entrainment of dirt and debris that gives rise to filter problems. It also provides fringe benefits in reducing exposures, and reduces labor costs.

Ion exchangers are used to the maximum extent, avoiding the relatively higher maintenance of evaporators and minimizing wastes, including solids from evaporators, liquids from flush lines and off gas stripping columns.

Other solid wastes are eliminated by the operating philosophy and design features in support thereof. For example, hot tool rooms permit storage of tools without the need for extensive decontamination (they don't leave the radiation control zone).

The liquid, gaseous, and solid waste management systems are designed to protect plant personnel, the general public, and the environment by providing means to collect, generate, store, process, sample and monitor radioactive wastes. These systems are designed to meet the limiting requirements on releases in 10 CFR 20, Appendix B; 10 CFR 50, Appendix A (General design criteria 60, 61, and 64); and 10 CFR 50, Appendix I (the ALARA Objectives). These are non-nuclear safety related systems and have no accident mitigation functions. However, they are designed in accordance with the guidance provided by ANS1/ANS 55.2 and USNRC Regulating Guide 1.143 which require sufficient redundancy in the design to tolerate a single major component failure. The System 80 + radioactive waste managements system are describe in Section 11 of CESSAR-DC.

\section{Liquid Waste Management System (LWMS)}

The LWMS provides a means to collect, store, process, sample and monitor radioactive liquid waste. The LWMS consists of collection tanks, process pumps and vessels, monitor tanks, and appropriate instruments and controls to permit most operation to be conducted remotely. The process equipment and connection for mobile semipermanent or leased equipment are located so that they have crane or monorail hoist and access for ease of repair, replacement, or reconfiguration.

Radioactive wastes are segregated by routing to an initial collection sump or tank. This permits more effective processing of each type of waste and may lead to reduced solid waste volumes. Segregation is accomplished by means of a subsystem that processes different waste categories.

The LWMS is divided into the following subsystems:

Low-Level Waste Subsystem

High-Level Waste Subsystem

Laundry and Hot Shower/Chemical Waste Subsystem

Containment Cooler Subsystem 
Waste collection and monitor tanks are provided in pairs so that one may be available to receive waste while the other is being processed or discharged.

The principal process is ion exchange. This allows flexibility for tailoring the process to specific wastes or operating conditions while retaining simplicity of operation. The process vessels with mixed bed resins can also be loaded with granulated carbon, Zeolite or other sluicible media which may enhance process filtration or ion exchange adsorption.

Remote valves and piping are arranged so that process vessels may be used cyclically on a given waste stream. Valves and piping are also arranged to allow linkage of the demineralizers of a train in series or process influent waste from either of the subsystems.

The demineralizer arrangements available allow flexibility in selecting the appropriate processing path to process waste influent during selected operational or influent transients.

Processed liquid radioactive waste is sampled prior to release from the monitor tanks. Radiation monitors are provided in the discharge line.

Estimated annual average quantities of radioactivity released in liquid effluents during normal operation, including operational occurrences, is provided in CESSAR-DC Table 11.2-1. The methology of US NRC NUREG-0017 is used in determining these values. Maximum annual individual doses, presented in CESSAR-DC Table 11.2-4 and reproduced as Table 8.3.1-3, satisfy the 10 CFR 50, Appendix I numerical design objectives. It is fully expected that the LWMS presented in CESSAR-DC will pass the ALARA test for most proposed sites without modification. LWMS modifications resulting from site-specific Cost-Benefit analyses will reduce the individual doses presented in Table 8.3.1-3.

\section{Gaseous Waste Management System (GWMS)}

Process gases contain radioactive xenon and krypton fission products from fuel and tramp uranium on fuel surfaces. The process gas portion of the GWMS receives fission gases from the Process Gas Header (PGH) and uses charcoal adsorber beds to retain and delay the process gases for decay prior to release. The primary input source to the PGH are gases stripped from reactor coolant by the CVCS Gas Stripper and Volume Control Tank. The reactor Drain Tank and Equipment Drain Tank process vent surge volumes comprise the balance of the hydrogenated gaseous inputs to the PGH. The flow in the PGH primarily consists of hydrogen and noble gases with some trace quantities of other fission gases and water vapor. The removal of fission gases by the gas stripper maintains the fission gas concentration in the reactor coolant at a low residual level. This minimizes the escape of radioactive gases during the maintenance 
on the reactor coolant system and releases resulting from the leakage of reactor coolant.

The GWMS uses charcoal at ambient temperature to delay the passage of radioactive gases through the system. When operating at design conditions the mass of charcoal provided in the adsorber beds is sufficient to provide a minimum of 60 days delay for xenon and a minimum of 3 days delay for krypton. The cooler condenser conditions process gases to provide the moisture and temperature necessary for the desired performance of the charcoal adsorbers.

The cooler condenser cools the stripped gases and condenses and removes water vapor to a dew point below $45^{\circ} \mathrm{F}$ before the gas enters the charcoal adsorber beds. A humidity analyzer downstream of the cooler condenser is provided to detect inadequate moisture removal.

The charcoal guard bed is provided upstream of the charcoal process adsorber beds. The guard bed is normally not in service by provides additional capacity in the event of excess moisture. Nitrogen purge is available to dry charcoal beds in the event of excessive moisture contamination. A guard bed and six charcoal absorbers containing a total of 15,300 pounds of charcoal are employed for xenon and krypton delay. The tanks are located in a shielded vault.

The GWMS operates at pressures slightly above atmospheric thus limiting the potential for oxygen in-leakage. Leakage from the GWMS is further limited through the use of welded connections wherever not restricted due to maintenance requirements. All control valves are provided with bellows seals to minimize leakage through the valve topworks.

Where potential for explosive mixtures of hydrogen and oxygen exists, the GWMS is designed to maintain system integrity by first, preventing information or buildup of explosive mixtures and secondly, monitoring and purging any concentrations above $1 \%$ oxygen in the atmosphere.

Gas analyzers are used to detect the formation of gas mixtures. The system is designed to alarm both locally and in the main control room for remedial action. The gas analyzers take continuous samples from the GWMS and in addition, from sources to the system, i.e., the gas stripper, volume control tank, equipment drain tank, and reactor drain tank.

The gas analyzer is set for a high alarm at $1 \%$ oxygen. Alarms allow ample time for remedial actions to lower concentrations of hydrogen and oxygen.

The process vent portion of the GWMS is designed to collect the low activity aerated gas streams from the potentially contaminated vents headers in the Nuclear Annex and Radwaste Building. The process vents, except from the condenser evacuation system, 
are monitored filtered through its respective building ventilation system, and released through the unit vent. The condenser evacuation system is monitored and then discharged through the unit vent.

For non-safety plant ventilation systems, initial performance tests are performed to verify the operability of the components, instrumentation, and control equipment. During reactor operation and system is used at all times and requires no additional periodic testing. Periodic visual inspections and preventative maintenance are conducted according to normal industrial practices. Safety-related ventilation systems are tested as per Technical Specifications in accordance with Regulator Guide 1.52.

Estimated annual gaseous releases from plant sources during normal operation, including anticipated operational occurrences are provided in CESSAR-DC Table 11.3-4. The calculations are based on assumptions consistent with those of NREG-0017. Gaseous effluents are released through the common unit vent with the exception of relatively small quantities released through the turbine building vents. Atmospheric dilution and relative deposition factors at the worst case locations for the respective pathways are assumed in this analysis and will become minimum design criteria to be verified during the site selection process and documented in the Environmental Report.

The off-site doses associated with the annual gaseous releases in postulated maximum individual doses shown in CESSAR-DC Table 11.3-5 and reproduced as Table 8.3.1-4. These doses are calculated using the methods and assumptions of USNRC Regulatory Guide 1.109. Population doses resulting from radioactive gaseous releases are strongly related to site characteristics. Therefore, it is necessary to defer population dose projections to the site-specific environmental reports. Potential GWMS modifications resulting from site-specific, cost-benefit analyses may reduce the individual doses presented in Table 8.3.1-4.

\section{Solid Waste Management System (SWMS)}

Primary functions of the SWMS include providing means by which spent resin, filters, etc. from the LWMS and primary letdown systems are processed to ensure economical packaging within regulatory guidelines, as well as handling dry, low activity wastes for shipment to a licensed burial facility.

The spent resin transfer system is designed to transfer expended radioactive demineralizer and ion exchanger resins from their vessels to the spent resin tank. The system also provides holdup of the resin and transfer of the resin to the solidification system. The major components of this system are spent resin tanks, spent resin surge tanks, spent resin transfer pumps, and filters.

The spent resin tanks provide settling capacity for radioactive bead resins transferred from various demineralizers. Capability is provided for solidification of dewatered resins or sluicing to containers approved for shipping and disposal of dewatered ion 
exchange resins. Also, connections are provided for use of vendor supplied services such as rapid dewatering or waste drying systems when it is determined that the use of these methods represents a savings over the permanently installed alternatives.

A shielded onsite storage area is provided to allow for interim storage of higher activity packaged wastes. The facility is sized such that it is capable of storing the maximum number of full shipping containers generated in any one year period containing the greatest expected waste generation. The process and storage areas include a dedicated overhead crane with direct access to adjacent truck bays with sufficient overhead clearance to facilitate direct trailer loading of waste packages. Crane operation may be performed remotely with the aid of crane-mounted video cameras or locally to provide additional flexibility.

Building space is also provided to sort miscellaneous contaminated dry solids from uncontaminated solids for appropriate and cost effective packaging and disposal. Miscellaneous solid waste consisting of contaminated or potentially contaminated rags, paper, clothing, glass, and other small items is received by the Solid Radwaste System when it arrive at the low-level handling and packaging area. Although waste forms are segregated and bagged at generation points throughout the plant, this area provides spacer where the waste is further segregated le.g., compactible versus noncompactible, radioactive versus non-radioactive) on sorting tables. When a sufficient quantity of contaminated waste has been accumulated, the compactor is operated. Radioactivity of filled containers is monitored so that proper handling, storage, and disposal are assured. Filled containers may be stored in the low-level package storage area until shipped.

Systems 80 + annual solid waste generation source terms are developed by averaging recent disposal volume and activity data for several actual operating nuclear power units with similar waste processing systems. The operational data used to develop the SWMS volume and activity source term estimates is presented in CESSAR-DC in Tables 11.4-2 and 11.4-3, respectively. The estimated burial volume and activity estimates for the various solid waste types that will be shipped for disposal from the System $80+$ is provided in CESSAR-DC Table 11.4-4 and reproduced as Table 8.3.1-5.

The System $80+$ waste streams described above reflect the $\mathrm{UO}_{2}$ core fuel cycle. The uses of a MOX core results in a somewhat different distribution of fission products. Consequently, the details of radionuclide distribution will be different. However, system modifications are not expected to be needed in order to keep within the regulatory requirements. In addition, site-specific characteristics will be reflected in the design to meet the ALARA objective of 10 CFR 50, Appendix 1 . One specific modification identified in the need for a tritium removal system in order to accommodate the higher tritium buildup in the primary coolant than the $\mathrm{UO}_{2}$ equilibrium core. 
TABLE 8.3.1

SUMMARY OF ENVIRONMENTAL CONDITIONS EOR NUGLEAR FUEL (URANIUML CYCLE

\begin{tabular}{|c|c|c|c|}
\hline & Total Cycle & $\begin{array}{l}76 \% \text { CF, } \\
1256 \text { MWe }\end{array}$ & $\begin{array}{l}\text { \% Present } \\
\text { (M,M,C,E) }\end{array}$ \\
\hline \multicolumn{4}{|l|}{ LAND } \\
\hline Temorary use, $10^{4} \mathrm{~m}^{2}$ & 24 & 28 & 100 \\
\hline Permanent use, $10^{4} \mathrm{~m}^{2}$ & 1.9 & 2.2 & 96 \\
\hline Overburden moved, $10^{\circ} \mathrm{kg}$ & 2.7 & 3.2 & 100 \\
\hline \multicolumn{4}{|l|}{ WATER } \\
\hline Discharged, $10^{6} \mathrm{~m}^{3}$ & 42.8 & 50.4 & 100 \\
\hline \multicolumn{4}{|l|}{ FOSSIL FUEL } \\
\hline $\begin{array}{l}\text { Cool (Electric Equiv.), } \\
10^{6} \mathrm{~kg}\end{array}$ & 115 & 136 & 100 \\
\hline Natural Gas, $10^{6} \mathrm{~m}^{3}$ & 2.6 & 3.1 & 96 \\
\hline \multicolumn{4}{|l|}{ EFFLUENTS } \\
\hline \multicolumn{4}{|l|}{$\frac{\text { Chemical }}{\left(10^{3} \mathrm{~kg}\right)}$} \\
\hline \multicolumn{4}{|l|}{ Gases: } \\
\hline $\mathrm{SO}_{x}$ & 4398 & 5178 & 99 \\
\hline $\mathrm{NO}_{x}$ & 1170 & 1377 & 99 \\
\hline Hydrocarbon & 13.5 & 15.8 & 100 \\
\hline CO & 28.7 & 33.8 & 100 \\
\hline Particulates & 1153 & 1358 & 100 \\
\hline F. & 0.61 & 0.72 & 100 \\
\hline \multicolumn{4}{|l|}{ Liquids } \\
\hline $\mathrm{SO}_{4}=$ & 9.9 & 11.7 & 100 \\
\hline $\mathrm{NO}_{3}$ & 25.8 & 30.4 & 11 \\
\hline Flouride & 12.9 & 15.2 & 68 \\
\hline $\mathrm{Ca}-$ & 5.4 & 6.4 & 100 \\
\hline
\end{tabular}


IABLE 8,3.1 (Cont'd)

SUMMARY OF ENVIRONMENTAL CONDITIONS

EOR NUGLEAR FUEL (URANIUML CYCLE

\begin{tabular}{|c|c|c|c|}
\hline & Total Cyole & $\begin{array}{l}75 \% \text { CF. } \\
1258 \text { MWo }\end{array}$ & $\begin{array}{l}\% \text { Present } \\
\text { (M,M,C,E) }\end{array}$ \\
\hline $\mathrm{Cl}+$ & 8.4 & 9.9 & 100 \\
\hline $\mathrm{Na}$ & 11.6 & 13.7 & 100 \\
\hline $\mathrm{NH}_{3}$ & 11.5 & 13.5 & 13 \\
\hline Tailing Solution & 240,000 & 283,000 & 100 \\
\hline Fo & 0.4 & 0.5 & 100 \\
\hline \multicolumn{4}{|l|}{ Solids } \\
\hline Mill tailings & 91,000 & 107,000 & 100 \\
\hline Enrichment tails & 130 & 153 & 100 \\
\hline \multicolumn{4}{|l|}{$\begin{array}{l}\text { Radiolegical } \\
\text { (Ci) }\end{array}$} \\
\hline \multicolumn{4}{|l|}{ Gases: } \\
\hline Rn-222 & 74.5 & 87.7 & 100 \\
\hline $\mathrm{Ra}-226$ & 0.02 & 0.02 & 100 \\
\hline Th-230 & 0.02 & 0.02 & 100 \\
\hline $\begin{array}{l}\text { Uranium } \\
\text { (entrained) }\end{array}$ & 0.032 & 0.038 & 100 \\
\hline \multicolumn{4}{|l|}{ Liquids: } \\
\hline $\begin{array}{l}\text { Uranium } \\
\text { (products) }\end{array}$ & 2.1 & 2.5 & 99 \\
\hline $\mathrm{Ra}-226$ & 0.0034 & 0.0040 & 100 \\
\hline Th-230 & 0.0015 & 0.0018 & 100 \\
\hline \multicolumn{4}{|l|}{ Solids: } \\
\hline Other than high level & 601 & 708 & 100 \\
\hline \multicolumn{4}{|l|}{ THERMAL } \\
\hline Process heat loads, TJ & 3480 & 4100 & 100 \\
\hline
\end{tabular}


IABLE 8.3.1-2

COMMERCIAL SCALE MIXED OXIDE FUEL FABRICATION PLANT PARAMETERS AND SOLID WASTE VOLUME

A) Typical Facility Paramotere:

Effective Operating Capacity

Ventilation Rate

$50 \mathrm{MT}(\mathrm{U}, \mathrm{Pu}) \mathrm{O}_{2}$ /year

$7000 \mathrm{cfm}$

Electrical Requirements

1 MWe

Water Requirements

$10,500 \mathrm{gal} / \mathrm{day}$

Cooling Tower Capacity

$2,200,000 \mathrm{Btu} / \mathrm{hr}$

Scrap Recycle Rate (U, Pu) $\mathrm{O}_{2}$ /year

Product:

Liquid Waste Treatment:

8 MT HM clean scrap/year (2 kg HM $\times 16$ HI $\times 245$ Days)

0.5 MT HM dirty scrap/year $1.14 \mathrm{~kg} \mathrm{HM} \times 16$ He $\times 245$ Dava)

Dry blend of $\mathrm{PuO}_{2}$ and $\mathrm{UO}_{2}$ (to pelletize and encapsulate in MOX fuel rods)

Process chemicals are recovered and recycled; all contaminated liquids are either, (1) solidified, (2) evaporated and with evaporator bottoms solidified, or (3) sampled and released as liquid offluent.

Liquid Effluente:

Cooling Water Blowdown

$1,800 \mathrm{gal} / \mathrm{day}$

Sanitary water

$2,200 \mathrm{gal} / \mathrm{day}$

Potentially Contaminated Liquids

$2,800 \mathrm{gal} / \mathrm{day}$ 
IABLE 8,3,1-2 (Cont'd)

COMMERCIAL SCALEMIXED OXIDE FUEL FABRICATION PLANT PARAMETERS AND SOLID WASTE VOLUME

B) Eatimated Solld Waste Volume and $\mathrm{PuO}_{2}$ content per year:

\begin{tabular}{|c|c|c|c|c|}
\hline \multirow{2}{*}{ Waste Stream } & \multirow{2}{*}{$\begin{array}{l}\text { Approximate } \\
\text { Volume Bofore } \\
\text { Packaging (cu } \mathrm{ft} \text { ) }\end{array}$} & \multicolumn{2}{|c|}{$\begin{array}{c}\text { No. of Container } \\
\text { Drums }\end{array}$} & \multirow{2}{*}{$\begin{array}{l}\mathrm{PuO}_{2} \\
\text { Content } \\
\text { (kg) }\end{array}$} \\
\hline & & 55 Gal. & 80 Gal. & \\
\hline HEPA Filters & 115 & 5 & 26 & 2.0 \\
\hline $\begin{array}{l}\text { Solidified Liquid } \\
\text { Wastes }\end{array}$ & 305 & 40 & - & 0.1 \\
\hline General Process Waste & 805 & 110 & - & 1.2 \\
\hline $\begin{array}{l}\text { Major Process } \\
\text { Components }\end{array}$ & 400 & $=$ & 38 & 0.1 \\
\hline TOTAL & 1,625 & 155 & 64 & 3.4 \\
\hline
\end{tabular}




\section{TABLE 8.3.1-3}

ESTIMATED DOSES FROM RADIOACTIVE LIOUID EEFLUENTS

\section{RELEASED FROM THE STATION}

$\begin{array}{lcc}\text { Maximum Total Body Dose From All } & \begin{array}{c}\text { Annual Dose } \\ \text { Imrem/yel }\end{array} & \begin{array}{c}\text { Appondix I } \\ \text { Objectivo [2] } \\ \text { [mrem/yr) }\end{array} \\ \begin{array}{l}2.32 \\ \text { (Adult) }\end{array} & 3 \\ \begin{array}{l}\text { Maxposure Pathways [1] } \\ \text { From All Exposure Pathways }\end{array} & \begin{array}{c}3.18 \\ \text { (Child-Bone) }\end{array} & 10\end{array}$

Notes: [1] Liquid effluent exposure pathways considered include fish ingestion, drinking water, and external exposure from shoreline sediments.

[2] 10 CFR 50, Appendix I numerical design objectives to meet the criterion - "As Low As Reasonably Achievable". 


\section{Combustion Engineering, Inc.}

\section{TABLE 8.3.1-4}

\section{ESTIMATED ANNUAL DOSES FROM GASEOUS EEFLUENT}

EROM A SINGLE UNIII

\section{Dose}

7.8

2.1

Maximum Beta Air Dose (mrad/yr)

Maximum Gamma Air Dose (mrad/yr)

MAXIMUM INDIVIDUAL ANNUAL DOSE (mrem/yr)

Skin Dose (1)

Total Body Dose (1)

Maximum Organ Dose (2)
6.0

1.3

13.9

(Infant-Thyroid)
Appendix 1 Objective

20

10

\section{NOTES: (1) Exposure from noble gas plume immersion pathway.}

12) Maximum exposure from tritium, iodine and particulate airborne effluent releases via the terrestrial exposure pathways (i.e., ground plane, vegetable, meat, and milk) and the inhalation exposure pathway. 
TABLE 8.3.1-5

\section{CESSAR SYSTEM 80 + ESTIMATED SOLID WASTE GENERATION}

BURIAL VOLUME BASIS III

$\begin{array}{lcc} & \begin{array}{c}\text { AVG VOLUME } \\ \text { CUBIC FEET/IYR-UNIT] }\end{array} & \begin{array}{c}\text { AVG ACTIVITY } \\ \text { CURIE/YYR-UNIII }\end{array} \\ \text { HIGH ACTIVITY BEAD RESINS [2] } & 506 & 283 \\ \text { LOW ACTIVITY BEAD RESINS [3] } & 1251 & 2 \\ \text { MECHANICAL FILTERS [4] } & 191 & 34 \\ \text { DRY ACTIVE WASTE [5] } & 2057 & 15\end{array}$

NOTES: [1] Burial volume following volume reduction. Extensive offsite volume reduction assumed for Dry Active Waste consistent with current industry practice. Average VR factor for DAW shipped from Duke system is approximately 18:1.

[2] High Activity Resins include primary cleanup and liquid radwaste processing resins.

[3] Low Activity Resins include secondary side condensate and steam generator blowdown cleanup resins.

[4] Mechanical filters include bag and cartridge type filters.

[5] Dry Active Waste includes contaminate rags, paper, and clothing. 


\subsubsection{Plutonium Carryover}

The plutonium carryover into the waste stream of the mixed oxide fuel fabrication facility was included in the overall discussion of the Fuel Fabrication Facility Waste Stream, Section 8.3.1.2. Table 8.3.1-1 summarizes the estimated $\mathrm{PuO}_{2}$ unrecovered from waste stream: $3.4 \mathrm{~kg}$ per year. Section 8.3.1.2.4 provides an estimate of the heavy metal dispersed to the atmosphere through the filtered exhaust system: $0.050 \mathrm{gm}$ of heavy metal $10.047 \mathrm{gm}$ uranium and 0.003 gm plutonium), annually.

In the reactor plant, heavy metal carryover to the radwaste management systems results from tramp contamination (contamination on the fuel rod surface due to fabrication or previous fuel rod leakage) or fuel fragments escaping from a pin-hole leak in the cladding. This heavy metal will circulate through the primary coolant loop, fissioning and transmuting. Some of it will precipitate out on the fuel rod surface and the steam generator tube surface with corrosion products (crud). Some will be deposited in the primary coolant cleanup and liquid radwaste processing resins or in various mechanical filters.

No explicit analyses are performed for the System $80+$ plant to estimate or bound the amount of heavy metal that could ultimately end up in the waste streams. Although, the activity of $\mathrm{Np}^{233}$ in the reactor coolant during normal operation is calculated, this is based on the very prescriptive guidance provided in USNRC NUREG-0017. The results for the System $80+\mathrm{UO}_{2}$ equilibrium core are provided in CESSAR-DC Section 11.1. Section 11.2 of CESSAR-DC provides the design basis average liquid effluent concentrations in the Liquid Radwaste Management System, as well as the normal operating daily liquid effluent concentrations. Included in the reported activities is one heavy metal isotope: $\mathrm{Np}^{238}$. These values also reflect the methodology of NUREG-0017. No other heavy metal isotope is identified. However, the presence of ${ }^{239} \mathrm{~Np}$ implies the presence of $\mathrm{U}^{238}$ and $\mathrm{Pu}^{238}$, but their activities are presumably sufficiently low that they do not warrant inclusion in the tables.

The Solid Waste Management System receives resins from the Chemical and Volume Control System, the Liquid Waste Management System, the secondary side condensate cleanup system, and the steam generator blowdown cleanup system. It receives bag and cartridge type filters and dry active waste (rags, paper, and clothing). Activity of radionuclide carryover to the Solid Waste Management System for System 80 + is provided in CESSAR-DC Section 11.4 and does include activities for several isotopes of $\mathrm{Pu}, \mathrm{Am}$, and $\mathrm{Cm}$. Table 8.3.2-1 is an abstract from CESSAR-DC Table 11.4-5, Solid Waste Source Term for Normal Operation. These values are not explicitly linked to any assumptions of reactor behavior or failed fuel, but are based on Duke Power facilities operational data over a specific period of time. 


\section{Combustion Engineering, Inc.}

A quantitative calculation of the plutonium carryover into the waste streams of a System $80+$ reactor used for plutonium disposition has not been made. The MOX fuel heavy metal loading includes $6.75 \%$ plutonium, and the discharge fuel will have $\mathrm{Pu}$ isotopes similar to discharge from an $\mathrm{UO}_{2}$ core. For the $\mathrm{Pu}$ disposition mission, the overall quantity of heavy metal in the waste stream is expected to be the same as given in a $\mathrm{UO}_{2}$ core, but a higher plutonium content should be anticipated. 
Iable 8.3.2.1

CESSAR SYSTEM 80 + SOLID WASTE SOURCE TERM FOR NORMAL OPERATION ESTIMATED AVERAGE RADIONUCLIDE CONCENTRATIONS (wCi/om) W11

\begin{tabular}{||l|l|l|l|l||}
\hline $\begin{array}{l}\text { High Activity } \\
\text { Nuclide }\end{array}$ & $\begin{array}{l}\text { Low Activity } \\
\text { Resin }\end{array}$ & $\begin{array}{l}\text { Mechanical } \\
\text { Resin }\end{array}$ & $\begin{array}{l}\text { Dry Active } \\
\text { Filters }\end{array}$ & Waste $^{(\mathrm{e})}$ \\
\hline \hline${ }^{237} \mathrm{~Np} /{ }^{242} \mathrm{Pu}$ & $1.6 \mathrm{E}-05$ & $1.2 \mathrm{E}-07$ & $1.5 \mathrm{E}-05$ & $6.2 \mathrm{E}-06$ \\
\hline${ }^{238} \mathrm{Pu}$ & $1.7 \mathrm{E}-04$ & $1.8 \mathrm{E}-05$ & $1.6 \mathrm{E}-02$ & $4.1 \mathrm{E}-05$ \\
\hline${ }^{239} \mathrm{Pu} /{ }^{240} \mathrm{Pu}$ & $1.0 \mathrm{E}-04$ & $4.6 \mathrm{E}-06$ & $6.1 \mathrm{E}-03$ & $3.6 \mathrm{E}-05$ \\
\hline${ }^{241} \mathrm{Pu}$ & $8.1 \mathrm{E}-02$ & $1.9 \mathrm{E}-04$ & $8.6 \mathrm{E}-01$ & $2.6 \mathrm{E}-03$ \\
\hline${ }^{241} \mathrm{Am}$ & $4.8 \mathrm{E}-05$ & $5.0 \mathrm{E}-07$ & $2.3 \mathrm{E}-03$ & $1.5 \mathrm{E}-05$ \\
\hline${ }^{242} \mathrm{Cm}$ & $1.7 \mathrm{E}-04$ & $8.5 \mathrm{E}-07$ & $1.6 \mathrm{E}-02$ & $1.6 \mathrm{E}-05$ \\
\hline${ }^{243} \mathrm{Am}$ & $1.3 \mathrm{E}-06$ & $8.4 \mathrm{E}-08$ & 0.0 & $7.8 \mathrm{E}-07$ \\
\hline${ }^{243} \mathrm{Cm} / /^{244} \mathrm{Cm}$ & $6.1 \mathrm{E}-05$ & $5.0 \mathrm{E}-07$ & $5.1 \mathrm{E}-03$ & $9.4 \mathrm{E}-06$ \\
\hline
\end{tabular}

Notes: [1]

(a)

(b)

(c)

(d)
Based on Duke Power facility averages for January ' 89 through June '92.

High activity resins include primary cleanup and liquid radwaste processing resins.

Low activity resins include secondary side condensate and steam generator blowdown cleanup resins.

Mechanical filters include bag and cartridge type filters.

Dry Active Waste includes contaminate rags, paper, and clothing. 


\subsection{Protection Againat Criticality}

A criticality accident is defined as being the occurrence of conditions producing a self-sustaining or divergent neutron chain reaction. Because the nuclear reaction produces large amount of neutron-and gamma-radiation, the personnel present in the accident area must evacuate it immediately. In $\mathrm{MF}^{2}$ the safety of the workers, relating to criticality, rests on the prevention, the detection, the alarm systems and the personnel evacuation.

\subsubsection{Prevention}

Criticality accidents can be prevented by the design of the equipment, the lay out of the process area and the full implementation of well defined operating procedures. The equipment must be designed with such dimensions that criticality accidents could never occur. Also storage cell, ventilated enclosures and process areas are designed such that the quantities of fissile materials are limited to well defined amounts. The physical dimensions of the equipment as well as the authorized amounts of fissile material in each operation is determined by criticality calculations, operating conditions and safety criteria.

\subsubsection{Detection and Alarm}

Detaction and alarm systems are provided wherever there is a potential criticality risk. They are designed to detect a criticality accident within a very short time delay. Gamma-ray detection can be used uniformly throughout the system and the alarm signal is distributed to be heard in all areas which are to be evacuated.

\subsubsection{Eyacuation}

If a criticality accident occurs, the affected area must be evacuated. The personnel will evacuate by the quickest and most direct practicable routes which are clearly marked out. The MOX process areas are so designed that within a well defined time delay, any individual can leave the area where the accident has occurred, and the thickness of the walls, separating the process areas, will minimize the radiation doses received by operating personnel in other areas of the plant. The detection and alarm system is designed in such a way that, consequently to an alarm signal, it is possible to confirm the accidental situation and to measure the dose rate in the accident area. This will facilitate decisions and rescue operations, corrective action and/or permit personnel access to areas previously vacated. 
9.0 NON-PLUTONIUM DISPOSITIONING OPERATIONS

$9.1 \quad$ Tritium Production

\subsubsection{Introduction}

The objectives for the Plutonium Disposition Study were specified by DOE in a Requirements Document released on January 21, 1993 (Reference 1). A requirement specified in the Requirements Document was that the reactor complex have the option of producing a specified quantity of tritium. This part of the report addresses the tritium production capability and technical issues associated with producing tritium in the CE System 80 + reactor concept. While not explicitly identified as a requirement, the tritium production mission has been configured so that weapons-grade plutonium is burned as fuel during the tritium production mission. The flexibility of System $80+$ to produce tritium, dispose of plutonium and produce electric power provides overall cost benefits, minimization of the number of units needed to perform these functions and benefits the mission schedule.

\subsubsection{Scope of Studx}

Work objectives include neutronic analysis to determine the assembly and target design parameters required to produce contract quantities of tritium. Changes in the plutonium burning only design required to produce tritium are analyzed for their effect on plant operations and safety. Impacts on reactor control systems, core thermal performance and transients, and fuel management options are identified and assessed. The effects on operational and environmental issues are addressed.

In addition to plant operations, a discussion of the current state of light water tritium target development is included. The additional facilities and operations required for target fabrication and tritium extraction are described. Additional target development needs are addressed.

Tritium production in uranium fueled start-up cores was also assessed. It is anticipated that reactor construction may be complete before fuel fabrication facilities are available to provide the plutonium fuel for destruction. In the event that tritium production is desired during this period of time, the feasibility of producing tritium with a uranium fueled core was investigated.

\subsubsection{Iritium Production Assembly Desion Description}

The development of a fuel assembly design which will produce tritium as well as burn plutonium in a light water reactor is an evolution of a plutonium burning assembly developed by CE. The plutonium burning assembly has its genesis in the commercial CE System $80+$ design. The plutonium burning version has been designated as the 
System $80+P$. The evolution to an assembly which both burns plutonium and produces tritium is designated as the System $80+$ PT.

The System $80+\mathrm{PT}$ assembly design is based on the System $80+\mathrm{P}$ design, with only minor modifications to the mechanical design. The mechanical modifications to the design are needed to accommodate the tritium production mission. Since the design modifications are minor, and most effects of the modifications are expected to be within the operational and safety envelope of the System $80+P$ design, all performance and safety effects of the modifications are related directly to the System $80+P$ design. The intent is to show that the System $80+P$ and the System $80+P T$ can operate within the same design envelope. However, modifications to the fuel cycle are required to meet production requirements.

\subsubsection{Reference Plutonium Desion (System $80+P$ )}

The reference System $80+P$ assembly design is described in detail in Section 2.0 of this report and in Reference 9.1-2. A brief summary is provided here to allow for comparison to the tritium production design.

Table 9.1-1 gives a summary of the major System $80+P$ design parameters. The design operating core power for the System $80+P$ is $3800 \mathrm{MWth}$. This power is obtained with a loading of $6.7 \mathrm{w} / 0$ weapons-grade plutonium in heavy metal and an average erbium oxide loading of less than 2.5 w/o in MOX. Each assembly in the System $80+P$ core has twelve burnable poison rod (BPR) locations. Figure 9.1-1 shows the assembly layout of the System $80+P$ design.

The reference System $80+P$ design is expected to meet all required neutronic and thermal hydraulic safety margins necessary for the licensing of a commercial reactor core. Preliminary studies of control margins have been performed using the additional control locations available in the System $80+$, and the indication is that sufficient rod worths and control margins exist in the reactor to operate safely. Since the basic assembly and balance-of-plant design is the same as the System $80+$, and the average linear heat generation rate is the same as the System $80+$, thermal margin and transient performance are expected to be within the design envelope of the commercial System $80+$ design. For a more complete discussion of the System $80+P$ design, see Section 2 of this report.

\subsubsection{Plutonium Burning-Tritium Producing Assembly Desion (System $80+$ PT)}

\section{Euel Mechanical Design Requirements}

The tritium production option has been assessed for the System $80+P$ reactor design. The conceptual design of the System 80 + PT allows for the continued destruction of plutonium while at the same time producing desired tritium quantities. The design characteristics of the fuel assembly have been slightly modified, however, such that 
plutonium burning and power production are no longer optimized. The deviations in design are sufficiently minor that major plant design modifications are not required.

Thirty-two target rods per assembly are required to produce the desired tritium quantities. The quantity of tritium which can be produced per target rod is limited by target rod design considerations. To meet production requirements set forth in DOE guidance' while staying within the established target performance envelope, more targets are required in a fuel assembly than the available BP locations. A detailed discussion of the target design is provided in Section 9.1.7.

In order to make room for the thirty-two target rods, the twelve BPR locations and twenty of the fuel rod locations will be designed to accommodate target rods. Each target rod will have a non-structural guide tube of the same design as those used for BPRs in the System $80+P$ design. These guide tubes hold the targets in place in the assembly, and provide easy insertion and removal of targets after every cycle. They also protect the targets from thermal heat-up during transients.

The fuel mechanical design requirements for modification of the ABB/CE System $80+P$ core design for tritium production are minor; the fuel assembly hardware for the System $80+P T$ core will be nearly the same as that for the System $80+P$ core. The target rods will have the same diameter as the BPRs in the System $80+P$ assembly design, and will fit into the same guide tubes used for BPRs in the System $80+P$ design.

The target rods will be affixed to a base plate that fits under the top nozzle flow plate. The target rods will slide into the guide tubes provided in the fuel assembly, and the target base plate will have the same flow orifices as the top nozzle flow plate. The target subassembly will be constructed and placed in the fuel assembly at the fabrication plant.

\section{Iritium Production Operational Requirements}

To meet production requirements, the reactor fuel cycle must also be altered. Analysis has shown that greater than contract quantities of tritium are produced in the System $80+$ PT core when a one-batch core is operated on a 1-year cycle, with fresh fuel being loaded every cycle. Multi-batch cores have not been analyzed for this study. Tritium can also be made using multi-batch cores or longer cycles, however some tritium production capability is likely to be lost.

Since the desired goal is to remain within the same safety design envelope as the System $80+P$ assembly design, maintaining the same average linear heat generation rate (LHGR) is a reasonable method of accomplishing this objective. The average LHGR for the System $80+P$ core is approximately $5.5 \mathrm{~kW} / \mathrm{ft}$. The removal of 20 fuel pins

Letter from J. A. Delos Santos to D. F. Newman dated March 19, 1993 
per assembly to accommodate the target rods requires that the total core power be reduced in order to maintain this average LHGR. The System $80+P T$ core is therefore proposed to operate at a reduced power of $3410 \mathrm{MWth}$.

Table 9.1-1 lists the major design features of the System $80+$ PT. Comparison to the System $80+P$ parameters indicates additional minor changes which were made to further optimize the tritium production assembly design. Figure 9.1-2 shows the assembly pin layout in the System $80+$ PT core including the additional target pins.

\section{Euel Assembly Leading}

The System $80+$ PT conceptual core has been analyzed using an averaged fuel assembly design. Full core calculations have not yet been performed, so the effects of variations in axial or radial enrichment patterns have not yet been determined. It is anticipated that continued work would include parametric calculations which will lead to design optimization.

The System $80+\mathrm{PT}$ fuel rods contain a single enrichment of $7.38 \mathrm{w} / 0 \mathrm{PuO}_{2}$ and 0.5 $\mathrm{w} / 0 \mathrm{Er}_{2} \mathrm{O}_{3}$ in MOX. The fuel and poison loadings in the System $80+P T$ core are marginally different from the System $80+P$. The $\mathrm{PuO}_{2}$ concentration has been increased slightly from $6.7 \mathrm{w} / 0$ to $7.38 \mathrm{w} / 0$ to maintain the same total core mass of plutonium as in the System $80+P$. This additional concentration is required because of the removal of fuel pins to accommodate the required targets. By increasing the plutonium concentration in fuel and maintaining the same fissile content as the System $80+P$, the effective amount of weapons-grade plutonium dispositioned per year remains constant.

The neutronic design for the System $80+$ PT assemblies was performed using the WIMS-E neutronics code (Reference 3). The WIMS-E code model uses a twodimensional, integral transport methodology to calculate reactivity, temperature coefficients, and tritium production capabilities of the tritium production assembly. Figure 9.1-3 shows reactivity plotted against burnup for the tritium production core, and Figures 9.1-4 and 9.1-5 show the moderator temperature coefficients and doppler coefficients, respectively, with burnup.

The calculated moderator temperature coefficients for the System $80+P$ core are also provided in Figure 9.1-4 for comparison. This comparison indicates that the System $80+P$ and the System $80+P T$ cores are neutronically similar, having coefficient values within acceptable ranges of each other. The two cores would therefore be expected to operate similarly during moderator temperature transients. Fuel temperature coefficients were not available for comparison to the System $80+$ PT. However, the coefficients shown in Figure 9.1-5 are comparable to coefficients in commercial reactor cores, which are in the range of $-2.0 \times 10^{-5}$ to $-1.0 \times 10^{-5} \Delta p^{\circ} \mathrm{F}$. 
The two cores will differ slightly in the total number of plutonium atoms destroyed per year since the total core power in the System 80+PT is lower than in the System $80+P$. Figure 9.1.6 shows the plutonium isotopic destruction in the System $80+P T$ and the System $80+P$. This comparison shows that the total number of plutonium atoms that can be destroyed in a tritium producing core is only about $1 \%$ less than in the System $80+P$ at the same exposure.

The erbium loading in the tritium production assembly is smaller than in the System $80+P$. This is largely due to the reactivity effects of the increased core poison loading held in the target rods. The tritium target rods effectively act as burnable poisons in the tritium core, and the total poison loading of target rods is greater than the BPRs in the System $80+P$. The erbium loading must therefore be lowered to meet total core reactivity requirements.

Parametric studies on fuel design parameters have not yet been performed for the System $80+$ PT. Studies performed would investigate how variations in design parameters such as fuel, target and poison loadings affect performance, safety, and production parameters. The results of these parametric studies would be used to further optimize the tritium production assembly. These parametric studies are not appropriate to the level of this study. Full core calculations have not been performed, and it is expected that the results of full core calculations will be required to optimize the design. It is expected that these studies will allow the design to be further optimized to enhance plutonium destruction as well as tritium production. As an example, core design optimization will probably permit an increase in core power during the tritium production mode.

\subsubsection{Iarget Desion}

The System $80+$ PT core design utilizes tritium producing targets located in guide tubes. The targets are similar in design to the targets which have been developed as part of the Light Water NPR Tritium Target Development Program (TTDP). Design parameters for fabrication and tritium extraction from the System $80+P T$ targets are expected to be well within the development and performance parameters of the targets designed for the TTDP.

The TTDP was brought to a premature end in FY-1992. The qualification of the target rods for use in an LWR was therefore not completed. A brief summary of the accomplishments of the TTDP are provided here. The specific design used for the System $80+P T$ is also detailed in this section. Additionally, a brief plan for completion of target rod qualification activities is provided, including cost estimates and schedules.

\subsection{TTDP Summary}

The mission of the TTDP was to demonstrate and qualify a high temperature target system for use in a LWR with the fabrication and extraction processes sufficiently 
confirmed to ersure a deployable system consistent with production needs. To meet the performance requirements of the getter-barrier target rod concept, the target rod must be capable of meeting production requirements; it must retain the tritium within acceptable limits in a PWR environment; and the tritium produced in the rod must be extractable by means of a feasible, production compatible process that meets waste minimization and environmental requirements.

By the end of FY-1992, when the program was terminated, the technical feasibility of the target concept to produce tritium in an LWR had been demonstrated. However, the full qualification of the getter-barrier target rod design necessary for implementation of the complete system had not been completed. Selected highlights of the project that pertain to the performance of the getter-barrier target rod design are as follows:

-

- 
 \\ Combustion Engineering, InC. NON.PLUTONIUM DISPOSITIONING OPERATIONS}

testing the PRF of cladding using $D_{2}$, thus avoiding the problems associated with $\mathrm{T}_{2}$.

- Extraction demonstrations were conducted with 4-ft. long target rods using hydrogen- and deuterium-loaded getters.

The feasibility of an extraction method that uses a single puncture of the rod, release of the tritium during heat-up, and reseal of the hole to facilitate disposal were demonstrated. The data were used to benchmark an extraction model.

In addition to the above getter-barrier target rod performance evaluations, neutronics and thermal hydraulics analyses were performed to evaluate the tritium production capability of $5 \%$ and $10 \%{ }^{238} \mathrm{U}$-enriched cores.

\subsection{System 80+ PT Target Design}

Figure 9.1-7 shows a cut-away of the target structure. Table 9.1-2 lists the dimensions and composition of the target components. The major functional components of the target are the pellet, the liner, the getter, the barrier-coated clad and the non-structural guide tube. The pellet is lithium aluminate. Lithium-6 in the target pellet absorbs neutrons to form tritium and helium as shown in the reaction below:

$$
{ }^{0} \mathrm{Li}+\mathrm{n} \rightarrow{ }^{3} \mathrm{H}+{ }^{4} \mathrm{He}
$$

The zirconium liner effectively dissociates any THO or $\mathrm{T}_{2} \mathrm{O}$ which forms into its constituent atoms. The getter is made of nickel coated zirconium. The zirconium absorbs tritium atoms in the target and keeps them immobile. The nickel coating prevents oxide layers from building and prohibiting the passage of tritium into the getter. The stainless steel cladding encapsulates the target components to contain the tritium, and the aluminum barrier coating is an effective permeation barrier to tritium.

The target guide tube function is twofold. The first function is merely to hold the target in place in the core, and to allow easy removal and replacement of the targets. It is essentially a tube into which the target is slid. The second purpose is to protect the target from the effects of transients. In design basis transients such as LOCAs, the guide tube thermally isolates the target from the potentially high radiative heat transfer from the fuel pins. In extreme cases, the guide tube may reduce the maximum temperature of the target clad by $400^{\circ} \mathrm{F}$ when compared to the same design basis event (DBE) using targets without guide tubes.

The target mechanical design is governed by the expected neutronic and mechanical performance requirements in the core. The target performance envelope is defined primarily by two considerations: the gas-to-volume ratio (GVR) in the target and the 
potential target internal gas pressure during a transient. This performance envelope controls many aspects of the fuel assembly design because it governs the quantities of tritium that can be made per target, and therefore the number of targets needed to produce a given quantity of tritium.

The GVR criterion is imposed because the evolution of excess gaseous products in a given target volume may cause the target pellet to disintegrate. Relocation of the target pellet poison material after disintegration could cause detrimental reactivity effects in the core, possibly leading to excessive localized power peaking. The maximum GVR of the maximum exposure target in the core must therefore be lower than a specified limit to ensure that no target pellets suffer disintegration from internal gas effects.

The GVR limit for the target design has been set conservatively low. Indications from the TTDP are that higher limits could be set, but the premature termination of the TTDP did not allow this to be verified. In addition to the conservative design limit, the exposure calculation used for design calculations assumes a conservatively high average total peaking factor of $\mathbf{2 . 0}$ for the entire irradiation period of the target. It would not be expected that any one target would experience total peaking to this extent for the entire cycle. This is a conservative power peaking assumption, thereby adding additional conservatism in the target design.

The assumed target internal gas pressure used for target design is conservatively high. High internal gas pressures could result from a DBE such as a large break LOCA. During such accidents, the target temperature rises, increasing internal target gas pressure. Additionally, at higher temperatures some tritium desorbs from the getter and target pellet, increasing the internal gas pressure further. The cladding yield strength also decreases with increasing temperature.

Indications from the TTDP are that the desorption of tritium from the target materials occurs slowly relative to the time length of a DBE. Design basis transients would only produce high temperatures for a few minutes at most, but for target design purposes it is assumed that $100 \%$ of the gas is immediately released from the getter and target pellet. The targets are then designed not to breach even during this maximum pressure loading. This design basis is even more stringent than the design basis for fuel pins, for which a limited number of fuel pins are permitted to rupture during design basis events.

Since the target performance envelope used in this study is considered to be very conservative, there is a high degree of confidence that target integrity will be maintained during all operating and transient conditions. The target is considered extremely robust, and is likely to maintain integrity at least as long, if not longer, than typical fuel rods during a DBE. Activities performed under the TTDP have increased the understanding of some target phenomena, and the confidence in the performance capabilities of the target is very high. Further design development of the targets is still 
required. However this development will probably allow for a better understanding of the target performance and a reduction in the conservatism now used in the design.

Having assumed that $100 \%$ of the gas releases to the target free volume, the maximum target cladding temperature for which the design yield stress will not be exceeded is $1300^{\circ} \mathrm{F}$. Again, it is assumed that the transient occurs at EOC, when the gas inventory is greatest, and that the peak target has experienced an average 2.0 peaking factor during the cycle. It must also be remembered that the target guide tube is protecting the target clad, and that the guide tube temperature may be much higher than $1300^{\circ} \mathrm{F}$.

The LWR tritium target design is very flexible within the bounds of the performance envelope. Continued development of the tritium target technology would allow a decrease in the conservatism used in the target design. Also, further analysis of the System $80+$ PT core design would allow refinement of reactivity and power peaking factors which may allow further reductions in conservatism, thereby allowing further optimization of the target and assembly designs.

\subsection{Target Rod Qualification Plan}

Although the getter-barrier target rod development effort was extensive (about \$70M was spent from FY-1989 through FY-1992) and was well on its way to completing the technical validation activities necessary to establish the final qualification package for the target, it was recognized at the time the project was terminated that some additional activities were required before a fully qualified, licensable target design package could be produced. At the request of DOE-NPR, the activities required to complete the development of the getter-barrier LWR target were evaluated near the time the program was terminated. At the time (February 1992), it was estimated that this could be accomplished in two years for an estimated cost of $\$ 30 \mathrm{M}-\$ 40 \mathrm{M}$.

The remaining activities associated with qualification of the target rod performance have been reviewed in relation to the current objectives and needs of the System $80+$ Plutonium Disposition Study, and with regard to the changes which have occurred since February 1992. Because the equipment that supported the program has been disposed of, a rough estimate of the cost and time required to re-establish the needed capabilities and perform the work was also developed. Table 9.1-3 lists the estimates costs associated with completion of the TTDP work. Figure 9.1-8 shows a projected schedule for completion of the work.

\section{Preliminary Desian Review}

A preliminary design review is required to formally incorporate lessons learned and empirical experience into a revised target rod design to form the basis for completion of the development of the getter-barrier target. This review will establish new performance requirements or standards and revised specifications for target rod 
fabrication processes. One important design-related consideration is evaluation of the data base to potentially support eliminating the aluminide barrier on the outer surface of the cladding tubes. If this is possible, it would simplify the fabrication process, thereby reducing cost and improving compatibility of the target rods with the reactor coolant environment.

\section{Vendor Qualification}

The qualification of commercial vendors to produce getters, form the aluminide barrier coatings on the surface of full-length cladding tubes, and produce lithium-aluminate target pellets on a production scale that meets or exceeds the engineering specifications is required.

\section{Eabrication Demonstration}

A large lot (100-200 rods) target rod fabrication demonstration must be conducted with full-length rods to validate the assembly process specifications. Based on the experience gained, refine the process for production quantities. The activity would include the development of the conceptual layout for the target rod assembly and inspection steps.

\section{NDE System Qualification}

The operating procedures and demonstration of a fully tested, validated NDE system for evaluating barrier coating quality on a production basis must be prepared

\section{Lead Test Assembly Irradiation Demonstration}

A Lead Test Assembly (LTA) containing getter-barrier target rods for a full-term irradiation demonstration in a commercial reactor must be designed and fabricated. More than one LTA may be needed to achieve core symmetry.

\section{Assembly Mechanical Testing}

Flow and vibration testing of typically-designed assemblies containing target rods dispersed among standard $\mathrm{UO}_{2}$ rods to confirm acceptable mechanical performance of the assembly under prototype flow conditions must be conducted.

\section{Post-Irradiation Evaluation (PIE)}

Non-destructive and destructive PIE on selected irradiated LTA rods must be performed to confirm burnup, tritium production, tritium retention by the getter, and tritium partitioning among the target rod components. In order to accomplish this, it will be necessary to reestablish a PIE facility capability. 


\section{$\mathrm{D}_{2} \mathrm{I}_{2}$ Correlation Validation}

The permeation correlation of $D_{2}$ and $T_{2}$ through barrier-coated stainless steel cladding as a function of time, temperature, and pressure must be validated by means of a comprehensive set of experiments. Validation of this correlation is needed to support the use of $D_{2}$ instead of $T_{2}$ for evaluating the quality and acceptability of barrier-coated cladding tubes, for evaluating the validity of extraction tests using $D_{2}$, and for predicting target rod behavior during normal, extraction, and off-normal conditions.

\section{Iritium Release Kinetics Validation}

Tests must be conducted to establish the tritium release kinetics from the getter material and the lithium aluminate target pellets as a function of time, temperature, and pressure. This data is needed to optimize the extraction process, to develop an integrated target performance model, and to reduce conservative tritium release assumptions in LBLOCA and cladding breach models.

\section{Eull-Length LOCA Testing}

Breach tests must be conducted on full-length target rods to establish the ejection behavior of the reactive lithium aluminate pellets under LBLOCA conditions. Tests conducted on target rods up to four feet long indicate that minimal amounts of pellet relocation occurs, but this result needs to be confirmed using full-length rods.

\section{Eull-Length Target Rod Extraction Testing}

Extraction tests must be conducted on full-length target rods using $D_{2}$-loaded getter material to optimize the extraction processing parameters and evaluate furnace operation to establish design and processes for the production scale tritium extraction facility. The results of these tests will also be used to establish processing parameters and facilities that minimize tritium releases to the environment.

\section{Final Target Rod Qualification Package}

The Final Target Rod Qualification Package will form the basis of the licensing submittal for the target rods. It will consist of a Target Rod Fabrication Data Package; a Target Rod Design Data Package; a Tritium Extraction Process Data Package; and a Handling, Storage, Transportation, and Waste Characteristics Data Package.

\section{Iarget Rod Fabrication Data Package}

This package will serve as the design basis for the target rod fabrication facility. The package will include fabrication specifications, material specifications, process descriptions, NDE equipment specifications, process and $\mathrm{QC}$ procedures, a $\mathrm{QA}$ inspection plan, and the supporting data bases. 


\section{Iarget Bod Desion Data Package}

This package will serve as the basis for regulatory review of the getter-barrier target and development of reactor core configurations. The specifications will include inreactor performance limits, response of the target to off-normal conditions, rod tritium production, rod characteristics, and the supporting data bases.

\section{Iritium Extraction Process Data Package}

This package will serve as the design basis for the extraction facility. It will include process descriptions; furnace, vacuum system, and tritium recovery system performance specifications; and the supporting data bases.

\section{Handling, Storage, Transportation, and Waste Characteristics Data Package}

This package will serve as the basis for shipping cask design and the design of auxiliary irradiated target rod storage and handling systems.

\subsection{TTDP Notes}

Evaluation of the effectiveness of the aluminide barrier coating on the inside and outside surfaces of the stainless steel cladding tubes as a tritium permeation barrier was a major focus of the TTDP. The effects of different processing parameters used during application of the coatings were investigated, and an NDE method was refined that permitted characterization of the coatings along with a correlation with PRF.

Tests were performed to evaluate the relative permeation effectiveness of the coatings on the inside and outside cladding surfaces. Autoclave tests showed that the barrier coating on the outside cladding surface corroded rapidly, i.e., in a matter of hours, when exposed to simulated PWR coolant conditions. Post-irradiation examination of the cladding from one of the capsule test rods also showed that the coating on the outside surface was severely degraded during reactor exposure. Analysis of the permeation results indicated that the barrier coating on the inside surface maintained an acceptable PRF for the cladding. In addition, in-reactor tritium permeation results from the capsule test with a rod that did not have a coating on the outside surface indicated that although the tritium leakage was greater than the capsule that had cladding coated on both surfaces, the tritium leakage rate was satisfactory within a factor of about two.

The reason for pointing out the observations and conclusions cited above is that there is a significant incentive in building a case for eliminating the barrier coating on the outside cladding surface of the getter-barrier design target rods. Elimination of thie barrier on the outer cladding surface would simplify the fabrication process and reduce costs, as well as eliminating the corrosion and aluminum contamination of the PWR coolant. 


\section{PLUTONIUM DISPOSITION STUDY
Combustion Engineering, InC. NON-PLUTONIUM DISPOSITIONING OPERATIONS}

Because of the nature of the tests that were performed and differences that existed in the tests, there are nuances in the data bases from which the above conclusions are made. Thus, there is a need to re-examine the data base with the objective of assessing the validity of eliminating the outer barrier for the getter-barrier target design. However, for the purpose of the Target Rod Qualification Plan, it was judged that evaluation of the data base will justify and support the argument for eliminating the barrier coating on the outer cladding surface. Although there is a recognized risk in this approach, it is on this basis that an additional irradiation test in the ATR loop prior to LTA irradiations in a commercial reactor is not proposed. Such a test would be costly, and it would take about five years to obtain the results. 
Combustion Engineering, Inc.

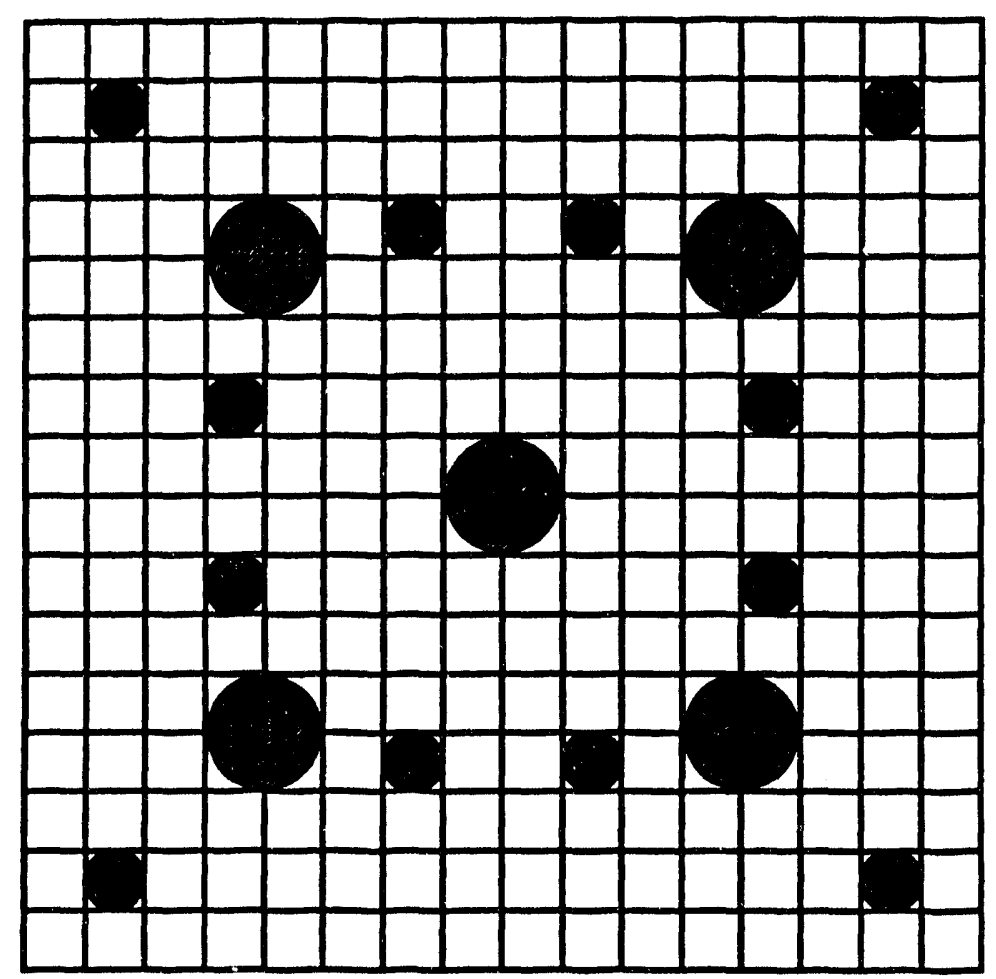

Burnable Poison Rod

Control Rod

Instrument Tube

FIGURE 9.1-1

SYSTEM 80+ P FUEL ASSEMBLY LAYOUT 
Combustion Engineering, Inc.

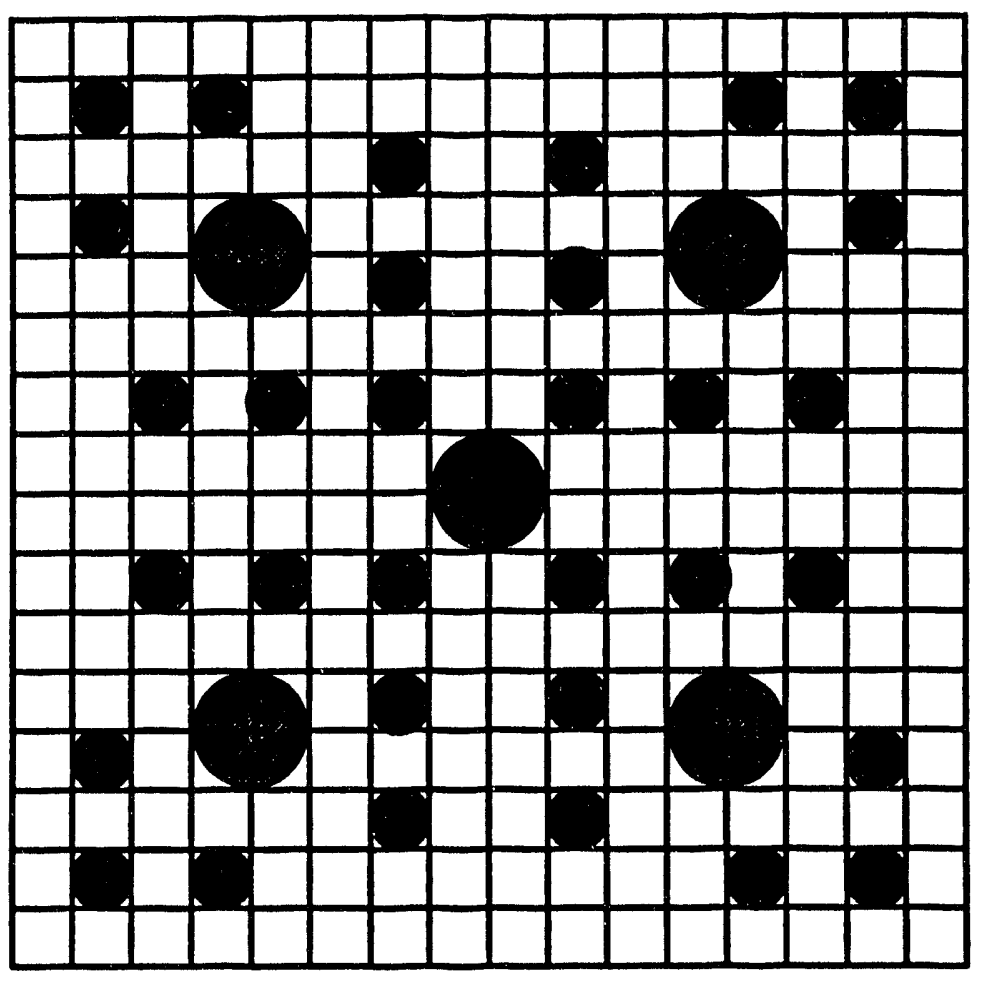

Tritium Target

Control Rod

Instrument Tube

FIGURE 9.1-2

SYSTEM 80+ PT FUEL ASSEMBLY LAYOUT 
Combustion Engineering, Inc.

at 1000 ppm Natural Boron



MWD/MT

FIGURE 9.1-3

REACTIVITY BURNUP CURVE FOR SYSTEM 80+ PT FUEL 
Combustion Engineering, Inc.

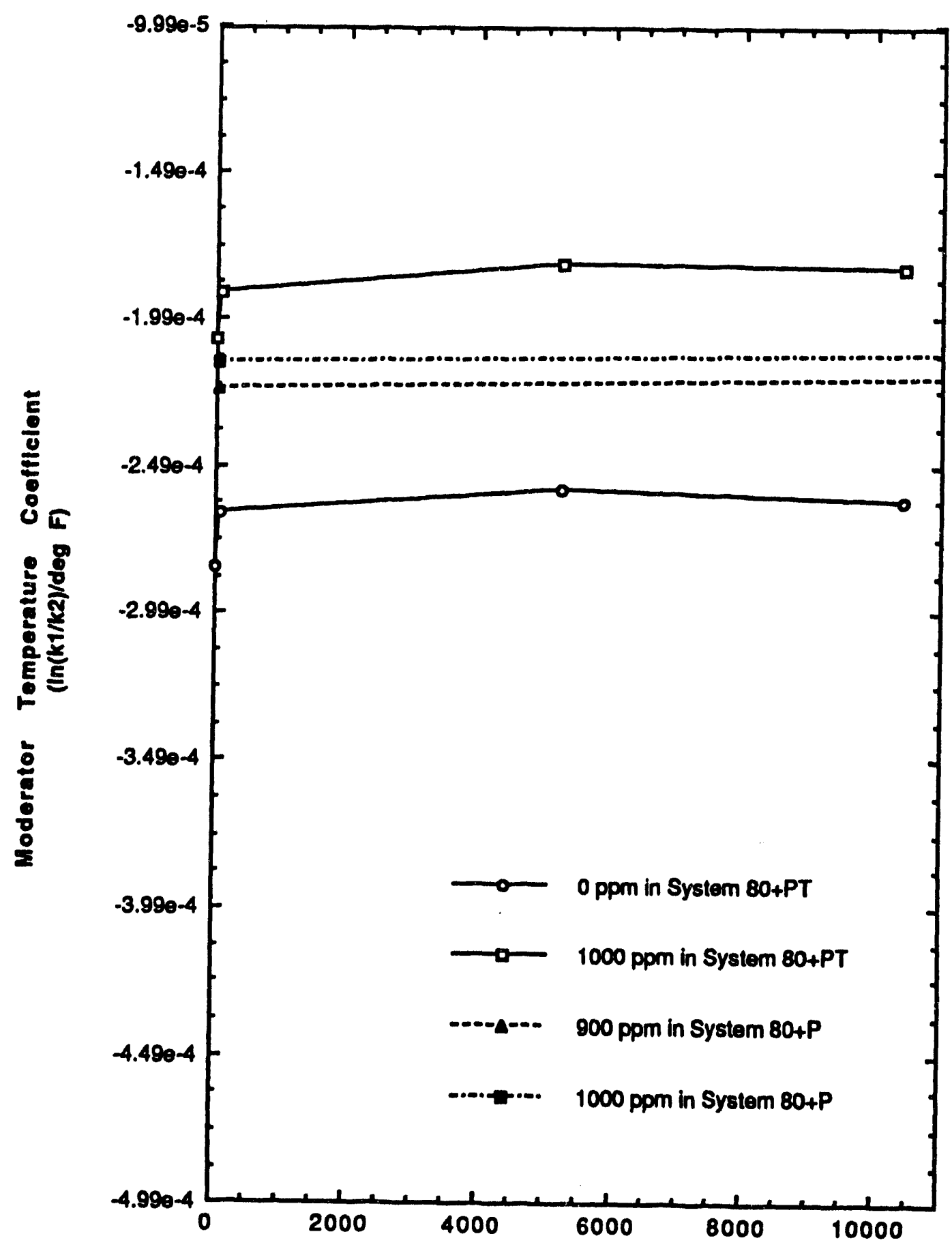

MWDIMT

FIGURE 9.1-4

MODERATOR TEMPERATURE COEFFICIENT CURVES FOR SYSTEM 80+ P AND SYSTEM 80+ PT FUEL 
Combustion Engineering, Inc.

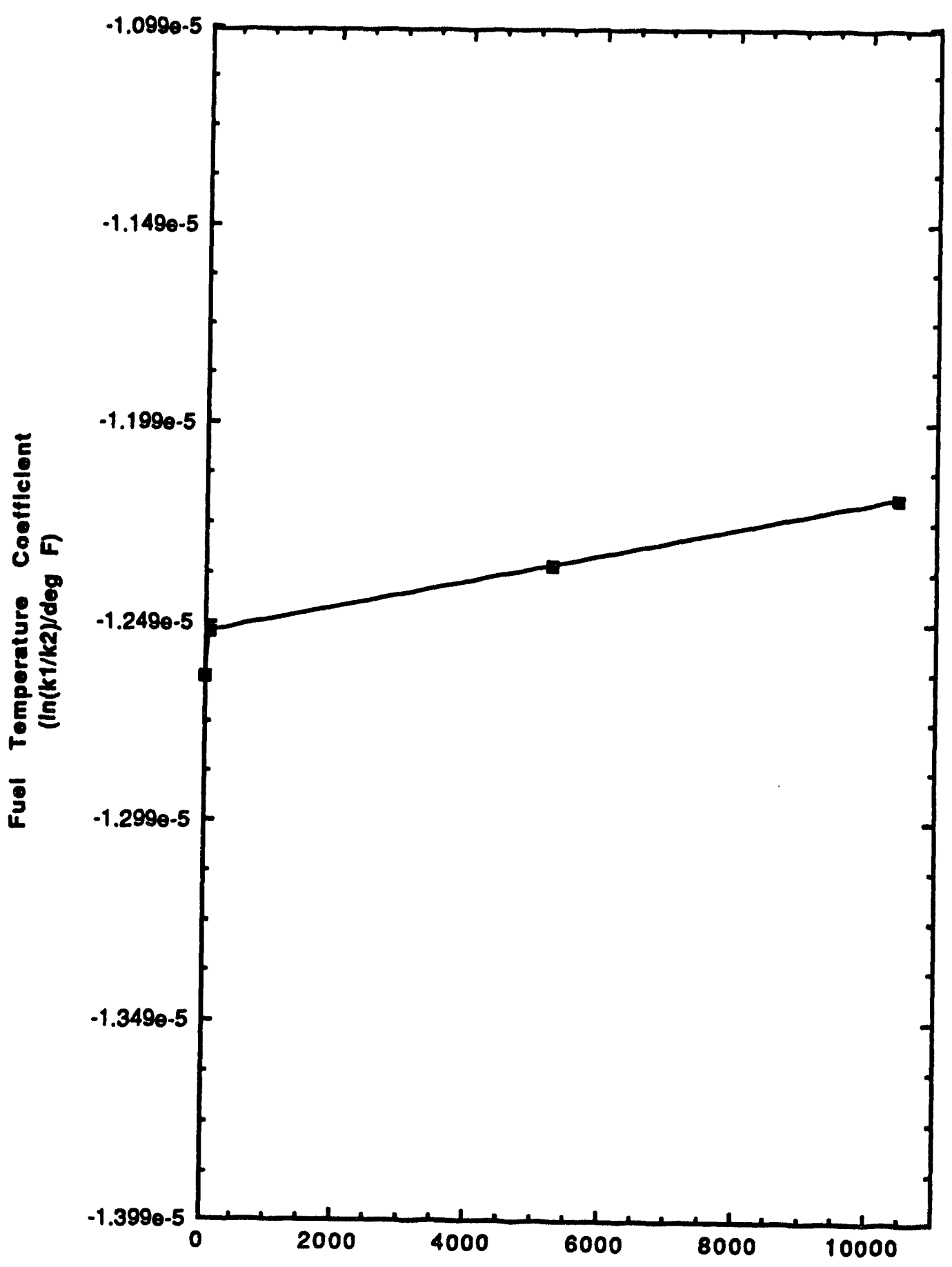

MWDIMT

FIGURE 9.1-5

DOPPLER COEFFICIENT CURVES FOR SYSTEM 80+ PT FUEL 
Combustion Engineering, Inc.

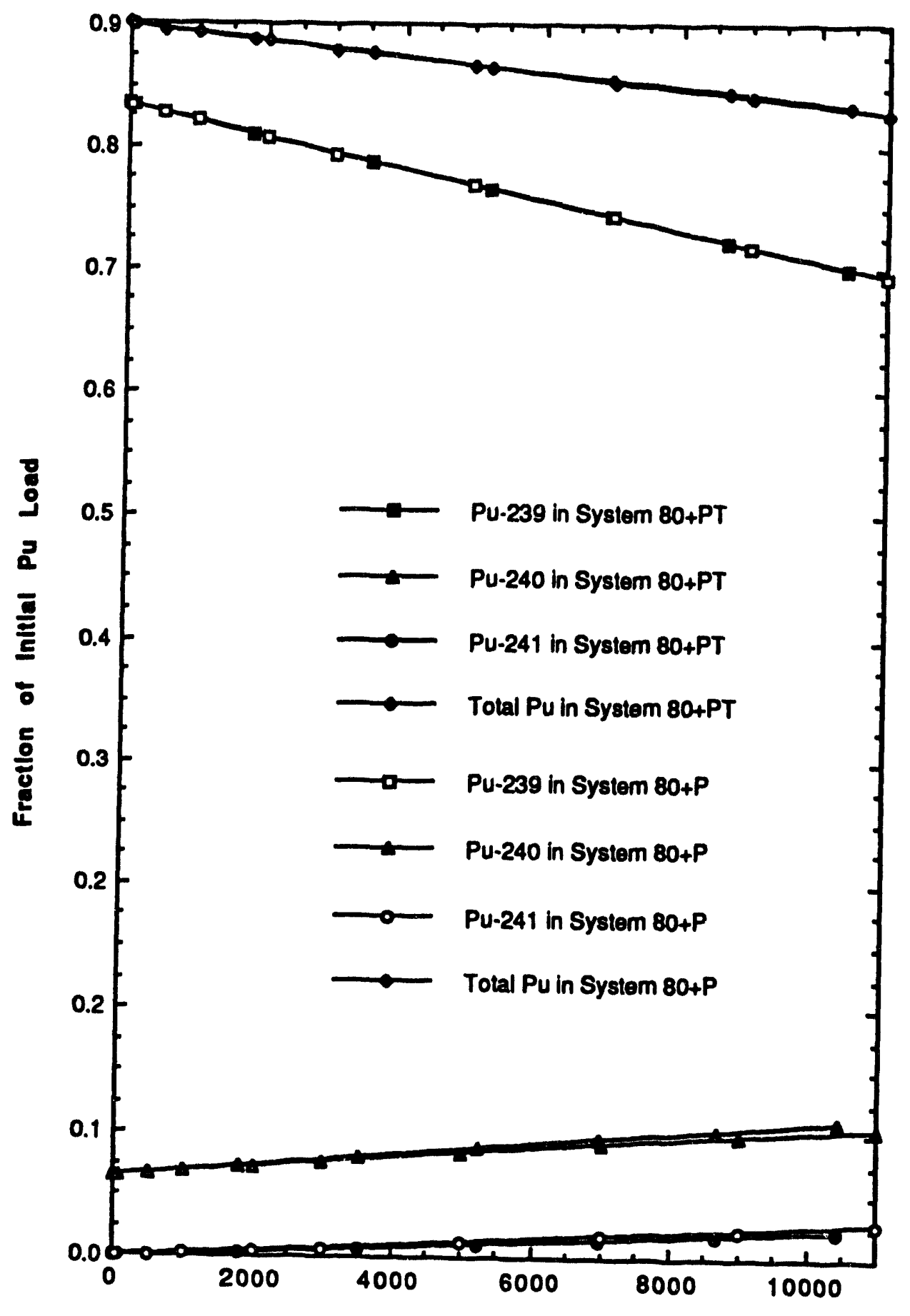

MWDIMT

FIGURE 9.1-6

PLUTONIUM ISOTOPIC FRACTIONS AS A FUNCTION OF BURNUP FOR SYSTEM 80+ P AND SYSTEM 80+ PT FUEL 
Combustion Engineering, Inc.


Not to scale

FIGURE 9.1-7 
Combustion Engineering, Inc.

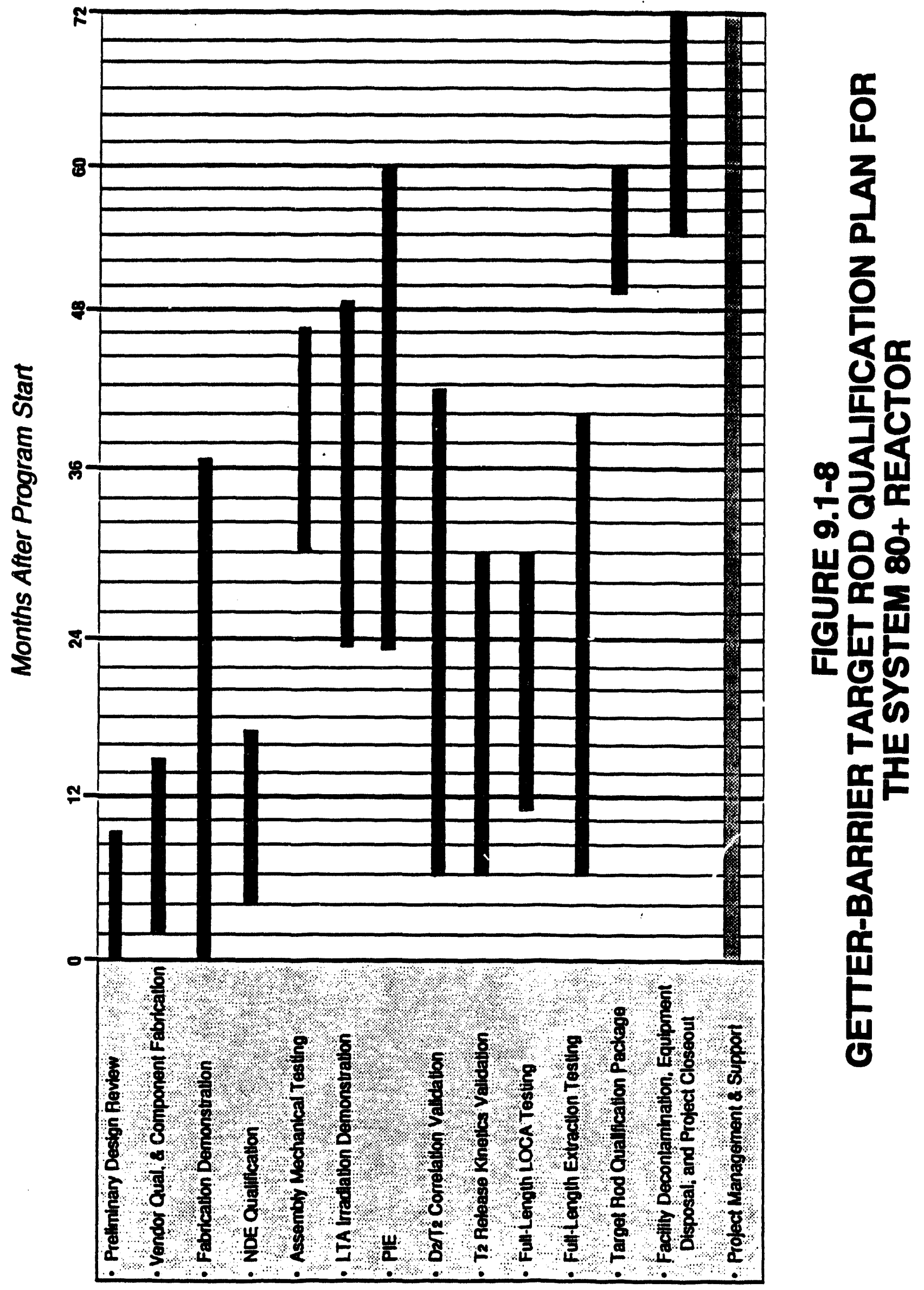




\subsubsection{Syatem $80+$ PT Operational Features}

\subsubsection{Iritium Production Capabllity}

The proposed tritium production assembly design is expected to make greater than contract quantities of tritium per year as required in the guidance document. This tritium requirement is made using a one-cycle, one-batch core configuration. The design is reasonably versatile in that variations in production requirements can be accommodated by altering lithium loadings and erbium concentrations. Data is not presented here, but design iterations have shown that this assembly design is capable of making greater than contract quantities of tritium, as well as in excess of 1/8 and $3 / 8$ of October 1989 goal quantities per year. Design optimization for any of these quantities can be achieved without difficulty.

\subsubsection{Euel Management Options}

The System $80+$ PT design can be operated with fuel management and cycle length strategies similar to the System $80+P$. Functionally, the tritium targets in the System $80+$ PT core displace other poisons (BPs, soluble boron or erbium) which are present in the System $80+P$ design. With design iteration and optimization, it is expected that a tritium production core could meet any reasonable cycle length or loading scheme requirements.

The System $80+$ PT core will only produce greater than contract quantities of tritium under certain cycle conditions, however. The System $80+$ PT is designed to exceed contract production requirements for tritium in a one-batch core on an annual cycle. The design contains sufficient reactivity to provide 274 EFPDs per cycle. The tritium assembly design presented will produce greater than contract quantities of tritium only if a one-batch core is used, and if the core is loaded with fresh fuel every cycle. The one-batch option is the only core loading option which has been analyzed at this point. Conversion to a three-batch core or to longer cycle lengths in a tritium production mode is feasible with additional design effort, but production penalties will likely be incurred unless plutonium concentrations are altered.

Conceptual core loading patterns tave not yet been developed for the System $80+$ PT core. It is likely that when full core design analysis is performed, fuel bundles with slightly different plutonium, erbium, or lithium concentrations will be developed to obtain the desired core power profiles.

Burnup reactivity control in the System $80+$ PT core is accomplished by a combination of target depletion, erbium depletion, and soluble boron. The System $80+$ PT core will use soluble boron enriched in boron-10 for reactivity control. The use of enriched boron maintains consistency with the boron enrichment planned for use in the System $80+P$ design. Since maximum flexibility between the tritium mission and non-tritium missions is required, the soluble boron requirements for the two concepts are the same. 


\subsubsection{Safety Impacts}

\subsubsection{Impact on Reactor Control Systems}

No specific analysis has been performed to determine control rod worths in the tritium production core. The reactor control systems designed for the System $80+P$ are expected to be sufficient for use with the System $80+P T$ core. The fissile content is the same, and effort has been made to maintain the same reactivity and safety margins for the tritium core as the System $80+P$ core. As has been shown previously, the core temperature coefficients throughout the cycle are aiso similar. No radical design changes have been made which would create a challenge to the control system during normal or transient operations. It is therefore expected that no modifications or upgrades to the System $80+P$ design would be needed. In either case, a complete analysis of the control rod worths will be required before a tritium production core is implemented.

\subsubsection{Core Thermal Performance}

Preliminary thermal hydraulic analysis of the System $80+$ PT assembly has been performed to ensure that the modified fuel assembly and the target designs are within the design envelope of the System $80+P$ core. At this time, only normal operating conditions have been assessed. However, this assessment has been coupled with assessments made for the Light Water NPR program to infer the results that would be expected from a full transient analysis.

\section{Euel Analysis}

The System $80+P T$ fuel pin design is the same as the System $80+P$ design. However, the number of fuel pins and the power in each pin has been altered. To show that the thermal margins have not been compromised, thermal analysis of the fuel pins has been perforined.

At this time, analysis of fuel thermal margins is limited to calculation of the departure from nucleate boiling ratio (DNBR). The calculated DNBR is compared to the minimum allowable DNBR for the design. Since the DNBR criteria ensures that the cladding temperature remains close to the coolant temperature, no additional criteria for cladding temperature is required for normal operation and DBEs.

The design limit DNBR that is used depends strongly on the DNB correlation and analytical methods used. For the purpose of this analysis, the non-proprietary B\&W-2 correlation is used. The design DNBR limit for $15 \times 15$ and $17 \times 17$ pin fuels is approximately 1.35 (Reference 9.1-4). To apply the correlation to the CE $16 \times 16$ pin configuration, the limit was conservatively increased to 1.45 to account for any undetermined uncertainties in the application of the correlation. Additional conservatism is added to determine a design goal. This design goal maintains the 
margin between the DNBR goal and the DNBR limit at values similar to commercial light water cores. For purposes of conceptual design of the System $80+$ PT core, a minimum DNBR goal of 2.21 is assumed to maintain the same margins as commercial core designs.

The thermal-hydraulic analysis of the System $80+\mathrm{PT}$ fuel has been performed using the VIPRE-01 sub-channel code (Reference 5). The hydraulic design matches the available parameters for the System $80+$ PT design. Pie-shaped, 1/8 sections of symmetry of the hot fuel assembly have been considered for evaluating the limiting design conditions.

A DNBR analysis was performed for the System $80+$ PT design at the design operating condition of $102 \%$ overpower (3478 MW), 2205 psia system pressure, $558^{\circ} \mathrm{F}$ inlet temperature, and $95 \%$ core inlet mass flow rate $(160.7 \mathrm{Mlbm} / \mathrm{hr})$. Since full core power profiles are not yet available, total core peaking is based on an estimated core average axial peaking (a symmetrical chopped cosine), the expected maximum radial peaking at any location in the core, and a conservative local peaking factor. A total peaking of 2.35 was therefore assumed.

The DNBR analysis for the design operating conditions indicate a calculated DNBR of 2.66. Comparing to the goal of 2.21 , this indicates that there will be sufficient thermal margin in the System $80+$ PT design. Further analyses will be required to establish specific margins, including using correlations optimized for CE fuel designs.

Fuel temperatures and other related fuel performance parameters for steady-state operation have not yet been thoroughly analyzed for the System $80+$ PT. Estimates for preliminary light water NPR fuel pin designs were performed and reported in Reference 9.1-4. Since the System 80 + PT design has not yet been analyzed in detail, a comparison is made to the results of the NPR designs. See Reference 9.1-4 for the fuel temperature comparisons of the previous core designs.

The estimated steady state fuel temperatures for the $16 \times 16$ System $80+$ PT fuel are a core average fuel temperature of $1330^{\circ} \mathrm{F}$, with a peak fuel temperature of $3540^{\circ} \mathrm{F}$. The peak occurs at the centerline at the design operating condition. These temperatures compare favorably with other plant designs.

\section{Iarget Analysis}

Total target peaking for the DNBR analysis was set to 2.15. This value is more conservative than the power factor of 2.0 used for the production calculations in order to account for and conservatively bound any uncertainties which have not been identified. The target power used is $8.46 \mathrm{~kW} / \mathrm{rod}$, which is conservatively based on previous target heat rate calculations performed (Reference 4) and ta':es into account reactor design differences. The analysis values chosen are expected to conservatively bound the System $80+$ PT core target design. The estimated target temperatures for 
the System $80+$ PT target design are a core average target temperature of $755^{\circ} \mathrm{F}$, with a peak target temperature of $980^{\circ} \mathrm{F}$.

\section{Pressure Lesses}

The core pressure loss for the 0.382 inch OD fuel pin design has been estimated by the VIPRE-01 sub-channel code using a Blasius relationship for rough tube friction factors. The equation coefficients are delined for the specific relative roughness. The roughness of drawn tubing was assumed ti) be $5 \times 10^{-6} \mathrm{ft}$. It was also assumed that six grid spacers were equally spaced within the active zone. The grid spacer pressure loss coefficients were assumed to be 1.20 .

The active zone total pressure loss for the 0.382 inch $O D$ fuel pin design was estimated to be 22.4 psi for the core active zone at a core flow of $160.7 \mathrm{Mlbm} / \mathrm{hr}$.

\subsubsection{Reactor Transient Performance}

The reactor response to transients is driven by both the neutronic and thermal design parameters of the reactor system. No detailed calculation of transient scenarios has been performed on the System $80+$ PT core configuration to date. However, insight as to the expected transient response of the tritium core in relation to the System $80+P$ core can be gained from other basic design information.

Reactor power during a transient is driven by the core response to the upset condition before a scram is initiated. The core response is governed mainly by the changes in the coolant or fuel temperature levels. The assembly moderator temperature and fuel doppler coefficients (Figures 9.1-4 and 9.1-5) give an indication of the core response rates. As previously discussed, the System $80+$ PT moderator coefficients are similar in magnitude to System $\mathbf{8 0}+P$ or commercial reactor coefficients. Since it is likely that fuel temperature coefficients will also be similar, it is therefore expected that the neutronic response to temperature transients will also be similar.

Because of the modest fuel temperatures and adequate MDNBR margins present in the System 80 + PT core when compared with existing commercial plant designs, no major differences are expected in transient performance. The 0.382 inch OD design shows margin to DNB comparable to commercial cores at the design operating condition. However, detailed analyses should be performed to confirm this observation before a final design is produced. 


\subsubsection{Impact On Plant Operations}

\subsubsection{Refueling Operations}

Other than those required to accommodate the different fuel management, little difference is expected between refueling operations for the System $80+P$ core concept and the System $80+$ PT concept. Fuel assemblies will contain 32 targets in the tritium core, 20 of which displace fuel rods in the System $80+P$. The total plutonium content per assembly is the same, and the weight of the assemblies will not be significantly different. Therefore, the assembly envelope will not be changed, and manipulation of the assemblies will not be affected. The cycle length will remain at one year and all assemblies will be replaced each cycle. Consequently, there will be no change in the method of shuffling assemblies.

In addition to the refueling operations, however, provisions must be made for removal and replacement (if desired for multi-cycle cores) of the targets in the irradiated assemblies and for transport of the irradiated targets to an extraction facility. Target removal should be no more difficult than removal of BPRAs from assemblies, as is routinely done at commercial reactor sites. Target removal and replacement has been made as simple as possible by placing the targets in guide tubes and attaching them to a spider or baseplate assembly. Target replacement would occur if multi-batch cycles are planned during tritium production missions. If a tritium mission is no longer required, but it is desired to burn the fuel further, BPRAs could simply be placed in the target guide tubes since the target guide tubes and the BPR guide tubes are identical.

Insertion and removal of target rods will be a fairly quick and simple operation due to the ease with which the CE top nozzle flow plate can be removed and reattached. Target rods may be removed from the fuel assembly by simply removing the top nozzle and sliding out the target subassembly. If desired, new target subassemblies may then be inserted for the next cycle. The top nozzle is then reattached.

\subsubsection{Target Handling and Storage}

Target rods will be loaded into the fuel assemblies at the fuel fabrication plant. There are no special handling requirements for the target rods; they will be loaded in the same manner as the fuel rods. Completed fuel assemblies will be shipped from the fuel fabrication facility and placed into dry storage at the reactor site prior to being loaded into the reactor. After irradiation, the fuel assemblies will be removed from the reactor and placed into wet storage in a spent fuel pool.

Consideration must be given to the handling of irradiated targets and the transportation of the targets to the extraction facility. Proper shielding will be required for target storage and shipping since the irradiated stainless steel clad will be highly activated after neutron exposure. This is likely to require the development of storage or shipping casks for the targets if current designs are unsuitable. Protection against tritium 
releases to the environment during storage and transport must also be considered. Since the tritium desorption rate from the targets is very slow, this is not considered a technical challenge.

The irradiated target subassemblies may be stored in the spent fuel pool, in a fuel assembly storage location, but will need to be placed in a support cradle within each storage location. The target base plate will rest on top of an upper support plate, and the target rods will slide through holes in the support plate.

The target subassemblies may be transported in standard fuel shipment casks, but since the target subassemblies will be shipped horizontally, the target rods will need to be supported along their length. Support will be provided by a cask insert with support plates spaced along the length of the target subassembly. The target rods will pass through holes in the support plates.

\subsubsection{Maintenance}

The production of tritium in a light water reactor is not expected to affect normal maintenance activities to any significant extent.

\subsubsection{Routine Releases}

An Environmental Impact Statement (EIS) was prepared for the NPR program (Reference 6) that evaluated potential tritium releases from a light water tritium production reactor. The EIS states that a tritium mission in a light water reactor would have an upper limit projection of 20,000 curies of tritium annually released to the environment, as compared to approximately 900 curies per year from a commercial light water plant. The projected environmental exposures resulting from these upperbound releases were well within prescribed dose limits.

The EIS was written at a time when goal tritium production was much higher, and before much of the TTDP work was completed. Actual releases and exposures are expected to be significantly lower for the System $80+$ PT design than the upper limit projections in the EIS for the following reasons:

- There would be far fewer target rods irradiated in the System $80+$ PT core than assumed in the TTDP since the required tritium production is lower. With fewer target rods, fewer target failures would be expected, and tritium releases would be lower.

The upper limit release estimate for the EIS assumed failure of two target rods per year at EOC. The failed rods were assumed to release their full inventory of tritium. TTDP work has indicated that the targets are far more robust than originally expected, and that two per year is very conservative. Although the average of two failed rods per year was conservative and 
- TTDP analysis indicates that when target rods do fail, only one-fourth to one-half of the inventory would be released on the average from a failed target rod.

- Tritium permeation factors from the target rods for the upper limit projections used in the EIS are based on the use of a diffusion barrier which provides a permeation reduction factor (PRF) on the order of 100-200. Results of later TTDP laboratory work indicated that a PRF of 300-1000 or more may be achievable.

The tritium concentration and release estimates for NPR EIS purposes are calculated for an equilibrium cycle following many years of operation. First year concentrations and releases would be from one-tenth to one-half the equilibrium values, and if an equilibrium tritium mission is not used, the values would be further decreased.

Using a qualitative evaluation of the reductions in conservatism used in the EIS, and considering the above factors, the release value for the System $80+$ PT should have an upper bound limit of less than $15 \%$ of the EIS estimate, or approximately 3,000 curies per year. Again, this should be compared with release estimates from commercial reactors, which are in the neighborhood of 900 curies. The additional release for the System $80+$ PT over that of the standard plant is due to the deliberate production of trituim.

\subsubsection{Impact On The Balance-Of-Plant}

Impact to the balance-of-plant would be limited to the possible inclusion of a detritiation facility. Current ALARA guidelines provided by 10 CFR 50 Appendix I require that cost/benefit analyses, using a value of $\$ 1,000$ per person-rem, be performed for potential designs which could reduce radiation exposure to individuals within a 50-mile radius of the facility. Such an analysis was performed for a light water tritium production reactor in 1991 (Reference 7). This study found that the capital cost of an adequate on-line detritiation system would be in the range of $\$ 30$ million to $\$ 100$ million (1991 dollars). This corresponds to a cost/benefit ratio on the order of $\$ 1$ million per person-rem of public exposure. Therefore, ALARA considerations do not require a detritiation system. 
Although a detritiation system is not considered necessary based on current costbenefit analysis, it may become desirable to add such a facility at a later date. It may also be decided that a detritiation system is necessary to assist in recovery from an offnormal condition in which large amounts of tritium are released into the primary coolant system. Evaluations of facility size and candidate technologies follow.

Under normal conditions, tritium concentrations in the coolant would be very low, and the flow rate to the detritiation system should be low as well 4 gallons per minute or less). For normal operations, a water distillation system would seem to be the most applicable technology. Under design-basis accident conditions, however, a large number of target rods could release their tritium inventory to the primary coolant, and the tritium concentration could rise by several orders of magnitude. A low flow rate system might not be adequate in this scenario.

One alternative approach would be a "feed-and-bleed" type of system, in which the primary coolant is flushed directly into a large tank while providing the reactor with a pure water makeup. Because the makeup stream would dilute the primary coolant while it is draining, the tank would need a capacity several times that of the primary coolant system. A tank of about 500,000 gallon capacity would allow reduction of the tritium concentration in the primary coolant to below its equilibrium value during normal operation. Once the flushing operation is complete, the water in the tank could be processed with a low flow rate detritiation system.

Another approach would be to provide a surge capability for the solid waste system. The primary coolant could be quickly withdrawn, and converted into a stable, sealed grout for disposal. As a one-time contingency method, this may be more cost-effective than the "feed-and-bleed" approach, and has the added advantage of disposing of the fission product inventory in the coolant with the tritium.

Work performed for the TTDP concluded that a detritiation facility was not cost beneficial for the light water NPR. Since this conclusion was reached for a reactor which produced far more tritium, and for which the release estimates were overly conservative, it is expected that a detritiation facility would not be required for the System $80+$ PT concept. Therefore, no further impacts are expected in comparison to the System $80+P$.

\subsubsection{Suppent Facilities}

The purpose of this section is to provide a description of process and facility requirements for the support facilities required to meet a tritium mission. The basis for the information contained in this seation is found in the many documents written as part of the TTDP. This section should be considered a brief summary of the information in those documents. It is recommended that the referenced documents from the TTDP be reviewed for a more detailed description of facilities and requirements. 


\section{Combustion Engineering, InC. NON-PLUTON PLUTONIUM DISPOSITION STUDY}

The following facility information includes descriptions of equipment needed to operate the facility, the estimated cost of the equipment, the space required to operate the equipment, and the estimated number of operations personnel required to run the facility.

\subsubsection{Iargat Fabrication}

Most of the target components are expected to be procured from commercial sources. Under the TTDP, commercial vendors were contracted to provide barrier coated cladding and nickel-plated getter materials (Reference 9.1-8). While these components can be procured from commercial sources, DOE facilities must be available to perform some fabrication work because certain design features of the targets must be protected. It is anticipated that the lithium blending, pressing, and sintering processes will be required to be performed on a DOE site, and that final assembly of the targets using these components will also be performed on a DOE site.

The technology required to fabricate some of the target components was developed under the TTDP. The TTDP accomplishments are described in Section 9.1.3.3. Most of the major technical difficulties concerning target components were addressed as part of the TTDP. Some additional development would be required before production targats could be fabricated.

Once the target components are procured, the actual operation of a target fabrication facility is a straightforward process similar to operation of a fuel fabrication facility. A general process flow is outlined in Figure 9.1-9. The process is as follows. Lithium aluminate powder is pressed into pellets and sintered. The pellets and inner liner are encapsulated in short getter tubes to form target "pencils." The pencils are then inserted into the target cladding, and the end cap is welded on. Targets are then attached to a base plate, and the target assemblies are taken to the fuel bundle assembly area for insertion into the target guide tubes in the fuel assemblies.

The end product of the target fabrication facility would be a target rod similar in design to that developed in prior design studies and experiments (References 9.1-9, 9.1-10), the basic difference being the diametral dimensions of the components. Completed target rods would be installed in fuel assemblies and would most likely be performed at the fuel fabrication site and/or the irradiation site.

\section{Eabrication Costs}

The equipment requirements are based upon an annual production capacity of approximately 9500 target rods, and assume single shift operation and an $80 \%$ final product vield. The estimates provided are based upon prior tritium target rod design descriptions (Reference 9.1-10) and fabrication and inspection development topical reports (References 9.1-11, 9.1-12), (References 9.1-13, 9.1-14, 9.1-15). Fabrication 
of acceptable target rods is conditioned upon the completion of the outstanding TTDP items listed in Section 9.1.3.3.

Components to be procured from commercial sources and target fabrication facility unit process operations are identified in Table 9.1-4. It is assumed that component supplieis will be able to meet the security requirements for this work. Cladding tubes are a long lead item, requiring from eighteen months to two years of procurement lead time, depending in part upon the availability of double vacuum melted 316 stainless steel meeting the requirements of ASTM A771-83. Acquisition of lithium with the required $\mathrm{Li}^{6}$ enrichment may be a long lead item depending upon the status of government enrichment facilities.

Examination of Table 9.1-4 shows a need for receiving inspection, target rod assembly, in-process inspection, final inspection, and supporting analytical laboratory capability. Estimates of equipment, unit operational space, and direct manning requirements for components receiving inspection, target rod assembly, in-process inspection, and final inspection operations are shown in Table 9.1-5. Direct personnel in addition to those shown in Table 9.1-5 include the following:

1) Fabrication Task Leader (1 FTE)

2) Fabrication Engineer (1 FTE)

3) Process Technology Support (1 FTE)

4) Quality Engineer (1 FTE)

5) Quality Assurance Technician (1 FTE)

6) Nondestructive Test Engineer (1 FTE)

7) Inspection and Acceptance Task Leader (1 FTE)

8) Analytical chemistry and metallographic support (1.5 FTE)

9) Maintenance and machine shop support (1 FTE)

The total number of direct operations personnel is estimated to be 7 exempt full time equivalent (FTE) employees and 12.5 non-exemp+ (FTE) employees.

\section{Eacility and Equipment Costs}

Facility and equipment cost estimates were based on the assumption that fabrication would occur on the Hanford site. It was therefore assumed that maximum use of available facilities would be made in order to reduce total capital and operating costs.

Estimates of equipment, unit operational space, and direct manning requirements for components receiving inspection, target rod assembly, in-process inspection, and final inspection operations are shown in Table 9.1-5. It is estimated that approximately $3300 \mathrm{ft}^{2}$ of space, in addition to the unit operational space shown in Table 9.1-5, will be required for office, corridor, ingress, egress, rest room, change room, etc. Thus, the total space requirement is estimated to be $5600 \mathrm{ft}^{2}$. 
Equipment for receiving inspection, target rod assembly fabrication, in-process inspection, and final inspection is estimated to cost $\$ 1,390,000$. Refurbishment of existing facilities and equipment installation are estimated to cost an additional $\$ 1,120,000\left(\$ 200 / \mathrm{ft}^{2} \times 5600 \mathrm{ft}^{2}\right)$. The total of these cost estimates plus a $45 \%$ contingency is $\$ 3,640,000$.

It is assumed that supporting machine shop, analytical laboratory, and maintenance services would be provided from existing centralized facilities. Therefore, equipment requirements and facility space applicable to these services are not included herein.

\subsubsection{Iritium Recovery Facility}

Tritium recovery from irradiated targets will require operation in a hot cell to protect operators from the gamma dose from the irradiated stainless steel cladding. The hot cell is required to be reasonably large because of the operations which must be performed and the equipment which must be used to extract the tritium. The cell must accommodate storage of the thirteen foot long target rods and waste materials, the target preparation areas, and the extraction furnaces. The size of the facility is ultimately dependent on the size of the equipment needed for the process design.

A simplified process flow diagram is shown in Figure 9.1-10. The target rods are received at the hot cell facility in transport casks. When removed from the casks, they will be stored on racks in the hot cell until required in the preparation area. The preparation area will be vacuum sealed since target pre-puncturing or cutting will occur in the area, and the gases that escape during pre-puncture need to be recovered. The targets will then be moved to a vacuum furnace where they will be heated to extract the tritium from the target structural materials. It is expected that $99.5 \%$ of the tritium in the targets will be extracted. Tritium and helium extracted from the target will be vacuum pumped to a storage area. The remaining target structural materials and their residual tritium will be stored or disposed of as radioactive waste (References 9.1-16, 9.1-17).

The estimated radiation level from one irradiated target rod at one meter is about $2.9 \mathrm{R} / \mathrm{hr}$, after 180 days of cooling. Assuming a full core load of target rods (about 8000 rods) in hot cell storage racks, the field outside the hot cell, where plant workers would be remotely manipulating the rods, is estimated to be less than $10^{-6} \mathrm{R} / \mathrm{hr}$. This assures 1 meter ( $3 \mathrm{ft} 3 \mathrm{in}$ ) of air space between the storage rack and the cell wall, and a $6 \mathrm{ft}$ thick concrete cell wall.

The process equipment needs, facilities requirements, cost estimates, and personnel manning requirements for an extraction facility are addressed in detail in TTDP documents. The needs are based upon completion and outfitting of certain facilities within the FMEF in the Hanford 400 area for this mission. Cost estimates (in 1988 dollars) and manning requirements to achieve such a capability within the FMEF are shown in Tables 9.1-6 and 9.1-7 (excerpted from these TTDP documents). The design 
capacity for the facility described in the TTDP was 1.6 times the requirement of the facility needed to satisfy the requirements of this study. Considering the various manning positions shown in Table 9.1-6, it seems reasonable that the reduced capacity would reduce the total manning requirements to 32 exempt and 95 non-exempt positions. The impact of the reduced capacity upon line item capital, expense, and CENRTC estimates shown in Table 9.1-7 is believed to be within the error of those estimates. The schedule shows completion of the project in the seventh year beyond the date of authorization.

\subsubsection{Greenfield Estimates}

Specific greenfield studies had not been performed during the TTDP. All cost estimates were based on the use of existing facilities at the Hanford site if they were available. Broadening the scope to that of a "greenfield" study will include the following activities:

1 The facility configuration for tritium target fabrication would need to be established to include all support services, i.e. maintenance, analytical, radiological safety, security, etc. This would require process flow diagrams of the tritium target fabrication process, and layout and P \& ID drawings of the facility. These would be based upon the current required production capacity.

2) The facility configuration for tritium extraction would need to be established. This would require process flow diagrams of the tritium extraction process and layout and P \& ID drawings of the facility. These would also be based upon the current required production capacity.

3) New construction cost estimates for both target fabrication and tritium extraction facilities would need to be developed.

4) Equipment lists for both processes and facilities including all support services would need to be prepared.

5) Equipment cost and installation estimates would be required.

6) Cost estimates for other project support such as EIS, PSAR, and SAR would be required.

7) Project expense cost estimates (i.e. engineering development and testing, FDC, CDR, and other project expenses) would be needed.

Establishing a complete greenfield estimate would be a multidisciplinary effort, much of which would involve working with classified information. No specific information for a greenfield study has been developed to date for the TTDP. 


\section{Combustion Engineering, Inc.}

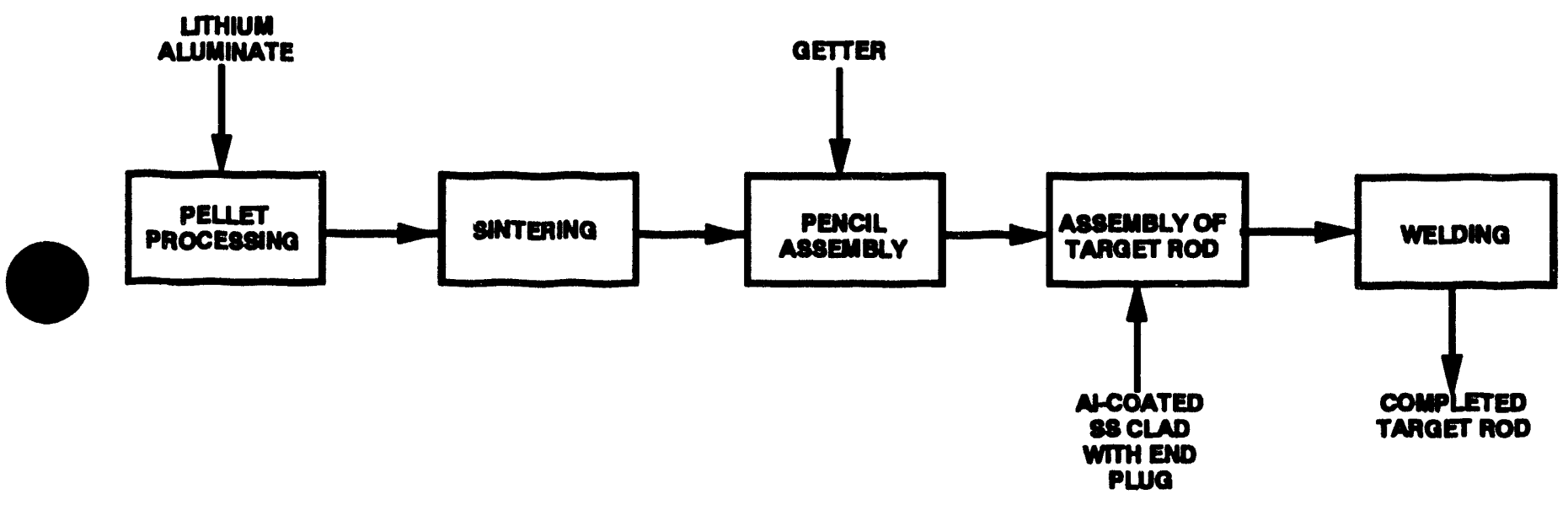




\section{Combustion Engineering, Inc.}

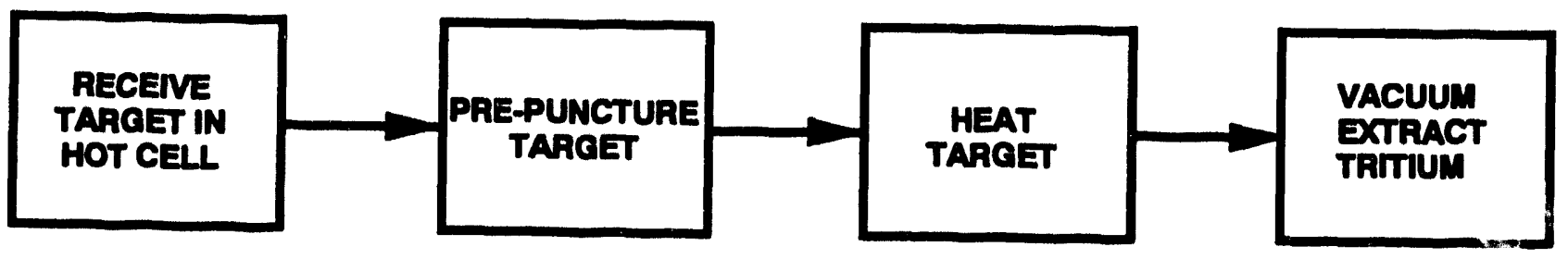




\subsubsection{Uranium Start-up Core Tritium Production Options}

Based on projected schedules, it is possible that the reactor facility will be ready for operation before the MOX fuel fabrication facility. In the event that tritium production is required before MOX fuel can be fabricated, production of tritium in the reactor using a uranium dioxide fueled start-up core configuration has been investigated.

The uranium start-up core requirements are essentially the same as the System 80 +PT with regard to thermal and mechanical performance. The assembly design maintains the $5.5 \mathrm{~kW} / \mathrm{ft}$ average LHGR, so fuel performance during operations and transients is expected to be the same as the System $80+P$ and System $80+P T$ assembly designs. The only further limitation is that the fuel must be bought commercially, so the fuel enrichment must be less than $5 \% U^{235}$. Five percent is currently the licensed enrichment limit for commercial fuel vendors.

Two start-up options for tritium production were investigated. The first option was a once-through, one-batch core using an assembly design which is the same as the design used in the System $80+$ PT. The only change made was to substitute enriched uranium fuel for the MOX.

The second option investigated was the use of a two-batch core. In this case, it was presumed that one of the two-reactor options were chosen such that only about half of the contract quantity of tritium would need to be produced in each reactor per year. For this case, the System 80 + PT assembly design was slightly modified in order to accommodate the use of once-burned fuel for production.

The analysis for both of these start-up designs was very preliminary. A uniform uranium enrichment was used in all fuel pins, and pin power flattening was not attempted. For assessment of tritium production, this provides an adequate model for scoping calculations. It is recognized, however, that if either of these configurations were further investigated, design optimization would be required to meet all thermal margins and tritium production requirements.

\section{Qne-batch Fuel Desion}

The $16 \times 16$ fuel assembly design similar to the System $80+$ PT fuel assembly 132 targets per assembly) was assessed for its ability to produce tritium using a uranium oxide fuel cycle. Using the same target design as the System $80+$ PT, and a core thermal power of 3410 MWth power in the reactor, tritium production in excess of contract quantities can be produced using a uniformly loaded $4.4 \%$ enriched uranium core. 

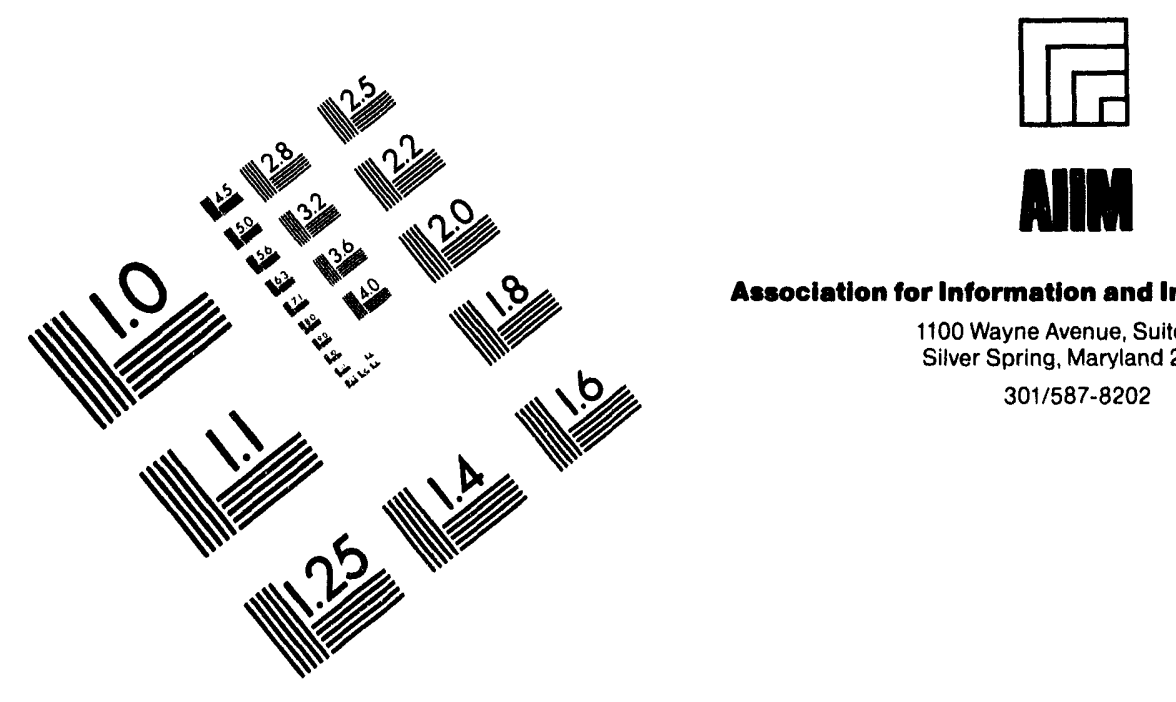

Association for Information and Image Management

1100 Wayne Avenue, Suite 1100

Silver Spring, Maryland 20910

301/587-8202

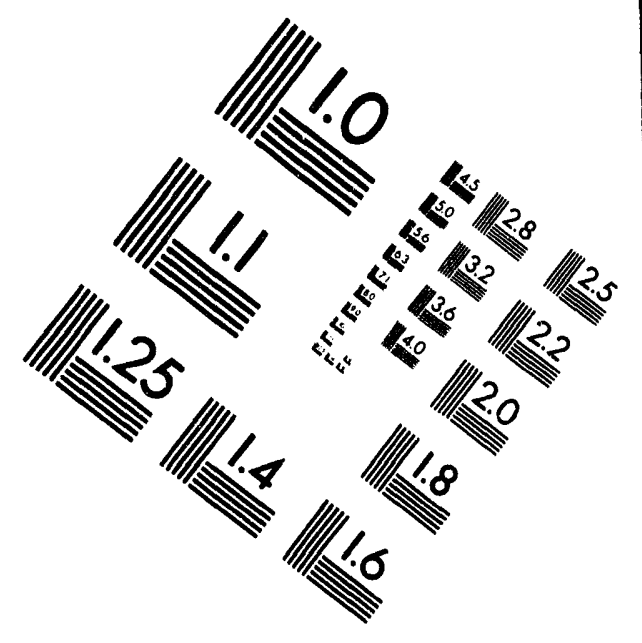

Centimeter

$\begin{array}{llllllllllllllll}1 & 2 & 3 & 4 & 5 & 6 & 7 & 8 & 9 & 10 & 11 & 12 & 13 & 14 & 15 & \mathrm{~mm}\end{array}$

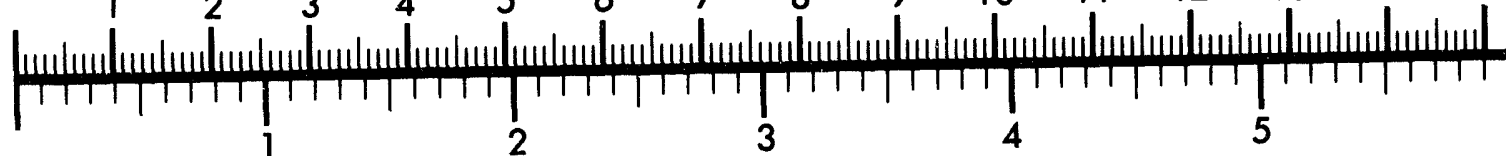
Inches
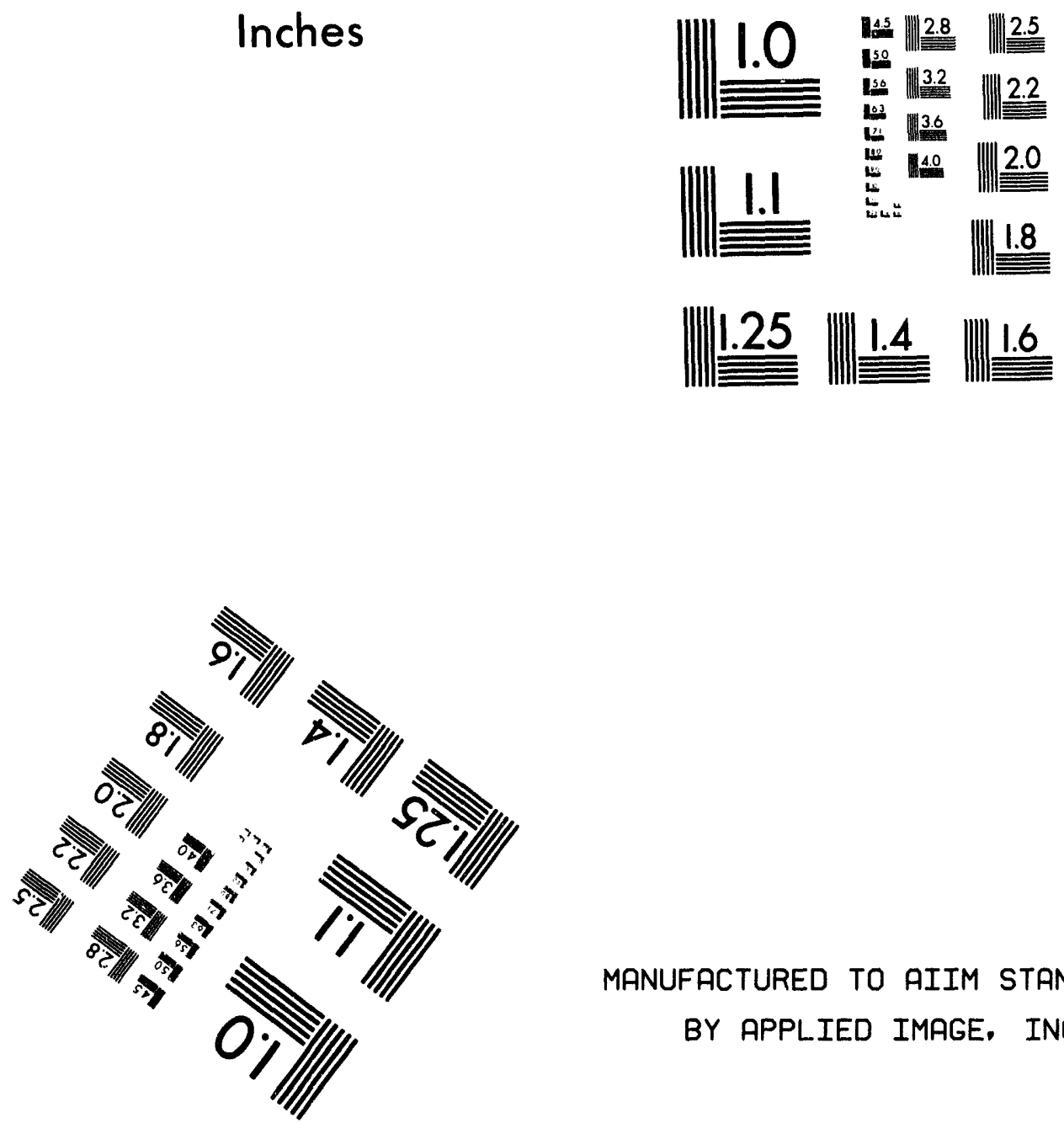

MANUFACTURED TO AIIM STANDARDS

BY APPLIED IMAGE, INC.

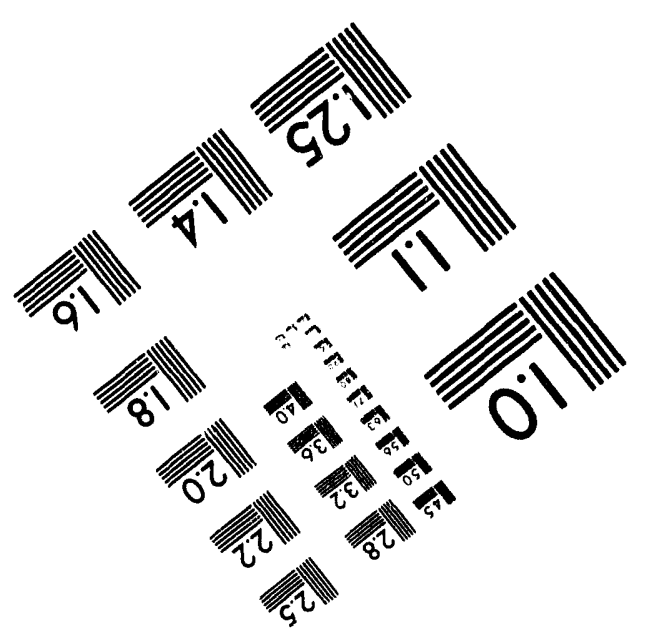



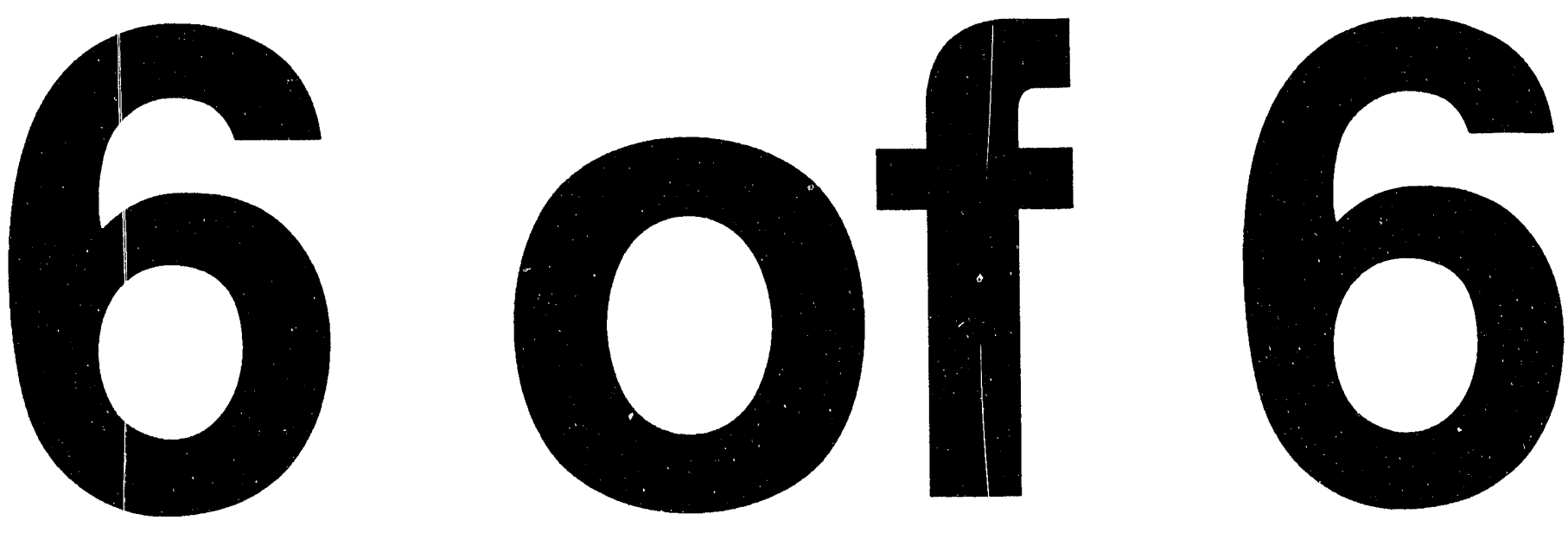


\section{Iwo-batch Fuel Design}

The fuel assembly design for assessment of the two-batch start-up option used a slightly modified version of the System $80+$ PT assembly design. The two-batch design has only 24 target locations per assembly rather than 32 . This change was made because the reduced tritium production required in each core (half of contract quantity) did not require the use of as many targets. Also, the larger number of targets would have made it difficult to meet reactivity requirements for a 274 day cycle. The target locations which were removed from the assembly were replaced with fuel pins. This increase in core fuel mass allowed the core power to be increased to $3477 \mathrm{MWth}$ while still maintaining the $5.5 \mathrm{~kW} / \mathrm{ft}$ average LHGR in the assembly.

Its is presumed that the target rods will be loaded into the fresh fuel assemblies at the fuel fabrication facility. Twenty-four targets will be loaded into each fresh fuel assembly.

The old targets will be removed from the once-burned assemblies as discussed in Section 7.1 of this report. However, fresh targets will be loaded into the once-burned fuel assemblies before the top nozzle is replaced. The assemblies will then be returned to the reactor to be burned for an additional cycle.

In order to provide some power flattening between assembly types, only 16 target rods would be loaded into the once-burned assemblies This allows for a more even reactivity balance between the assemblies, and also allows all fresh targets to be of the same enrichment. The remaining eight locations will be left as water-filled guide tubes. The extra water in the assembly and the reduced poison allows for higher power production in the once-burned assemblies.

Given this two-batch scheme, the total core target loading will be 4824 targets of the same type designed for the System $80+$ PT. The total number of fuel pins will be increased to 51,092 . Total reactor power is estimated to be $3477 \mathrm{MWth}$.

It was concluded that greater than one-half of contract quantity of tritium per year can be produced per year using the two-batch operation scheme described above. This production can be achieved by using fresh fuel reloads containing $3.3 \%$ enriched uranium fuel.

\subsubsection{Conclusions}

From the analysis performed to date, it has been concluded that the production of greater than contract quantities of tritium in a reactor core designed to destroy weapons-grade plutonium is feasible, and can be considered as an option for meeting tritium requirements. The design of such a core is expected to perform within the operational and safety envelope of a core dedicated to the destruction of plutonium. The only effect on the plutonium destruction mission is that the total number of 
plutonium atoms destroyed is reduced by about $1 \%$ for fuel at the same exposure. The total mass of plutonium denatured in a spiking or power generation mode is exactly the same.

There is a high degree of confidence that the proposed target design will perform well in a light water reactor. The mechanical design is flexible to suit changing production requirements. The physical parameters indicate a robust mechanical design which should perform well under all operating conditions. Further development pertaining to target mechanical design should allow design conservatism to be reduced while maintaining adequate safety margins.

A significant amount of target fabrication and tritium extraction technique development was performed under the TTDP. Further development work is required, but the TTDP has demonstrated the technical feasibility of all of the major processes involved. It is not expected that support facility development would inhibit a light water tritium production mission.

It has also been shown that uranium start-up cores can be used to produce tritium if desired. Both one- and two-batch core schemes have been identified which could be employed to produce the required quantities of tritium. 


\section{PLUTONIUM DISPOSITION STUDY
Combustion Engineering, InC. NON-PLUTONIUM DISPOSITIONING OPERATIONS}

TABLE 9.1-1

\section{SUMMARY OF SYSTEM $80+P$ AND SYSTEM $80+$ PT DESIGN PARAMETERS}

Design Parameter

Power Level

Core

Average Linear Power ${ }^{2}$

Core Dimensions

Active Core Length

Equivalent Core Diameter

Fuel Assemblies

Number

Dimensions

Array

Fuel Rods per Assembly

Fuel Rods in Core

Fuel Rods

Outside Diameter

Cladding Thickness

Fuel Pellet Material

Plutonium in MOX

Erbia in MOX

Cladding Material

Guide Tubes ${ }^{3}$

Number in Core

Number per Assembly

Outside Diameter

Thickness

Material

Burnable Poison Rod Assemblies (BPRA)

Number BPRAs in Core

BPRs per Assembly

BPRs in Core

BPR Outside Diameter

Cladding Thickness
System $80+P$

$3800 \mathrm{MW}($ th)

$17.7 \mathrm{~kW} / \mathrm{m}(5.40 \mathrm{~kW} / \mathrm{ft}) \quad 17.7 \mathrm{~kW} / \mathrm{m}(5.40 \mathrm{~kW} / \mathrm{ft})$
$3.81 \mathrm{~m}$ (150 in)
$3.65 \mathrm{~m}$ (143.6 in)
$3.81 \mathrm{~m}$ (150 in)
$3.65 \mathrm{~m}$ (143.6 in)

241

$202.7 \mathrm{~mm} \times 202.7 \mathrm{~mm}$

(7.972 in $\times 7.972$ in)

$16 \times 16$

224

53,984

241

$202.7 \mathrm{~mm} \times 202.7 \mathrm{~mm}$

$(7.972$ in $\times 7.972$ in)

$16 \times 16$

204

49,164

$9.7 \mathrm{~mm}(0.382 \mathrm{in})$

$0.64 \mathrm{~mm}(0.025 \mathrm{in})$

$9.7 \mathrm{~mm}(0.382 \mathrm{in})$

$\mathrm{UO}_{2}-\mathrm{PuO}_{2}-\mathrm{Er}_{2} \mathrm{O}_{3}$

$6.7 \%$ in $\mathrm{HM}$

$<2.5 \mathrm{w} / \mathrm{o}$

Zircaloy-4

$0.64 \mathrm{~mm}(0.025 \mathrm{in})$

$\mathrm{UO}_{2}-\mathrm{PuO}_{2}-\mathrm{Er}_{2} \mathrm{O}_{3}$

$7.38 \%$ in $\mathrm{HM}$

$0.5 \mathrm{w} / \mathrm{o}$

Zircaloy-4

2892

12

$11.2 \mathrm{~mm}$ (0.440 in)

$0.91 \mathrm{~mm}(0.032 \mathrm{in})$

Zircaloy-4

7712

32

$11.2 \mathrm{~mm}$ (0.440 in)

$0.91 \mathrm{~mm}$ (0.032 in)

Zircaloy-4

2 Based on 0.975 average energy deposition fraction in the fuel.

3

Non-structural guide tubes are added to accommodate BPRAs and/or TTAs in all fuel assemblies. These guide tubes should be differentiated from the structural guide tubes in control locations. 


\section{IABLE 9.1-1 (Cont'd)}

\section{SUMMARY OF SYSTEM $80+P$ AND SYSTEM $80+$ PI DESIGN PARAMETERS}

\section{Design Parameter}

BPR Absorber

BPR Cladding Material

Tritium Target Assemblies (TTA)

Number TTAs in Core

Number TTs per Assembly

Number TTs in Core

TTA Outside Diameter

Cladding Thickness

TTA Absorber

TTA Cladding Material

Control Element Assemblies (CEA)

Number CEAs in Core

12-element Assemblies

4-element Assemblies

CEA Rod OD

Cladding Thickness

CEA Absorber

Cladding Material
System $80+P$

System $80+P T$

$$
\mathrm{Al}_{2} \mathrm{O}_{3}-\mathrm{B}_{4} \mathrm{C}
$$

Zircaloy-4

241

32

7712

$8.7 \mathrm{~mm}(0.344 \mathrm{in})$

$0.76 \mathrm{~mm}$ (0.030 in)

$\mathrm{LiAlO}_{2}$

SS-316

101

48

101

53

$20.7 \mathrm{~mm}$ (0.816 in)

$0.89 \mathrm{~mm}(0.035 \mathrm{in})$

$\mathrm{B}_{4} \mathrm{C} /$ Feltmetal and

Reduced Diam. $\mathrm{B}_{4} \mathrm{C}$.

Inconel 625
48

53

$20.7 \mathrm{~mm}(0.816 \mathrm{in})$ $0.89 \mathrm{~mm}$ (0.035 in) $\mathrm{B}_{4} \mathrm{C} /$ Feltmetal and Reduced Diam. $\mathrm{B}_{4} \mathrm{C}$ Inconel 625 
IABLE 9.1-2

\section{IARGET DESIGN FOR THE SYSTEM $80+P I$}

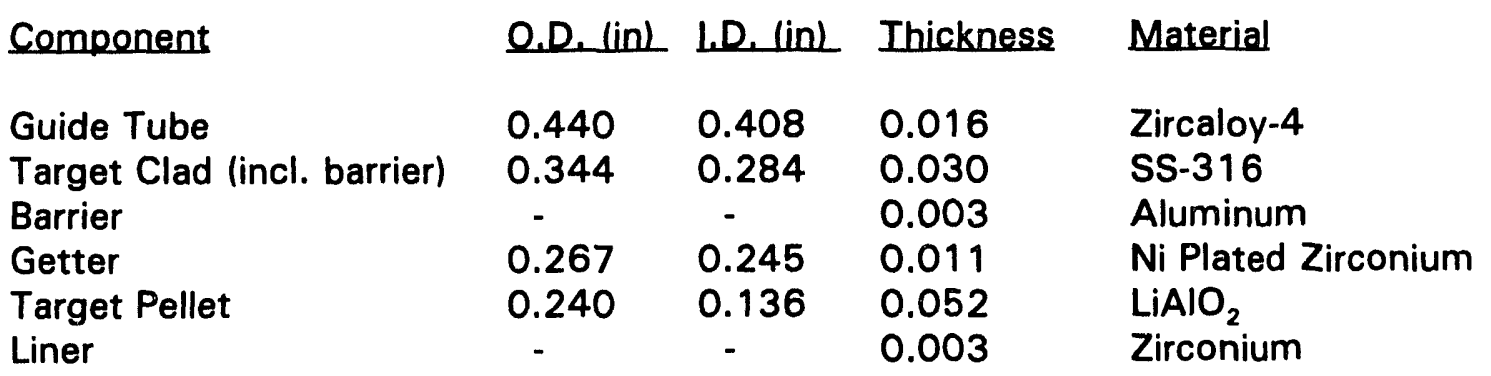




\section{IABLE 9.1-3}

\section{COST ESTIMATE FOR COMPLETION OF THE TTDP}

\begin{tabular}{|c|c|c|c|}
\hline & $\begin{array}{c}\text { Facilities, } \\
\text { Equipment, } \\
\text { \& Test Articles } \\
\text { \$M } \\
\end{array}$ & $\begin{array}{l}\text { FTEs } \\
\mid \text { SMM }\end{array}$ & $\begin{array}{l}\text { Duration } \\
\text { (months) }\end{array}$ \\
\hline Preliminary Design Review & - & 1.5 & 8 \\
\hline $\begin{array}{l}\text { Vendor Qualification and } \\
\text { Component Fabrication }\end{array}$ & - & 3.0 & 12 \\
\hline Fabrication Demonstration & 2.5 & 2.0 & 36 \\
\hline NDE System Qualification & 0.5 & 1.0 & 12 \\
\hline Assembly Mechanical Testing & 1.5 & 2.5 & 18 \\
\hline $\begin{array}{l}\text { Lead Test Assembly Irradiation } \\
\text { Demonstration* }\end{array}$ & 1.0 & 2.0 & 42 \\
\hline Postirradiation Evaluation & 8.0 & 3.0 & 54 \\
\hline $\mathrm{D}_{2} / \mathrm{T}_{2}$ Correlation Validation & 3.0 & 2.5 & 18 \\
\hline Tritium Release Kinetics Validation & 1.0 & 2.0 & 24 \\
\hline Full-Length LOCA Testing & 1.0 & 1.0 & 18 \\
\hline $\begin{array}{l}\text { Full-Length Target Rod Extraction } \\
\text { Testing }\end{array}$ & 3.0 & 2.0 & 36 \\
\hline $\begin{array}{l}\text { Final Target Rod Qualification } \\
\text { Package }\end{array}$ & - & 2.0 & 8 \\
\hline $\begin{array}{l}\text { Facility Decontamination, } \\
\text { Equipment Disposal, and Project } \\
\text { Closeout }\end{array}$ & - & 3.0 & 18 \\
\hline \multirow[t]{2}{*}{ Project Management and Support } & - & 3.0 & \\
\hline & $\$ 21.5 \mathrm{M}$ & $\$ 31.5 \wedge 1$ & \\
\hline
\end{tabular}

*Assumes 32 target rods/assembly are inserted into $\mathrm{Al}_{2} \mathrm{O}_{3}-\mathrm{B}_{4} \mathrm{C}$ burnable abs orber rod positions.

Does not include the cost of the $\mathrm{UO}_{2}$ or MOX assembly.

Does not include the cost of the assembly design.

Does not include irradiation costs or cost arrangements with the utility. 
TABLE 9.1-4

COMPONENTS/ASSEMBLIES FOR FABRICATION OF TARGET RODS

\begin{tabular}{|c|c|}
\hline $\begin{array}{l}\text { Compone its Procured } \\
\text { From Corimercial Sources } \\
\text { For Target Rod Fabrication } \\
\text { Process }\end{array}$ & Target Fabrication Unit Process Operation \\
\hline $\begin{array}{l}316 \text { Stainless Steel } \\
\text { Cladding Tubes }\end{array}$ & \multirow{2}{*}{$\begin{array}{l}\text { 1. Receiving Inspection } \\
\text { 2. Weld Lower End Caps into Cladding Tubes } \\
\text { 3. Final Inspection (Visual, He Leak Test, and } \\
\text { Radiography) }\end{array}$} \\
\hline $\begin{array}{l}316 \text { Stainless Steel Target } \\
\text { Rod End Caps }\end{array}$ & \\
\hline $\begin{array}{l}\text { Annular Lithium Aluminate } \\
\text { Pellets }\end{array}$ & \multirow{4}{*}{$\begin{array}{l}\text { 1. Components Receiving Inspection (Pellet Chemistry, } \\
\text { Li }{ }^{6} \text { Enrichment and Density, Dimensional, Visual, } \\
\text { Gettering Rate Qualification Sample) } \\
\text { 2. Fabricate Getter Pellet Assembles, Lower Getter Pellet } \\
\text { Assemblies, and Upper Getter and Disc Assemblies } \\
\text { 3. Inspection of Getter Pellet Assemblies (Visual, } \\
\text { Dimensional, Pellet Weight) }\end{array}$} \\
\hline $\begin{array}{l}\text { Ni Plated Zircaloy Getter } \\
\text { Tubes }\end{array}$ & \\
\hline $\begin{array}{l}\text { Ni Plated Zircaloy Getter } \\
\text { Discs }\end{array}$ & \\
\hline Inner Zircaloy Shrouds & \\
\hline $\begin{array}{l}\text { Stainless Steel } \\
\text { Compression Spring }\end{array}$ & $\begin{array}{l}\text { Receiving Inspection (Visual, Dimensional, Spring } \\
\text { Constant) }\end{array}$ \\
\hline $\begin{array}{l}\text { Aluminized Lower End Cap } \\
\text { and Cladding Tube } \\
\text { Assembly }\end{array}$ & $\begin{array}{l}\text { Receiving Inspection (Visual, Dimensional, Eddy Current } \\
\text { Test, Metallurgical Sample, D Permeability Test of } \\
\text { Selected Sample(s)) }\end{array}$ \\
\hline \multirow[t]{3}{*}{ N/A } & $\begin{array}{l}\text { Load Internal Components (i.e. Lower Getter and Pellet } \\
\text { Assembly, Getter and Pellet Assemblies, Upper Getter } \\
\text { Assembly, and Compression Spring) into Aluminized } \\
\text { Lower End Cap and Cladding Tube Assembly }\end{array}$ \\
\hline & $\begin{array}{l}\text { Helium Backfilling, Upper End Cap Insertion into Loaded } \\
\text { Cladding Tube Assembly, and Final Closure Weld }\end{array}$ \\
\hline & $\begin{array}{l}\text { Final Inspection of Target Rod (Visual, Dimensional, X- } \\
\text { Radiography, He Leak Test) }\end{array}$ \\
\hline
\end{tabular}




\begin{tabular}{|c|c|c|c|}
\hline $\begin{array}{l}\text { ESTIMATES OF EQUIPMENT, UNIT OPERATIONAL SPACE. AND DIRECT MANNING REOUIREMENTS FOR } \\
\text { COMPONENTS RECEIVING INSPECTION. TARGET ROD ASSEMBLY AND FINAL INSPECTION OPERATIONS }\end{array}$ & \multicolumn{3}{|c|}{$\begin{array}{l}\text { TABLE9.1-5 } \\
\end{array}$} \\
\hline Equipment & $\begin{array}{l}\text { Estimated } \\
\text { Equipment } \\
\text { Cost } \\
\quad(\$ K) \\
\end{array}$ & Unit Operational Space & Direct Manning \\
\hline Receiving Inspection & $\$ 730 \mathrm{~K}$ & $645 \mathrm{ft}^{2}$ TOTAL & 4 FTE TOTAL \\
\hline $\begin{array}{l}\text { 1a. Air Gage Scanner System for bare tube } \\
\text { assembly (computerized air gage and scanner } \\
\text { system) }\end{array}$ & 95 & $\begin{array}{l}175 \mathrm{ft}^{2} \text { (35 ft. long } \times 5 \mathrm{ft} \\
\text { wide) }\end{array}$ & $\begin{array}{l}1 \text { FTE (longitudinal (one } \\
\text { circumferential orientation) scan } \\
\text { of } 10 \% \text { of tubes) }\end{array}$ \\
\hline $\begin{array}{l}\text { 2a. Eddy Current Scanner System (eddy scope, } \\
\text { helical scanner, computer, printer, and software) }\end{array}$ & 90 & $\begin{array}{l}175 \mathrm{ft}^{2} \text { (35 ft. long } \times 5 \mathrm{ft} \\
\text { wide each system) }\end{array}$ & $\begin{array}{l}1 \text { FTE (Full coverage scan of all } \\
\text { tubes and aluminized tube } \\
\text { assemblies) }\end{array}$ \\
\hline 3a. Deuterium Permeation System & 500 & $\begin{array}{l}120 \mathrm{ft}^{2} \text { (15 ft. long } \times 8 \mathrm{ft} \\
\text { widel }\end{array}$ & $\begin{array}{l}1 \text { FTE (Sample approximately } \\
10 \% \text { of aluminized tube } \\
\text { assemblies) } \\
\end{array}$ \\
\hline $\begin{array}{l}\text { 4a. Visual and dimensional inspection station (15 ft. } \\
\text { long } X 2 \mathrm{ft} \text {. Wide Surface Plate) }\end{array}$ & 15 & $\begin{array}{l}75 \mathrm{ft}^{2} \text { (15 ft. long } \times 5 \mathrm{ft} \\
\text { wide) }\end{array}$ & 1 FTE \\
\hline 5a. Optical Coinparator & 20 & $\begin{array}{l}50 \mathrm{ft}^{2} \text { (10 ft. long } \times 5 \mathrm{ft} \\
\text { wide) }\end{array}$ & \\
\hline 6a. Misc. Inspection Equipment & 10 & $\begin{array}{l}50 \mathrm{ft}^{2} \text { (10 ft. long } \times 5 \mathrm{ft} \\
\text { wide) }\end{array}$ & \\
\hline Process & $\$ 274 K$ & $1179 \mathrm{ft}^{2}$ & 4 FTE \\
\hline 1b. Bottom end cap closure weld station & $\begin{array}{l}\text { Cost } \\
\text { included in } \\
\text { item } 6 b . \\
\text { below }\end{array}$ & $\begin{array}{l}90 \mathrm{ft}^{2}(15 \mathrm{ft} . \text { long } \times 6 \mathrm{ft} \\
\text { wide) }\end{array}$ & $.4 \mathrm{FTE}$ \\
\hline
\end{tabular}


IABLE 9.1-5 (Cont'd)

ESTIMATES OF EQUIPMENT. UNIIT OPERATIONAL SPACE, AND DIRECT MANNING REQUIREMENTS FOR COMPONENTS RECEIVING INSPECTION. TARGET ROD ASSEMBLY, AND FINAL INSPECTION OPERATIONS

\begin{tabular}{|c|c|c|c|}
\hline Equipment & $\begin{array}{l}\text { Estimated } \\
\text { Equipment } \\
\text { Cost } \\
\quad \text { (\$K) } \\
\end{array}$ & Unit Operational Space & Direct Manning \\
\hline $\begin{array}{l}\text { 2b. Aluminized lower end cap and cladding tube } \\
\text { assembly cleaning station }\end{array}$ & 20 & $\begin{array}{l}175 \mathrm{ft}^{2} \text { (35 ft. long } \times 5 \mathrm{ft} \\
\text { wide) }\end{array}$ & .5 FTE \\
\hline 3b. Getter tube and disc assembly spot weld station & 15 & $\begin{array}{l}50 \mathrm{ft}^{2}(10 \mathrm{ft} . \text { long } \times 5 \mathrm{ft} \\
\text { wide) }\end{array}$ & .2 FTE \\
\hline 4b. Getter pellet assembly station & 50 & $\begin{array}{l}50 \mathrm{ft}^{2} \text { (10 ft. long } \times 5 \mathrm{ft} \\
\text { wide) }\end{array}$ & 1 FTE \\
\hline $\begin{array}{l}\text { 5b. Target rod assembly station for loading internal } \\
\text { components into aluminized lower end cap and } \\
\text { cladding tube assembly }\end{array}$ & 20 & $\begin{array}{l}175 \mathrm{ft}^{2} \text { (35 ft. long } \times 5 \mathrm{ft} \\
\text { wide) }\end{array}$ & $.6 \mathrm{FTE}$ \\
\hline $\begin{array}{l}\text { 6b. Vacuum outgas, Helium backfill, and final } \\
\text { closure weld station }\end{array}$ & 150 & $\begin{array}{l}175 \mathrm{ft}^{2} \text { (35 ft. long } \times 5 \mathrm{ft} \\
\text { wide) }\end{array}$ & $.6 \mathrm{FTE}$ \\
\hline 7b. In-Process component storage & 2 & $\begin{array}{l}176 \mathrm{ft}^{2} \text { (16 ft. long X } 11 \mathrm{ft} \\
\text { wide) }\end{array}$ & .2 FTE \\
\hline 8b. Finished target rod storage & 2 & $\begin{array}{l}128 \mathrm{ft}^{2} \text { (16 ft. long } \times 8 \mathrm{ft} \\
\text { wide) }\end{array}$ & .2 FTE \\
\hline 9b. Misc. fixturing and transfer equipment & 15 & $\begin{array}{l}160 \mathrm{ft}^{2} \text { (16 ft. long X } 10 \mathrm{ft} \\
\text { wide) }\end{array}$ & .3 FTE \\
\hline In-Process and Final Inspection & $\$ 385 K$ & $475 \mathrm{ft}^{2}$ & 2 FTE \\
\hline $\begin{array}{l}\text { 1c. Helium leak test system for: 1) lower end cap } \\
\text { and cladding tube assembly and 2) completed target } \\
\text { rod }\end{array}$ & 40 & $\begin{array}{l}175 \mathrm{ft}^{2} \text { (35 ft. long } \times 5 \mathrm{ft} \\
\text { wide) }\end{array}$ & .5 FTE \\
\hline
\end{tabular}


IABLE 9.1-5 (Cont'd)

ESTIMATES OF EQUIPMENT, UNIT OPERATIONAL SPACE, AND DIRECT MANNING REQUIREMENTS FOR COMPONENTS RECEIVING INSPECTION. TARGET BOD ASSEMBLY. AND FINAL INSPECTION OPERATIONS

\begin{tabular}{|c|c|c|c|}
\hline Equipment & $\begin{array}{c}\text { Estimated } \\
\text { Equipment } \\
\text { Cost } \\
\text { (\$K) } \\
\end{array}$ & Unit Operational Space & Direct Manning \\
\hline $\begin{array}{l}\text { 2c. Component placement and closure weld } X \text { - } \\
\text { radiography station }\end{array}$ & 320 & $\begin{array}{l}175 \mathrm{ft}^{2} \text { (35 ft. long } \times 5 \mathrm{ft} \\
\text { wide) }\end{array}$ & 1 FTE \\
\hline $\begin{array}{l}\text { 3c. Final visual and dimensional inspection station } \\
\text { (15 ft. long X } 2 \mathrm{ft} \text {. Wide Surface Plate) }\end{array}$ & 15 & $\begin{array}{l}75 \mathrm{ft}^{2} \text { (15 ft. long } \times 5 \mathrm{ft} \\
\text { wide) }\end{array}$ & \multirow[t]{2}{*}{.5 FTE } \\
\hline 4c. Misc. Dimensional Examination Equipment & 10 & $\begin{array}{l}50 \mathrm{ft}^{2} \text { (10 ft. long } \times 5 \mathrm{ft} \\
\text { wide) }\end{array}$ & \\
\hline
\end{tabular}




\begin{tabular}{|c|c|c|c|c|c|}
\hline \multicolumn{6}{|c|}{$\begin{array}{l}\text { IABLE 9,1-6 } \\
\text { IRITIUM EXTRACTION FACILITY PERSONNEL REQUIREMENTS }\end{array}$} \\
\hline Position & Per XYZ shift & Per ABCD shift & Day shift + & Total exempt & Total \\
\hline Process operators & 7 & 2 & 6 & - & 35 \\
\hline Maintenance & 4 & 0 & 8 & - & 20 \\
\hline Planner/schedulers & 0 & 0 & 3 & 3 & 3 \\
\hline Rad. protection & 0 & 1 & 2 & - & 6 \\
\hline Shift management & 1 & 1 & 2 & 9 & 9 \\
\hline Power operators & 0 & 1 & 1 & - & 5 \\
\hline SNM specialists & 0 & 0 & 2 & 2 & 2 \\
\hline Misc. management & 0 & 0 & 5 & 5 & 5 \\
\hline Process engr. & 1 & 0 & 6 & 9 & 9 \\
\hline Prog/fac. mgnt. & & & 5 & 5 & 5 \\
\hline Other dayshift & & & 5 & & 5 \\
\hline Transportation & 0 & 0 & 3 & 1 & 3 \\
\hline Laboratory & 3 & & 5 & 5 & 14 \\
\hline Financial support & & & 2 & 2 & 2 \\
\hline Other support & & & 5 & 5 & 5 \\
\hline $\begin{array}{l}\text { Total per shift } \\
\text { Totals }\end{array}$ & $\begin{array}{l}16 \\
48 \\
\end{array}$ & $\begin{array}{r}5 \\
20 \\
\end{array}$ & $\begin{array}{l}60 \\
60 \\
\end{array}$ & 46 & 128 \\
\hline
\end{tabular}


TABLE 9.1-7

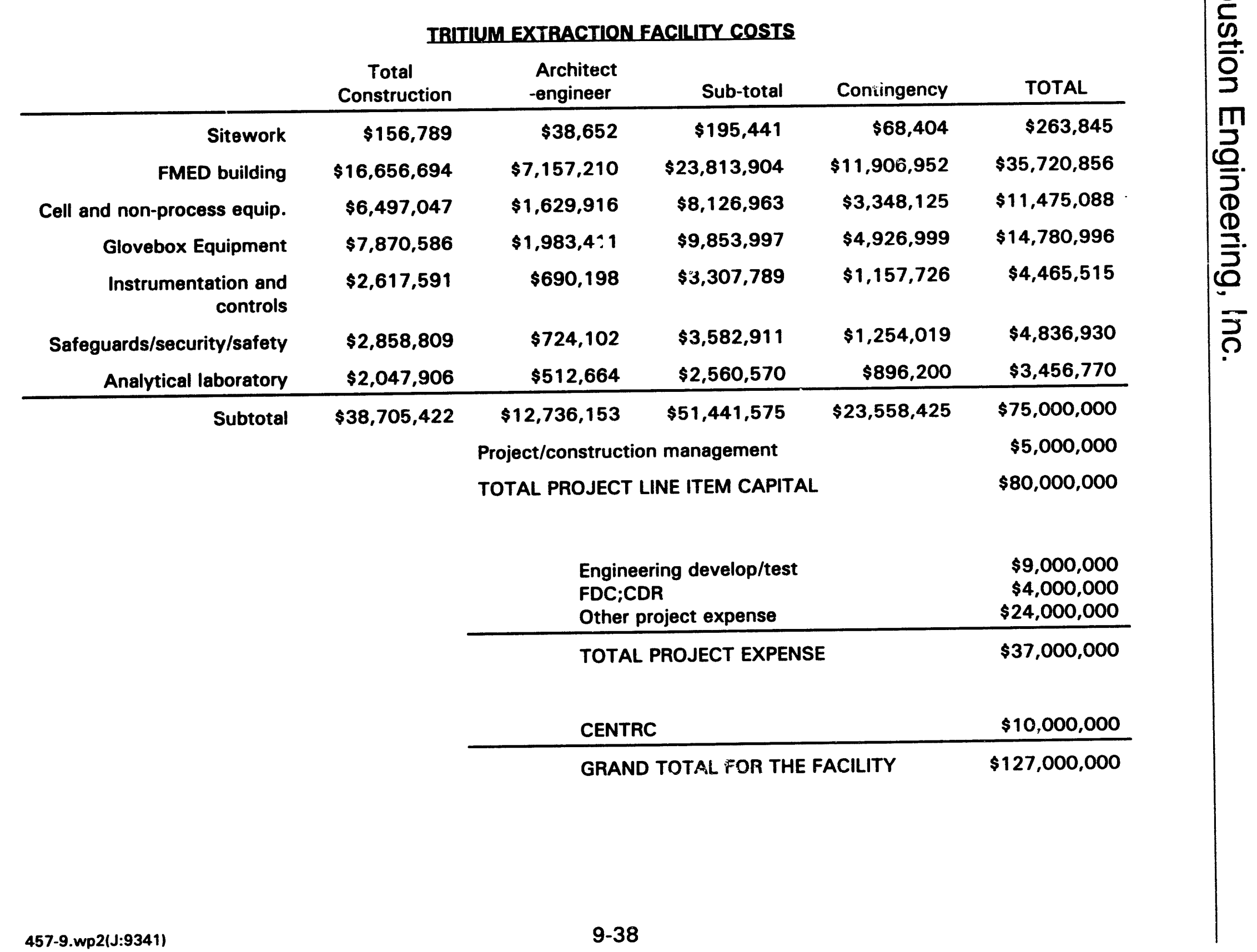




\section{References}

9.1-1. "Plutonium Disposition Study Draft Requirements Document", U. S. Department of Energy Office of Nuclear Energy, Washington D.C., January 21, 1993.

9.1-2. "DOE Plutonium Disposition Study Pu Consumption in ALWRs", prepared by ABB-Combustion Engineering under Contract No. DE-AC03-93 SF19682, Windsor, Connecticut, May 15, 1993.

9.1-3. Askew, J. R. and Roth, M. J., WIMS-E A Scheme For Neutronics Calculations, AEEW-R1315, United Kingdom Atomic Energy Authority, Winfrith, UK, June 1982.

9.1-4. Pauley, K. A., et. al., May '91 5\% Reference Core Design, PNL-7952, Pacific Northwest Laboratory, Richland, Washington, January 1992.

9.1-5. Stewart, C. W. et. al., VIPRE-01: A Thermal-Hydraulic Code For Reactor Cores, EPRI NP-2511 Revision 2, Prepared for the Electric Power Research Institute by Battelle Pacific Northwest Laboratories, Richland, Washington, July 1985.

9.1-6. Draft Environmental Impact Statement for the Siting, Construction, and Operation of New Production Reactor Capacity, DOE/EIS-0144D, U. S. Department Of Energy, Washington D.C., $1991 \mathrm{~b}$.

9.1-7. Westinghouse Hanford Company, Detritiation Considerations for a Light Water New Production Reactor, WHC-SP-0683, Westinghouse Hanford Company, Richland, Washington, $1991 \mathrm{c}$.

9.1-8. Pilger, J. P., et. al., NPLWR Tritium Target Fabrication Topical_Report, Volume 1, PNL-8128, Pacific Northwest Laboratory, Richland, Washington, September 1992.

9.1-9. Gesh, C.J., Hawkes, E.C., Jenquin, U.P., Merrill, E.T., Pauley, K.A., Reid, B.D., Schmitt, B.E., JAN91 10\% Reference Core Desion, PNL-7883, Limited Distribution, December, 1991, Pacific Northwest Laboratory, Richland Washington.

9.1-10. Weber, J.W., Iopical Report: NPLWR Tritium Target Desian, WHC-SP-0840, September, 1992, Westinghouse Hanford Company, Richland Washington. 
9.1-11. Blahnik, D.E., Klein, R.F., Page, R.E., Pilger, J.P., LWNPR Tritium Target Development Project - LWNPR Tritium Target Fabrication Development Iopical Report, PNL-8128 Vol I and Vol II, Limited Distribution, September, 1992, Pacific Northwest Laboratory, Richland Washington.

9.1-12. Powers, H.G., NPR/LWR Tritium Target Development Project NP Tritium Iarget Barrier Non- Destructive Evaluation Methods Topical Report, PNL8129, Limited Distribution, September, 1992, Pacific Northwest Laboratory, Richland Washington.

9.1-13. Page, R.E., Pilger, J.P., Powers, H.G., NPR/LWR Tritium Target Development Project Cladding Aluminide Barrier Development Beport, PNL-8130, Limited Distribution, September, 1992, Pacific Northwest Laboratory, Richland Washington.

9.1-14. Allen, R.P., Brimhall, J.L., Gilbert, E.R., Deuterium Permeation Through Aluminized Stainless Steel Tubes, PNL-8305, September, 1992, Pacific Northwest Laboratory, Richland Washington.

9.1-15. Allen, R.P., Baldwin, D.L., Brimhall, J.L., Clemmer, R.G., Gilbert,E.R., McKinnon, M.A., Ruff, E.S., NPR/LWR Tritium Target Development Project Ex-Reactor Testing Topical Report, PNL-8137, Limited Distribution, September, 1992, Pacific Northwest Laboratory, Richland Washington.

9.1-16. Thornhill, C. K. and Sevigny, G. J., Status of LWR Extraction Technology Development, Volume 1, PNL-8140, Pacific Northwest Laboratory, Richland, Washington, October 1992.

9.1-17. Light Water New Production Reactor Technical Question Resolutions, WHC-EP-0484, Westinghouse Hanford Company, Richland Washington, November 1991. 


\section{Combustion Engineering, Inc. Now-Pturomivi

\subsection{Commercial Fuel Operation}

The System $80+$ reactor system has a design life of 60 years. After the completion of the Plutonium disposition mission, the reactor(s) will be available for power production using commercially available $\mathrm{UO}_{2}$ fuel. The power rating will be increased to the certified reactor power of $3931 \mathrm{MWth}$ (gross generated power of $1392 \mathrm{MWe}$ ). All of the systems and components are designed to operate at this higher, certified power level.

Table 9.2-1 contains information that would be typical of the $\mathrm{UO}_{2}$ fuel cycle that would be used for commercial operation. 
IABLE 9.2-1

\section{SYSTEM $80+\mathrm{UO}_{2}$ EQUILIBRIUM CYCLE}

NSS THERMAL POWER, MWt

3.931

CORE POWER, MWt

3914

NUMBER OF FUEL ASSYS.

FEED BATCH ASSY

80

FEED ENRICHMENT, wt\%

4.20

FEED U, MTU

34.98

CYCLE LENGTH, months

CYCLE LENGTH, EFPD

432

AVG CAP FACTOR, \%

79 


\subsection{Spent Fuel Storage (Final Ten Years)}

Disposition of plutonium will be complete after 30 years of plant operation, at which time the plant will be converted to accommodate commercial grade uranium fuel. The spent fuel pool has adequate capacity to store the spent MOX fuel generated during the final ten years of operation, including storage space for a full core off-load, if required. The fuel handling and storage facilities are describeo further in Section 2.5.

During the 10-year cooling period for one of the alternative cores (100 MT Pu over life of the reactor), there could be spent MOX fuel that resides in the pool after the remainder of the plant has been shut-down and decommissioned. The requirements for fuel pool cooling, purification, spent fuel handling and monitoring will need to be maintained. The licensing of this particular area of the plant will have to be extended in order to complete the cooling period. This will also involve demonstration of the continued capability of the systems involved to continue their functions. This situation, however, is really no different than one that would confront a commerciallyoperated LWR wherein, after plant shutdown and decommissioning, the spent $\mathrm{UO}_{2}$ fuel is kept in the spent fuel pool until it can be removed to a repository.

\subsection{Other Applications of this Technology}

The use of a System $\mathbf{8 0}+$ Advanced Light Water Reactor has additional impacts important to the interest of the U.S.A. Among the benefits for other applications are:

- A demonstration through detailed design, construction, and operation of a System 80 + Nuclear Power Plant designed in accordance with the EPRI Utility Requirements Document.

- An application of a System $80+$ Certified Design to demonstrate the economy of constructing a Nuclear Power Plant that was certified in advance and to validate the wisdom of the DOE sponsorship of certification.

- Construction of a Nuclear Power Plant taking advantage of the Design for Constructability Programs sponsored by DOE and conducted by Stone \& Webster and Duke Engineering and Services, Inc.

- Develop in the design of a modern MOX facility a standard for DOE in designing and operating Plutonium handling facilities in an integrated manner with ES\&H and Safeguard Vulnerability receiving necessary attention.

- Demonstrate to the world the commitment of the U.S. Government to responsibly address the disposition of Plutonium.

- $\quad$ Provide a potential for a joint government/private project.

- Should other influencing policy issues prove it desirable, provide the capability to produce trillium with either uranium or MOX cores. 


\subsection{ALTERNATIVE CASES}

10.1 Departures from Information in Sections 2.0 through 9.0 for Alternates 1. 2 and 3

There are no departures from the information presented in Sections 2.0 through 9.0 in the Reference Case or in Alternates 1, 2, and 3.

In accordance with Section 1.4, the Reference and Alternative 1, 2, and 3 cases are as follows:

\begin{tabular}{||l|l|l|}
\hline \multirow{2}{*}{ Mission Time } & \multicolumn{2}{|c|}{ Mission Quantity of Pu } \\
\cline { 2 - 3 } & $50 \mathrm{MT}$ & $100 \mathrm{MT}$ \\
\hline \hline 25 Years & Reference & Alt 1 \\
\hline Life of Plant & Alt 2 & Alt 3 \\
\hline
\end{tabular}

\subsection{Other Proposed Variations - Plant Desian Features}

Variations have been developed to illustrate the effects of changing parameters as listed below from those specified in the Reactor Report Outline (RRO) to values which better reflect the design features of System $80+$ :

a. Capacity factor of $87 \%$ (rather than $75 \%$ )

b. Plant lifetime of 60 years (rather than 40 years).

Each of these changes is the result of features which were specifically incorporated in the design in order to meet the EPRI ALWR Utility Requirements Document (URD), and are discussed further in Sections 10.2.1 and 10.2.2 below. These features affect the capital cost. Unless the benefits of these features are recognized in the evaluation, the System 80 + design will be penalized by showing the capital cost effect only, without the corresponding benefits in reliability and lifetime.

The resulting variations are designated as follows:

Alt Rc: Same as Reference Case except with a capacity factor of $87 \%$.

Alt 21: Same as Alt 2 except with a plant life of 60 years.

Alt 2cl: Same as Alt 2 except with a capacity factor of $87 \%$ and a plant life of 60 years.

Alt 3c: Same as Alt 3 except with a capacity factor of $87 \%$.

Alt 31: Same as Alt 3 except with a plant life of 60 years. 
Alt 3cl: Same as Alt 3 except with a capacity factor of $87 \%$ and a plant life of 60 years.

These cases are included in the listing of Case Characteristics, Table 10.4-1. Results of the analyses are tabulated in Table 10.5-1 and are shown graphically in Figure 10.5-1.

\subsubsection{Capacity Factor Increased from $75 \%$ to $87 \%$}

The System $80+$ plant is specifically designed to support the URD requirement for $87 \%$ availability.

\section{a. Planned outages}

Refueling and maintenance outage schedules which contribute to achieving this goal are described in Section 4.4, including the most important design features that minimize outage duration.

The System $80+$ standard core design can accommodate a variety of fuel cycle lengths. The System $80+\mathrm{UO}_{2}$ equilibrium fuel cycle is presently designed for a 18 month refueling interval. For Plutonium Disposition, a combination of 12 and 18 month fuel shuffles would be scheduled within an overall 4 year core life.

System $80+$ is designed for a fast refueling scheme with an estimated refueling-only outage time of 17 days. The design incorporates many features which assist in reducing the refueling outage time. Key features that contribute to a significantly reduced refueling interval as compared to other plants are described in Section 4.4.

\section{b. Forced Outages}

It is estimated that System $80+$ forced outages will average no more than one per year, with a three day duration.

System $80+$ is designed to achieve high capacity factors by incorporating advanced control system designs and where appropriate, redundant design features. To the extent possible, redundant active components are provided in both the nuclear and turbine islands to achieve and maintain full power capabilities.

Historically, a large fraction of unanticipated trips result from faults initiated in the main feed and steam systems. To minimize the impact on capacity factors, System $80+$ incorporates a Reactor Power Cutback System (RPCS) designed to accommodate full load rejections and a loss of one main feed pump without initiating a reactor trip and opening primary/secondary safety valves. The System $80+$ design also incorporates an Extended Range Feedwater Control System which allows for automatic steam generator water level control from zero to full power. The automatic control of steam 
generator levels at low power operation eliminates the difficulty in manually controlling levels, which has also resulted in numerous reactor trips. These advanced design features eliminate the need for automatic start of a standby component should a loss of component function occur that might result in a turbine/reactor trip.

As an example, the System $80+$ design can accommodate a fault in the main feed system with insignificant impact on plant capacity iactor. A fault with a main feed pump and/or controls will result in the actuation of RPCS, which will automatically reduce reactor power by insertion of CEAs and initiate turbine cutback and runback to prevent a reactor trip on low secondary or primary pressure. Once the plant has been stabilized at approximately $60 \%$, the standby main feedwater pump can be placed in service and the plant can be quickly returned to full power operation. These design features have been demonstrated during testing ard operations at PVNGS.

The ABB turbine generator is of a highly reliable, well proven design, being utilized in over 60 nuclear power plants. These turbine generators have an aggregate electrical output in excess of $46,000 \mathrm{MWe}$. The ABB System $80+$ turbine generator design is currently in operation in 20 nuclear power plants in Europe.

In addition, reliability is further improved with full flow testing of safeguards, higher pressure and more rugged residual heat removal, and a diverse plant computer system.

\section{c. Extended Refurbishment Outages}

Certain features in the System $80+$ design are specifically directed at eliminating needs for an extended refurbishment outage. These features include:

- double the thermal margin of the most advanced plant in operation or under construction

- a 60-year plant design life

- long-lived pump seals

- a larger steam generator tube plugging margin.

\section{d. Current Experience}

Numerous units of older designs are achieving capacity factors in the $80 \%$ range. The System $80+$ evolutionary design, which uses and improves on the design features of these older plants, without introducing new developmental features which may in fact result in reduced availability, should clearly be given credit for its design.

\subsubsection{Life of the Plant Increased from 40 Years to 60 Years}

The System 80 + plant is specifically designed to support the EPRI ALWR requirement for a 60-year lifetime. As a result, the System $80+$ design includes many features to extend plant operation compared to present plants with a conventional 40 year life. 
The 60 year plant design life for System $80+$ has been accomplished through a combination of design, material selection, design analysis, procurement requirements, pre- and in-service inspection, maintenance, and replacement features for individual components and systems. These issues are included in the licensing case, are explicitly addressed in CESSAR-DC, and have been reviewed by ACRS. They are as much a part of the plant design as other features described in CESSAR-DC.

Major Nuclear Steam Supply System (NSSS) components are not expected to be replaced during the 60 year design life of the plant. The component design life leg, the reactor vessel) is confirmed through analysis and is monitored throughout the plant life as described in CESSAR-DC. For example, CESSAR-DC Section 3.9.1.1 describes the approach to fatigue analysis of the NSSS based on the transients expected through a 60 year plant life. For the reactor vessel, improved material specifications are stated in Section 5.2.3.2 and the neutron irradiation analysis for 60 year's is documented in Section 5.3.2.1.

Similarly, turbine generator (T-G) components are not expected to be replaced during the 60 year design life of the System $80+$ plant. The design and inspection requirements for the turbine are also reviewed in CESSAR-DC, Sections 10.2.3 and 10.2.5.

In addition to the above design features and the excellent performance record of ABBCE steam generators, the design of the System 80 + plant facilitates the replacement of major plant equipment if necessary, including the steam generators.

The above features are discussed in more detail in Appendix $\mathbf{C}$.

\subsection{Other Proposed Variations - Financial Parameters}

Variations have been developed to illustrate the effects of changing financial parameters as listed below from those specified in the Reactor Report Outline (RRO) to values of interest or which better reflect System $80+$ :

a. Construction at the Sayannah River Site (SRS).

b. Removal of the capacity "Firmness" penalty.

The Capacity "Firmness" penalty is further discussed in Section 10.3.1 below.

The resulting variations are all based on a capacity factor of $87 \%$ and a plant life of 60 years. They are designated as follows:

Alt 2s: Alt 2cl constructed at SRS.

Alt 2sf: Alt $2 \mathrm{cl}$ constructed at SRS and without the "firmness" penalty.

Alt 3s: Alt 3cl constructed at SRS.

Alt 3sf: Alt $3 \mathrm{cl}$ constructed at SRS and without the "firmness" penalty. 
Alt 3'sf: Alt 3cl using a single unit constructed at SRS and without the "firmness" penalty.

\subsubsection{Capacity "Firmness" Penalty.}

Oak Ridge National Laboratory letter of April 8, 1994, describes a proposed capacity "firmness" fraction to be applied to stations of less than four units in assessing the economics of the Reference and Alternative cases. System $80+$ is a particularly efficient plant for disposition of plutonium, due to its capability to use $100 \% \mathrm{MOX}$ fuel. The plant capacity required per unit of plutonium is therefore low, resulting in a relatively small number of units required for any given mission.

Using representative values from the referenced letter, it will be seen that the penalty for one and two unit stations compared to less efficient four unit stations with the same total capacity is severe:

$$
\begin{aligned}
& \text { Midwest Site - Total Avoided Cost } \\
& \text { Mills/KWhr (Capacity + Energy) }
\end{aligned}
$$

\begin{tabular}{lcccc} 
& \multicolumn{3}{c}{ No. of Units } & \% Penalty \\
Year & 4 & 2 & 1 & 1 unit vs. 4 \\
1993 & & & & \\
2010 & 29.19 & 26.26 & 24.19 & $17 \%$ \\
2020 & 35.90 & 32.97 & 30.90 & $14 \%$ \\
& 38.77 & 39.09 & 33.77 & $13 \%$
\end{tabular}

According to the letter, the "firmness" factor reflects the degree to which a utility might rely on the Plutonium Disposition Reactor (PDR) as a generation capacity asset, and the historical basis for the penalty is $\mathbf{N}$ Reactor experience.

Based on the following, System $80+$ should not be subject to the "firmness" penalty:

- Nuclear power has become a mature technology since the time of $\mathbf{N}$ Reactor.

- While some penalty may be appropriate for plants with developmental features, System $80+$ is an evolutionary commercial design, not a developmental plant. As discussed in Section 10.2.1 above, it is expected to be a highly reliable design, with minimal unplanned outages and capacity factors at least as high as those being achieved by plants of current design, which are not penalized for "firmness".

- While the $\mathbf{N}$ Reactor was large compared to its system at the time, units of $1000 \mathrm{MWe}$ and larger are now commonplace, and the development of power pools and large interconnected systems substantially reduce the potential impact of unplanned outages by individual units. 
In the " $f$ " cases, which investigate the impact of removing the "firmness" penalty from the System 80 + economics, the revenues per kilowatt hour given in the ORNL letter for "4 unit" (no penalty) cases iave been used for System $80+$.

\subsection{Summary of Cases}

The cases evaluated are summarized in Table 10.4-1.

The base case (50 MT over 25 years) is discussed in other sections (2.0 through 9.0) with annual cycles at a capacity factor of $75 \%$. This section discusses the results of analyzing the other required alternatives $(A 1, A 2, A 3)$ also with annual cycles and at $75 \%$ capacity factors. In addition, results are presented for additional alternatives, described above, thac will either provide more energy extraction (more revenue) and/or shorter time .0 accomplish the mission.

The alternatives are compared to the base case in Table 10.4-2. The first three required alternatives differ only in the number of units necessary to accomplish the mission. Alternatives 2 and 3 relax the time to perform the mission and show that the number of units required is half that of the Reference case and Alternative 1 resulting in lower plant cost to accomplish the respective missions.

The deployment strategies are illustrated in Tables 10.4-3 through 10.4-5 for Alternatives 1 through 3, respectively. The deployment strategies for the additional cases are illustrated in Tables 10.4-6 through 10.4-8 for Alternatives Rc, A2L, and $A 2 c L$, respectively.

Alternative $\mathrm{Rc}$ is presented as a variation of the base case operating with a capacity factor of $87 \%$ and a plant life of 40 years. The increase in plant life from 40 years to 60 years is illustrated in two cases, $A 2 L$ and $A 2 \mathrm{cL}$. Alternative $A 2 L$ shows the effect of modifying case A2 with a longer plant life; resulting in longer time to burn commercially available uranium fuel. With the increase of the capacity factor to $87 \%$ and the increase plant life, the results are shown in alternative $\mathrm{A} 2 \mathrm{cL}$.

Two things are necessary to get to a higher capacity factor. The first is to get more energy out of the fuel; then take advantage of the design features to accomplish all the required maintenance and refuelling operations in less than 90 days per outage.

The first step to get more energy is accomplished by running three 16 month cycles instead of four 12 month cycles. This saves $25 \%$ of the outage times (90 days) and generates $8 \%$ more energy in the same 4 year period. This is a variation of the 18 month cycle that is currently in favor with many US utilities. If desired by the utility, the fuel management has the flexibility to also run 2 eighteen month cycles and a 12 month cycle. An additional $3400 \mathrm{MWD} / \mathrm{THM}$ is extracted from the same fuel and results in $8 \%$ more energy production. There is a slight increase in Plutonium destruction and $\mathrm{Pu}-240$ isotopic fraction as shown in Table 10.4-9. The fuel charging 
and discharge and shipping plans are the same as in the base case. The only difference is in the discharge isotopics.

Since System $80+$ is designed with the consideration of maintenance and operational evolutions, it is possible to reduce the outage time from 90 days to 55 days and still accomplish all required maintenance and refurbishing activities. If refuelling is the only critical path activity for the outage, the length is estimated to be only 17 days. See Section 10.2.1, above, for further details. In this case, the $87 \%$ capacity factor is accomplished by first reducing the number of outages from 4 to 3 for every four year period and then to decrease in the outage time from 90 days to 55 days. This 55 days is a planned refuelling outage of 51 days with an average of 4 days per cycle of lost power operation. Alternative Rc shortens the time to perform the plutonium disposition mission from the base case of 290 months by 30 months lover 1 year earlier). This would produce the same energy as the reference case, but over a shorter time period, and would allow several additional cycles of commercial operation for the 40 year operation on each unit. The Plutonium destruction and discharge isotopics are improved as shown above. 
Combustion Engineering, Inc.

CASE CHARACTERISTICS

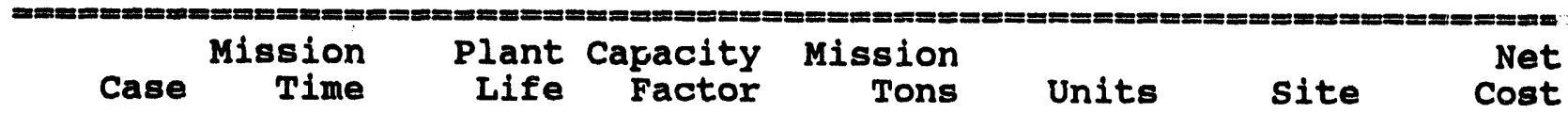

Specified Cases

$\begin{array}{lrlrrrrr}\text { R } & 25 & 40 & 75 & 50 & 2 & \text { MW } & -949 \\ \text { A1 } & 25 & 40 & 75 & 100 & 4 & \text { MW } & -4769 \\ \text { A2 } & \text { LOP } & 40 & 75 & 50 & 1 & \text { MW } & 784 \\ \text { A3 } & \text { LOP } & 40 & 75 & 100 & 2 & \text { MW } & -1022\end{array}$

Additional Cases

Re 25

A21 LOP

LOP

$\begin{array}{ll}A 2 c 1 & \text { LOP } \\ \text { A31 } & \text { LOP }\end{array}$

A3C LOP

A3c1 LOP

A2s IOP

A2sf LOP

A3s LOP

LOP

A3'sf IOP

$\begin{array}{rrr}40 & 87 & 50 \\ 60 & 75 & 50 \\ 60 & 87 & 50 \\ 60 & 75 & 100 \\ 40 & 87 & 100 \\ 60 & 87 & 100 \\ 60 & 87 & 50 \\ 60 & 87 & 50 \\ 60 & 87 & 100 \\ 60 & 87 & 100 \\ 60 & 87 & 100\end{array}$

$\begin{array}{lrr}2 & \text { MW } & -2264 \\ 1 & \text { MW } & 221 \\ 1 & \text { MW } & -545 \\ 2 & \text { MW } & -2512 \\ 2 & \text { MW } & -2383 \\ 2 & \text { MW } & -4154 \\ 1 & \text { SRS } & -1203 \\ 1 & \text { SRS } & -2069 \\ 2 & \text { SRS } & -5040 \\ 2 & \text { SRS } & -5997 \\ 1 & \text { SRS } & -2077\end{array}$

NOTE - Case Designation Codes:

$R$ Reference Case

A Specified Alternative Cases

cl Plant Life 60 Years and

1 Plant Iife 60 Years

c Capacity Factor $87 \%$

Capacity Factor 87

s "cl" + Savannah River site sf "g" + no "firmness" penalty

CASES SORTED BY MISSION TONS AND NO. OF UNITS

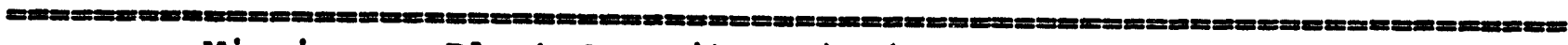

\begin{tabular}{|c|c|c|c|c|c|c|c|}
\hline Case & $\begin{array}{l}\text { sion } \\
\text { Time }\end{array}$ & $\begin{array}{r}\text { Plant } \\
\text { Life }\end{array}$ & $\begin{array}{r}\text { Capacity } \\
\text { Factor }\end{array}$ & $\begin{array}{r}\text { Mission } \\
\text { Tons }\end{array}$ & Units & site & $\begin{array}{l}\text { Net } \\
\text { Cost }\end{array}$ \\
\hline $\begin{array}{l}\text { A2 } \\
\text { A21 } \\
\text { A2C1 } \\
\text { A2s } \\
\text { A2sf }\end{array}$ & $\begin{array}{l}\text { LOP } \\
\text { LOP } \\
\text { LOP } \\
\text { LOP } \\
\text { LOP }\end{array}$ & $\begin{array}{l}40 \\
60 \\
60 \\
60 \\
60\end{array}$ & $\begin{array}{l}75 \\
75 \\
87 \\
87 \\
87\end{array}$ & $\begin{array}{l}50 \\
50 \\
50 \\
50 \\
50\end{array}$ & $\begin{array}{l}1 \\
1 \\
1 \\
1 \\
1\end{array}$ & $\begin{array}{r}\text { MW } \\
\text { MN } \\
\text { MW } \\
\text { SRS } \\
\text { SRS }\end{array}$ & $\begin{array}{r}784 \\
221 \\
-545 \\
-1203 \\
-2069\end{array}$ \\
\hline $\begin{array}{l}\mathbf{R} \\
\mathbf{R} \mathbf{C}\end{array}$ & $\begin{array}{l}25 \\
25\end{array}$ & $\begin{array}{l}40 \\
40\end{array}$ & $\begin{array}{l}75 \\
87\end{array}$ & $\begin{array}{l}50 \\
50\end{array}$ & $\begin{array}{l}2 \\
2\end{array}$ & $\begin{array}{l}\text { MW } \\
\text { MW }\end{array}$ & $\begin{array}{r}-949 \\
-2264\end{array}$ \\
\hline $\begin{array}{l}\text { A3 } \\
\text { A31 } \\
\text { A3C } \\
\text { A3Cl } \\
\text { A3s } \\
\text { A3sf } \\
\text { A3' } \mathrm{sf}\end{array}$ & $\begin{array}{l}\text { LOP } \\
\text { LOP } \\
\text { LOP } \\
\text { LOP } \\
\text { LOP } \\
\text { LOP } \\
\text { LOP }\end{array}$ & $\begin{array}{l}40 \\
60 \\
40 \\
60 \\
60 \\
60 \\
60\end{array}$ & $\begin{array}{l}75 \\
75 \\
87 \\
87 \\
87 \\
87 \\
87\end{array}$ & $\begin{array}{l}100 \\
100 \\
100 \\
100 \\
100 \\
100 \\
100\end{array}$ & $\begin{array}{l}2 \\
2 \\
2 \\
2 \\
2 \\
2 \\
2 \\
1\end{array}$ & $\begin{array}{l}\text { MW } \\
\text { MW } \\
\text { MW } \\
\text { MW } \\
\text { SRS } \\
\text { SRS } \\
\text { SRS }\end{array}$ & $\begin{array}{l}-1022 \\
-2512 \\
-2383 \\
-4154 \\
-5035 \\
-5997 \\
-2077\end{array}$ \\
\hline$A 1$ & 25 & 40 & 75 & 100 & 4 & $\mathbf{M W}$ & -4769 \\
\hline
\end{tabular}


Combustion Engineering, Inc.






\section{TABLE 10.4-3}

DEPLOYMENT STRATEGY

Alternative $1100 \mathrm{MT} P u$ in 25 years

Schedule - Months since start of contract

Number of Reactor Units

Core Power Rating

Cycle Length

$\begin{array}{rrr}\text { Months } & \begin{array}{r}4 \\ 3800 \\ \text { EFPD }\end{array} & \text { MWth } \\ & & \\ 12 & 274 & 0.75 \\ 12 & 274 & 0.75 \\ 12 & 274 & 0.75 \\ 12 & 274 & 0.75\end{array}$

First Core Startup Test Period:

6 months

Number of Feed Cores for Mission:

15

100.05

MT Pu

Operating Cycles

Feed Core

Cycle

Unit 1

Unit 2

Unit 3

Unit 4

11

174

292

$3 \quad 104$

$4 \quad 116$

21

1
2
3

98

110

122

134

31

1
2

3

41

2

3

... 1

2

3

131

$\begin{array}{ll}1 & 224 \\ 2 & 236 \\ 3 & 248\end{array}$

4260

141

$\begin{array}{ll}1 & 242 \\ 2 & 254 \\ 3 & 266\end{array}$

4

278

151

1
2
3
4


IABLE 10.4-4

DEPLOYMENT STRATEGY

Alternative 2 - 50 MT Pu in 40 years

Schedule - Months since start of contract

Number of Reactor Units

Core Power Rating

Cycle
Cength
Cycle 1
Cycle 2
Cycle 3
Cycle 4

Months

12
12
12
12

First Core Startup Test Period:

Number of Feed Cores for Mission: Operating Cycles

Feed Core

Cycle

Unit 1

Unit 3

Unit 4

1

2

3

4

5.

6

7

8

1
2
3
4

74

92

104

116

128

140

152

164

176

188

200

212

224

236

248

260

$\begin{array}{ll}1 & 320 \\ 2 & 332 \\ 3 & 349\end{array}$

356

320

332

344

356

368

380

392

404

416

428

440

452 


\section{IABLE 10.4-5}

ALTERNATIVE 3 - 100 MT PU IN 40 YEARS

\section{SCHEDULE - MONTHS SINCE START OF PROJECT}

Number of Reactor Units

Core Power Rating

Cycle Length

Cycle 1

Cycle 2

Cycle 3

Cycle 4

2
3800 MWth
Months
12
12
12
12

First Core Startup Test Period: Number of Feed Cores for Mission
6 months 15

EFPD
274
274
274
274



Cap Factor

0.75
0.75

0.75

0.75

Operating Cycles

Feed Core

Cycle

Unit 1

Unit 2

Unit 3

Unit 4

31

2

4

41

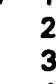

..
368

380

392

404

14 ?

2

3

151

1
2
3
4

416

428

440

452
98

110

122

134
128

140

152

164

74
92

104

16

98
110
122
134

146

158

170

182

422 


\section{TABLE 10.4-6}

ALTERNATERC

87\% CF AND 3 @15-MO CYCLES

Schedule - Months since start of Project

Number of Reactor Units

Core Power Rating

2

3800 MWth

Cycle Length

Cycle 1
Cycle 2
Cycle 3
Cycle 4

Months EFPD

15
15
15

15

N/A

365.333
Cap Factor
365.333
365.333
N/A

0.87

0.87

0.87

6 months

First Core Startup Test Period:

Number of Feed Cores for Mission:

8

Operating Cycles

Feed Core

Cycle

Unit 1

Unit 2

Unit 3

Unit 4

1

2

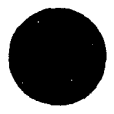

3

4

5

6

7

8

$\begin{array}{rr}1 & 74 \\ 2 & 95 \\ 3 & 110\end{array}$

95
110

125

140

155

170

185

200

$$
\begin{array}{r}
98 \\
113 \\
128
\end{array}
$$

158

173

\section{8}

203

218

233

248

263 
IABLE 10.4-7

\section{DEPLOYMENT STRATEGY}

Alternative A2L - $50 \mathrm{MT}$ Pu in 60 year plant Life

Schedule - Months since start of contract

Number of Reactor Units Core Power Rating

Cycle

Length
Cycle 1
Cycle 2
Cycle 3
Cycle 4

First Core Startup Test Period: Number of Feed Cores for Mission: Operating Cycles

Feed Core Cycle

1
2

1

2

3

4

5

6

7

8

$\begin{array}{ll}1 & 416 \\ 2 & 428 \\ 3 & 440 \\ 4 & 452\end{array}$

Unit 1

74

92

104

116

128

140

152

164

176

188

200

212

224

236

248

260

320

332

344

356

320

332

344

356

368

380

392

404

416

440

452 


\section{IABLE 10.4-8}

ALTERNATE A2CL

\section{7\% CF3 @15-MO CYCLES}

\section{YEAR PLANT LIFE}

$\begin{array}{cc} & \text { Schedule Months since st } \\ & \begin{array}{l}\text { Number of Reactor Units } \\ \text { Core Power Rating }\end{array} \\ \text { Cycle Length } & \text { Months } \\ \text { Cycle 1 } & \\ \text { Cycle 2 } & 15 \\ \text { Cycle 3 } & 15 \\ \text { Cycle } 4 & 15 \\ \end{array}$

First Core Startup Test Period: Number of Feed Cores for Mission:
$8 \quad 53.36$
6
MT Pu

Operating Cycles

Feed Core

$$
\text { Cycle }
$$

Unit 1

Unit 2

Unit 3

Unit 4

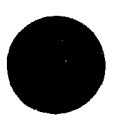

1

3

5

6

7

8 $\begin{array}{lll}4 & 1 & 215\end{array}$

$\begin{array}{lr}1 & 74 \\ 2 & 95\end{array}$

3110

$1 \quad 125$

2140

$3 \quad 155$

$1 \quad 170$

$2 \quad 185$

3200

2230

$3 \quad 245$

1260

$2 \quad 275$

3290

$\begin{array}{lll}6 & 1 & 305\end{array}$

$2 \quad 320$

$3 \quad 335$

1350

$2 \quad 365$

$3 \quad 380$

1395

$2 \quad 410$


IABLE 10,4-9

DISCHARCED FUEL ACTINIDE ISOTOPIC COMPOSITION

87\% CF AND HICHER BURNUP OPTIONS CORE TONNES






\subsection{Results}

The results of the evaluations are given in Table 10.5-1 and are displayed graphically in Figure 10.5-1. Figure 10.5 -1 displays the results in three panels:

a. $\quad 50$ metric ton missions using single units (Alt $A 2$ and its variations).

b. $\quad 50$ metric ton missions using two unit stations (the Reference Case and its variation).

c. $\quad 100$ metric ton missions using two unit stations (Alt A3 and its variations).

Section 10.5.1 discusses insights gained from comparing the results, and Section 10.5.2 contains conclusions.

\subsubsection{Insights}

Inspection of Figure 10.5-1 provides the following insights:

a. In all three panels, it will be seen that either increased capacity factor ("c" cases) or increased plant life ("I" cases), and combinations of the two ("cl" cases), result in reductions of net discounted cost.

b. Single unit cases $A 2$ and $A 21$ are the only ones evaluated which result in a positive cost, and the $A 2$ cost becomes negative (ie, the plant becomes economic) with consideration of the System 80 + capacity factor of $87 \%$.

c. The "s" cases (construction at the Savannah River Site) have systematically lower costs than their "cl" counterparts at the Midwest site, due to lower construction labor costs at SRS.

d. The "sf" cases (SRS without the "firmness" penalty) result in reduced costs in the order of $\$ 1$ billion compared to their " $s$ " counterparts. The penalty is thus seen to be very large.

e. Comparing all three panels, it will be seen that 2 unit stations characteristically have lower net costs than a single unit station. This is because of the greater total power sales, and will be observed in any case in which the total kilowatt hour generation per unit of plutonium is greater than the minimum, whether because of inefficient dispositioning of the plutonium or because of extended operation.

f. Case A3'sf investigates execution of a $100 \mathrm{mt}$ mission with a single unit having a 60 year life (this is in fact not quite sufficient). This case has not been plotted in Figure 10.5-1, because it would be essentially the same as single unit $50 \mathrm{mt}$ Case A2sf (minus 2,077 vs. minus 2,069). The insight here is that the net cost of whatever station is chosen is not sensitive to the 
amount of plutonium actually dispositioned within the total lifetime of the plant.

\subsubsection{Conclusions}

a. The System $80+$ PDR generally produces negative net discounted cost (positive economics).

b. The penalties for using less than the design capacity factor and/or plant lifetime are substantial. System $80+$ should be evaluated with its design capacity factor and lifetime.

c. The "firmness" penalty which results from the high System $80+$ efficiency in dispositioning plutonium is severe and should not be assessed against an evolutionary plant such as System $80+$.

d. Apparently lower net costs can result either from extended generation or from inefficient plutonium disposition and correspondingly increased total generation.

e. In the face of uncertainty in the mission quantity, building of additional efficient capacity to assure adequacy will not materially affect the total net discounted cost over the plant lifetime. 


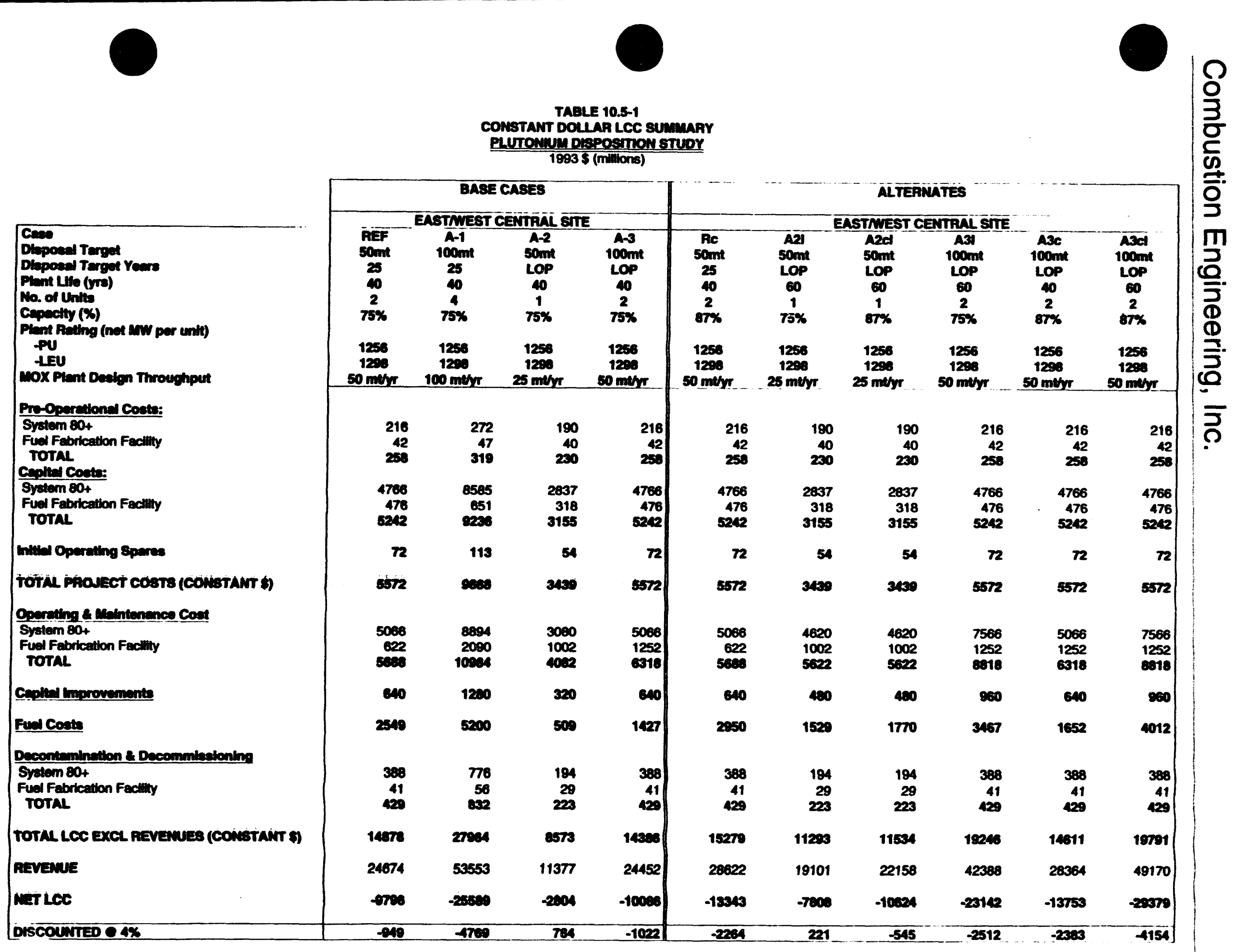


TABLE 10.5-1 (continuad)

COUSTANT DOLLAR LCC SUMMnAY

PLITOMnin Disposmon sTupr

1993 (millons)

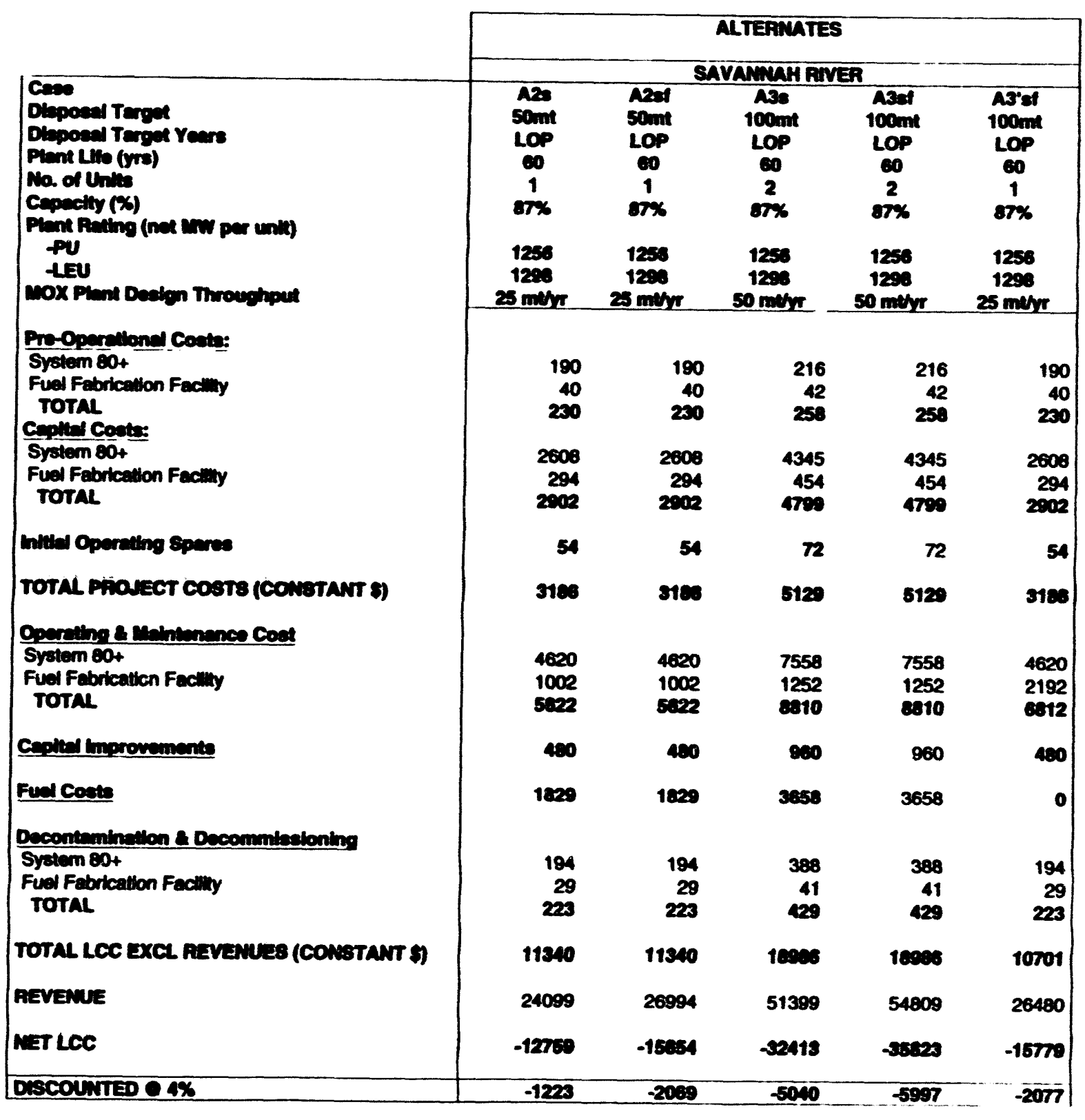

menamesA:T1051_B.WK1 
Combustion Engineering, Inc.
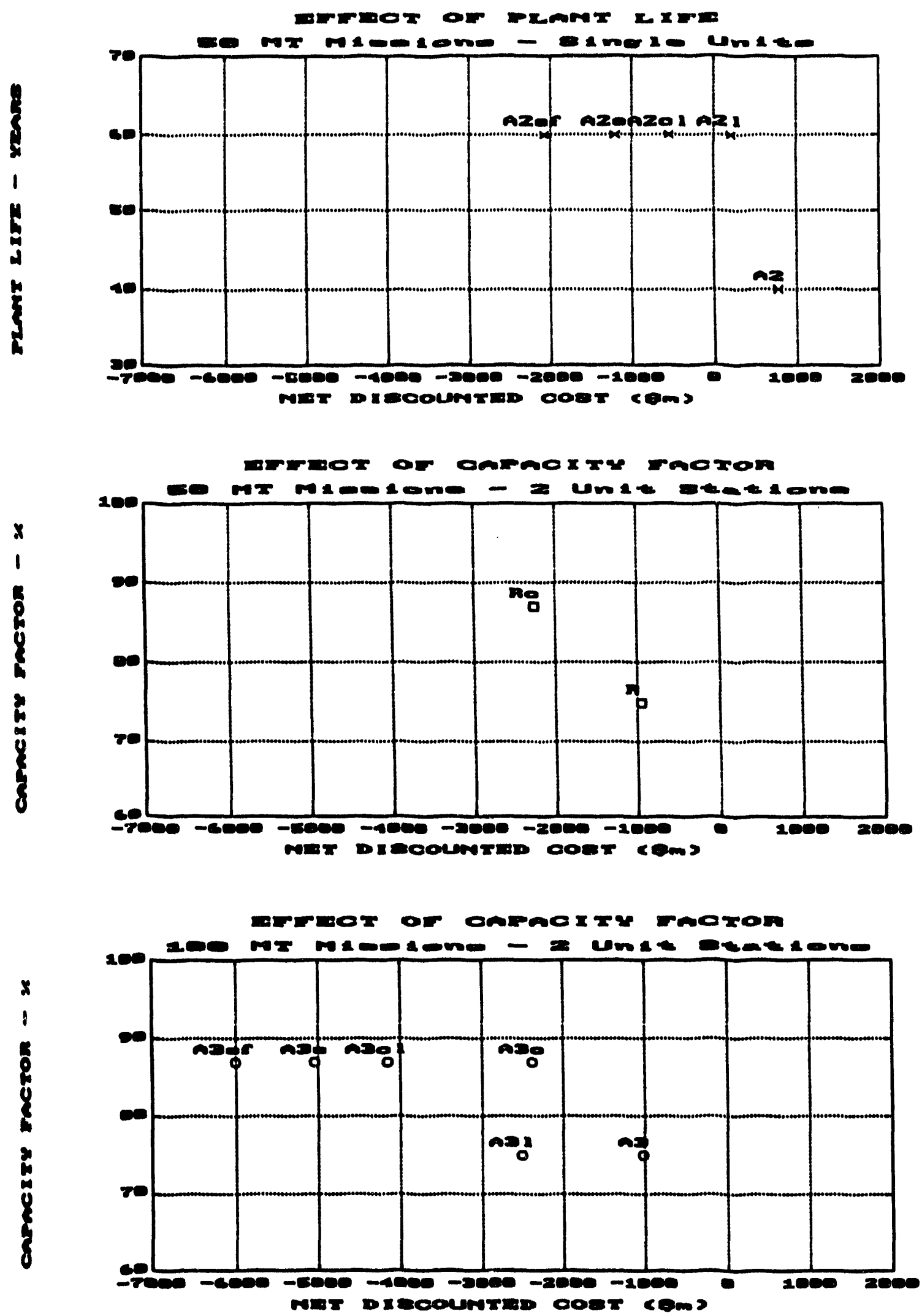

FOUAE 10.5-1

CONSTANT JOUAR LCC EUMMARY

PLUTONIUM DisPOSITON ETUDY

1003 s(nuluows) 


\subsection{LINKAGE WITH DISPOSITION IN RUSSIA AND OTHER COUNTRIES}

The disposal of surplus plutonium in the U.S. is expected to be linked to disposal of surplus plutonium in Russia and perhaps other countries. The linkages may involve aspects of transparency, proprietary issues, reciprocity, collaboration, and long term surveillance. Potential linkages are described in the following sections.

\subsection{Trangearency and Propriotary lasues}

The steps in the disposal process must be open to mutual verification and inspection as required under the terms of agreement. Sensitive information, whether associated with weapons' security or industrial security, must be protected from being divulged to other parties. At the same time the other parties must be able to ascertain that the plutonium originated from dismantled weapons, or other sources covered by agreements, and that the plutonium is converted into System $\mathbf{8 0}+$ fuel and irradiated as covered by agreement. For the System $80+$ fuel, it is assumed that the MOX plant will receive plutonium, as metal or oxide, in a form that contains no weapons' sensitive information. Issues associated with transparency prior to receipt of the plutonium at the MOX plant are outside the scope of this report. The fabrication and subsequent irradiation of the System $80+$ MOX fuel will be open such that the processing and flow of the plutonium can be verified. The protection of proprietary information, which will be limited to a few process steps and parameters, will not diminish the traceability of the plutonium. Reciprocal procedures with Russia and other countries need to attain the same degree of traceability of Russian plutonium while protecting their sensitive information.

\subsection{Transferabillity of Technology and Equipment}

To the extent possible technology and equipment for disposing of the surplus plutonium will be shared under reciprocal agreements consistent with the protection of sensitive information described above. The shared technology and equipment is expected to flow primarily from the U.S. to Russia. Issues of liability, product, performance, and safety, associated with proposed transfers need to be addressed and resolved. The transfers from the U.S. are expected to facilitate and speed up plutonium disposal in Russia and increase safeguards, accountability, and verifiability. Transfers of Russian technology and equipment to the U.S. for similar purposes, confidence building, and mutual benefit will be encouraged.

\subsection{Potential for Joint Programs}

The potential for joint programs is expected to be primarily in the areas of safeguards, accountability, verifiability and proliferation resistance. The System $80+$ reactor and fuel cycle differ substantially from Russian reactor designs and fuel cycles; joint programs or exchanges on generic topics are possible in these technologies. Examples of potential joint programs in these areas are research and development of plutonium 
fuels and proliferation-resistant fuel cycles and automation of MOX fuel fabrication processes.

\subsection{Enduring Monitoring and Control of Fissile Materials}

Two categories of fissile material are of concern. First, the spent MOX fuel will contain nearly all of the originally surplus plutonium. The composition and properties of the spent MOX fuel are nearly identical to spent uranium fuel such that the same control and disposal procedures and methods can be used for both. Second, the waste from the MOX fabrication plant is expected to be less than one percent of the original quantity of surplus plutonium. Fabrication plant waste is in two forms; a) waste from the glove boxes, e.g. filters, gloves, etc, in which plutonium is a minor constituent and b) dirty MOX scrap. In both cases the recovery of the plutonium is not cost-effective, but both sources are concerns because of the potential for diversion. The glove box wastes will be compacted, or otherwise reduced in volume, packaged and disposed of. Similar safe packaging and disposal practices will be used by all parties. This waste will need to be monitored and controlled to ensure that there is no risk of diversion, that the waste conforms to expectations, and that plutonium recovery is impractical. Similarly, dirty scrap must be packaged and disposed of. Because of the higher plutonium concentration in the scrap, more stringent monitoring and long term control procedures are required to guard against diversion or potential recovery of the plutonium prior to ultimate disposal. 


\subsection{PUBLIC AND POLITICAL ACCEPTANCE}

\subsection{Approach for Achieving Public Acceptance}

\subsubsection{Introduction}

This section provides an analysis and recommendation on an effective program for public outreach services and communication activities designed to evaluate the local impact and feasibility of siting and building an ABB-Combustion Engineering System $80+$ Evolutionary Advanced Light-Water Reactor. The facility's mission would be to simultaneously burn excess weapons grade plutonium, produce tritium if needed by the government and generate electricity for sale to regional utilities, sometimes referred to as the "triple mission."

The mission outlined above is not only politically sensitive, but will require significant involvement and commitments from a broad range of interests for a program of this magnitude to proceed. For example, siting System $80+$ reactor(s) and accompanying facilities on the Savannah River Site would require private and government commitments for capital costs associated with the facilities' construction; the federal government's commitments for the mixed oxide fuel source, responsibility for the spent fuel generated by the reactor(s), and the purchase of tritium if/when needed; and, the regional utility commitments to purchase the electricity generated. However, one of the most important commitments that must be obtained is from the local communities and economic impact zones affected by the facility siting. The project's development would easily prove unsuccessful and financially and politically costly without the local and regional public support and involvement.

Historically, technical and financial considerations dominated nuclear facility siting. Governments and companies made decisions, and citizens trusted the government to protect their interests. This, however, is no longer true. Social scientists and other experts agree that public involvement in the decision-making process is extremely vital. The "Decide-Announce-Defend" (DAD) strategy of the past must yield to a more interactive and open approach.

Public involvement can cover a broad spectrum -- from simply keeping the public informed to directly involving the public in the decision-making and negotiating process. Generally, the level of public participation in each situation is linked to the level needed and appropriate in order to reach a legitimate decision with which all stakeholders agree.

As is the case for most new industrial facilities, the proposed deployment of a System $80+$ reactor to carry out the triple mission carries inherent tradeoffs between the benefits and drawbacks to the facility's siting. In addition, the political ramifications surrounding the plutonium disposition and the potential tritium production missions will not only generate local interest, but national and international attention as well. In this 
regard, proactive information programs and public participation will be essential to the deployment strategy. Further, these efforts must be initiated early to ensure maximum exposure and to provide the most benefit to the public and to the Government/industry consortium.

In May 1989, the Department of Energy named Duke Engineering and Services, Inc., as the Utility Engineering Group (UEG) for the Department's Office of New Production Reactors (ONPR). The UEG was charged with providing technical and management expertise to the New Production Reactors Program, based on Duke's extensive experience in design, construction and operation of commercial nuclear facilities.

The UEG also was asked to provide counsel on outreach development and implementation strategies that would support the ONPR mission: "To provide new production reactor capacity on an urgent schedule for an assured supply of nuclear materials, primarily tritium, to maintain the Nation's nuclear deterrent capability."

A plant, named Outreach, was developed that represented a distillation of lessons learned from the commercial sector, as well as findings from scoping visits to the potential sites and surrounding communities, meetings with site outreach representatives, informal research and attendance at Savannah River Site restart public hearings. A similar plan is needed for a Plutonium Disposition Reactor (PDR). As such, some desirable aspects of such a plan may be drawn from the prior efforts for the NPR Program. The following paragraphs outline how the originally developed plan could be modified to encompass the plutonium disposition minion.

\subsubsection{The Qutreach Plan}

The plan should include recommendations for communication and public involvement efforts designed to foster understanding and acceptance of the program. Outreach efforts should be directed toward engaging state and local decision-leader support for the project, building grassroots community acceptance, and averting potential opposition.

More definite recommendations may be developed later. However, it is clear that DOE project management must realize that Outreach will need to be an ongoing and evolving process. Outreach must be able to exercise flexibility in responding to changing conditions and emerging issues.

A coordinated, targeted Outreach strategy is critical to the success of any reactor disposition project. Proactive communication initiatives can build grassroots support and acceptance of the project. Outreach efforts can also change or neutralize negative opinions regarding the project's mission, and inform and shape unbiased attitudes. 
In this process, DOE must demonstrate a commitment and responsiveness to the public. By establishing a framework of open, honest and timely communications, Outreach can build confidence and promote trust and credibility among the public, which in turn can pave the road for overall project acceptance and implementation.

Without a well-developed, goal-oriented Outreach strategy, the project will be at great risk. Ignoring public concern and interest and responding belatedly and/or reactively to inquiries will characterize DOE as unsympathetic to the human dimension of the project. Such a negative characterization could thwart future communication and education efforts, and cause long term damage to both PDR implementation and other future DOE endeavors.

The Outreach effort should develop logically around a core of key issues. The plan should include a detailed discussion of major issues relevant to the reactor disposition of plutonium, in general. Major issues of the Outreach effort may include the need and desirability of disposing of excess weapons plutonium, potential need for new tritium capacity, and the economic and environmental impacts of the project.

In addition to overall program issues, Outreach will need to identify pivotal local issues and prepare to address them in an open, honest, and responsible manner. Identifying local issues will help ensure that Outreach efforts are "market-driven" and respond to the needs and interests of key audiences. Community profiles should be developed in the plan to help direct the identification of local issues.

Once audiences and issues associated with the project have been identified and analyzed, Outreach must develop focused messages. The messages should convey DOE policy, create an understanding of the Plutonium Disposition Program, and responsibly address key issues of the project. For messages to be effective, they should be relevant to the audiences identified and compatible with the value system of the audience. Messages should be clear, consistent and couched in simple, nontechnical language.

Messages should be conveyed through an integrated system of communication strategies, including media relations, community relations, public meetings, employee and vendor relations, and regulatory and governmental affairs. These strategies should be outlined in the plan. Recognizing that the credibility and effectiveness of the message is dependent to a great degree on the message carrier, the plan should also include guidelines for communications training in the areas of issues, speaker skills, media skills and risk communications.

Successful Outreach strategy implementation will rely greatly on management commitment to Outreach and management participation in the Outreach process. Without the buy-in and involvement of program and project management, Outreach efforts may be seriously jeopardized. 
A comprehensive catalog of support materials will be needed to aid all Outreach efforts. A project Speakers Bureau, teleproduction capabilities, exhibits, publications, and educational programs may serve as creative communication tools for the Outreach effort.

The structure of Outreach program will also contribute to Outreach success. The plan should provide recommendations regarding such structural elements as experience of Outreach personnel for target audiences. It should also address Outreach accountability and monitoring of Outreach efforts through an information data storage and retrieval system.

Additional information needed to support the plan include detailed, comprehensive listings of government officials, news media, civic leaders and special interest groups; examples of support materials used in communication efforts for civilian nuclear programs, and a host of reference material.

In addition, the following informal recommendations should be considered.

- Consideration should be given to employing descriptive nomenclature to identify the Plutonium Disposition Reactor(s)

Program success depends in large part on public acceptance and support. NASA astronauts were proclaimed national heroes before their training -- much less their mission -- was under way. Their crafts were known as Apollo, Gemini, and more recently, Columbia, Challenger, and Discovery. NASA reaped the rewards of capturing the public's imagination and sense of scientific adventure. The commercial nuclear industry names facilities as well, developing names with regional connotation. A similar approach may help to instill community pride and acceptance of the project. It is a genuinely positive connotation to be destroying weapons materials and reaping the energy benefits while minimizing the cost to the government. This may provide a powerful and unifying theme.

- Experience in the commercial sector has proven time and time again that Outreach efforts are most effective if conducted on a local, grassroots level.

Outreach should realize early on that the public will view and respond to the project on a very personal level: What does this mean for me? How will it affect my family, home, and community? Will this affect our local economy? What about our drinking water, air quality, and crops?

Outreach should take a concentrated grassroots approach to project communications, and utilize local professional communicators (on a consulting or support basis) for the Outreach effort. Such professionals are familiar with local history, politics, values, and opinions. They know on a first-name basis the civic leaders, elected officials, and other local decision leaders whose support will be vital to the Outreach effort. 
- Team support will be an important link in Outreach efforts. Neither DOE nor contractors or vendors can be as effective operating separately as with team coordinated functions. Outreach must work as a team effort by sharing clear, common objectives and communicating on a regular basis.

We rarely distinguish between the two groups, DOE and others. We believe the Outreach function should be viewed as a single, coordinated function, regardless of the number of participants involved. This will help assure that the messages are delivered consistently, and will further contribute to building trust and credibility.

- Outreach should be considered an integral function of the Plutonium Disposition Program. Outreach personnel should be involved in project planning to the same degree that Design or Quality Assurance is involved.

DOE should expect the same degree of experience and skills in its Outreach personnel as for design, quality assurance or any other technical function. Experienced communication professionals should be one of the key components of a quality Outreach effort. 


\subsection{Likelihood of National Political Acceptance}

In March of 1992, a national poll found that $66 \%$ of Americans agreed that if people were more familiar with nuclear energy, they would be inclined to support the construction of nuclear power plants. In addition, $16 \%$ of Americans said they had visited a nuclear power plant. Among them, $71 \%$ were impressed with the management and operation, $72 \%$ believed nuclear energy was an efficient energy source and $56 \%$ came away with a better appreciation of nuclear energy than before their visit.

Clearly, over the years the Savannah River Site has developed an outstanding infrastructure to educate the public on the value and importance of nuclear energy for the nation and their community. Despite the inherent support, implementing proactive educational measures in support of the Pu Disposition project should not be neglected. This established relationship between the site and the public is merely a building block to use in developing unique, interactive communication and education programs specifically focused on the System $80+$ and the "new mission" at the site.

The likelihood of national political acceptance at the Savannah River Site is perhaps as good as or better than at any other site in the country. Acceptance on a national level must originate in the Congress, with the concurrence of the Executive Branch. Although the latter has shown no overt signs for support of nuclear energy, and clearly the deployment of a Pu disposition mission using the ALWR does border on such support, there are strong arguments, as delineated in the National Academy of Sciences report, that provide positive arguments that the mission is in the best interests of the United States. A proposal that responds to the NAS report recommendations, that also does not require large outlays of government funding, and is a one-shot proposition (not clothed as future support for the nuclear option) should be able to garner the bi-partisan support needed for deployment over the three or four decades of the project life. 


\section{Combustion Engineering, Inc.}

\subsection{Likelihood of Lecal or Regional Acceptance}

As has been mentioned before, the strong position of the Savannah River Site relative to local acceptance has been clearly established. Recent examples of the local press quotations show the strong commitment to the SRS by the local community, and a desire to develop the area, with the assistance of the DOE, into a major technological center, that would play a vital role in peacetime as well as in times of conflict. These recent quotations by Rep. Butler Derrick (D-SC), reflecting on two visits by Secretary O'Leary to the SRS, were made in the context of a planned unsolicited proposal by a consortium team headed up by ABB-CE to construct a System $80+$ plant at SRS on a private initiative basis, to fulfill the triple mission functions.

With the conduction of a public acceptance approach as has been outlined in this section, together with a careful selection of the site for the facilities, there should be a good chance of local and also national acceptance of a Pu disposition mission, using an ALWR having all the latest safety features required by the NRC for design certification. 


\subsection{CONCLUSIONS AND RECOMMENDATIONS}

\subsection{Five Key Challenges to Implementing Proposed Operation}

The five key challenges to implementing a Plutonium Disposition mission in a new System $80+$ Power Plant are believed to be :

- The design, construction and operation of a Mixed Oxide Fuel Fabrication Facility.

- The licensing of MOX Fuel Fabrication Facility and the licensing of the MOX Fuel in the Certified System $80+$ Reactor.

- Deployment of the facility at a Government site (i.e. Savannah River) using predominantly private finding and executing the required agreements.

- Public acceptance of the mission and the facility at the selected locations.

- Executing a large Nuclear Project in the United States.

\subsection{Five Key Advantages to Implementing Proposed Operation}

The five key advantages to implementing a Plutonium Disposition Mission in a new System 80 + Power Plant are believed to be:

- The least technical risk methodology in disposition of Plutonium is the mission of Plutonium in an Evolutionary Advanced Light Water Reactor such as System $80+$.

- The least cost option to the U.S. Government and perhaps the only option to storage is use of an ALWR for Plutonium disposition with privatized finding.

- The least risk schedule is constructing a known pre-certified Nuclear Power Plant such as System $80+$.

- Truly achieving the spent fuel standard when one considers retrievability and presence of weapons grade Plutonium is readily achievable in the System $80+$ and questionable in the vitrification option.

- System $80+$ and its predecessor System 80 were designed for $100 \%$ MOX operation with no compromise in safety. The ability to cover the core with control rod access to each fuel assembly is a design basis for System $80+$ and the reason why for twenty years industry experts have recognized 


\section{Combustion Engineering, Inc.

System 80 and System $80+a s$ the only reactors in the world truly designed for $100 \%$ MOX operation.

\subsection{Recommendation}

ABB-CE has submitted a program plan to the D.O.E. to develop the highly detailed, accurate cost, schedule, and revenue information necessary for a consortium to privately fund deployment of a System $80+$ standardized Advanced Light Water Reactor (ALWR) nuclear facility, including a Mixed Oxide (MOX) fuel fabrication facility, at the DOE's Savannah River Site. ABB-CE recommends that the DOE pursue discussions with ABB-CE to implement this plan in order to properly evaluate with realistic, detailed information the reactor disposition option versus other options that survive the DOE screening criteria. 

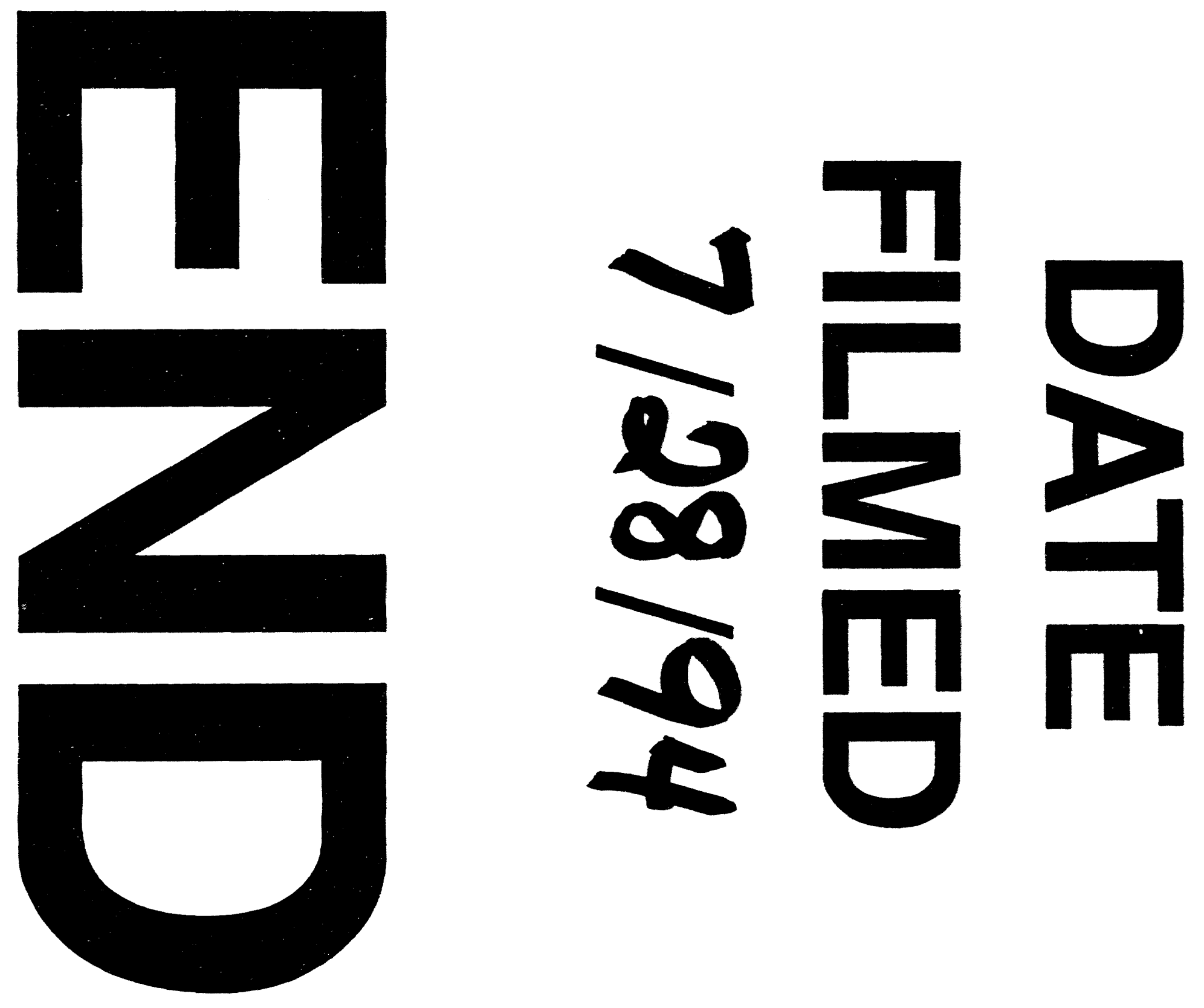


$$
\omega_{-\infty}
$$

